\title{
Política de Seguridad Alimentaria Nutricional (SAN) y Desarrollo Territorial en Colombia
}

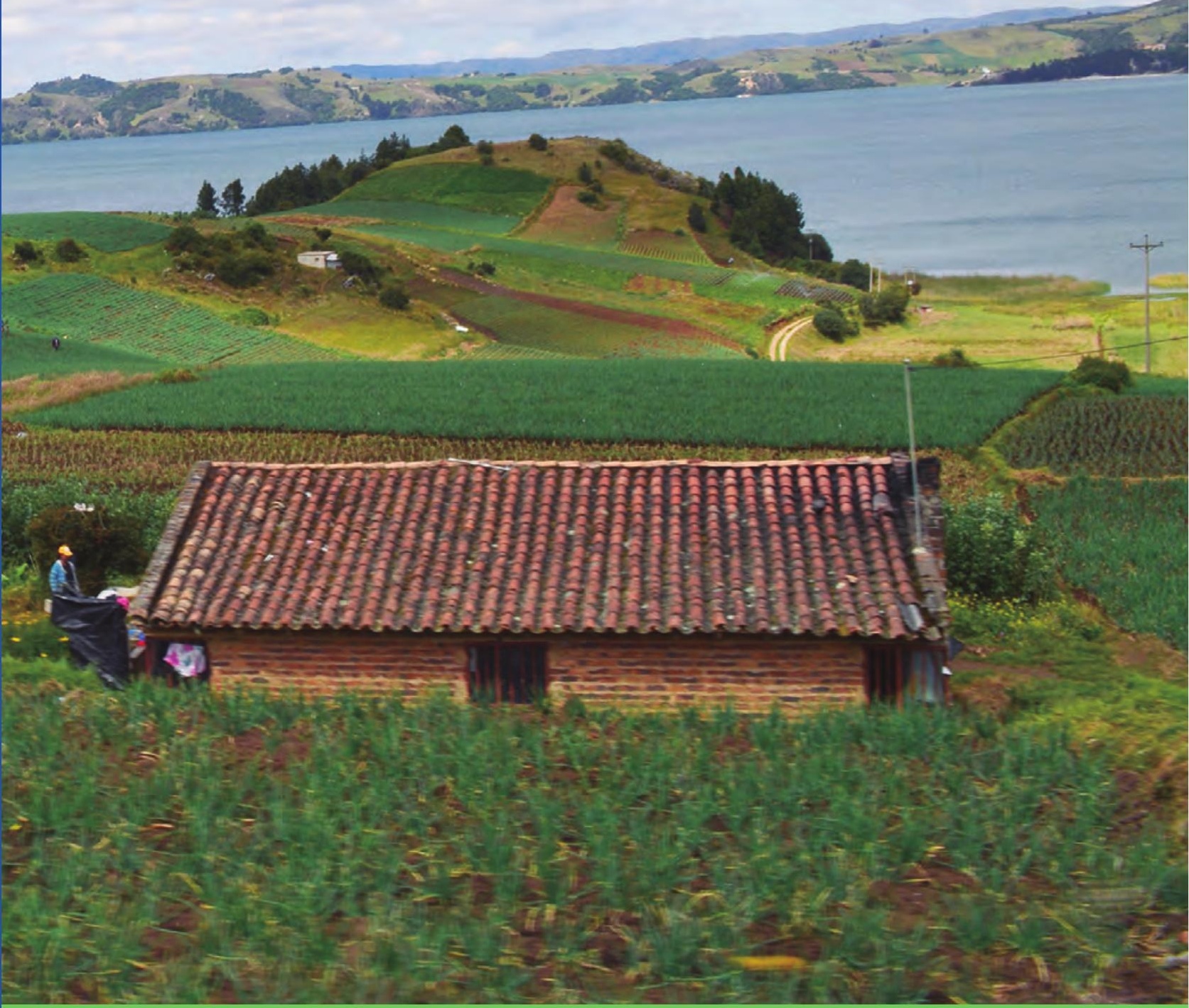

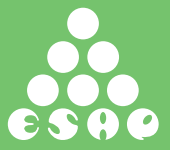

Escuela Superior de Administración Pública 




\title{
POLÍTICA DE SEGURIDAD ALIMENTARIA NUTRICIONAL (SAN) Y DESARROLLO TERRITORIAL EN COLOMBIA
}

\section{MAURICIO BETANCOURT GARCÍA}

\author{
Ph. D en Gobierno y Administración Pública
}





\section{POLÍTICA DE SEGURIDAD ALIMENTARIA NUTRICIONAL (SAN) Y DESARROLLO TERRITORIAL EN COLOMBIA}

\section{MAURICIO BETANCOURT GARCÍA}

Ph. D en Gobierno y Administración Pública

Esta obra corresponde al trabajo de tesis doctoral desarrollado por el autor en 2015 y presentado a la Universidad Complutense de Madrid en convenio con la Fundación Instituto Universitario de Investigación José Ortega y Gasset

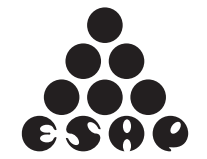

Escuela Superior de Administración Pública 


\title{
POLÍTICA DE SEGURIDAD ALIMENTARIA NUTRICIONAL (SAN) \\ Y DESARROLLO TERRITORIAL EN COLOMBIA
}

\author{
MAURICIO BETANCOURT GARCÍA
}

Primera edición 2017

\section{ISBN 978-958-652-427-8}

Catalogación en la publicación - Biblioteca Luis Oswaldo Beltrán Jara - ESAP

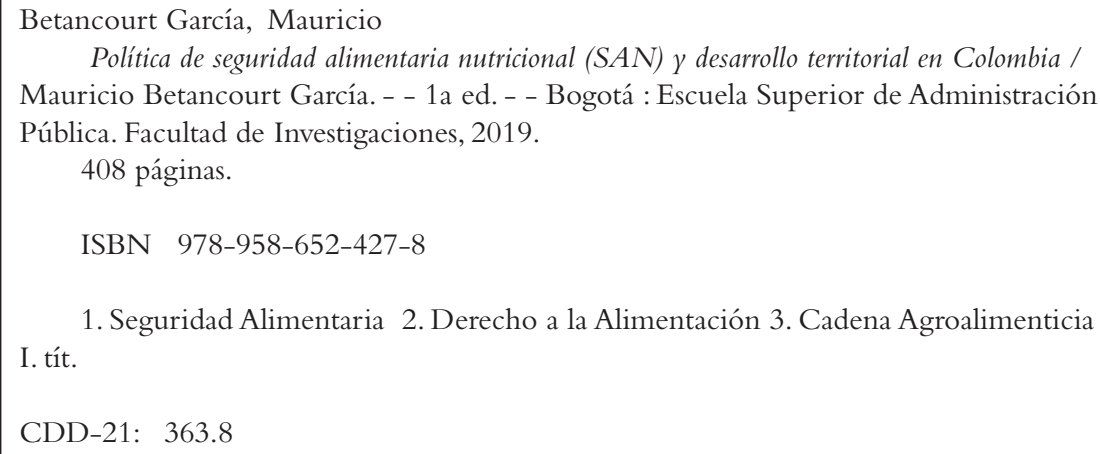

ESCUELA SUPERIOR DE ADMINISTRACIÓN PÚBLICA

Claudia Marcela Franco Domínguez, Directora Nacional (E)

Claudia Inés Ramírez Méndez, Subdirectora Académica

Alexander Cruz Martínez, Subdirector de Proyección Institucional

Oswaldo Bernal Sánchez, Subdirector (E) de Alto Gobierno

Claudia Marisol Moreno Ojeda, Decana (E) Facultad de Investigaciones

Luz Stella Parrado, Decana Facultad de Pregrado

Maryyuri Rocío Galeano Jiménez, Secretaria General (E)

Coordinación editorial, Facultad de Investigaciones y Grupo de Publicaciones

Fotografía de cubierta: Natalia Betancourt; Mundo rural, Laguna de Tota.

Diseño de cubierta: Claudia Rangel

Diseño contenido: Carlos Müller

Bogotá D.C., diciembre de 2017

Todos los derechos reservados. Esta obra no puede ser reproducida sin el permiso escrito de la Escuela Superior de Administración Pública. La responsabilidad de las opiniones expresadas en este documento compete exclusivamente a sus autores y no compromete de modo alguno, el pensamiento oficial de la Escuela Superior de Administración Pública, salvo en aquellos casos en que expresamente así se indique. 


\section{AGRADECIMIENTOS}

toda mi familia, por sus ayudas en todo momento; a mis hijas Estefanía y
Natalia, por su tranquilidad en mi ausencia; a Olga, por su compañía, paciencia
y crítica a pesar de su partida.

A Nicolás, Pablo, Simon y Emanuel que nacieron finalizando la investigación; y porque esta generación no debe sufrir con los alimentos y las nuevas enfermedades causadas por su consumo o su déficit.

A las personas entrevistadas, que permitieron entender desde las regiones los problemas institucionales que afectan la seguridad alimentaria de la gente que necesita acciones públicas coherentes e integrales.

A la Escuela Superior de Administración Pública (ESAP), por los apoyos institucionales, y a sus estudiantes, por la participación en diferentes momentos de la investigación, tanto en la sede de Bogotá como en el resto del país, en especial Medellín, Cartagena, Cúcuta y Neiva.

A la Universidad Complutense de Madrid y al Instituto de Investigación Ortega y Gasset, por el espacio abierto a los latinos para desarrollar este doctorado.

A los profesores del doctorado: Pedro Medellín, que nos incentivó en Colombia a cursarlo; Esther del Campo, por su orientación para el trabajo en el doctorado; José Manuel Ruano de la Fuente, por ser quien desde la propuesta de investigación revisó los distintos escritos e hizo las observaciones de manera continua, lo que permite que hoy se entregue este documento de tesis. 



\section{ÍNDICE GENERAL}

$\begin{array}{ll}\text { AGRADECIMIENTOS } & 7\end{array}$

ÍNDICE GENERAL 9

ÍNDICE DETABLAS

ÍNDICE DE FIGURAS

LISTADO DE SIGLAS 22

INTRODUCCIÓN GENERAL 25

PRIMERA PARTE

DISEÑO METODOLÓGICOYTEÓRICO DE LA INVESTIGACIÓN EN SEGURIDAD ALIMENTARIA NUTRICIONAL (SAN)

CAPÍTULO I. LOS ELEMENTOS METODOLÓGICOS DE LA INVESTIGACIÓN EN SEGURIDAD ALIMENTARIA

NUTRICIONAL (SAN) 31

1.1. PROPUESTA GENERAL DE LA INVESTIGACIÓN 31

1.1.1. Justificación 31

1.1.2. Objeto y objetivos de la investigación 36

1.1.2.1. Objeto de la investigación 36

1.1.2.2. Objetivo general 37

1.1.2.3. Objetivos específicos 37

1.1.3. Formulación de hipótesis 37

1.2. DISEÑO METODOLÓGICO 38

1.2.1. Identificación de los territorios 38

1.2.2. Descripción y periodización de la información 38

1.2.3. Fuentes de información para la investigación 40

1.2.3.1. Información estadística y seriada 40

1.2.3.2. Documentos públicos nacionales 40

1.2.3.3. Entrevistas 41

1.2.4. Organización y sistematización de la información 41

1.2.5. Cálculo para determinar las regiones SAN 43 
2.1. DERECHO 45

2.2. ECONOMÍA $\quad 46$

2.2.1. La discusión del desarrollo regional y local $\quad 47$

2.2.1.1. La revalorización territorial 48

2.2.1.2. Territorio y planeación $\quad 53$

2.2.1.3. Acercamiento entre territorio y agroalimentos 54

2.2.1.4. Tipificación general regional 58

2.2.2. Economía e instituciones $\quad 62$

2.3. CIENCIA POLÍTICA 63

2.3.1. Elementos teóricos conceptuales generales 63

2.3.1.1. La interdisciplinariedad 63

2.3.1.2. Los elementos teóricos $\quad 64$

2.3.1.3. Elementos definitorios de una política pública 65

2.3.2. Política pública y seguridad alimentaria nutricional 67

2.3.2.1. La política económica $\quad 68$

$\begin{array}{ll}\text { 2.3.2.2. Política pública y territorios } & 70\end{array}$

2.3.2.3. El SSAN, la necesidad de integración de la política SAN 73

2.3.2.4. Gobiernos, territorios, sistemas y sectorialidad 74

2.3.2.5. Territorio y cultura $\quad 75$

2.4. PROPUESTA DE LA TESIS PARA EL ANÁLISIS DE LA POLÍTICA DE SEGURIDAD ALIMENTARIA NUTRICIONAL (SAN)

2.4.1. Análisis integral de la SAN, a partir de la
teoría crítica de sistemas sociales

2.4.2. La interdisciplinariedad $\quad 79$

2.4.3. El carácter interdisciplinar para el análisis de la SAN 80

2.4.4. Construcción de regiones SAN y desarrollo territorial 81

SEGUNDA PARTE

LOS CONTEXTOS DE LA SEGURIDAD ALIMENTARIA

NUTRICIONAL (SAN)

CAPÍTULO III. CONTEXTO INTERNACIONAL DEL

SISTEMA DE SEGURIDAD ALIMENTARIA NUTRICIONAL,

CADENA ALIMENTARIA Y POLÍTICA PÚBLICA

GLOBAL DE ALIMENTOS BÁSICOS 


\subsection{ELEMENTOS GENERALES DE LA SEGURIDAD}

ALIMENTARIA GLOBAL $\quad 84$

3.1.1. Evolución de orientaciones e interpretaciones de la FAO 84

3.1.2. La dieta básica mundial 85

3.1.3. Elementos generales de la demografia 87

3.2. POLÍTICAS PÚBLICAS ALIMENTARIAS GLOBALES 88

3.2.1. Generales 89

3.2.2. Salud pública y contaminación, alimentación y nuevas enfermedades 93

3.2.3. Patentes y multinacionales 95

3.2.4. Los futuros conflictos entre agrocombustibles y agroalimentos 97

\subsection{ELEMENTOS DE LA CADENA} AGROALIMENTARIA GLOBAL $\quad 98$

3.3.1. Disponibilidad de alimentos básicos 98

3.3.1.1. La tierra y las condiciones para producir agroalimentos; usos y aprovechamiento de tierras en el mundo 98

3.3.1.2. La producción de agroalimentos 101

3.3.2. Distribución mundial de agroalimentos 107

3.3.2.1. Comercio exterior de cereales 109

3.3.3. Acceso a los alimentos mundiales 110

3.3.4. Uso biológico de los alimentos mundiales 112

3.3.5. Recapitulación 114

CAPÍTULO IV. EL DERECHO A LA ALIMENTACIÓN 117

\subsection{ELEMENTOS DE BASE DEL DERECHO}

4.1.1. Los derechos subjetivos 118

4.1.2. Los derechos inalienables 120

4.1.3. Los metaderechos 123

4.1.4. Los derechos fundamentales 124

4.1.5. El mínimo vital 125

4.1.6. El derecho internacional 126

4.1.7. Los derechos económicos 127

4.1.8. El enfoque de derechos y la SAN 128

4.2. LA EVOLUCIÓN FORMAL LEGAL 129

4.2.1. Internacional 130

4.2.2. América Latina 134

4.2.3. Nacional 135 
4.3. EL CÍRCULO VICIOSO DEL DERECHO A LA ALIMENTACIÓN 138

4.3.1. Recapitulación

CAPÍTULOV.LA SOBERANÍA ALIMENTARIA

5.1. ELEMENTOS GENERALES DE LA SOBERANÍA

5.2. ELEMENTOS ESPECÍFICOS DE LA SOBERANÍA ALIMENTARIA

5.2.1. Soberanía alimentaria y territorio

5.2.2. Soberanía alimentaria, comercio y empresas transnacionales

5.2.3. Soberanía alimentaria y la política pública de SAN

6.1.1. Nuevas condiciones generales del capitalismo

6.1.2. Empresas transnacionales, globalización y alimentos

6.1.3. Asimetrías institucionales y globalización

6.1.4. Cambios en las dinámicas de acción del Estado

\subsection{TERRITORIO Y AGROALIMENTOS}

6.2.1. Elementos históricos generales sobre el territorio 164

6.2.2. Producción de alimentos y territorio

6.2.2.1. Un repaso general de la evolución de

\subsection{COLOMBIA: TERRITORIO, INSTITUCIONALIDAD} Y CONFLICTO AGRARIO

6.3.1. Territorio colombiano y producción de alimentos 171

6.3.2. Dos décadas de políticas territoriales en Colombia 173

6.3.2.1. Las políticas regionales, 1980-2010 175

6.3.2.2. Las políticas locales 179

6.3.3. Recapitulación 
CAPITULO VII. LA CADENA ALIMENTARIA

7.1. CONTEXTUALIZACIÓN DE LA CADENA

ALIMENTARIA, EL SISTEMA ALIMENTARIO Y EL GOBIERNO

182

7.1.1. Cadena alimentaria y calidad 186

7.1.2. Cadena alimentaria, participación y competitividad 188

7.1.3. Cadena alimentaria, inocuidad y medioambiente 190

7.1.4. Condiciones institucionales y políticas de SAN en Colombia 192

7.1.4.1. Política económica 193

7.1.4.2. Políticas sectoriales de seguridad alimentaria 194

7.2. DISPONIBILIDAD Y ESTABILIDAD 196

7.2.1. Los elementos generales de la disponibilidad 196

7.2.1.1. Las preguntas 196

7.2.1.2. Evolución del concepto 197

7.2.1.3. Movilidad de cultivos y alimentos 200

7.2.2. Condiciones y políticas 202

7.2.2.1. Institucionalidad y conflicto agrario 202

7.2.2.2. Políticas agrarias 205

7.2.2.3. Nuevo modelo de desarrollo y nuevos derechos 209

7.2.3. Conflictos estructurales, elementos que afectan la disponibilidad y estabilidad de los alimentos 212

7.2.3.1. Colombia, conflictos de usos de la tierra 1996-2009 212

7.2.3.2. Desplazamiento y despojo de tierras 214

7.2.3.3. La concentración de la tierra en Colombia 1996-2008 y la producción de alimentos 220

7.2.4. Disponibilidad y políticas 223

7.2.5. Las disponibilidades de alimentos 226

7.2.5.1. Nivel nacional 226

7.2.5.2. Lo regiolocal: la disponibilidad de los ejes dinamizadores 233

7.2.5.2.1. La disponibilidad en el eje Medellín 233

7.2.5.2.2. La disponibilidad en el eje de Cartagena 243

7.2.5.2.3. Disponibilidad en el eje de Neiva 254

7.2.5.2.4. Disponibilidad eje de Cúcuta 264

7.3. DISTRIBUCIÓN DE ALIMENTOS 272

7.3.1. Elementos generales de la distribución de alimentos 272

7.3.1.1. Evolución de la distribución $\quad 273$

7.3.1.2. Relación de origen y destino de los agroalimentos 277 
7.3.2. Colombia: características en la distribución de alimentos 278

7.3.3. Distribución en los ejes dinamizadores 283

7.3.3.1. Distribución en el eje Medellín 283

7.3.3.2. Distribución en el eje Cartagena $\quad 289$

7.3.3.3. Distribución en el eje Neiva 295

7.3.3.4. Distribución en el eje Cúcuta 301

7.4. ACCESO A LOS ALIMENTOS $\mathbf{3 0 5}$

7.4.1. Elementos generales del acceso 305

7.4.2. Acceso, cultura y SAN 308

7.4.3. Características e intervenciones en el acceso a los alimentos $\quad 310$

7.4.3.1. Acceso a nivel nacional 311

7.4.3.2. Acceso en los ejes dinamizadores $\quad 315$

7.4.3.2.1. Acceso en el eje dinamizador Medellín 315

7.4.3.2.2. Acceso en el eje dinamizador Cartagena 319

7.4.3.2.3. Acceso en el eje dinamizador Neiva 322

7.4.3.2.4. Acceso en el eje dinamizador Cúcuta 326

7.5. USO BIOLÓGICO Y UTILIDAD DE LOS ALIMENTOS 329

7.5.1. Elementos generales de uso biológico y utilidad de los alimentos 330

7.5.1.1. Cadena alimentaria, inocuidad, nutrición y gobiernos 333

7.5.1.2. Salud, alimentación y nutrición 334

7.5.2. Particularidades del uso biológico y la utilidad de los alimentos, niveles nacionales y regionales $\quad 337$

7.5.2.1. Condiciones nacionales de uso y utilidad 338

CONCLUSIONES

ANEXO A: METODOLÓGICO SOBRE ELTRABAJO EN LOS

TERRITORIOS SAN ENTREVISTAS SEMIESTRUCTURADAS 355

ANEXO B: METODOLOGÍA PARA DETERMINAR LA DEMANDA

IDEALY REAL DE LOS MUNICIPIOS EJES DINAMIZADORES 363

ANEXO C:TABLAS ESTADÍSTICAS DE AGROALIMENTOS EN

COLOMBIA, PERIODO 1987-2009 379

BIBLIOGRAFÍA 


\section{ÍNDICE DE TABLAS}

Tabla 1.1. Casos de estudio determinados para la investigación

Tabla 1.2. Relaciones de transversalidad y verticalidad de las políticas públicas en el SSAN y la cadena alimentaria

Tabla 2.1. El territorio: delimitación de su campo problemático

50

Tabla 2.2. Glurbanización frente a glocalización

Tabla 2.3. Elementos generales por tener en cuenta en el análisis de una política pública

Tabla 2.4. Características del diseño y análisis de una política pública y el sistema de seguridad alimentaria nutricional SSAN

Tabla 2.5. Condiciones del diseño de la política pública en seguridad alimentaria nutricional

Tabla 3.1. Uso de tierras a nivel mundial (1000 ha), 2000-2008

Tabla 3.2. Número y prevalencia de personas subnutridas en el mundo, 1969-2008

Tabla 5.1. Elementos comunes en soberanía y seguridad alimentaria

Tabla 5.2. Los 30 gigantes de la industria agroalimentaria mundial

Tabla 6.1. Características de los procesos de integración y las etapas expansión del capitalismo, imperialismo y la globalización

Tabla 6.2. Evolución de las condiciones agroalimentarias

Tabla 7.1.1. Colombia 2003, distribución de establecimientos y ventas de la agroindustria de alimentos

Tabla 7.1.2. Colombia, políticas públicas vinculadas con el sistema seguridad alimentaria y la cadena alimentaria hasta el 2008

Tabla 7.2.1. Colombia, sustitución de agroalimentos por palma de aceite en algunos municipios de la Costa Atlántica

Tabla 7.2.2. Colombia 1946, producción nacional y consumo interno

Tabla 7.2.3. Colombia, superficie total y aprovechamiento de la tierra (total nacional, 1996-2009)

Tabla 7.2.4. Colombia, estimativos de hectáreas abandonadas por la población desplazada

Tabla 7.2.5. Autorías intelectuales y materiales del despojo por periodos de tiempo 1900-2010, en Córdoba, Sucre y Bolívar 
Tabla 7.2.6. Colombia 1995-2010, distribución de tierras abandonadas según rangos catastrales de tamaño de predios

Tabla 7.2.7. Colombia, distribución de los PSM, por usos del suelo, según tamaño (total nacional, 1996-2004)

Tabla 7.2.8. Colombia 2008, área y cantidad de unidades productivas según uso del suelo y tamaño

Tabla 7.2.9. Colombia 2008, área y cantidad de unidades productivas según uso del suelo y tamaño, cultivos transitorios y permanentes

Tabla 7.2.10. Colombia 2008, cultivos transitorios proporción del área plantada y de las explotaciones agropecuarias según tamaño de la explotación (total nacional)

Tabla 7.2.11. Colombia 2008, cultivos permanentes, proporción del área plantada y de las explotaciones agropecuarias según tamaño de la explotación (total nacional)

Tabla 7.2.12. Antioquia, superficie total y aprovechamiento de la tierra 234 1996-2008

Tabla 7.2.13. Antioquia 2004-2009, predios y áreas abandonadas (ordenados según \% de predios)

Tabla 7.2.14. Antioquia, municipios con mayor afectación por abandono forzado de predios hasta 2010

Tabla 7.2.15. Departamento de Antioquia, tamaño de las unidades agrícolas familiares según región relativamente homogénea y municipio

Tabla 7.2.16. Antioquia 2009, características de la dinámica de las UAF

Tabla 7.2.17. Departamento de Antioquia, distribución de los PSM, por usos del suelo, según tamaño, 1996-2004

Tabla 7.2.18. Comparativo de disponibilidad de la región inmediata por grupos de agroalimentos y la demanda ideal del eje Medellín, 2006

Tabla 7.2.19. Bolívar, superficie total y aprovechamiento de la tierra, 1996-2008

Tabla 7.2.20. Bolívar 2004-2009, predios y áreas abandonadas (ordenados según \% de predios)

Tabla 7.2.21. Bolívar, municipios con mayor afectación por abandono forzado de predios hasta 2010

Tabla 7.2.22. Departamento de Bolívar, tamaño de las unidades agrícolas familiares según región relativamente homogénea y municipio

Tabla 7.2.23. Bolívar 2009, características de la dinámica de las UAF 
Tabla 7.2.24. Departamento de Bolívar, distribución de los PSM, por usos del suelo, según tamaño, 1996-2004

Tabla 7.2.25. Comparativo de disponibilidad de la región inmediata por grupos de agroalimentos y la demanda ideal del eje Cartagena

Tabla 7.2.26. Huila, superficie total y aprovechamiento de la tierra, 1996-2008

Tabla 7.2.27. Huila 2004-2009, predios y áreas abandonadas (ordenados según \% de predios)

Tabla 7.2.28. Huila, municipios con mayor afectación por abandono forzado de predios hasta 2010

Tabla 7.2.29. Departamento del Huila, tamaño de las unidades agrícolas familiares según región relativamente homogénea y municipio

Tabla 7.2.30. Huila 2009, características de la dinámica de las UAF

Tabla 7.2.31. Departamento del Huila, distribución de los PSM, por usos del suelo, según tamaño, 1996-2004

Tabla 7.2.32. Comparativo de disponibilidad de la región inmediata por grupos de agroalimentos y la demanda ideal del eje Neiva

Tabla 7.2.33. Norte de Santander, superficie total y aprovechamiento de la tierra, 1996- 2008

Tabla 7.2.34. Norte de Santander 2004-2009, predios y áreas abandonadas ordenado según \% de predios

Tabla 7.2.35. Norte de Santander, municipios con mayor afectación por abandono forzado de predios hasta 2010

Tabla 7.2.36 Departamento de Norte de Santander, tamaño de las unidades agrícolas familiares según región relativamente homogénea y municipio

Tabla 7.2.37. Norte de Santander 2009, características de la dinámica de las UAF

Tabla 7.2.38. Departamento de Norte de Santander, distribución de los PSM, por usos del suelo, según tamaño, 1996-2004

Tabla 7.2.39. Comparativo de disponibilidad de la región inmediata por grupos de agroalimentos y la demanda ideal del eje Cúcuta

Tabla 7.3.1. Colombia 1998-2000, número y participación de ventas según modalidad de participación en los canales de comercialización del mercado de alimentos

Tabla 7.3.2. Medellín, 2008, gastos de las familias en alimentos según canales de distribución

Tabla 7.3.3. Cartagena, 2008, gastos de las familias en alimentos según canales de distribución 
Tabla 7.3.4. Neiva, 2008, gastos de las familias en alimentos según canales de distribución

Tabla 7.3.5. Cúcuta, 2008, gastos de las familias en alimentos según canales de distribución

Tabla 7.4.1. Sisbén Colombia, total de personas, corte 3 de marzo del 2009

Tabla 7.4.2. Sisbén Colombia, total de hogares, corte 3 de marzo del 2009

Tabla 7.4.3. Sisbén Medellín, total de personas, corte 3 de marzo del 2009

Tabla 7.4.4. Sisbén Medellín, total de hogares corte 3 de marzo del 2009

Tabla 7.4.5. Medellín, tasa de desempleo: desocupados/PEA 2001-2009

Tabla 7.4.6. Sisbén Cartagena, total de personas corte 3 de marzo del 2009

Tabla 7.4.7. Sisbén Cartagena, total de hogares corte 3 de marzo del 2009

Tabla 7.4.8. Cartagena, tasa de desempleo: desocupados/PEA 2001-2009

Tabla 7.4.9. Sisbén Neiva, total de personas, corte 3 de marzo de 2009

Tabla 7.4.10. Sisbén Neiva, total de hogares corte 3 de marzo de 2009

Tabla 7.4.11. Neiva, tasa de desempleo: desocupados/PEA 2001-2009

Tabla 7.4.12. Sisbén Cúcuta, total de personas corte 3 de marzo del 2009

Tabla 7.4. 13. Sisbén Cúcuta, total de hogares corte 3 de marzo del 2009

Tabla 7.4.14. Cúcuta, tasa de desempleo: desocupados/ PEA 2001-2009

Tabla 7.4.15. Cúcuta, plan de desarrollo componente: pobreza y población vulnerable

Tabla 7.5.1. Colombia, comparación de desnutrición y exceso de peso en niños de 0 a 4 años, ENSIN 2005-2010, según características sociodemográficas

Tabla 7.5.2. Colombia, comparación de desnutrición crónica de niños de 0 a 4 años, ENSIN 2005-2010

Tabla 7.5.3. Colombia, comparación de desnutrición y exceso de peso en niños y jóvenes de 5 a 17 años, ENSIN 2005-2010, por departamento y regiones

\section{TABLAS DEL ANEXO B}

Tabla 1.1. Alimentos de la canasta agropecuaria

Tabla 1.2. Valor calórico y nutricional de un intercambio de alimentos según agrupaciones de alimentos.

Tabla 1.3. Número de intercambios según densidad de nutrientes y grupos de alimentos

Tabla 1.4. Requerimientos de consumo diario de kilocalorías según rangos de edad y sexo 
Tabla 1.5. Consumo nacional de los principales agroalimentos

Tabla 1.6. Cantidad de alimento que compone un intercambio

Tabla 1.7. Factor de ajuste para peso neto de los alimentos

Tabla 1 8. Caracterización y construcción general de las regiones SAN

Tabla 1.9. Demandas eje dinamizador Medellín

Tabla 1.10. Demandas eje dinamizador Cartagena

Tabla 1.11. Demandas eje dinamizador Cúcuta

Tabla 1.12. Demandas eje dinamizador Neiva

\section{TABLAS DEL ANEXO C}

Tabla 1. Colombia, superficie $(h a)$ de los principales cultivos transitorios, 1987 y 2009

Tabla 2. Colombia, producción y rendimiento de los principales cultivos transitorios, 1987-2009

Tabla 3. Colombia, superficie (ha) de los principales cultivos permanentes 1987 y 2009

Tabla 4. Colombia, producción y rendimientos de los principales cultivos permanentes, 1987 y 2009

Tabla 5. Departamento de Antioquia, superficie, producción y rendimiento de los principales cultivos permanentes, 1987-2009

Tabla 6. Departamento Antioquia, superficie, producción y rendimiento de los principales cultivos transitorios, 1987-2009

Tabla 7. Departamento Bolívar, superficie, producción y rendimiento de los principales cultivos transitorios, 1987-2009

Tabla 8. Departamento Bolívar, superficie, producción y rendimiento de los principales cultivos permanentes, 1987-2009

Tabla 9. Departamento Huila, superficie, producción y rendimiento de los principales cultivos transitorios, 1987-2009

Tabla 10. Departamento Huila, superficie, producción y rendimiento de los principales cultivos permanentes 1987-2009

Tabla 11. Departamento Norte de Santander, superficie, producción y rendimiento de los principales cultivos transitorios 1987-2009

Tabla 12. Departamento Norte de Santander, superficie, producción y rendimiento de los principales cultivos permanentes 1987-2009 


\section{ÍNDICE DE FIGURAS}

Pág.

Figura 2.1. Dinámicas SAN regiolocales, nacionales e internacionales

Figura 2.2. Niveles de análisis de la teoría general de sistemas y la teoría general de los sistemas sociales, cambio de paradigma en la teoría de sistema

Figura 2.3. Sistema de seguridad alimentaria nutricional SSAN

Figura 2.4. Sistema de seguridad alimentaria nutricional y entorno 79

Figura 2.5. Interdisciplinariedad (Coordinación por concepto de nivel superior) $\quad 80$

Figura 4.1. Características y sustentación del derecho a la alimentación 128

Figura 4.2. Colombia. Los obligados y las obligaciones en la realización del derecho a la alimentación

Figura 4.3. Derecho a la alimentación y cadena alimentaria

Figura 7.1.1. Características generales del sistema de seguridad alimentaria nutricional

Figura 7.1.2. Condiciones de control y calidad en cada fase de la cadena alimentaria nutricional

Figura 7.2.1. Sistema alimentario, disponibilidad y estabilidad en la cadena alimentaria

Figura 7.3.1. Sistema alimentario, la distribución en la cadena alimentaria.

Figura 7.3.2. Medellín, mecanismos de distribución de panela

Figura 7.3.3. Medellín, mecanismos de distribución de maíz y fríjol

Figura 7.3.4. Medellín, mecanismos de distribución de plátano

Figura 7.3.5. Medellín, mecanismos de distribución de verduras y frutas

Figura 7.3.6. Medellín, mecanismos de distribución de provisión de abarrotes

Figura 7.3.7. Cartagena, mecanismos de distribución de principales productos regionales

Figura 7.3.8. Cartagena, mecanismos de distribución de bollo de maíz

Figura 7.3.9. Cartagena, mecanismos de distribución de verduras y frutas

Figura 7.3.10. Neiva, mecanismos de distribución de la producción de agroalimentos

Figura 7.3.11. Neiva, organización del comercio para la distribución de frutas

Figura 7.3.12. Neiva, mecanismos de distribución de frutas

Figura 7.3.13. Neiva, mecanismos de distribución de provisión de víveres y granos

Figura 7.3.14. Cúcuta, mecanismos de distribución de fríjol fresco 
Figura 7.3.15. Cúcuta, mecanismos de distribución de arroz

Figura 7.3.16. Cúcuta, mecanismos de distribución de papa

Figura 7.3.17. Cúcuta, mecanismos de distribución de plátano

Figura 7.4.1. Sistema alimentario, el acceso en la cadena alimentaria

Figura 7.5.1. Sistema alimentario, uso biológico y utilidad en la cadena alimentaria.

Figura 7.5.2. Elementos asociados al desarrollo de la desnutrición 


\section{LISTADO DE SIGLAS}

ACNUR Alto Comisionado de las Naciones Unidas para los Refugiados

AECID

Agencia Española de Cooperación Internacional para el Desarrollo

AIEPI

APS

ASDI

AU Atención Integrada a las Enfermedades Prevalentes de la Infancia

BIRF Atención Primaria en Salud

CAR

Agencia Sueca para el Desarrollo Internacional

Agricultura Urbana

CARDIQUE

CCI

Banco Internacional de Reconstrucción y Fomento

Corporación Autónoma Regional de Cundinamarca

CEDETEP

Corporación Autónoma Regional del Canal del Dique

Corporación Colombia Internacional

CENABASTOS Central de Abastos de Cúcuta S.A

CEPAL

Comisión Económica para América Latina y el Caribe

CONPES

Consejo Nacional de Política Económica y Social

CORPOICA

Corporación Colombiana de Investigación Agropecuaria

DANE

Departamento Administrativo Nacional de Estadística

DNP

Departamento Nacional de Planeación

ENSIN

Encuesta Nacional de la Situación Nutricional en Colombia

FAO Organización de las Naciones Unidas para la Alimentación y la Agricultura

FEDEARROZ Federación Nacional de Arroceros

FENALCO Federación Nacional de Comerciantes

ICA Instituto Colombiano Agropecuario

ICBF Instituto Colombiano de Bienestar Familiar

IDEMA Instituto de Mercadeo Agropecuario

IGAC Instituto Geográfico Agustín Codazzi

IICA Instituto Interamericano de Cooperación para la Agricultura

IMC Índice de Masa Corporal

INA Instituto Nacional de Agua

INCODER Instituto Colombiano de Desarrollo Rural

INCORA Instituto Colombiano de la Reforma Agraria

INDUARROZ Industriales del arroz

INVIMA Instituto Nacional de Vigilancia de Medicamentos y Alimentos

IPAA Índice de Precios al Consumidor en el Sector Alimentos 
IPC

MADR

MANA

MEN

MPS

OGM

OMC

ONU

PAN

PIN

PMA

PNR

POMCH

POT

PSM

PSU

OCDE

ODM

SAN

SIPSA

SISBEN

SSAN

TLC

UAF

UNESCO

UNICEF

USAID

ZODES
Índice de Precios al Consumidor

Ministerio de Agricultura y Desarrollo Rural

Mejoramiento Alimentario y Nutricional de Antioquia

Ministerio de Educación Nacional

Ministerio de Protección Social

Organismo Genéticamente Modificado

Organización Mundial del Comercio

Organización de las Naciones Unidas

Plan de Alimentación y Nutrición

Plan de Integración Nacional

Programa Mundial de Alimentos

Plan Nacional de Rehabilitación

Plan de Ordenamiento y Manejo de Cuenca Hidrográfica

Plan de Ordenamiento Territorial

Unidad de medida de observación muestral para la entrevistas, sobre

la propiedad de la tierra, se concibe como un área continua

Plan Social Único

Organización para la Cooperación y el Desarrollo Económico

Objetivos de Desarrollo del Milenio de la ONU

Seguridad Alimentaria Nutricional

Sistema de Información de Precios del Sector Agropecuario

Sistema de Identificación de Potenciales Beneficiarios de Programas

Sociales

Sistema de Seguridad Alimentaria Nutricional

Tratado de Libre Comercio

Unidad Agrícola Familiar

Organización de las Naciones Unidas para la Educación, la Ciencia y la Cultura

Fondo de las Naciones Unidas para la Infancia

Agencia de los Estados Unidos para el Desarrollo Internacional

Zonas de Desarrollo Económico y Social 



\section{INTRODUCCIÓN GENERAL}

E ste trabajo de investigación sobre la Política de seguridad alimentaria nutricional (SAN) y desarrollo territorial en Colombia se desarrolla en el marco del doctorado en Gobierno y Administración Pública de la Universidad Complutense de Madrid y el Instituto Ortega y Gasset.

El objeto de esta investigación es la evolución y el cambio de la Política de Seguridad Alimentaria Nutricional en el periodo 1987-2008 en Colombia, en el contexto de la globalización. Esta investigación se desarrolla por las implicaciones del tema para la población colombiana, dado que es un problema social, ambiental y económico que afecta a comunidades, familias e individuos de diferentes edades, sectores sociales y territorios.

Se realizaron estudios de caso en cuatro ciudades: Medellín, Cartagena, Cúcuta y Neiva, consideradas ejes dinamizadores, pues representan diversas condiciones regionales, sociales, económicas, ambientales, históricas y culturales de la zona urbana y de la región inmediata. Se identificó la canasta de alimentos y su relación con los requerimientos nutricionales de las poblaciones de cada ciudad eje. Posteriormente, se determinó la región de Seguridad Alimentaria y Nutricional (SAN) inmediata: el departamento.

En Colombia, las condiciones geográficas y regionales tienen la capacidad de suplir la oferta alimentaria que se necesita. Esto exige que el Estado disponga un manejo soberano de la producción de agroalimentos, en función de no seguir afectando el compromiso con el derecho a una alimentación adecuada y de permitir que las diferentes normas puedan cumplirse, para que la vida de muchas personas no quede en peligro. En la medida en que una población en estado de desnutrición ve afectada su salud y educación de forma estructural, también se afecta negativamente el desarrollo posterior de los individuos, las familias, las regiones y el país.

El periodo definido se contextualiza desde una serie de reformas del Estado colombiano, algunas de las cuales están relacionadas con la descentralización que determinaron nuevas funciones y competencias en los diferentes niveles de gobierno. Ello ha generado desajustes intergubernamentales con relación a las acciones públicas que debe realizar cada nivel de gobierno sobre la seguridad alimentaria nutricional. 
Uno de los principales desajustes es el hecho de que los gobiernos subnacionales impulsen dinámicas de desarrollo local al promover la producción de agroalimentos a través de la agricultura; sin embargo, estas acciones en los territorios no son posibles de ejecutar, por el control de la política económica del Gobierno nacional para el sector externo. Así, los casos del trigo, el arroz y la cebada muestran que esta situación afecta la capacidad de la disponibilidad agroalimentaria municipal, regional y nacional, y convierte la disponibilidad de agroalimentos en un tema dependiente de su resolución en el exterior.

Otras reformas tuvieron lugar en la década del noventa. Por un lado, se implementó un proceso de apertura comercial que reorientaba el modelo de desarrollo, ahora dirigido por el mercado, lo cual influyó claramente en la producción de agroalimentos en el país. Durante estos años se realiza una serie de reformas administrativas del sector agrario, así como en la orientación de las políticas agrarias, comerciales, financieras y sociales. Por otro lado, una segunda reforma surgió cuando se estructuró la Constitución política de 1991, que reorienta nuevas condiciones instituciones, de políticas y de derechos para los colombianos.

Por otra parte, durante el periodo se emitió una serie de normas que inciden en el manejo de los territorios en Colombia: la Ley 99 de 1993, que reorganiza el sector público para la gestión y conservación del medioambiente; y la Ley 152 de 1994, Orgánica del Plan de Desarrollo, con la que se busca que la nación y las entidades territoriales ejerzan sus funciones en materia de planificación. Además, con la aprobación de la Ley 388 de 1997, sobre desarrollo territorial, que permite al municipio, en ejercicio de su autonomía, promover el ordenamiento de su territorio, buscando que la utilización del suelo por parte de sus propietarios garantice la función social y ecológica de la propiedad.

También hay una serie de compromisos adquiridos por el Estado colombiano en diferentes conferencias mundiales sobre el desarrollo, la población, el hambre, la alimentación, la nutrición y la construcción de los objetivos de desarrollo del milenio (ODM). En la dirección anterior, el Estado colombiano desarrolló otras normas reglamentarias y organizó, en 1994, el Comité Nacional de Nutrición y Seguridad Alimentaria (CONSA) y aprobó el Plan Nacional de Alimentación y Nutrición (PNAN, 1996-2005).

El marco teórico para desarrollar la tesis parte de la interdisciplinariedad, con una visión global e integral y no especializada del problema, que permite diseños y análisis 
de las políticas públicas del Sistema de Seguridad Alimentaria y Nutricional (SSAN). Así, por un lado, se construye un marco del derecho, desde las lógicas del derecho a la alimentación, como parte y sustento de los derechos humanos; por otro, desde la economía se relaciona el criterio de escasez, el desarrollo territorial y la producción de agroalimentos. También con la ciencia política se aborda la política pública desde sus determinaciones, construcciones y el análisis general relacionado con la seguridad alimentaria nutricional.

La visión integral de la cuestión alimentaria tiene en cuenta la soberanía alimentaria, concepto que permite introducir un análisis del territorio, donde lo nacional, lo regional, lo local y lo global se dimensionan de forma distinta a la manera como se han manejado las políticas de agroalimentos, es decir, sin integración. Se aborda también el concepto de cadena alimentaria como instrumento que permite analizar diversos ángulos, por ejemplo, el territorio y la política pública. Y otro aspecto relaciona la satisfacción de necesidades alimentarias y nutricionales de una sociedad, pasa por la construcción de derechos y equidad económica y social. Lo anterior lleva proponer el desarrollo económico territorial a partir de los mínimos de SAN en cada uno de los ejes. Allí, la sostenibilidad ambiental es analizada de manera integral y territorial, desde la cercanía a la mesa y los alimentos limpios.

Por tanto, pueden construirse regiones SAN a partir de la identificación de las mínimas necesidades nutricionales de una población y de su conversión en agroalimentos para producirlos en las zonas más cercanas a las ciudades eje. Se identifica de este modo la necesidad institucional del Estado y los gobiernos nacional y subnacionales de implementar acciones sobre las lógicas de la cadena alimentaria, pero con una integralidad interinstitucional e intergubernamental y a través de la aplicación sistémica de la política pública en seguridad alimentaria nutricional.

El desarrollo de la investigación se compone de siete capítulos, distribuidos en tres partes.

La primera parte, constituye el diseño metodológico y teórico de la investigación en seguridad alimentaria nutricional. Trabaja dos capítulos.

El capítulo 1 señala los elementos metodológicos de la investigación en SAN. Muestra las formas de recolección de la información de tipo cualitativo y cuantitativo en los ámbitos internacional, nacional, regional y local, en diferentes periodos y según fuentes primarias y secundarias. Se identificaron las relaciones entre canasta de alimentos y 
requerimientos nutricionales de la población de las ciudades eje: Medellín, Cartagena, Neiva y Cúcuta, y se desarrollaron sus caracterizaciones. Este proceso se enmarca en una investigación que describe, interpreta y propone alternativas de abordaje frente al fenómeno de la SAN.

El capítulo 2 constituye el marco teórico de la investigación sobre la SAN.Allí se justifica y argumenta la necesidad de discusiones y propuestas sobre el tema orientadas desde la interdisciplinariedad y la integralidad, explicadas por la teoría de los sistemas sociales. Se trabaja desde tres disciplinas del conocimiento: el derecho, que permite analizar el derecho a una alimentación adecuada; la economía política, desde el desarrollo regional y local y sus relaciones con las instituciones; y la ciencia política, para comprender los procesos de las políticas públicas, a partir de las teorías del Estado y el funcionamiento de la acción pública. Desde estas directrices, se encuentran lineamientos para identificar regiones SAN y generar desarrollo territorial, partiendo de los mínimos de SAN y de la dinámica de los cuatros componentes de la cadena alimentaria: disponibilidad, distribución, acceso y uso biológico, y utilidad.

La segunda parte contextualiza el Sistema de Seguridad Alimentaria Nutricional (SSAN). Está conformada por tres capítulos.

El capítulo 3 desarrolla el contexto internacional, a través de la identificación del pensamiento de la FAO y el papel que desempeñan los órganos globales en las políticas públicas de alimentos básicos. A su vez, se abordan aspectos como la demografia, el papel de las empresas multinacionales y el comportamiento de los componentes de la cadena alimentaria mundial, con sus características específicas. Además, se muestran los elementos que permiten entender la incidencia de las políticas de los organismos internacionales y sus relaciones con los mayores países productores de agroalimentos que forman parte de la dieta global.

El capítulo 4 está orientado a la alimentación adecuada, entendida como un derecho humano fundamental; para ello, desarrolla cuatro puntos: los elementos generales conceptuales del derecho a la alimentación adecuada, la evolución formal y legal que este ha tenido a partir de las políticas globales, sus evidencias articuladas en las constituciones de América Latina y las reglamentaciones nacionales tanto de orden legal como de política pública. Analiza también el círculo vicioso del derecho a la alimentación adecuada: pobreza-hambre-malnutrición-enfermedad; y, por último, las condiciones que afectan su aplicación en cada una de las partes de la cadena alimentaria. 
El capítulo 5, referido a la soberanía alimentaria, analiza este concepto desde los elementos generales de la soberanía, con el nacimiento del Estado nacional hasta la conformación del Estado red, donde hay organismos globales sin Estado global que los controle; en consecuencia, las particularidades de la soberanía alimentaria hoy permiten comprender, al integrar estos aspectos, que en el mundo contemporáneo se evidencian unas dinámicas de relaciones desiguales entre países productores y no productores de agroalimentos.

La tercera parte, aborda los territorios, la cadena alimentaria y la SAN. Está conformada por dos capítulos.

El capítulo 6, referido al territorio y los agroalimentos, describe y analiza las nuevas dimensiones dadas al territorio, desde lo conceptual, lo histórico, lo organizativo operativo, lo ambiental, lo político-administrativo y el papel de la cadena alimentaria con sus dinámicas, las acciones y las políticas territoriales en Colombia. Este capítulo incluye una caracterización de las unidades político administrativas de los departamentos y sus regiones como contexto inmediato de las ciudades ejes dinamizadores.

El capítulo 7 trata la cadena alimentaria, trabajándola desde dos aspectos: por un lado, el total del comportamiento de esta en Colombia y, por otro, la región inmediata: los departamentos de los cuatro ejes dinamizadores (Medellín, Cartagena, Cúcuta y Neiva). Estos ejes son analizados desde los componentes de la cadena alimentaria: disponibilidad, distribución, acceso y uso biológico, y utilidad. En cada uno se identifican sus características, tanto en el orden nacional como en el regional y local, así como las implicaciones de la visión sectorial y los diferentes factores que inciden en la política pública alimentaria.

En la dinámica de los componentes de la cadena alimentaria se encuentran diferentes conflictos que los afectan. Estos son de diferente orden:legales, intergubernamentales, administrativos, económicos, fiscales, ambientales y aquellos que se encuentran vinculados al conflicto de la violencia política, con desplazamientos y despojos de campesinos en distintas partes del país, que constituyen expresiones particulares en cada una de las regiones de influencia de los ejes dinamizadores. Se muestra la propuesta de construir regiones SAN a partir de la determinación de los mínimos de requerimientos nutricionales de la población de cada eje dinamizador, expresados a través de las demandas de sus canastas alimentarias de consumo real e ideal de cada eje. 
Además, tres anexos complementan este trabajo: el anexo A presenta la forma de trabajo en los territorios con las entrevistas semiestructuradas; el anexo B explica la metodología que permitió determinar la demanda ideal y real de los ejes dinamizadores; el anexo C contiene cuadros estadísticos de agroalimentos en Colombia entre 19872009. Adicionalmente, al inicio del documento se hace una presentación o resumen en inglés de los principales aspectos o problemas abordados en la tesis. 
PRIMERA PARTE

DISEÑO METODOLÓGICO Y TEÓRICO DE LA INVESTIGACIÓN

EN SEGURIDAD ALIMENTARIA NUTRICIONAL (SAN)

\section{CAPÍTULO I. \\ LOS ELEMENTOS METODOLÓGICOS DE LA INVESTIGACIÓN \\ EN SEGURIDAD ALIMENTARIA NUTRICIONAL (SAN)}

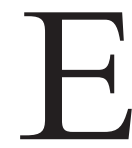

ste capítulo presenta la forma en la cual se abordó el trabajo de investigación. Por un lado, consolida la propuesta general de investigación, que desarrolla la justificación, el objeto, el objetivo general, los objetivos específicos y la hipótesis. Estos puntos orientan el estudio relacionado con el territorio y el periodo de análisis de la información, en los niveles internacional, nacional y subnacional.

El siguiente apartado muestra el diseño metodológico del trabajo investigativo, que identifica los cuatro estudios de caso, el carácter interdisciplinario de la investigación y la organización y periodización de la información, en la cual se tuvo en cuenta la fuente emisora, la revisión bibliográfica, las estadísticas nacionales e internacionales, los documentos públicos nacionales y territoriales y las entrevistas. Toda la información se abordó desde el ciclo de la cadena alimentaria como forma de análisis.

Por último, se desarrolla la metodología para determinar la demanda agroalimentaria de los municipios ejes dinamizadores: se identificó la canasta de alimentos, su relación con los requerimientos nutricionales poblacionales y la determinación de la región SAN inmediata, el departamento.

\subsection{PROPUESTA GENERAL DE LA INVESTIGACIÓN}

\subsubsection{Justificación}

La crisis del desarrollo, con resultados deficientes en los diferentes indicadores sociales nacionales — como la salud, la educación, la vivienda y la seguridad alimentaria-, evidencia el agotamiento de las visiones sectoriales, así como la desarticulación de las acciones públicas en los niveles nacional, departamental, municipal y distrital, que respondan de manera integral, efectiva y pertinente a estas situaciones. La seguridad 
alimentaria, tema de la investigación, se identifica como uno de los factores con mayor incidencia sobre el bienestar de la población, particularmente entre 1987 y 2008.

La visión sectorial sobre la seguridad alimentaria afecta diferentes condiciones, empezando por el derecho humano fundamental a una alimentación adecuada; además, ello provoca desajustes en las relaciones intergubernamentales por la vía de las acciones de las políticas públicas del Gobierno nacional y su aplicación por parte de los gobiernos subnacionales.

A partir de 1987, inicio del periodo de análisis, se promueve una serie de reformas del Estado; entre ellas, para determinar el periodo de estudio, tiene especial importancia la reforma descentralizadora del Estado colombiano, que buscó dar mayor autonomía a los diferentes gobiernos subnacionales existentes en los municipios y distritos, a través de la descentralización política, administrativa y fiscal. Su mayor expresión fue la primera elección popular de alcaldes en 1988, extendida a los departamentos con la elección popular de gobernadores a partir de la Constitución de 1991.

Estas reformas determinan nuevas funciones y competencias en los diferentes niveles de gobierno, al trasladar algunas del nivel nacional a los ámbitos subnacionales. Ello ha generado desajustes intergubernamentales con relación a las acciones públicas que sobre la seguridad alimentaria nutricional debe realizar cada nivel de gobierno. Uno de los principales desajustes es el hecho de que los gobiernos subnacionales impulsen dinámicas de desarrollo local al promover la producción de agroalimentos a través de la agricultura; sin embargo, estas acciones en los territorios no son posibles por el control de la política económica nacional para el sector externo: los casos del trigo, el arroz y la cebada muestran que esta situación afecta la capacidad de la disponibilidad agroalimentaria municipal, regional y nacional, y convierte la disponibilidad de agroalimentos en un tema dependiente de su resolución en el exterior.

Según lo anterior, la competencia de los gobiernos subnacionales para tener una disponibilidad regional se contradice con las decisiones del Gobierno nacional por la vía de las políticas agraria, comercial y financiera. Así, desde esta vía, la decisión de usos del suelo rural, que es competencia de los gobiernos y concejos municipales y distritales, es cambiada por la decisión de la política económica nacional.

Es importante tener en cuenta que a partir de la década del noventa, Colombia inicia un proceso de apertura comercial que reorienta el modelo de desarrollo, ahora dirigido 
por el mercado. Esto influyó claramente en la producción de agroalimentos en el país. Durante estos años se realiza una serie de reformas administrativas del sector agrario en el interior del Estado, así como en la orientación de las políticas agrarias, comerciales, financieras y sociales.

Por otra parte, durante el periodo se emitió una serie de normas que inciden en el manejo de los territorios en Colombia: la ley 99 de 1993, que crea el Ministerio del Medio Ambiente, reorganiza el sector público para la gestión y conservación del medioambiente, por cuanto orienta las acciones públicas ambientales sobre los territorios; y con la ley 152 de 1994, Orgánica del Plan de Desarrollo, se busca que la nación y las entidades territoriales ejerzan sus funciones en materia de planificación.

Un punto central en estos procesos legales es la aprobación de la Ley 388 de 1997 sobre desarrollo territorial. Esta norma crea los mecanismos que permiten al municipio, en ejercicio de su autonomía, promover el ordenamiento de su territorio, el uso equitativo y racional del suelo y la preservación y defensa del patrimonio ecológico y cultural, buscando que la utilización del suelo por parte de sus propietarios garantice la función social de la propiedad. Promueve además la concurrencia de la nación, las entidades territoriales, las autoridades ambientales y las instancias y autoridades administrativas y de planificación, las cuales determinan en esta dirección los usos del suelo en la zona urbana y rural. En este último caso se identifican las áreas para la producción de agroalimentos, y de esta forma se confirman las competencias de cada nivel de gobierno sobre el territorio.

De manera simultánea, con la Constitución de 1991, Colombia ratifica diferentes compromisos internacionales relacionados con derechos fundamentales de niños y niñas a una alimentación equilibrada, y en este sentido, orienta acciones hacia el acceso. También establece una protección especial a la producción de agroalimentos y defiende los derechos colectivos y del ambiente, con lo cual busca garantizar las condiciones de inocuidad, de forma transversal, para los procesos presentes en la cadena alimentaria.

Por lo tanto, los compromisos adquiridos por el Estado colombiano en diferentes conferencias mundiales sobre el desarrollo, la población, el hambre, la alimentación, la nutrición y la construcción de los objetivos del milenio, desde 1994 hasta el 2009, tuvieron en cuenta problemas sociales, nutricionales, económicos y de desarrollo. En estos se consideró la necesidad del bienestar a partir de la nutrición humana, la cual retribuiría con mayor productividad el aprendizaje e implicaría menores gastos en salud 
para las diferentes poblaciones. En gran medida, en el diseño e impulso de la política de seguridad alimentaria y nutricional hay un compromiso internacional del Estado con estas conferencias, las cuales fueron desarrolladas durante el periodo contemplado en la investigación.

En la dirección anterior, el Estado colombiano desarrolló otras normas reglamentarias y organizó en 1994 el Comité Nacional de Nutrición y Seguridad Alimentaria (CONSA); además, aprobó el Plan Nacional de Alimentación y Nutrición (PNAN, 1996-2005). Las líneas de acción de este plan orientan la producción e importación de alimentos para satisfacer las necesidades y alimentar a una población, a la vez que analizan la situación de las familias, las personas y los diversos factores que afectan su seguridad alimentaria.

En este periodo se promueven diferentes políticas sociales nacionales a través de algunos documentos CONPES ${ }^{1}$ : el 91 del 2005, sobre las metas y estrategias de Colombia para el logro de los Objetivos de Desarrollo del Milenio 2015 (ODM); el 3375 del 2005, que trata sobre la Política Nacional de Sanidad Agropecuaria e Inocuidad de Alimentos para el Sistema de Medidas Sanitarias y Fitosanitarias; y el 102 del 2006, sobre la Red de Protección para la Reducción de la Extrema Pobreza. También se encuentra el decreto 3039 del 2007, que crea el Plan Nacional de Salud Pública (PNSP), periodo 2007-2010.

Un argumento central en la orientación del Estado hacia la SAN se plantea al final del periodo (año 2008) en los siguientes términos:

Una de las principales restricciones para el logro de la SAN ha sido la inexistencia de una instancia de alto nivel que logre vincular a todos los sectores y niveles que intervienen en su planeación, desarrollo, seguimiento y evaluación, cada uno desde sus competencias, y que lidere y coordine las acciones derivadas en el tema, establezca lineamientos de política y normativos y articule la seguridad alimentaria y nutricional con otras políticas públicas, tales como la de pobreza ${ }^{2}$.

1 Son documentos de política pública colombiana. Su sigla refiere al Consejo Nacional de Política Económica y Social.

2 Consejo Nacional de Política Económica y Social (CONPES) 113 de 2008, Política Nacional de Seguridad Alimentaria y Nutricional (PSAN), Bogotá, pág. 34. 
En este sentido, se configura una reorganización institucional para orientar la política de SAN. El documento CONPES 113 tiene en cuenta una mayor integralidad para la Política Nacional de SAN, y a través de la Comisión Intersectorial de Seguridad Alimentaria y Nutricional (CISAN) crea una instancia responsable de la coordinación de esta política, con el fin de comprometer a las entidades públicas nacionales desde una visión sectorial. De acuerdo con los componentes de la cadena alimentaria, las competencias institucionales se distribuyen así:

- Disponibilidad: Ministerio de Agricultura y Desarrollo Rural; Ministerio de Comercio, Industria y Turismo; Instituto Colombiano de Desarrollo Rural.

- Acceso: Departamento Administrativo para la Prosperidad Social; Ministerio de Educación Nacional; Instituto Colombiano de Bienestar Familiar.

- Aprovechamiento: Ministerio de Salud y Protección Social; Ministerio de Vivienda, Ciudad y Territorio; Ministerio de Ambiente y Desarrollo Sostenible.

- Consumo: Ministerio de Salud y Protección Social; Ministerio de Educación Nacional; Asociación Colombiana de Facultades de Nutrición.

- Calidad e inocuidad: Ministerio de Ambiente y Desarrollo Sostenible; Departamento Nacional de Planeación.

Por otra parte, esta Comisión Intersectorial tiene varias funciones: la coordinación de la Política Nacional de Seguridad Alimentaria y Nutricional; la elaboración, concertación, articulación, promoción e implementación del Plan Nacional de Seguridad Alimentaria y Nutricional (Plan SAN), y la promoción y creación del Observatorio de Seguridad Alimentaria y Nutricional (OBSAN). Ahora bien, es necesario tener en cuenta que durante el 2008 se realizaron diferentes encuestas y el trabajo de campo para la investigación, tanto para los estudios de caso como en relación con los otros territorios. Estas dinámicas contaron con el apoyo del grupo de investigación sobre desarrollo territorial de la Escuela Superior de Administración Pública (ESAP).

A partir de estas múltiples situaciones, se considera necesario trabajar el problema alimentario de otra manera: identificar los puntos que contribuyan a proponer integralmente estrategias nacionales, departamentales, municipales y distritales que 
garanticen el derecho a la alimentación adecuada, la soberanía alimentaria y el desarrollo territorial en el marco de la globalización.

\subsubsection{Objeto y objetivos de la investigación}

\subsubsection{Objeto de la investigación}

El objeto de la investigación es la evolución y el cambio de la Política de Seguridad Alimentaria Nutricional (SAN) en el periodo 1987-2008 en Colombia, en el contexto de la globalización. Esta investigación se desarrolla por las implicaciones del tema para la población colombiana, dado que es un problema social que afecta a comunidades, individuos de diferentes edades, sectores sociales y territorios. Para el diseño metodológico se tuvieron en cuenta varios elementos: la identificación de los requerimientos nutricionales para la población de los estudios de caso, según sus necesidades y de acuerdo con la estructura etaria y el sexo. Estos requerimientos se traducen en los agroalimentos que necesitan los individuos en los diferentes territorios, y posteriormente se determina dónde se producen o de dónde vienen. Para este diseño se consideraron los componentes de la cadena alimentaria, la cultura y la cercanía a la mesa.

A partir de los requerimientos nutricionales identificados para la población de los estudios de caso, se determinan los alimentos que los aportan, junto a la dinámica de la cadena alimentaria. Por otro lado, a través de los gobiernos se analizan las acciones públicas que generan procesos de desarrollo regional y local, a partir de los mínimos de seguridad alimentaria nutricional y de la producción territorial de agroalimentos.

En Colombia, las condiciones geográficas y regionales tienen la capacidad de suplir la oferta alimentaria que se necesita. Esto exige un manejo soberano por parte del Estado de la producción de alimentos, en función de no seguir afectando el compromiso con el derecho a una alimentación adecuada y permitir que las diferentes normas puedan cumplirse, para que la vida de muchas personas no quede en peligro. En tanto una población en estado de desnutrición ve afectada su salud y educación de forma estructural, también se afecta negativamente el desarrollo posterior de los individuos, las familias, las regiones y el país.

Las ciudades para los estudios de caso fueron Medellín, Cartagena, Cúcuta y Neiva, consideradas ejes dinamizadores, pues representan diversas condiciones regionales, sociales, económicas, ambientales, históricas y culturales en la zona urbana y en la 
región inmediata: el departamento. Por tanto, se analiza el vínculo entre estos ejes dinamizadores y su región inmediata como oferente de agroalimentos.

Adicionalmente, se identifican las desarticulaciones existentes en las relaciones intergubernamentales e interinstitucionales presentes entre los niveles nacional, departamental, municipal y distrital, y aquellas otras relacionadas con la seguridad alimentaria nutricional. Por otro lado, se analizan las políticas en la SAN a través de los componentes de la cadena alimentaria: disponibilidad, distribución, acceso y uso biológico de los alimentos.

La investigación, entonces, se acerca al problema alimentario en Colombia partiendo del análisis desde diferentes disciplinas y sectores sociales, y teniendo en cuenta la intervención de los diferentes gobiernos territoriales.

\subsubsection{Objetivo general}

Analizar la política de seguridad alimentaria en Colombia en relación con la garantía de la autonomía alimentaria a partir del estudio de cuatro ejes territoriales.

\subsubsection{Objetivos específicos}

- Describir los factores condicionantes de la política alimentaria: económicos, sociales, políticos y ambientales, vinculados a la cadena alimentaria y a las condiciones intra e interterritoriales.

- Analizar la política pública de seguridad alimentaria nutricional en Colombia, tomando como referencia la acción de los Gobiernos nacional y subnacionales.

- Contrastar mediante estudios de caso la ejecución de la política pública de seguridad alimentaria nutricional en los ejes territoriales de Medellín, Cartagena, Cúcuta y Neiva.

\subsubsection{Formulación de hipótesis}

La política de seguridad alimentaria colombiana, basada en la orientaciones emanadas de organizaciones supranacionales y formulada por el Gobierno central de forma homogénea para todo el territorio nacional, está atravesada por desajustes interinstitucionales en la fase de implementación en el territorio. 


\subsection{DISEÑO METODOLÓGICO}

El tipo y diseño investigativo tiene instrumentos cuantitativos y cualitativos; además, por las características que presenta el problema alimentario, este se realiza desde una visión interdisciplinaria. Para dar cumplimiento al objetivo general descrito, se analizan cuatro territorios, y en cada uno de ellos se diferencia un eje urbano dinamizador y la unidad político-administrativa departamental a la que pertenece. Los territorios fueron seleccionados a partir de los siguientes criterios:

- Representatividad cultural de las regiones geográficas del país.

- Heterogeneidad en las condiciones de los ejes urbanos y las unidades políticoadministrativas departamentales

- Heterogeneidad en las condiciones que presenta la cadena alimentaria.

- Existencia de información institucional relacionada con la SAN.

- Pertinencia del estudio de acuerdo a las prioridades en salud pública.

\subsubsection{Identificación de los territorios}

El nivel nacional contextualiza las acciones que se desarrollan en los diferentes territorios seleccionados como caso, tanto en el orden de las políticas públicas como en el de la información cuantitativa y cualitativa recolectada desde diferentes fuentes. Por su parte, en el orden territorial, la espacialidad está determinada a partir de la identificación de los centros urbanos con demanda de alimentos e infraestructura para el funcionamiento de la cadena alimentaria. En ellos se concentran las instituciones políticas y administrativas y del departamento; este último, como unidad político-administrativa al que estas pertenecen, e identificado desde el punto de vista metodológico como la región inmediata del eje.

Estos centros urbanos se han denominado ejes dinamizadores, y todos corresponden a capitales de departamento, con elementos comunes en cuanto a la acogida de población desplazada por el conflicto regional y nacional, su mayor concentración poblacional en cada departamento y su diversidad cultural: costa caribe, zona andina, piedemonte llanero y zona de frontera internacional (tabla 1.1).

\subsubsection{Descripción y periodización de la información}

Para el desarrollo de la investigación, se recogió información cuantitativa disponible en fuentes institucionales. Su emisión, periodicidad y sistematización varían, por tratarse de 
Tabla 1.1. Casos de estudio determinados para la investigación

\begin{tabular}{|c|c|}
\hline Eje dinamizador & Departamento \\
\hline Medellín & Antioquia \\
\hline Cartagena & Bolívar \\
\hline Cúcuta & Norte de Santander \\
\hline Neiva & Huila \\
\hline
\end{tabular}

información procedente de organizaciones nacionales e internacionales. En concreto, la información sobre la que se ha trabajado en la investigación es la siguiente:

a. Caracterización de la estructura demográfica del municipio eje y la producción departamental de agroalimentos. Se toma un año de corte de la información requerida: el 2006.

b. Producción agroalimentaria en los ámbitos departamental y nacional, periodo 1987- 2009.

c. Tamaño de la propiedad por tipo de cultivo nacional y departamental, año 2008.

d. Concentración de la tierra en los ámbitos nacional y territorial, periodo 19962004.

e. Usos de la tierra y su aprovechamiento nacional y departamental, periodo 1996-2008.

f. Predios y áreas abandonadas por la violencia reciente de orden nacional y departamental, periodo 2004-2009.

g. Características de las Unidades Agrícolas Familiares (UAF), nacionales y departamentales, año 2009.

h. Canales de distribución y gastos de las familias en el orden nacional y territorial, año 2008.

i. Tasas de desnutrición en el orden nacional y territorial, 2005 y 2010.

j. A nivel internacional se presentan: la población de 1999-2010; el uso y aprovechamiento de tierras en 2000-2008; la producción mundial de agroalimentos en el periodo 1994-2009; el comercio exterior de cereales por país exportador e importador en 1994-2008; y la población en estado de subnutrición por país de más de 1.500.000 personas, periodo 1999-2009.

La información cualitativa se recogió a través de entrevistas estructuradas realizadas a diferentes actores sociales en el 2008, en los niveles nacional, departamental y local. 


\subsubsection{Fuentes de información para la investigación}

Se han trabajado diferentes fuentes de información que permiten un análisis general tanto de orden primario como secundario. En este caso, respecto a la información cualitativa y cuantitativa, cada tabla presenta al pie la fuente y el ejercicio de cálculos.

\subsubsection{Información estadística y seriada}

Para la información estadística internacional, la principal fuente de información institucional seriada y consultada fue la emitida por la Organización de las Naciones Unidas para la Agricultura y la Alimentación (FAO), el Programa Mundial de Alimentos (PMA) y el Fondo de las Naciones Unidas para la Infancia (UNICEF). En gran medida, estas instituciones recopilan los datos sobre la situación de alimentación mundial y la inseguridad alimentaria. En este caso, los documentos oficiales y periódicos de cada entidad forman parte de las consultas realizadas.

La información estadística nacional fue tomada de diferentes oficinas del Gobierno nacional, departamental y municipal en Colombia, cuyos organismos son responsables de la información social y económica del país. Fueron consultadas las siguientes entidades públicas y privadas:

- Departamento Administrativo Nacional de Estadística (DANE)

- Ministerio de Agricultura y Desarrollo Rural (MADR)

- Departamento de Acción Social de la Presidencia de la República

- Instituto Colombiano de Bienestar Familiar (ICBF)

- Instituto Geográfico Agustín Codazzi (IGAC)

- Departamento Nacional de Planeación (DNP)

- Corporación Colombia Internacional (CCI)

\subsubsection{Documentos públicos nacionales}

Diferentes oficinas de los gobiernos a nivel nacional, departamental y municipal en Colombia elaboran documentos que permiten identificar las acciones por desarrollar en cada uno de los territorios. En este sentido, fueron documentos orientadores de las políticas públicas: 
- Planes de desarrollo nacional y municipal

- Planes de ordenamiento territorial de los municipios ejes

- Regulaciones de nivel nacional, departamental y municipal

- Informes de la presidencia de la república y de las entidades territoriales de muestra

\subsubsection{Entrevistas}

En el anexo A se relacionan las 135 personas entrevistadas y se presentan los guiones de las entrevistas semiestructuradas, realizadas a funcionarios públicos de diferentes niveles de gobierno: municipales (45), distritales (11), departamentales (31), nacionales (8), expertos (32) y actores sociales (8). Esta información cualitativa se relaciona con la cuantitativa, y su análisis se desarrolla en el capítulo VII.

Las aclaraciones de tipo conceptual y teórico se efectuaron con profesionales de la salud y nutricionistas, a fin de entender las relaciones entre alimentación y crecimiento físico, y entre capacidades de estudio y trabajo de las personas. Con profesionales del derecho se consultaron o resolvieron las dudas relacionadas con el derecho a la alimentación, para determinar las necesidades kilocalóricas en productos.

Además, con comerciantes de plazas de mercado se consultó información sobre el origen de los productos agroalimentarios de la canasta familiar, su acopio y distribución, en las plazas de Medellín (La Mayorista), Neiva (Surabastos), Cúcuta (Cenabastos) y Cartagena (Bazurto).

Se consultó también como fuente afuncionarios públicos encargados de los programas de SAN, en cada componente de la cadena alimentaria, de acuerdo con las funciones y competencias de cada nivel de gobierno. Por último, con expertos se abordaron temas especializados en el interior de cada componente de la cadena alimentaria.

\subsubsection{Organización y sistematización de la información}

La información recogida se estructuró y analizó tomando como criterio organizador los cuatro componentes de la cadena alimentaria: a) disponibilidad y estabilidad, b) distribución, c) acceso y d) uso y utilidad biológica. En cada caso se revisan diferentes fuentes primarias y secundarias, las cuales permiten tener una información con los mismos ítems tanto en las políticas como en las acciones, las condiciones y los territorios. 
Los elementos anteriores muestran unas relaciones verticales, que se dan en el interior de cada proceso entre los gobiernos y entre los actores. Estas relaciones operan en cada componente de la cadena alimentaria, en términos de disponibilidad, distribución, acceso y usos y utilidad biológica; además, muestran la incomunicación entre los gobiernos y los actores. Las otras relaciones presentadas son de orden transversal, las cuales funcionan entre los componentes a lo largo de la cadena donde las vinculaciones inversas no muestran el carácter comunicativo. Los dos tipos de relaciones se muestran en la tabla 1.2.

Tabla No. 1.2 Relaciones de transversalidad y verticalidad de las políticas públicas en el SSAN y la cadena alimentaria

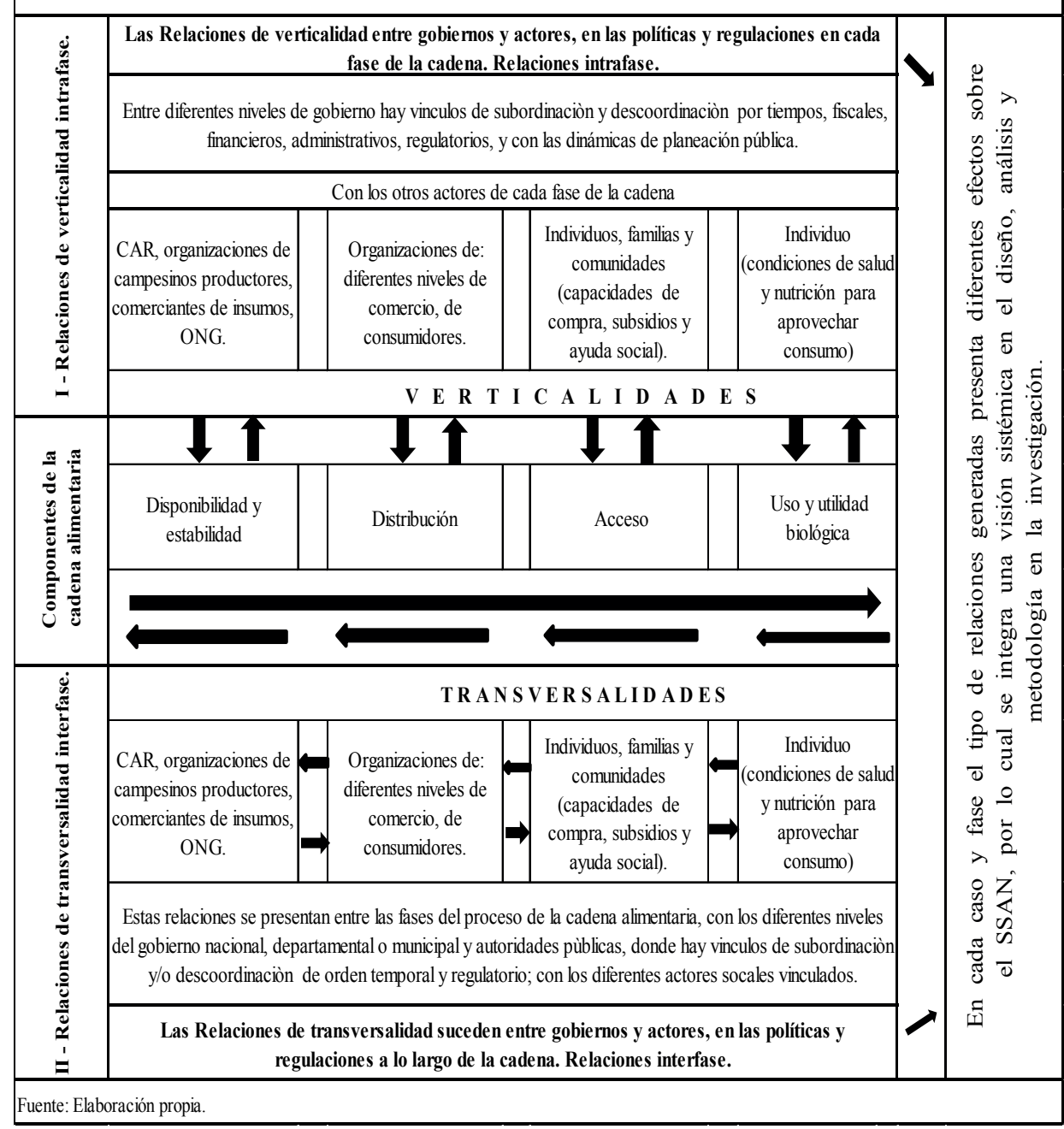




\subsubsection{Cálculo para determinar las regiones SAN}

La determinación de las regiones SAN, entendidas como la unidad territorial mínima que permite satisfacer las necesidades alimentarias y nutricionales de una población, se calculó a partir de los siguientes criterios que se desarrollan en el anexo B: canasta de alimentos, relaciones entre canasta de alimentos y requerimientos nutricionales de la población, caracterización general y particular de los municipios ejes dinamizadores y determinación de la región SAN inmediata (el departamento). 



\title{
CAPÍTULO II. MARCO TEÓRICO DE LA INVESTIGACIÓN SAN
}

\begin{abstract}
71 presente marco teórico toma elementos de distintas áreas del conocimiento E para hacer un análisis a través de la interdisciplinariedad, lo cual permitirá dar una visión más global, integral y no especializada del problema.
\end{abstract}

Desde varias disciplinas se plantea la necesidad de construir una visión integral de la cuestión alimentaria; por ello, esta es pensada desde diferentes planos: por un lado, desde la soberanía alimentaria, concepto que permite introducir un análisis del territorio, donde lo nacional, lo regional, lo local y lo global se dimensionan de forma distinta a como se han manejado las políticas de agroalimentos sin integración ${ }^{3}$; por otro lado, desde la cadena alimentaria (disponibilidad, distribución, acceso y uso biológico), analizando diversos ángulos tanto del territorio como de la política pública e identificando las necesidades alimentarias y nutricionales de una población respecto a los derechos y la equidad económica y social; por último, desde el desarrollo económico territorial, a partir de los mínimos de SAN y en relación con la sostenibilidad ambiental, vista y analizada de manera compleja.

De acuerdo con lo anterior, el orden teórico se fundamenta en tres aspectos de diferentes disciplinas: el primero es el horizonte de los derechos humanos; el segundo proviene de la economía y se relaciona con el criterio de escasez, la relación económica de los alimentos y las mercancías, el desarrollo territorial, los territorios y agroalimentos; el tercero se construye a partir de la ciencia política y las políticas públicas al ubicar sus determinaciones, construcciones y análisis general en relación con la seguridad alimentaria nutricional.

En este estudio también se explica la propuesta de la tesis, que busca entender y relacionar dos elementos sustanciales en el trabajo: por un lado, la interdisciplinariedad y, por el otro, la teoría crítica de los sistemas sociales. Las dos herramientas permiten analizar y percibir la SAN de una forma integrada.

\subsection{DERECHO}

Sustentado en los derechos humanos conexos al de una alimentación adecuada, y dada la trascendencia de este componente teórico en términos de las políticas y las

3 Este tema es abordado en el capítulo 5 del presente documento. 
obligaciones del Estado, el capítulo cuarto trata tanto las argumentaciones jurídicas como los compromisos nacionales e internacionales en esta materia, como forma de responsabilidad de los órganos globales, los Estados nacionales y la sociedad.

\subsection{ECONOMÍA}

Desde la perspectiva de la economía vinculada a los alimentos, el problema no es la escasez; sin embargo, excepcionalmente lo será por condiciones imprevistas de orden natural. Aunque esto no se muestra en las discusiones de política económica de agroalimentos, en economía no pueden separarse los intereses y las acciones de los actores que dirigen el Estado. En este sentido, se habla de economía política.

Moore y Collins plantean en este sentido: "La época de los comestibles de bajo precio parece haber terminado para siempre. La demanda sin precedente de los países pobres está ejerciendo presión sobre los recursos alimentarios de los grandes exportadores"4. Las preocupaciones de estos autores muestran que la crisis de sobreproducción de los años treinta del siglo XX dejó en evidencia que "hay escasez, pero no de alimentos. Lo que escasea es población con acceso a los medios para producir sus propios alimentos o al dinero para comprarlos" ${ }^{5}$. Esta tendencia puede verse hoy en la dinámica global de producir agroalimentos por países, como puede rastrearse en el capítulo tercero. Esta investigación muestra que los problemas de desnutrición en Colombia no son de disponibilidad de alimentos, sino de acceso.

En este punto puede indicarse con Moore y Collins, a partir de su obra Comer es primero:

Mientras los alimentos se compren y se vendan como cualquier otra mercancía y mientras gran parte de la gente sea demasiado pobre para comprar los alimentos que necesita, el principal problema de los economistas agrícolas seguirá siendo la amenaza de los excedentes, no la escasez ${ }^{6}$.

\footnotetext{
4 MOORE L., Francés y COLliNS, Joseph (1982): Comer es primero. Más allá del mito de la escasez. Siglo XXI Editores, México, pág. 56.

5 Ibíd., pág. 59

6 Ibíd., pág. 59
} 


\subsubsection{La discusión del desarrollo regional y local}

Se parte de la siguiente afirmación de Coraggio:

El espacio real es categoría (determinación constitutiva) de los objetos físicos —donde el término 'objeto' no se limita a designar las 'cosas', sino así mismo las relaciones de los procesos físicos-. Esto se expresa gnoseológicamente en que no pueden elaborarse sistemas teóricos que den cuenta de los procesos físicos sin una conceptualización acerca de la espacialidad de estos fenómenos. El espacio no es algo que está 'al lado de otros' objetos físicos, sino que es condición de existencia de estos ${ }^{7}$.

La discusión sobre desarrollo económico lleva a preguntar sobre el territorio: ¿de qué se habla al intervenir económicamente para orientar, reorientar o iniciar procesos de desarrollo en alguna zona del país, del mundo, de una región o microrregión? Independientemente del tamaño, se define un territorio a partir de dinámicas sociales, ambientales, económicas, políticas, político-administrativas y de la administración pública. Esta discusión no es nueva ${ }^{8}$ : se refiere a las interrelaciones presentadas para organizar el territorio hacia una acción pública relacionada con la economía en los territorios.

Entender hoy el desarrollo regiolocal significa analizar la revalorización del territorio 9 en todas sus dimensiones y funciones, ya que el Estado nacional dejó de ser "unidad de

7 CORAGGIO, José L. (1989): “Sobre la espacialidad social y el concepto de región”. En La cuestión regional en América Latina (autores varios). Quito Ediciones, Quito, pág. 69.

8 Una buena síntesis, entre otras, de estas discusiones la vemos en: PIPITONE, Ugo (2003): Ciudades, naciones, regiones. Los espacios institucionales de la modernidad. Fondo de Cultura Económica, México. En esta obra se relacionan varios procesos organizativos en el territorio desde la ciudad mercantil, el Estado nacional y la región plurinacional, pensando en sus diferentes dinámicas territoriales.

9 Entre otros, los siguientes trabajos permiten entender esta discusión desde los procesos de interpretación económica: BENKO, Georges y LIPIETZ, Alain (1994): "El nuevo debate regional". En Las regiones que ganan distritos y redes. Los nuevos paradigmas de la geografía económica. Edicions Alfons, Valencia; FURIÓ, Elies (1996): Evolución y cambio en la economía regional. Ariel, Barcelona; y POLÈSE, Mario (1998): Economía urbana y regional introducción a la relación entre territorio y desarrollo. Libro Universitario Regional, Costa Rica. 
control y gestión del capitalismo"10. Esta función es propia ahora de los territorios y sus unidades político-administrativas, así como en los gobiernos departamentales distritales y municipales, a partir de regulaciones impulsadas por políticas e instituciones globales a través del Estado nacional.

\subsubsection{La revalorización territorial}

En lo territorial, el desarrollo regiolocal ${ }^{11}$ y su revalorización expresan "conceptos y paradigmas como el desarrollo endógeno, la competitividad territorial, la innovación y la sociedad del conocimiento, [...] construidos de la mano de la teoría del desarrollo económico local"12. Así, la revalorización del territorio está vinculada a las presiones del capital en la globalización y en la era de la información, lo que conlleva una división en el interior de los territorios para su expansión. Estrada habla de una:

[...] reorganización geográfica del proceso de producciónreproducción. La imposición de una nueva lógica territorial de acumulación ha traído consigo el surgimiento y despliegue no concluido, de una nueva espacialidad capitalista; [por la] extensión de la relación social capitalista a territorios anteriormente no sometidos y otro, la redefinición del papel de territorios ya vinculados a ellas ${ }^{13}$.

Esta expansión del capitalismo y su reorientación muestra pugnas por el control de los recursos, los circuitos y las áreas de mercado por parte de empresas transnacionales y grandes agronegocios. Estas son nuevas condiciones y funciones para revalorizar hoy el territorio para el desarrollo, a partir de políticas y acciones que exigen territorios dinámicos y con autonomía para reducir costos.

10 Chomsky, Noam, citado en CUERVO, Luis M. (2003): Ciudad y globalización en América Latina: estado del arte. ILPES-CEPAL, Santiago de Chile, pág. 12.

11 Es entendido en primera instancia, para efectos de esta tesis, como los límites políticoadministrativos del departamento.

12 CEPAL (2009): Economía y territorio en América Latina y el Caribe: desigualdades y políticas. Santiago de Chile, pág. 141.

13 ESTRADA A., Jairo (2010): Derechos del capital dispositivos de protección e incentivos a la acumulación en Colombia. Universidad Nacional de Colombia, Bogotá, pág. 36. En esta misma línea está la obra de CUERVO, Luis M. (2006): Globalización y territorio. ILPES-CEPAL, Santiago de Chile. 
Ubicados en territorios específicos de intervención y de decisión, es necesario entender los simbolismos donde "los actores sociales (individuales o colectivos) proyectan sus concepciones del mundo" "Esto implica que las acciones públicas, colectivas o privadas definen criterios de identidad y cultura territorial. En el territorio se identifican generalidades y particularidades, sin desconocer que hay otras características, como anota Milton Santos:

[Hay] situaciones intermedias entre la universalidad y la individualidad. Lo universal es el Mundo como Norma [...], pero que crea y recrea espacios locales; lo particular viene dado por el país, esto es, el territorio normalizado; y lo individual es el lugar, el territorio como norma. La situación intermedia entre el mundo y el país viene dada por las regiones supranacionales. La situación intermedia entre el país y el lugar es el conjunto de regiones infranacionales, subespacios legales o históricos. El orden global busca imponer, en todos los lugares, una única racionalidad y los lugares responden al mundo según los diversos modos de su propia racionalidad ${ }^{15}$.

Estas relaciones se sustentan en la tecnología de la era de la información y se integran a las condiciones físicas de los territorios. La relación territorio-agroalimentos requiere condiciones de proximidad, lo que no implica que sean condiciones autárquicas, por razones ambientales, económicas, sociales y racionales en el uso de los recursos, aspectos que son abordados a lo largo de este trabajo.

Al integrar los vínculos de lo global y lo local, se encuentran e identifican diferentes espacios en la revalorización territorial: "Los conceptos de espacio, territorio, región, localidad y otros se utilizan como sinónimos de una realidad difusa"16, lo cual se reconfigura a la luz de nuevos acontecimientos sociales, ambientales, políticos, tecnológicos, económicos y culturales.

14 GIMÉNEZ, Gilberto (2000): “Território, cultura e identidades. La región sociocultural”. En Martín-Barbero, Martín et al. (Eds.): Cultura y región. CES, Universidad Nacional de Colombia y Ministerio de Cultura, Bogotá, pág. 25.

15 SANTOS, Milton (2000): La naturaleza del espacio. Técnica y tiempo. Razón y emoción. Ariel, Barcelona, pág. 289.

16 LIRA C., Luis (2003): La cuestión regional y local en América Latina. ILPES-CEPAL, Santiago de Chile, pág. 7. 
El campo problemático de análisis del territorio se delimita en la tabla 2.1, que contempla los componentes pasivos y activos y los vínculos relacionales del ser humano con la naturaleza. Las dimensiones estratégicas expresan estas relaciones. Hay una cuarta dimensión estratégica, que tiene símbolos por recuperar hoy en las políticas sobre los territorios, al retomar relaciones ancestrales y actuales de las comunidades indígenas en sus territorios y los vínculos de la vida con la naturaleza. Esta es una interpretación del territorio no necesariamente relacionada con la dominación de la naturaleza, sino con su adaptación y entendimiento.

\begin{tabular}{|c|c|c|c|}
\hline \multicolumn{4}{|c|}{ Tabla 2.1 EI Territorio: delimitación de su campo problemático } \\
\hline $\begin{array}{c}\text { Dimensión } \\
\text { estratégica }\end{array}$ & $\begin{array}{c}\text { Componente pasivo: } \\
\text { determinación de Io } \\
\text { natural sobre Io social }\end{array}$ & $\begin{array}{c}\text { Componente activo: } \\
\text { determinación de Io } \\
\text { social sobre Io natural }\end{array}$ & $\begin{array}{c}\text { Aspecto } \\
\text { dominante }\end{array}$ \\
\hline 1. Poder & Supervivencia & Control & Político \\
\hline 2. Soportes físicos & Adaptación & Dominio & Económico \\
\hline 3. Representaciones & Reproducción & Construcción & Cultural \\
\hline 4. Interpretaciones & Entendimiento & Vinculación/Adaptación & $\begin{array}{c}\text { Cultura } \\
\text { Ancestral }\end{array}$ \\
\hline $\begin{array}{l}\text { Fuente: Dimensiones 1,2 y 3 CUERVO Luis M. 2006. “Globalización y territorio". ILPES-CEPAL Serie Gestión } \\
\text { Pública No. 56. Santiago de Chile. Pág 29; la cuarta dimensión propuesta de Mauricio Betancourt. }\end{array}$ \\
\hline
\end{tabular}

Moncayo $^{17}$ sintetiza las perspectivas políticas y económicas del nuevo paradigma y de la discusión territorial determinante, desde las formas del Estado región, la nueva geografia económica, las características tecnológicas, el proceso de acumulación, la competitividad, el institucionalismo, el capital social y la perspectiva ambiental. Estos elementos interpretativos se integran a través de diferentes factores: la descentralización, el crecimiento endógeno, las ventajas locales, los compromisos cívicos y la nueva interpretación ambiental desde la bioregión y las ecoregión.

La propuesta de un nuevo paradigma encuentra ausente la teoría crítica sobre vínculos regiolocales de los procesos de acumulación, los sectores sociales que los dinamizan, sus caracteres específicos e institucionales reflejados en cada territorio regiolocal y los elementos de la economía espacial regional y urbana, que deben entender "su capacidad explicativa al servicio de las disciplinas y los problemas con las que toma contacto" ${ }^{18}$, así como vincular la discusión sobre territorio, ciudad y espacios urbanos.

17 MONCAYO J., Edgard (2004): Nuevos enfoques del desarrollo territorial: Colombia en una perspectiva latinoamericana. Universidad Nacional de Colombia, Red de Estudios de Espacio y Territorio (RET), UNDP-CEPAL, pág. 51.

18 CUERVO, Luis M. (2006): Globalización y territorio. ILPES-CEPAL, Santiago de Chile, pág. 23. 
La ciudad identificada como el eje dinamizador regional de la SAN integra la economía regional y urbana, al reconocer un "requisito básico para comprender la relación de doble vía" ${ }^{19}$ : entre los territorios urbanos y rurales, los cuales estarían vinculados al desarrollo regiolocal. Para ello, se requiere conocer la demografia e identificar la demanda de agroalimentos, así como definir límites regionales e identifica la huella alimentaria, base de la política SAN.

La resignificación y revalorización del territorio tienen sentido en lo que Cuervo y González llaman mesoeconomía espacial. Desde allí se transforma y encuentra la importancia del "territorio, la región y la ciudad como unidades que compiten entre sí por la atracción de capitales. [...] La participación de grandes corporaciones y del Estado sigue siendo importante" ${ }^{20}$, para lo cual han de diseñarse estrategias diferenciadas sobre actuaciones del Estado y gobierno en los territorios, en función de asegurar condiciones atractivas locales físico-urbanísticas, sociales, laborales, financieras, tributarias y fiscales, para que las corporaciones analicen sus ofertas y rentabilidad y decidan invertir en ese territorio.

Lo regiolocal parte del análisis general y de los caracteres de un territorio; además, no es estático, y se requiere entenderlo y analizarlo dinámicamente, a partir de diferentes procesos que en su interior se desarrollan. Coraggio plantea un ciclo recurrente cuyo propósito describe así:

[...] la fase final de la misma reproduzca las condiciones cualitativas de la primera fase y que haya una conexión necesaria entre las fases consecutivas de cada ciclo. Proceso implica, entonces, repetición, autorregulación, permanencia de condiciones para un movimiento de ciclo y, por lo tanto, estructura y posibilidad de reproducción de dicha estructura ${ }^{21}$.

Esta dinámica exige una visión y un análisis desde los sujetos y sus relaciones en el interior de cada territorio durante la producción y reproducción de las condiciones del ciclo.

19 CUERVO, Luis y GONZÁLEZ, Josefina M. (1997): Industria y ciudades en la era de la mundialización un enfoque socioespacial. TM Editores Colciencias-CIDER. Bogotá, pág. 49.

20 Ibíd., pág. 19.

21 CORAGGIO, José L. (1989): Sobre la espacialidad social... Op. cit., pág. 79. 
Se requieren ver los niveles y las escalas de la competencia entre territorios, entidades territoriales y gobiernos locales que, en muchos casos, están definidos por las políticas nacionales y globales, vistas desde la competitividad y el emprendimiento que deben desarrollarse por las ciudades. Jessop plantea que es necesario "ubicarse económicamente, sino también en la esfera extraeconómica que, en la actualidad, son fundamentales para una eficaz competencia estructural o sistémica" ${ }^{22}$. En este sentido, se vincula la “glurbanización”y “glocalización”, su relación de estrategias y dinámicas de los territorios y el capital reubicado por su revalorización, como lo muestra Jessop (tabla 2.2).

\begin{tabular}{|c|c|c|}
\hline \multicolumn{3}{|c|}{ Tabla 2.2 Glurbanización frente a Glocalización } \\
\hline Actores Estratégicos & GLURBANIZACIÓN & GLOCALIZACIÓN \\
\hline Estrategias & $\begin{array}{c}\text { Estrategias basadas en el lugar y en el } \\
\text { espacio }\end{array}$ & $\begin{array}{c}\text { Estrategias basadas en la empresa o o } \\
\text { nacionales) } \\
\text { estratégicas) el sector }\end{array}$ \\
\hline $\begin{array}{c}\text { Nuevas Escalas de Actividades } \\
\text { y Temporalidades }\end{array}$ & $\begin{array}{c}\text { Crea diferencias locales para capturar flujos e } \\
\text { incentivar el capital móvil. }\end{array}$ & $\begin{array}{c}\text { Desarrolla nuevas formas de división } \\
\text { escalar y/o espacial del trabajo }\end{array}$ \\
\hline $\begin{array}{c}\text { Gobernanza Cronotópica } \\
\text { Fuente: JESSOP Robert 2008. "E Futuro del Estado capitalista" Los Libros de la CATARATA 2008 FUENCARRAL 70 Madrid. Pág. 234 } \\
\text { estructurales }\end{array}$ & $\begin{array}{c}\text { Rearticula el tiempo y el espacio para lograr } \\
\text { ventajas competitivas sistémicas o } \\
\text { lograr ventajas competitivas dinámicas }\end{array}$ \\
\hline
\end{tabular}

Con la glurbanización se mejoran las condiciones materiales y los incentivos al capital, y ello adecúa el atractivo para las exigencias del capital a través de los procesos de glocalización, donde las empresas controlan la dinámica sobre la división espacial en la que se integra lo global y lo local. Estas situaciones permiten analizar la regionalización a partir de los procesos sociales que hacen presencia y muestra sus formas de reproducción, que en el capitalismo se relaciona con varios aspectos:

La reproducción del capital social, tanto en lo que hace a la reproducción de las condiciones controladas directamente por los capitales como a las condiciones generales de producción; [...] reproducción global de la fuerza de trabajo, otras modalidades de producción mercantil (campesina, artesanal) y la gestión (no en tanto capital) del Estado en lo que hace a la provisión de tales condiciones generales $^{23}$.

22 JESSOP, Robert (2008): El futuro del Estado capitalista. Editorial Catarata, Madrid, pág. 234.

23 CORAGGIO, José L. (1989): Sobre la espacialidad social... Op. cit., pág. 96. 


\subsubsection{Territorio y planeación}

La revalorización analiza actores de las decisiones del desarrollo local y regional, las políticas descentralizadoras y las nuevas relaciones intergubernamentales que buscan mejorar las condiciones en el territorio y el manejo de instrumentos para mejorar la reproducción social, económica, política, ambiental. También aborda la gobernabilidad, a partir de la reivindicación de "una nueva esfera de acción pública: el ordenamiento del territorio, que rescata la planificación urbana y la complejiza con la planificación ambiental"24. Así, es necesario un ligero repaso de los instrumentos planificadores urbanos del siglo XX.

La planificación urbana en los ejes dinamizadores tiene una conformación y altos niveles de informalidad de la urbanización, aspectos que afectan los procesos SAN en distribución, acceso y uso biológico. Por tanto, se configura un criterio, en la segunda mitad del siglo XX, frente a la situación de las ciudades:

Las ciudades, tal como existen hoy, se construyen en condiciones contrarias al bien público y privado. Nuestra tarea actual consiste en arrancarlas del desorden mediante planes en los que se escalonarán en el tiempo los distintos proyectos. El problema del alojamiento, de la vivienda, tiene la primacía sobre todos los demás ${ }^{25}$.

Estas bases impulsan en Colombia los planes reguladores urbanos en las principales ciudades. Así, a finales de los años sesenta y mediados de los años setenta, estos planes se amplían a la región, y el tema ambiental se asume en la planeación territorial.

Otra fase de organización y planeación urbana se inicia con la globalización, donde naciones, regiones y ciudades, para localizar inversiones nacionales o extranjeras y acciones para el desarrollo, hacen reformas con políticas descentralizadoras que buscan planificar el territorio y mejorar las situaciones, al ordenar usos del suelo y relaciones sostenibles con la naturaleza.

24 LIRA C., Luis (2003): La cuestión regional y local en América Latina. ILPES-CEPAL, Santiago de Chile, pág. 7.

25 LE CORBUSIER (1971): Principios de urbanismo (La Carta de Atenas). Discurso preliminar de Jean Giraudoux. Ariel, Barcelona, pág. 55. 
Sin embargo, la informalidad urbana crece, y aunque busque reducirse, vía legislación, presionando el ordenamiento de los territorios, esta se acrecienta por pobreza, especulación y concentración del mercado de tierras, como lo afirma Clichevsky:

Desde fines de los años setenta se agudiza la inequidad existente entre la población de la región, pero es durante la década de los noventa que esta se agrava, así como la situación de pobreza e indigencia, lo que amplía la cantidad de población cuya única alternativa es vivir algún tipo de informalidad urbana ${ }^{26}$.

Esta autora resalta las acciones en trece países latinoamericanos desde los diferentes niveles de gobierno, a partir de instrumentos de planeación urbana impulsados como parte de las políticas de desarrollo territorial, para resolver los problemas de ausencia de desarrollo en muchas zonas urbanas y así buscar establecer una nueva cara para las inversiones del capital.

\subsubsection{Acercamiento entre territorio y agroalimentos}

Las relaciones entre territorios urbanos y rurales son, entre otros aspectos, generadas por las necesidades agroalimentarias. Estas relaciones pueden analizarse a través de la huella ecológica alimentaria y los complejos territoriales, conceptos que a continuación se desarrollan.

La huella ecológica y alimentaria. Es la cantidad de tierra que requieren las ciudades eje para tener alimentos para su población a través de cada región SAN. También puede definirse como el requerimiento que tiene "una persona para satisfacer sus necesidades en términos de territorios y ecosistemas. Tal demanda depende de las personas, de su nivel de exigencias y de los sistemas de soporte de su hábitat" ${ }^{27}$.

26 CLICHEVSKY, Nora (2006): Regularizando la informalidad del suelo en América Latina y el Caribe. Una evaluación sobre la base de 13 países y 71 programas. CEPAL, Santiago de Chile, pág. 9. Estos programas se expresan por la aplicación de leyes nacionales que apuntan a mejorar las condiciones sociales y urbanísticas en los tiempos de la globalización, y se accionan por los gobiernos municipales o integrados con otros niveles de gobierno.

27 MÁRQUEZ, Germán (2005): "Ecosistemas estratégicos para la sociedad: bases conceptuales y metodológicas”. En Región ciudad y áreas... Op. cit., pág. 46. 
Con este tipo de mediciones, diferentes países calculan la necesidad de territorios y ecosistemas para lograr sobrevivir ${ }^{28}$.

Las mediciones no reflejan el cálculo de otros ecosistemas que contribuyen a esta realización, como los costos ambientales del transporte por el uso de recursos naturales utilizados en la movilización y su contaminación, lo cual exige producir los agroalimentos cerca de la mesa, como se propone en esta tesis. En este sentido, el problema de la SAN no es solamente económico. Estas dinámicas territoriales articulan "la ciudad a través de relaciones sociales que movilizan los flujos de productos del campo a la ciudad y viceversa" ${ }^{29}$. Por lo tanto, allí no solo definen espacios físicos en hectáreas dedicadas a la producción de alimentos, sino que se ven condiciones socioeconómicas, políticas, tecnológicas, culturales y del conflicto rural presentes en los territorios dispuestos para la producción agroalimentaria ${ }^{30}$.

Gómez propone un modelo de interpretación del sistema agroalimentario general que "perciba cómo se modifican las relaciones hombre-naturaleza, las causas de estas modificaciones y las consecuencias en la forma de hacer uso de los recursos naturales" ${ }^{31}$. En términos metodológicos, se utiliza el concepto de huella ecológica para analizar estas relaciones.

El cálculo de la huella ecológica alimentaria en Bogotá, realizado por Jaime Forero ${ }^{32}$, vincula los agroalimentos producidos en estructuras campesinas de los departamentos de Colombia y ofrecidos en los mercados de la ciudad. Resalta el 51,7\% referido a los agroalimentos provenientes de Cundinamarca.

28 Hay que tener presente que "para el habitante urbano medio de este siglo, la naturaleza es un concepto accesorio ajeno, antagónico a su propio entorno y por tanto exótico. Para este ciudadano, la procedencia de los alimentos como la leche, el pescado o las verduras se ubica en el supermercado. [...] Tal alienación del habitante urbano respecto al entorno rural y natural, que hace posible su bienestar, se acentúa a medida que la ciudad crece". AGUDELO, Luis Carlos (2005): "La articulación urbano regional. Indicadores de sostenibilidad y ordenación del territorio. Huella ecológica y ecosistemas estratégicos en Medellín”. En Región, ciudad $y$ áreas protegidas. Manejo ambiental participativo. Fescol-Ecofondo-Acción Ambiental-Cerec, Bogotá, pág. 249.

29 RODRÍGUEZ, Bladimir (2005): “Nuestro pan de cada día. La huella ecológica alimentaria de Bogotá”. En Región ciudad y áreas... Op. cit., pág. 224.

30 Este aspecto se analiza con más detalle en el capítuloVII en la fase de disponibilidad.

31 GÓMEZ G., Luis Jair (2001): El sistema agroalimentario y la sostenibilidad ecológica: los efectos de una diacronía. Universidad Nacional de Colombia, Medellín, pág. 20.

32 FORERO A., Jaime (2002): La economía campesina colombiana, 1990-2001. Corporación Corabastos, Bogotá, pág. 19. 
Territorio y complejos territoriales. Los sistemas agroalimentarios regiolocales permiten conocer las condiciones de la reproducción social, cultural, política y económica en los territorios, a partir de diferentes criterios:

\begin{abstract}
Modelos de desarrollo agroalimentarios basados en la valorización de los recursos locales [...] organizaciones de producción y de servicio asociadas por sus características y su funcionamiento a un territorio específico, [...] produciendo una forma de organización agroalimentaria en una escala espacial $\mathrm{dada}^{33}$.
\end{abstract}

Estos sistemas agroalimentarios territorializados presentan vínculos de distinto orden, a veces en contra de las políticas públicas nacionales, como es el caso del té de coca, que en Colombia solo tuvo reconocimiento legal después de una batalla de los productores indígenas por su legalización, en medio de una acción de criminalización de la hoja que le da origen.

Los componentes de las regiones SAN funcionan a partir de los flujos entre zonas urbanas y rurales cercanas que producen alimentos y son, en general, "las tierras que rodean algunas ciudades, (...) dependiendo únicamente de los dictados marcados por la energía económica de la ciudad" ${ }^{34}$. Así, las dinámicas territoriales de crecimiento de los centros urbanos se posicionan como factores esenciales para el concepto de región SAN, compuesta por un eje urbano con demandas de agroalimentos regionales. Para caracterizar el desarrollo regiolocal sobre las dinámicas agroalimentarias y sus flujos de origen y destino de la zona rural a la urbana, la definición de Coraggio resulta muy útil:

Los complejos territoriales en el contexto de los subsistemas de producción y circulación: el primero, los subsistemas de relaciones de producción y circulación, determinan posiciones, funciones o papeles definidos por la necesaria inserción en esas relaciones de agentes

33 CIRAD-SAR (1996): Systémes agroalimentaires localisés: organisations, innovation dans le développement local, citado en Muchnik, José (2004): "Identidad territorial de los alimentos: alimentar el cuerpo humano y el cuerpo social". En Territorios y sistemas agroalimentarios locales. Universidad Nacional de Colombia, Bogotá, pág. 30.

34 JACOBS, Jane (1986) Las ciudades y la riqueza de las naciones, principios de la vida económica. Ariel, Barcelona, pág. 52. 
o grupos económicos particularizados, y se establecen los flujos y principales relaciones agregadas entre tales agrupamientos ${ }^{35}$.

Los flujos tienen una expresión local, regional, nacional o global, vinculada a diferentes estructuras económicas, políticas y sociales, que no terminan en los límites nacionales ni regiolocales. Hay subsistemas de relaciones de producción y circulación con sus límites (figura 2.1), donde cada círculo tiene particularidades.

En otro análisis, Coraggio explica 'los complejos de articulación”. Señala que los agentes sociales entran en relaciones particulares y especifican las determinaciones físico-técnicas de los elementos involucrados en tales relaciones; así, los "agentes individualizados" requieren:

\section{[...] visualizarlos como agentes de múltiples estructuras, insertos en diversas relaciones de manera simultánea, y con comportamientos efectivamente determinados por el interés económico, pero también por determinantes ideológicos, políticos, culturales ${ }^{36}$.}

Los subsistemas de relaciones de producción y circulación y los complejos de articulación con agentes individualizados de múltiples estructuras son puntos que, integrados, caracterizan los complejos territoriales de producción y reproducción e identifican lo regiolocal con regiones SAN. Ello determina diferentes dinámicas de sus relaciones sociales en las regiones tipificadas de los ejes dinamizadores, aunque las políticas públicas reflejen intereses diferentes en la SAN de los territorios.

En esta investigación, la regionalización caracteriza territorios de producción y reproducción a partir de mínimos: la capacidad de producción regiolocal de productos agroalimentarios, la capacidad de la zona rural por la actividad generada de disponibilidad de agroalimentos y sus vínculos por flujos origen-destino, que identifican la dinámica regiolocal.

35 CORAGgiO, José Luis (2004): La gente o el capital. Desarrollo local y economía del trabajo. Espacio, Buenos Aires, pág. 31. Acá se encuentra una recopilación de diversos artículos referidos al desarrollo local y la economía del trabajo, los cuales fueron escritos entre 1982 y el 2003.

36 Ibíd., pág. 32. 
Al integrar las políticas públicas nacionales, regionales y locales que inciden en las lógicas de producción y reproducción de cada región específica, al tener en cuenta la cercanía a los centros urbanos o ejes dinamizadores de la oferta regiolocal de agroalimentos y al determinar mínimas dinámicas que integran territorios urbanos y rurales, es posible formular varias preguntas: ¿Cuáles niveles de autonomía inciden para construir el desarrollo regiolocal?, ¿cómo se integran los vínculos económicos en el interior y el exterior de los territorios con los intereses y las culturas base, a fin de configura dinámicas de apropiación de los procesos generados en la cadena alimentaria?

Lo anterior implica combinar factores del desarrollo territorial (económicos, políticos, sociales, culturales, ambientales y sectoriales) y las relaciones interinstitucionales, políticas y organizativas con los niveles de gobierno y las políticas públicas, que permiten construir las regiones SAN para Colombia.

\subsubsection{Tipificación general regional}

Tipificar regiones (figura 2.1) con dinámicas de flujos de alimentos en los dos sentidos, entre el eje dinamizador y los centros abastecedores de alimentos regionales nacionales o internacionales, implica analizar flujos en doble sentido: la dinámica del eje y la del contexto departamental como región SAN. A su vez, es importante analizar las condiciones para potenciar acciones sobre el desarrollo territorial local y regional.

El núcleo central regional es el eje dinamizador de la demanda de alimentos de origen agropecuario y agroindustrial, consecuencia del total de la población y su estructura demográfica, así como de las características específicas de los sectores sociales, que son los que determinan el espacio georegional de la dinámica SAN. Lo anterior implica que unos componentes de la dieta estén cerca y otros más lejos dentro del mismo país, o que estén en otro, como es el caso del trigo, que antes se producía Colombia, pero hoy se trae del exterior. Estos componentes son parte de la dieta básica de los pobladores en los ejes, cuya dinámica local y regional pasó de una disponibilidad nacional cercana a la mesa a una disponibilidad de algunos agroalimentos lejana de la mesa (disponibles solo en el mercado internacional).

En la figura 2.1, los puntos concéntricos son los que cubren las demandas básicas del núcleo central regional. Así, se determinan los anillos SAN regional agrícolas como las estructuras agroalimentarias que permiten caracterizar algunos productos básicos de las dinámicas de otras ciudades o del exterior, y allí los agroalimentos son centrales en la dieta de SAN. 


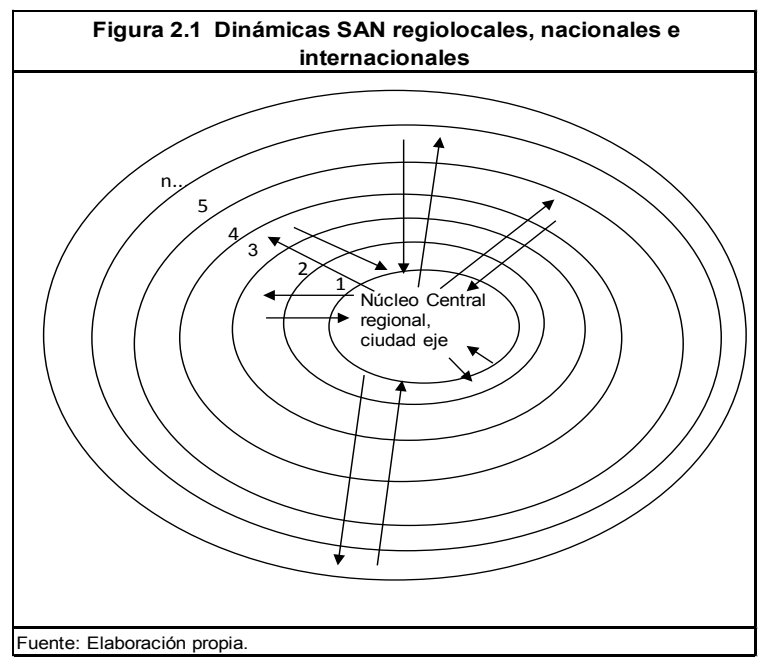

La numeración de núcleos 1, 2, hasta...n, refleja las diferentes distancias (cercanas o lejanas) donde se encuentra la disponibilidad de los agroalimentos. Estos son anillos que identifican los diversos tipos que se producen por anillo regional: arroz, aceite vegetal, azúcar-productos elaborados, raíces, tubérculos, plátanos, frutas, leche, derivados de cereales pan, arepas, hortalizas, verduras, panela, miel, carnes de res, pollo, cerdo y pescado. A partir de estos agroalimentos identificados en la entidad territorial de origen, se constituyen las unidades político-administrativas para desarrollar la disponibilidad, la caracterización que determina el tipo de agroalimento, su capacidad nutricional, el ciclo y la cobertura por zona en la región, en función del núcleo central regional.

En cada región se tipifican características de los subsistemas de producción y circulación que muestran para los estudios regiolocales colombianos, así como el análisis de las políticas públicas en SAN. También se ven los subsistemas de reproducción social en cada territorio y los complejos de articulación que inciden en las acciones de SAN.

Se define región $S A N$, desde los complejos territoriales de producción y reproducción, a aquel territorio nacional o internacional donde se producen los agroalimentos de un núcleo central regional, a partir de ciertas condiciones de relaciones sociales, políticas, ambientales, tecnológicas e institucionales que determinan sus formas de producción y reproducción. Por metodología, los círculos de la figura 2.1 son cerrados, pero para efectos de análisis son abiertos, lo que permite caracterizar las dinámicas regiolocales y sus condiciones, pues son estas las que indican los niveles de apertura que se tiene hacia otras áreas. 
El análisis propuesto no desconoce los componentes referidos a los ejercicios de roturación y ampliación de la oferta agrícola, a partir de su expansión en el mercado y de las dinámicas de la renta agraria. Estas categorías han sido trabajadas desde los siglos XIX y XX por diferentes autores, como Von Thünen, Marx y Kausky; o, en Colombia, Jesús Bejarano, Salomón Kalmanovitz y Absalón Machado, entre otros. Interesa hoy la forma como se suple la SAN, al vincular una función de la agricultura: la oferta de agroalimentos para la población urbana.

Este esquema es diferente para el caso de comunidades indígenas, negras, campesinas, municipios o familias, que cubren requerimientos sobre el manejo de la parcela o de propiedades colectivas, y distribuyen el uso del suelo para producción de alimentos para el autoconsumo familiar o colectivo, o bien, como excedentes para el mercado, desde dinámicas sociales, culturales y ambientales en el territorio, cuyo objetivo no es la utilidad como fin último de la disponibilidad.

Para completar el análisis de las dinámicas de la región SAN a partir de la ampliación de los requerimientos y las necesidades agroalimentarias de las poblaciones en los centros urbanos, es necesario concebir los agroalimentos como una mercancía disponible para el consumo y desde el criterio de cercanía. Esto exige que, para el desarrollo de una región SAN, se materialice la propuesta de Montagut y Dogliotti:

La producción para el mercado local permite que los agricultores y los consumidores tomen parte activa en las decisiones sobre qué alimentos producen y cómo los producen, quedando en sus manos el control de la agricultura y la alimentación. Permite, así, respetar los diferentes ecosistemas en los que la agricultura a desarrollarse de forma armoniosa. Permite mantener y proteger las diferentes culturas campesinas y alimentarias que expresan la sabiduría con que las sociedades han interactuado con su medio natural. Se sitúa, pues, en el centro de una estrategia de resistencia a la comida basura y de ínfima calidad producida industrialmente esquilmando la naturaleza y arruinando a millones de campesinos. Una estrategia de resistencia al neoliberalismo y a sus consecuencias en la agricultura y en la alimentación ${ }^{37}$.

37 MONTAGUT, Xavier y DOGLIOTTI, Fabrizio (2006): Alimentos globalizados, soberanía alimentaria y comercio justo. Icaria, Barcelona, págs. 8 y 9. 
La cercanía integra diferentes características ambientales, sociales, económicas y culturales relacionadas con la promoción del desarrollo local. La ausencia de cercanía no tiene en cuenta los impactos del cambio climático sobre la producción de agroalimentos y la situación crítica del recurso hídrico. Al respecto, Roberts anota:

El aumento de las temperaturas y los cambios de los patrones de frecuencia de las lluvias y las tormentas conllevarán una disminución de la producción mundial de alimentos, y esta disminución coincidirá con un crecimiento de la demanda mundial. Para el año 2070, [...] la alarma será aún mayor a raíz de la escasez de agua que están empezando a sentir los agricultores. La agricultura consume más agua que cualquier otro sector y la demanda creciente está agotando los recursos hídricos en todas las regiones del mundo ${ }^{38}$.

El cambio climático se refiere al uso de tecnologías contaminantes y vincula las importaciones de productos alimenticios, cuando muchos de estos pueden producirse en cercanías de los asentamientos que los consumen; por tanto, los costos ambientales, la crisis del transporte y el impacto en los monoproductores conlleva un alto deterioro ambiental, frente a lo cual hay que prevenir situaciones críticas de acceso a los agroalimentos:

Cualquier irregularidad en el transporte (por alza en costos) o en la capacidad exportadora de los países (por pérdida de cosecha) plantea el riesgo, extremadamente real, de dejar aisladas regiones que hoy en día se dedican únicamente al monocultivo, o aun peor, que prácticamente no producen alimentos de consumo propio y que, por tanto, dependen de las importaciones ${ }^{39}$.

Desde el principio de previsión y precaución frente a potenciales crisis alimentarias para los que tienen acceso, debe orientarse la disponibilidad de alimentos cerca de la mesa para todos.

38 ROBERTS, Paul (2009): El hambre que viene. La crisis alimentaria y sus consecuencias. Ballén, Barcelona, págs. 24 y 25.

39 Ibíd., pág. 27. 


\subsubsection{Economía e instituciones}

Para Helmsing, el proceso de revalorización territorial tiene diferentes dinámicas económicas e institucionales que vinculan:

[...] actores e instituciones locales pueden tener un efecto y una eficiencia mayores, [...] si son capaces de organizarse socialmente en sistemas de coordinación económica y de apoyo institucional ${ }^{40}$.

Esto supone cierto nivel de autonomía de las instituciones y dinámicas de las administraciones locales y regionales, a la vez que desconoce relaciones interinstitucionales entre niveles de gobierno que inciden con mayor fuerza en los territorios y pueden ser más conflictivas en el diseño y la aplicación de acciones sobre la economía e inversión territorial local.

Cuervo y González analizan en la dinámica entre economía y territorio, que deben entenderse sus relaciones bidireccionales y la construcción institucional a partir de “un canal de doble vía (lo económico determina y es determinado por lo territorial), construyendo algunas reglas que respeten la peculiaridad de lo territorial" ${ }^{41}$. En este caso hay una dimensión de autonomía donde el territorio construye instituciones determinadas por la "doble vía” de esta relación, lo cual redefine la economía socioespacial como:

[...] el conjunto en el que se intersectan varias disciplinas cuyo objetivo preciso es discernir en qué y cómo las formas espaciales intervienen sobre el comportamiento de los agentes económicos y, en sentido inverso ${ }^{42}$.

Esta bidireccionalidad explica la intersección de varias disciplinas, lo cual demanda una visión heterodoxa para entender las dinámicas territoriales a partir de:

40 HELMSING, A.H.J. (2000): "Hacia una reapreciación de la territorialidad del desarrollo económico". En Territorios, Revista de Estudios regionales y urbanos. CIDER, Universidad de los Andes, Bogotá, pág. 51.

41 CUERVO, Luis M. (2006): “Globalización y territorio". ILPES-CEPAL, Santiago de Chile, pág. 23.

42 CUERVO, Luis M y GONZÁLEZ, Josefina (1997): Industria y ciudades en la era de la mundialización (1980-1991). Un enfoque socioespacial ColcienciasCider Tercermundo Editores, Bogotá, pág. 149. 
Elaborar conceptos socioespaciales específicos que sirvan de punto de partida y de llegada a la construcción de los argumentos explicativos $[y][\ldots]$ comprender las particularidades de la dinámica socioespacial, diferenciando los procesos de reproducción y de cambio, de estabilidad y de transformación ${ }^{43}$.

Las incidencias de los gobiernos sobre estas dinámicas dejan abierta la discusión en el orden teórico, conceptual, metodológico e interpretativo. Es importante aclarar que aun desde las corrientes económicas que estudian estos procesos territoriales se necesita la interacción de varias disciplinas.

\subsection{CIENCIA POLÍTICA}

Toda política pública apunta a la resolución de un problema público reconocido como tal en la agenda gubernamental. Representan pues la respuesta del sistema político-administrativo a una situación de la realidad social juzgada políticamente como inaceptable ${ }^{44}$. Comprender el proceso de las políticas públicas requiere tener un conocimiento de los objetivos, de las percepciones de cientos de actores en todo el país, que posiblemente incluyan cuestiones técnico-científicas y legales muy específicas ${ }^{45}$.

\subsubsection{Elementos teóricos conceptuales generales}

\subsubsection{La interdisciplinariedad}

La política pública integra la interdisciplinariedad como forma de entender la dinámica de los problemas de seguridad alimentaria nutricional y permite la discusión sobre la autonomía disciplinar de esta, al preguntar si forma parte del "cruce de saberes ya establecidos, de los cuales toma prestados sus principales conceptos" ${ }^{46}$.

\section{Ibíd., pág. 150.}

44 SUBIRATS, Joan, KNOEPFEL, Peter, LARRUE, Corrine y VARONE, Frédéric (2012): Análisis y gestión de políticas públicas. Ariel, Barcelona, pág. 35.

45 SABATIER, Paul A. (2010): Teorías del proceso de las políticas públicas. Presidencia de la Nación-República Argentina, Buenos Aires, pág.6.

46 MULLER, Pierre (1998): “Génesis y fundamentos del análisis de políticas públicas”. Innovar, Revista de Ciencias Administrativas y Sociales, núm. 11, enero-junio, pág. 99. 
Al respecto, Meny y Thoenig y plantean:

\begin{abstract}
El análisis de las políticas públicas invita, también, a romper las fronteras tradicionales de las disciplinas, tal como se han podido desarrollar y fosilizar a través de la profesionalización y de la especialización de los campos científicos ${ }^{47}$.
\end{abstract}

En este contexto, Subirats señala que "el análisis de políticas públicas ha sido y es un campo multidisciplinar" ${ }^{48}$. Estas discusiones justifican en términos académicos, investigativos, metodológicos y conceptuales el trabajo de la SAN desde la interdisciplinariedad. En esta dirección hay varias líneas de interpretación y formas de intervención del Estado, los gobiernos, la sociedad, las organizaciones sociales, la familia y el individuo, que se encuentran en los territorios llamados ejes dinamizadores y regiones inmediatas $S A N$.

\title{
2.3.1.2. Los elementos teóricos
}

Para analizar las políticas públicas, Subirats y $\mathrm{Knoepfel}^{49}$ las dividen en tres corrientes teóricas: la primera, vinculada con las teorías del Estado de Meny y Thoenig, caracteriza las políticas públicas desde diferentes enfoques: el social, el individuo y el pluralismo social que considera al Estado la ventanilla que atiende las demandas sociales; otra analiza el Estado como instrumento de una clase social, en tanto concibe la distribución de las parcelas de poder entre los actores y sus interacciones (neocorporativismo).

La segunda teoría busca explicar el funcionamiento de la acción pública "para comprender su operatividad" 50 y analiza el Estado "no como actor único, sino como un sistema político-administrativo complejo y frecuentemente heterogéneo cuyo funcionamiento es necesario comprenderlo". Esto último se explica desde cuatro orientaciones: una analiza procesos de toma de decisiones, estrategias de los actores y análisis de los sistemas-actores o sistemas de acciones concretas; otra se centra en herramientas e instrumentos del sector público con enfoques económicos y de economía política; la tercera aborda los intereses, las estructuras, los procedimientos y

47 MENY, Ives y THOENIG, Jean-Claude (1992) : Las políticas públicas. Ariel, Barcelona, pág. 266. 48 SUBIRATS, Joan, KNOEPFEL, Peter, LARRUE, Corrine y VARONE, Frédéric (2012): Análisis y gestión de políticas públicas. Ariel, Barcelona, pág. 19.

49 Ibíd., subpunto 1.1.1.

50 Ibíd., págs. 22 y ss. 
las formas institucionales de la administración pública, las reformas administrativas y la descentralización; finalmente, el enfoque cognitivo analiza las políticas públicas como expresiones cognitivas y normativas constituyentes de la interpretación de la realidad donde actores públicos y privados sitúan sus acciones.

La tercera corriente evalúa los efectos de la acción pública sobre la sociedad a partir de los objetivos en la construcción de metodologías o caja de herramientas propias de la dinámica de evaluación, como también el proceso mismo de evaluación y ejecución en relación con la gestión pública y su influencia en la toma de decisiones ${ }^{51}$.

\subsubsection{Elementos definitorios de una política pública}

El contexto del Estado, sus formas históricas de intervención, los instrumentos usados, las instituciones creadas o suprimidas, los actores internos y el manejo de sus estructuras de poder, desde donde toman las decisiones públicas vinculadas a las políticas públicas sobre seguridad alimentaria y nutricional con sus implicaciones ${ }^{52}$, son factores para pensar qué es una política pública, para determinar de qué se habla y qué se analiza. Por tanto, la política pública se define como:

[...] El resultado de la actividad de una autoridad investida de poder político y de legitimidad gubernamental [...] se presenta bajo la forma de un conjunto de prácticas y de normas que emanan de uno o de varios actores públicos. En un momento dado, en un contexto dado estas prácticas pueden ser: formas de intervención, reglamentación, provisión de prestaciones, represión - en este sentido la consideran - como un programa de acción gubernamental en un sector de la sociedad o en un espacio geográfico ${ }^{53}$.

Desde estos criterios se analiza la política pública de seguridad alimentaria y nutricional, así como las acciones gubernamentales en espacios regiolocales. Puede decirse, en este

51 Ibíd., pág. 25.

52 Con apoyo de otros trabajos, como los de Muller, Meny-Thoenig, la compilación de Aguilar, el trabajo práctico y comparativo en Colombia de Alejandro Lozano, Alejo Vargas, Noe Roth, el del BID-Planeta (2006).

53 MENY, Ives y THOENIG, Jean-Claude (1992): Las políticas públicas. Morata y Ariel, Barcelona, pág. 89. 
sentido, que la política pública "no es otra cosa que el estudio de la acción de las autoridades públicas en el seno de la sociedad. ¿Qué producen quienes nos gobiernan, para lograr qué resultados, a través de qué medios?"54; o como expone Vargas Alejo:

[...] la política pública como el conjunto de sucesivas iniciativas, decisiones y acciones del régimen político frente a situaciones socialmente problemáticas y que buscan la resolución de las mismas o llevarlas a niveles manejables ${ }^{55}$.

La esencia definitoria de política pública está en acciones iniciadas por el gobierno o el régimen político para resolver problemas o, por lo menos, manejarlos, mediante la intervención en los territorios de las situaciones problemáticas (tabla 2.3). Dada la diversidad de actores sociales, es importante tener en cuenta que la acción sobre los territorios está condicionada por quien tiene la facultad de decidir para implementar las políticas públicas. Esto conduce a entender el poder de una manera particular:

[...] la capacidad relacional que permite a un actor social influir de forma asimétrica en las decisiones de otros actores sociales de modo que favorezca la voluntad, los intereses y los valores del actor que tiene el poder. El poder se ejerce mediante la coacción y/o mediante la construcción de significado ${ }^{56}$.

Según lo anterior, es importante integrar las acciones de políticas públicas buscando solucionar un problema por parte de quien tiene el poder de decidir desde el Estado. En este sentido, Machado afirma que para analizar las políticas en la intervención del Estado, debe conocerse la composición e influencia de las clases sociales en su interior:

Es el estado el que define la fórmula y ejecuta la política económica general y, en particular, las políticas agrarias; lo hace en función de la representatividad que en él tienen las clases sociales, los intereses de clase y los grupos y fracciones de clase ${ }^{57}$.

54 Ibíd., pág. 7.

55 VAR GASV.,Alejo (1999): Notas sobre el estado y las políticas públicas. Almudena, Bogotá, pág. 57.

56 CASTELLS, Manuel (2010): Comunicación y poder. Alianza Editorial, Madrid, pág. 33.

57 MACHADO C. Absalón, TORRES O. Jorge (1987). El sistema agroalimentario una visión integral de la cuestión agraria en América Latina. Siglo XXI editores. Pág. 327. 


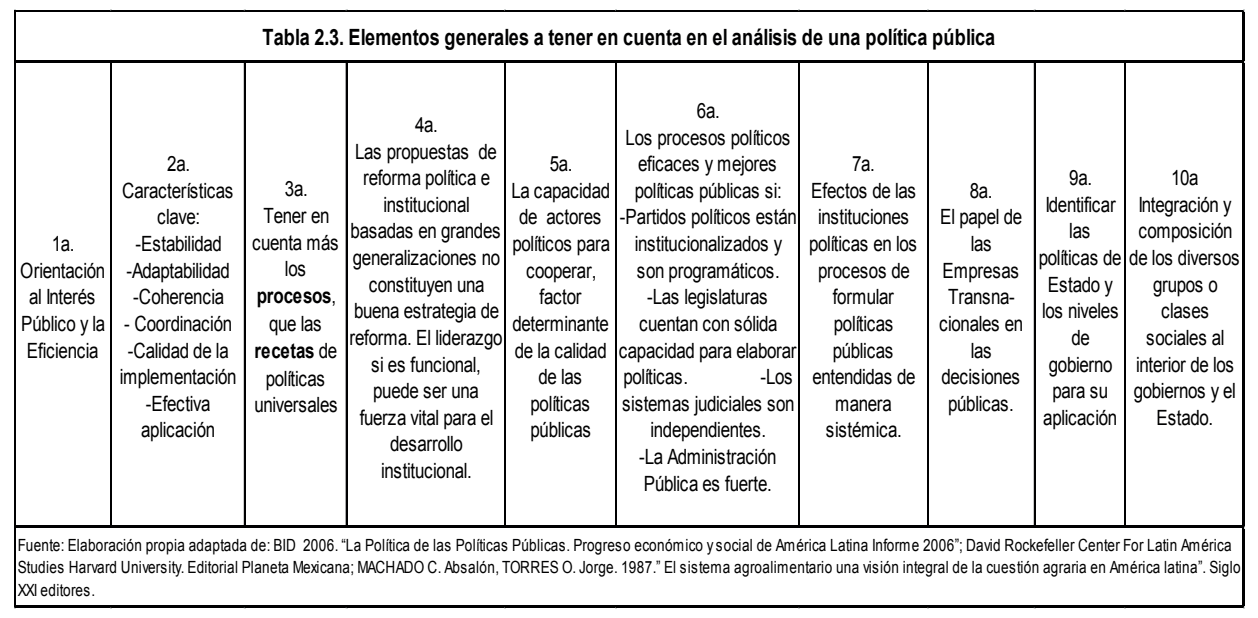

Puede indicarse que encontrar el interés del Estado presentado como formulador y garante del diseño de las políticas públicas, y su influencia en las decisiones públicas, exige analizar la composición y representación de clases sociales en la dirección de este, $\mathrm{y}$ es quien representa las decisiones en cada momento.

\subsubsection{Política pública y seguridad alimentaria nutricional}

Vivero y Ramírez afirman sobre este aspecto:

[...] las políticas de Estado contra el hambre han de contar con el respaldo de los gobiernos, los congresos, los partidos de la oposición, los medios de comunicación, la academia, las iglesias, la sociedad civil organizada y el sector privado. Además se requiere la existencia de liderazgos aglutinadores y de una inversión del presupuesto público adecuada a la magnitud de la desnutrición, predecible y bien focalizada ${ }^{58}$.

El análisis del profesor Medellín respecto a la reforma del Estado y la relación entre capital y trabajo resulta aquí muy ilustradora:

58 VIVERO, José y RAMÍREZ, Pablo (2009): “Leyes, políticas e instituciones contra el hambre en el contexto latinoamericano". En Derecho a la alimentación, políticas públicas e instituciones contra el hambre. LOM Ediciones y Fundación Henry Dunant América Latina, Santiago de Chile, pág. 124. 
La reforma del Estado capitalista está atravesada por una ambigüedad: la socialización del Estado, entendida como la exigencia de los ciudadanos para que el Estado extienda los beneficios del desarrollo, o la estatización de la sociedad, entendida como la exigencia que hace el Estado para que los ciudadanos asuman la responsabilidad financiera, operativa o de dirección de la gestión de los asuntos públicos — la ambigüedad de la reforma—, es en realidad la expresión de la vigencia que mantiene en las nuevas condiciones la pugna entre el capital y el trabajo ${ }^{59}$.

Por consiguiente, es necesario el análisis de las diferentes políticas que se relacionan con la SAN.

\subsubsection{La política económica}

El análisis de las políticas públicas del SSAN diferencia cada intervención del Estado, al hacer énfasis en las acciones que buscan resolver el problema identificado de forma integral. Un inconveniente es separar las acciones que orientan la política económica, por su predominio sobre el resto de las políticas. Además, una dificultad adicional en su aplicación es la dinámica de coordinación entre niveles de gobierno en relación con decisiones nacionales y subnacionales, desde la vinculación de temática sectoriales de cada nivel y su relación con el otro. Otra dificultad es la asincronía entre niveles de gobierno para ejecutar acciones directas y simultáneas en la ejecución presupuestal. La última dificultad consiste en considerar la política económica como expresión de la política pública que resuelve la seguridad alimentaria al sectorizarla como parte de la política agraria y resolver la disponibilidad de agroalimentos.

La discusión de las relaciones entre la política económica y las demás, en particular la alimentaria, es planteada por Timmer, Falcón y Pearson, al abrir el análisis del manejo de las políticas alimentarias y sus vínculos directos con la económica:

¿Puede un país abrigar la esperanza de resolver sus problemas alimentarios en tanto que persisten los problemas globales de

59 MEDELLÍNT., Pedro (1989): "La reforma del Estado en América Latina: desnacionalización del Estado y transnacionalización del capital”. En La reforma del Estado en América Latina. FESCOL, Bogotá, pág. 53. 
escaseces periódicas y de inestabilidad de los precios? ¿Tiene la política económica interna la capacidad de reducir la pobreza y el hambre, o debe reformarse el sistema económico internacional antes de que se puedan lograr progresos dentro de los países pobres? El debate de estas cuestiones es importante para los analistas de la política alimentaria, ya que los mercados cerealeros son componentes integrales de la economía global ${ }^{60}$.

Estos autores, con la homogenización de la dieta global por los cereales, vinculan política económica y alimentaria por medio del ciclo de precios y las coyunturas de escasez que puedan presentarse en los mercados de agroalimentos. Este punto relaciona los niveles de dependencia del sistema agroalimentario que controlan las empresas transnacionales en la oferta de insumos, semillas e investigación para la producción, al igual que en lo relacionado con la distribución y el mercadeo. Por tanto, la escasez no es un principio que argumente el problema de la política económica: los autores construyen de la economía una visión disciplinar de disponibilidad, distribución, consumo y sus relaciones microeconómicas con el sistema alimentario, mediante el análisis del comportamiento económico del individuo. Este enfoque clásico desconoce la dimensión sistémica de los procesos presentes en el SSAN.

Los efectos de la política macroeconómica sobre el SSAN pueden rastrearse en varias aspectos: los impactos de las políticas salariales, el manejo de la inflación, la tasa de interés, las políticas de comercio exterior, los precios relativos de los alimentos, la capacidad de generar ingresos vía salarios, lo cual afecta, por un lado, la disponibilidad de agroalimentos y, por otro, las condiciones de acceso. En la evolución de la política económica hay elementos de esta que no son del resorte de países del tercer mundo. La FAO y la Comunidad Andina señalan que, dadas las condiciones de negociación del mercado subregional y los términos de las políticas agroalimentarias relacionadas con el mercado externo, deben tenerse en cuenta varias condiciones:

i) subsidios internacionales, ii) acceso preferencial a mercados externos, iii) aranceles y iv) mecanismos de estabilización de precios; [para] extraer las conclusiones que permitan avanzar en el diseño de

60 TIMMER C., Peter, FALCÓN, Walter y PEARSON, Scott (1985): Análisis de políticas... Op. cit., pág. 21. 
una política de Seguridad Alimentaria sostenible y consistente con una visión de integración ${ }^{61}$.

Estas cuatro condiciones inciden en las dinámicas del mercado subregional y afectan las políticas públicas de seguridad alimentaria de los países andinos. La política económica para el SSAN no puede verse solo desde los ángulos macroeconómicos de ajustes, sin una orientación desde la experiencia de los países desarrollados, que entienden las condiciones globales pero piensan y actúan desde la intervención nacional.

\subsubsection{Política pública y territorios}

Cuervo plantea condiciones generales para cambiar las políticas territoriales, al considerar la siguiente sustitución:

“[...] el concepto de política regional por el de política económica territorial. Mientras la primera se preocupa por la regulación de la brecha de desarrollo subnacional, teniendo al Estado central como actor principal, la segunda conjuga lo primero con la política de desarrollo local, surgida desde abajo y construida a partir de las regiones y localidades en base a sus propios recursos ${ }^{62}$.

El autor compara dos políticas diferentes para aplicar en un mismo espacio; su diferencia está en que son temas separados con formuladores de política distintos: el Gobierno nacional o los subnacionales. Esta interpretación presenta problemas en el mundo real de las acciones públicas, ya que considera altos niveles de autonomía y soberanía en las decisiones de las políticas y las lógicas de acumulación territorial y global, en función de orientar los procesos de inversión. Estos aspectos entran en conflicto si no hay una visión integral del SSAN.

Ahora bien, en las dinámicas reales del desarrollo local se presentan conflictos por desinterés privado, el espacio sobre el que se va a invertir, la estrechez del mercado,

61 FAO y Comunidad Andina (2004): Comunidad Andina: factores macroeconómicos, comerciales, sectoriales y la seguridad alimentaria. Lima, pág. 58

62 CUERVO, Luis M. (1999): "El rompecabezas de la intervención económica territorial". En Territorios, Revista de Estudios Regionales y Urbanos. Universidad de los Andes, Bogotá, pág. 78. 
los bajos ingresos de la población, o bien, porque la política nacional no se integra en los intereses de la regiolocal y genera roces intergubernamentales. Desde la dinámica político-administrativa del territorio, la CEPAL considera las intervenciones de las últimas tres décadas en América Latina, vinculadas en los territorios:

El binomio descentralización/federalismo se ha impuesto como realidad mayor, diluyendo en algunos casos el amparo conceptual ofrecido por la teoría del desarrollo económico local, mezclándose con él en otros y sustituyéndolo en la mayoría ${ }^{63}$.

Supone la CEPAL que aplicar la descentralización en algunos países tiene tal nivel de autonomía en el territorio que integra o sustituye discusiones sobre teorías del “desarrollo económico local”. Ello está soportado sobre el instrumento de una política territorial regional y local que admita su desarrollo vía instrumentos y capacidades de gestión pública permitidas por la política descentralizadora; no obstante, se desconocen los conflictos de intereses por niveles de gobierno. En este sentido, Restrepo considera sobre la descentralización en América Latina:

No es un grito de autonomía federal en el sentido de las fuerzas territoriales que defendieran a nivel central sus soberanías y pactaran, un poco por residuo, otro tanto por incapacidad y conveniencia, las competencias y recursos a manos del nivel central del Estado. No, en la época contemporánea la descentralización es una estrategia del centro, en el sentido que es "en el centro" y "desde el centro" que se norma, se reforma y se negocia entre actores nacionales relevantes el andamiaje formal de las regulaciones descentralizadas ${ }^{64}$.

Se entiende que la descentralización, como base de la política regiolocal en América Latina, presenta dos conflictos: el intergubernamental y el de los intereses entre capital y trabajo. La descentralización como eje de la política pública territorial en América Latina, desde las posiciones de la CEPAL y autores como Restrepo y Medellín, demanda

63 CEPAL (2009): "Economía y territorio en América Latina y el Caribe: desigualdades y políticas”. Santiago de Chile, pág. 141.

64 RESTREPO, Darío (2006): "Las fracturas del Estado en América Latina”. En Historias de descentralización transformación del régimen político y cambio en el modelo de desarrollo América Latina, Europa y EUA. UN, GTZ, USAID y Agencia Colombiana de Cooperación, Bogotá, pág. 37. 
que se analicen los cambios institucionales y los acuerdos crecientes en las relaciones intergubernamentales:

[Existe una] relevancia del Gobierno central en los procesos de descentralización, no solo por su parte en la transferencia de espacios de poder a los gobiernos subnacionales, cuyas voluntades y decisiones son sustanciales, sino porque nuevos estados unitarios requieren de una gestión armónicamente compartida entre los niveles de gobierno ${ }^{65}$.

Se exige de esta manera que lo regiolocal tenga algunos mínimos de autonomía en sus funciones y decisiones, para que existan, como dice Cuervo, "políticas territoriales desde abajo". Lo anterior implica tener espacios de autonomía para el desarrollo regiolocal y que, en los mínimos determinados para las regiones SAN, las políticas nacionales se integren en función de los territorios, y no de las políticas globales. Otra perspectiva de las relaciones entre economía, desarrollo local, territorio y política pública territorial es considerada por L. Lira:

[Hay una] posibilidad de convertirse en actores dados los procesos de descentralización que surgen a partir de los noventa [...] que perpetúa las improntas territoriales del sistema capitalista y se plantea un modelo de intervención que combina los enfoques de arriba hacia abajo (top-down) con los enfoques de abajo hacia arriba (bottomup) dado el avenimiento de un modelo de producción flexible o neofordista $^{66}$.

Un análisis integral y cercano a las dinámicas territoriales, al reconocer la descentralización como acción política, es el que permite algunos "grados de libertad" para las intervenciones sobre y desde el territorio, así como los mínimos agroalimentarios regiolocales aquí propuestos.

65 HERZ SAENZ, Carlos (2008): “Descentralización: ¿desafio pendiente en la región andina?”. En Procesos de descentralización en la región andina: Bolivia, Perú, Ecuador y Colombia. Ministerio Federal de Cooperación Económica y Desarrollo, Perú, pág. 13.

66 LIRA C., Luis (2003): La cuestión regional y local...Op. cit., pág. 10. 


\subsubsection{El SSAN, la necesidad de integración de la política SAN}

En la política del SSAN hay varios aspectos de la acción pública que deben tenerse presentes: el concepto de interdisciplinariedad, para ver integralmente a la política pública específica del SSAN; el de la cadena alimentaria, para analizar los niveles y la estructura de los gobiernos; y las organizaciones públicas, privadas y comunitarias, que inciden en su dinámica por procesos de organización y gestión, y resultan en políticas, reglas ambientales, salud pública, condiciones higiénicas mínimas para distribuir alimentos, decisiones de acceso y políticas sociales.

La tabla 2.4 muestra las características para el diseño y análisis de una política pública y el SSAN, seis elementos generales, y el de especificidad de la política del Sistema de Seguridad Alimentaria Nutricional, propuesto por esta investigación.

Tabla 2.4 Características del diseño y análisis de una política pública y el sistema de seguridad alimentaria nutricional SSAN

\begin{tabular}{|c|c|c|c|c|c|c|c|}
\hline \multicolumn{6}{|c|}{ Generales para el Diseño y Análisis de una Política Pública } & \multicolumn{2}{|c|}{$\begin{array}{l}\text { Específicos para Política } \\
\text { Pública del SSAN }\end{array}$} \\
\hline \multirow[b]{2}{*}{$\begin{array}{c}1^{\text {a }} \\
\text { Un } \\
\text { contenido, } \\
\text { determinado } \\
\text { por el } \\
\text { "problema de } \\
\text { investigación } \\
\text { para la acción". }\end{array}$} & \multirow[b]{2}{*}{\begin{tabular}{|c|}
$2^{\mathrm{a}}$ \\
Un programa, con \\
un eje específico, un \\
sector de \\
intervención, del \\
problema tratado, \\
"la constancia del \\
decisor público en \\
sus opciones e \\
intenciones".
\end{tabular}} & \multirow[b]{2}{*}{\begin{tabular}{|c|}
$3^{\mathrm{a}}$ \\
Una \\
orientación \\
normativa, \\
expresando \\
finalidades y \\
preferencias de \\
las decisiones.
\end{tabular}} & \multirow[b]{2}{*}{$\begin{array}{c}4^{\mathrm{a}} \\
\text { Un factor de } \\
\text { coerción, naturaleza } \\
\text { autoritaria del actor } \\
\text { gubernamental, una } \\
\text { legitimidad, el "acto } \\
\text { público se impone", } \\
\text { sobre otros actores } \\
\text { públicos o privados. }\end{array}$} & \multirow[b]{2}{*}{$\begin{array}{c}5^{\mathrm{a}} \\
\text { Una competencia } \\
\text { social, identifica } \\
\text { "al público, a los } \\
\text { individuos, grupos o } \\
\text { instituciones que } \\
\text { componen el campo } \\
\text { de acción" }\end{array}$} & \multirow[b]{2}{*}{$\begin{array}{l}6^{\text {a }} \\
\text { Un diseño } \\
\text { institucional, } \\
\text { que varían en } \\
\text { función de las } \\
\text { formas de } \\
\text { organización del } \\
\text { Estado y la } \\
\text { sociedad. }\end{array}$} & \multicolumn{2}{|r|}{$7^{\mathrm{a}}$} \\
\hline & & & & & & \begin{tabular}{|c}
7.1 Una visión \\
sistémica e \\
integral de los \\
diferentes ejes \\
que afectan la \\
política pública
\end{tabular} & $\begin{array}{l}\text { 7.2. Una visión } \\
\text { interdisciplinaria } \\
\text { que permita analizar } \\
\text { los diferentes } \\
\text { factores que incluyen } \\
\text { las acciones de SAN. }\end{array}$ \\
\hline Barcelona & . & SIIENY, y yea & ítica pública ej & tru & sis" & & $\begin{array}{l}\text { torial Ariel, } \\
\text { nento de }\end{array}$ \\
\hline
\end{tabular}

Según lo anterior, se requiere, por tanto, superar la visión sectorial del problema del sistema de seguridad alimentaria y nutricional, para verlo integralmente. Dado que las acciones de política han sido vinculadas por varias décadas a una parte de la cadena alimentaria:la producción de agroalimentos, puede afirmarse que "la política alimentaria con la política agrícola" ${ }^{67}$ tenían solo en cuenta la disponibilidad, independientemente de la inocuidad, la nutrición, la distribución, el acceso y el uso biológico.

67 SCHEJTMAN, Alexander (1994): Economía política de los sistemas alimentarios en América Latina. FAO/CEPAL, Santiago de Chile, pág. 1. 


\subsubsection{Gobiernos, territorios, sistemas y sectorialidad}

Aclarar las competencias relacionadas con políticas por niveles de gobierno permite vincular una nueva visión: la salud pública, la política social y la política urbana. Por ejemplo, Schejtman analiza la política alimentaria, y así diferencia la referida a la alimentación a la alusiva a la nutrición:

Por política alimentaria se entenderá, entonces, a toda iniciativa pública destinada a incidir en el sistema alimentario de modo directo; esto implica abandonar la visión estrechamente sectorial, que tendría a identificar la política alimentaria con la de estímulo a la producción agrícola de alimentos, o con la de intervenciones nutricionales y pasar a reconocer el carácter sistémico [...], criterio principal para evaluar el funcionamiento de los sistemas alimentarios ${ }^{68}$.

Se insiste en que la política de seguridad alimentaria debe tener una visión sistémica que supere lo sectorial. Ello demanda concebir la integralidad del problema, lo cual requiere examinar la cadena alimentaria y sus dinámicas internas, el contexto que determina elementos como la salud pública, la inocuidad, los servicios públicos domiciliarios, las condiciones sociales y ambientales, el derecho social y la soberanía.

Además, han de identificarse acciones que integralmente impulsen los gobiernos en los espacios territoriales, las estructuras productivas, sociales y políticas, que muestren unas relaciones sociales particulares en cada caso, con el vínculo a los complejos territoriales de articulación y producción, considerados por Coraggio (véase el capítulo VII).

Las condiciones (tabla 2.5) para el diseño de la política pública de SAN son varias: la CEPAL, en el 2006, identifica siete aspectos para tener presentes en esta política pública, ampliados por Machado y Torres, con dos adicionales vinculados con las empresas transnacionales y las condiciones coyunturales y estructurales; y esta tesis agrega el número 10, con el fin de tener presente la continuidad y la estabilidad de las políticas a través de las relaciones transversales y verticales por tener en cuenta en el diseño de la política.

68 Ibíd., pág. 155. 


\begin{tabular}{|c|c|c|c|c|c|c|c|c|}
\hline $\begin{array}{l}\text { 1o. Nivel que } \\
\text { ocupa el } \\
\text { problema } \\
\text { alimentario } \\
\text { en la } \\
\text { agenda } \\
\text { pública }\end{array}$ & \begin{tabular}{|c}
20. \\
Presencia \\
o no de \\
políticas \\
de estado \\
de largo \\
plazo con \\
leyes \\
acordadas \\
a nivel \\
nacional
\end{tabular} & \begin{tabular}{|} 
3o. Grado de \\
continuidad \\
de las \\
políticas, y la \\
integración con \\
políticas \\
intersecto- \\
riales
\end{tabular} & $\begin{array}{c}40 . \\
\text { Presupuest } \\
\text { o nacional } \\
\text { asignado y } \\
\text { nivel de } \\
\text { inversión del } \\
\text { sector }\end{array}$ & \begin{tabular}{|c|}
50. \\
Infraestructura y \\
recursos \\
humanos de \\
sectores \\
asociados a la \\
seguridad \\
alimentaria y \\
desnutrición, en \\
la operación, \\
control y \\
evaluación de \\
procesos \\
productivos, \\
canales de \\
comercialización \\
y manipulación de \\
alimentos
\end{tabular} & $\begin{array}{l}\text { 6o. Cobertura de } \\
\text { los programas } \\
\text { ejecutados por los } \\
\text { distintos sectores } \\
\text { (salud, educación y } \\
\text { agropecuario), en } \\
\text { alimentación para } \\
\text { gestantes, lactantes } \\
\text { y preescolares, de } \\
\text { fortificación de } \\
\text { alimentos para } \\
\text { reducir la prevalencia } \\
\text { de déficit de Hierro, } \\
\text { Yodo, Vitamina A y } \\
\text { Znc; educación } \\
\text { alimentaria }\end{array}$ & \begin{tabular}{|c|} 
7o. Apoyo \\
financiero y \\
asistencia \\
técnica para \\
la \\
producción; \\
saneamiento \\
y agua \\
potable; \\
efectividad que \\
han tenido las \\
políticas y \\
programas en \\
la promoción, \\
control y \\
fomento de la \\
SAN
\end{tabular} & \begin{tabular}{|} 
8o. Papel de \\
las \\
Empresas \\
Transna- \\
cionales de \\
agroalimentos \\
en las \\
decisiones \\
públicas del \\
SSAN
\end{tabular} & $\begin{array}{c}90 . \\
\text { Aspectos } \\
\text { coyunturales } \\
\text { y } \\
\text { estructurale } \\
\text { s en las fases } \\
\text { de } \\
\text { disponibilidad } \\
\text { y acceso de } \\
\text { la cadena } \\
\text { alimentaria. }\end{array}$ \\
\hline \multicolumn{9}{|c|}{ 10o. Relaciones transversales y verticales a partir de: - Integralidad - Gradualidad - Sostenibilidad } \\
\hline \multicolumn{9}{|c|}{$\begin{array}{l}\text { Fuente: Elaboración propia adaptada de: FERNANDEZ Andrés, MARTINEZ Rodrigo. 2006. "Modelo de análisis del impacto social y económico de la desnutrición infantil } \\
\text { en América Latina" División de Desarrollo Social, manuales } 52 \text { Santiago de Chile, diciembre de 2006. CEPAL-PMA; MACHADO C. Absalón, TORRES O. Jorge. 1987 "EI } \\
\text { sistema agroalimentario una visión integral de la cuestión agraria en América latina" CEGA Siglo XXI editores; FAO-COMUNIDAD ANDINA. 2004. "Comunidad Andina: } \\
\text { Factores Macroeconómicos, Comerciales, Sectoriales Y La Seguridad Alimentaria". La condición } 10 \text { es aporte de esta investigación. }\end{array}$} \\
\hline
\end{tabular}

\subsubsection{Territorio y cultura}

En Colombia, por las características regionales existentes, hay que ver la relación entre cultura y territorio ${ }^{69}$, mediada por hábitos de consumo y manejo de alimentos en condiciones específicas del territorio. Estas son identificadas por las formas en que las poblaciones se apropian del territorio y por los elementos mínimos ofrecidos para su sostenimiento. Inciden en estas dinámicas el modelo de desarrollo, la urbanización, la modernización y la globalización, pues modifican patrones de consumo en algunos territorios, especialmente urbanos.

Los hábitos nutricionales territoriales inciden en la morbimortalidad asociada a los cambios en hábitos de vida, como el incremento del sedentarismo, las dietas de comidas rápidas y el control de multinacionales de alimentos para homogenizar dietas. Esto consolida culturas únicas de consumo, fenómeno que se debe a necesidades creadas por los medios de comunicación, el desarrollo de una cultura urbana de consumo de alimentos y el desconocimiento de patrones tradicionales. También, la sustitución de

69 "En casi todos los países, los factores sociales y culturales tienen una influencia muy grande sobre lo que come la gente, como preparan sus alimentos, sus prácticas alimentarias y los alimentos que prefieren" LATHAM, Michael [2002]: Nutrición humana en el mundo en desarrollo. FAO, Roma, pág. 35. 
cultivos hacia actividades extractivas (como es el caso del Pacífico colombiano) ha tenido consecuencias en calidad y variedad de la ingesta de la población:

La simplificación productiva, mucha veces por la dedicación casi exclusiva a las actividades extractivas, se ha traducido en una simplificación y pérdida de la calidad de la dieta, [...] pérdida de etnotécnicas, abandono de cultivariedades, sobreexplotación de ecosistemas y ruptura de la dinámica de cultivo e intercambio de productos a lo largo de las cuencas. En numerosos lugares, las comunidades sufren el deterioro de su patrimonio natural silvestre y cultivado, en especial de los recursos biológicos necesarios para la alimentación y la supervivencia; es decir, se han afectado los sistemas comunitarios de seguridad alimentaria ${ }^{70}$.

La cultura de algunos pobladores urbanos, dada la forma de apropiación de los territorios y la herencia de sus ancestros, permite construir acciones de políticas territoriales diferentes, por las "maneras populares de construir territorio; [...] es precisamente desde allí que deberían formularse las políticas públicas y no a partir de fórmulas preconcebidas" ${ }^{\prime 71}$. Ello implica tener en cuenta ciertas prácticas al ejecutar las políticas, así como entender la cultura de la alimentación.

\subsection{PROPUESTA DE LA TESIS PARA EL ANÁLISIS DE LA POLÍTICA DE SEGURIDAD ALIMENTARIA NUTRICIONAL (SAN)}

La propuesta de análisis para el desarrollo del trabajo investigativo de la SAN en Colombia tiene dos elementos: el referido a la teoría crítica de sistemas, la cual permite establecer diversas relaciones y condiciones en que se desenvuelven las acciones de la política pública en SAN; y el que relaciona la definición de las dimensiones presentes en el enfoque interdisciplinar.

70 ALZATE, Óscar y LÓPEZ, Juan Diego (2003): Una estrategia de seguridad alimentaria para el Pacifico colombiano desde la perspectiva de las comunidades. Pronatta, Bogotá, pág. 52. 71 FRANCO S., Francisco (2008): Construcción cultural del territorio desde lo popular: cotidianidad y proyectos de futuro en Bogotá y Soacha. Escuela Superior de Administración Pública, Bogotá, pág. 270. 


\subsubsection{Análisis integral de la $\mathrm{SAN}$, a partir de la teoría crítica de sistemas sociales}

El marco epistémico se soporta en la teoría de los sistemas sociales, propuesta por Luhmann y expresada en la figura 2.2. Los sistemas sociales, referidos a interacciones, organizaciones y sociedades, determinan un cambio de paradigma de la teoría general de sistemas. Luhmann considera que "la teoría general de sistemas sociales estará orientada por la teoría general de sistemas; con esto justificamos el empleo del concepto de "sistema"',72.

A partir de ello definió los elementos que componen la argumentación de la teoría, a la vez que destaca el sistema y el entorno como elementos base de partida para el análisis, porque permite sustituir la diferencia del todo y las partes por una teoría de diferenciación de sistemas.

\begin{tabular}{|c|c|c|c|c|}
\hline \multicolumn{5}{|c|}{$\begin{array}{l}\text { Figura } 2.2 \text { Niveles de análisis de la teoría general de sistemas y la teoría } \\
\text { general de los sistemas sociales - cambio de paradigma en la teoría de } \\
\text { sistemas }\end{array}$} \\
\hline 1. & \multicolumn{4}{|c|}{ Sistemas } \\
\hline 2. & Máquinas & Organismos & $\begin{array}{l}\text { Sistemas } \\
\text { Sociales }\end{array}$ & $\begin{array}{l}\text { Sistemas } \\
\text { Psíquicos }\end{array}$ \\
\hline 3. & & Interacciones & Organizaciones & $\begin{array}{c}\text { Sociedade } \\
\mathrm{s}\end{array}$ \\
\hline
\end{tabular}

Por su parte, Sánchez plantea la diferencia del concepto de sistema, entendido no desde el entorno: "Cualquier sistema necesita de su entorno y los límites con el entorno para poder identificarse. El sistema y el entorno nacen juntos y necesitan uno del otro para existir". [...] El conocimiento representa un elemento constituyente de la autopoiesis del sistema social" $" 73$.

Ahora bien, es necesario aclarar la diferencia de jerarquización y entender la causalidad que ha de ser distribuida entre sistema y entorno. Esencialmente, la argumentación

72 LUHMANN, Niklas (1984): Sistemas sociales. Lineamientos para una teoría general, Anthropos y Universidad Iberoamericana, México, pág. 39.

73 SÁNCHEZ ROMERO, Gerardo (2011): Revista Mad, Universidad de Chile, n. ${ }^{\circ}$ 24, pp. $30-60$. 
diferencia elemento y relación, porque permite pensar la unidad de la diferencia como constitutiva:

La unidad es constituida por el sistema en el momento en que un elemento es tomado como elemento para la relacionalidad; [...] elemento es, por consiguiente, aquella unidad no más reductible del sistema. No más reductible significa también que un sistema solo puede constituirse y cambiar relacionando elementos, y nunca mediante la desintegración y la reorganización ${ }^{74}$.

Se encuentra en esta explicación la base del cambio de los sistemas. Este componente epistémico de la teoría de los sistemas sociales permite entender la SAN como producto de una realidad integral vinculada a diferentes interrelaciones. Al identificar, desde varias de sus partes, los componentes del SSAN, la desarticulación de las acciones y la necesidad de que su análisis tenga un método de trabajo interdisciplinario, se logró un primer acercamiento a una visión sistémica del SSAN (figura 2.3).

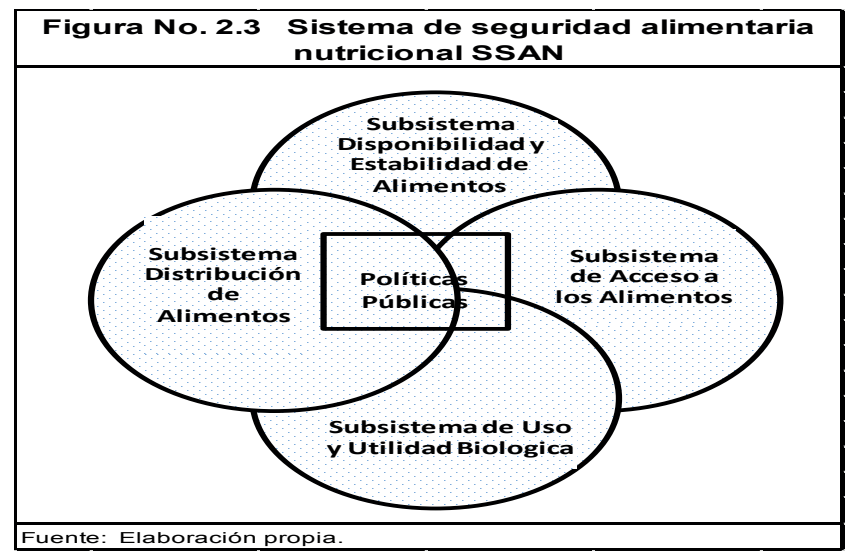

Como se observa en la figura, cada uno de los subsistemas tiene diversas formas de interrelacionarse; sin embargo, hay una que se cruza con todos como parte de sus elementos: la acción pública, que a través de las diversas políticas públicas interviene en cada uno de los subsistemas. En cada uno de los casos, para los subsistemas de disponibilidad y estabilidad, distribución, acceso, y uso y utilidad, se identifican

74 LUHMANN, Niklas (1984): Sistemas sociales. Lineamientos... Op. cit., pág. 45. 


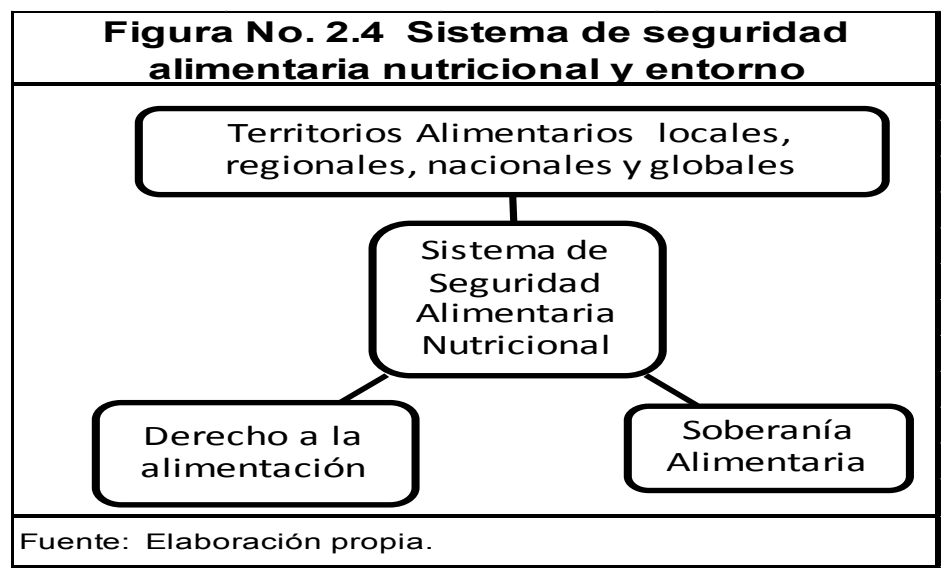

diferentes niveles de procesos para los componentes del SSAN, según la clasificación de García ${ }^{75}$, que parten de la cadena alimentaria.

Por otro lado, la figura 2.4 muestra los vínculos entre el SSAN y los componentes del entorno: territorios alimentarios, el derecho a la alimentación y la soberanía alimentaria.

\subsubsection{La interdisciplinariedad}

El concepto de la interdisciplinariedad permite un análisis de la SAN más cercano a las diferentes acciones y decisiones que hay que caracterizar y determinar como parte de las lógicas conceptuales, contextuales y metodológicas que están presentes en el análisis de su política. Puede definirse interdisciplinariedad así:

La transformación de los objetos de conocimiento e investigación en áreas conexas, en estado real. Lo cual exige romper con los actuales criterios de regulación de las normas académicas y su fragmentación cognitiva y metodológica ${ }^{76}$.

García, a su vez, enuncia un precepto que devino guía del presente trabajo:

75 GARCÍA, Rolando (2008): Sistemas complejos. Conceptos, métodos y fundamentación epistemológica de la investigación interdisciplinaria. Gedisa, Barcelona, pág. 57.

76 NOGUEIRA D., Ángel (1997): Niklas Luhmann. La sociedad como teoría de sistemas autorreferenciales y autopoiéticos de comunicación. Nuevos presupuestos críticos, nuevos conceptos e hipótesis en la investigación sociológica de la sociedad contemporánea. Revista Anthropos, n. ${ }^{\text {os }} 173-174$, Barcelona, pág. 4. 
Las relaciones que determinan la estructura del sistema no se descubren a posteriori de los estudios disciplinarios parciales, sino que deben plantearse desde el inicio y se continúan elaborando y replanteando a través de toda la investigación. Por eso insistimos en concebir la investigación interdisciplinaria como un proceso y no como un acto de coordinación de resultados ${ }^{77}$.

Por otro lado, la idea de Max-Neef de la interdisciplinariedad se organiza a través de tres niveles jerárquicos que implican coordinación entre el orden inferior y superior; en esta dirección, "introduce un sentido de propósito cuando la axiomática común a un grupo de disciplinas se define en el nivel jerárquico inmediatamente superior"78 (figura 5). El primer nivel está orientado por el componente ideal que conduce a determinar lo que debe hacerse; el segundo es normativo, determina lo que se quiere hacer; y el tercero es propositivo, muestra lo que se es capaz de hacer. En gran parte, este esquema de Max-Neef permite determinar las direcciones de la interdisciplinariedad para el análisis de la política SAN.

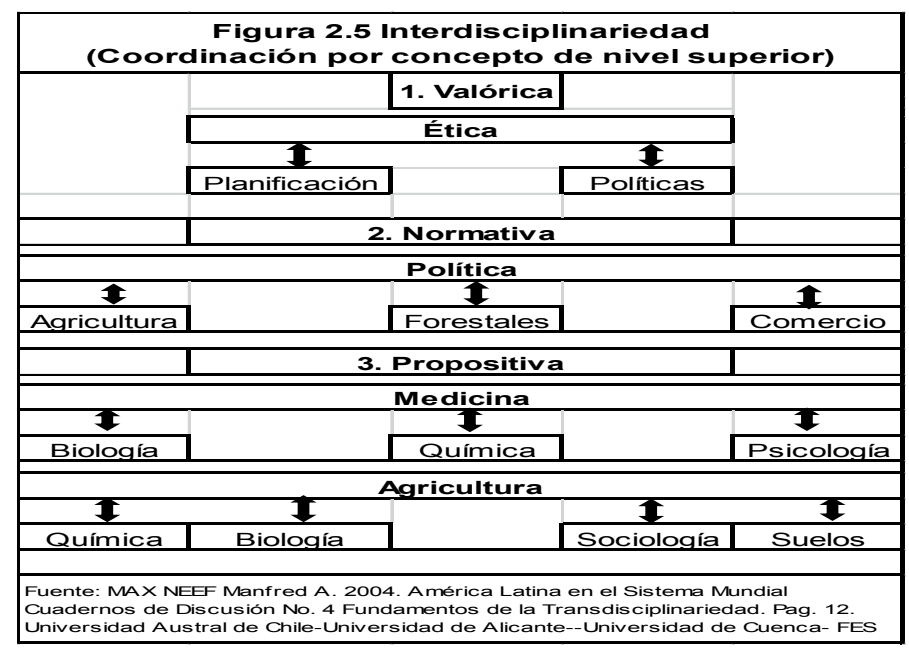

\subsubsection{El carácter interdisciplinar para el análisis de la SAN}

En el terreno de las disciplinas trabajadas como parte de las dimensiones del enfoque, se incluyen la economía, el derecho, la ciencia política y algunos temas marginales pero

77 GARCÍA, Rolando (2008): Sistemas complejos conceptos... Op. cit., pág. 99.

78 Max-Neef, Manfred A. (2004):América Latina en el Sistema Mundial. Cuadernos de Discusión, n. ${ }^{\circ}$ 4. Alicante, Universidad de Cuenca, pág. 11. 
significativos vinculados con la salud pública y la nutrición, así como su relación con la alimentación, la cultura, la geografia, la historia. En resumen, varias áreas de las ciencias sociales forman parte de este enfoque interdisciplinar.

\subsubsection{Construcción de regiones SAN y desarrollo territorial}

La propuesta de construir regiones SAN parte de identificar los mínimos requerimientos nutricionales de la población urbana, definida como la que habita en el eje dinamizador y la capacidad de producir los agroalimentos en las zonas rurales cercanas al departamento del respectivo eje, definidas como lo regiolocal. Ello permite identificar una necesidad institucional de los Gobiernos nacional y territorial, que buscan la integralidad.

Esta integralidad exige acciones y regulaciones que permitan interacciones en el SAN, en diferentes procesos: producción, distribución, acceso y uso biológico; lo cual requiere coordinación de las diferentes políticas públicas y de las estructuras gubernamentales. Para el caso de la producción y estabilidad de los alimentos, se requiere tener presente, desde el principio de cercanía, los siguientes cuatro elementos de la disponibilidad: para el consumo regiolocal, para el consumo nacional, para la prevención y solidaridad y para las exportaciones.

Para el caso de la distribución, se deben tener en cuenta las regulaciones nacionales, regionales, locales, de tipo sanitario, ambiental, de salud pública y urbanística. Por su parte, en el manejo del acceso no son solo han de tenerse en cuenta las regulaciones sobre los precios de los alimentos o la coordinación de las políticas públicas de aplicación territorial de orden nacional, regional, local, barrial y veredal, sino que estas han de ejecutarse integralmente con intervención directa de los pobladores.

Y respecto al uso biológico, la información sobre los cuadros nutricionales de la población exige mayores niveles de integración y conocimiento individual de la población objeto de las políticas públicas respectivas.

Las estrategias para construir estos sistemas de manejo interdisciplinar exigen dos elementos: por un lado, el concepto de hasta dónde va lo regiolocal, para entender e interpretar el desarrollo sobre los mínimos de seguridad alimentaria nutricional de una región o un eje dinamizador; por el otro, el manejo biológico y agroecológico de la producción de alimentos, temas que relacionan las acciones de control ambiental y sanitario. La integralidad de las políticas en el SAN se debe 
realizar a través de la identificación sistémica e interdisciplinar de las condiciones de intervención, interacción y regulación para su aplicación en los territorios, el Estado y los gobiernos específicos. 


\section{SEGUNDA PARTE \\ LOS CONTEXTOS DE LA SEGURIDAD ALIMENTARIA \\ NUTRICIONAL (SAN)}

\section{CAPÍTULO III. CONTEXTO INTERNACIONAL DEL SISTEMA DE SEGURIDAD ALIMENTARIA NUTRICIONAL, CADENA ALIMENTARIA Y POLÍTICA PÚBLICA GLOBAL DE ALIMENTOS BÁSICOS}

"La producción anual mundial de granos básicos — arroz, trigo, maíz y otros granos secundarios- la comparé con la población total del mundo con un descubrimiento alarmante. Si el grano se convierte en calorías y proteínas per cápita diarias, el total es significativamente mayor que la cantidad de nutrientes necesarios para la supervivencia humana. Además, en el curso de los tres decenios pasados el mundo ha producido más grano per cápita no menos.Y, sin embargo en cualquier año dado de esa historia reciente, varios millones de seres han muerto por causas relacionadas con el hambre. [...] Dado que la alimentación es tan básica para nuestro bienestar fisiológico y emocional, ¿por qué las sociedades no elaboran mecanismos para distribuir los alimentos con más igualdad?" ${ }^{79}$

$\mathrm{E}$ ste capítulo contextualiza la situación y condiciones de la SAN a nivel internacional, analizando varios aspectos: los elementos generales que identifican la SAN a nivel global, partiendo del pensamiento de la FAO en sus primeros cincuenta años, que refleja la tendencia en construcción de la dieta global de productos básicos manifestada en el consumo generalizado de trigo, cereales, arroz, yuca, oleaginosas, azúcar, carnes y lácteos, los cuales han estado presentes desde la antigüedad, y hoy se presentan bajo los agronegocios mundiales con sus dinámicas de homogenización y rentabilidad.

Otro aspecto es el referido a las políticas públicas alimentarias globales: los elementos generales de estas, que se inician con el grito de los segadores del siglo XVII: "Muera el mal gobierno"; las relaciones de salud pública, contaminación, alimentación y nuevas enfermedades vincula nuevos cuadros de morbimortalidad en el mundo; los vínculos

79 TIMMER C., Peter, FALCON, Walter P. y PEARSON, Scott R. (1985): Análisis de políticas alimentarias. Banco Mundial y Editorial Tecnos, Madrid, pág. 15. 
de patentes y control de las multinacionales en la cadena alimentaria mundial; y los conflictos entre agrocombustibles y agroalimentos.

Por último, se analiza la cadena alimentaria mundial en sus componentes:la disponibilidad, caracterizando la tierra y su aprovechamiento mundial desde el 2000 al 2008; la distribución mundial de cereales por países exportadores e importadores; el acceso con los contrastes entre necesidades y condiciones; y el uso biológico de los alimentos, viendo las situaciones de pobreza, hambre y desnutrición desde 1990 en el mundo.

\subsection{ELEMENTOS GENERALES DE LA SEGURIDAD ALIMENTARIA GLOBAL}

\subsubsection{Evolución de orientaciones e interpretaciones de la FAO}

En el repaso de la situación alimentaria mundial, se miran las dinámicas presentadas por la FAO en los últimos sesenta años con las políticas generadas desde su creación en la conferencia de Hot Springs, Estados Unidos (1943). En los años cincuenta, la discusión era el manejo de los excedentes agrícolas en los países desarrollados; además, vinculaba el concepto de seguridad alimentaria a la autosuficiencia alimentaria total o parcial por cada país.

En los sesenta se buscó abordar los problemas generados por el hambre y la malnutrición, a pesar de los excedentes de la década anterior. Así, se creó el Plan Mundial de Alimentos (PMA), en 1961, y se consideró que el ingreso de los países creciera más rápido que la producción de alimentos. En 1963, el Congreso de Estados Unidos generó recomendaciones que reiteraría en la Conferencia Mundial de la Alimentación de 1974 y en la Cumbre Mundial sobre la Alimentación de $1996^{80}$, que hoy siguen siendo válidas.

Otro aspecto de esta década se refiere a la escasez de alimentos que venía desde 1958 en China, con las pérdidas humanas que algunos señalan en cerca de 10 millones de personas. En 1993, Sen estimó que durante el periodo 1958-1961, entre 23 y 30 millones de personas murieron como consecuencia de aquella catástrofe, que representó el fracaso del programa agrícola del "Gran salto hacia adelante".

80 FAO (1992): "La alimentación y la agricultura en el mundo: enseñanzas de los cincuenta últimos años". En El Estado de la alimentación y la agricultura. FAO, pág.32 
En los setenta, la discusión giró alrededor de la crisis alimentaria mundial y los retrocesos de la agricultura mundial disminuyeron la producción de cereales. La paradoja consistió en que aumentó la desnutrición porque subieron los precios de los pocos alimentos. Esta década discute los avances relacionados con semillas, desde el principio de "neutralizar la naturaleza [considerando como] las nuevas semillas son de alto rendimiento en y por sí mismas" ", referidas a sus características, porque "responden en alto grado a ciertos insumos básicos, tales como la irrigación y los fertilizantes. De acuerdo con el criterio de Palmer hemos decidido usar el término 'variedades de alto grado de respuestas' para dar una idea más clara de su verdadera naturaleza" ${ }^{22}$; es decir, las semillas responden a unas condiciones exigidas para sembrar.

En los ochenta, la crisis económica replantea el concepto de seguridad alimentaria sobre tres componentes: disponibilidad, estabilidad y acceso, solo por vía de autoproducción o ingreso de los individuos. La FAO propuso adoptar un pacto mundial de seguridad alimentaria, que algunos países en desarrollo asumieron, pero para otros "implicaba una obligación demasiado vinculante en un momento en que los gobiernos trataban de evitar compromisos" 83 , pues se vivía el desmonte del Estado de bienestar que acarreaba adelgazarlo y ampliar las decisiones orientadas por el mercado.

\subsubsection{La dieta básica mundial}

La tendencia a construir una dieta global de productos básicos de la alimentación, reflejada en el consumo generalizado de trigo, cereales, arroz, yuca, oleaginosas, azúcar, carnes y lácteos, está presente desde la antigüedad, y hasta la primera revolución industrial (siglo XVIII); sin embargo, antes, la variedad era parte de la dieta alimenticia de la población (ver tabla 6,2, capítulo VI).

La homogenización global de los alimentos genera un proceso económico manejado como cualquier mercancía; en consecuencia, su producción depende de la rentabilidad dada por los costos de producción y los incentivos financieros, de protección, tecnológicos y fiscales otorgados por el Estado, a partir del concepto de seguridad

81 PALMER, Ingrid (1972): “Science and agricultural production". Ginebra, UNRISD, citado en: MOORE L. Francés y COLLINS, Joseph (1982): Comer es primero. Más allá del mito de la escasez. Siglo XXI Editores, México, pág. 120.

82 MOORE L. Francés y COLLINS, Joseph (1982). Comer e sprimero...op. cit., pág. 121.

83 FAO (1992): La alimentación y la... Op. cit., pág. 35. 
nacional, traducida en subsidios. Esta situación, en la mayoría de casos, se presenta en la cadena alimentaria y se controla por grandes empresas nacionales y multinacionales. De este modo, la dieta se homogeniza y la rentabilidad para su producción se generaliza.

Esta combinación de homogenización, rentabilidad y subsidios lleva a producir los alimentos lejos de los territorios donde se consumen; son los "alimentos viajeros [los cuales] no solo conllevan una contaminación medioambiental creciente, sino que inducen a la uniformización y a la estandarización productiva" ${ }^{84}$. Se pierde de esta forma, cada vez más, la biodiversidad por vía de la homogenización en disponibilidad y menor capacidad nutritiva por los insumos para su preservación. Por estas situaciones se considera en esta tesis que la región SAN maneja el principio de disponibilidad de alimentos nutritivos cerca del consumidor final.

La homogenización vincula los controles que ejercen pocos países en el mundo sobre la disponibilidad de agroalimentos ${ }^{85}$. Entre 10 y 15 controlan más del 70\%, como anota Aranguren:

Estados Unidos controla el 73\% del mercado de maíz del mundo; cinco países (Estados Unidos, Corea, Japón, Tailandia y China) controlan el 90\% de las exportaciones de arroz; otros cinco países (Estados Unidos, Canadá, Australia, Rusia y Francia) controlan el $60 \%$ del trigo; en la práctica 500 empresas controlan el 70\% del mercado alimentario y tres empresas agrícolas (Cargill, Bunge y ADM) se reparten la mayoría del comercio de cereales ${ }^{86}$.

La concentración de la disponibilidad y distribución de agroalimentos se combina con políticas públicas dadas en función del proceso concentrador y centralizador, a través de subsidios, tratados comerciales bilaterales o multilaterales y controles sanitarios orientados al control y la homogenización de la dieta global que ayudan a entender " $E l$ hambre oculta", de Josué de Castro, como una calamidad humana:

84 VIVAS, Esther y MONTAGUT, Xavier (2009): Del campo al plato. Los circuitos de producción y distribución de alimentos. Icaria, Barcelona, pág. 31.

85 La información de disponibilidad de alimentos mundiales fue tomada en el periodo 19942009 de las estadísticas de la FAO.

86 ARANGUREN, Felipe L. (2012): El negocio del hambre. La especulación con alimentos. Icaria, Barcelona, pág. 20. 
La monotonía alimentaria, impuesta por la civilización, el hábito del hombre civilizado de alimentarse a base de un número restringido de sustancias alimenticias [...]. El primitivo disponía de un número infinito de plantas nativas y de animales que le servían de alimento ${ }^{87}$.

Esta tendencia hacia la homogenización ha restringido la variedad y el abastecimiento regular de agroalimentos de la dieta alimentaria, lo cual ha generado problemas de desnutrición en unos y malnutrición en otros.

\subsubsection{Elementos generales de la demografía}

Se caracteriza la población mundial ${ }^{88}$ a partir de tres dinámicas: el crecimiento demográfico, la participación en el total global y su distribución entre países.

El crecimiento demográfico de la última década caracteriza tres grupos de países por niveles de desarrollo. Un grupo con tasas de crecimiento superiores al 20\%, encabezado por el Congo, con el 33,3\%; Tanzania, con el 31,9\%; Keniac, con el 29,9\%; Etiopía, con el 29,7\%; Nigeria, con el 26,7\%; Pakistán, con el 24,7\%; Sudán, con el 23,8\%, y Filipinas, con el 20,5\%. El fuerte de este grupo se ubica en África y Asia, con altos índices de pobreza y dependencia.

Otro grupo tiene tasas entre el 10\% y el 20\%: 16,8\% en Bangladesh; 16,5\% en India; 16,1\% en Argelia; 13,9\% en Turquía; 13,3\% en Indonesia; 12,5\% en Sudáfrica; 12,4\% en España; 12,3\% en Irán y Marruecos; 12,2\% en Brasil; 11,2\% en México; 10,4\% en Estados Unidos; y 10,1\% en Argentina. Estas tasas de crecimiento demográfico se consolidan en Estados Unidos y España por la alta migración, así como por el aumento poblacional absoluto en la India, con 171.877.000 habitantes (el mayor del mundo en la década).

Un tercer grupo, con tasas de un dígito, está encabezado por 9,2\% en Tailandia; $8,4 \%$ en Myanmar (Birmania); 6,9\% en China, Egipto y Colombia; 5,9\% en Francia; 5,2\% en Italia; 5,1\% en Reino Unido; 4,5\% en Corea; 0,2\% en Japón; y 0,0\% en Alemania.

87 CASTRO, Josué (1959): Geopolítica del hambre. Ensayo sobre los problemas alimentarios y demográficos del mundo. Ediciones Solar y Librería Hachette, Buenos Aires, págs. 69-70.

88 La información poblacional fue tomada del periodo 1999-2010 de las estadísticas de la FAO 2010. 
Un cuarto grupo con valores negativos son:-7,1\% en Ucrania;-4,3\% en Rusia;-1,0\% en Polonia, países que formaban parte del antiguo bloque socialista.

La participación del total de población mundial está en 10 países con el 60\%, durante el periodo 1999-2001. En el 2010 tenían el 59,3\%; sin embargo, en términos de número de habitantes, pasan de 3.670.805.000 a 4.096.607.000 en el periodo. La participación relativa en la mayoría de casos disminuye, la absoluta aumenta, excepto en Rusia, Alemania, Ucrania y Polonia. Los casos en que aumentan las dos participaciones se refieren a países en vía de desarrollo, en Asia y África.

La distribución de la población entre países con más del 0,5\% de esta se caracteriza por: dos países asiáticos concentran más de la tercera parte, China en 1999 con el 20,8\% y en 2010 con el 19,7 \%; e India con el 17\% y 17,6\% en cada año, participando con el $37,8 \%$ y $37,3 \%$ del total de la población en el periodo. El tercero, Estados Unidos, aunque pierde un poco en relación a 1999, continúa por la inmigración, y baja del 4,7\% al 4,6\% su participación.

\subsection{POLÍTICAS PÚBLICAS ALIMENTARIAS GLOBALES}

La situación se resume de manera histórica con el grito de los segadores:

¡Visca la terra, morí el mal govern! El grito de los segadores volvió a hacerse oír en las calles de Barcelona. [...] El mal gobierno de hoy se llama OMC, Banco Mundial y Fondo Monetario Internacional ${ }^{89}$.

Las políticas públicas buscan resolver problemas identificados por diferentes actores y que son puestos en la agenda pública. En relación con alimentos, hay problemas globales vinculados a la agenda de varias formas y en espera de que las instancias globales tengan una política alimentaria, donde haya "respuesta del sistema político administrativo a una situación de la realidad social juzgada políticamente como inaceptable"90. Las acciones de intervención global buscan resolver diferentes problemas de la cadena alimentaria en

89 DOGLIOTTI, Fabrizio y MONTAGUT, Xavier (2006): Alimentos globalizados... Op. cit., pág. 15.

90 SUBIRATS, Joan, KNOEPFEL, Peter, LARRUE, Corinne y VARONE, Frédéric (2012): Análisis y gestión de políticas públicas. Ariel, Barcelona, pág. 35. 
la misma escala, y no localmente, como los seres humanos lo han resuelto siempre; esto se propone en este trabajo con las regiones SAN, sin desconocer las situaciones globales.

\title{
3.2.1. Generales
}

Se considera que la política pública busca resolver el problema alimentario referido hoy globalmente, y su solución se encuentra en políticas globales, presentes hoy en los diversos organismos internacionales que fungen en lo público con capacidad de orientar las estrategias de gran número de gobiernos. Estas políticas operan desde una minoría para una mayoría de países y, en su interior, para un reducido grupo de inversionistas que creen que su intervención está en función de los intereses generales mejor expresados a través de ellos. Siguiendo lo planteado desde el siglo XVIII por Smith, a propósito de la presencia de los británicos en las Indias Orientales, puede señalarse

\begin{abstract}
En un país naturalmente fértil, despoblado desde hace mucho tiempo y donde, por consiguiente, no debe ser muy dificil ganarse el sustento, el hecho de que mueran de hambre y miseria de trescientas a cuatrocientas mil personas en un año es señal evidente de que los fondos destinados a mantener al pobre trabajador se hayan próximos a agotarse. La diferencia entre el espíritu de la Constitución británica, que protege y gobierna Norteamérica, y el de la compañía mercantil que oprime y domina las Indias Orientales, no puede ilustrarse acaso de mejor manera que contemplando la diferente situación de estos países ${ }^{91}$.
\end{abstract}

Sin embargo, las diferencias con el mundo del siglo XXI son varias: hay escasez en el fondo de salarios global y cerca de 850 millones de personas subnutridas en el mundo. Hoy hay constituciones con enfoque de derechos, a diferencia del siglo XVIII. No solo tenemos una zona con una empresa mercantil, sino un grupo de empresas multinacionales que imponen sus intereses en el concierto global, a través de lo que los segadores de 1646 llamarían "un mal gobierno global".

En los albores del tercer milenio hay "un mundo dirigido enteramente por empresas multinacionales, restringidas élites políticas nacionales y sus organismos planetarios, el

91 SMITH, Adam (1958): Investigación sobre la naturaleza y causas de la riqueza de las naciones (2.a ed.). Fondo de Cultura Económica, México, pág. 72. 
control global de la producción, distribución y consumo de alimentos ha asumido un valor estratégico de primera magnitud"92. En este contexto están las intervenciones públicas en algunos países por parte de los organismos globales.

La versión moderna de Smith está en la frase del presidente de la General Motors y exsecretario de Defensa de los Estados Unidos, Charles E. Wilson, convertida en el símbolo del capitalismo estadounidense: "Lo que es bueno para la General Motors es bueno para el país, lo que la comunidad financiera opina que es bueno para la economía global es realmente bueno para la economía global y debe ser puesto en práctica" ${ }^{93}$. Así se encuentra la política pública alimentaria global hoy: el interés general decidido por empresas multinacionales a través de organismos globales sin controles de magnitud apropiada.

Lo anterior es analizado por Stiglitz, exfuncionario del Banco Mundial, quien considera que la ausencia de un Gobierno mundial tiene repercusiones claras:

[...] Un sistema que cabría denominar Gobierno global sin estado global, en el cual un puñado de instituciones - Banco Mundial, el FMI, la OMC - y unos pocos participantes — los ministros de Finanzas, Economía y Comercio, estrechamente vinculados a algunos intereses financieros y comerciales - controlan el escenario pero muchos de los afectados por sus decisiones no tienen casi voz ${ }^{94}$.

Al aplicar políticas generales para la mayoría y particulares para la minoría de países, tocan un problema estructural y de fondo de las políticas públicas globales, impulsadas por instancias internacionales, sin el control ciudadano. Las intervenciones generales afectan unos países y productos, y benefician a otros, como en los casos del arroz en Haití e India, el del maíz en México, el del trigo en Colombia, los cuales fueron sustituidos por la política general de aperturas e impuestos, solucionando así la disponibilidad vía importaciones de Estados Unidos, con políticas particulares y desde acuerdos bilaterales o dumping:

92 DOGLIOTTI, Fabrizio y MONTAGUT, Xavier (2006): Alimentos globalizados, soberanía alimentaria y comercio justo. Icaria, Barcelona, pág. 14.

93 STIGLITZ, Joseph E. (2002): El malestar en la globalización. Santillana, y Taurus, Madrid, pág. 247.

94 Ibíd., pág. 48. 
La agricultura fue otro ejemplo del doble rasero inherente a la agenda de liberalización que promovimos. Aunque insistimos en que otros países redujeran sus barreras ante nuestros productos y eliminaran las subvenciones a los productos que competían con los nuestros, Estados Unidos mantuvo las barreras a los productos de los países en desarrollo, además de continuar con sus subvenciones masivas ${ }^{95}$.

Estas asimetrías frente a la toma de decisiones requieren de organismos globales justos, que respondan ante los pueblos afectados por las decisiones, y no solamente ante los inversionistas beneficiados. Por tanto, se requiere que las instancias de discusión global orienten políticas de producción de agroalimentos planteando varias condiciones: igualdad entre países para negociar las políticas; la prioridad para la producción y distribución de alimentos debe ser la población, su salud, nutrición, el medioambiente, y no las ganancias; los agroalimentos deben estar cerca de la población, y debe evitarse el manejo de "alimentos viajeros".

Otra expresión de intervención pública de los organismos globales sobre los países y los intereses de los pequeños y medianos agricultores la muestra Keet Doot:

Europa proclama en la OMC que está reduciendo sus subsidios a la exportación, pero está manteniendo subsidios indirectos para los agricultores europeos. Bajo la liberalización actual, liderada por el FMI y el BM, está llegando al continente arroz asiático, maíz americano y trigo europeo, y en muchas zonas los productores locales lo están sufriendo. Pero incluso los pequeños productores que crían ganado, cerdos, pollos [...] ven cómo entra carne europea, los huevos, la leche que es más barata y está muy bien empaquetada. [...] En Sudáfrica la producción local está siendo destruida porque estamos importando yogur y queso francés, nata italiana ${ }^{96}$.

95 STIGLITZ, Joseph E. (2003): Los felices 90. La semilla de la destrucción. Santillana y Taurus, Madrid, pág. 254.

96 VIVAS, Esther y MONTAGUT, Xavier (2009): “KEET, Doot. Activista e investigadora del Alternative Information and Development Center (AIDC) en Sudáfrica”. Entrevista publicada en Del campo al plato... Op. cit., pág. 68. 
Las cumbres alimentarias para resolver problemas de poblaciones vulnerables terminan con observaciones como la Cumbre de Alto Nivel sobre Seguridad Alimentaria de la FAO:

[Allí se consensuó] entre la ONU, el Banco Mundial y el FMI para mantener unas políticas económicas y comerciales de dependencia Sur-Norte y de apoyo a las multinacionales de la agroalimentación. Las recomendaciones lanzadas a favor de una mayor apertura de los mercados en el Sur, de subvencionar las importaciones de alimentos a partir de la ayuda al desarrollo $[\ldots]^{97}$.

En este contexto, puede decirse que en la buena voluntad del desarrollo para unos está el agronegocio de otros. Vivas y Montagut plantean elementos estructurales para el manejo de la cadena agroalimentaria, porque en esta hay "multinacionales que controlan cada uno de los tramos de la cadena agroalimentaria, cuentan con el apoyo explícito de las élites políticas y de las instituciones internacionales que anteponen los beneficios de estas empresas a las necesidades alimenticias de las personas y el respeto al medio ambiente" ${ }^{98}$. Se evidencia la empresa mercantil de Smith del siglo XVIII, ajustada al siglo XXI desde el control de las multinacionales. Por su parte, en el 2008, un informe de la Comisión Europea y la Oficina del Alto Representante de Política Exterior de la Unión Europea advierte:

El hambre, la pobreza, el cambio climático y la lucha por los recursos (agua y tierra) aparecen ya como las nuevas amenazas a Europa y a la inestabilidad mundial. [...] Los conflictos armados que han tenido lugar en 146 países desde 1980 hasta 2004, PinstrupAndersen y Shimokawa (2008) hallaron una correlación positiva entre el deteriorado estado de salud y nutricional de la población y el surgimiento de conflictos [...] entre aquellos que aparecen como responsables los países desarrollados, sus empresas transnacionales, sus especuladores y sus industrias contaminantes ${ }^{99}$.

97 VIVAS, Esther y MONTAGUT, Xavier (2009): Del campo al plato... Op. cit., pág. 27.

98 Ibíd., pág. 27.

99 VIVERO, José L. y RAMÍREZ, Pablo (2009): "Leyes, políticas e instituciones contra el hambre en el contexto latinoamericano". En Derecho a la alimentación, políticas públicas e instituciones contra el hambre. LOM, Fundación Henry Dunant América Latina, Santiago de Chile, pág. 128. 
Las orientaciones se encaminan a solucionar la amenaza de revolución social por parte de los desnutridos, pero no a resolver los problemas de las poblaciones y el medioambiente. El primero reclama acciones sociales, alimentos para vivir, en tanto el segundo exige una explotación menor de sus recursos en virtud de las problemáticas asociadas al cambio climático. El desarrollo de los agronegocios mundiales se sustenta en los subsidios creados en la gran depresión del siglo XX, en Norteamérica, para salvar a los agricultores:

Para lo que en realidad han servido es para asegurar a las compañías multinacionales de alimentación y comercio radicadas en Estados Unidos. [...] Los subsidios de la UE han producido los mismos resultados en favor de las empresas multinacionales europeas ${ }^{100}$.

Allí está la base de las políticas sectoriales orientadas por los mayores países productores, teniendo en cuenta que:

Una inseguridad alimentaria que, debido a las dependencias con respecto al sistema agroalimentario globalizado, sus métodos de producción, distribución y consumo, y las políticas internacionales que lo protegen, aunque en distinta forma y medida, afecta a las y los productores y consumidores tanto del norte como del sur ${ }^{101}$.

Por tanto, el problema por resolver no será la inseguridad alimentaria, sino las condiciones de producción agroalimentaria desde parámetros sociales, ecológicos, económicos y políticos que no afecten a la población ni a la naturaleza.

\subsubsection{Salud pública y contaminación, alimentación y nuevas enfermedades}

La FAO tiene en cuenta los puntos por considerar en la política pública sobre seguridad alimentaria y salud, al analizar la incidencia de la capacidad nutricional sobre el desarrollo del individuo y de la sociedad: "La desnutrición redunda en pérdidas de productividad importantes, por ejemplo a causa de las tasas elevadas de morbilidad y

100 LAWRENCE, Felicity (2009): ¿Quién decide lo que comemos? Cómo el negocio de la alimentación perjudica la salud, la economía y el medio ambiente. Urano, Barcelona, pág. 55.

101 GALLAR H., David y RIVERA, Marta G. (2013): “Soluciones a la inseguridad alimentaria: soberanía alimentaria y derecho a una alimentación adecuada". En Procesos hacia la soberanía alimentaria: perspectivas y prácticas desde la agroecología política. Icaria, Barcelona, pág. 35. 
trastornos del desarrollo cognoscitivo" ${ }^{102}$. Por tanto, combinar alimentos con una sana y buena capacidad nutricional mejora vínculos entre trabajo, salud y los procesos de crecimiento económico y desarrollo territorial. La dinámica de la alimentación exige prevenciones diferentes para la salud humana, por la contaminación y las relaciones con la naturaleza. María Pérez señala al respecto:

La frase de Aristóteles: "Qué tu alimento sea tu medicamento”, servía para cuando el alimento era biológico. Sus propiedades curativas, más las medicinas que administraba el médico, tenían como fin la curación integral del enfermo. Ahora los ministerios de agricultura permiten que se adulteren y contaminen los productos alimentarios, tanto los de origen vegetal como los de origen animal ${ }^{103}$.

Pérez hace un llamado a la ética pública y a la responsabilidad con el conocimiento y las profesiones, al considerar que "los ciudadanos estarán más sanos el día en que el médico luche para que se retiren los químicos tóxicos de los alimentos"104. El debate de fondo sobre las consecuencias se ve en la cruzada contra los aditivos venenosos denunciados por el doctor Wiley, biólogo, médico y químico, que en 1917 mostró que “ya estaban penetrando en el mercado alimentos tóxicamente adulterados"105.

La FAO ${ }^{106}$ considera cuatro puntos en la relación entre los alimentos, la nutrición y la salud, que, a su vez, son ejes para el diseño de políticas públicas: disfrute comiendo alimentos variados, coma lo suficiente para cubrir sus necesidades, preserve la calidad e inocuidad de sus alimentos y, por último, manténgase activo y en forma. Así, por ejemplo, la irradiación o el uso de aditivos tiene consecuencias en algunos alimentos. En el 2004, el doctor Takahahi declaró:

Las patatas irradiadas causaron problemas arteriales y mutaciones.

Las cebollas irradiadas causan cambios en los ovarios y en los testículos.

El arroz irradiado causa perturbaciones en la pituitaria, tiroides,

102 FAO (1996): Cumbre Mundial sobre la Alimentación (documento técnico n.o 5), op. cit., pág. 22.

103 PÉREZ, María Isabel (2011): Caos en la alimentación. ElViejo Topo, Madrid, págs. 45 y ss.

104 Ibíd., pág. 47.

105 Ibíd., pág. 49.

106 Estos puntos fueron tomados de Food, Nutrition and Agriculture, n.o 16: "Nutrition education for the public". 
corazón y pulmones. Después que un alimento se ha irradiado se vuelve mucho más vulnerable a hongos e insectos ${ }^{107}$.

Esto ha cambiado el cuadro global de morbimortalidad y la oferta de nuevos medicamentos para sus tratamientos.

\subsubsection{Patentes y multinacionales}

La privatización de conocimientos ${ }^{108}$ en la producción de agroalimentos globales está asociada a la conservación, la variedad y la calidad. De esta forma, se controlan partes básicas de la cadena agroalimentaria, independientemente de si estos conocimientos fueron conservados socialmente por comunidades campesinas e indígenas a través de la historia de la humanidad. Para semillas, las formas de mejoramiento, conservación, clasificación y diferenciación, según tierras y tiempos, siempre fueron de uso y conocimiento social, el cual se transfería entre generaciones. Hoy, el control global del mercado de semillas, fertilizantes, insecticidas y otros incide de manera directa en la producción de agroalimentos y lleva al control de cada insumo por las transnacionales. Solo el tema de las semillas es ya bastante ilustrador:

Diez de las mayores compañías mundiales (Monsanto, Dupont, Syngenta, Bayer...) controlan la mitad de sus ventas, [...] los riesgos que su control entraña para la seguridad alimentaria de las personas. Las leyes de propiedad intelectual, que dan a las compañías derechos exclusivos sobre las semillas, han estimulado más la concentración empresarial y ha erosionado de base el derecho campesino al mantenimiento de las semillas autóctonas y la biodiversidad. De hecho, el 82\% del mercado de semillas comerciales está compuesto por semillas patentadas ${ }^{109}$.

107 PEREZ, María I. (2006): La manzana de Blancanieves. Salud, industria y alimentación. Icaria, Barcelona, pág. 42

108 "Mientras el conocimiento del hombre permitió únicamente al ser vivo como totalidad no apropiable, no hubo problema en la relación entre el derecho, la ciencia y la tecnología" (PÉREZ, María I. [2006]: La manzana de... Op. cit., pág. 42.

109 VIVAS, Esther y MONTAGUT, Xavier (2009): Del campo al plato. Op. cit., pág. 25. 
Si al inicio de la cadena alimentaria se encuentran monopolizados los insumos para producir agroalimentos, las semillas y los cambios en relación con el derecho y las patentes llevan a las empresas transnacionales a pedir apoyo de la OMC para determinar que tienen "el derecho" a reclamar el monopolio de la propiedad de los alimentos y de la vida misma, por cuanto aseguran tener derechos de propiedad intelectual en productos como el arroz:

Hace poco RiceTec, una firma de Texas, sacó una patente del arroz Basmati. Esto es un acto de biopiratería en perjuicio de la India y Pakistán. La misma firma y muchas otras firmas estadounidenses están comercializando arroz Jasmine amenazando directamente a las comunidades campesinas del sudeste asiático. El arroz Jasmine proviene de Tailandia, donde actualmente lo cultivan más de cinco millones de agricultores de escasos recursos ${ }^{110}$.

Este tipo de acciones no solo están dirigidas contra la mayoría de la población mundial, sino también en contra de comunidades milenarias que han conservado las semillas y la agricultura tradicional. A los actos de biopiratería se suman los transgénicos como un mecanismo de control mayor en la fase inicial de la cadena alimentaria:

El primer transgénico que comercializó Monsanto, empresa que controla el $90 \%$ de los transgénicos que se comercializan, servía para que la soja modificada pudiera resistir al herbicida Roundup (glifosato de amonio) que fabrica la propia empresa, Al cabo de poco tiempo la soja se vuelve resistente al Roundup, se necesitan más cantidades de herbicida y el riesgo de que el veneno llegue a la cadena alimentaria aumenta; [...] al añadir un gen que hace que las semillas se vuelvan estériles se aseguran la dependencia absoluta de los agricultores. La FAO ya ha alertado que los cultivos transgénicos se crearon para reducir costes e insumos, y no para dar de comer a los países en desarrollo ${ }^{111}$.

110 MasiPág./Farmer. Scientist Parnership for Development, 336 Aguila ST., Rhoda's Sbd. Los baños, Laguna, 4030 Filipinas. Citado en DOGLIOTTI, Fabrizio y MONTAGUT, Xavier (2006): Alimentos globalizados... Op. cit., pág. 93

111 ARANGUREN, Felipe L. (2012): El negocio del hambre... Op. cit., pág. 34. 
Los apoyos y alertas de la FAO se vuelven como las semillas controladas por la empresas transnacionales: estériles, lo cual muestra que en las organizaciones globales las empresas transnacionales tienen un poder diferenciador. Esta es una de las consecuencias de la privatización de la investigación social e histórica: "Los nuevos híbridos, como los que se basen en la tecnología llamada Terminator, obligarán a los agricultores a comprar cada temporada semillas a las empresas transnacionales" ${ }^{\prime 12}$. Este es el claro círculo de privatización, patente, mercancía, dependencia campesina y control alimentario mundial.

\subsubsection{Los futuros conflictos entre agrocombustibles y agroalimentos}

Un conflicto con la SAN es el uso de tierras para producir agrocombustibles en cambio de agroalimentos: ¿los productos van a la mesa o al motor? En las relaciones entre la producción de agroalimentos versus agrocombustibles, las políticas de algunos gobiernos y regiones las vinculan a principios de seguridad nacional, donde algunos priorizan la seguridad para producir alimentos en sus territorios. En la medida en que "EE.UU. no puede abastecer la creciente demanda interna de agrocarburantes sin provocar graves distorsiones en el mercado de alimentos, intenta ahora asegurarse un suministro (barato) de etanol en Brasil y en otros países del Sur" ${ }^{\prime 13}$. No pone en segundo plano la comida, sino la gasolina.

El gobierno de la India promueve la sustitución de gasolina por etanol, pero “concede prioridad a la seguridad alimentaria [...] alentando la producción de bioetanol a partir de melazas, subproducto de la fabricación de azúcar de caña, en lugar de utilizar cereales como materia prima" 114 . En este caso, se sustituyen los usos de los subproductos alimenticios. Por su parte, China prioriza los alimentos:

El Consejo de Estado, preocupado por la subida de precios de los alimentos y la creciente utilización de maíz para etanol lo ha paralizado. China concede una gran importancia a la seguridad alimentaria nacional, [...] condiciona apoyo a los agrocarburantes que no compitan con la producción de alimentos ${ }^{115}$.

112 DOGLIOTTI, Fabrizio y MONTAGUT, Xavier (2006). Alimentos globalizados... Op. cit., pág. 92.

113 VARGAS, Mónica (coord.) (2008): Agrocombustibles, ¿otro negocio es posible?. Icaria, Barcelona, pág. 29.

114 Ibíd., pág. 34.

115 Ibíd., pág. 38. 
Estos grandes países, Estados Unidos, India y China, se han vuelto los mayores productores de la dieta básica mundial, pero han priorizado la SAN a partir de la seguridad nacional.

\subsection{ELEMENTOS DE LA CADENA AGROALIMENTARIA GLOBAL}

\subsubsection{Disponibilidad de alimentos básicos}

\subsubsection{La tierra y las condiciones para producir agroalimentos; usos y aprovechamiento de tierras en el mundo}

Para analizar la disponibilidad de agroalimentos globales, se ven los siguientes puntos: la situación sobre el uso de la tierra de una forma general, y por países, que cubren el $70 \%$ del total del mundo entre 2000 y 2008; el aprovechamiento de regadíos, donde están construidos el $80 \%$ de estos, controlados por 22 países; y las relaciones entre las tierras con regadío y aquellas arables ${ }^{116}$.

En la tabla 3.1 vemos el uso de las tierras en el mundo entre el 2000 y el 2008 , donde las constantes son las de producción, con un 10,6\%, mientras que los cultivos permanentes pasan de $1,0 \%$ al 1,1\%; es decir, es la única que crece en este periodo. Por último, los pastos representan el $25,8 \%$, por lo que es esta la única área que disminuye. El control sobre la tierra, recurso principal para producir agroalimentos en diferentes partes del mundo, está en pocas manos. Sucede en el norte y en el sur:

La monopolización del agro se extiende por la India, Bangladesh, México, Filipinas, Colombia: virtualmente en todos los países en que la modernización subsidiada por los gobiernos significa que la obtención de ganancias abultadas depende de la cantidad de tierras que es posible controlar y no de la capacidad de cultivarla bien ${ }^{117}$.

Grain identifica esta nueva situación como el "nuevo ciclo mundial de apropiación de tierras":

116 La información de tierras, usos y aprovechamiento fue tomada del periodo 2000-2008 de las estadísticas de la FAO 2010.

117 MOORE LAPPE, Francés y COLLINS, Joseph (1982): Comer es primero... Op. cit., pág. 129. 
La situación de inseguridad alimentaria ha llevado a determinados gobiernos, como los de Arabia Saudita, Japón, Corea, Libia, Egipto, entre otros, que dependen de las importaciones de alimentos, a adquirir tierras agrícolas en distintos lugares del planeta con el objetivo de producir alimentos propios para el consumo interno ${ }^{118}$.

Es notable no solo la monopolización de la tierra, sino la competencia por su apropiación para producir agroalimentos para cada país, pero por fuera de sus fronteras y bajo su control, lo que se ha convertido en un componente estratégico de la seguridad alimentaria. También el FUHEM Ecosocial puntualiza:

Existe un consenso general sobre una serie de factores que distinguen la oleada de acaparamiento de tierras más reciente respecto del pasado. Primero, el fenómeno se desarrolla a un ritmo relativamente rápido, incentivado por las dinámicas de cambio en el sistema alimentario global, las respuestas de seguridad energética al pico del petróleo, la protección ambiental en el contexto del cambio climático y el flujo internacional de capital financiero que busca inversiones seguras, después del colapso de los mercados hipotecarios del Norte ${ }^{119}$.

Tabla No. 3.1 Uso de tierras a nivel mundial (1000 ha) $2000-2008$

\begin{tabular}{|c|c|c|c|c|c|c|c|}
\hline \multirow{2}{*}{\multicolumn{2}{|c|}{ Superficie de terreno }} & \multicolumn{6}{|c|}{ Años } \\
\hline & & 2000 & & 2005 & & 2008 & \\
\hline \multicolumn{2}{|c|}{ Año 2008} & \multicolumn{6}{|c|}{ Tierras de producción } \\
\hline \multirow{5}{*}{$13.003 .469,20$} & \multirow{5}{*}{100,0} & $1.382 .339,20$ & 10,6 & $1.391 .825,90$ & 10,7 & $1.380 .515,27$ & 10,6 \\
\hline & & \multicolumn{6}{|c|}{ Cultivos permanentes } \\
\hline & & $132.072,00$ & 1,0 & $142.190,80$ & 1,1 & $146.242,12$ & 1,1 \\
\hline & & \multicolumn{6}{|c|}{ Pastos } \\
\hline & & $3.426 .601,50$ & 26,4 & $3.381 .758,00$ & 26,0 & $3.356 .940,18$ & 25,8 \\
\hline
\end{tabular}

Sobre el aprovechamiento de tierras en el mundo ${ }^{120}$, debe indicarse: de 183 países, durante el periodo 2000-2008, en relación con la superficie de terreno, hay 25 países que poseen $73 \%$ del total, mientras que 158 poseen el $27 \%$. Cabe resaltar que los niveles

118 VIVAS, Esther y MONTAGUT, Xavier (2009): Del campo al plato... Op. cit., pág. 32.

119 Transnacional Institute (TNI) (2013): El acaparamiento global de tierras. Guía básica. FUHEN Ecosocial, pág. 11.

120 La información de tierras, usos y aprovechamiento fue tomada del período 2000-2008 de las estadísticas de la FAO 2010. 
de concentración se tienen en tan solo 9 países, que poseen el 52,7\% de la superficie, a saber: Rusia, con el 12,6\%; China, con el 7,2\%; Estados Unidos, con el 7,0\%; Canadá, con el 7,0\%; Brasil, con el 6,5\%; Australia, con el 5,9\%; India, con el 2,3\%; Argentina, con el 2,1\%; y Kazakstán, con el 2,1\%.

En las tierras dedicadas a la producción, el primer lugar lo ocupa Estados Unidos, con el $12,7 \%$ en el 2000 y el $12,4 \%$ en el 2008. A pesar de la caída en el uso de las tierras de 4.132.000 hectáreas en el periodo 2000-2008, aún ocupa el primer lugar, seguido de India, con el 11,8\% y el 11,5\%, respectivamente, también con caída de tierras en producción. En el caso del resto de países, se presenta caída total en el periodo, excepto en 9 de los 25 que crecieron en tierras y en producción: Brasil, Argentina, Kazakstán, Sudán, Indonesia, Níger, Chad, Angola y Malí. Entre tanto, en el total de los demás hay un aumento de uso de tierras. Colombia no está exenta de la caída: pasó de 2.818 a 1.830 ha en el periodo.

En los cultivos permanentes, el país más importante es Indonesia: 9,9\% y 10,3\%, con la mayor dinámica de crecimiento de estos. También se destacan China, India, Canadá, México, Irán, Perú y Níger. Por su parte, en la variable de pastos, el primero es Australia, que en el 2000 tenía el 11,9\% del total; seguido de China, con el 11,7\%; Estados Unidos, con el 6,9\%; Brasil, con el 5,7\%; Kazakstán, con el 5,4\%; Arabia, con el 5,0\%; Mongolia, con el 3,8\%; Sudán, con el 3,4\%. Sin embargo, el resto de países decrecen en este uso, lo cual es una tendencia general.

Respecto al uso del regadío en el mundo, para el periodo 1999-2008, el 81\% de este se concentra en 22 países, con una tendencia creciente en su uso, lo cual significa planeación en la producción mundial al prever el uso del agua para la producción agropecuaria. Se puede ver que hay una "contribución de la agricultura bajo riego [...], [la cual] proporciona una poderosa herramienta de manejo contra las incertezas de las lluvias" ${ }^{121}$. El regadío se vuelve infraestructura básica para producir agroalimentos.

De los 22 países concentradores del riego, solo 13 tienen crecimientos absolutos y relativos en el periodo y muestran la tendencia mundial. Rusia es el único que decrece. Así, se identifica que "la lluvia es la fuente de agua para la producción de cultivos en las zonas más húmedas del mundo donde se produce cerca del 60 por ciento de la

121 FAO (2002): “Agua para la producción sostenible de alimentos; el alivio de la pobreza y el desarrollo rural”. Disponible en www.fao.org/docrep/006/y4525s/y4525s05.html 
producción agrícola" "122; por lo tanto, la producción de agroalimentos se determina y reconoce por los altos rendimientos relacionados con la planeación del recurso hídrico.

En la década analizada, hay diez países que concentran el 65,1\% de la infraestructura de riego a nivel mundial. En orden de importancia en el periodo 1999-2001 son: India, con el 21,2\%; China, con el 19,3\%; Estados Unidos, con el 7,9\%; Pakistán, con el 6,3\%; Irán, con el 2,8\%; México, con el 2,2\%; Tailandia, con el 2,0\%; Indonesia, con el 1,9\%; Turquía, con el 1,7\%; y Rusia, con el 1,6\%. De estos diez países, en el 2008 el primer lugar lo ocupaba China, con el 20,9\%, mientras que India tenía el 20,3\%, y los demás continúan con el mismo índice.

Este uso del agua debe tener en cuenta la contaminación, ya que, según la FAO, tiene que ver con el comportamiento de la agricultura con riego, donde el "agua de drenaje es por lo general de menor calidad que el agua que fue extraída, debido a la contaminación por los agroquímicos y las sales percoladas del perfil del suelo" ${ }^{123}$. Esto es algo que debe tenerse en cuenta para la producción de alimentos, sin olvidar la demanda hídrica para agrocombustibles y minería. La FAO muestra también que en el mundo, el 80\% de las tierras arables aplican la agricultura de secano, y el riego aplica un 20\%, dinámica desde la que se produce el $40 \%$ de los alimentos. Para satisfacer la demanda futura, se esperan más cultivos producidos bajo riego, en lugar de secano, y similares cantidades de alimentos provendrán de ambas agriculturas.

\subsubsection{La producción de agroalimentos}

La base de este análisis es la información ${ }^{124}$ de la FAO, para el periodo 1994-2009, sobre varios productos de la dieta mundial: cereales, oleaginosas, leguminosas, hortalizas, raíces y tubérculos, carnes de bovino, ovino, caprino, cerdo y pollo, leche y huevos. Para su selección se partió de la sumatoria en superficie y producción para los productos sembrados; para los animales, el peso en toneladas, y que los países productores superaran dos terceras partes del producto mundial en cada caso.

122 Ibíd.

123 Ibíd.

124 La información de producción de agroalimentos a nivel mundial fue tomada de las estadísticas de la FAO, periodo 1994-2009. 
Cereales. La concentración de la superficie dedicada a la producción de cereales en el mundo se encuentra en 21 países. El 72,1\% del área sembrada del periodo 1994-1996, comparada con el 2009, presenta una caída: pasó al 69,7\% del total, mientras que en el resto del mundo crece de $27,9 \%$ al 30,3\% en el mismo período.

Diez países concentran el 54,8\% de la superficie dedicada a la producción de cereales para el periodo de 1994-1996: India, con el 14,4\%; China, con el 13,0\%; Estados Unidos, con el 9,0\%; Rusia, con el 7,3\%; Brasil y Canadá, con el 2,7\%; Kazakstán, con el 2,5\%; Indonesia y Australia, con el 2,1\%; y Turquía, con el 2,0\%. De estos, seis tuvieron bajas en las superficies cosechadas durante el periodo, y solo cuatro, encabezados por India, crecieron. Por otra parte, cuatro países (India, China, Estados Unidos y Rusia) tienen el $43,7 \%$ de la superficie que se utiliza para producir cereales, convertidos en oligopolio de producción de cereales, dieta básica de la alimentación mundial.

Además, en la producción de cereales en el mundo hay cambios por aumento de los rendimientos. La tecnología se disputa en todas las dimensiones, como anota el Banco Mundial:

Desde la década de 1960, los crecientes rendimientos de los cereales han estado determinados por el más amplio uso de la irrigación, las variedades mejoradas de cultivos y los fertilizantes. Aunque las mejoras en los cultivos se han extendido más allá de las zonas con irrigación, hasta inmensas áreas de agricultura sin riego ${ }^{125}$.

Hay un cambio del orden de los países que producen cereales, donde los diez primeros tienen el 59,9\% de los cereales del mundo; de estos, cinco concentran el 50,1\% de la producción mundial: China, 19,5\%; Estados Unidos, 14,9\%; India, 9,9\%; Rusia, 3,2\%; e Indonesia, 2,6\%. Los cambios en sus rendimientos muestran una tendencia creciente y constante desde 1994 hasta el 2009, en todos los países productores: Francia, Estados Unidos, China,Vietnam y Argentina.

Contrasta la tendencia de la creciente producción de cereales con un decrecimiento de la superficie cosechada, lo que implica aumentos de producción vía rendimientos, resultado del cambio tecnológico. Por tanto, las mayores demandas futuras de agroalimentos disponen de más tierras para producir.

125 Banco Mundial (2008): Informe sobre el desarrollo mundial (2008). Agricultura para el desarrollo. Banco Mundial, Mundi-Prensa y Mayo Ediciones, Bogotá, pág. 42 
Oleaginosas. El cultivo con más producción, investigación, experimentación y comercialización a nivel mundial forma parte de los agroalimentos de la dieta alimenticia y hoy se disputa un lugar para producir agrocombustibles. El Ministerio de Agricultura y Desarrollo Rural en Colombia identifica características generales de los cultivos:

La canasta de oleaginosas tradicionalmente la componen principalmente trece cultivos: ajonjolí (sesame); algodón (cotton seed); coco (coconut); colza (rape seed); girasol (sunflower); linaza (linseed); maíz (corn); maní (groundnut); oliva (olive); palma de aceite (oil palm); palmiste (oil palm kernel); ricino (castor); soya (soy bean). La de grasas animales la componen manteca de cerdo (lard); sebo (tallow); mantequilla (butter) y aceite de pescado (fish oil). Diez son los cultivos que en la actualidad son los de mayor producción y cotizados en los mercados de todo el mundo; a saber: soya, canola, cártamo, algodón, girasol, olivo, maíz, lino, cacahuate y ajonjolí126.

En el periodo 1994-2009 se observa que la superficie cosechada en todos los países presenta un crecimiento constante: India, Estados Unidos y China pasan de 95.846.000 ha a 103.912.000 ha, y en números relativos muestran una caída: en el primer periodo 1994-1996 representaban el 47,0\%, mientras que en 2009 solamente tenían el 39.8\%. En suma, perdieron el 7,2\% de participación. Sin embargo, ocupan los tres primeros lugares junto con Brasil; tenían un control del 53,2\% en 1994, pero en el 2009 caen al 48,8\%: así, cuatro países controlan cerca del $50 \%$ de la superficie dedicada a producir oleaginosas.

Los países con más crecimiento de la superficie cosechada aumentan su participación con una tasa de crecimiento de más del 60\%; incluso, en algunos casos, superaban en el 2009 el 100\%, como son Brasil, Argentina, Indonesia, Rusia, Ucrania y Myanmar (Birmania).

En relación con la producción, el primer productor para 1994-1996 es Estados Unidos, con el 15,4\%; seguido de China, con el 13,4\%; Malasia, con el 9,9\%; India, con el 9,7\%; e Indonesia, con el 8,2\%. Estos cinco países controlaban el 56,6\% en 1994 y el 55,1\% en el 2009. No obstante, en términos porcentuales el orden cambia, sobre todo en el último año analizado, donde estaban primero Indonesia, con el 14\%; Malasia, con

126 Observatorio de Competitividad Agrocadenas (2001). "La cadena de oleaginosas, aceites y grasas”. Ministerio de Agricultura y Desarrollo Rural, Bogotá, pág. 10. 
el 12,6\%; y Estados Unidos, con el 11,8\%. En Colombia aumenta la superficie y la producción. Por último, sobre los rendimientos en la producción se destacan Malasia, Colombia, Indonesia, Alemania y Francia.

Leguminosas. Cinco países tienen más del 50\% de producción de leguminosas en el periodo 1994-1996, con el 54,1\%, en tanto en el 2009 tienen el 52,7\%. Su orden para cada año es: India, 32.4\% y 28,9; Brasil, 7,2\% y 5,9\%; Nigeria, 5,2\% y 6,3 \%; China, 4,6\% y 4,1\%; y Níger, 4,6\% y 7,6\%. De estos cinco países, solo dos presentan crecimiento. Níger es el país más importante en el uso de tierras.

Los 20 mayores productores de leguminosas tienen el control del 82,7\% de la superficie cosechada en 1994-1996, y el 81,5\% en el 2009. Estos productores controlan más de cuatro quintas partes de la tierra dedicada a estos cultivos. En el proceso de cambio y crecimiento en la superficie, entre los dos períodos, los más dinámicos, aparte de los anteriores, son Myanmar, Canadá, Etiopía, Estados Unidos, Uganda y Tanzania. Además, la producción de los países cambia: por una parte, están los que aumentan sus niveles de participación, relativa y absoluta, y se destacan por mayores niveles de productividad: Canadá, Myanmar, Nigeria, Etiopía, Níger y Estados Unidos; los que encabezan la lógica contraria son India, Brasil y China.

Hortalizas. El $59.2 \%$ de la superficie mundial cosechada la tienen 5 países, caracterizados por el crecimiento constante de esta. En la década pasada, China pasa de 38,3\% en 1991-2001 al control de 45,5\% en el 2009, con el mayor incremento. Otro país mantiene su participación constante con un 3\%: Nigeria. Por su parte, India, Turquía y Estados Unidos pierden participación relativa durante el periodo. Por último, 28 países controlan en el periodo 1999-2001 el 81,4\% de la superficie cosechada, y para el 2009 esta participación creció al 83,7\%, mientras que el resto pasan de 18,6\% al $16,3 \%$ en el mismo período.

Cinco países controlan el 63,8\% de la producción mundial de hortalizas, con China, junto con India, que son los principales productores del Asia y controlan el $50 \%$ de la producción mundial: en 1999-2001, con el 50.8\%, y en el 2009, con el 57,5\% el total. Respecto a los otros tres países, Estados Unidos pierde participación durante la década; Turquía y Egipto entran en los productores de hortalizas en el periodo, y lo hacen creciendo en la producción. 
Raíces y tubérculos. La superficie cosechada en el mundo tiene diez países, con el $62,2 \%$, encabezado por China, que, sin dejar de ocupar el primer lugar en la década, presenta una caída en participación de la superficie cosechada: pasa del 20,3\% en 19992001 a 16,7\% en el 2009. Nigeria tiene una relación inversa: pasa del 14,4\% al 16,6\% en el mismo periodo.

Los cinco países con caídas porcentuales durante la década son: Rusia, de 6,1\% a 4,1\%; Congo, de 3,9\% a 3,7\%; Indonesia, de 3,1\% a 2,8\%; Ucrania, de 3,0\% a 2,6\%. El país más crítico en este descenso es Polonia, del 2,3\% al 0,9\%. Esta tendencia de decrecimiento en la superficie cosechada en los 23 países pasa del 79,2\% al 77,9\%, caída influenciada por China, Rusia y Polonia.

Los países más dinámicos por el crecimiento durante el período fueron: India, que pasa de 3,1\% al 4,2\%; Brasil, de 3,6\% al 3,9\%; y Ghana, del 3,4\% al 3,9\%. Desde esta perspectiva de crecimiento de los 23 países, los más dinámicos para utilizar nuevas superficies cosechadas son los países africanos.

La producción tiene diferencias en los 10 primeros países, con una tendencia a la disminución: pasa de un $64,1 \%$ al $60,9 \%$, aunque continúen los dos primeros con tendencias inversas: China, con 27,3\%, cae al 20,8\%; y Nigeria, con el 9,5\%, sube al $11,9 \%$. La mayor productividad en el mundo es la de Estados Unidos, que pasa del lugar 19 en superficie al 6 en producción. En la década disminuyen la producción Rusia y Polonia; y crecen India, Brasil, Indonesia, Tailandia y Ucrania.

Carne bovina. La producción se caracteriza porque más de la mitad de esta se concentra en 5 países que controlan, en la década, el 50,4\% al inicio, y terminan con el 51,8\%. Están encabezados por Estados Unidos, con el 21,7\% en 1999-2001 y el 19,2\% en el 2009, lo cual muestra la tendencia general de crecimiento de la producción de carne bovina.

Los cuatro países con un comportamiento inverso al de Estados Unidos son: Brasil, con 11,8\%, pasa al 14.6\%; China pasa del 8,5\% al 9,9\%; Argentina pasa del 4,7\% al 4,6\%; y Australia, del 3,7\% al 3,5\%. En la participación, los 18 países más productores tienen una tendencia decreciente, lo que conlleva un crecimiento frente al resto del mundo, y en este contexto, Colombia gana participación. 
Ovino y caprino. En la producción mundial, hay 10 países productores que controlan, a inicios del periodo 1999-2001, el 44,4\%, en tanto en el 2009 lo hacen con el 46\%, con un crecimiento lento similar al mundial en el subtotal de los mayores productores, encabezados por China, que pasa del 47,6\% al 48,7\% durante el periodo. El resto del mundo tiene más del $50 \%$ de la producción, en particular países con economías campesinas.

Entre los 10 mayores productores mundiales, China, con mayor crecimiento, pasa del 23,3\% en 1999 al 29,6\% en el 2009; es seguido de Rusia, que crece de 1,2\% a $1,4 \%$, mientras los otros 8 presentan indicadores decrecientes en producción y en participación.

Cerdo. La producción mundial está controlada por 10 países con más de las tres cuartas partes: el 75,6\% en 1999 y el 75,8\% en el 2009. Los tres primeros, con un crecimiento de la producción, mientras cinco muestran caída y dos permanecen constantes: Brasil y Canadá. Además, 19 países controlan el 86,7\% de la producción en 1999 y el 85\% en el 2009. Con dinámicas crecientes en participación y producción están Rusia,Vietnam, Filipinas y Colombia.

Más de la mitad de la producción de carne de cerdo es controlada por China y Estados Unidos, con el 54,9\% en 1999 y el 56,9\% en el 2009. La dinámica de crecimiento de la producción en China es mayor que la de Estados Unidos.

Pollo. En la producción mundial, 10 países controlan el 64\% en 1999 y el 59,8\% en el 2009, con una tendencia decreciente en Estados Unidos y China. En los otros casos hay dinámicas inversas, excepto Brasil y México. Por otra parte, los 19 primeros países productores pasan del 77,1\% en 1999 a controlar 76,2\% en el 2009.

Entre los cuatro mayores productores en el mundo son los dos primeros: Estados Unidos, con el 24\% en 1999 y el 20,5\% en el 2009; y China, con el 15\% y el $14,4 \%$, respectivamente. Aunque muestran una pérdida en la participación, más en Norteamérica, la caída no se refleja en la producción, la cual aumenta en ambos casos. Los países latinoamericanos que crecen en producción y participación son: Brasil, con el 10,2\% y pasa al 12,5\%; y México, del 3,2\% al 3,3\%.

Leche. Hay 10 países que controlan más de la mitad de la producción, pasando del 54,5\% en 1999 al 55,6\% en el 2009; y 22 países controlaban en 1999-2001 el 73\%, en tanto en el 2009 solo lo hacían con el 72,5\%. El mayor control lo ejercen países 
con altos índices de desarrollo. Los diez más productores son: India, que encabeza la producción mundial y pasa del 13,9\% en 1999 al 15,8\% en el 2009; Brasil, que pasa del 3,5\% al 4\%; y China, del 2,2\% al 5,8\%, sube del noveno lugar en 1999 al tercero en el 2009. Otros países presentan una caída relativa, mas no en la producción: Estados Unidos, Rusia y Alemania; y los que caen en participación y producción son Francia, Reino Unido, Ucrania e Italia.

Huevos. La producción en el mundo está controlada por cinco países con más del 60\%; 16 pasan del 78,6\% en 1999 al 78,2\% en el 2009, la mayoría de los cuales son desarrollados. Las características de los diez países con mayor producción son: un grupo con más dinámica por indicadores de crecimiento relativo y de producción, encabezados por China, India, México, Brasil y Tailandia; otros dos pierden en participación, pero no caen en la producción (Estados Unidos y Rusia); el tercer grupo cae a la vez en producción y participación (Japón, Francia y Alemania).

\subsubsection{Distribución mundial de agroalimentos}

La distribución de agroalimentos muestra las formas en que el capital comercial opera y transforma sus estructuras organizativas, técnicas-administrativas y financieras para las necesidades humanas crecientes en términos de alimentación y nutrición. La tecnología permite la segmentación de la distribución, entendida como "la aparición de nuevas formas de dependencia ligadas a las deslocalizaciones de las multinacionales"127. Estas dinámicas mueven principios de comercialización de agroalimentos en el mundo globalizado. Algunos de estos aspectos se observar en las ciudades de los países en desarrollo, donde existen redes y mecanismos de distribución más pequeños y otras formas de relación con los demandantes de agroalimentos.

En esta distribución se identifican: los mercados en municipios rurales, que tienen un día especial para su realización; las tiendas en los barrios de los centros urbanos; los pequeños distribuidores por localidad; las plazas de mercado; los centros de abastos de las ciudades; el comercio mayorista; los especializados en el manejo de agroalimentos perecederos; las grandes superficies; los mercados móviles campesinos, con una relación directa entre productor rural y consumidor urbano; y los carretilleros, que venden puerta a puerta agroalimentos al menudeo.

127 DOGLIOTTI, Fabrizio y MONTAGUT, Xavier (2006). Alimentos globalizados... Op. cit., pág. 19 
Hay regiones o países con más concentración en sus estructuras organizativas y empresariales en la distribución de agroalimentos:

En Europa, entre años 1987 y 2005, la cuota de mercado de las diez mayores multinacionales ha ido en aumento. [...] Se pronostica que ésta podría llegar a un 75\% en los próximos 10-15 años. [...] Las grandes corporaciones con su matriz en los países occidentales absorben las cadenas más pequeñas en todo el planeta asegurándose su expansión a nivel internacional y, especialmente, en los países del Sur global ${ }^{128}$.

En este sentido, el vínculo de las transnacionales en la distribución de agroalimentos irrumpe en todos los países:

Estas empresas han logrado ocupar una posición hegemónica en varios productos básicos agrícolas: 20 de ellas controlan el comercio del café, seis dominan el 70 por ciento del comercio del trigo y una controla el 98 por ciento de la producción de té envasado. En los últimos años las empresas transnacionales han modificado su estrategia y han desplazado su interés de las actividades de producción a las de financiación, formación e investigación, subcontratando muchas fases de la producción ${ }^{129}$.

Sin embargo, hoy, en los países en desarrollo, parte de la comercialización se hace por micro, pequeños y medianos comerciantes, que mueven los agroalimentos por redes de distribución local y regional; por tanto, y como lo señalan Vivas y Montagut, es importante indicar:

La mayoría de alimentos y productos agrícolas que la humanidad consume siguen siendo productos de proximidad, que se producen, se elaboran y se comercializan en los mercados locales, nacionales o

128 VIVAS, Esther y MONTAGUT, Xavier (2009): Del campo al plato... Op. cit., pág. 26.

129 Asociación Europea de Comercio Justo (EFTA) (1998): Anuario de comercio justo 19982000. Citado en FERNÁNDEZ, Yon y MAETZ, Materne (2003): Tendencias del comercio mundial $y$ de productos agrícolas. FAO, pág. 25. 
en comunidades más amplias pero bien delimitadas; [...] productos básicos como el trigo (17\%), la carne (9\%), el arroz (6\%) o los cereales para la alimentación animal (11\%) están presentes en el mercado internacional en cantidades muy bajas ${ }^{130}$.

A veces, los controles ejercidos por países productores de agroalimentos sirven de presión para las políticas comerciales y financieras de otros países.

\subsubsection{Comercio exterior de cereales}

Se referencia el comercio de cereales ${ }^{131}$ porque es un producto esencial en la dieta global y su comercio es significativo en dicho mercado. Hay 16 países exportadores de cereales que controlan el 73,3\% en 1994-1996 y pasan en el 2008 al 68,6\%. En este periodo, cinco países manejan más de la mitad del mercado de cereales, pero pasan del 61,1\% en 1994 al 50,5\% en el 2008, con una tendencia decreciente. La producción en cada país no decreció; en la mayoría de casos se duplicó o triplicó. Aunque pierdan participación relativa en el total, se ve un crecimiento generalizado de la demanda de los cereales que forman parte de la dieta básica global.

Entre los cinco principales exportadores de cereales, se encuentran: Estados Unidos, que pasó de controlar en 1994 el 33,6\% al 26,8\% en el 2008; Francia pasó del 12,8\% al 9,2\%; Australia, del 6,4\% al 4,2\%; Alemania, del 4\% al 3,3\%. Sin embargo, en el periodo, estos países duplicaron su producción real; el más dinámico fue Argentina, que multiplicó por 3,5 veces la producción de cereales, mientras China mantuvo un lento crecimiento. La mayoría de los principales exportadores de cereales son países desarrollados.

Con los países importadores hay dependencia alimentaria de la dieta mundial, con baja participación en el total y referidos al mundo desarrollado, excepto Japón, que es el primer importador de cereales del mundo. Este país, aunque pierde participación relativa, duplica la importación en el periodo analizado. Por otra parte, el grueso de las importaciones se vincula con países en desarrollo.

130 DOGLIOTTI, Fabrizio y MONTAGUT, Xavier (2006): Alimentos globalizados... Op. cit., pág. 20.

131 La información de comercio exterior de cereales a nivel mundial fue tomada de las estadísticas de la FAO, periodo 1994-2008 
En el caso de China, hay tendencia a caer porcentual y realmente en el mercado de cereales, pero impulsó medidas desde 2004 para promover su producción, como subvenciones directas de los gobiernos regionales y provinciales, a través del fondo para riesgos en materia de cereales para apoyar directamente a productores, con reducción de impuestos que pagan los productores y control a pedidos ilegales de tierras agrícolas ${ }^{132}$. En este contexto, la FAO destaca las acciones de varios países frente a la situación cerealera mundial, por establecer políticas "encaminadas a reducir la intervención del gobierno y promover un entorno más orientado al mercado" ${ }^{133}$. Por tanto, la rentabilidad del mercado determina las acciones públicas nacionales o globales expresadas en los costos económicos, más los subsidios públicos; y quienes lo hacen, tienen capacidades financieras y políticas diferenciadas globalmente.

\subsubsection{Acceso a los alimentos mundiales}

La estrategia de desarrollo referida a continuación describe posibles formas de acceso a los alimentos para algunos países:

Otra de las cosas que Europa nos dice es: 'tú debes producir flores exóticas, las exportas a Europa, donde conseguirás buenos precios, y así puedes comprar comida europea'. ¿Qué significa esto? Que estamos perdiendo nuestra producción de alimentos, estamos produciendo flores en lugar de alimentos. Exportamos más flores, más diamantes, más oro [...] para poder importar comida. ¿¿Importar comida? ¿Y éste es un continente agrícola? ${ }^{3134}$

Los análisis de hambrunas de la humanidad las identifican como típicas del precapitalismo por la incapacidad de producir alimentos, desastre natural o falta de acceso. Durante el capitalismo se creyó que solo sucedía en los países en desarrollo; sin embargo, en un informe de 1929, "la Cruz Roja norteamericana estimó que había 3 millones de muertes por inanición. En el mismo informe se describió la abundancia existente entre

132 FAO (2005): "Examen de las políticas sobre productos alimenticios básicos 2003-2004". Roma, pág. 37.

133 Ibíd., pág. 59.

134 KEET, Doot. Activista e investigadora del Alternative Information and Development Center (AIDC) en Sudáfrica. Entrevista publicada en VIVAS, Esther y MONTAGUT, Xavier (2009): Del campo al plato... Op. cit., pág. 69. 
las élites"135. Por lo tanto, el acceso a los alimentos es el componente de la cadena alimentaria que determina hoy las condiciones de las hambrunas en las poblaciones.

Otro punto que afecta el acceso son las acciones de guerra o las condiciones de seguridad nacional, como lo planteado por Churchill a los hindúes. Así, se identifican los alimentos como mercancías, al hacerlos vulnerables a las especulaciones con precios. Es el caso del arroz exportado por Bengala en 1942 en medio de la guerra, lo que conduce a la pregunta sobre el papel del Estado en situaciones críticas frente a los alimentos y el acceso de la población en ciertos momentos:

Se exportaron 185.000 toneladas en los primeros siete meses de 1942. Se envió alimento a donde había dinero y se obtuvieron así grandes utilidades. [...] En 1943, la Royal Famine Commission comentó: 'Nos hemos referido a la atmósfera de miedo y codicia que, en ausencia de controles, fue una de las causas del rápido incremento en el nivel de precios. Aprovechando esta calamidad, se obtuvieron enormes ganancias. En estas circunstancias, las utilidades de unos significaban la muerte de otros ${ }^{136}$.

Un punto del acceso a los alimentos es su precio, manejado como el de cualquier mercancía, en función de la oferta y la demanda, o dado por fenómenos naturales o acaparamientos en distribución, lo que afecta al consumidor final. Estos precios de agroalimentos están mediados en la cadena alimentaria, por intermediarios en la distribución o controladores de insumos en la disponibilidad. La crisis alimentaria ocasionada por el alza de precios de inicios de los años setenta del siglo XX "fue en gran parte resultado directo e intencional de la política norteamericana del "poder alimentario', que vio en la escasez la oportunidad de incrementar tanto el volumen como los precios de las exportaciones agrícolas"137. Hoy esto se ve repetido por la lógica del manejo del alimento como mercancía.

Los crecientes precios de alimentos e insumos afectan el acceso de las poblaciones urbanas y los pequeños productores rurales; implica además que, dada la duración de

135 MOORE L., Francés y COLliNS, Joseph (1982): Comer es primero... Op. cit., pág. 81.

136 Ibíd., pág. 80.

137 Ibíd., pág. 56 y ss. 
estas situaciones, se requieren establecer" la crisis" ${ }^{138}$. Ante este incremento de precios con alimentos e insumos, no se interviene; pero si se hace sobre las consecuencias a largo plazo, allí aparecen los gastos del Estado que mitigan la situación: no hay prevención. La FAO considera que los precios de los agroalimentos van a continuar creciendo; por tanto, el acceso enfrenta un panorama incierto en relación con los objetivos del milenio:

Los países pequeños dependientes de las importaciones, especialmente en África, se vieron profundamente afectados por la crisis de los alimentos y la crisis económica, [...] los precios de los productos alimenticios básicos seguirán siendo relativamente elevados durante el próximo decenio ${ }^{139}$.

\subsubsection{Uso biológico de los alimentos mundiales}

Las políticas públicas en SAN no desconocen la relación salud-alimentación, ni las implicaciones sobre el desarrollo, pues hay diferentes estudios que tratan estos aspectos:

Cada niño que sufre un retraso en su desarrollo físico o cognitivo debido al hambre y la malnutrición corre el riesgo de perder entre el 5 y el 10 por ciento de sus ingresos a lo largo de toda su vida. A escala mundial, cada año en que el hambre se mantiene en los niveles actuales está causando muertes y minusvalías que supondrán un coste para la productividad futura de los países en desarrollo, de un valor actual neto igual o superior a los 500000 millones de dólares ${ }^{140}$.

Esta síntesis y cuantificación económica de la desnutrición muestra los efectos sobre la sociedad, la economía, la familia y el individuo durante el ciclo de la vida de cada persona.Tener en cuenta las capacidades nutricionales de los alimentos es responsabilidad del SSAN: una cantidad de alimentos suficiente para cubrir las exigencias calóricas del

138 FAO (2011): El estado de la inseguridad alimentaria en el mundo ¿cómo afecta la volatilidad de los precios internacionales a las economías nacionales y la seguridad alimentaria? Pág. 47.

139 Ibíd., pág. 11 y ss.

140 FAO (2004): El estado de la inseguridad alimentaria en el mundo. Seguimiento de los avances en la consecución de los objetivos de la Cumbre Mundial sobre Alimentación y de los Objetivos de Desarrollo del Milenio. FAO, Italia, pág. 5. 
organismo; la calidad completa en su composición para ofrecer las sustancias que se requieren; el equilibrio o armonía, principios nutritivos de los alimentos, debe guardar una proporción determinada; y la adecuación: "El régimen alimenticio debe estar supeditado al organismo que lo consume" ${ }^{141}$.

Es importante también el papel de la cultura, porque los alimentos deben ser aceptados por la población; de allí la necesidad de definir dietas diferenciadas por países y, en su interior, por regiones. ¿En qué sociedad vivimos, que permite que se tenga información de más de cuatro décadas, donde existen más de 850 millones de personas en condiciones de subnutrición? ¿Quiénes son las personas con mayores niveles de vulnerabilidad? Los más afectados por el hambre son la población infantil, los adolescentes, las mujeres gestantes y los adultos mayores, grupos poblacionales con el mayor déficit nutricional y alimentario; y el de mayor vulnerabilidad por los efectos irreversibles son los recién nacidos ${ }^{142}$.

La población subnutrida ${ }^{143}$ en 52 países, cada uno con más de 1,5 millones de personas en el periodo 1990-2007, tiene las siguientes características (tabla 3.2): en los cinco primeros, el número de personas desnutridas suman más del 50\%: India, China, Bangladesh, Etiopía e Indonesia, que para el periodo 1990-1992 tenían el $59,2 \%$ del total, el cual bajó en el periodo 2005-2007 a 55,6\%. Por una parte, con comportamientos diversos están los que crecen: India y Bangladesh, mientras que China, Etiopía e Indonesia muestran una dinámica inversa. En específico, China disminuyó en 48 millones de personas.

\begin{tabular}{|c|c|c|}
\hline \multicolumn{3}{|c|}{$\begin{array}{c}\text { Tabla No. 3.2 } \\
\text { Número y prevalencia de } \\
\text { personas subnutridas en el mundo } \\
\mathbf{1 9 6 9 - 2 0 0 8}\end{array}$} \\
\hline Años & $\begin{array}{c}\text { Núme ro } \\
(\mathbf{0 0 0 . 0 0 0 )}\end{array}$ & $\%$ \\
\hline $2006-2008$ & 850 & 13 \\
\hline $2000-2002$ & 836 & 14 \\
\hline $1995-1997$ & 792 & 14 \\
\hline $1990-1992$ & 848 & 16 \\
\hline $1979-1981$ & 853 & 21 \\
\hline $1969-1971$ & 878 & 26 \\
\hline Fuente: FAO 2012 & & \\
\hline
\end{tabular}

141 VARGAS OVIEDO, Wenceslao (1991): Fundamentos de ciencia alimentaria. Universidad Nacional de Colombia, Bogotá, pág. 46 y ss.

142 FAO (2004): El estado de la inseguridad alimentaria en el mundo... Op. cit., pág. 8 y ss.

143 La información demográfica a nivel mundial fue tomada de las estadísticas de la FAO, en el periodo 1990-2007. 
La FAO menciona que, en Latinoamérica, Brasil, Perú, Colombia y Ecuador redujeron la población en condiciones de desnutrición;Venezuela permanece constante, y los que aumentan son República Dominicana y Bolivia. Al respecto, Morales considera:

En América Latina, en los pasados 21 años (coincidentes con la expansión del neoliberalismo) se han generado más hambrientos (que los que han reducido) si bien en el último decenio pareciera haber una ligera disminución de ellos ${ }^{144}$.

El director general adjunto de la FAO en el 2008 confirmaba: "Las causas estructurales del hambre, como la falta de acceso a la tierra, crédito o empleo, combinados con los altos precios de los alimentos, continúan siendo una triste realidad"145. El mayor número de personas (más del 90\%) en desnutrición se encuentran en Asía, África y América Latina.

\subsubsection{Recapitulación}

El control que tienen en el interior de la cadena alimentaria las empresas multinacionales, en términos de la disponibilidad, la distribución y el acceso a los alimentos, lleva a un proceso centralizador, concentrador y de mayor dependencia de los alimentos.

Teniendo en cuenta los impactos negativos sobre la salud y el medioambiente generados por producir los agroalimentos a grandes distancias de los sitios de consumo, estos deben estar disponibles cerca de la mesa, lo cual implica producción de orden local y el mínimo de alimentos viajeros (por los altos costos económicos y ambientales).

Los organismos globales inciden en las políticas agroalimentarias para tomar decisiones nacionales, locales y comunitarias, mientras que pocos países controlan los mercados de agroalimentos de la dieta básica mundial.

Los cambios en la producción mundial de agroalimentos se caracterizan así: China se convirtió en el principal productor mundial de estos, la India ocupó el segundo lugar, y

144 MORALES G., Juan Carlos (2006): El hambre al servicio del neoliberalismo. Ediciones Desde Abajo, Bogotá, pág. 67.

145 HAFEZ, Ghanem (2008): Director General Adjunto de la FAO, presentación edición del informe de la FAO sobre el hambre: El estado de la inseguridad alimentaria en el mundo. 
Estados Unidos, el tercero; en América Latinase encuentran el cuarto y el quinto lugar: Brasil y Argentina, principal productor mundial per cápita.

La gran paradoja es esta: la mayor población en condiciones de subnutrición se encuentra en Asía y es particular, porque allí es donde están los mayores productores mundiales de agroalimentos (India y China). El mismo caso se repite en África y en América Latina, pues Brasil, que ocupa el cuarto lugar en la producción, está en uno de los primeros lugares en subnutrición. 



\section{CAPÍTULO IV. \\ EL DERECHO A LA ALIMENTACIÓN}

"Un derecho es un poder, soberanía o dominio de la voluntad, concedido por el orden jurídico"146.

"El derecho a la alimentación es una cuestión de justicia social y de dignidad humana:

¿Puede haber alguien que opine lo contrario?’”147.

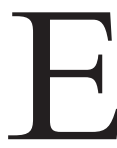
ste capítulo presenta la discusión sobre el acceso a una alimentación adecuada ${ }^{148}$, a partir del derecho mismo, los derechos subjetivos, los inalienables, los de trasfondo e institucionales, los sociales fundamentales y los económicos familiares (Sen), con componentes teórico-jurídicos. Para la SAN, este concepto es el que tiene más evolución y argumentación en las últimas décadas: el derecho de los seres humanos a tener alimentos para la vida. Además, se aborda la dinámica de las organizaciones públicas, privadas y sociales; las legislaciones de tipo internacional y nacional; las decisiones públicas; y la lucha moral individual y colectiva frente a los informes y políticas en términos temporales y espaciales.

La FAO exige en el mundo actual el derecho a la alimentación: "Todos los hombres, mujeres y niños tienen el derecho inalienable a no padecer hambre"149. Por lo tanto, este debe asegurarse para un número creciente de personas, que por diferentes razones

146 WINDSCHEID B., Lehrbuch des Pandektenrechts (1906), citado en HABERMAS, Jürgen (1998): Facticidad y validez sobre el derecho y el Estado democrático de derecho en términos de teoría del discurso. Trotta, Madrid, pág. 151.

147 HAUENSTEIN SWAN, Samuel y VAITLA, Bapu (2007): El hambre injusta, una crónica reciente de la lucha por los alimentos y la dignidad. Hunger watch informe 2007-2008. Icaria, Barcelona, pág. 16.

148 La discusión sobre este derecho cambia cuando los fundamentos sobre los cuales se sustenta el concepto de seguridad alimentaria superan el componente típicamente económico. Hoy encontramos que están "todos los elementos de la seguridad alimentaria, incluida la disponibilidad, accesibilidad y utilización de los alimentos, pero trasciende el concepto de seguridad alimentaria porque se hace hincapié en la rendición de cuentas. El enfoque basado en los derechos hace hincapié en el hecho de que progresar para reducir el porcentaje de personas hambrientas constituye una obligación jurídica, no solamente una preferencia o una elección" (Ziegler Jean, 2002); por tanto, ahora este cambio en la obligación centra la discusión sobre la seguridad alimentaria en el terreno imperativo de las políticas públicas, hacia la solución de un problema de la ética humana.

149 FAO (1974). 
no pueden acceder. La sociedad y el Estado tienen la responsabilidad en esta situación, pues en ellos recae cumplir este derecho. La ONU formula en esta materia:

El derecho a la alimentación es el derecho a tener acceso, de manera regular, permanente y libre, sea directamente, sea mediante compra en dinero, a una alimentación cuantitativa y cualitativamente adecuada y suficiente, que corresponda a las tradiciones culturales de la población a que pertenece el consumidor y que garantice una vida psíquica y física, individual y colectiva, libre de angustias, satisfactoria y digna ${ }^{150}$.

Este es un derecho de segunda generación reivindicado desde fines del siglo XIX desde la definición de derechos económicos, sociales y culturales (DESC), cuya satisfacción exige "medios económicos para garantizarlos, y por ello solo podrán satisfacerse gradualmente de acuerdo al momento histórico y a las posibilidades de cada estado" ${ }^{151}$. Esta realización requiere de voluntad política, dado que los recursos públicos se dirigen a sectores.

\subsection{ELEMENTOS DE BASE DEL DERECHO A LA ALIMENTACIÓN}

Hay un desfase entre los conceptos teórico-jurídicos y sociales, las normas, las políticas públicas nacionales e internacionales y la moral individual o colectiva frente a las muertes por inanición.

\subsubsection{Los derechos subjetivos}

La discusión sobre el derecho a una alimentación requiere ver la evolución de los derechos subjetivos, cómo estos se individualizan a partir del derecho. Allí, la coerción que permite su aplicación y la demanda para su ejecución quedan en cabeza de las personas y las responsabilidades del Estado. Kant considera a partir de la teoría del derecho:

150 ONU (2005): El derecho a la alimentación (nota del Secretario General, Documento A/60/30, septiembre). Pág. 5 .

151 MEDINA REY, José M. (2006) La lucha contra el hambre desde el enfoque de los DESC. En Seminario seguridad alimentaria y lucha contra el hambre. CEHAP- Universidad de Córdoba. Pág. 3. 
[Los] derechos subjetivos naturales [...] otorgan a toda persona la capacidad de ejercer coerción contra las vulneraciones de sus libertades de acción, que esos derechos aseguran. Con el tránsito del derecho natural al derecho positivo esas facultades de ejercer coerción, las cuales, tras la monopolización ejercida de todos los medios de coerción legítima por parte del Estado ya no pueden ser ejercitadas directamente por las personas jurídicas particulares, se convierten en facultades de ejercer una acción o demanda ${ }^{152}$.

El poder del Estado sintetiza la realización de los derechos en cabeza de los individuos. Estos últimos, por no asegurarse, ver vulneradas sus "libertades de acción" y se convierten en demandantes de derechos ante un Estado que no cumple. Sin embargo, las nuevas dimensiones y competencias del Estado desde los modelos actuales cambian las responsabilidades de los diferentes sujetos:

El derecho moderno opera un desplazamiento por lo que antes se exigía normativamente de los individuos, los cuales de este modo quedan por así decir, moralmente exonerados, se transforma en exigencias que ahora se hacen a las leyes, las cuales han de asegurar la compatibilidad de las libertades de acción. Estas reciben legitimidad de un procedimiento legislativo que se apoya a su vez en el principio de soberanía popular ${ }^{153}$.

Hay un hecho fundamental para realizar los derechos, que combina libertades de acción con aseguramiento de los derechos ciudadanos para ejercer su autonomía política, y no dejar solo en el Estado la responsabilidad que recae en el individuo, la familia y las empresas. Así, Habermas anota que los derechos ciudadanos "en tanto derechos subjetivos, tienen la misma estructura que todos los derechos que otorgan al individuo esferas de libertad de arbitrio" 154 . Hay una justificación que vincula los derechos subjetivos como condición de igualdad frente a la libertad; por tanto, se reconoce tener un derecho subjetivo "cuando el orden jurídico deja al implicado la realización de un fin reconocido, es decir, la satisfacción de un interés reconocido, y para tal propósito le

152 HABERMAS, Jürgen (1998). Facticidad y validez sobre el derecho y el Estado democrático de derecho en términos de teoría del discurso. Editorial Trotta. España. Pág. 90

153 Ibíd. Pág. 148.

154 Ibíd. Pág. 150. 
dota de un poder jurídico" ${ }^{155}$. Este es un derecho que permite un poder en el mismo nivel que los derechos civiles y políticos. Por ello, se requiere ubicar los derechos subjetivos como camino hacia el derecho:

El derecho subjetivo es conceptualmente una facultad jurídica, conferida al individuo por el orden jurídico, y por su fin un medio para la satisfacción de intereses humanos. La referencia al disfrute y al interés permitió la extensión de los derechos subjetivos privados a derechos en general, autorizado mediante la voluntad de quien manda, y también viene dotado de la validez de un deber ${ }^{156}$.

Desde esta perspectiva, el derecho subjetivo satisface intereses humanos, permite reconocer al que legisla y al que posee el deber de hacerlo cumplir en función de las libertades individuales y colectivas. En este sentido, los derechos subjetivos, analizados por Arango, muestran que acá "se construye el ordenamiento jurídico moderno. [...] [Estos derechos] otorgan a los actores un espacio de acción en el que actuar" ${ }^{\prime 57}$. Ello sustenta el ingreso de los individuos a las titulaciones de derechos, lo cual implica otras responsabilidades.

\subsubsection{Los derechos inalienables}

Estos derechos integran la relación entre derechos subjetivos e irrenunciablidad de derechos, así como el argumento y el desarrollo de las libertades individuales. Meyers sostiene que en "la existencia de derechos inalienables debe demostrarse que ciertos derechos establecen entre sus presuntos titulares y un bien una relación que estos individuos no pueden romper" ${ }^{158}$. Así se relacionan individuos, colectivos y Estado, o titulares de derechos y responsables de la aplicación, sin que unos y otros se desprendan de sus deberes y responsabilidades, que en ambos casos son irrenunciables.

Meyers considera también que los derechos inalienables sustentan el logro del “objetivo elemental en los sistemas morales". Estos son: "El derecho a la vida; la libertad

155 Ibíd., pág. 151.

156 Ibíd., pág. 151.

157 ARANGO, Rodolfo (2005): El concepto de los derechos sociales fundamentales. Universidad Nacional de Colombia y Legis, Bogotá, pág. 28.

158 MEYERS, Diana T. (1988): Los derechos inalienables. Editorial Alianza Universidad, Madrid, pág. 24. 
personal; al buen trato; y a la satisfacción de las necesidades básicas". A estos derechos "no se puede renunciar [...] por razones de conciencia"159. Así, lo importante es responder con diferentes acciones de los responsables de su protección, ya que son imperativos morales y políticos en la sociedad contemporánea. De este modo, para cumplir el derecho inalienable a la satisfacción de las necesidades básicas, se exige de sus titulares:

[Que dispongan] de comida adecuada, agua, ropa, vivienda, cuidados médicos para sobrevivir y protección ante cierto tipo de privaciones -y por supuesto su no satisfacción, conlleva a los titulares de estea causar dolor y por tanto deteriorar la acción moral, [...] [pues] si estas carencias no se solucionan pueden ir acumulándose y matar a la persona que las sufre, y por tanto destruir la acción moral exactamente igual que si se tratase de una violación del derecho a la vida ${ }^{160}$.

Este es un aspecto fundamental para entender la titularidad, la responsabilidad y la irrenunciablidad del derecho a la alimentación, como parte del derecho a la vida; por tanto, el individuo, la población, la colectividad, el estar en este mundo los hace titulares de un derecho irrenunciable y exigible, y al cual la sociedad, las empresas y el Estado deben responder como atenuante moral. Así también, el derecho a la tierra se integra a esta situación de vida:

La tierra es un recurso vital para la mayoría de las comunidades rurales, no solo para la realización de sus derechos económicos, sociales y culturales (alimentación, vivienda, trabajo, vida cultural), sino también para el goce de los derechos civiles y políticos (a la vida, a ser libre de servidumbre, a la protección judicial, a la participación política ${ }^{161}$.

En consecuencia, la tierra, que es una condición básica para la vida de muchos campesinos, se convierte en un derecho inalienable. De esta manera, tal discusión

159 Ibíd., pág. 59. Este apartado no se ocupará de la discusión sobre la irrenunciablidad de los derechos, ya que lo que interesa ahora, en términos del trabajo, es la sustentación del derecho a una alimentación adecuada como base de acción de las políticas públicas. Este tema es tratado de forma extensa en el texto citado de Diana Meyers.

160 Ibíd., pág. 69.

161 MONSALVE S., Sofía (2004): "Derecho a la tierra y derechos humanos". En El otro derecho. 31-32, derecho a la tierra, conceptos, experiencias y desafíos. Instituto Latinoamericano de Servicios Sociales Alternativos y Anthropos, Bogotá, pág. 41 
se ubica sobre el tipo de moral que puede tener una sociedad en cierto momento; por tanto, "las personas tienen derechos inalienables porque los sistemas morales no pueden autoanularse ni autorrescindirse, o porque los sistemas morales deben apoyar la acción moral" ${ }^{162}$. Por supuesto, el hambre, la malnutrición y la muerte por falta de acceso a una alimentación acorde y necesaria ponen en conflicto diferentes valores, como la moral individual y social.

Asimismo, aplicar los derechos inalienables en el mundo contemporáneo implica la pregunta: ¿quién o quiénes deben ser los responsables de lograr que estos derechos se cumplan: los individuos, la familia, las empresas, la sociedad a través de sus diversas formas de organización o el Estado como representante de esta? La respuesta requiere tener en cuenta algunas condiciones:

Si los derechos a la asistencia y ayuda se respetan, todos los que necesitan ayuda deben ser identificados, el coste que esto supone debe ser repartido proporcionalmente a la riqueza de los que lo pagan y las formas más adecuadas de ayuda deben ser proporcionadas a los que realmente lo necesitan ${ }^{163}$.

Esto implica una metodología de investigación que identifique diferentes actores públicos, comunitarios y privados, así como las relaciones que se pongan en marcha para cumplir estos derechos. Hay que tener en cuenta los territorios para asumir esta responsabilidad en el mundo actual, y esto no solo es un problema de las naciones, sino de la comunidad internacional, en la medida en que "las fronteras nacionales no subdividen a la comunidad de agentes morales a menos que establezcan barreras para tal acción" ${ }^{164}$. Si esto ocurriera, las naciones ricas se salvarían de responsabilidades frente a los derechos, en tanto las pobres se llevarían la peor parte.

Lo anterior cuestiona las acciones de los Estados, ya que los organismos que funcionan en el interior de estos "tienen todos los resortes para controlar un proceso de distribución [y] la ventaja de los programas internos de ayuda que pueden ser supervisados" "165. Los entes más eficaces para ejecutar una política pública para poblaciones identificadas son

162 MEYERS, Diana T. (1988). Los derechos... Op. cit., pág. 113

163 Ibíd., pág. 163.

164 Ibíd., pág. 164.

165 Ibíd., pág. 165. 
las organizaciones públicas, comunitarias, privadas y sociales, sobre todo las ubicadas en los territorios locales.

\subsubsection{Los metaderechos}

La realización de los derechos se integran al metaderecho, concepto planteado por Sen y definido así: "Un metaderecho a algo X puede ser definido como el derecho a tener políticas $\mathrm{p}(\mathrm{X})$ que persigan genuinamente el objetivo de hacer realizable el derecho a X"166. El autor llega a este análisis para responder la pregunta: “¿Tienen las personas derecho a estar libres de hambre?", con la cual inicia la discusión entre derechos y metaderechos. Además, tiene en cuenta los conceptos de Dworkin, referidos a los derechos de trasfondo, que justifican decisiones políticas; los institucionales, que proveen el organismo específico para $X$ decisión; los abstractos, como objetivos generales sin ponderación frente a otros objetivos políticos; y los concretos, como objetivos específicos priorizados.

Lo anterior le permite a Sen ubicar los metaderechos así: "El metaderecho a ser liberado del hambre es el derecho a tal política pero que en últimas está tras ese derecho objetivo de alcanzar esa libertad" ${ }^{167}$. Por lo tanto, el fin último del derecho a no tener hambre vincula el poder de ser libre, dando la inalienabilidad que es irrenunciable y desarrollando las libertades.

Arango $^{168}$, por su parte, considera que el concepto de metaderecho cumple tres funciones en la discusión sobre los derechos: la transformación categorial, que acerca el discurso de los objetivos políticos y el de los derechos; el control político, que ofrece la propuesta de exigir la política necesaria para hacer posible la realización de los derechos positivos; y la responsabilidad política, vinculada al legislador y al control público frente a tomar las medidas necesarias para realizar los derechos positivos. Así, el ángulo de los metaderechos permite un acercamiento general y justifica una política de SAN acorde con necesidades de las personas, independientemente de su ubicación en la sociedad y en el mundo, lo cual permite hacer un acercamiento al concepto del mínimo vital.

166 SEN, Amartya K. (2002): El derecho a no tener hambre. Universidad Externado de Colombia, Bogotá, pág. 15.

167 Ibíd., pág. 16

168 Ibíd., presentación de ARANGO, Rodolfo, pág. 9. 


\subsubsection{Los derechos fundamentales}

Identificar los derechos fundamentales implica determinar su estructura, saber cuáles son y quiénes son los responsables de su ejecución. Ferrajoli los define desde la teoría del derecho como "los derechos que están adscritos universalmente a todos en cuanto personas, o en cuanto ciudadanos o personas con capacidad de obrar, y que son por tanto indisponibles e inalienables" $"$ ". Desde la filosofia política, el autor considera que identificarlos requiere "criterios meta-éticos y meta-políticos" relacionados a partir de tres puntos:

El primero es el nexo entre derechos humanos y paz, [...] segundo tema del derecho de las minorías es el nexo entre derechos e igualdad, [...] tercero el papel de los derechos fundamentales como leyes del más débil. [...] Bajo el tercer criterio ubica tres derechos: el derecho a la vida, el derecho a la inmunidad y a la libertad y el de los derechos sociales, que son derecho a la supervivencia contra la ley de quien es más fuerte social y económicamente ${ }^{170}$.

Desde los derechos fundamentales y la SAN, se sustenta el derecho a la alimentación como una condición de los procesos de desarrollo social. Desde esta argumentación, "los derechos sociales fundamentales son derechos del individuo frente al Estado en demanda de acciones fácticas positivas" ${ }^{171}$, relacionadas con exigencias de los titulares: individuos, familias o colectivos, que no tienen acceso a los alimentos por diferentes razones, lo cual vulnera las condiciones de vida. Analizar los lazos entre derechos subjetivos, inalienables, metaderechos y derechos fundamentales es posible al retomar la definición de derecho subjetivo de Maurer:

El poder legal reconocido a un sujeto por medio de una norma legal, para la persecución de intereses propios, mediante la exigencia a otro de hacer, permitir u omitir algo, esto lleva a entender el derecho subjetivo caracterizado por: (i) una norma jurídica (M1), (ii) una obligación jurídica (M2) de otro derivada de esta norma, y (iii)

169 FERRAJOLI,Luigi (2007):“Los derechos fundamentales”.En Teoría del neoconstitucionalismo. Ensayos escogidos. Universidad Nacional Autónoma de México y Trotta, Madrid, pág. 73.

170 Ibíd., págs. 74 y ss.

171 ARANGO, Rodolfo (2005): El concepto de los derechos... Op. cit., pág. 113. 
un poder jurídico (M3) para la consecución de intereses propios reconocidos al sujeto (es decir, una posición jurídica) ${ }^{172}$.

¿Cuándo operan los derechos subjetivos, las normas, las obligaciones y el poder jurídico? Cuando pueden aplicarse como derechos sociales fundamentales, que permiten la acción de la política pública y su reconocimiento formal, mediante la estructuración de acciones para solucionar y atender el derecho a la alimentación, conexo con la vida, la moral, la igualdad y la libertad. Las dificultades que determinan el objeto de estos derechos deben plantearse, identificarse y reconocerse de una manera particular:

No debe resolverse a favor de fines funcionales o de razones organizativas del Estado (mediante la resolución de conflictos de competencias), sino en beneficio de los derechos fundamentales del individuo; ello porque los derechos fundamentales vinculan a todos los organismos estatales y exigen de estos contribuir decididamente a su realización ${ }^{173}$.

Se requieren, entonces, acciones integrales expresadas en las políticas públicas de los diferentes niveles de gobierno, que apliquen la racionalidad del gasto público del Estado para su solución e integren acciones en territorios priorizados graves, frente a un problema identificado directamente con la vida.

\subsubsection{El mínimo vital}

Este concepto es definido como "aquella suma estrictamente necesaria para cubrir las necesidades básicas de alimentación, educación, vestuario, vivienda, sin la cual es prácticamente imposible lograr el objeto constitucional enunciado dentro de los postulados del Estado Social de Derecho" ${ }^{174}$. Para su desarrollo, se presenta como un derecho innominado ${ }^{175}$ que tiene varios puntos relacionados con derechos conexos.

172 Citado por ARANGO, Rodolfo..., ibíd., pág. 9.

173 Ibíd., pág. 111.

174 Corte Constitucional de Colombia (1999): Sentencia T-1006/99, pág. 4

175 "Para la Corte el derecho al mínimo vital es un derecho fundamental innominado, [...] los jueces constitucionales reconocen los derechos fundamentales innominados a partir de una concepción holista [sic] de la Constitución". Véas: ARANGO, Rodolfo y LEMAITRE, Julieta (2002): Jurisprudencia constitucional sobre el derecho al mínimo vital. Universidad de los Andes, Bogotá, pág. 11. En lo fundamental, este punto se desarrolla a partir de consultas de decisiones de la Corte Constitucional y de este texto. 
Esto le exige al Estado social de derecho un esfuerzo para construir las condiciones que aseguren a los habitantes del país una vida digna, dentro de las posibilidades económicas que estén a su alcance.

Para potenciar las capacidades, se requiere que las autoridades actúen y mantengan o mejoren el nivel de vida, que incluye alimentación, vivienda, seguridad social y los medios en dinero para desenvolverse en sociedad ${ }^{176}$. La Corte Constitucional de Colombia considera también el concepto del mínimo vital:

[Se parte de] los derechos fundamentales que incluyen en determinadas circunstancias a los derechos sociales como derechos justiciables. Detrás de ello, está una teoría de la justicia como justicia distributiva, en particular una concepción de la justicia distributiva a partir de las capacidades actuales del individuo ${ }^{177}$.

Esto significa exigirle al Estado que garantice el mínimo vital desde el derecho, y este se relaciona con la renta básica desde la economía.

\subsubsection{El derecho internacional}

Forma parte de los conceptos jurídicos aplicables en el ámbito nacional y que son obligatorios para los Estados. El derecho internacional encuentra un "pluralismo jurídico" que, en las condiciones actuales, "tiene que ver con la idea de que más de un sistema jurídico opera en una misma unidad política" ${ }^{178}$. Surge así la pregunta: ¿cuáles son las normas aplicables en el territorio donde están los dueños de las titularidades del hambre? Por tanto, son imperativas acciones integrales de los Gobiernos nacional, departamental y municipal, así como de otros Estados, las organizaciones globales y de cooperación. Se destaca en este sentido a Ziegler, quien considera que la SAN hoy es superada por las obligaciones de los Estados, y no solo por las regulaciones jurídicas. En esta situación surge la pregunta: ¿puede

176 Corte Constitucional de Colombia (1992): Sentencia T-426/92.

177 ARANGO, Rodolfo y LEMAITRE, Julieta (2002): Jurisprudencia constitucional sobre el derecho... Op. cit., pág. 64.

178 SOUSA SANTOS, Boaventura de (1998): La globalización del derecho. Los nuevos caminos de la regulación y la emancipación. Universidad Nacional de Colombia e Instituto Latinoamericano de Servicios Legales Alternativos, Bogotá, pág. 24. 
hablarse de pluralidad jurídica cuando las funciones de autodeterminación interna y externa de los pueblos están en entredicho?:

En la era de la globalización ambas funciones no solo han dejado de realizarse, sino que se han vuelto irrealizables a través de la fundación de nuevos Estados. El Estado no solo ha dejado de ser un instrumento de la unificación y pacificación interna, sino que se ha convertido en un obstáculo tanto para una como para otra ${ }^{179}$.

¿Aplicar el derecho a la alimentación adecuada debe analizarse desde una situación coyuntural, estructural nacional o internacional? En función de la respuesta deben plantearse las disposiciones de políticas para su ejecución.

\subsubsection{Los derechos económicos}

Consideran las relaciones con el desarrollo, planteada por Sen, a partir de este criterio: "La capacidad de adquirir alimentos hay que ganársela"180. Se pone así el problema no en la disponibilidad o la distribución, sino fundamentalmente en el acceso:

[Esto depende del] 'derecho económico' de que disfruta cada persona: los bienes sobre los que puede demostrar su propiedad y control. Los individuos padecen hambre cuando no pueden demostrar su derecho económico sobre una cantidad suficiente de alimentos $^{181}$.

De esta manera, se mantiene una acción atravesada por la incapacidad del individuo de demostrar "su derecho económico y su capacidad de ganárselo". Se sustentan desde allí las acciones integrales sobre el derecho a la alimentación, o los metaderechos, que justifican cambios de gobierno o exigencias de la población para su aplicación; o bien, la rebelión frente a su ausencia.

179 FERRAJOLI, Luigi (2007): Los derechos fundamentales... Op. cit., pág. 77.

180 SEN, Amartya (2000): Desarrollo y libertad. Planeta, Bogotá, pág. 201.

181 Ibíd., págs. 201 y ss. 


\subsubsection{El enfoque de derechos y la SAN}

Este enfoque en perspectiva de derechos requiere una acción concreta por parte de las personas titulares:

[Que] exijan responsabilidades a los gobiernos por los compromisos adoptados en materia de seguridad alimentaria. De esta manera, los ciudadanos se convierten en sujetos de derecho en vez de ser el objeto de la asistencia ${ }^{182}$.

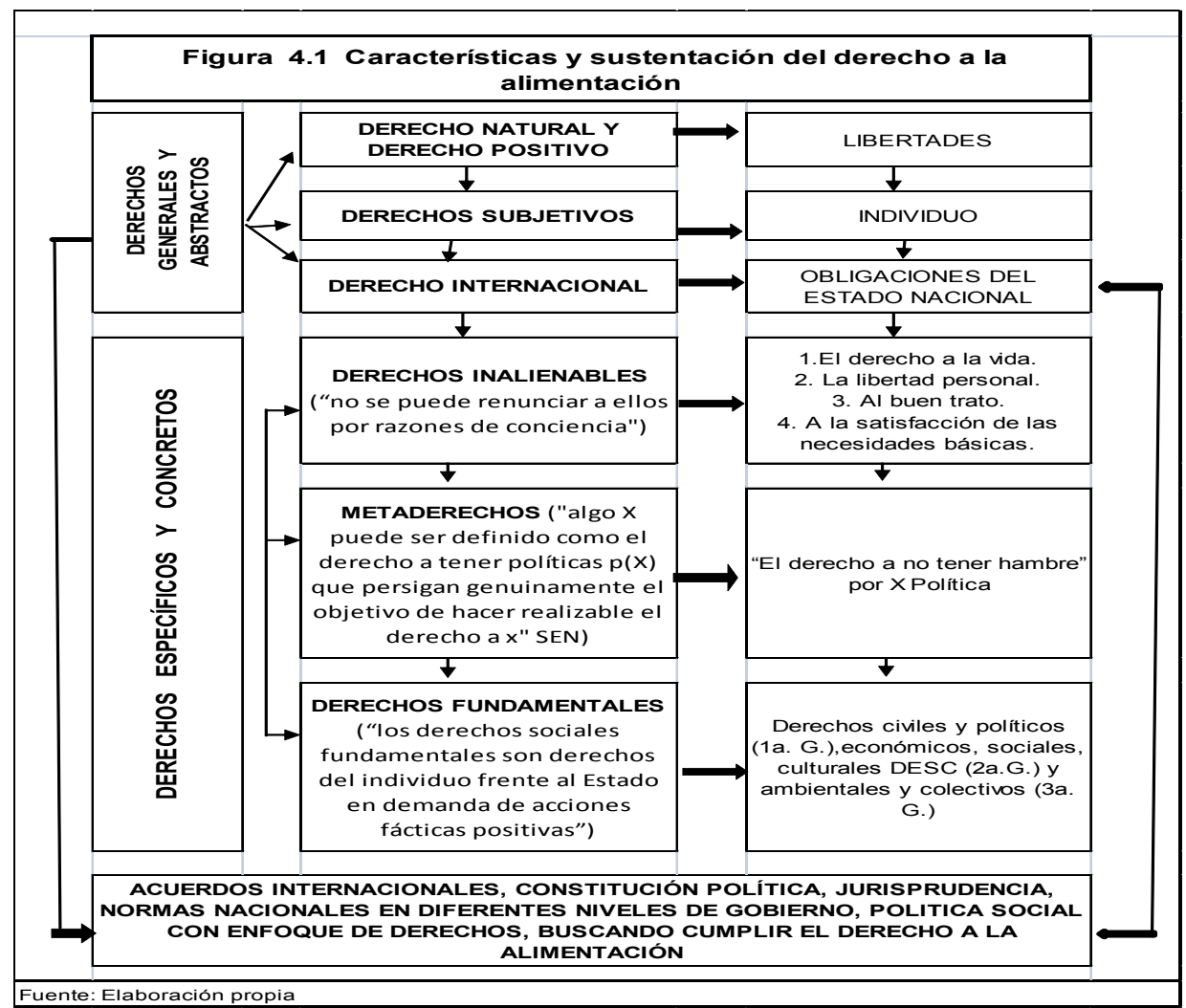

182 VIVERO, José Luis y RAMÍREZ, Pablo (2009): "Hambre, derechos humanos y la consolidación del Estado en América Latina”. En Derecho a la alimentación, políticas públicas e instituciones contra el hambre. LOM Ediciones, y Fundación Henry Dunant, Santiago de Chile, pág. 50. 
Esta exigencia cambia los principios frente a acciones de desarrollo de las políticas públicas y la SAN, y busca la construcción de ciudadanía para exigir derechos, más que la buena voluntad del Estado o la sociedad para cumplir con condiciones mínimas para la vida:

[Se necesita] el reconocimiento de derechos, a partir de identificar a sus titulares, y las instancias de participación, por el acceso a los mecanismos de garantías judiciales o de control ciudadano. Es decir, en la conjunción de empoderamiento con participación se puede tender el primer puente entre la perspectiva de derechos y las estrategias de desarrollo ${ }^{183}$.

El reconocimiento de los derechos realizado por la CEPAL señala una conclusión para establecer acciones inmediatas y simultáneas entre los derechos civiles y políticos, los DESC y las acciones de las políticas públicas, entendiendo que estas se encuentran en el mismo nivel:

Una vez que los derechos económicos, sociales y culturales son consagrados como derechos inalienables y ratificados por los gobiernos, la ciudadanía social ya no puede plantearse ni como posterior ni como secundaria respecto de la ciudadanía civil o política. En este sentido, el sistema de derechos rompe la perspectiva lineal, vale decir, impugna el supuesto de que en primer lugar hay que garantizar los derechos civiles y políticos, y solo una vez que estos se instituyen plenamente correspondería comenzar a prestar atención a los derechos sociales ${ }^{184}$.

\subsection{LA EVOLUCIÓN FORMAL LEGAL}

Las relaciones entre derechos, normas y acciones requeridas para solucionar el problema de SAN están cruzadas por la moral, la libertad y la política. Estas relaciones

183 PAUTASSI, Laura C. (2009): "Los difusos vínculos de articulación entre las políticas públicas y los derechos humanos”. En Derecho a la alimentación, políticas públicas... Op. cit., pág. 30. 184 Comisión Económica para América Latina (2006): La protección social de cara al futuro: acceso, financiamiento y solidaridad (trigésimo primer periodo de sesiones, Montevideo, Uruguay, 20-24 de marzo). Pág. 17. 
demandan condiciones y disposiciones de diferentes organizaciones para desarrollarlas. La evolución de la reglamentación del derecho a una alimentación adecuada queda explícita de varias maneras: desde declaraciones y encuentros internacionales, hasta normas constitucionales, legales y reglamentarias de orden nacional, departamental y local, donde el Estado asume los deberes internacionales.

\subsubsection{Internacional}

Las siguientes declaraciones, pactos, convenciones y cumbres, desde 1948 hasta la actualidad, dan cuenta de las acciones de la ONU, la FAO, el PMA y UNICEF, que para los Estados firmantes son de aceptación y aplicación inmediata, a fin de solucionar un problema que afecta la moral global.

En la Declaración Universal de los Derechos Humanos de la segunda posguerra del siglo XX (1948), el artículo 25 considera: "Toda persona tiene derecho a un nivel de vida adecuado que le asegure, así como a su familia, la salud y el bienestar, y en especial la alimentación, el vestido, la vivienda, la asistencia médica y los servicios sociales necesarios”.

Las responsabilidades en las acciones públicas y privadas por desarrollar en los derechos humanos están determinadas porque "todos los seres humanos participan ahora de un único orden institucional global, todos los derechos humanos por satisfacer se han vuelto, al menos potencialmente, una responsabilidad de todos" ${ }^{185}$. Ello incluye el orden nacional y subnacional en cada país, al igual que el mundo actual:

El orden institucional global existente no es un orden natural ni tampoco divino, sino que lo han configurado y lo mantienen los gobiernos más poderosos y otros actores controlados por estos (como la UE, la OTAN, la ONU, la OMC, la OCDE, el Banco Mundial y el FMI $)^{186}$.

Este compromiso, que afecta moral e institucionalmente al capitalismo contemporáneo, exige acciones globales, nacionales, subnacionales y sociales. Por otro lado, respecto a la Declaración Americana de los Derechos y Deberes del Hombre, de 1948, es importante

185 POGGE, Thomas (2005): La pobreza en el mundo y los derechos humanos. Paidós, Barcelona, pág. 218.

186 Ibíd., pág. 220 
destacar sobre lo analizado por la Defensoría del Pueblo: “Ambos instrumentos consagran normas y principios del derecho internacional consuetudinario que son de obligatorio cumplimiento por los estados"187, lo cual obliga en Colombia su aplicación por parte del Estado.

El Pacto Internacional de Derechos Económicos Sociales y Culturales (PIDESC), de 1966, señala que los Estados firmantes entran a reconocer "el derecho de toda persona a un nivel de vida adecuado [...] incluso alimentación" (artículo 11). El Estado debe tomar medidas para que su población tenga acceso y suplir este derecho. Por su parte, en 1979, la OMS y Unicef consideran que, para proteger a los lactantes, deben plantearse reglas específicas, como la siguiente:

\begin{abstract}
Establecer un código para controlar las prácticas inadecuadas de comercialización de sucedáneos ${ }^{188}$ de la leche materna y alimentos infantiles, razón por la cual en 1981 publica el Código Internacional de Comercialización de Sucedáneos de la Leche Materna (CIC), que regula estas actividades en el ámbito mundial ${ }^{189}$.
\end{abstract}

En Colombia hay varios programas vinculados con este acuerdo: Instituciones Amigas de la Mujer y la Infancia (IAMI),Atención a las Enfermedades Prevalentes de la Infancia (AIEPI), el Plan Decenal de Lactancia Materna y la Estrategia "De cero a siempre".

La Convención Mundial sobre los Derechos del Niño, de 1989, estima que ante la ausencia de alimentos, los primeros afectados son los niños; por consiguiente, se asumió un compromiso para "combatir las enfermedades y la malnutrición mediante el suministro de alimentos nutritivos y adecuados”. Luego, la Cumbre Mundial de la Infancia, de 1990, estableció metas que apuntaban a mejorar la salud y la calidad de vida de los niños, los jóvenes y las mujeres gestantes y lactantes.

187 GÓMEZ M., María Paula (2006): El derecho a la alimentación en la constitución, la jurisprudencia y los instrumentos internacionales. Defensoría del Pueblo y PROSEDHER, Bogotá, pág. 35.

188 Sucedáneos de la leche materna: todos aquellos productos nacionales o extranjeros procesados, manufacturados o industrializados, que por sus características, publicidad o promoción comercial tengan por objeto cumplir total o parcialmente la función de la leche materna en niños o niñas menores de dos años, sean adecuados o no para este fin.

189 Plan de Alimentación y Nutrición del Distrito Capital, 1999-2003: Un plan conViabilidad Local, pág. 21 
La Conferencia Internacional de Nutrición, de 1992, señala que ante la situación de desnutrición mundial, es necesario concretar compromisos internacionales para los países participantes, con metas regionales, en busca de mejorar la situación nutricional. Por su parte, la Cumbre Mundial de la Alimentación, de 1996, realizada en Roma, Italia, ratifica:

Nosotros jefes de Estado y de Gobierno [...] reafirmamos el derecho de toda persona a tener acceso a los alimentos sanos y nutritivos, en consonancia con el derecho a una alimentación apropiada y con el derecho fundamental de toda persona a no padecer hambre.

El Comité de Derechos Económicos, Sociales y Culturales, de 1999, define el derecho a una alimentación adecuada: "Cuando todo hombre, mujer, niño o niña, ya sea solo o en común con otros, tiene acceso físico y económico, en todo momento, a la alimentación adecuada y a los medios para obtenerla" (Observación General número 12)" ${ }^{190}$. Desde estos compromisos, para poder ejercer el derecho a la alimentación, hay que tener en cuenta la disponibilidad, el acceso y la aceptación cultural por la población; por tanto, en esta dirección se requiere viabilizar ciertas condiciones:

Respetar el acceso existente a una alimentación adecuada requiere que los Estados no adopten medidas de ningún tipo que tengan por resultado impedir este acceso. Esto significa que los desalojos forzados o el arrebato de tierras sin una compensación adecuada por parte del Estado son violaciones al derecho a la alimentación porque las victimas pierden el acceso a las tierras fuente de su sustento. La obligación de proteger requiere que el Estado parte adopte medidas para velar porque las empresas o los particulares no priven a las personas del acceso a una alimentación adecuada ${ }^{191}$.

Por consiguiente, el cumplimiento de este derecho vincula la posibilidad de que la población en zonas rurales tenga acceso a alimentación adecuada, lo que habrá de permitirles generar ingresos o producir alimentos, a partir de utilizar del recurso tierra.

190 FEBRER, María Teresa de (2004): Agencia de información solidaria. Pág. 2.

191 MONSALVE S., Sofia (2004): "Derecho a la tierra y derechos humanos". En Derecho a la tierra. Conceptos, experiencias y desafíos. El Otro Derecho 31-32. ILSA, Bogotá, pág. 49. 
En la Cumbre del Milenio, en el 2000, la ONU declara los Objetivos del Milenio (ODM). En esta cumbre, 189 países se comprometen a resolver 8 objetivos, 18 metas y más de 40 indicadores, los cuales deben hacerse realidad para el 2015, aspirando así al desarrollo social global. La relación directa con la alimentación está en el primer objetivo: "Erradicar la pobreza extrema y el hambre", cuyos indicadores para su logro son reducir a la mitad, para el 2015, la proporción de personas que sufren hambre y de personas cuyos ingresos son inferiores a un dólar diario; conseguir pleno empleo productivo y trabajo digno para todos, incluyendo mujeres y jóvenes.

La Cumbre Mundial Sobre la Alimentación se realizó en el 2002, y cinco años después se convirtió en la Alianza Internacional Contra el Hambre. De esta cumbre se resalta la reserva de Estados Unidos, que no quiere asumir responsabilidades ni garantizar estos derechos (anexo II: Reserva):

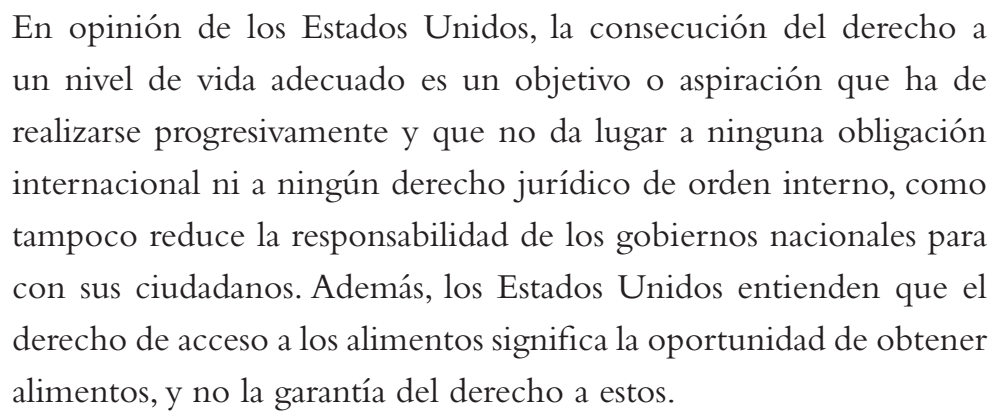

Para el gobierno de los Estados Unidos, las condiciones de hambre en el mundo no conducen a obligaciones internacionales ni derechos jurídicos, aunque exista responsabilidad de los gobiernos para resolver el problema. Además, su posición sobre el acceso es más una oportunidad que una garantía, lo cual resta obligación a los Estados y resalta la condición del mercado para su solución.

En el marco del sexagésimo periodo de sesiones de la ONU (2005), el Secretario General anotó, haciendo referencia a la responsabilidad en un contexto de mundialización:

Para cumplir plenamente sus obligaciones relacionadas con el derecho a la alimentación, las organizaciones internacionales deben 
respetar, proteger y respaldar el logro del ejercicio del derecho a la alimentación por sus Estados miembros ${ }^{192}$.

Estas decisiones son imperativas para los Estados y para las organizaciones globales; por consiguiente, se exigen compromisos nacionales e internacionales, públicos y privados, para aplicar este derecho. A su vez, las condiciones morales e institucionales comprometen acciones mancomunadas entre instituciones globales, gobiernos nacionales y subnacionales, empresas transnacionales, la sociedad y las familias:

Nuestro orden económico global actual produce una pauta estable de malnutrición generalizada y de mortalidad por falta de alimentos entre los pobres, no son meramente personas pobres que mueren de hambre, sino personas a las que empobrece y mata de hambre un orden institucional que les viene impuesto en coerción ${ }^{193}$.

Desarrollar propuestas alternativas apunta a la solución de este problema generalizado en muchos países. Este trabajo se acerca a proponer acciones en esta dirección, las cuales se encuentran planteadas en los capítulos 6 y 7, y cuyos vínculos esenciales se vislumbran con el desarrollo de procesos regiolocales a partir de los mínimos de demandas urbanas de alimentos nutricionales, ofertados cerca de la mesa.

\subsubsection{América Latina}

En América Latina hay disposiciones constitucionales y de política alimentaria en cada uno de los países ${ }^{194}$; todo en función de cumplir con el derecho a la alimentación establecido en los Objetivos del Milenio (ODM). En todos los países se encuentran normas constitucionales, leyes y políticas o planes relacionados con la SAN. Así, de 19 países, hay 12 a nivel constitucional que lo consideran de manera directa, en tanto 7 lo hacen vía conexidad con otros temas, como el derecho a la salud o la seguridad social, y en muchos casos están presentes niños y ancianos. En la reglamentación del

192 ONU (2005): "El derecho a la alimentación" (nota del Secretario General, Documento A/60/30, septiembre). Pág. 22.

193 POGGE, Thomas (2005): La pobreza en el mundo... Op. cit., pág. 225

194 Los datos son tomados de:VIVERO, José Luis y RAMÍREZ, Pablo (2009). "Leyes, políticas e instituciones contra el hambre en el contexto latinoamericano". En Derecho a la alimentación, políticas públicas e instituciones contra el hambre. LOM Ediciones y Fundación Henry Dunant, Santiago de Chile, pág. 169 
derecho vía leyes sobre SAN hay 8 países donde se encuentra explícita esta acción constitucional, en 7 está en discusión y en 4 no existe. En relación con la construcción de una política pública en SAN que oriente acciones, solo 7 países tienen una política nacional de SAN, el resto están vinculados con los planes nacionales de desarrollo de salud, agrario o social.

\subsubsection{Nacional}

La ratificación de los compromisos internacionales es asumida por parte del Estado colombiano. En la Constitución de 1991 se definen estas responsabilidades; así, el artículo 44 dice: "Son derechos fundamentales de los niños: la vida, la integridad física, la salud y la alimentación equilibrada". Sin embargo, hay un cuerpo jurídico al derecho a la alimentación de manera amplia ${ }^{195}$.

La Constitución de 1991, en el artículo 65, referido a los derechos sociales, económicos y culturales, considerados de segunda generación, se señala: "La producción de alimentos gozará de especial protección del Estado, [...] de igual manera el Estado promoverá la investigación y transferencia de tecnología para la producción de alimentos". En esta dirección, la Constitución determina principios para orientar las políticas en función de la disponibilidad nacional de alimentos. A su vez, en el capítulo III, sobre derechos colectivos y del ambiente, el artículo 78 dice:

La ley regulará el control de calidad de bienes y servicios ofrecidos y prestados a la comunidad, así como la información que debe suministrarse al público en su comercialización. Serán responsables, quienes en la producción y en la comercialización de bienes y servicios, atenten contra la salud, la seguridad y el adecuado aprovisionamiento a consumidores y usuarios.

Lo anterior sugiere un principio sobre el derecho a la salud y a la alimentación, vía inocuidad de los productos. Adicionalmente, en el caso colombiano, dados los niveles del conflicto político, social y de violencia, se generan procesos de desplazamiento de

195 GÓmEZ M., María Paula (2006): El derecho a la alimentación... Op. cit. Este trabajo, promovido por la Defensoría del Pueblo, es el que mejor da cuenta de estas normas de carácter nacional y su respectiva jurisprudencia. En la figura 4.2 se relacionan los diferentes compromisos y los elementos que deben tenerse presentes en la aplicación de este derecho tanto en el plano de los obligados como de las obligaciones. 
la población rural. Es necesario que el Estado en diversos niveles tenga en cuenta la obligación de respetar el acceso a la alimentación en las zonas rurales. En este sentido, la FAO es enfática al señalar que en el mundo rural es necesario resolver la situación crítica del hambre:

Cerca del $80 \%$ de las personas que han padecido hambre o desnutrición en todo el mundo vive en zonas rurales. Los pequeños $\mathrm{y}$ las pequeñas agricultoras en tierras marginales, las familias sin tierra y los jornaleros y jornaleras constituyen los grupos sociales más afectados por el hambre en el mundo entero. [...] Garantizar el acceso a los recursos productivos como la tierra para que las personas puedan realizar plenamente su derecho a alimentarse es un asunto que obviamente requiere recursos ${ }^{196}$.

\begin{tabular}{|c|c|c|c|}
\hline \multicolumn{4}{|c|}{$\begin{array}{c}\text { Figura 4.2. Colombia: los obligados y las obligaciones en la realización del } \\
\text { derecho a la alimentación }\end{array}$} \\
\hline \multicolumn{4}{|c|}{ I } \\
\hline 1. La familia & 2. La sociedad & $\begin{array}{c}\text { 3. Empresas transnacionales } \\
\text { y otras empresas } \\
\text { comerciales }\end{array}$ & $\begin{array}{l}\text { 4. Instituciones } \\
\text { internacionales }\end{array}$ \\
\hline \multicolumn{4}{|c|}{ Estado } \\
\hline \multirow{7}{*}{$\begin{array}{l}5.1 \text { Obligaciones } \\
\text { sobre la cadena } \\
\text { alimentaria }\end{array}$} & \multirow{7}{*}{$\begin{array}{l}5.2 \text { Obligaciones } \\
\text { de respeto, } \\
\text { protección y } \\
\text { realización }\end{array}$} & $\begin{array}{l}5.3 \text { Obligaciones de efecto } \\
\text { inmediato }\end{array}$ & $\begin{array}{l}5.4 \text { Obligaciones de } \\
\text { cumplimiento } \\
\text { progresivo }\end{array}$ \\
\hline & & I & T工 \\
\hline & & $\begin{array}{c}\text { Medidas: legislativas, } \\
\text { judiciales, presupuestales, } \\
\text { administrativas, educativas }\end{array}$ & \multirow{5}{*}{$\begin{array}{c}\text { Mecanismos para } \\
\text { observar el derecho a } \\
\text { la alimentación } \\
\text { nacional e } \\
\text { internacional }\end{array}$} \\
\hline & & Estrategias y programas & \\
\hline & & $\begin{array}{l}\text { Garantizar la no } \\
\text { discriminación }\end{array}$ & \\
\hline & & $\begin{array}{c}\text { No adoptar medidas } \\
\text { regresivas }\end{array}$ & \\
\hline & & $\begin{array}{l}\text { Vigilar el grado de } \\
\text { realización }\end{array}$ & \\
\hline \multicolumn{4}{|c|}{$\begin{array}{l}\text { Fuente: elaboración propia a partir de: GÓM EZ M., Maria Paula (2006): El derecho a la alimentación en la } \\
\text { constitución, la jurisprudencia y los instrumentos internacionales. Defensoria del Pueblo y PROSEDHER, } \\
\text { Bogotá. }\end{array}$} \\
\hline
\end{tabular}

En estas condiciones, el derecho a la tierra, a pesar de sus restricciones, se vincula con el derecho a la alimentación, al permitir o restringir el acceso a los alimentos por la vía de la producción o el ingreso. En este punto es fundamental tener presente: "La literatura que se ocupa de este tema es que no toca de manera explícita la cuestión de un

196 Citado en MONSALVE S., Sofia (2004): Derecho a la tierra... Op. cit., pág. 49. 
'derecho humano a la tierra', sino que se usan vías indirectas para abordarlo" ${ }^{197}$, como "los derechos a la tierra", los "derechos humanos relacionados con la tierra" o los "derechos de propiedad" o "a la propiedad" de la tierra. El problema de la tierra en Colombia está cruzado por varios conflictos, lo que agrava el derecho a la alimentación de la población desplazada la cual. La Oficina Presidencial Acción Social considera sobre esto:

\begin{abstract}
El abandono de tierras por parte de campesinos y granjeros desplazados, y su cambio de destinación a labores de ganadería, a la producción de biocombustibles o como tierras ociosas en manos de los nuevos dueños, reduce la oferta de alimentos y materias primas para la industria ${ }^{198}$.
\end{abstract}

Esta situación del conflicto interno afecta el problema alimentario por el despojo y la sustitución de producción de alimentos, sobre todo a la población vulnerable por el desplazamiento y la pérdida de tierras. El capítulo VII muestra las condiciones que afectan la disponibilidad de alimentos para los centros urbanos y los campesinos desplazados, por la incapacidad de acceso de la población vulnerable en las zonas urbanas.

\title{
4.2.4. Regiolocal
}

En Colombia, los encargados de garantizar el derecho a la alimentación son los Gobiernos nacional, departamentales y municipales. Ello se materializa desde políticas públicas territorializadas y a través de la cadena alimentaria, que son acciones requeridas para su cumplimiento, como se muestra en las figuras 4.3 y 7.1.1 (capítuloVII), donde se identifican las competencias de los gobiernos en este derecho, expresadas en planes, decisiones públicas y normas específicas en cada fase de la cadena. Ello ha de aplicarse en cada los ejes dinamizadores: Medellín, Cartagena, Cúcuta y Neiva, donde hay acuerdos

197 HERREÑO H., Ángel L. (2004). ”Evolución política y legal del concepto de territorio ancestral indígena en Colombia", publicado en El Otro Derecho 31-32, Derecho a la tierra conceptos, experiencias y desafios. Instituto Latinoamericano de Servicios Sociales Alternativos ILSA. Ediciones Ántropos. Bogotá. Pág. 250.

198 Presidencia de la República, Acción Social (2010): Unidades agrícolas familiares, tenencia y abandono forzado de tierras en Colombia. Proyecto de Protección de Tierras y Patrimonio de la Población Desplazada, Bogotá, pág. 99. También cita la III Encuesta Nacional de Verificación de la Comisión de Seguimiento: "El 60\% de los migrantes forzosos provienen de zonas rurales, el $24 \%$ de centros poblados y de cabeceras municipales el $15 \%$. Conforme a esta encuesta el $83 \%$ de las personas perdió alguno de sus bienes: $72 \%$ ganado o animales productivos; $50 \%$ maquinaria o vehículo; $42 \%$ tierras; $24 \%$ infraestructura productiva; y 19\% bienes raíces no rurales". 


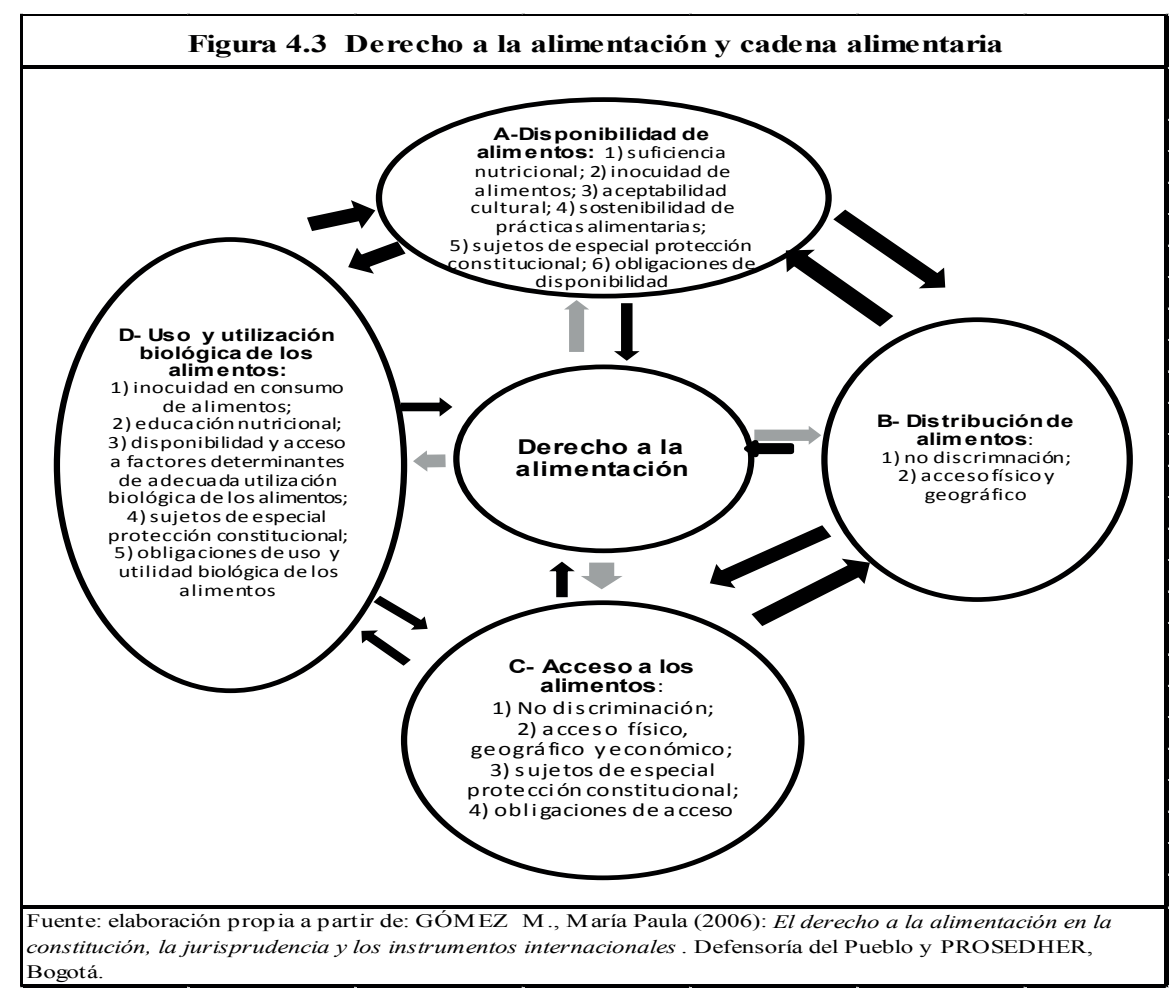

y decretos municipales, normas regiolocales y políticas locales. Con las transferencias fiscales automáticas del Gobierno nacional a los subnacionales, se tienen porcentajes obligatorios por invertir en cada municipio, para cumplir con el derecho en cuestión.

Sin embargo, estas inversiones públicas no se hacen desde una visión de desarrollo local o regional, sino que impulsan ejecuciones presupuestales públicas a través de los planes de desarrollo municipal y departamental. Si las inversiones públicas presentaran una visión de desarrollo, generarían dinámicas con valor agregado local y regional, a través de alimentos en fresco de tipo regiolocal, con un mayor nivel de nutrición a partir de sus productos y la cultura local.

\subsection{EL CÍRCULO VICIOSO DEL DERECHO A LA ALIMENTACIÓN}

Frente al desarrollo de este derecho, hay un círculo vicioso, en la medida en que las poblaciones afectadas por hambre física son las que estructuralmente sufren la ausencia de políticas públicas sociales claras y de mecanismos de redistribución de ingresos. Esto deriva en una cadena de pobreza-hambre-malnutrición-enfermedad, lo cual trae coyunturalmente políticas internacionales, nacionales, regionales y locales para atacar 
este problema, mediante la promoción del acceso a los alimentos y la salud con diversas acciones, pero sin solución de fondo.

Las acciones a veces llegan tarde, pues los problemas generados por la falta de una alimentación adecuada conllevan enfermedades irreversibles: "Casi una tercera parte del total de los niños de los países en desarrollo sufre un retraso del crecimiento y su estatura es muy inferior al promedio normal de los niños de su edad, lo que indica una subnutrición crónica"199. Las implicaciones para el resto de la vida de estos individuos y la sociedad son graves, pues se ataca un problema con salud pública mientras el daño no ha sido reparado.

Esta incoherencia grave de la política pública, que busca soluciones que mitigan el problema, requiere promover políticas que tengan en cuenta el ciclo de vida e identifiquen donde aplicar acciones de prevención más que las de curación, esto es, acciones de prevención y coordinación a través de una visión integral de desarrollo. Allí el Estado debe cumplir con el derecho a la alimentación.

\subsubsection{Recapitulación}

En este capítulo se analizaron tres componentes integrados al derecho a la alimentación. El primero explica los elementos desde el derecho, provenientes de derechos generales y abstractos, y específicos y concretos, los cuales identifican los compromisos de la sociedad y la exigibilidad al Estado para aplicarlos. El argumento de la política se determina a partir del enfoque de derechos, y diferencia las acciones por los derechos de los individuos, base del derecho a la alimentación.

En segundo lugar, se han repasado diferentes compromisos legales del Estado de acuerdo con las propuestas de la política internacional sobre el derecho a la alimentación, que se expresan en varias cumbres internacionales, las cuales relacionan la temática directa o indirectamente. Allí, el Estado se convierte en garante de las acciones nacionales, al integrarlas desde el plano constitucional, las leyes o los diseños de política, en función de cumplir con el compromiso de proteger el derecho a la alimentación.

Por último, se analizan los elementos que afectan el derecho a la alimentación en forma general y a través de algunos eslabones de la cadena alimentaria.

199 FAO (2004): El estado de la inseguridad alimentaria en el mundo... Op. cit., pág. 8 



\title{
CAPÍTULO V. LA SOBERANÍA ALIMENTARIA
}

\begin{abstract}
"Nuestro concepto de soberanía permite a la gente pensar por ellos mismos, sin ningún modelo agrícola o social impuesto, y vivir en solidaridad entre todos. Esta soberanía significa acceso independiente a los alimentos: ser autosuficientes y escoger lo que uno se va a comer, [...] la solidaridad, el intercambio cultural y el comercio justo son bienvenidos" ${ }^{200}$.
\end{abstract}

$\mathrm{E}$ n este capítulo se revisan dos aspectos: el primero analiza las relaciones y los elementos generales del concepto de soberanía, vinculada con el Estado nacional, las políticas de cada momento hasta la situación actual del Estado red y sus responsabilidades con los diferentes niveles de gobierno; el segundo aborda tres elementos específicos relacionados con la soberanía alimentaria: el territorio, el comercio y las empresas transnacionales, y las políticas públicas SAN.

\subsection{ELEMENTOS GENERALES DE LA SOBERANÍA}

El referente para la comprensión de la soberanía parte de la caracterización del nuevo Estado planteada por Castells:

Existe realmente una crisis del Estado nación como entidad soberana. [...] Hemos asistido a la transformación del Estado nación soberano que surgió en la Edad Moderna en una nueva forma de Estado: lo que he conceptualizado como Estado red. El nuevo Estado red se caracteriza por compartir la soberanía y la responsabilidad entre distintos Estados y niveles de gobierno ${ }^{201}$.

Esta caracterización de "compartir la soberanía", diferente al concepto referido al Estado como poder y ordenación ${ }^{202}$, identifica la soberanía en los términos de Heller, quien la define así:

200 BOVÉ, José, citado en DESMARAIS, Anette A. (2007): La vía campesina, la globalización y el poder del campesinado. Editorial Popular, Madrid, pág. 56.

201 CASTELLS, Manuel (2010): Comunicación y poder. Alianza Editorial, Madrid, págs. 69-70.

202 No se entra en las discusiones sobre dónde se encuentra el soberano y de qué tipo de soberano se habla en términos políticos; solamente se hace referencia a la soberanía vinculada con los Estados nacionales, su capacidad de manejo interno de los territorios y las relaciones con otros de su tipo. 
La capacidad, tanto jurídica como real, de decidir de manera definitiva y eficaz en todo conflicto que altere la unidad de cooperación socialterritorial. [...] La soberanía supone un sujeto de derecho capaz de voluntad y de obrar que se impone regularmente a todos los poderes, organizados o no, que existen en el territorio; lo que significa que tiene que ser un poder de ordenación territorial de carácter supremo y exclusivo ${ }^{203}$.

Por tanto, se redefinen las funciones de los Estados nacionales por las relaciones entre ellos, a partir de su "capacidad, tanto jurídica como real, de decidir", lo cual vincula al país y a sus reglas con el entorno internacional:

El Estado, como organización territorial soberana, es creador supremo de las normas y tiene el monopolio del poder de coacción física legítima, la última ratio de todo poder. [...] La soberanía del Estado no es más que la consecuencia necesaria de su función social ${ }^{204}$.

Desde esta orientación, la soberanía se vincula al Estado nacional al cumplir con su función social. La evolución del concepto es un elemento del pensamiento político, y hoy es la idea del Estado territorial autónomo, modo de organización política que conlleva problemas en su accionar, pues las instituciones globales inciden en las acciones de los Estados nacionales:

La soberanía se concentra intensamente en un único nivel: los estados. Para aproximadamente cada ser humano, y para casi cada fragmento de territorio hay exactamente un gobierno con autoridad preeminente sobre, y con responsabilidad primordial por, esta persona o territorio. [...] Los gobiernos controlan y dominan el proceso de toma de decisiones de las subunidades políticas, así como las decisiones supranacionales que se suelen adoptar mediante negociación intergubernamental ${ }^{205}$.

203 HELLER, Herman (1987): Teoría del Estado. Fondo de Cultura Económica, México, pág. 262.

204 Ibíd., pág. 264.

205 POGGE, Thomas (2005): La pobreza en el mundo y los derechos humanos. Paidós, Barcelona, pág. 227. 
Actualmente, la soberanía está mediada por organizaciones globales que fijan y siguen las políticas para los niveles nacionales y locales de cada gobierno. Su incidencia se da según el tipo de Estado, su nivel de desarrollo y control sobre la economía del mundo, lo cual sugiere que hay unos Estados más soberanos que otros. A su vez, el concepto de soberanía vincula Estado, territorio y poder; y cuando se analiza el territorio "es imposible comprenderlo sin concebir las relaciones de poder que determinan la soberanía" ${ }^{206}$. Desde esta línea, deben tenerse en cuenta la capacidad y autonomía de las naciones, los territorios, los gobiernos, las comunidades y los individuos, para tomar la decisión de usar los territorios para sembrar alimentos u otras actividades más rentables.

Los criterios sobre SAN y soberanía alimentaria de las políticas han de ver la nueva situación local, municipal, distrital, metropolitana, departamental, regional, nacional e internacional, así como los conflictos entre las políticas públicas de los diferentes niveles de gobierno y los organismos globales; por tanto, debe construirse una política de Estado con los elementos generales de la soberanía y sus instrumentos estratégicos, como la política pública de seguridad nacional que aplican los países desarrollados, y que en el orden interno se resuelvan los conflictos intergubernamentales de las decisiones sobre SAN.

\subsection{ELEMENTOS ESPECÍFICOS DE LA SOBERANÍA ALIMENTARIA}

Este concepto ${ }^{207}$ busca integrar dinámicas de autonomía y derechos, además de resolver preguntas como: ¿qué alimentos producir?, ¿dónde producirlos?, ¿entre quiénes

206 MANCANO F, Bernardo (2009): “Territorio, teoría y política”. En Las configuraciones de los territorios rurales en el siglo XXI. Pontificia Universidad Javeriana, Bogotá, pág. 41.

207 Este se hizo público como resultado de la conferencia internacional de laVía Campesina, en Tlaxcala, México, en abril de 1996. Los delegados decidieron que deseaban una representación adecuada en ocasión de la Conferencia Técnica Internacional sobre Recursos Filogenéticos ,celebrada en Leipzig, Alemania, en junio de 1996, y de la Cumbre Mundial sobre la Alimentación, celebrada en Roma en noviembre del mismo año, así como en los foros paralelos de las organizaciones de la sociedad civil (OSC). El objetivo era animar a las organizaciones no gubernamentales (ONG) y a las OSC a discutir alternativas a las propuestas neoliberales, para alcanzar la seguridad alimentaria. Allí, la definición de soberanía alimentaria está determinada por "el derecho de las persona a alimentos adecuados desde el punto de vista saludable y cultural, obtenidos a través de métodos sostenibles y ecológicos, y su derecho a definir sus propios sistemas alimentarios $y$ agrícolas".

CUÉLLAR P., Mamen y SEVILLA G., Eduardo (2013): "La soberanía alimentaria: la dimensión política de la agroecología”. En Procesos hacia la soberanía... Op. cit., pág. 20. 
producirlo?, ¿cuáles distancias implican costos ambientales mínimos en el transporte de los alimentos? Estas preguntas orientan la necesidad de ubicar espacios de producción de alimentos acordes con culturas y territorios cercanos, que permiten conocer las condiciones de producción. Duch considera al respecto:

La perca del Nilo, a veces vendida como mero, llega a Europa desde el lago Victoria, en el centro de África. Brasil ya es el máximo exportador mundial de pollos; al igual que Chile lo es en el negocio de criar, engordar y repartir salmones por el mundo entero. Los pepinos de España viajan a Holanda en invierno; en verano hacen la ruta en sentido contrario. Los espárragos de Navarra solo se envasan en Navarra una vez llegan allí procedentes de Perú o China. El filete de panga que sirven a la hora de las comidas en las escuelas españolas viajó desde Vietnam, el atún enlatado con marcas hispanas proviene de El Salvador o los mares de Somalia, donde se pesca sin pedirle permiso a nadie $[. .$.$] ¿necesitamos correr riesgos?, ¿todos los$ alimentos han de tener pasaporte para recorrer el mundo?208

Cuando se desconocen las formas y tecnologías con las cuales se producen los alimentos que se consumen, surge la pregunta: ¿hasta dónde estamos preparados para enfermedades desconocidas? Hoy se reconocen nuevas mutaciones y cambios de gérmenes productores de comida:

[Hay] métodos de cultivo agrícola [que] afectan negativamente la calidad de nuestros alimentos. El objetivo, ahora más que nunca, es producir y producir, no importa las herramientas que se utilicen (pesticidas, fertilizantes químicos, aditivos sintéticos durante el procesado) aunque, además de intoxicar, jueguen con la genética o modifiquen la composición del terreno 209 .

Ante estas circunstancias y preguntas, el movimiento globalVía Campesina ha expuesto las bases de una propuesta organizativa para el manejo de los alimentos agropecuarios

208 DUCH, Gustavo (2011): Alimentos bajo sospecha. Editorial Los Libros del Lince, Barcelona, págs. 11 y 53.

209 HERNÁNDEZ R., Felipe (2010): Que tus alimentos sean tu medicina (7. . ed.). RBA Libros, Barcelona, pág. 27. 
que incluya a los campesinos y se enfrente a las tendencias mundiales de los agronegocios y el control monopólico de los agroalimentos, que buscan solamente lucro en los resultados del producto, el alimento, la semilla, el gen o el insumo producido ${ }^{210}$.

Hoy la soberanía alimentaria busca el derecho a "controlar las políticas, la distribución de recursos y la toma de decisiones nacional e internacional para todos aquellos que se ven directamente afectados por estas políticas" ${ }^{211}$. Las acciones para construir estas políticas públicas deben hacerse colectivamente en y desde los territorios. Los elementos comunes de la soberanía y la seguridad alimentaria se muestran en la tabla $5.1^{212}$.

\begin{tabular}{|c|c|c|c|c|c|c|c|c|c|}
\hline \multicolumn{10}{|c|}{ Tabla 5.1. Elementos comunes en soberanía y seguridad alimentaria } \\
\hline $\begin{array}{c}\text { 1. Priorizar } \\
\text { producción } \\
\text { agrícola } \\
\text { saludable } \\
\text { local. }\end{array}$ & $\begin{array}{l}\text { 2. Acceso a: pequeños } \\
\text { productores, pastores, } \\
\text { pescadores artesanales y } \\
\text { personas sin tierra a: } \\
\text { tierra, agua, semillas, } \\
\text { razas de animales y } \\
\text { crédito, reforma agraria; } \\
\text { lucha contra los OGM y } \\
\text { las patentes sobre } \\
\text { semillas, razas de } \\
\text { animales y genes; del } \\
\text { libre acceso a áreas de } \\
\text { pesca para pescadores } \\
\text { artesanales. }\end{array}$ & $\begin{array}{c}\text { 3. El } \\
\text { derecho de } \\
\text { pequeños } \\
\text { productores } \\
\text { a producir } \\
\text { alimentos. }\end{array}$ & $\begin{array}{c}\text { 4. El derecho } \\
\text { de } \\
\text { consumidores } \\
\text { a decidir qué } \\
\text { consumen, } \\
\text { cómo y por } \\
\text { quién es } \\
\text { producido. }\end{array}$ & $\begin{array}{l}\text { 5. El derecho de los } \\
\text { países a protegerse } \\
\text { de importaciones } \\
\text { agricolas y de } \\
\text { alimentos tasados } \\
\text { por debajo de su } \\
\text { valor,detener todas } \\
\text { las formas de } \\
\text { dumping. Costos } \\
\text { agricolas vinculados } \\
\text { a costos de } \\
\text { producción. }\end{array}$ & $\begin{array}{c}\text { 6. La } \\
\text { participación } \\
\text { de la } \\
\text { población en } \\
\text { la toma de } \\
\text { decisiones } \\
\text { en política } \\
\text { agrícola. }\end{array}$ & $\begin{array}{c}7 . \\
\text { Reconocer } \\
\text { derechos } \\
\text { de las } \\
\text { mujeres } \\
\text { productoras }\end{array}$ & $\begin{array}{c}\text { 8. La } \\
\text { agroecologia } \\
\text {, forma de } \\
\text { producir } \\
\text { alimentos y } \\
\text { medios de } \\
\text { vida } \\
\text { sostenibles. }\end{array}$ & $\begin{array}{c}\text { 9. Políticas de } \\
\text { comercio y } \\
\text { acceso a } \\
\text { insumos } \\
\text { agrícolas, } \\
\text { soberanía } \\
\text { sobre semillas } \\
\text { y razas de } \\
\text { animales. }\end{array}$ & $\begin{array}{c}\text { 10. Rechazo } \\
\text { a todas las } \\
\text { formas de } \\
\text { monopolizar } \\
\text { y privatizar } \\
\text { recursos } \\
\text { públicos } \\
\text { como el } \\
\text { agua. }\end{array}$ \\
\hline
\end{tabular}

La soberanía alimentaria determina las acciones autónomas de un Estado, una sociedad, una organización comunitaria o una población, realizadas en un territorio para procurar sus alimentos. La posibilidad de los países para producir de manera autónoma los bienes agroalimentarios que su población demanda implica resolver democrática e internamente estas preguntas: ¿qué producir?, ¿cómo producir? y ¿dónde deben producirse los alimentos que demanda su población? De esta forma, se llega a un

210 WINDFUHR, Michael y JONSÉN, Jennie (2005): Soberanía alimentaria: hacia la democracia en sistemas alimentarios locales. FIAN-Internacional, pág.74

211 Ibíd., pág. 35

212 En esta dirección, Altieri considera los mismos elementos. ALTIERI, Miguel A. (2010): “¿Por qué la agricultura campesina? Agroecología, movimientos sociales y políticas a favor de la soberanía alimentaria”. En ¿Cambio de rumbo en las políticas agrarias latinoamericanas? Estado, movimientos sociales campesinos y soberanía alimentaria. Icaria, Barcelona. 
acuerdo nacional entre los diferentes actores, en términos de cantidades, calidades y precios, para suplir esta necesidad ${ }^{213}$.

La desarticulación en el manejo de la soberanía alimentaria como política de gobierno se expresa así: el Gobierno central maneja el sector externo, lo cual afecta la producción de agroalimentos en los territorios, en la medida en que decide qué importar, y lo hace independiente de los procesos de desarrollo regiolocal impulsados por las acciones públicas de los gobiernos subnacionales.

\subsubsection{Soberanía alimentaria y territorio}

La argumentación de la seguridad alimentaria se relaciona con la soberanía alimentaria en los espacios regiolocales, que son determinantes para desarrollar las acciones al respecto. A su vez, enfatiza el criterio de cercanía de productores y consumidores, fundamental para la sostenibilidad, como lo plantea Altieri:

El concepto emergente de Soberanía Alimentaria enfatiza el acceso de los agricultores a la tierra, las semillas y el agua, se enfoca en la autonomía local, los mercados y ciclos de consumo y producción local, la soberanía energética y tecnológica, y las redes de campesino a campesino ${ }^{214}$.

El criterio de cercanía entre producción y consumo de alimentos a través de la soberanía alimentaria conlleva el mejoramiento del trabajo campesino y la nutrición urbana. Las escalas de producción y comercialización de alimentos requieren materializar lo planteado porVía Campesina:

Dar prioridad a la producción de alimentos saludables, de buena calidad y culturalmente apropiados en primer lugar para el mercado

213 En términos de Montagut yDogliatti: "La soberanía alimentaria es el derecho de los pueblos, de sus países o uniones de estados a definir su política agraria y alimentaria, [...] adquiere su sentido en ámbitos locales, nacionales o regionales, que es donde debe ir dirigida fundamentalmente la producción de alimentos" (MONTAGUT, Xavier y DOGLIATTI, Fabricio [2006]: Alimentos globalizados, soberanía alimentaria y comercio justo. Icaria, Barcelona, pág. 110.

214 ALTIERI, Miguel A. (2010): “¿Por qué la agricultura campesina? Agroecología, movimientos sociales y políticas a favor de la soberanía alimentaria”. En ¿Cambio de rumbo en las políticas agrarias latinoamericanas? Estado, movimientos sociales campesinos y soberanía alimentaria. Icaria, Barcelona, pág. 29. 
doméstico. Es fundamental mantener una capacidad de producción de alimentos basados en un sistema de producción agrícola diversificado, [...] suministrar precios competitivos para los agricultores, [...] desarrollar una producción sostenible basada en la familia agraria, $[\ldots]$ abolir cualquier ayuda a la exportación directa o indirecta ${ }^{215}$.

Lo anterior constituye la base de la propuesta para cambiar de modelo agroindustrial de grandes extensiones para exportar y sustituir alimentos por biocombustibles, dinámica que conlleva unas relaciones sociales en las zonas rurales que conducen a más pobreza para la mayoría y riqueza para los pocos dueños de los agronegocios. Desde esta óptica, cambiar en la tendencia del modelo de producción y comercialización de agroalimentos en gran escala implica realizar varias acciones:

Frenar la espiral creciente de la pobreza, los salarios bajos, la migración rural y urbana, el hambre y la degradación ambiental.Los movimientos rurales sociales abrazan el concepto de Soberanía Alimentaria como una alternativa al modelo neoliberal que promueve un comercio internacional injusto para solucionar el problema alimentario mundial. La Soberanía Alimentaria se enfoca en la autonomía local, los mercados locales, los ciclos locales de producción-consumo ${ }^{216}$.

Según estas condiciones, hay vías alternas para construir desarrollo regiolocal, con los mínimos de demandas de agroalimentos de la población de los ejes dinamizadores, en la medida en que estos vinculan alimentos frescos de sus regiones, que integran productores y productos regiolocales con manejos culturales de la alimentación. En esta línea, Montagut propone parámetros de cercanía y pequeñas escalas que prioricen "las necesidades humanas. [...] El control de la alimentación por parte de la población, de los agricultores y de los consumidores es el núcleo de la estrategia de la Soberanía Alimentaria” ${ }^{217}$. Este núcleo integra, en lo regiolocal, los alimentos saludables, la democracia económica y la gestión del territorio por la apropiación y reapropiación de las poblaciones.

215 DESMARAIS Annette A. (2007): La Vía Campesina. La globalización y el poder del campesinado. Editorial Popular, Madrid, pág. 56.

216 ALTIERI, Miguel A. (2010): ¿Por qué la agricultura campesina? Agroecología... Op. cit., pág. 39. 217 MONTAGUT, Xavier (2010): “Introducción”. En ¿Cambio de rumbo en las políticas agrarias latinoamericanas? Estado, movimientos sociales campesinos y soberanía alimentaria. Icaria, Barcelona, pág. 15. 
Estas propuestas conforman una acción de política soberana, con intervenciones a través de la SAN en el proceso de acceso a los alimentos:

La producción de alimentos en huertas familiares o comunitarias no solamente brinda alimentos que la agricultura industrial generalmente no puede ofrecer, sino también un grado de dignidad, cooperación e independencia, [...] la soberanía alimentaria implica que el sistema alimentario mundial debería dar un giro de 180 grados. Han sido los campesinos, los pescadores tradicionales, los pastores y los pueblos indígenas quienes han alimentado al mundo desde hace miles de años. Para lograr un mundo sin hambre, un mundo donde todos y todas tengan acceso a alimentos nutritivos producidos localmente ${ }^{218}$.

Además, la seguridad alimentaria hoy requiere que las acciones de política pública que conduzcan a la soberanía alimentaria tengan en cuenta este panorama:

La producción de alimentos, base de la subsistencia humana, ya no está amenazada por ejércitos feudales, sino por un modelo industrial arrasador y por un puñado de multinacionales. La tierra, el agua, las semillas, la biodiversidad, los vitales recursos de la naturaleza se han transformado en mercancías sujetas a las rígidas leyes del mercado. Nuestra libertad y nuestros derechos, como ciudadanos y consumidores, están en entredicho desde hace tiempo. Y los agricultores de todo el mundo, los defensores de la tierra, están en la primera línea de una lucha de toda la población por defender la tierra, su cosecha, el territorio y el derecho a la soberanía alimentaria ${ }^{219}$.

De esta forma, es necesario pensar las intervenciones públicas en cada país, de cara a la SAN y la soberanía alimentaria, en función de potenciar el desarrollo territorial. Ello implica vincular la producción de agroalimentos con la cercanía al mercado regiolocal de consumo, proceso que, en varios casos, puede lograrse sin llegar a la autarquía.

218 GRAIN. "Soberanía alimentaria y sistema alimentario mundial. Respuesta al viaje de Chirac por África Francófona”.

219 MONTAGUT, Xavier y DOGLIOTTI, Fabricio (2006): Alimentos globalizados... Op. cit., pág. 14. 


\subsubsection{Soberanía alimentaria, comercio y empresas transnacionales}

Es necesario analizar ahora el comercio internacional en medio de la globalización, de forma tal que no suceda lo de mediados del siglo XIX en América Latina, por la especialización de las ventajas comparativas:

La comida, la necesidad más elemental de las personas, se subordina a las normas y regulaciones del comercio internacional; el comercio es como un Dios, nada debe interferirle, ni siquiera la comida; un país no puede adoptar unas leyes que le permitan alimentar a su población si esas leyes contravienen el llamado "comercio libre" 220 .

Estos no pueden ser los principios que rijan el comercio para los agroalimentos; es necesario ver las condiciones del país en su conjunto, que se resuelva la cuestión alimentaria con sus recursos utilizados productivamente, y no solo a partir de los agronegocios ubicados en otros países. En otras palabras, significa promover diferentes formas de producción de agroalimentos regiolocales como resistencia a la homogenización globalizadora de las multinacionales:

[Debe dársele] prioridad a la producción de subsistencia y culturalmente apropiada de alimentos sanos, nutritivos, de buena calidad y a precios razonables, para el mercado interno y los mercados subregionales y regionales. La liberalización actual del comercio, que deja en mano de las fuerzas del mercado y poderosas empresas transnacionales las decisiones acerca de qué y cómo se producen y se comercializan los alimentos ${ }^{221}$.

Esto exige nuevas relaciones y condicionamientos de los gobiernos y las sociedades locales y regionales, para aplicar políticas de Estado con criterios sociales de largo plazo, y no solo cuestiones comerciales inmediatas. Esta es base del desarrollo regiolocal para comunidades y territorios vulnerables, si se aplica el principio de Mandeley: "La alimentación es una fuente de nutrición y solamente en segundo

220 MADELEY, John (2003): El comercio del hambre, el precio que pagan los pobres por el comercio libre. Intermón Oxfam, Barcelona, pág. 15.

221 NANSEN, Karin (2002): Nuestro mundo no está en venta... Op. cit., pág. 20. 
lugar un artículo de comercio" 222 . Por su parte, en México, Barkin y Suárez consideran:

[La sociedad] ha dejado de ser autosuficiente en productos agropecuarios. Ya todo el pan y la tortilla no se manufacturan con materias primas hechas en el país. [...] No obstante la pérdida de la autosuficiencia no es exclusivamente un fenómeno nacional. Es también un problema de individuos que tradicionalmente se han organizado para procurar un alto grado de seguridad personal con la producción local o regional de los víveres y otros bienes necesarios para su supervivencia. La internacionalización del capital hace más dificil seguir con esta estrategia ${ }^{223}$.

Aparece ahora un nuevo elemento en esta apreciación: la supervivencia como mecanismo de solución individual y temporal para producir agroalimentos. Es necesario, por tanto, aportar para construir colectivamente esta resistencia. Además, se requiere diferenciar entre autosuficiencia por barreras naturales y producción soberana de alimentos, resultado de la protección de los Estados. En suma, se requieren prácticas limpias y saludables de los pequeños productores, con bajos costos ambientales por cercanías y bajos precios por costos de transporte, no por dumping. La discusión sobre la soberanía alimentaria y nutricional frente a las apuestas nacionales, regiolocales y globales se presenta en un momento crucial:

[La soberanía alimentaria está] socavada por las instituciones multilaterales y por el capital especulativo. El control cada vez mayor de las empresas multinacionales sobre las políticas agrícolas ha sido facilitado por las políticas económicas de las organizaciones multilaterales tales como la OMC, El Banco Mundial y el FMI. Por lo tanto, se requiere de la regulación y el establecimiento de impuestos sobre el capital especulativo y el cumplimiento estricto de un Código de Conducta para las ETNs ${ }^{224}$.

222 WINDFUHR, Michael y JONSÉN, Jennie (2005): Soberanía alimentaria, hacia la democracia en sistemas alimentarios locales. FIAN-Internacional, pág. 62

223 BARKIN, David y SUÁREZ, Blanca (1986): El fin de la autosuficiencia alimentaria. Centro de Ecodesarrollo Océano, México, pág. 227.

224 Ibíd., pág. 76. 
Estas condiciones de incertidumbre las reiteran países con intereses especiales para continuar así; más aún, cuando el clúster agroalimentario global está caracterizado por una dinámica de concentración empresarial "que comprende empresas del sector químico, de construcción de maquinaria agrícola, centros de investigación de biotecnología, la distribución en grandes superficies y los fondos de inversión que aportan a capital para el acaparamiento de tierras" 225 . La tabla 5.2 relaciona la alta concentración de la industria agroalimentaria mundial en diferentes partes de la cadena.

Además de lo anterior, los condicionamientos políticos para la firma de los tratados entre países no se hacen entre iguales:

El Presidente [de los EE.UU.] puede [...] retirar o suspender la designación de un país como beneficiario del ATPDEA [o] retirar, suspender o limitar la aplicación del tratamiento preferencial. Si, luego de esa designación, el Presidente determina que, como resultados de un cambio en las circunstancias, la actuación de dicho país no es satisfactoria ${ }^{226}$.

\begin{tabular}{|c|c|c|c|}
\hline \multicolumn{4}{|c|}{$\begin{array}{c}\text { Tabla 5.2. Los } 30^{*} \text { gigantes de la industria } \\
\text { agroalimentaria mundial }\end{array}$} \\
\hline Agroquímica & Semillas & $\begin{array}{c}\text { Producción y } \\
\text { comercio } \\
\text { agrícola }\end{array}$ & $\begin{array}{l}\text { Distribución, } \\
\text { grandes } \\
\text { superficies }\end{array}$ \\
\hline Bayer & Monsanto & Cargill & \multirow{6}{*}{$\begin{array}{c}\text { Wall Mart } \\
\text { Carrefour } \\
\text { Tesco } \\
\text { Swarz Group } \\
\text { Aldi } \\
\text { Kruger } \\
\text { Rewe Group } \\
\text { Metro } \\
\text { Edeka }\end{array}$} \\
\hline \multicolumn{2}{|c|}{ Dupont } & Bunge & \\
\hline \multirow{4}{*}{$\begin{array}{l}\text { Bristol } \\
\text { Meyers }\end{array}$} & \multirow{4}{*}{ Sygenta } & Chiquita & \\
\hline & & Archer Daniels & \\
\hline & & Del Monte & \\
\hline & & Dole Food & \\
\hline \multicolumn{4}{|c|}{$\begin{array}{l}\text { Fuente: Red de Investigación y Observatorio de la Solidaridad (2013): } \\
\text { Soberanía alimentaria: /ecciones desde la experiencia en Latinoamérica. } \\
\text { Tirant Humanidades, Valencia, pág. } 31 \text {. *Las } 10 \text { que no están, representan } \\
\text { alimentos envasados y dispensadores de comidas. }\end{array}$} \\
\hline
\end{tabular}

Es evidente la desigualdad de estas cláusulas en los tratados, que formalmente son entre países iguales, pero en las dinámicas reales de negociación son asimétricos y afectan las condiciones de negociación.

225 Red de Investigación y Observatorio de la Solidaridad (2013): Soberanía alimentaria: lecciones desde la experiencia en Latinoamérica. Tirant Humanidades, Valencia, pág. 28.

226 FAO y Comunidad Andina (2004): Comunidad Andina: factores macroeconómicos, comerciales, sectoriales y la seguridad alimentaria. Pág. 78. 


\subsubsection{Soberanía alimentaria y la política pública de SAN}

El criterio de soberanía alimentaria emitido por el Foro Mundial de La Habana (2001), es estratégico para diseñar una política pública en seguridad alimentaria nutricional en el nivel nacional:

Entendemos por soberanía alimentaria el derecho de los pueblos a definir sus propias políticas y estrategias sustentables de producción, distribución y consumo de alimentos que garanticen el derecho a la alimentación para toda la población. [...] La soberanía alimentaria implica el reconocimiento a la multietnicidad de las naciones y el reconocimiento y valoración de las entidades de los pueblos originarios. Esto implica, además, el reconocimiento al control autónomo de sus territorios, recursos naturales, sistemas de producción y gestión del espacio rural, semillas, conocimientos y formas organizativas ${ }^{227}$.

La política pública en SAN debe configurarse a partir de una política estratégica de seguridad nacional del Estado, para que haya soberanía alimentaria en condiciones de globalización, donde las relaciones entre lo global, lo regional, lo nacional y lo local exigen más autonomía para los territorios, lo que implica una discusión que parta de principios diferentes a la rentabilidad económica. En este sentido, la soberanía y la seguridad alimentarias son conceptos integrales que construyen autonomías e integración de los gobiernos para las acciones públicas.Y aquí cabe la propuesta de Podge para construir la soberanía alimentaria: "Necesitamos centralización y descentralización [...] donde las personas deberían ser ciudadanas de, y gobernarse a sí mismas por medio de, un abanico de unidades políticas de diferente tamaño" ${ }^{228}$.

Para el concepto de soberanías como expresiones individuales y territoriales, en el marco de diferentes gobiernos con autonomía local y regional229, se insiste desde la

227 Foro Mundial de La Habana (2001): “Declaración final sobre soberanía alimentaria”. En Con la comida no se juega. Transgénico vs. soberanía alimentaria. FICA, Bogotá, págs. 183 y ss.

228 POGGE, Thomas (2005): La pobreza en el mundo y los derechos... Op. cit., pág. 227.

229 Se insiste en que esta situación no implica autarquía de los territorios, sino que requiere acuerdos mínimos sobre las condiciones de cada contexto territorial. 
academia, las instituciones, los gobiernos y las organizaciones sociales en la importancia de la cercanía de la fase de disponibilidad de agroalimentos con la de acceso y uso biológico. En Colombia, la seguridad y soberanía alimentarias se consideraron en el marco de la Asamblea Constituyente, y se adoptaron por la Corte Constitucional en los siguientes términos:

\begin{abstract}
El grado de garantía que debe tener toda población, de poder disponer y tener acceso oportuno y permanente a los alimentos que cubran sus requerimientos nutricionales, tratando de reducir la dependencia externa y tomando en consideración la conservación y equilibrio del ecosistema para beneficio de las generaciones futuras ${ }^{230}$.
\end{abstract}

Esta orientación es estratégica para impulsar el desarrollo territorial, y su aplicación varía en función de cada territorio con tres componentes: requerimientos nutricionales, disminución de la dependencia externa y conservación del equilibrio del ecosistema, y no solo los costos económicos. De hecho, hay formas colectivas y comunitarias para resolver los problemas de seguridad alimentaria y la soberanía, a partir de las relaciones soberanas, donde en muchos casos las comunidades indígenas, los campesinos, los colonos y los afrodescendientes tienen el manejo de la seguridad alimentaria como forma de subsistir.

En esta dirección, uno de los mayores problemas que afecta los componentes de la soberanía y la seguridad alimentaria en Colombia está relacionado con la tendencia a la mayor concentración de la propiedad de la tierra en las zonas rurales, lo cual afecta la disponibilidad y el acceso a los pequeños productores campesinos (ver capítulo VII, disponibilidad por ejes):

De los 2.4 millones de propietarios de predios privados que hay en el campo colombiano, apenas 91.200 (el 3.8 por ciento) tienen más de 200 hectáreas. Sin embargo, sus terrenos abarcan el 41 por ciento de toda la superficie registrada. En contraste, los 943.200 dueños de menos de 3 hectáreas ( 39 por ciento de los propietarios) reúnen solamente el 3.7 por ciento de toda la base catastral ${ }^{231}$.

230 Corte Constitucional de Colombia (1998): Sentencia C-678 de 1998.

231 El Tiempo (2011, 9 de octubre): “El país tiene cada vez más terratenientes”. Pág. 9. 
En esta situación de inequidad se busca ingresar a mercados globales, a través del TLC con varios países desarrollados. Esta inequidad se amplía en los estudios de caso del capítulo VII (apartado 7.2.3).

\subsubsection{Recapitulación}

Hasta ahora se han relacionado los conceptos actuales de la soberanía y el Estado nacional, la soberanía alimentaria y sus vínculos esenciales con la producción de alimentos, el trabajo, el territorio, el comercio, las empresas transnacionales, el medioambiente. Se finaliza el capítulo con la relación que articula la soberanía alimentaria con el gobierno como aspecto inicial para el debate alimentario y las políticas públicas nacionales y su ejecución en los territorios. 
TERCERA PARTE

TERRITORIOS, CADENA ALIMENTARIA Y SAN

\section{CAPÍTULO VI. TERRITORIO Y NUEVAS CONDICIONES}

$\mathrm{E}$ ste capítulo vincula territorio y alimentos a partir de: a) analizar la revalorización de los territorios hoy, en relación con los nuevos procesos económicos y las condiciones ambientales; b) relacionar territorio y agroalimentos, considerando la forma en que el hombre se apropia y periodiza sus relaciones sociales, históricas, económicas, políticas y tecnológicas, y las integra para producir agroalimentos; y c) relacionar las formas de la institucionalidad colombiana para intervenir e identificar el conflicto agrario, que parte de apropiar estos territorios para producir agroalimentos o agrocombustibles.

\subsection{REVALORIZACIÓN DEL TERRITORIO}

Las preguntas que orientan este apartado son: ¿por qué hay revalorización del territorio? y ¿cuáles son los nuevos elementos del desarrollo territorial? Responderlas requiere ver las nuevas condiciones generales del capitalismo, las empresas transnacionales, la relación entre la globalización y los alimentos, la relación entre las instituciones y la globalización, y los cambios en las acciones del Estado.

\subsubsection{Nuevas condiciones generales del capitalismo}

Desde el siglo XVI, el capitalismo presenta dos procesos relacionados entre la “economía-mundo" y las estructuras menores del Estado. Wallerstein argumenta en este sentido:

La característica distintiva de una economía-mundo capitalista es que las decisiones económicas están orientadas primariamente hacia la arena de la economía-mundo, mientras que las decisiones políticas están orientadas principalmente hacia las estructuras menores que 
tienen control legal, los Estados (naciones-Estado, ciudades-Estado, imperios), en el seno de la economía mundo ${ }^{232}$.

Según lo anterior, se precisa el nacimiento y desarrollo del capitalismo, su estructura económica y sus procesos legales y organizativos, así como construir el Estado y estructurar la economía-mundo, en cuanto uno y otra sustentan la apropiación de riquezas a través de nuevas formas de enriquecimiento legalizadas y legitimadas por los Estados. El cambio de la Revolución Industrial modifica las relaciones capitaltrabajo, las funciones del Estado, las relaciones entre territorios, entre naciones y en el interior de estas. Estos procesos a fines del siglo XX y principios del XXI cambian las funciones de las relaciones territoriales con las políticas que hay sobre ellos. Al respecto, Castells plantea:

El mismo capitalismo ha sufrido un proceso de reestructuración profunda, caracterizado por una mayor flexibilidad en la gestión; la descentralización e interconexión de las empresas, tanto interna como en su relación con otras; un aumento de poder considerable del capital frente al trabajo, con el declive concomitante del movimiento sindical; una individualización y diversificación crecientes en las relaciones de trabajo; [...] la intervención del estado para desregular los mercados de forma selectiva y desmantelar el estado de bienestar; [...] la intensificación de la competencia económica global en un contexto de creciente diferenciación geográfica y cultural de los escenarios para la acumulación y gestión del capital ${ }^{233}$.

Por su lado, Negri y Hardt introducen el derecho, en las condiciones donde se construye el imperio, como "una nueva noción [...] o, más aún, una nueva inscripción de la autoridad y un nuevo diseño de la producción de normas e instrumentos legales de coerción que garanticen los contratos y resuelvan los conflictos" ${ }^{234}$. Señalan también las

232 WALLERSTEIN, Inmanuel (1979). El moderno sistema mundial... Op. cit., pág. 93. El aspecto de la "economía-mundo" es considerado por Amín como una visión europeizante: "El capitalismo europeo habría sido el primer sistema social en unificar el mundo, [...] las sociedades anteriores al siglo XVI no estaban aisladas”. AMÍN, Samir (1999): Los desafíos de la mundialización. Siglo XXI y UNAM, México.

233 CASTELLS, Manuel (1999): La era de la información: economía, sociedad y cultura (Vol I: La sociedad red). Siglo XXI Editores, México, págs. 27-28.

234 NEGRI, Toni y HARDT, Michael (2001): Imperio. Ediciones Desde Abajo, Bogotá, pág. 54. 
nuevas funciones del Estado bajo el capitalismo globalizado, la resolución de conflictos, la garantía de los contratos y la desregulación selectiva de mercados.

En una línea similar, la CEPAL explica respecto a las transformaciones del capitalismo:

[Estas se sustentan en] las sucesivas revoluciones tecnológicas y, muy en particular, de las que han logrado reducir los costos de transporte, información y comunicaciones, [...] el acceso masivo a la información solo se hace posible gracias a las tecnologías de información y comunicaciones ${ }^{235}$.

Sobre lo social, la CEPAL considera que, en América Latina, las políticas de desarrollo cambiaron la estructura productiva regional, urbana y rural, y redistribuyeron en el territorio la población del campo a la ciudad; por tanto, reestructuración profunda, nueva noción del derecho y cambio tecnológico son los ejes de hoy, pero las condiciones sociales no fueron integradas de la misma manera que las económicas, lo que resultó en crecimiento sin desarrollo:

La gran mayoría de los latinoamericanos vive en países en los que la desigualdad en la distribución del ingreso registró un aumento en el último cuarto del siglo XX, [...] el incremento de la desigualdad característico de la década de 1980 no se revirtió en la década de $1990^{236}$.

Estas situaciones afectan la seguridad alimentaria en disponibilidad y acceso. Elizalde considera sobre este problema:

La globalización hace emerger el cuadro local y lo valoriza, pues es en la escala local que las formas de organización productiva se consolidan, generando un fenómeno de territorialización como elemento determinante de la competitividad de los sistemas de producción ${ }^{237}$.

235 Cepal (2002): Globalización y desarrollo. Vigesimonoveno periodo de sesiones, Brasilia, Brasil, 6-10 de mayo, pág. 19.

236 Ibíd., pág. 85.

237 ELIZALDE HEVIA, Antonio (2003): Planificación estratégica territorial... Op. cit., pág. 11. 
Tabla 6.1. Caracteristicas de los procesos de integración y las etapas de expansión del capitalismo, el imperialismo y la globalización

\begin{tabular}{|c|c|c|c|c|}
\hline \multirow{2}{*}{ Periodo } & CEPAL* & WALLERSTEIN & DIAZARENA** & AMíN \\
\hline & \multicolumn{4}{|c|}{ Características Generales de Algunos de los Autores sobre la Globalización } \\
\hline $\mid \begin{array}{c}\text { Fines } 1400 \\
\text { y principios } \\
1500\end{array}$ & $\begin{array}{l}\text { Expansión capitalista único fenómeno } \\
\text { histórico con alcances globales, } \\
\text { desiguales, América Latina y el Caribe están } \\
\text { vinculados desde fines del siglo XV. }\end{array}$ & $\begin{array}{c}\text { Nació lo que podriamos llamar una } \\
\text { economia-mundo europea, sistema } \\
\text { social que el mundo no habia conocido } \\
\text { antes. Entidad económica pero no } \\
\text { política. Sistema Mundial porque es } \\
\text { mayor que cualquier unidad politica } \\
\text { juridicamente definida. La energía política } \\
\text { para asegurar derechos monopolísticos. }\end{array}$ & $\begin{array}{l}\text { Imperialismo mercantilista } \\
\text { S.XV-XVI-XVII-XVIII. S. XVI } \\
\text { relaciones de dominación } \\
\text { interpopulos, nuevos sujetos } \\
\text { estados-naciones, sometieron } \\
\text { pueblos extracontinentales con } \\
\text { función de proveedores en } \\
\text { mercantilismo. }\end{array}$ & $\begin{array}{l}\text { Las sociedades anteriores al siglo XVI no } \\
\text { estaban aisladas, sino que competian } \\
\text { entre si dentro de sistemas regionales (y } \\
\text { quizá incluso dentro de un sistema } \\
\text { mundial); Forma Mercantilista 1500- } \\
\text { 1800, Previa a Revolución Industrial } \\
\text { moldeada por capital mercantil. }\end{array}$ \\
\hline $1700-1800$ & \multicolumn{3}{|c|}{$\begin{array}{l}\text { ** Imperialismo Industrial, de fines Siglo XVIII y principios XIX. Base la Revolución Industrial, agricola, financiera, } \\
\text { cultural, politica y social. Los medios de la expansión:organización empresarial, innovaciones en armas y potencial } \\
\text { naviero. Las formas: expediciones cientfficas, asentamiento de residentes, red comercial y crediticia e influencia } \\
\text { informativa, cultural e ideológica. }\end{array}$} & \\
\hline $1870-1913^{*}$ & $\begin{array}{c}\text { La internacionalización de la producción } \\
\text { de las empresas se remonta a fines del } \\
\text { siglo XIX, subproducto de la concentración } \\
\text { económica en los paises industrializados, dio } \\
\text { y sigue dando origen a las grandes } \\
\text { empresas } \\
\text { transnacionales. Gran movilidad de capitales } \\
\text { y mano de obra, auge comercial por } \\
\text { reducción de costos de transporte, más que } \\
\text { libre comercio. }\end{array}$ & \multirow{2}{*}{\multicolumn{2}{|c|}{$\begin{array}{l}\text { **Imperialismo financiero, cambio de capitalismo multifabril al } \\
\text { monopolista. limplicó cambio del imperialismo industrial al financiero, a } \\
\text { partir de la concentración. Capital financiero es el capital bancario } \\
\text { monopolista fundido con grupos monopolistas industriales y el reparto del } \\
\text { mundo se encuentra en la politica colonial de dominación monopolista del } \\
\text { globo. }\end{array}$}} & \multirow[t]{2}{*}{$\begin{array}{l}\text { Modelo Clásico. Define formas básicas } \\
\text { del capitalismo, con division internacional } \\
\text { del trabajo entre: } 10 \text {. bienes primarios en } \\
\text { la periferia, construyendo Estados- } \\
\text { nación, como en el centro; } 20 . \\
\text { industriales, progreso en sistemas } \\
\text { nacionales autocentrados. }\end{array}$} \\
\hline $1914-1945^{*}$ & $\begin{array}{c}\text { Globalización interrumpida por la Primera } \\
\text { Guerra Mundial, origen de un periodo con } \\
\text { imposibilidad de retomar las tendencias } \\
\text { anteriores a la década de } 1920 \text { y la } \\
\text { retracción en los años treinta. }\end{array}$ & & & \\
\hline $1945-1973^{*}$ & $\begin{array}{c}\text { Desarrolla instituciones internacionales } \\
\text { de cooperación financiera y comercial, y } \\
\text { por la notable expansión del comercio de } \\
\text { manufacturas entre paises desarrollados, } \\
\text { pero también por la existencia de una gran } \\
\text { variedad de modelos de organización } \\
\text { económica y una limitada movilidad de } \\
\text { capitales y de mano de obra }\end{array}$ & \multicolumn{2}{|c|}{$\begin{array}{l}\text { **Imperialismo tecnocrático, caracterizado desde la Segunda Posguerra } \\
\text { por la revolución tecnológica, el pentagonismo y el bipolarismo mundial. }\end{array}$} & $\begin{array}{l}\text { Período de posguerra } 1945 \text { - 1990: } \\
\text { erosiona las dos caracteristicas } \\
\text { anteriores, simultáneamente desmantela } \\
\text { producción nacional autocentrada, } \\
\text { constituye un sistema integrado de } \\
\text { producción mundial. }\end{array}$ \\
\hline
\end{tabular}


Tabla 6.1 (cont.). Caracteristicas de los procesos de integración y las etapas de expansión del capitalismo, el imperialismo y la globalización

\begin{tabular}{|c|c|c|c|}
\hline \multirow[b]{2}{*}{ Periodo } & CEPAL* & DIAZARENAS ${ }^{\star *}$ & AMíN \\
\hline & \multicolumn{3}{|c|}{ Características Generales de Algunos de los Autores sobre la Globalización } \\
\hline $1975^{*}$ & \begin{tabular}{|c|} 
Último cuarto del siglo XX se \\
consolidó una tercera fase de \\
globalización, cuyas principales \\
características son la gradual \\
generalización del libre comercio, la \\
creciente presencia en el escenario \\
mundial de empresas transnacionales \\
que funcionan como sistemas de \\
producción integrados, la expansión y la \\
considerable movilidad de los capitales, y \\
una notable tendencia a la \\
homogenización de los modelos de \\
desarrollo, pero en la que también se \\
observa la persistencia de restricciones al \\
movimiento de mano de obra.
\end{tabular} & $\begin{array}{l}\text { Imperialismo planetario, la implantación neoliberal, el colapso } \\
\text { soviético y la Guerra del Golfo, los ejes de las relaciones } \\
\text { internacionales globalizadas. Los estados naciones dejaron de ser } \\
\text { sujetos protagónicos en el mundo actual; motivaciones contra lo } \\
\text { estatal, reivindicación de lo local, la "desujetivación" del mercado, la } \\
\text { exaltación de lo sistémico. La globalización jerarquiza el conjunto de } \\
\text { estados-naciones. }\end{array}$ & $\begin{array}{l}\text { A partir de 1990, hay nuevas formas } \\
\text { de polarización. Por incapacidad del } \\
\text { sistema de desarrrollar: } 10 \text {. Nuevas } \\
\text { formas de organización social y } \\
\text { política más allá del Estado-nación, } \\
\text { requisito de sistema globalizado de } \\
\text { producción; } 20 \text {. Relaciones políticas y } \\
\text { económicas que reconcilien } \\
\text { industrialización periferica competitiva } \\
\text { de América Latina y Asia con } \\
\text { crecimiento mundial y 3o. Una relación } \\
\text { no excluyente con la periferia africana, } \\
\text { no implicada en industrialización } \\
\text { competitiva. }\end{array}$ \\
\hline
\end{tabular}

Para Robinson . "La distinción determinante entre una Economía mundial y una global es la globalización del propio proceso de producción, o el surgimiento de circuitos globalizados de producción y acumulación...Con la aparición de las cadenas de producción transnacional y los circuitos de acumulación, los capitalistas nacionales orientados transnacionalemente cambian sus puntos de vista de mercados nacionales a mercados globales. Las propiedaddes estructurales de estas cadenas o redes son globales". (2007-27-37)

Para Jessop, la globalización es un término polivalente, ambiguo y controvertido que con frecuencia oculta más de lo que revela acerca de los recientes cambios económicos, políticos, sociales y culturales. Es multi-céntrica, porque surge de las actividades realizadas en muchos lugares y no en un solo centro; Es multiescalar, porque nace de las acciones en muchas escalas, desarrolla y profundiza la división espacial y escalar del trabajo, la globalización con otros puntos de vista escalares, como internacionalización, triadización, formación de bloques regionales, crear redes de ciudades globales, regiones transfronterizas, localización internacional, globalización, gluburbanización o transnacionalización; es multi-temporal, reestructura y rearticula los horizontes temporales, implicando las nociones de distanciamiento y compresión espaciotemporal. Es multicausal y multiforme. Un momento estructural; como procesos interdependientes entre las acciones, organizaciones e instituciones de diferentes subsistemas funcionales, economía, derecho, educación, ciencia, deporte, y diferentes esferas del mundo de la vida. Se desarrolla de forma desigual tanto en la forma como en el tiempo. Un momento estrategico, referido a los diferentes intentos de los actores por coordinar globalmente sus actividades en distintos subsistemas funcionales y de la vida; no implica presencia física de todos los actores, con el meta-pilotaje, (diseño constitucional o institucional); con proyectos como gobierno mundial, gobernanza global y gobernanza global horizontal o un nuevo orden mundial. La globalización implica tanto estructural como estratégicamente la creación o reestructuración de la escala como relación social y como lugar donde se dan las relaciones sociales, en diferentes ámbitos, en escalas menores, urbana, transnacional, nacional, y macroregional, lugares sustantivos de las actividades de la economía real.

Para Castells, la sociedad red global: "Una sociedad red es aquella cuya estructura social está compuesta de redes activadas por tecnologías digitales de la comunicación y la información basadas en la microlectrónica. Entiendo por estructura social aquellos acuerdos organizativos humanos en relación con la producción, el consumo, la reproducción, la experiencia y el poder expresados mediante una comunicación significativa codificada por la cultura(...) las fuerzas que impulsaron la globalización solo pudieron desencadenarse porque tenían a su disposición la capacidad de conexión en red global que proporcionan las tecnologías digitales de comunicación y los sistemas de información(...) es esto lo que diferencia en tamaño, velocidad y complejidad al actual proceso de globalización de otras formas de globalización en anteriores épocas históricas".

Fuente: elaboración propia a partir de la información y periodización de: WALLERSTEIN, Immanuel (1979). El mundo moderno. Sistema mundial, la agricultura capitalista y los orígenes de la economía-mundo europea en el siglo XVI. Siglo XXI Editroes, México; AMIN, Samir (1999): El capitalismo en la era de la globalización. Paidós, Madrid. En Los fantasmas del capitalismo, una crítica a las modas intelectuañes contemporáneas, texto publicado en el el Áncora Editores, La caracterización de Amin en la última etapa operada a partir de cinco controles monopolicos: los tecnológicos, los financieros, recursos naturales, comunicación y medios de comunicación masiva y el de las armas de destrucción masiva. SARMIENTO A. Libardo, "Sistema Mundo Capitalista fábrica de riqueza y miseria" Ediciones desde abajo; DíAZ A. Agustina, " Relaciones Intremacionales de Dominación 2a. edición, Universidad Nacional de Colombia; NEGRI Toni, HARDT Michael "Imperio" Ediciones desde abajo; ROBINSON William I 2007. "Una Teoría sobre el capitalismo global Producción, clases y Estado en un mundo transnacional" Ediciones desde Abajo Bogotá JESSOP Robert 2008. "EI Futuro del Estado capitalista" Editorial CATARATA. Los Libros de la Catarata. Madrid. CASTELLS Manuel 2009. "Comunicación y Poder". Alianza Editorial Madrid 2010. 
Así, los territorios y las formas de organizar los gobiernos implican reformas y exigencias para entender que "todos los gobiernos subnacionales, de una manera u otra, están siendo presionados para ajustarse y adaptarse a las nuevas condiciones de la economía mundial" ${ }^{238}$. Estos son requerimientos actuales del capital para llegar a todos los puntos de la tierra, así como para revalorizar lo local y territorial con acciones de planificación pública. Según lo anterior, se necesita una nueva organización político-administrativa del gobierno, con nuevas funciones y competencias. La tabla 6.1 periodiza las características de los procesos de expansión del capitalismo con base en la síntesis de varios autores.

\subsubsection{Empresas transnacionales, globalización y alimentos}

Las formas de organización de las empresas transnacionales y sus controles forman parte de la cadena alimentaria, bien sea en disponibilidad, directamente a través de los mercados de materias primas e insumos para la producción, o en las cadenas de distribución globalizadas:

[Es] la Bolsa de Materias Primas Agrícolas de Chicago (Chicago Commodity Stock Exchange) la que, en los días laborables, fija el precio de los principales alimentos. Seis empresas multinacionales del sector agroalimentario y de las finanzas controlan esta bolsa. Los precios fijados diariamente son casi siempre fruto de complicadas especulaciones en torno a contratos a plazos, pirámides de derivados y otras variables ${ }^{239}$.

En este punto se requiere profundizar en el impacto de estos controles de alimentos en pocas empresas, las cuales definen los precios de los principales alimentos. Por su parte, el Banco Mundial indica sobre la concentración económica de las empresas del sector:

De las cien economías más importantes del mundo, 51 son empresas multinacionales y 49 países, [...] el sector del trigo, del maíz, y de la soja está controlado por cinco compañías; el del café por seis, el del azúcar por cuatro, el de los plátanos y del cacao por tres, así

238 Ibíd., pág. 8.

239 ZIEGLER, Jean (2001): La esquizofrenia de Naciones Unidas: una lucha sin medios contra el hambre. Dadas las características de esta tendencia de concentración, se requiere de un trabajo posterior más profundo con las implicaciones que tiene sobre las políticas globales de los ODM. 
como el caso del té. Estamos hablando en realidad de unas veinte multinacionales: entre las más poderosas encontramos Cargill, Archer, Daniels Midland (ADM), Conagra, Sara Lee, Louis Dreyfus, Monsanto, del Monte, Continental. Lo curioso es que la mayoría de la gente nunca ha oído hablar de ellas ${ }^{240}$.

Otra tendencia es la referida a las patentes, explicada con la pregunta y respuesta de Robin:“¿Qué es la ley de Monsanto? Es la de las patentes. La empresa siempre ha dicho que la manipulación genética era un medio de obtener patentes" ${ }^{241}$. La investigación al servicio de las multinacionales y no de poblaciones replantea los avances en la revolución verde: ambientales, de salud pública y de SAN. Ahora bien, hay que tener presentes tres partes sobre los agroalimentos: a) el control de precios; b) la centralización y concentración económica para manejar insumos y su distribución; y c) los avances de la ciencia, con la mira puesta en las utilidades, con ayuda de políticas de gobiernos con protección y atracción, pero sin muchos controles a estas inversiones.

\subsubsection{Asimetrías institucionales y globalización}

Un cambio en el ámbito global expresa las nuevas reglas para las relaciones entre las naciones. En este contexto cobra importancia la decisión de políticas por organismos internacionales con desequilibrios en información, así como la aplicación y discusión de los instrumentos operativos de las políticas globales para los países. Estas reglas son construidas sobre los principios de eficiencia y eficacia del libre mercado, en "todas" las economías. Sin embargo, hay asimetrías en la aplicación de las mismas decisiones, por cuenta de los distintos mecanismos de protección gubernamental; y en estos espacios hay instituciones globales sin gobierno de tal magnitud.

Se aplican así políticas globales diferenciadas por el poder de cada gobierno en las organizaciones internacionales, pues aunque se quiera atacar un fenómeno como el dumping en productos de la canasta básica de alimentos agrícolas, hay una doble moral

240 Citado en MONTAGUT, Xavier y DOGLIOTTI, Fabrizio (2006): Alimentos globalizados, soberanía alimentaria y comercio justo. Consum Xarxa Solídari, Agéncia Catalana de Cooperació al Desenvolupament e Icaria, Barcelona, pág. 29.

241 ROBIN, Marie-Monique (2008): El mundo según Monsanto: de la dioxina a los OGM. Una multinacional que les desea lo mejor. Ediciones Península, Barcelona, pág. 454. 
para quienes tienen el poder de influir en las decisiones, como consecuencia de los recetarios de los organismos o gobiernos que representan:

Los grandes operadores económicos y comerciales internacionales, [...] el sistema de intercambios realmente existente no contempla ni igualdad ni autorregulación ni juego limpio ni, por supuesto, criterios éticos o morales. Por eso, la lucha contra el dumping no puede ser un asunto de la OMC ni de fantasiosos códigos éticos empresariales ${ }^{242}$.

Por tanto, hay instituciones globales sin gobiernos del mismo nivel, como tampoco "un Gobierno mundial, responsable ante los pueblos de todos los países, que supervise el proceso de globalización. [...] En vez de ello, tenemos un sistema que cabría denominar Gobierno global sin Estado global" ${ }^{243}$. Allí, pocas instituciones (como BM, FMI y OMC) toman decisiones sin el compromiso de todos los integrantes o en igualdad de condiciones; se encuentran también instituciones globales que hacen reglas para participantes, pero con desiguales niveles de intervención en su construcción y su decisión.

\subsubsection{Cambios en las dinámicas de acción del Estado}

La revalorización territorial presente en el capitalismo actual está dada por la evolución y transformación de funciones y competencias del Estado nacional, desde su nacimiento hasta el actual contexto de globalización. Esta adaptación del Estado nacional y la política de gobierno pueden definirse así:

El Estado liberal puede presentar tanto la forma de régimen de la monarquía constitucional — Gran Bretaña- como la de la república parlamentaria -Francia- El Estado intervencionista puede presentarse bajo varias formas de régimen: régimen presidencial norteamericano, régimen parlamentario inglés de dos partidos, régimen parlamentario europeo continental multipartidista ${ }^{244}$.

242 MONTAGUT, Xavier y DOGLIOTTI, Fabricio (2006). Alimentos globalizados... Op. cit., pág. 65.

243 STIGLITZ, Joseph E. (2002): El malestar en la globalización. Santillana, Bogotá, págs. 47-48. 244 POULANTZAS, Nicos (1977): Poder político y clases sociales en el estado capitalista. Siglo XXI Editores, México, pág. 192. 
Estas son formas de organización del Estado y los gobiernos dentro del desarrollo capitalista. En el caso de América Latina, puede decirse que la formación del Estado nacional se realizó durante la segunda mitad del siglo XIX e inicios del XX, con cambios que anunciaban otras relaciones de poder, tanto en sus vínculos externos como en el interior del país, y entre poderes regionales, locales y nacional.

A fines del siglo XX, en el nuevo panorama del Estado, sus funciones y las nuevas dinámicas de acumulación implican que las políticas del desarrollo territorial se reorientarán para los nuevos procesos organizativos, administrativos e institucionales. Ello conllevó un "retraimiento del Estado de bienestar keynesiano ${ }^{245}$-EBK - en el nivel nacional, surge un Estado trabajo shumpeteriano en los niveles regionales y locales" 246 , o bien, el paso del fordismo al posfordismo. Este cambio de funciones del Estado se caracteriza por:

$1^{\circ}$. La promoción de innovaciones de productos, de procesos organizacionales y de mercados; $2^{\circ}$. El mejoramiento de la competitividad estructural de las economías abiertas; $3^{\circ}$. La subordinación de la política social a las exigencias de flexibilidad del mercado de trabajo y de competitividad estructural. El Estado nacional está sujeto a varios cambios que llevan a su vaciamiento. Esto no significa que el Estado nacional haya perdido toda su importancia ${ }^{247}$.

En las nuevas funciones del Estado, los territorios reorganizados o revalorizados muestran condiciones para diferenciar la política pública en un momento de "vaciamiento de los Estados". Las relaciones globales, económicas, políticas, sociales y ambientales tienen un

245 En este punto es necesaria la aclaración de Muñoz de Bustillo: "La necesidad de no confundir el Estado keynesiano con el EB, [...] todos los EB son keynesianos, en el sentido de que sería esta interpretación del funcionamiento de las economías de mercado la que contribuye, parcialmente al menos, a su legitimación, y la que pone en manos del sector público una capacidad de gasto". MUÑOZ DE BUSTILLO, Rafael (2000): "Retos y restricciones del Estado de bienestar en el cambio de siglo". En El Estado de bienestar en el cambio de siglo: una perspectiva comparada. Alianza Editorial, Madrid, pág. 38.

246 MONCAYO J., Édgard (2004): Nuevos enfoques del desarrollo territorial: Colombia en una perspectiva latinoamericana. Universidad Nacional de Colombia, y CEPAL, Bogotá, pág. 49.

247 JESSOP, Bob (1999): Crisis del estado de bienestar. Hacia una nueva teoría del Estado y sus consecuencias sociales. Siglo del Hombre Editores y Universidad Nacional de Colombia, Bogotá, pág. 66. 
Estado que direcciona políticas generales internas; su acción directa se refleja en cada función y competencia de los gobiernos subnacionales en los territorios.

Por otro lado, la dirección está en las instancias globales del capitalismo. Las acciones de intervención y orientación del Estado, relacionadas con la política social, económica y territorial, afectan la seguridad alimentaria nutricional a través de la cadena alimentaria, en tanto los ejes de este cambio tienen implicaciones particulares:

[Se] han producido cambios cualitativos en las políticas sociales y en su articulación con la política económica, habiéndose concedido la primacía a esta última. Una creciente presión a la baja sobre el salario social considerado como un coste de producción; [...] cambios en las formas y funciones del consumo colectivo; [...] cambios en las políticas públicas para los trabajadores desempleados; el rediseño de las políticas de pensiones para reducir los costes de largo plazo y promover el sector de servicios financieros ${ }^{248}$.

Así, se observa que las nuevas acciones del Estado se orientan y adecúan a las exigencias del gran capital del mundo globalizado, desfavoreciendo las condiciones de demanda de la población y el SSAN.

\subsection{TERRITORIO Y AGROALIMENTOS}

\subsubsection{Elementos históricos generales sobre el territorio}

El conocimiento del territorio requiere un principio de interdisciplinariedad para ver como el ser humano expresa su existencia e identifica ciertas manifestaciones y relaciones sociales, la cultura, la economía, los vínculos con la naturaleza, la política, el poder, las formas político-organizativas y administrativas de este y sus relaciones con el entorno. Los diversos vínculos del ser humano con el contexto que rodea su hábitat, los problemas y las relaciones entre territorios rurales, urbanos, locales y regionales, y sus formas de construcción permiten entender la cultura territorial:

248 JESSOP, Robert (2008): El Futuro del Estado capitalista. Editorial Catarata, Madrid, págs. 188 y ss. 
Aquella cuya espacialidad y temporalidad se hallan ligadas a un territorio — que va desde lo local, ya sea regional o municipal, al nacional- y por una temporada larga, esto es capaz de sedimentar costumbres, de formar arquetipos, de engendrar tradiciones. Entendemos por cultura desterritorializada aquella cuya relación con el espacio es móvil, nómada ${ }^{249}$.

Hay dos elementos de la cultura (la territorial y la desterritorializada) que vinculan el análisis propuesto en este trabajo con la dinámica y las lógicas internas de la cadena alimentaria. El territorio supone diferenciar los elementos constitutivos que lo identifican, lo definen, lo dinamizan y determinan sus conflictos; en este sentido, es "un conjunto de vínculos de dominio de poder, de pertenencia o de apropiación [...] con un determinado sujeto individual o colectivo" ${ }^{250}$. Así, se identifican relaciones de poder presentes, lo cual requiere entender cómo se articulan e inciden en las decisiones públicas del desarrollo territorial. Estas relaciones de poder muestran su esencia:

Totalidad, soberanía, multidimensionalidad y multiescalaridad, [...] los territorios como espacios de gobernancia y como propiedad. Esta relación está determinada por las políticas de desarrollo; por tanto, quien determina la política define también la forma de organización del territorio ${ }^{251}$.

En Colombia, estas relaciones de poder en los territorios definen sus formas de apropiación por parte de la población y determinan su uso, que depende de quien gobierne y su concepción para las acciones públicas, regionales y municipales; en ausencia de Estado, permite presencia institucional informal de actores armados que se adjudican esta función.

249 CUERVO, Luis M. (1999): “¿Existe una cultura económica territorial?”. En Memorias Primer Seminario Internacional sobre Territorio y Cultura... Op. cit., pág. 73.

250 MONTAÑEZ G., Gustavo (2001): "Introducción, razón y pasión del espacio y el territorio". En Espacio y territorios: razón, pasión e imaginarios. Universidad Nacional de Colombia, Bogotá, pág. 21.

251 MANCANO F., Bernardo (2009): Territorio, teoría y política... Op. cit., pág. 53. 


\subsubsection{Producción de alimentos y territorio}

Esta relación es histórica y está mediada por la estructura demográfica, las condiciones tecnológicas, las relaciones sociales, las dinámicas económicas de los procesos productivos, las formas de uso y el tipo de suelo determinantes para producir agroalimentos:

Antes el uso del suelo estaba determinado por las necesidades alimenticias generales de la población [...] fundado en las leyes bioecológicas de rendimientos de energía o proteína nutricionales por unidad de superficie, a la sombra del gasto de energía para su transporte al sitio de consumo, [...] la tierra no era objeto de comercio solo generaba renta del suelo, comúnmente en especie, [...] el capitalismo impone un reacomodo del hombre con la naturaleza, consecuencia de las relaciones sociales que se confunden con las de producción, [...] la forma de explotación del suelo dictada por las condiciones del mercado. [...] Es entonces la rentabilidad en el mercado y no las necesidades alimenticias las que jerarquizan el uso del suelo ${ }^{252}$.

Se produce un cambio con las relaciones territorio-alimentos y desarrollo del capitalismo, cuando este jerarquiza la producción de agroalimentos para el mercado, llevando a estos a ser una mercancía más, que es el punto de mayor conflicto ético en la actualidad. Hoy, los países desarrollados combinan varios criterios para tener disponibilidad de agroalimentos: incentivos públicos estatales, seguridad nacional, salud pública y protección vía dumping a sus productos agroalimentarios. Ello permite controlar la cadena alimentaria en la disponibilidad y distribución (capítulo III).

Otra tendencia de los siglos XIX, XX y XXI es la movilidad y sustitución de cultivos para producir bienes agroalimentarios: se generan nuevas formas de apropiación rural, donde la producción se caracteriza, desde mediados del siglo XX e inicios del XXI, por tres formas, según Mancano:

La que vincula el territorio al agronegocio y representa la gran escala de producción, el monocultivo y la producción para la exportación; la del territorio campesino, bajo la pequeña escala la heterogeneidad

252 GÓMEZ G., Luis Jair (2001): El sistema agroalimentario y la sostenibilidad ecológica: los efectos de una diacronía. Universidad Nacional de Colombia y Editorial Lealon, Medellín, pág. 121. 
del paisaje la diversificación de alimentos para el desarrollo local, regional y nacional; y el territorio campesino monopolizado por agronegocios, distinguido por escala y homogeneidad del paisaje se caracterizan por trabajo subordinado y controlado técnicamente por los comodities utilizados en territorios campesinos ${ }^{253}$.

Según esta modalidad de cambio en la globalización actual, se sustituyen usos y paisajes de manera violenta por la expulsión del campesinado: en el primer caso, la expulsión campesina para homogenizar el paisaje; y en el tercero, la subordinación de la población campesina para los nuevos usos en diferentes regiones, pero bajo control del agronegocio. Zuluaga identifica en Colombia la apropiación de tierras para otros usos y propietarios, con la expansión paramilitar: "La geografía de la expansión paramilitar a partir de 1994 coincide con la del desplazamiento forzado y la de los cultivos de palma" 254. Este fenómeno afectó la disponibilidad de tierras para agroalimentos (capítulo VII) e impllicó una dinámica de expansión y un cambio en los usos, lo cual fue generado por diferentes formas de violencia.

\subsubsection{Un repaso general de la evolución de la producción de agroalimentos}

Cuando se habla de agroalimentos, se vinculan procesos de producción en territorios rurales; procesos con relaciones cambiantes, porque las necesidades entre producción de agroalimentos, sociedad y territorio son históricas. Además, estos procesos evolucionan en función de cambios demográficos, tecnológicos, comerciales, políticos y las relaciones sociales; por tanto, hay condiciones diferentes en cada proceso y en cada alimento, lo que afecta la forma en que hombres y mujeres construyen, se adaptan o buscan controlar el territorio como individuos, grupos, organizaciones o Estados.

Estas dinámicas temporales en la cadena alimentaria inciden en cambios institucionales formales e informales existentes en el interior de los territorios, el Estado, las formas de los modelos económicos, políticos, sociales y ambientales, que orientan en función de las escalas del territorio, y del desarrollo de la agricultura, los cambios en la relación

253 MANCANO F., Bernardo (2009): Territorio, teoría y política... Op. cit., pág. 57.

254 ZULUAGA N., Jaime (2009): "Orígenes, naturaleza y dinámica del conflicto armado". En Las otras caras del poder. Territorio, conflicto y gestión pública en municipios colombianos. GTZ y Foro Nacional por Colombia, Bogotá, pág. 81. 
alimentos territorios. La forma como se establecen las relaciones hombre-naturaleza determinan los vínculos demográficos y los requerimientos de la población con sus necesidades agroalimentarias, pero estos cambian con la cultura, la geografia, la dinámica social, económica y política y las relaciones sociales en el territorio.

La evolución histórica de las condiciones agroalimentarias a partir de las periodizaciones y sus características puede verse en la tabla 6.2.

\begin{tabular}{|c|c|c|c|c|}
\hline \multicolumn{4}{|c|}{ 10. Períodizaciones agroalimentarias } & \multirow[b]{2}{*}{$\begin{array}{l}\text { 20. Características, condiciones de la evolución agroalimentaria según } \\
\text { periodizaciones agroalimentarias y de acuerdo con la relación hombre- } \\
\text { naturaleza }\end{array}$} \\
\hline $\begin{array}{l}\text { Etapas históricas } \\
\text { económicas de } \\
\text { la alimentación } \\
\text { humana }\end{array}$ & $\begin{array}{l}\text { Épocas de la } \\
\text { alimentación } \\
\text { humana }\end{array}$ & & oria & \\
\hline \multirow{2}{*}{ 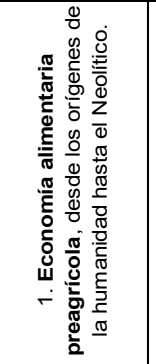 } & \multirow{2}{*}{ 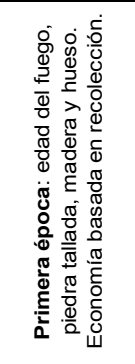 } & \multirow{2}{*}{ 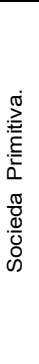 } & \multirow{2}{*}{ 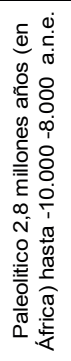 } & \begin{tabular}{|c|} 
La alimentación dependia de recolectar plantas, tubérculos y otros vegetales, \\
ingestión de insectos, huevecillos de insectos y animales pequeños, caza y \\
carroñeo; el tamaño de la población humana regulado por disponibilidad de \\
alimentos, con poca división del trabajo, aparece esta división entre hombres y \\
mujeres; no agreden el medio natural; no lo expoliaban ni acumulaban \\
alimento innecesariamente; al contrario, a menudo actuaban como \\
requladores del medio. \\
\end{tabular} \\
\hline & & & & $\begin{array}{c}\text { Los avances tecnologicos se hacen en respuesta a necesidades de } \\
\text { supervivencia específicas, como cazar, cortar la carne de las presas, } \\
\text { desenterrar raices para comer, protegerse del ataque de animales, } \\
\text { guarecerse del clima frío, calentar la comida o la vivienda; se tienen utensilios } \\
\text { de hueso, madera y piedra. }\end{array}$ \\
\hline \multirow{4}{*}{ 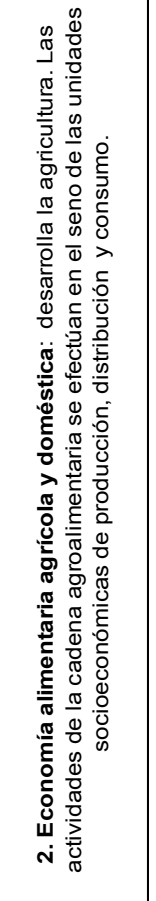 } & \multirow{4}{*}{ 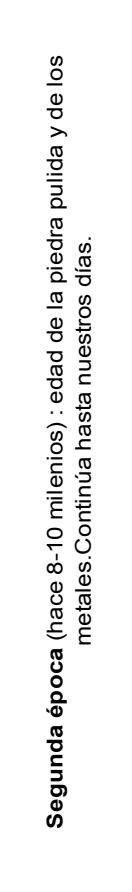 } & \multirow{4}{*}{ 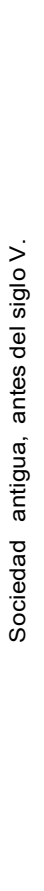 } & \multirow{4}{*}{ 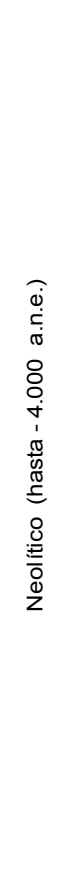 } & $\begin{array}{c}\text { Primera transformación de la forma de vida humana, pasa de ser nómada a } \\
\text { sedentaria y de economía recolectora (caza, pesca y recolección) a } \\
\text { productora (agricultura y ganadería). }\end{array}$ \\
\hline & & & & $\begin{array}{c}\text { Cosecha alimentos que se conservan durante bastante tiempo, generando el } \\
\text { desarrollo de nuevas técnicas y artesanías como la cerámica, la cestería y } \\
\text { muchas otras. Aparecen excedentes permitiendo la especialización y división } \\
\text { del trabajo, la aparición del comercio, la acentuación de las diferencias } \\
\text { sociales; proceso de revolución urbana. }\end{array}$ \\
\hline & & & & $\begin{array}{l}\text { Los cereales siguen siendo la base de la alimentación humana en la } \\
\text { actualidad. Centeno, trigo y cebada son originarios de la zona del Creciente } \\
\text { Fértil, frutos de higuera que demuestran una selección intencionada en la } \\
\text { zona de Medio Oriente, otros territorios donde surgió la agricultura y la } \\
\text { ganadería: las altiplanicies mexicanas (cultura del maíz) o ciertas regiones de } \\
\text { China (cultura del arroz) o del África subsahariana (cultura del sorgo), las } \\
\text { legumbres, concretamente las lentejas, también tienen un cultivo muy antiguo, } \\
\text { y algo menos los árboles frutales (cítricos -China-, manzanos, ciruelos) o los } \\
\text { plátanos (Sureste de Asia). En la Amazonia la domesticación de especies } \\
\text { vegetales se basó inicialmente en la mandioca amarga y comenzó hace unos } \\
5000 \text { años. }\end{array}$ \\
\hline & & & & $\begin{array}{c}\text { La domesticación de animales (ovino, bovino y caprino) procede también de la } \\
\text { zona del Creciente Fértil; el caballo en las estepas de Asia Central, papel que } \\
\text { en otras zonas correspondió a los camélidos (dromedarios, camellos, llamas } \\
\text { y alpacas), el cerdo, aves de corral, como gallinas y patos, y otras como las } \\
\text { palomas - para alimentación y uso colombofilico- y las rapaces - utilizadas } \\
\text { en cetrería; e incluso insectos, abeja y gusano de la seda; utilización } \\
\text { ganadera de reptiles, iguanas y cocodrilos, con menos extensión. }\end{array}$ \\
\hline
\end{tabular}


Tabla 6.2 (cont. 1). Evolución de las condiciones Aaroalimentarias

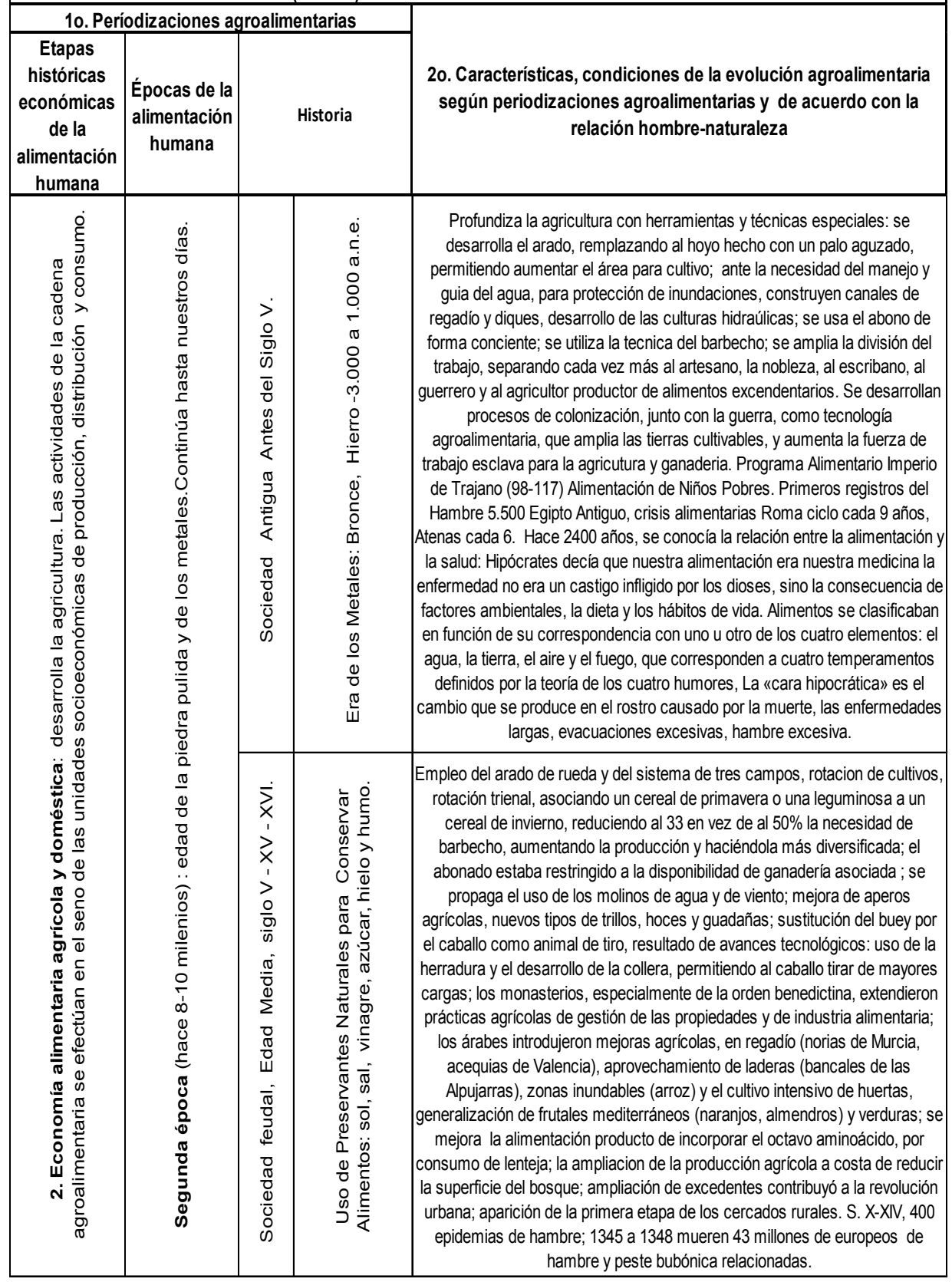




\begin{tabular}{|c|c|c|c|c|}
\hline \multicolumn{5}{|c|}{ Tabla 6.2 (cont. 2). Evolución de las condiciones agroalimentarias } \\
\hline \multicolumn{4}{|c|}{ 10. Períodizaciones agroalimentarias } & \multirow[b]{2}{*}{$\begin{array}{l}\text { 20. Características, condiciones de la evolución agroalimentaria según } \\
\text { periodizaciones agroalimentarias y de acuerdo con la relación hombre- } \\
\text { naturaleza }\end{array}$} \\
\hline $\begin{array}{l}\text { Etapas } \\
\text { históricas } \\
\text { económicas de } \\
\text { la alimentación } \\
\text { humana }\end{array}$ & $\begin{array}{l}\text { Épocas de la } \\
\text { alimentación } \\
\text { humana }\end{array}$ & & Historia & \\
\hline 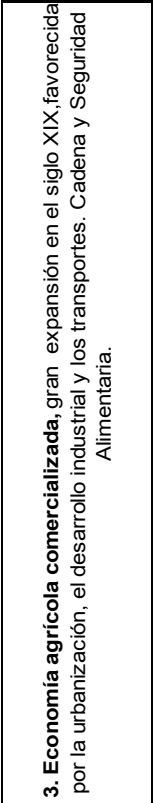 & 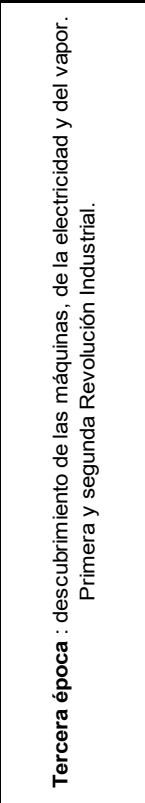 & \multirow[t]{2}{*}{ 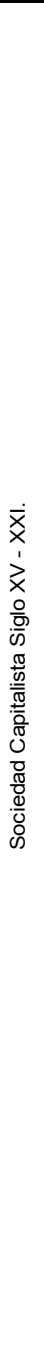 } & 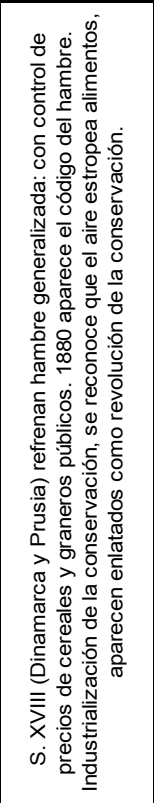 & $\begin{array}{c}\text { Fines Siglo XV y principios del XVI, nace la economía-mundo europea, el elemento } \\
\text { central económico la agricultura, las relaciones sociales basadas en el acceso de los } \\
\text { miembros de la sociedad a los medios de producción; aparece el amparo de la } \\
\text { propiedad privada, el terrateniente, la tierra es una mercancía no por producir sino } \\
\text { porque tiene precio; los animales separados del cultivo y objeto de explotación en si } \\
\text { mismos, generadores de articulos alimenticios. Aparece el cercado que delimita la } \\
\text { propiedad individual y como componente tecnológico, objetivo de la producción de la } \\
\text { familia campesina y de la sociedad en general, busca primero la generación de } \\
\text { excedentes, para pagar el trabajo agrario, la renta del suelo, la ganancia capitalista, } \\
\text { garantizando, la acumulación o reproducción ampliada diferente a la autosuficiencia. } \\
\text { "Ya no se trata de producir para subvenir las necesidades alimentarias de la } \\
\text { sociedad, sino de responder a las demandas del mercado, donde se reunen } \\
\text { quienes tienen capacidad adquisitiva de sus alimentos", la población de la zona } \\
\text { urbana, conformada por comerciantes, manufactureros, gobernantes, nobleza, militares, } \\
\text { clerecia y obreros, consumidores de alimentos; en la zona rural, con campesinos, } \\
\text { unicos productores y consumidores de alimentos; la producción de lana para la } \\
\text { manufactura, compite por tierra para los alimentos; el avance de la industria genera } \\
\text { demandas de materias primas, alimentos y suelos urbanos en crecimiento, lo que } \\
\text { requiere ampliación de la frontera agrícola, ayudado por el desarrollo de los sistemas de } \\
\text { transporte que permitian las condiciones de acceso y distribución de productos } \\
\text { agroalimentarios. Crecimiento de agricultura demanda mayor abono creciendo el } \\
\text { ganado, el cultivo de forrajes sustituye el barbecho; animales domésticos ahora } \\
\text { tecnicamente explotados; el arado pesado y con vertedera, el rastrillo, diversidad de } \\
\text { cereales, nuevos cultivos de oriente, generación de selección de semillas y animales, } \\
\text { control de plagas, racionalidad de las rotaciones, relaciones entre clima y producción; } \\
\text { cambio de agricultura de vecindad a región implicando: ampliar la frontera agricola, } \\
\text { difundir las tecnologias, facilitar la especialización por regiones, y la alimentación } \\
\text { animal con unidades forrajeras. }\end{array}$ \\
\hline 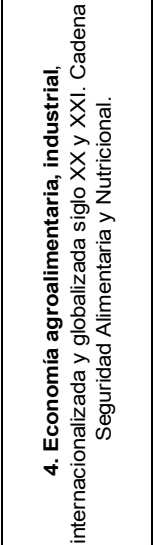 & 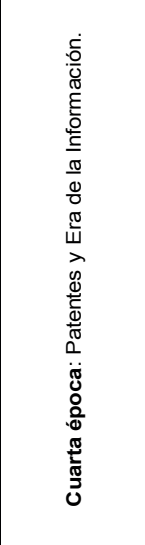 & & 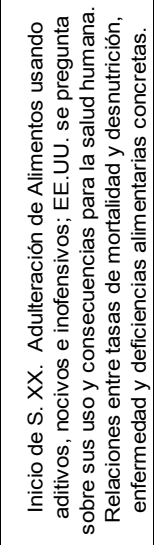 & $\begin{array}{l}\text { La revolución agrícola se caracteriza por: el monocultivo sustituye al } \\
\text { policultivo; la rotación por razones estrictamente bioecológicas de tipo } \\
\text { estacional, aprovechamiento del suelo, control de plagas,la siembra, la } \\
\text { recolección y el control manual de malezas, son remplazados por la } \\
\text { mecanización completa; el control esporádico y selectivo de plagas es } \\
\text { entregado íntegramente al efecto del uso masivo e indiscriminado de } \\
\text { plaguicidas químicos; y, por último, el abono orgánico complementado con } \\
\text { abonos químicos, es sustituido por la utilización de abonos químicos a gran } \\
\text { escala, específicamente formulados para cultivos y suelos. Unas prácticas } \\
\text { son drásticamente arrasadas por otras, el desarrollo de los agronegocios, } \\
\text { patentes, semillas certificadas, cultivos transgénicos, biocombustibles, }\end{array}$ \\
\hline \multicolumn{5}{|c|}{$\begin{array}{l}\text { Fuentes: elaboración propia a partir de la información y periodización de: BERNAL John D. (1979): La ciencia en la historia. Universidad Nacional Autónoma de } \\
\text { México y Editorial Nueva Imagen. GÓMEZ G. Luis Jair (2001): El sistema agroalimentario y la sostenibilidad ecológica: Los ffectos de una diacronía. Universidad } \\
\text { Nacional de Colombia y Editorial Lealon, Medellin. FOGEL, Robert (2009): Escapar del hambre y la muerte prematura, 1700-2100. Europa, América yel Tercer } \\
\text { Mundo. Alianza Editorial, Madrid; MORALES G., Juan C. (2006): El hambre al servicio del neoliberalismo. Ediciones Desde Abajo, Bogotá. PÉREZ, María I. (2006): } \\
\text { La manzana de Blancanieves: salud, industria y alimentación. Icaria, Barcelona; Wikipedia La Enciclopedia Libre. Diseño-IniZiativas.net @ } 2005 \text { alimentacion y } \\
\text { nutricion, "Historia breve de la alimentación humana", (adaptado de J Claudian. Evolución de la Alimentación Humana. En: La Alimentación Humana. Eds. H Dupin, } \\
\text { JL Coq, MI Malewiak, C.Leynaud-Rouaud, AM Berthier. Ed Bellaterra, 1997). WWW. Proyecto Salón Hogar Prehistoria. }\end{array}$} \\
\hline
\end{tabular}




\subsection{COLOMBIA: TERRITORIO, INSTITUCIONALIDAD Y CONFLICTO AGRARIO}

\subsubsection{Territorio colombiano y producción de alimentos}

Las condiciones de infraestructura y la organización territorial para producir agroalimentos para el desarrollo regiolocal tiene varios elementos: la identidad territorial y una especificidad construidas en las relaciones de estos con el resto. Los límites político-administrativos no definen lo regiolocal; las realidades específicas son las que determinan estas relaciones. Las acciones de gobierno son de antes del siglo $\mathrm{XX}^{255}$; en el XIX, la preocupación por el territorio para vincular los mercados externos a Bogotá era determinante, así afectara otros territorios con menor influencia sobre el Gobierno nacional, aunque estuvieran mejor posicionados geográficamente:

Las harinas de Nueva York llegan hasta el mismo pie de la explanada de Bogotá, productora de trigos, las veinte leguas que la separan del Magdalena son para el comercio un obstáculo tan grande, como las mil setecientos que median entre el Alto Magdalena. [...] No se crea que esto es exageración. El primer punto que merece un estudio detenido al tratarse de una vía carretera al Magdalena es, sin duda, el sitio de la ribera de este río en que aquella deba terminar la línea que debe recorrerse en el tránsito ${ }^{256}$.

Ubicar un sitio que asociara a Bogotá con Nueva York o Europa requería ubicar vías que lo conectaran a través del río Magdalena, para desarrollar este territorio. Por otro lado, la concentración de la propiedad de la tierra en las zonas rurales y las relaciones sociales precapitalistas en estas son un problema que en Colombia continúa a mediados del siglo XX, en el territorio de las haciendas:

255 Las observaciones que se hacen en los siguientes renglones son tomadas de uno de los trabajos presentados por Mauricio Betancourt para ascender en el escalafón docente a profesor titular de la ESAP. Una síntesis fue presentada en una ponencia en el Seminario de Historia de Cundinamarca: Perspectivas para el Siglo XXI, realizado en Fusagasugá en septiembre 22 y 23 del 2004. El resumen de la ponencia fue publicado en: Historia y sociedad en Cundinamarca: aporte histórico, figuras y documentales de la vida política y de lo público. ESAP (2006).

256 CAMACHO ROLDÁN, Salvador (1858): Camino carretero al Magdalena. Bogotá, págs. 16 y 20. 
Hay que reconocer que esta clase de haciendas impide a las familias desposeídas, o a aquellas propietarias de extensiones demasiado reducidas el acceso a la tierra para obtener un vivir satisfactorio, [...] el ganado engorda en las planicies mientras que la gente lucha en las montañas para lograr una subsistencia apenas suficiente ${ }^{257}$.

Currie muestra las condiciones del trabajo campesino en las haciendas azucareras del Valle del Cauca, así como los conflictos de uso del suelo rural. Por tanto, la producción de agroalimentos se caracteriza en función del tiempo, el sistema vial, la región, la cultura, la forma, el tamaño y el tipo de producción, una parte en la organización de granjas familiares, colectivas, comunitarias, campesinas o grandes propietarios; los mercados de destino locales, regionales, nacional e internacional; el tipo de producto agroalimentario; la distribución espacial de la población; y, por último, el modelo de desarrollo del país. La producción agroalimentaria encontrada por Currie en 1950 da cuenta de la diversidad en la producción de bienes agrícolas en Colombia. En varios de estos productos se tenía autosuficiencia, a pesar de que más del 50\% del territorio estaba cubierto por bosques:

Los terrenos que no están cubiertos de bosques se utilizan, para los cultivos que ocupan el 2 por ciento del territorio y varían según la altitud, o para la ganadería que se desarrolla especialmente en los fértiles valles y mesetas y en las faldas montañosas cuya parte baja está cultivada. Los principales cultivos son: café, caña de azúcar, maíz, papa, arroz, trigo, yuca y plátano. El trigo, la papa y la cebada junto con el maíz y los fríjoles son los principales productos agrícolas comerciales que se cultivan a altitudes de más de 7.000 u 8.000 pies. La parte media de las faldas montañosas se utiliza principalmente para el cultivo del café, el maíz los frijoles, la yuca, el plátano, algunas frutas cítricas, caña de azúcar para la elaboración de panela y fique para la extracción de fibra. El arroz, la caña de azúcar, el algodón, el ajonjolí, el cacao, el tabaco y unas pocas frutas cítricas para el consumo doméstico, son los principales cultivos ${ }^{258}$.

257 CURRIE, Lauchlin (1951): Bases de un programa de fomento para Colombia (2. ${ }^{a}$ ed.). Banco de la República, Bogotá, pág. 73.

258 Ibíd., pág. 71. 
En este punto es posible reconocer el conflicto entre uso y aptitud del suelo rural. Las tierras del sector agropecuario tenían usos inadecuados relacionados con las necesidades del capitalismo colombiano del momento, en tanto las unidades campesinas tecnificadas y de subsistencia se sustentan en la oferta de agroalimentos: "Las tecnificadas preservan sus características familiares, acumulando cantidades relativamente limitadas de capital; en contraste con las unidades familiares las cuales no acumulan sino que tienen por fin su reproducción" 259 .

Independientemente del nivel tecnológico de cada unidad, estas han soportado la mayor parte de la oferta nacional de agroalimentos. La importancia de los campesinos en esta producción y sus transformaciones son analizadas por la Misión Rural:

La producción originada en los pequeños agricultores en 1960 era alta; los campesinos con parcelas menores de 20 hectáreas, eran responsables del 51\% de la superficie sembrada, y del $45.8 \%$ del volumen de la producción agrícola nacional; [...] sin embargo, la desaparición de numerosas explotaciones campesinas por la vía de la violencia, y posteriormente, a partir de 1968, la expulsión masiva de arrendatarios y aparceros consecuencia de la ley 1/68, así como el arrinconamiento de las unidades restantes por el latifundio, impidió a la economía campesina crecer en igual proporción a la demanda de alimentos ${ }^{260}$.

Esta afectación a los productores de agroalimentos en el siglo XX (años cincuenta y sesenta) se mantiene desde la década del noventa hasta hoy.

\subsubsection{Dos décadas de políticas territoriales en Colombia}

En las reformas del Estado para el desarrollo regional están las competencias de los gobiernos para el ordenamiento del territorio, que buscan ajustar la institucionalidad

259 ARANGO R., Mariano (1990): “Tendencias productivas y recientes en la economía campesina 1975-1987”. En El campesino contemporáneo, cambios recientes en los países andinos. Cerec, Fescol y Tercer Mundo Editores, Bogotá, pág. 283.

260 Ministerio de Agricultura y Departamento Nacional de Planeación (1990): El desarrollo agropecuario en Colombia (tomo I: Misión de estudios del sector agropecuario). Bogotá, págs. 338 y ss. 
pública con las dinámicas y acciones derivadas de los procesos de acumulación regional y local, impulsada por la inversión privada y el manejo del conflicto. Estos cambios muestran el papel de cada territorio revalorizado:

Ya no se fundamenta en la producción nacional y mucho menos en la organización nacional estatal de la actividad económica, [estas nuevas bases] descansan sobre la inserción plena y sin condiciones en las dinámicas transnacionales actuales de la acumulación capitalista, [...] [lo que ha implicado] durante las últimas décadas es un alistamiento del territorio, organizado, en gran medida, en función de esas dinámicas transnacionales, [...] la que está emergiendo de las dinámicas territoriales de la acumulación, posee en la esencia los rasgos de una economía de enclave, es decir, de una economía cuya disposición responde más a la nueva organización del capitalismo transnacional que a su articulación de acuerdo con una lógica de reproducción nacional ${ }^{261}$.

Se destacan así seis sectores medulares del nuevo eje de la acumulación en Colombia: hidrocarburos, recursos minerales, agrocombustibles, biodiversidad, cocaína y la plataforma para exportar bienes y servicios. Los territorios para esta fase están en la Amazonía, la altillanura del Orinoco y el Pacífico.

Hay arreglos institucionales del nivel nacional, departamental y local que se adecúan a los procesos de acumulación regional y están vinculados transnacionalmente. En los territorios revalorizados, "las nuevas dinámicas regionales de la acumulación ha demandado la ocupación de nuevos territorios, así como la desocupación o reocupación de otros [...] en genuinos procesos de acumulación por desposesión"262. Estas son características centrales de los procesos regionales vinculados a las lógicas globalizadoras actuales, en clara reapropiación territorial. Este proceso de reapropiación por desposesión lo muestra la Agencia Presidencial para la Acción Social y la Cooperación Internacional, en un informe sobre desplazamiento de la población de sus territorios:

261 ESTRADA A., Jairo (2010): Derechos del capital... Op. cit., págs. 36-37.

262 Ibíd., pág. 39. 
El análisis realizado a partir de los registros oficiales muestra que las 3.624.426 personas expulsadas violentamente y forzadas a abandonar sus bienes entre 1995 y el 2010, hay 256.480 jefes de hogar que afirman haber dejado abandonados 270.680 bienes inmuebles (predios), cuya área se calcula en 6’556.978 hectáreas ${ }^{263}$.

Esta forma de acumulación afecta a la SAN desde la cadena alimentaria y el desarrollo territorial, en cuanto a la disponibilidad y el acceso, dado que evidencia lógicas vinculadas a los territorios rurales en Colombia, violencia, poder y acumulación regional con la nueva función de la tierra y los agronegocios.

\subsubsection{Las políticas regionales, $1980-2010$}

\section{2-1998, el Plan Nacional de Rehabilitación (PNR)}

Uno de los antecedentes de las políticas nacionales para regionalizar el país se encuentra en la propuesta del PNR, surgida en el gobierno de Belisario Betancur, que caracteriza las condiciones de marginalidad social, económica y regional como base para desarrollar acciones por parte los grupos insurgentes. Así, identificó “áreas donde los enfrentamientos armados han dejado de ser choques esporádicos para afectar sensiblemente las condiciones de vida de los habitantes, han sido consideradas como las regiones objeto del Plan"264.

Un objetivo del PNR era erradicar los factores que configuraban un medio propicio para propagar la violencia. La estrategia busca que la comunidad tome conciencia del derecho a la paz y cumpla con la resolución pacífica de los conflictos de la vida social. En busca de la paz, se orientaron las acciones y se caracterizaron regiones PNR con tres criterios: territorial, económico y social.

263 Presidencia de la República de Colombia, Acción social (2010): Unidades agrícolas familiares, tenencia y abandono forzado de tierras en Colombia. Proyecto Tierras y Patrimonio de la Población Desplazada, Bogotá, pág. 120. Este proyecto contó con el apoyo del Alto Comisionado de las Naciones Unidas para los Refugiados (ACNUR), el Banco Mundial, la Agencia Sueca de Cooperación Internacional para el Desarrollo (ASDI), la Unión Europea y la Agencia Española de Cooperación Internacional para el Desarrollo (AECID), la embajada de Canadá y la Agencia de los Estados Unidos de América para el Desarrollo Internacional (USAID).

264 DANE y DAPRE (1986): El plan social por la paz una estrategia de participación comunitaria. Bogotá, pág. 15. 
Además, el gobierno de Barco argumentó con el PNR diferencias de interpretación sobre las condiciones que identifican el conflicto interno, y consideró que las disparidades regionales no eran por imperfecciones del mercado, sino resultado del "efecto de un modelo de desarrollo en el que las políticas públicas y nuestro propio ordenamiento institucional han convertido en excluyente el desarrollo para algunas regiones" 265 . Los factores que propagan la violencia son causas explícitas de la ausencia de desarrollo de estas regiones. Cambió objetivos, caracterización regional y orientación para el PNR, con una característica económica vinculada a dicha falencia.

Así, entonces, el principio del PNR pasaba a ser este: "Propiciar oportunidades de desarrollo autosostenido para los grupos y zonas marginadas, con miras a lograr su integración económica, social e institucional, con las áreas más dinámicas del país”266. Aunque planteaba el desarrollo, reconocía la marginalidad y la descentralización como una herramienta de desarrollo regional y local, a fin de disminuir disparidades e inequidades regionales. Ello permitiría fortalecer funciones y competencias de gobiernos locales, así como la participación ciudadana en las decisiones públicas, y legitimaría al Estado en aquellos territorios donde no hacia presencia.

El gobierno de la 'Revolución Pacífica' reorienta el PNR con el principio de dar "apoyo institucional a los municipios, transfiriendo a las administraciones locales mecanismos de trabajo comunitario que ha desarrollado, habilitándolas para asumir directamente la gestión" ${ }^{267}$. De este modo se combinaba descentralización, paz y trabajo comunitario, desde cuatro estrategias: ampliar la participación en los consejos municipales de rehabilitación; garantizar una acción permanente y efectiva de las entidades nacionales en las zonas PNR; categorizar los municipios para temporalizar la intervención; y transferir gradualmente a los gobiernos subnacionales las responsabilidades de la administración del Plan en su área.

En las memorias del PNR hay un elemento estratégico de la política descentralizadora vinculada con los movimientos sociales: los Consejos de Rehabilitación: "Con los

265 Presidencia de la República, Consejería para la Reconciliación, Normalización y Rehabilitación y Secretaria de Integración Popular (1988). Plan nacional de rehabilitación. Una estrategia de desarrollo social y regional para la reconciliación 1986-1990. Bogotá, pág. 9.

266 BARCO,Virgilio (1987): Plan de economía social DNP. Pág., 498.

267 Presidencia de la República y DNP (1991): La Revolución Pacífica. Plan de Desarrollo Económico y Social 1990-1994. Bogotá, pág. 540 y ss. 
Consejos se ha forjado un instrumento donde el Estado y la sociedad, de manera continua y real, han podido suplir la función que equivocadamente cumplían los paros cívicos y las marcha campesinas" ${ }^{268}$. Este componente constituye una finalidad legitimadora de la descentralización. Para la evaluación de 1982 y 1994, la cobertura pasó de 159 a 450 municipios.

\section{8-2010, Plan Colombia y Acción Social}

Un aspecto de la intervención del Estado para la paz y el desarrollo regional fue el Plan Colombia, que combina "acciones de atención humanitaria con las de desarrollo, dejando atrás el tradicional esquema asistencialista" ${ }^{269}$. Allí se proponen tres enfoques de trabajo regional: sustitución de cultivos ilícitos por medio de programas y desarrollo alternativo; atención de la población desplazada; y desarrollo de acciones priorizadas y focalizadas hacia las regiones donde la violencia había asumido un carácter crítico. Por su parte, el primer gobierno de Uribe buscó ordenar la política territorial con la planificación del desarrollo:

Una organización político administrativa moderna, flexible, que reconozca las particularidades regionales y culturales y que active y jalone el desarrollo [...] y creación de capacidades internas en los territorios para que gestionen autónomamente su propio desarrollo ${ }^{270}$.

Así, se buscaban impulsar acciones en zonas deprimidas y en conflicto con "intervenciones diferenciales y flexibles adaptadas a las condiciones específicas del conflicto en las regiones" 271 , teniendo en cuenta tres fases: una de preparación, participación y priorización, otra de desarrollo de acciones priorizadas y la última de “consolidación de programas y proyectos hacia la autogestión del desarrollo regional y local"272. Estas proyectos buscaban intervenir, de acuerdo con la vocación del suelo y la expansión de los cultivos ilícitos, en:"a) zonas con alto potencial productivo y vocación

268 Plan Nacional de Rehabilitación, Programa Presidencial para la Convivencia (1994): Memorias del PNR 1982-1994. Bogotá, pág. 29.

269 Presidencia de la República y DNP (1999): Plan Nacional de Desarrollo 1998-2002: Cambio Para Construir la Paz. Bogotá, pág. 376.

270 Presidencia de la República y DNP (2003): Plan Nacional de Desarrollo 2002-2006. Hacia un Estado Comunitario. Bogotá, 2003, pág. 275.

271 Ibíd., pág. 70.

272 Ibíd., pág. 71. 
económica; b) zonas ambientalmente estratégicas especialmente del Sistema Nacional de áreas Protegidas; y c) zonas con cultivos ilícitos"273.

El segundo gobierno de Uribe identificó un problema del desarrollo regional, al encontrar que las acciones de intervención del Estado estaban desarticuladas. De este modo, propuso "articular políticas, programas y recursos de los diferentes niveles de Gobierno, a partir del reconocimiento de las particularidades y capacidades diferenciales de desarrollo de los territorios" ${ }^{274}$. Se reconocían diferencias regionales y necesidades de articular sector público, privado y comunitario, en función de fortalecer lo local para contribuir al desarrollo regional.

Caracterizada la región o el territorio, se analizan las capacidades endógenas por etapa de desarrollo. Con ello se busca que las acciones del gobierno diferencien las políticas según la fase de la entidad territorial, acabando así los desequilibrios ínter- e intrarregionales a partir del mejoramiento de la planificación y la gestión pública; el fortalecimiento institucional y financiero; el desarrollo económico local y regional. Las estrategias consistían en implementar apuestas productivas y regionalizar metas sectoriales; promover y fortalecer la capacidad fiscal de los territorios; e impulsar esquemas de organización y gestión acordes con los niveles y fases del desarrollo ${ }^{275}$.

A partir de la Declaración del Milenio, Colombia se comprometió a cumplir con ocho objetivos, que ayudan a "erradicar la pobreza extrema y el hambre". Para cumplirlos, considera la regionalización del país a partir del Índice de Condiciones deVida entre 1997 y 2003 en regiones, determinadas por una agregación de las unidades político-administrativas de las entidades territoriales. Estos territorios son: región del Atlántico, región oriental, región central, región del Pacífico, Orinoquía y Amazonía. Por departamentos son: Antioquia, Valle y San Andrés y Providencia; y la tercera, desde lo municipal, se concentraría en Bogotá D.C. y las regiones homogéneas en relación con el Índice de Condiciones de Vida, lo que "permite analizar el nivel de desarrollo y su cambio"276.

\section{Ibíd., pág. 74.}

274 Presidencia de la República y DNP (2007): Plan Nacional de Desarrollo 2006-2010: Estado Comunitario: Desarrollo para Todos. Bogotá, pág. 469.

275 Ibíd., pág. 475.

276 DPN y otros (s. f.): Los municipios colombianos hacia los Objetivos de Desarrollo del Milenio. Salud, educación y reducción de la pobreza. Departamento Nacional de Planeación, Programa de Naciones Unidas para el Desarrollo, Programa Nacional de Desarrollo Humano y Agencia de Cooperación Técnica Alemana al Desarrollo. Pág. 11 


\subsubsection{Las políticas locales}

Este apartado relaciona y acerca la integración de elementos generales del desarrollo regiolocal con prácticas de regionalización de los departamentos, a partir de la identificación de políticas, instrumentos y regionalización de los territorios SAN.

Políticas descentralizadoras. En Colombia hay, desde inicios del siglo XX (Ley 4 de 1913), normas sobre el régimen político municipal, su organización y competencias de las entidades departamentales y municipales. Puede hablarse de políticas locales en la segunda mitad del siglo: con la política de descentralización de los años ochenta hay reformas institucionales, con el fortalecimiento fiscal, administrativo, político y de participación de la ciudadanía, que se profundiza con la Constitución de 1991.

Instrumentos de acción local. Los avances de la descentralización crean instrumentos para lo municipal y lo distrital, con mínimos de autonomía territorial e impulsando la planeación pública, la participación ciudadana, las veedurías y los controles independientes de las instituciones del Estado. Los planes públicos de manejo interno del territorio y el plan de desarrollo municipal tienen una vigencia de 4 años; por su parte, los planes de ordenamiento territorial tienen vigencia de 12 años y permiten identificar elementos estructurales ambientales, urbanos y rurales del territorio.

Por otro lado, en los planes contextuales, el plan de ordenamiento y manejo de cuencas hidrográficas es realizado por una o varias corporaciones autónomas para prever manejos racionales de los recursos naturales en especial del agua. También se encuentran aquí el plan departamental de desarrollo y el plan nacional de desarrollo.

División político-administrativa. En las regiones de estudio se asumirá determinar la capital del departamento como eje dinamizador, en tanto el departamento se refiere al contexto del eje o su región inmediata. Las regiones SAN son generadas por el eje dinamizador a partir de la demanda de alimentos.

En Colombia, las funciones y competencias de los departamentos son: participar en la elaboración y ejecución de los planes y programas nacionales de desarrollo económico, social y de obras públicas, y coordinar la ejecución de estos; cumplir funciones y prestar servicios nacionales, o coordinar su cumplimiento y prestación en las condiciones que prevean las delegaciones que reciban y los contratos o convenios que para el efecto celebren; prestar asistencia administrativa, técnica y financiera a los municipios, 
promover su desarrollo y ejercer sobre ellos la tutela que las leyes señalen; colaborar con las autoridades competentes para la conservación del medioambiente y preservación de los recursos naturales.

\subsubsection{Recapitulación}

En este capítulo se relacionan los vínculos generales e históricos del territorio y las dinámicas de seguridad alimentaria nutricional. Inicia con la revalorización del territorio, analizando y describiendo las condiciones del capitalismo hoy, y sintetizando las grandes etapas de este desde el siglo XV hasta las condiciones del siglo XXI. Se abordan aquí los procesos tecnológicos, las relaciones laborales, las infraestructuras acordes con el territorio y exigidas por la globalización, y el papel de las empresas transnacionales de alimentos en el escenario global y local.

Otro factor que se ha tenido en cuenta son las relaciones intergubernamentales, donde las condiciones de lo local adquieren otra importancia, a través de las reformas del Estado desde un proceso descentralizador. En este contexto, lo local asume formas de mejorar las condiciones del territorio. Los cambios en las funciones del Estado implican pasar del "Estado de bienestar keynesiano a un estado de trabajo shumpeteriano". Las políticas territoriales plantean nuevas relaciones entre territorio, tecnología y empleo, por los cambios en las relaciones de capital y el trabajo en los territorios y países.

Al entrelazar las relaciones históricas territorio y producción de agroalimentos, se periodizan las etapas históricas económicas de la alimentación humana, lo cual ayuda a identificar las condiciones y la evolución de la producción agroalimentaria de acuerdo con la relación que el hombre ha tenido con la naturaleza.

Por último, se analizan las relaciones territoriales en Colombia con la producción de agroalimentos; para ello, se introducen las formas de apropiación del territorio y su disposición para tal fin, a partir de observaciones realizadas desde la década del cincuenta del siglo XX, con la inequidad y el uso irracional por parte de los hacendados. Se mira además el conflicto colombiano vinculado con el territorio y el problema agrario, así como las políticas territoriales de fines del siglo XX y principios del XXI. 


\section{CAPITULO VII. LA CADENA ALIMENTARIA}

“Alimentar la sociedad implica también alimentar los tejidos sociales que la constituyen”2277.

$\mathrm{E}$ ste capítulo aborda los puntos que desarrollan el trabajo en Colombia, los cuatro ejes dinamizadores y sus regiones de análisis. Uno contextualiza la cadena alimentaria y el sistema alimentario, mediante el análisis de las acciones del gobierno relacionadas con estos componentes, así como otros aspectos, a saber: las características generales de la cadena alimentaria y sus relaciones con la calidad, la participación de los diferentes actores y la competitividad, la inocuidad y el medioambiente presentes en su interior. Se inicia desde la pregunta: ¿cuál parte de la cadena ha de tener mayor atención en relación con la inocuidad de los alimentos? La respuesta: todas presentan el mismo nivel de atención y regulación. Otro contexto son las condiciones institucionales y políticas de la SAN en el país, a partir de las políticas agrarias, los planes y las políticas específicas de seguridad alimentaria nutricional.

El segundo apartado analiza la disponibilidad, la cual tiene varios puntos: los elementos generales de esta, la evolución del concepto y su aplicación, las relaciones entre movilidad de cultivos y alimentos. El siguiente aspecto muestra las condiciones y políticas de la disponibilidad, la institucionalidad y el conflicto rural en Colombia. El tercero profundiza los componentes estructurales del conflicto rural colombiano y sus efectos sobre la disponibilidad de alimentos, vinculado con los usos de la tierra, el desplazamiento, el despojo y la concentración de tierras. El cuatro relaciona las condiciones de disponibilidad y los conflictos con las diferentes políticas públicas. Por último, se trabajan las disponibilidades de agroalimentos a partir del área, la producción, los tamaños de la propiedad y los tipos de cultivos transitorios y permanentes en el nivel nacional, en el departamento de los ejes dinamizadores y en cada uno de ellos. Además, se abordan el uso y la concentración de la tierra, el desplazamiento, el despojo y las políticas de los agroalimentos, comparando la disponibilidad departamental y las demandas del eje.

277 MUCHNIK, José (2004): "Identidad territorial de los alimentos: alimentar el cuerpo humano y el cuerpo social". En Territorios y sistemas agroalimentarios locales. Varios Autores. Universidad Nacional de Colombia, Red de Desarrollo Rural y Seguridad Alimentaria, Bogotá, pág. 21. 
También se analiza la dinámica de distribución de agroalimentos: las características generales de la distribución, su evolución y los vínculos de origen y destino de los agroalimentos, el caso colombiano y, por último, la distribución en los ejes dinamizadores, teniendo en cuenta para cada uno condiciones de distribución de algunos productos de la canasta familiar, gasto de las familias según canales de distribución y reglamentaciones de ordenamiento territorial.

En el aspecto de las condiciones de acceso, se tratan las generales que determinan el acceso de los individuos a los alimentos, las relaciones entre acceso y cultura, y las características e intervenciones en el acceso. Esto último se despliega a partir de dos niveles: el nacional, que analiza el IPC de alimentos, el empleo y los programas rurales y urbanos; y los ejes dinamizadores, teniendo en cuenta, para cada uno, las características sociodemográficas, el índice de precios de los alimentos, el empleo, las políticas y los programas.

Por último, respecto al uso y la utilidad biológica, se trabaja lo referido a las relaciones entre nutrición, demandas calóricas y proteicas, analizando las relaciones entre cadena alimentaria, nutrición, inocuidad y acciones del gobierno en la salud, la alimentación y la nutrición. Se muestran también las particularidades del uso biológico y la utilidad de los alimentos en el nivel nacional, sin anotar la información para los individuos en los ejes.

\subsection{CONTEXTUALIZACIÓN DE LA CADENA ALIMENTARIA, EL SISTEMA ALIMENTARIO Y EL GOBIERNO}

Analizar la cadena alimentaria ${ }^{278}$ requiere identificar sus componentes: disponibilidad, distribución, acceso y uso biológico, al igual que las dinámicas de cada uno de estos en sus relaciones con el entorno. Las características de cada componente determinan la forma, el tipo de infraestructura, la organización social, económica, política, y la ubicación espacial de la población, lo cual hace posible entender los procesos de cada uno. Hay que tener en cuenta que la ubicación urbana de la mayoría de la población cambia las lógicas culturales y de infraestructura para la alimentación.

278 En este caso, se entiende la cadena alimentaria como un sinónimo de cadena agroalimentaria, en la medida en que está cruzada por diferentes factores. En específico, interesa aquí el punto de vista del manejo de la información, en especial de los alimentos agropecuarios, aquellos que van sin transformación de la parcela a la mesa. 
Las condiciones de la cadena alimentaria y el territorio relacionan una o varias partes de esta; por ejemplo, en la zona rural, el componente central es la disponibilidad, que vincula controles en el uso de insumos y tipos de aguas para la producción, la estructura y tenencia de la tierra, los conflictos de uso y aptitud del suelo, de violencia rural, despojo y concentración de la propiedad, como también la distribución y sus condiciones de acopio e infraestructura y el acceso para la población campesina. Cuando el territorio se vincula a la producción de alimentos, puede construirse una parte de las regiones SAN, como contexto de los ejes dinamizadores.

Por otro lado, en la zona urbana, con la mayoría de la población, hay tres componentes: la distribución, el acceso y el uso biológico. Esta investigación identifica cuatro ciudades capitales o ejes dinamizadores, donde los controles pasan por las condiciones de distribución de acceso y uso biológico, con procesos administrativos, económicos, logísticos y de inocuidad por la política pública de salud pública, integrada a estos componentes.

Machado, desde el concepto de sistema alimentario, contextualiza la cadena alimentaria integralmente relacionada con sus procesos internos y del entorno:

En el sistema alimentario, la agricultura es solo un eslabón de una cadena que se inicia con la producción en el campo y termina en el consumo de alimentos (procesados o no), pasando por el sector de la transformación industrial, el comercio y la distribución. El funcionamiento del sistema alimentario incluye el suministro de insumos, semillas y maquinaria a la agricultura para iniciar el proceso, y la disponibilidad de una serie de servicios o asistencia institucional para su buen desempeño ${ }^{279}$.

El sistema alimentario explica las relaciones de la cadena alimentaria, las sociales, las del hombre con la naturaleza, así como los contextos institucionales que inciden en

279 MACHADO C., Absalón (2003): "El papel de la agricultura y los sistemas alimentarios". En Ensayos sobre seguridad alimentaria. Universidad Nacional de Colombia, Red de Desarrollo Rural y Seguridad Alimentaria, Bogotá, pág. 57. 
la producción, la distribución y el consumo de alimentos ${ }^{280}$. Soler y Pérez consideran acerca del sistema agroalimentario globalizador:

[Es] el resultado de un proceso de construcción histórica marcado por la creciente mercantilización de la alimentación, el intento de control de los procesos ecológicos y la subordinación de la naturaleza a través de la tecnología y la desigualdad en el reparto social de los productos agroalimentarios ${ }^{281}$.

En la lógica del sistema de seguridad alimentaria,la cadena alimentaria muestra componentes vinculados a procesos aparentemente independientes, pero ayuda a entender cada uno, mientras el concepto y la lógica del sistema alimentario los muestra integralmente.

Por su parte, el Libro blanco de la seguridad alimentaria en Europa considera que las medidas y los controles para la inocuidad llevan "a extender al origen de la cadena, hacia atrás, la exigencia de la higiene y la seguridad"282.Por lo tanto, el sector primario debe tender hacia una producción más limpia, con productos nutritivos; en este sentido, hay una mirada de la cadena alimentaria en su conjunto: en calidad, inocuidad y sanidad, lo que implica operar como sistema en cada uno de sus componentes (véanse las figuras 7.1.1, 7.2.1, 7.3.1, 7.4.1 y 7.5.1 en este capítulo).

En la estructura de distribución, hay un aumento y una concentración de supermercados nacionales e internacionales, o su combinación. Además, se evidencian cambios en las prácticas del consumo que impone el ritmo de vida urbana:

280 "Se entiende por sistema alimentario el conjunto de interacciones, subordinaciones, relaciones técnicas y de intercambio, que establecen los agentes económicos, sociales e institucionales, directamente ligado al proceso que va desde la producción hasta el consumo y que contemplan las fases o esferas de actividad de: producción, comercialización, transformación, distribución, consumo y otras que le son complementarias, como la de asistencia de bienes y servicios, la de control y regulación proveniente del Estado, y la del sector externo". Oficina de Asesores del Presidente (1979): "Notas analíticas y lineamientos metodológicos para el proyecto Sistema Alimentario Mexicano (materiales de trabajo)". México, pág. 36, citado en MACHADO C., Absalón (1986): El papel de la agricultura... Op. cit., pág. 58.

281 SOLER M. Marta y PÉREZ N. David (2013): "Canales cortos de comercialización alimentaria en la construcción de sistemas agroalimentarios alternativos". En Procesos hacia la soberanía... Op. cit., pág. 63.

282 NEIRA GONZÁLEZ, María (2003): “En qué dirección va la seguridad alimentaria”. En Revista de Salud Pública, n. ${ }^{\circ}$ 3, mayo-junio, pág. 310. 
Dos de las causas y consecuencias más visibles de la transformación y consolidación de los sistemas alimentarios mundiales: desde la producción agrícola, pasando por el comercio, la elaboración y venta al por menor, hasta el consumo de alimentos [...] de las zonas urbanas, que cada vez dependen más de los alimentos elaborados y de las comidas adquiridas en los puestos ambulantes y en los restaurantes de comida rápida ${ }^{283}$.

Este nuevo ritmo urbano de consumo de alimentos exige acciones de control sobre la oferta para el acceso de la población a los alimentos, lo cual pasa por las competencias de los gobiernos subnacionales. En este sentido,Schejtman plantea tres objetivos para analizar la cadena:

[Identificar] conflictos: entre la esfera agrícola, la industria, el comercio y entre diversos tipos de productores; aumentar la transparencia de las relaciones y permitir el acceso a la información de los agentes más débiles; por último, introducir consideraciones sobre sustentabilidad ambiental ${ }^{284}$.

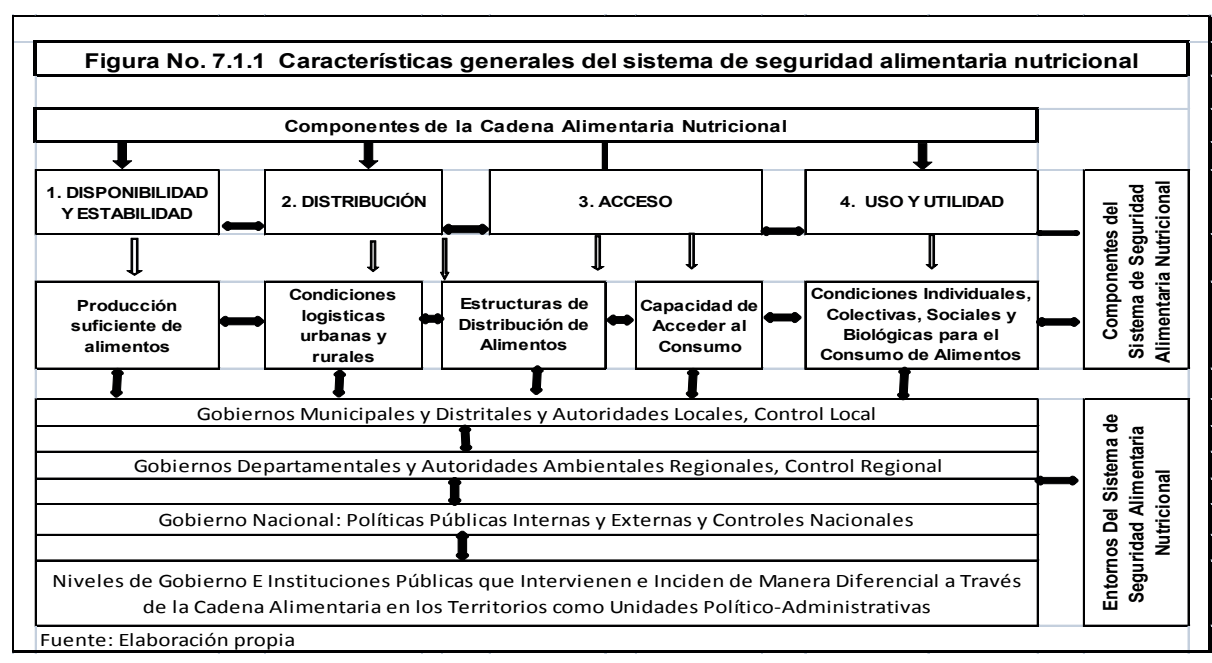

283 FAO (2004): El estado de la inseguridad alimentaria en el mundo... Op. cit., pág. 19.

284 SCHEJTMAN, Alexander (1994): Economía política de los sistemas alimentarios en América Latina. FAO-Cepal, Santiago de Chile, pág. 10. 
Hoy, la cadena requiere actores como el consumidor, y el regulador y organizador de políticas (los gobiernos nacional y subnacionales), con competencias en cada fase de la misma.

\subsubsection{Cadena alimentaria y calidad}

En el interior de la cadena alimentaria hay que ver las condiciones de calidad en la disponibilidad, la distribución, el acceso y el uso biológico, lo que implica que en cada fase se efectúen controles sobre los procesos. La visión sistémica permite entender relaciones entre procesos, instituciones, actores y organizaciones, y cómo opera cada uno para que la calidad sea una cuestión pública estatal, de responsabilidad privada, comunitaria y familiar. ¿Qué se entiende por calidad en los alimentos? Vargas ofrece la respuesta:
El conjunto de propiedades biológicas, químicas y físicas que determinan el grado de adecuación de un alimento o materia prima alimenticia, a los requerimientos sanitarios, nutricionales, sensoriales y físico mecánicos que él y ella deben satisfacer para su consumo humano directo 285 .

La calidad está presente en toda la cadena, en cada proceso y subproceso. Este último está referido a productos específicos, pues su calificación depende de factores específicos:

Cada producto, cada situación, exige un análisis particular. El tipo de mercado, el tipo de instituciones, los saberes y las técnicas utilizadas, las normas jurídicas que conciernen a los productos y los recursos naturales, condicionarán el proceso de calificación ${ }^{286}$.

A su vez, analizar las condiciones en que se desarrollan las actividades de la cadena, con sus restricciones de tiempo, modo y lugar para el control, implica tener en cuenta lo siguiente:

En los países del sur observamos a menudo una fragilidad de las estructuras de control; en esos casos es aún más importante no quemar

285 VARGAS O., Wenceslao (1991): Fundamentos de ciencia alimentaria. Fundación para la Investigación Interdisciplinaria y la Docencia (FIID), Bogotá, pág. 54.

286 MUCHNIK, José (2004): Identidad territorial de los alimentos... Op. cit., pág. 29. 
etapas, no proceder por decretos, sino dar el tiempo necesario para que los productores se organicen, concierten y establezcan, ellos mismos, las modalidades de control necesarias para que se respeten las normas establecidas. Esta dinámica ascendente (botton up) es sin duda más larga, pero muy probablemente más eficaz ${ }^{287}$.

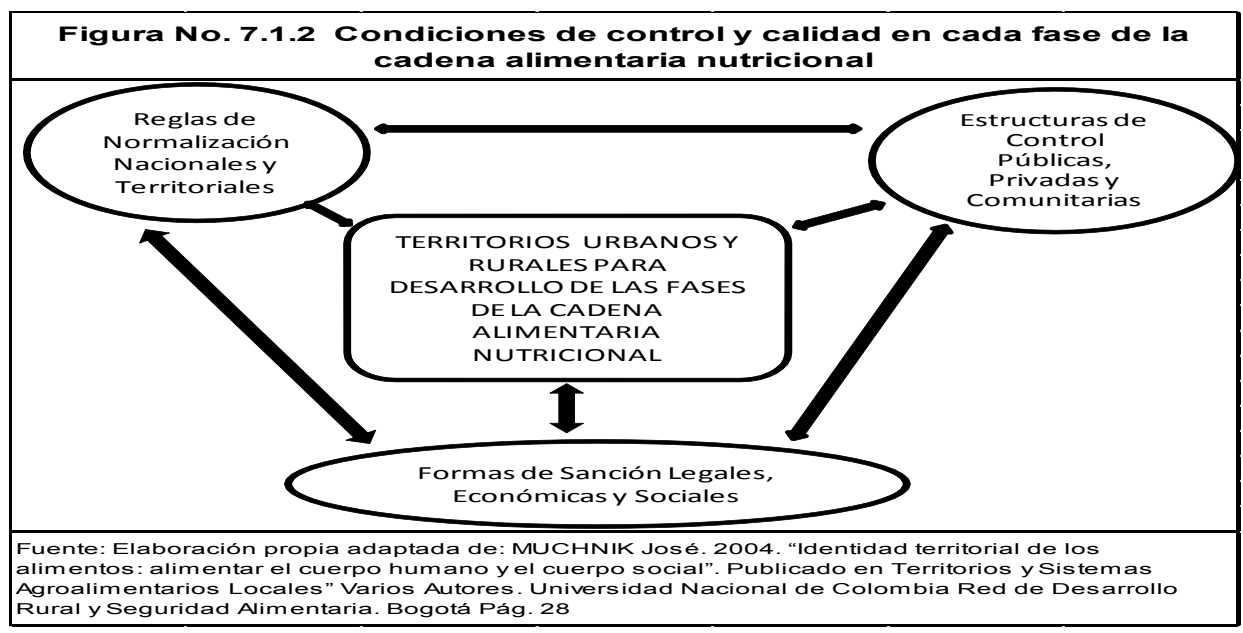

Sin embargo, por la desarticulación institucional, se tiene una baja capacidad para aplicar controles técnicos y coactivos en cada fase o subproceso, por desconocimiento de procesos o captura del Estado. ¿Cuáles son los controles ejercidos en cada uno de los procesos de la cadena alimentaria?, ¿quién o quiénes ejercen dichos controles?, ¿quién o quiénes determinan los controles y de qué tipo?, ¿los controles se realizan antes o después de que se desarrollan los procesos, o se realizan de forma simultánea al desarrollo de cada proceso? Estas son preguntas que orientan los análisis sobre la calidad alimentaria (véanse las figuras 7.1.1 y 7.1.2).

La calidad esencial en cualquier producto alimenticio se ve en las condiciones del sistema global de alimentación, tal como lo analiza Duch:

[Hay] alimentos baratos de tres tipos: los de baja calidad (las verduras y frutas de invernadero), los de dudosa calidad (los productos que contienen elementos transgénicos), y a veces, los claramente dañinos (alimentos contaminados con dioxinas), [...] jugar con alimentos

287 Ibíd., pág. 29. 
de orígenes tan diversos ha requerido incrementar las medidas de seguridad alimentaria ${ }^{288}$.

Duch ve que desde el sistema global, la calidad puede fácilmente diluirse en la disponibilidad de los alimentos, lo cual exige mayores controles allí donde aparentemente no hay problemas más que el de producir.

\subsubsection{Cadena alimentaria, participación y competitividad}

La competitividad requiere la participación de diferentes actores en cada parte de la cadena. El IICA considera estos conceptos como estratégicos:

La conformación de espacios de discusión y diálogo formales y permanentes — con participación de representantes de los actores de los distintos eslabones y del gobierno mismo- donde se definan políticas y acciones específicas para fortalecer la competitividad y donde los actores puedan coordinarse mejor ${ }^{289}$.

La cadena alimentaria, vista sistémicamente, con participación social en la construcción, ejecución y evaluación de la política pública, se analiza en el interior de la cadena productiva, en diferentes espacios de discusión, regiones y localidades del país ${ }^{290}$, con sus correspondientes desarticulaciones. El estudio del MADR-IICA los caracteriza así2 ${ }^{291}$ :

288 DUCH, Gustavo (2011): Alimentos bajo sospecha. Recetas para una alimentación inteligente. Los libros del Lince, Barcelona, pág. 16.

289 HERNÁNDEZ, Julio y HERRERA, Danilo (2003): Cadenas alimentarias. Políticas para la competitividad. COMUNIICA, n. ${ }^{\circ}$ 3, etapa 2, julio-septiembre, pág. 17.

290 En este punto es necesario resaltar el trabajo que se desarrolló en el Observatorio de Agrocadenas, del Ministerio de Agricultura y Desarrollo Rural e IICA; en especial, la publicación del 2006: Agroindustria y competitividad. Estructura y dinámica en Colombia 1992-2005. Allí se trabajando los casos de las agroindustrias de: grasas y aceites; azúcar; chocolates; papa; plátano; yuca; frutas; hortalizas; arroz; lácteos; carnes frescas y alimentos balanceados: "El conjunto de industrias transformadoras de bienes agropecuarios alimenticios aquí estudiadas representa el $48.4 \%$ del valor de la producción de la industria alimentaria, que a su vez representa el $14.2 \%$ de la industria manufacturera nacional” (pág. 13).

291 Ministerio de Agricultura y Desarrollo Rural e IICA, Observatorio de Agrocadenas (2006): Agroindustria y competitividad. Estructura y dinámica en Colombia 1992-2005. Las citas son tomadas de este texto. 


\begin{tabular}{|c|c|c|c|c|c|c|c|c|}
\hline \multirow[b]{2}{*}{ Agroindustria de Alimentos } & \multicolumn{4}{|c|}{$\%$ Número de establecimientos } & \multicolumn{4}{|c|}{$\%$ Ventas } \\
\hline & \begin{tabular}{|c|} 
Grande \\
Empresa \\
\end{tabular} & \begin{tabular}{|l|} 
Mediana \\
Empresa \\
\end{tabular} & \begin{tabular}{|l|} 
Pequeña \\
Empresa \\
\end{tabular} & \begin{tabular}{|c|} 
Micro \\
Empresa \\
\end{tabular} & \begin{tabular}{|c|} 
Grande \\
Empresa \\
\end{tabular} & \begin{tabular}{|l|} 
Mediana \\
Empresa \\
\end{tabular} & \begin{tabular}{|l|} 
Pequeña \\
Empresa \\
\end{tabular} & \begin{tabular}{|c|} 
Micro \\
Empresa \\
\end{tabular} \\
\hline Procesamiento papa, plátano y yuca & 3.2 & 1.6 & 5.6 & 89.6 & 96.3 & 0.8 & 2.5 & 0.4 \\
\hline $\begin{array}{c}\text { Transformación de frutas y } \\
\text { hortalizas }\end{array}$ & 2.4 & 2.2 & 7.8 & 87.7 & 71.8 & 15.8 & 10.4 & 2.0 \\
\hline Lácteos y derivados & 3.3 & 2.2 & 7.5 & 87.0 & 92.7 & 4.1 & 2.6 & 0.5 \\
\hline Chocolatería & 5.7 & 1.9 & 9.4 & 83.0 & 97.1 & 1.2 & 1.7 & 0.0 \\
\hline Plantas de beneficio (res-cerdo) & 14.0 & 7.0 & 20.2 & 58.8 & 86.0 & 3.7 & 4.5 & 5.7 \\
\hline Plantas de beneficio (pollo) & 34.2 & 6.8 & 6.8 & 52.1 & 98.0 & 1.2 & 0.4 & 0.3 \\
\hline Fabricación de aceites y grasas & 41.0 & 5.0 & 20.0 & 34.0 & 98.3 & 0.9 & 0.6 & 0.2 \\
\hline Molinería de arroz & 22.5 & 15.7 & 28.4 & 33.3 & 93.7 & 4.3 & 1.9 & 0.1 \\
\hline Azúcar & 100.0 & 0 & 0 & 0 & 100.0 & 0 & 0 & 0 \\
\hline
\end{tabular}

1) La agroindustria en Colombia tiene mayoría de microestablecimientos y pequeñas empresas: "No incompatible con los altos grados de concentración industrial. Se genera, en consecuencia, un dualismo tecnológico y el desarrollo de esquemas de cooperación y/o subordinación entre la pequeña y gran empresa"292 (véase la tabla 7.1.1, que muestra el número de establecimientos y ventas durante el 2003 del sector agroindustrial de alimentos).

2) La concentración agroindustrial medida por ventas se analiza a partir de cuatro categorías: "Competitiva: los cuatro mayores establecimientos concentran menos del 250 de las ventas de su propia rama. Oligopolio levemente concentrado: los cuatro mayores establecimientos explican entre el $25 \mathrm{~d}$ y el $50 \mathrm{y}$ de las ventas de su propia rama. Oligopolio moderadamente concentrado: los cuatro mayores establecimientos explican entre el $50 \mathrm{~d}$ y el $75 \mathrm{y}$ de las ventas de su propia rama. Oligopolio altamente concentrado: los cuatro mayores establecimientos explican entre el 751 y el $100 \mathrm{y}$ de las ventas de su propia rama" 293 .

Las características de la agroindustria colombiana de alimentos (tabla 7.1.1) y las categorías definidas muestran un mercado de carácter oligopólico, altamente concentrado en 8 sectores, y moderadamente concentrado en el sector de frutas y hortalizas. No existe la categoría competitiva para este mercado. Hoy, frente a la globalización, los sistemas agroalimentarios locales presentan diversas opciones:

292 Ibíd, pág. 15.

293 Ibíd., pág. 17. 
Solo en la medida en que se organicen como sistemas con identidades y pertenencias territoriales y con vínculos institucionales adecuados, podrán resistir el mundo de la globalización y la competencia más abierta. No son los productores solo los que pueden defenderse; es una sociedad, local o regional, la que debería defender un sistema que le es propio y en el cual fundamenta su futuro y su trabajo"294.

En esta dirección, los sistemas han de ser abiertos, articulados desde la sociedad, la economía, la cultura, la política y el Estado, con sus distintas estructuras.

\subsubsection{Cadena alimentaria, inocuidad y medioambiente}

La inocuidad para la seguridad alimentaria nutricional busca que los alimentos no estén contaminados y sean nutritivos. Al respecto, la FAO plantea:

La inocuidad alimentaria está relacionada con la ausencia de peligros en los alimentos [...] latentes en cualquier etapa de la cadena alimentaria, [...] los alimentos, los productos alimenticios o sus materias primas pueden sostener sustancias tóxicas para el consumidor, las cuales forman parte de la composición natural del producto, o son adquiridas o incorporadas durante la manipulación, elaboración y tratamientos ${ }^{295}$.

En este sentido, se necesita saber: ¿cuál es la historia de manejo de la inocuidad en cada proceso? La respuesta explica la inocuidad y la nutrición a través de la cadena; y ¿cuál parte de la cadena ha de tener mayor atención en relación con la inocuidad de los alimentos? Todas las partes deben tener el mismo nivel de atención y regulación. La FAO reconoce en este sentido:

La producción, elaboración, comercialización y el consumo de alimentos comparten la responsabilidad del suministro de alimentos inocuos, sanos y nutritivos. Los principales interesados incluyen a agricultores, pescadores, operadores de mataderos, elaboradores de alimentos, transportistas, distribuidores al por mayor y al por menor

294 MACHADO,Absalón (2004): Seguridad alimentaria y sistema agroalimentario... Op. cit., pág. 47.

295 VARGAS, Wenceslao (1991): Fundamentos de ciencia... Op. cit., pág. 54. 
y consumidores, así como a los gobiernos, que tienen la obligación de proteger la salud pública ${ }^{296}$.

Con estos parámetros, los instrumentos y diseños de políticas públicas de SAN deben velar por que no haya contaminación en la cadena, así como exigir integralidad e intersectorialidad para el control en las políticas de gobierno, tanto en las acciones privadas como en las organizaciones sociales. La Conferencia Regional FAO/OMS plantea sobre la inocuidad de los alimentos:

La visión de cadena agroalimentaria requiere redefinir los roles del estado y del sector privado, no solo considerando las instituciones encargadas de velar por la salud pública, sino contemplando la interacción con los organismos de agricultura y producción, de ambiente de defensa del consumidor. Se requiere en definitiva, articulación y coordinación por parte de los órganos del estado en los diversos niveles ${ }^{297}$.

La inocuidad debe asegurarse desde un trabajo integrado, multidisciplinario y sistémico, a partir de una política pública de SAN que defina reglas en el interior de la cadena alimentaria y tenga en cuenta lo siguiente:

[En las zonas rurales,] los agricultores necesitan también adoptar nuevas decisiones en los planos tecnológico y agrícola para satisfacer las demandas de un régimen saludable e inocuo como consecuencia de los nuevos reglamentos y normas, los cambios de los hábitos mundiales de consumo ${ }^{298}$.

296 FAO (2003): Estrategia de la FAO relativa al enfoque de calidad e inocuidad de los alimentos basado en la cadena alimentaria (documento marco para la formulación de la futura orientación estratégica). Comité de Agricultura, $17^{\circ}$ período de sesiones, Roma, 31 de marzo-4 de abril.

297 FAO y OMS (2005): Garantizar la inocuidad de los alimentos en los ámbitos de la producción y la elaboración. Documento preparado por Costa Rica para la Conferencia Regional FAO/ OMS, sobre inocuidad de los alimentos para las Américas y el Caribe. San José de Costa Rica, diciembre, pág. 77.

298 FAO (2003): Estrategia de la FAO relativa al enfoque de calidad e inocuidad de los alimentos basados en la cadena alimentaria... Op. cit., pág. 80. 
En los ejes dinamizadores, el abastecimiento presenta ventajas locales sobre el control de la cadena, que, al no realizarse resultan peligrosos; controles locales de las Secretarías de Salud y Medio Ambiente, regionales a través de las Corporaciones Autónomas Regionales (CAR), y nacionales con el Instituto Nacional de Vigilancia de Medicamentos y Alimentos (INVIMA), sobre los diversos procesos que afectan la cadena alimentaria. Las competencias públicas y las responsabilidades sociales, técnicas y económicas para la inocuidad de los alimentos envuelven a diferentes actores:

\begin{abstract}
[A] todos los actores de este sistema formado por la gente del campo; la distribución, el transporte y el comercio; los responsables de los controles sanitarios, la administración y también, claro, la población consumidora. Estamos todos en un mismo barco pero en camarotes $\operatorname{separados}^{299}$.
\end{abstract}

Lo anterior exige una información confiable del contenido nutricional y de inocuidad de los alimentos, así como una acción integral institucional y territorial sobre el control de los procesos.

\title{
7.1.4. Condiciones institucionales y políticas de SAN en Colombia
}

En Colombia, las políticas vinculadas con seguridad alimentaria se presentan por los gobiernos en los territorios, con exigencias de las políticas internacionales. Esto plantea unas preguntas para analizar la política de SAN: ¿en qué consiste el sistema alimentario colombiano?, ¿en qué consiste el sistema nutricional colombiano?, ¿cómo se relacionan e integran estos entre sí y con el resto de la sociedad, la economía, el medioambiente, los derechos individuales y colectivos, los gobiernos, el Estado y el modelo de desarrollo?, ¿cuáles son las relaciones de los dos sistemas con el contexto internacional institucional, ONU, FAO, OMC, Unesco, así como en los acuerdos con otros países de comercio, tecnología, patentes, cuotas, precios, medidas sanitarias de algunos de los productos?

Las anteriores preguntas llevan a discutir las políticas y competencias sectoriales del SSAN, al igual que las acciones de intervención a partir de la consideración de la FAO:

Insistir en el carácter integral que deben tener las políticas de seguridad alimentaria, cuyos alcances superan ampliamente los aspectos

299 DUCH, Gustavo (2011): Alimentos bajo sospecha... Op. cit., págs. 63-64. 
directamente relacionados a la promoción de la producción agraria o los programas de apoyo alimentario a población vulnerable ${ }^{300}$.

Las investigaciones desde las políticas económicas y sociales exigen que estas empiecen por tener objetivos similares e integrados.

\subsubsection{Política económica}

Vincular acciones de las políticas macro contra la pobreza requiere tener en cuenta que “evitar la pobreza a largo plazo es solo parte de una política alimentaria eficaz [...] a varios niveles gubernamentales" ${ }^{301}$. Estas políticas requieren más integración que otras en las acciones macro de los Gobiernos nacional y los gobiernos territoriales, con la sociedad y las organizaciones sociales.

Timmer, Falcón y Pearson proponen políticas alimentarias nacionales a partir de: crecimiento eficiente en los sectores alimentario y agrícola; mejoramiento de la distribución del ingreso, a través de la creación de empleos; estado nutricional satisfactorio, con la provisión de un nivel mínimo de subsistencia; y seguridad alimentaria adecuada, como protección contra cosechas deficientes, desastres naturales o suministros y precios mundiales inciertos de los alimentos ${ }^{302}$. Estas propuestas avanzan para analizar el problema alimentario y la política de seguridad alimentaria nutricional alrededor de la cadena.

Además, se requiere que la orientación de la política tenga en cuenta las relaciones externas. Así, la FAO plantea: "En el contexto de las relaciones internacionales, los acuerdos de libre comercio requieren, para garantizar el bienestar de los ciudadanos de los países involucrados, una negociación en igualdad de condiciones"303. Por consiguiente, las políticas alimentarias deben tener presente esta asimetría de las relaciones entre países.

300 FAO y Comunidad Andina (2004): Comunidad Andina: factores macroeconómicos, comerciales, sectoriales y la seguridad alimentaria. Pág. 111.

301 TIMMER C. Peter, FALCÓN, Walter y PEARSON, Scott (1985): Análisis de políticas... Op. cit., pág. 25.

302 Ibíd., págs. 27 y ss.

303 FAO y Comunidad Andina (2004): Comunidad Andina: factores macroestructurales... Op. cit., pág. 77. 


\subsubsection{Políticas sectoriales de seguridad alimentaria}

Los análisis de la política pública de SAN muestran que ha sido dispersa en las acciones y en concepciones y en los últimos tiempos trata de articular las acciones con mínimos de integralidad institucional.

Las intervenciones del SSAN a través de la cadena alimentaria ubican tres espacios: uno, identifica acciones desde entidades privadas, la iglesia y las ONG, con una visión caritativa y en función del acceso, para aliviar el hambre. Presente desde el siglo XIX, hoy continúa como caridad y responsabilidad social.

Otra, lo sectorial, desarticulada en acciones del Estado y el mercado, en la cadena alimentaria; las intervenciones del Estado de bienestar, y los procesos del mercado orientador de esta.

Por último, el Estado que busca una política pública integral de la SAN en el 2008, que plantea: principios orientadores, objetivos generales y específicos, estrategias, líneas de política y estructura institucional.

En la tabla 7.1.2, se identifican las políticas orientadas según cada parte de la cadena alimentaria, y los componentes transversales en cada una. Con la política de descentralización se transfieren recursos a los municipios: parte de las transferencias automáticas del Gobierno nacional a los subnacionales con asignaciones y competencias para las entidades territoriales, de aplicación obligatoria en seguridad alimentaria local.

Los planes nacionales de desarrollo identifican problemas de SAN, la mortalidad por desnutrición en niños menores de un año y en madres gestantes y, por otro lado, las orientaciones comerciales, de desarrollo y crecimiento económico.

Ante la disponibilidad hay acciones orientadas por los planes nacionales de desarrollo que buscan resolverla con infraestructura de riego, para que crezca la producción agrícola, expandiendo la frontera agrícola, utilizando intensamente la superficie con nuevas variedades e insumos y diversificando cultivos ${ }^{304}$.

304 Presidencia de la República-DNP (1991). La Revolución Pacífica Plan de Desarrollo Económico y Social 19900-1994. Bogotá. 
Posteriormente, estas políticas para el desarrollo rural cambian y conciben la disponibilidad a partir de que: "la estrategia de desarrollo rural debe privilegiar la visión sectorial y trascender la dimisión de los problemas agrícolas y pecuarios e involucrar todos los aspectos relacionados con la dinámica social" ${ }^{305}$; con coordinación interinstitucional; con núcleos de desarrollo productivo para reconstruir el "tejido social rural”; la reforma agraria, la educación rural, el apoyo a la producción interna de alimentos con:

[...] tratamiento preferencial al crédito de producción y comercialización [...] reclasificando el riesgo para acceder a créditos por parte del sector agropecuario, mejorando infraestructura y estableciendo los mecanismos de fomento a la producción y al consumo interno de alimentos ${ }^{306}$.

\begin{tabular}{|c|c|c|c|c|c|}
\hline \multicolumn{6}{|c|}{$\begin{array}{c}\text { Tabla No. 7.1.2 Colombia Políticas Públicas Vinculadas con el Sistema Seguridad Alimentaria y la } \\
\text { Cadena Alimentaria hasta el } 2008\end{array}$} \\
\hline Dis ponibilidad & \multicolumn{3}{|c|}{ Dis tribución } & Acceso & Uso Biológico \\
\hline \multirow{2}{*}{$\begin{array}{l}\text { Plan de Mejoramiento en } \\
\text { producción de frutas } \\
\text { Reforma Agraria Plan de } \\
\text { Manejo del Campo } \\
\text { Acceso a Factores } \\
\text { Productivos zona rural }\end{array}$} & \multirow{2}{*}{$\begin{array}{c}\text { Desarollo del } \\
\text { Mercado Interno y } \\
\text { externo para } \\
\text { pequeños y } \\
\text { medianos } \\
\text { productores } \\
\text { integrándolos a } \\
\text { cadena } \\
\text { agroalimentaria }\end{array}$} & $\begin{array}{l}\text { Acuerdos } \\
\text { Preferenciales } \\
\text { Arancelarios }\end{array}$ & $\begin{array}{c}\text { Sistema } \\
\text { Generalizado de } \\
\text { Preferencias } \\
\text { Andino }\end{array}$ & \begin{tabular}{|l|} 
Impulso a \\
Formas \\
Asociativas \\
que Generen \\
Empleo e \\
Ingresos \\
\end{tabular} & $\begin{array}{l}\text { Protección a la Salud y } \\
\text { Nutrición y Fomento a } \\
\text { Estilos de Vida } \\
\text { Saludables }\end{array}$ \\
\hline & & $\begin{array}{l}\text { Estados Unidos, } \\
\text { España, Holanda y } \\
\text { Francia }\end{array}$ & $\begin{array}{l}\text { España, } \\
\text { Holanda y } \\
\text { Francia }\end{array}$ & $\begin{array}{c}\text { Garantizar el } \\
\text { Acceso a los } \\
\text { Alimentos }\end{array}$ & \begin{tabular}{|l} 
Mejoramiento de los \\
Servicios Públicos, \\
Saneamiento \\
Ambiental y Entornos \\
Saludables. \\
\end{tabular} \\
\hline \multicolumn{6}{|c|}{ Asegurar la Calidad e Inocuidad en las diferentes fases de la Cadena Alimentaria } \\
\hline \multicolumn{6}{|c|}{ Desarrollo Institucional Comisión Nacional de Seguridad Alimentaria Nutricional (CONSAN) } \\
\hline \multicolumn{6}{|c|}{ Planes Territoriales de Seguridad Alimentaria Nutricional } \\
\hline \multicolumn{6}{|c|}{ Participación Comunitaria - Información, Educación y Comunicación } \\
\hline
\end{tabular}

Se tiene en cuenta la dinámica sectorial agraria base de la disponibilidad, y exhorta a mejorar condiciones internas para abastecimiento alimentario. Por su parte, el primer gobierno de Uribe propuso:

Una manera de asumir el reto de la seguridad alimentaria consiste en apoyar la economía campesina y los cultivos de pan coger, en función de las necesidades regionales, étnicas y culturales de la población ${ }^{307}$.

305 Presidencia de la República-DNP (1999). Plan Nacional de Desarrollo 1998-2002 Cambio Para Construir la Paz. Tomo 1. Bogotá. Pág. 427

306 Presidencia de la república-DNP (1999). Plan Nacional de Desarrollo 1998-2002 Cambio Para Construir la Paz. Tomo 2. Bogotá. Pág. 271.

307 Plan Nacional de Desarrollo 2002-2006. Hacia un Estado Comunitario Bogotá DNP (2003). Pág. 228. 
Se insiste en la seguridad alimentaria como problema agrario de disponibilidad, identifica factores regionales diferenciales en el hacer y pensar la seguridad alimentaria, la cercanía y la identidad regional. El segundo gobierno de Uribe, considera la política de SAN transversal y reconoce que el país no tiene:

[...] una conceptualización que permita a los diferentes actores articular programas y proyectos [...]. Se formulará una política de seguridad alimentaria y nutricional, estableciendo la responsabilidad de actores como el Ministerio de Agricultura y MPS en su coordinación y gestión ${ }^{308}$.

Busca implementar planes nacionales y regionales de SAN, articulando diversos sectores con alianzas estratégicas, participación comunitaria, e integrando la educación alimentaria y nutricional al sistema educativo.

\subsection{DISPONIBILIDAD Y ESTABILIDAD}

\subsubsection{Los elementos generales de la disponibilidad}

\subsubsection{Las preguntas}

Disponibilidad y estabilidad se refieren a la oferta general y constante de alimentos variados y suficientes que están en capacidad de suplir las demandas que tiene una sociedad, una nación, una ciudad, una localidad, un territorio definido o una población en todos los momentos de su vida. Estos dos conceptos se complementan para atender la oferta de alimentos (figura 7.2.1) y están sujetos a las siguientes preguntas sobre la SAN: ¿qué tipo de alimentos se producen y cuáles son sus calidades nutricionales?, ¿quién y dónde lo hace?, ¿cuántos alimentos se producen y con qué frecuencias?, ¿cuál es la tecnología usada?, ¿qué políticas públicas y qué entidades determinan las calidades y los controles en el proceso?, ¿cómo se afecta la producción de alimentos en Colombia?

Responder estas preguntas determina condiciones técnicas, económicas, sociales y políticas para una disponibilidad constante y creciente de alimentos. Además, permite

308 Plan Nacional de Desarrollo 2006-2010. Estado Comunitario: Desarrollo para todos. Tomo I Bogotá DNP (2007). Pág. 147. 
identificar los problemas por solucionar y las acciones de política pública en SAN para los diferentes gobiernos, con instrumentos para enfrentar el problema diferencialmente.

\begin{tabular}{|c|c|c|c|}
\hline \multicolumn{4}{|c|}{ Figura 7.2.1 Sistema Alimentario. Disponibilidad - Estabilidad en la cadena alimentaria } \\
\hline CONTROLES & DISPONIBILIDAD & ESTABILIDAD & INCENTIVOS \\
\hline \multicolumn{4}{|c|}{$\boldsymbol{I}$} \\
\hline $\begin{array}{c}\text { CAR Departamentos, } \\
\text { Municipios; instrumentos: } \\
\text { POMCH, PDD, PDM, POT, } \\
\text { PBOT, ЕOT. }\end{array}$ & \multicolumn{2}{|c|}{$\begin{array}{l}\text { Determinar las condiciones ambientales de los territorios, agua, } \\
\text { aptitudes y usos de los suelos, conflictos de usos. }\end{array}$} & \multirow{7}{*}{$\begin{array}{c}\text { Gobierno } \\
\text { Nacional, CAR } \\
\text { Departamentos, } \\
\text { Municipios; } \\
\text { instrumentos: } \\
\text { POMCH, PDD, } \\
\text { PDM, POT, } \\
\text { PBOT, EOT, e } \\
\text { Impuestos y } \\
\text { tasas locales, } \\
\text { regionales y } \\
\text { nacionales. } \\
\text { Políticas de } \\
\text { comercio } \\
\text { exterior. }\end{array}$} \\
\hline \multicolumn{3}{|l|}{ T } & \\
\hline \multirow{5}{*}{$\begin{array}{c}\text { Las Organizaciones } \\
\text { Nacionales, Regionales } \\
\text { Departamentales y Municipales } \\
\text { con Controles en la fase de } \\
\text { producción nacional en } \\
\text { insumos, semillas, aguas, } \\
\text { ambientales, usos del suelo. } \\
\text { MADR-INVIMA-MMA-MSPS- } \\
\text { SSDM. Sobre Las condiciones } \\
\text { y normas en producción de } \\
\text { agroalimentos }\end{array}$} & $\begin{array}{l}\text { Procesos de producción, productividad: } \\
\text { recursos, tipo de tecnologias usadas, } \\
\text { quimicas, biológicas, limpias, orgánicas, } \\
\text { las implicacionesde cada una con la } \\
\text { inocuidad y el medio ambiente; } \\
\text { producción nacional y regio-local, el } \\
\text { comercio exterior de agroalimentos y } \\
\text { alimentos agroindustriales. }\end{array}$ & $\rightarrow \begin{array}{c}\text { Ciclos Productivos } \\
\text { de bienes } \\
\text { agroalimentarios, } \\
\text { territorios regio-local } \\
\text { e internacional. }\end{array}$ & \\
\hline & T & & \\
\hline & $\begin{array}{r}\text { Campesinos, productores medianos y } \\
\text { comunitarias, sociales, gremios e importa } \\
\text { estos agrolaimentos no son claros }\end{array}$ & $\begin{array}{l}\text { grandes, organizaciones } \\
\text { idores (los controles sobre } \\
\text { ) de agroalimentos. }\end{array}$ & \\
\hline & 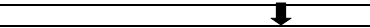 & & \\
\hline & $\begin{array}{l}\text { Producción Suficiente } \\
\text { Estable para la Oferta de }\end{array}$ & $\begin{array}{l}\text { Constante y } \\
\text { Agroalimentos }\end{array}$ & \\
\hline T & T & & 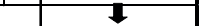 \\
\hline \multirow{2}{*}{\multicolumn{4}{|c|}{$\begin{array}{c}\text { Caracterizaciones regio-locales generales y especificas de los sistemas de produción agroalimentaria y los agroindustriales de } \\
\text { la cadena alimentaria. }\end{array}$}} \\
\hline & & & \\
\hline \multicolumn{4}{|c|}{$\begin{array}{c}\text { Desarrollo de las Relaciones Intergubernamentales, Nacionales, departamentales, regionales, municipales con la ciudad eje de } \\
\text { la región vinculados a la cadena alimentaria por politicas públicas e incentivos. }\end{array}$} \\
\hline
\end{tabular}

\subsubsection{Evolución del concepto}

Los documentos de la FAO muestran los inicios de esta evolución: "Una disponibilidad suficiente de alimentos significa que, por término medio, habrá que disponer de suficientes suministros alimentarios para cubrir las necesidades del consumo"309. En principio, la FAO vincula el concepto a la oferta de alimentos, sin pensar quiénes lo resuelven, cómo y dónde lo hacen. Tampoco tenía en cuenta la calidad, variedad y nutrición, que posteriormente integra. Morón y Schejtman entienden la disponibilidad alimentaria, integrada a políticas, así:

i) Suficiente para satisfacer la demanda efectiva y las necesidades básicas; ii) estable en lo que ha magnitud de las fluctuaciones de la oferta; iii) autónoma a nivel de política; iv) sustentable en relación a la capacidad de asegurar en el tiempo las condiciones anteriores, evitando el deterioro de los recursos renovables y no renovables; y v) inocuo ${ }^{310}$.

309 FAO (1996): La alimentación y el comercio internacional (vol. 3). Documentos técnicos de referencia, Cumbre Mundial sobre la Alimentación, documento n. ${ }^{\circ} 12$, pág. 7.

310 MORÓN, C. y SCHEJTMAN, A. (1997): "Situación de la seguridad alimentaria en América Latina". En Producción y manejo de datos de composición química de alimentos en nutrición. Universidad de Chile y FAO, Santiago de Chile, pág. 30 
De esta forma, se amplía el concepto de disponibilidad y se vincula con las políticas y las condiciones ${ }^{311}$.

Respecto a las condiciones de concentración mundial de la disponibilidad, esta se relaciona con la dieta básica de alimentos, que tiende a homogenizarse con cambios en el comercio exterior y el mayor control de esta. Se incluyen aquí los agroquímicos, las semillas, el transporte y la comercialización, en articulación con la agricultura:

[Hay] una agricultura mundial industrializada, con grandes producciones destinadas al mercado mundial y con una parte significativa de alimentos procesados genera inevitablemente la concentración de los recursos en manos de pocos agentes económicos, [...] sumando estos últimos años el muy rentable negocio de los Organismos Modificados Genéticamente ${ }^{312}$.

Por tanto, se evidencian condiciones controladas de la disponibilidad, por la dependencia en la compra de insumos, que tienen oferta monopólica. Y aunque el comercio internacional amplía la oferta de alimentos, los cultivos empiezan a sustituirse:

Los cultivos de subsistencia tradicionales y la crisis del campesino local (que trabaja únicamente para la exportación o es expulsado del campo para hacer espacio a las plantaciones intensivas) se pretenden subsanar con la importación de alimentos básicos adquiridos en el mercado mundial. La gente pierde el control sobre los cultivos y los alimentos tradicionales y al mismo tiempo pierde el poder adquisitivo para poder acceder con regularidad a los alimentos importados ${ }^{313}$.

311 Para un acercamiento empírico del comportamiento de esta parte de la cadena alimentaria en Colombia, véanse los siguientes trabajos: GARAY, Luis Jorge y RODRÍGUEZ, Adriana (2005): Colombia: diálogo pendiente. Documentos de Política Pública para la Paz, Planeta Paz y Ediciones Anthropos, Bogotá; BETANCOURT, Mauricio (2006): "La seguridad alimentaria nutricional (SAN), un acercamiento a la política pública”. Ponencia presentada en la Universidad delValle en el Foro Internacional: "Globalidad, Gobernabilidad y Territorio: Procesos Locales y Regionales”, Panel: Gobernabilidad política de los territorios, Cali. Ambos trabajos muestran las características esenciales de la disponibilidad de alimentos en Colombia. Véase también:VARÓN, Orminso, DÍAZ, Ricardo y DONADO, José (2008): Crisis alimentaria en Colombia. Universidad La Gran Colombia, Bogotá.

312 MONTAGUT, Xavier y DOGLIOTTI, Fabricio (2006): Alimentos globalizados, soberanía... Op. cit., pág. 27.

313 Ibíd., pág. 22. 
Esta sustitución de campesinos en la producción de agroalimentos es recurrente en el capitalismo. En el siglo XX, Colombia tiene el caso de la producción de trigo, que ha sido sustituida por importaciones, primero subsidiadas y luego vendidas a precios de mercado. Los subsidios fueron para productores de Estados Unidos, lo que bajó la producción en las zonas campesinas; el único departamento que aún produce es Nariño, que mantiene algunos mínimos.

Por otra parte, el concepto de estabilidad se determina por los comportamientos cíclicos de la producción. Estos ciclos de origen agropecuario son de corto, mediano y largo plazo, y se orientan por la función de los precios, la proyección de la demanda y las políticas. Para la FAO, la estabilidad "se refiere a reducir al mínimo la probabilidad de que, en años o temporadas difíciles, el consumo de alimentos pueda descender por debajo de las necesidades de consumo" 314 . Esto se encuentra determinado por variables económicas, la inversión social de los Gobiernos nacional, departamental y local, y los vínculos con el medioambiente, la sostenibilidad de recursos naturales y genéticos y las eventualidades climáticas.

Esta parte de la cadena agroalimentaria carece de líneas claras por la política pública, especialmente en lo atinente a los controles de inocuidad que deben tener los productos agropecuarios consumidos en fresco. Hay espacios institucionales y gubernamentales en la intervención sobre calidad, dados en la planeación y el ordenamiento local y regional, para identificar el conflicto entre usos y aptitudes de suelos, así como la sobreutilización en dosis de insumos agroquímicos, factores que incrementan la toxicidad en los alimentos producidos. A su vez, se desconocen mínimos de agroquímicos para agroalimentos de consumo humano, y las condiciones sanitarias y de calidad del recurso hídrico para el riego de estos agroalimentos. En consecuencia, la FAO demanda:

Legislación, regulaciones y normas alimentarías apropiadas, lo que a su vez exige medios para garantizar su cumplimiento [...], [que en el caso de algunos países] no tienen las instituciones o el personal para garantizar la inocuidad y el control de los alimentos ${ }^{315}$.

314 FAO (1996): La alimentación y el comercio internacional (vol. 3). Documentos Técnicos de Referencia, Cumbre Mundial sobre la Alimentación, documento n. ${ }^{\circ}$ 12, pág. 7.

315 FAO (2002): "Nutrición internacional y problemas alimentarios mundiales en perspectiva". Págs. 220 y ss. 


\subsubsection{Movilidad de cultivos y alimentos}

La movilidad de cultivos es el traslado de la producción de un bien agroalimentario a otro territorio nacional o internacional, es decir, pasa de una a otra zona, región o regiones; o bien, es sustituido por otro bien agrícola, o se traslada la producción a otro país. Básicamente, hay tres causas de esta movilidad: por diferenciales naturales de fertilidad de los suelos para su producción entre territorios; por políticas de represión frente a la producción de bienes de uso ilícito nacional o internacional; por incentivos fiscales, tributarios, financieros, tecnológicos de gobiernos con grandes capacidades presupuestales, desde el criterio de seguridad nacional.

La movilidad y sustitución de cultivos están presentes en Latinoamérica desde el siglo XIX, dada su especialización en bienes primarios. El siglo XX presenta cambios: el desarrollo del modelo sustitutivo, el diseño de seguridad nacional de la política de protección a la agricultura norteamericana (solo el caso del trigo) y, por último, la sustitución y movilidad de cultivos de uso ilícito, la hoja de coca, producción que se moviliza por la capacidad de los gobiernos de controlar y reprimir: "Con la implantación del Plan Colombia en el sur del país a partir del 2000 se disminuyó sensiblemente el área de cultivos de coca, en Putumayo, Caquetá y Guaviare, mientras se incrementó en Meta y Vichada" ${ }^{16}$. En estos cultivos opera la movilidad internacional Perú-Colombia-México.

La sustitución de agroalimentos por cambio de uso del mismo bien afecta la disponibilidad regional, en la medida en que se utiliza para biocombustibles, como son los casos del maíz y el creciente monocultivo de palma de aceite. En cualquiera de las situaciones de movilidad o sustitución, el eje es la rentabilidad económica: mover o sustituir producción y productores y ampliar la frontera agrícola. Tales

316 PÉREZ S., Bernardo (2007): "El paramilitarismo en Cundinamarca y Bogotá, 19972006". En Parapolítica: la ruta de la expansión paramilitar y los acuerdos políticos. Corporación Arco Iris e Intermedio, Bogotá, pág. 6. 
dinámicas están presentes en Colombia y Latinoamérica ${ }^{317}$. En Colombia, el conflicto de movilidad y sustitución se resuelve por la vía del más fuerte; aveces, el Estado no interviene, por incapacidad o por captura de este, con un agravante: la acumulación por desposesión es base del conflicto por la tierra.

Sustituir cultivos y producir para el mercado globalizado conlleva sustituir propietarios, nacionales o internacionales:

El campesinado no enfrenta solo ni principalmente a la 'vía terrateniente' sino especialmente al capital transnacional (interesado por ejemplo, en proyectos mineros o hidroeléctricos), y los grandes propietarios han aumentado la demanda por la tierra ante la expectativa de nuevos campos de acumulación o ante la necesidad de recomposición de sus capitales ${ }^{318}$.

\begin{tabular}{|c|c|c|c|}
\hline \multirow{2}{*}{ Departamento } & \multirow{2}{*}{ Municipio } & \multicolumn{2}{|c|}{ Productos } \\
\hline & & Cultivado & Sustituido por \\
\hline Bolívar & María La Baja & Arroz & \multirow{9}{*}{$\begin{array}{l}\text { Palma } \\
\text { Africana }\end{array}$} \\
\hline \multirow{5}{*}{ Magdalena } & Cienega & \multirow{5}{*}{ Banano y Plátano } & \\
\hline & Zona Bananera & & \\
\hline & Tucurinca & & \\
\hline & Aracataca & & \\
\hline & Fundación & & \\
\hline \multirow{3}{*}{ César } & Codazzi & Algodón & \\
\hline & San Alberto & Arroz & \\
\hline & Sabana de Torres & Arroz & \\
\hline
\end{tabular}

317 En el caso argentino, "la soja ocupa el 60\% del área sembrada; desplazó al trigo y al girasol y provocó la caída de la producción de arroz, avena y centeno, y de la fruticultura y la horticultura, lo que afecta la soberanía alimentaria del país - los beneficiados-, los contratistas o pools de siembra, que se nutren de los fondos de inversión y operan en gran escala con tierras arrendadas; los proveedores de agroquímicos (Monsanto, Dupont, Bayer) que se aprovechan de la gran dependencia que tienen los monocultivos de las semillas y fertilizantes; $y$ los grandes exportadores, porque en Argentina solo 5 empresas manejan el 90\% de las exportaciones, [mientras que en Brasil los cambios estructurales provocaron] que cada cadena productiva quedara en manos de solo tres o cuatro grandes empresas. En este modelo no hay espacio ni para la agricultura familiar ni para un mercado interno ni para la reforma agraria". ZIBECHI, Raúl (2009): "Los territorios como sustento del conflicto social”. En Las configuraciones de los territorios rurales en el siglo XXI. Pontificia Universidad Javeriana, Facultad de Estudios Ambientales y Rurales y Colciencias, Bogotá, págs. 321 y ss.

318 FRANCO L., Vilma y RESTREPO J., Diego (2011): "Empresarios palmeros, poderes de facto y despojo de tierras en el Bajo Atrato". En La economía de los paramilitares. Redes de corrupción, negocios y política. Corporación Nuevo Arco Iris, pág. 271, citado en MONGRAGÓN, Héctor (2002): Colombia: o mercado de tierras o reforma agraria. ANUC UR-Fensuagro, Bogotá. 
Esto afecta la disponibilidad y la oferta general en las estructuras campesinas, indígenas o de colectividades de negros, tanto para el mercado como para el autoconsumo. Otra forma de sustituir la producción de agroalimentos es la renta financiera, que desplazó campesinos en varias zonas del país, quienes, con la ilusión de las pirámides financieras, vendieron la tierra para vivir de los altos intereses: "En el municipio se presentó una sustitución de producción por las pirámides para vivir"319. Esta expectativa conllevó bajar la producción en departamentos del sur de Colombia (Huila, Putumayo, Nariño) ${ }^{320}$. También se dio por los “cambios de finca por camiones" ${ }^{321}$. Respecto a las políticas nacionales, anota un funcionario de la FAO: "La política macro y el control de la inflación bajan los precios de los alimentos y hay sustitución de agricultura por ganadería"322. Así, se dan formas variadas (privadas y públicas) de expulsar a los productores de agroalimentos de la zona rural.

\subsubsection{Condiciones y políticas}

En la disponibilidad y estabilidad de la política de SAN, las condiciones están cruzadas con diversos actores: organizaciones sectoriales, sociales, gremiales, territoriales, ambientales, no gubernamentales, Gobiernos nacional, departamental, municipal y la cooperación internacional. Por su parte, en las políticas de gobierno se presentan tres aspectos: a) la institucionalidad y el conflicto agrario; b) las políticas agrarias; y c) el modelo de desarrollo y los nuevos derechos.

\subsubsection{Institucionalidad y conflicto agrario}

Al analizar las intervenciones del gobierno desde la tercera década del siglo XX, es posible evidenciar cambios en las decisiones públicas sobre disponibilidad de alimentos, influidas por factores tecnológicos, económicos, sociales, políticos, organizativos,

319 BONILLA, Virginia (2008): Entrevista. Directora de UMATA, municipio de Algeciras, departamento del Huila. 5 de noviembre.

320 CISNEROS, Mauricio y CASTRO, Javier (2008): Entrevistas. Director UMATA y Secretario de Desarrollo Social, respectivamente. Municipio de Ipiales, departamento de Nariño. 12 de noviembre.

321 BONILLA,Virginia (2008): Entrevista. Op. cit.

322 MORENO, Mario (2008): ENTREVISTA. Director del "Proyecto de apoyo a desplazados urbanos y comunidades vulnerables rurales en alto riesgo de desplazamiento Sucre-BolívarChoco". FAO, municipio de Cartagena, departamento de Bolívar. 24 de octubre. 
ambientales, de la concentración de la tierra y de producción. Sin embargo, el modelo de desarrollo ha sido estable para orientar estas intervenciones. Un primer momento se ubica en la crisis de los años treinta hasta la segunda posguerra. Allí, las intervenciones de política agraria buscan que la agricultura cumpla sus funciones de producir materias primas y alimentos para la población urbana, al igual que proveer las divisas del comercio internacional.

En este contexto, hay un periodo de construcción de normas, como las leyes 200/1936 y 100 de 1944, las cuales presionaban a los latifundistas para responder por las funciones anteriores. Se crean, en consecuencia, organizaciones públicas para su impulso: la Caja de Crédito Agrario Industrial y Minero, el Instituto Nacional de Abastecimiento (INA), el Fondo de Desarrollo Agropecuario y el Plan Agrícola. En 1946, el informe del BIRF muestra una estructura específica de producción agrícola regional:

Ciertas regiones experimentan un déficit que lógicamente se reflejó en su nivel de vida y nutrición; otros sectores tenían exceso de producción de alimentos de bajo valor nutritivo que no podían transportarse a grandes distancias dentro del país, por su bajo costo. [...] Hacia 1946 Colombia era prácticamente autosuficiente en muchos de sus productos agrícolas" 323 .

La tabla 7.2.2 compara la producción nacional y el consumo interno. Además, el informe de la Misión Currie anota:

Probablemente el factor de más importante influencia en la baja productividad de la agricultura en Colombiaes la antieconómica y paradójica utilización de la tierra. Las tierras planas arables de buena calidad, situadas cerca de los centros populosos, son estrictamente limitadas. Sin embargo, en su mayor parte se dedican a la ganadería y generalmente pertenecen a propietarios ausentes que viven en las ciudades. Por otro lado, la mayor parte de los productos agrícolas se cultivan en pequeñísimas fincas situadas en inclinadas montañas

323 CURRIE, Lauchlin (1951): Bases de un programa de fomento para Colombia. Informe de la Misión del Banco Internacional de Reconstrucción y Fomento en colaboración con el Gobierno de Colombia. Librería Voluntad, Bogotá, págs. 419 y ss. 
y pobres suelos. La finca colombiana típica tiene sólo dos hectáreas de extensión cultivable y mucha son considerablemente más pequeñas ${ }^{324}$.

Se ratifica así el problema de inequidad en la distribución de la tierra, componente estructural de las zonas agrarias del país, que aún hoy está presente.

\begin{tabular}{|c|c|}
\hline \multicolumn{2}{|c|}{$\begin{array}{c}\text { Tabla. 7.2.2, Colombia 1946, producción nacional y } \\
\text { consumo Interno }\end{array}$} \\
\hline Producto & Porcentaje \\
\hline Cacao. & 60 \\
\hline Café.. & 650 \\
\hline Hilaza de algodón... & 18 \\
\hline 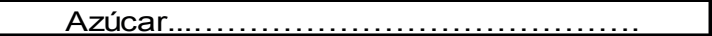 & 89 \\
\hline Arroz....... & 105 \\
\hline Trigo .................................. & 82 \\
\hline Banano y plátano........................... & 104 \\
\hline $\begin{array}{l}\text { Carne de res y de cerdo, pescado, panela, } \\
\text { maíz, fique, leche, frijoles, cebada, yuca, ñame y } \\
\text { papas................................. }\end{array}$ & 100 \\
\hline
\end{tabular}

El segundo momento va de los años cincuenta hasta mediados de los setenta, caracterizados por políticas de reforma agraria, Desarrollo Rural Integrado (DRI), Plan de Alimentación y Nutrición (PAN) y aparición de grupos guerrilleros rurales y urbanos. Finaliza con la violencia liberal-conservadora, que expulsa campesinos y baja los precios de la tierra, se crea el Frente Nacional, la planificación indicativa pública y los primeros ajustes al modelo de desarrollo sustitutivo.

El tercer momento va de finales de los años setenta hasta inicios de siglo XXI. En la zona rural aparece otra forma de expropiación de la tierra, por la violencia directa contra campesinos, indígenas y comunidades negras, ejercida por actores armados

324 Ibíd., pág. 443. 
y no armados. Por lo tanto, el conflicto por la tierra continúa con nuevas aristas ${ }^{325}$, vinculadas a las condiciones de colonización, los enclaves y el latifundio, lo cual incidió en la disponibilidad de alimentos, sea por infraestructura, usos y demandas o por improductividad en el uso de las tierras.

\subsubsection{Políticas agrarias}

La política agraria se vincula con la SAN para cumplir la función de la agricultura en la economía y la sociedad. La dinámica se desarrolló por la vía de la economía campesina, que en Colombia soporta la mayor producción de agroalimentos; sin embargo, las fallas de esta política con la SAN se expresan así:

El fracaso de las políticas gubernamentales para abordar en forma más eficaz el problema del hambre refleja la falta de comprensión de las causas directas e indirectas del hambre y su relación con el sistema alimentario de un país" 326 .

Resolver el problema del hambre y de SAN por medio de acciones públicas agrarias no supera lo sectorial y lo disciplinar, pues se requiere vincular la disponibilidad de alimentos mediante la estructuración de canastas alimenticias regionales. En este sentido, las relaciones entre la política agraria alimentaria y el modelo de acumulación demandan entender que estas no son "el resultado de la acción individual de un Ministerio de Agricultura, es, al contrario, la expresión de clase y de grupos sociales y, como tal, debe ser coherente con toda la política general que busca apoyar y mantener el proceso de acumulación periférica"327.

325 Reyes observa las movilizaciones rurales de los años ochenta, analizadas a partir de tres regiones tipificadas: “a) regiones de colonización campesina con procesos de concentración de la tenencia, como el Magdalena medio, el bajo Cauca, el Catatumbo, el alto Sinú, las estribaciones de la Sierra Nevada de Santa Marta y el complejo Ariari-Guayabero-Guaviare; b) enclaves agroindustriales o mineros, con alta inmigración y conflictos por la distribución de beneficios, como Urabá, Barrancabermeja y Arauca; y c) regiones dominadas por el latifundio improductivo y con alta densidad relativa de población, como Sucre, Córdoba, sur de Bolívar, sur del Atlántico, Magdalena, César, centro oriente del Cauca, sur del Tolima y centro-sur del Huila”. REYES P., Alejandro (2009): Guerreros y campesinos. El despojo de la tierra en Colombia. Fescol y Norma, Bogotá, pág. 39.

326 TIMMER C., Peter, FALCÓN, Walter y PEARSON, Scott (1985): Análisis de políticas... Op. cit., pág. 25.

327 MACHADO C.,Absalón y TORRES O.,Jorge (1987). El sistema agroalimentario... Op. cit., pág. 330. 
Así, la integralidad de la política agraria y alimentaria con otros sectores se desarrolla identificando las características del modelo de acumulación periférica con el problema social agrario colombiano. ${ }^{328}$

Reforma agraria. Las leyes 135 de 1961, 101 de 1993 y 160 de 1994 están vinculadas con la política pública de reforma agraria. La Ley 135 fue impulsada por la crisis interna del modelo sustitutivo, la situación rural de concentración de la propiedad, los cambios de ubicación espacial de la población con la urbanización, la Revolución cubana y su contrapartida: la alianza para el progreso.

Lo anterior introduce el debate en el país desde el gobierno, el Congreso, la academia y la política norteamericana, en pos de cambiar las estructuras de concentración de la propiedad y la tenencia, que afecta la demanda interna de bienes industriales y alimentos por el bajo ingreso. Esto llevó a que la política de reforma agraria fuera orientada por el Instituto Colombiano de la Reforma Agraria (Incora), encargado de dirigirla desde legal, financiera, económica y políticamente ${ }^{329}$. Galindo lo consideraba en el Congreso así: "No hay manera de hacer una planeación integral, una Reforma Agraria integral en el país, sino a través de un instituto centralizado, como es el Instituto de la Reforma Agraria que se proyecta" 330 .

328 Este problema es identificado a partir de la insuficiencia de la producción de alimentos, debido a múltiples factores: la estructura de la propiedad de los recursos (tenencia de la tierra, poder terrateniente, concentración del ingreso rural); la dificultad para generar divisas por exportar bienes agrícolas; la creciente importación de alimentos; la importación de patrones tecnológicos inadecuados; la intensa migración rural-urbana; la agudización de conflictos y las pugnas entre los campesinos, terratenientes y asalariados rurales, y entre estos y la burguesía urbana y rural y el Estado; la inadecuada estructura de distribución del excedente agrícola y desarticulación de estructuras de comercialización y producción; la pobreza rural, la desnutrición y el hambre; la existencia de una economía campesina cada vez más marginada social y económicamente; el surgimiento del semiproletariado rural; la carencia de servicios básicos para la población rural; y la ausencia de instituciones apropiadas al desarrollo rural. MACHADO C.,Absalón y TORRES O., Jorge (1987): El sistema agroalimentario una visión integral de la cuestión agraria en América latina. CEGA y Siglo XXI Editores.

329 INCORA (1988): 25 años de reforma agraria en Colombia. Ministerio de Agricultura e Instituto Colombiano de la Reforma Agraria, Bogotá, pág. 14.

330 GALINDO, Alberto (1961): Exponiendo en la discusión sobre la Reforma Agraria, Historia de las Leyes. Legislatura de 1961 (segunda etapa: Reforma Agraria, tomo II). Imprenta Nacional Bogotá, pág. 91. 
Este instituto, tardó 36 años solamente para caracterizar las unidades agrícolas familiares $(\mathrm{UAF})^{331}$.En 1996, con la Resolución 41, el Incora determinó el tamaño según municipio y región, dando aplicación a la Ley 160 de 1994, sobre las Zonas de Reserva Campesina y Desarrollo Empresarial, en áreas geográficas y con ciertos rasgos agroecológicos y socioeconómicos, cuya extensión mínima y máxima la determina la UAF.

Las leyes 101 de 1993 y 160 de 1994 buscan aplicar la Constitución de 1991: proteger la producción de alimentos, adecuar el sector agropecuario y pesquero a la internacionalización, elevar la eficiencia y la competitividad, modernizar la comercialización, mejorar el crédito y los incentivos a la capitalización rural y la asistencia técnica a pequeños productores, y establecer los fondos de estabilización de precios de productos agropecuarios. En específico, la Ley 160 organiza el Sistema Nacional de la Reforma Agraria y Desarrollo Rural Campesino. En el artículo 2 identifica el sistema así:
Mecanismo obligatorio de planeación, coordinación, ejecución y evaluación de las actividades dirigidas a prestar los servicios relacionados con la actividad campesina y a promover el acceso progresivo a la propiedad de la tierra de los trabajadores agrarios ${ }^{332}$.

331 La Ley 160 de 1994 establece: "Se entiende por Unidad Agrícola Familiar (UAF), la empresa básica de producción agrícola, pecuaria, acuícola o forestal cuya extensión, conforme a las condiciones agroecológicas de la zona y con tecnología adecuada, permite a la familia remunerar su trabajo y disponer de un excedente capitalizable que coadyuve a la formación de su patrimonio. La UAF requerirá solo el trabajo del propietario y su familia, sin perjuicio del empleo de mano de obra extraña, si la naturaleza de la explotación así lo requiere. Para efectos regionales y locales que el INCORA señala en cada caso, región o municipio, las extensiones máximas y mínimas adjudicables de las empresas básicas de producción y declarará, en caso de exceso del área permitida, que hay indebida ocupación de las tierras de la Nación. Para expedir las reglamentaciones sobre las extensiones máximas y mínimas adjudicables, el Instituto deberá tener en cuenta, entre otras, las condiciones agrológicas, fisiográficas, disponibilidad de aguas, cercanía a poblados de más de 3.000 habitantes y vías de comunicación de las zonas correspondientes. También se considerarán la composición y concentración de la propiedad territorial, los índices de producción y productividad, la aptitud y las características del desarrollo sostenible de la región. Para la extensión adjudicable de las UAF, se tendrá en cuenta la condición de aledaños a terrenos baldíos, o la distancia, a carreteras transitables por vehículos automotores, ferrocarriles, ríos navegables, a centros urbanos de más de 10.000 habitantes, o a puertos marítimos, cuando en este último caso dicha tierras se hallen ubicadas a menos de cinco (5) kilómetros de aquellos. No serán adjudicables los terrenos baldíos situados dentro de un radio de 5 kilómetros alrededor de las zonas donde se adelanten explotaciones de recursos naturales no renovables, las aledañas a Parques Nacionales Naturales y las seleccionadas por entidades públicas para adelantar planes viales u otros de igual significación cuya construcción pueda incrementar el precio de las tierras por factores distintos a su explotación económica".

332 Ley 160 de 1994, artículo 2. 
Productividad y dualidad agraria. En los años setenta del siglo XX se discute sobre la productividad agraria para la autosuficiencia alimentaria, la oferta de materias primas y los productos exportables. Las leyes 4 y 5 de 1973 consideran diferentes acciones para incrementar la productividad. Las políticas rurales concibieron dos sub-sectores en el campo: el moderno y el tradicional, o de subsistencia, que "produce más del 55\% de los alimentos de consumo directo del país y el $20 \%$ de los productos de uso industrial" 333 . Este se caracteriza por la escasez de recursos productivos y la falta de tecnología, y está compuesto por población subempleada, grupo más pobre de la sociedad; por tanto, impulsa la política e integra los programas DRI y PAN, al vincular la producción de alimentos y la nutrición:

La importancia que la producción de alimentos por parte del sector campesino tiene para el PAN, articular el conjunto de inversión pública y acción del Estado en función de las necesidades de desarrollo de la producción ${ }^{334}$.

El Plan de Integración Nacional ${ }^{335}$ (PIN) para el sector agropecuario de alimentos tiene cuatro estrategias: incrementar la productividad rural, para contar permanentemente con un crecimiento de la producción de alimentos y materias primas; aumentar la eficiencia y la competencia del sistema de comercialización de alimentos; desarrollar las potencialidades agroindustriales; e implementar la política de comercio exterior. Por otro lado, el DRI busca bajar precios de alimentos y ampliar su disponibilidad, en virtud del crecimiento del país:

En el período de 1960-1978 el país recuperó su capacidad exportadora neta de alimentos en términos fisicos. Las exportaciones físicas de materias primas alimenticias aumentaron a un ritmo de 13.1\% anual, en promedio a pesar de que su valor alcanzó una tasa de crecimiento inferior ${ }^{336}$.

333 DNP (1975): Para Cerrar la Brecha, Plan de Desarrollo Social, Económico y Regional 19751978. Bogotá, págs. 28 y ss.

334 Ibíd., pág. 45.

335 DNP (1979): Plan de Integración Nacional 1979-1982 (tomo II). Bogotá, pág. 250.

336 Ibíd., pág. 268. 
El gobierno de Virgilio Barco y el Programa Integral Campesino 337 (1988-1993) mostraron las disparidades del DRI y la disponibilidad alimentaria, partiendo de la desnutrición de la población pobre de la zona urbana y rural; por ello, consideraron “acciones dirigidas a asegurar la disponibilidad permanente de alimentos que constituyen la dieta básica de la población, en las cantidades y calidades adecuadas principalmente para el 25\% más pobre" 338 . Esto exigía regulaciones y controles en la producción para la estabilidad de agroalimentos.

En Colombia, la política agraria busca la autosuficiencia de alimentos con una disponibilidad y estabilidad creciente: "La diversidad de productos agrícolas que se pueden cultivar [facilita] la estabilidad en el crecimiento de esa producción y el abastecimiento alimentario de los colombianos"339. Sin embargo, la política de protección agrícola para materias primas de la industria genera cambios a mediados de los años setenta, y a partir de los noventa inicia el nuevo modelo, que cambia las protecciones en general para la agricultura y en especial para los agroalimentos.

\subsubsection{Nuevo modelo de desarrollo y nuevos derechos}

La década del noventa del siglo XX trae reformas estructurales en el modelo de desarrollo, con el fin de dar "mejor funcionamiento de los mercados, por medio de la competencia" 340 . Las razones: mayor eficiencia y mejor asignación de recursos, disminución del tiempo administrativo para eludir restricciones y regulaciones, y eliminación de obstáculos a la competencia, evitando invertir recursos para defender privilegios.

Para la disponibilidad de alimentos, el eje es el mercado y el manejo de infraestructura física adecuando tierras, "para el desarrollo de nuevas variedades agrícolas, las cuales

337 DNP (1998): Políticas para el cambio económico y social. Selección de documentos aprobados por el Conpes, enero de 1988- diciembre de 1988 (tomo III). Bogotá, pág. 16. Este documento considera que los fracasos son debidos al no ofrecimiento de solución del problema de la tierra. 338 BARCO,Virgilio: Así estamos cumpliendo... Op. cit., pág. 209.

339 GARCIA G., Jorge (1982): “¿Se ha protegido la producción de alimentos en Colombia?”. En La agricultura y las políticas sectoriales, Minagricultura 80 años. TM Editores, Banco Ganadero, Caja Agraria y Vecol. Bogotá, págs.3 y ss.

340 Presidencia de la República y DNP (1990): La Revolución Pacifica, Plan de Desarrollo Económico y social 1990-1994. Bogotá, págs. 63 y ss. 
presentan una alta dependencia del suministro suficiente y oportuno de agua" ${ }^{341}$. Entonces, los distritos de riego permiten continuidad en la producción de alimentos, cuya prioridad está caracterizada así:

Las estrechas interdependencias que se establecen entre el desarrollo óptimo del sector agropecuario, el de otros sectores de la economía y el crecimiento global, la política de seguridad alimentaria, agroindustrial y de exportaciones constituyen áreas prioritarias ${ }^{342}$.

Esta priorización de fines del gobierno Barco e inicios del de Gaviria considera la política de seguridad alimentaria vinculada a las acciones públicas del sector agropecuario, a partir de la modernización, la competitividad, la calidad y la cantidad de recursos, así como desde los propósitos de fortalecimiento de la economía campesina, erradicación de la pobreza, mejoramiento de las necesidades básicas de la población rural y vinculación de la disponibilidad con el acceso, siguiendo la visión sectorial de la SAN.

La Constitución de 1991, en los artículos 64 y 65, determina como deber del Estado promover el acceso progresivo a la propiedad de la tierra de los trabajadores agrarios, en forma individual o asociativa y a los servicios sociales, asistencia técnica para mejorar el ingreso y la calidad de vida de los campesinos; protección para producir alimentos, investigación y transferencia de tecnología para estos y las materias primas agropecuarias, impulsado por el gobierno del Salto Social (1994-1998)343. Además, retoma la reforma agraria: ante el problema que continúa de la gran concentración de la tierra, busca impulsarla, estableciendo la unidad agrícola familiar (UAF), empresas comunitarias u otros tipos asociativos de producción, así como constituir, ampliar, reestructurar y sanear resguardos indígenas.

Con el Plan de Desarrollo: Cambio para Construir la Paz (1998-2002), se busca en el sector agropecuario integrar y modernizar el sector rural, al proveer condiciones de desarrollo competitivo, equitativo y sostenible del campo, en su diversidad y complejidad. También busca lograrse eficacia para ejecutar programas participativos

341 Ibíd., pág. 372.

342 Ministerio de Agricultura y DNP (1990): Estrategias y políticas para el desarrollo agropecuario en Colombia. Informe final de la misión de estudios del sector agropecuario, pág. 137.

343 DNP (1994): El salto social 1994-1998 (capítuloV). 
y descentralizados, con un ajuste institucional, que facilite integrar y regionalizar las acciones y adecuar las instituciones al mercado reduciendo trámites, mejorando así la eficiencia y la coordinación entre las entidades ${ }^{344}$.

En los dos gobiernos de Uribe (2002-2010), la seguridad alimentaria se plantea diferente. En el primero cambia el modelo productivo para el campo, dirigido al mercado externo:

[...] Con intervención estatal directa en los mercados agrícolas. Esto dio paso a un proceso de modernización fundamentado en una mayor orientación a los mercados externos y una gradual especialización en la producción tropical ${ }^{345}$.

Desde la dinámica del sector rural, se fundamenta la disponibilidad de alimentos y propone: "Apoyar la economía campesina y los cultivos de pancoger ${ }^{346}$, en función de las necesidades regionales, étnicas y culturales de la población" 347 . Aquí se plantea la seguridad alimentaria sobre las economías campesinas y las relaciones cercanas de los territorios.

Por su parte, el segundo gobierno identifica un problema campesino: la falta de tierra, y concluye:"La mejora de la capacidad productiva de los campesinos requiere, entre otras cosas, facilitar el acceso a la tierra y garantizar la propiedad de la misma"348. Para esto, crea un programa de adjudicación y titulación de tierras, a fin de hacer reforma agraria, adjudicando las tierras que provienen de la extinción de dominio, titulando baldíos, dando un subsidio integral de tierras, defendiendo la propiedad pública y clarificando los derechos de propiedad colectiva ${ }^{349}$.

344 DNP (1999): Plan Nacional de Desarrollo 1998-2002... Pág. 269.

345 DNP (2003): Plan Nacional de Desarrollo 2002-2006... Pág. 221.

346 Cultivos que forman parte de la dieta básica mínima de la familia campesina y no se transan.

347 Ibíd., pág. 228.

348 DNP (2007): Plan Nacional de Desarrollo 2006-2010... Pág. 220.

349 Ibíd., pág. 221. 
Instrumentos de las últimas décadas. Las políticas agrarias se orientan desde cinco acciones ${ }^{350}$ combinadas: generar ingresos de la población rural; incrementar la competitividad agropecuaria; ampliar y diversificar el mercado interno y externo, y para las contingencias agropecuarias, fondos de estabilización; asegurar la equidad en el desarrollo regional; y asegurar la gestión del riesgo agropecuario.

\subsubsection{Conflictos estructurales, elementos que afectan la disponibilidad y estabilidad de los alimentos}

Hay varios conflictos que han afectado la disponibilidad y estabilidad de los alimentos en Colombia, entre los cuales se encuentran: el conflicto de usos de la tierra, la violencia en el área rural — que genera procesos de despojo y desplazamiento poblacional—y la concentración de la propiedad rural.

\subsubsection{Colombia, conflictos de usos de la tierra 1996-2009}

Los conflictos por usos de la tierra y aprovechamiento en este periodo marcan la continuidad de los problemas rurales presentes desde el siglo XIX; son identificados en diferentes estudios por ser un problema estructural que afecta los usos racionales de la tierra, con consecuencias ambientales, sociales, económicas y de desarrollo regiolocal, por sobreutilización y subutilización.

El último plan nacional de desarrollo analiza esta problemática; muestra que en la "región andina el 44\% del total del área presenta conflictos por sobreutilización, mientras que en el Caribe el $32 \%$ por subutilización" 351 . Identifica así las áreas por conflicto de uso y por sobreutilización en 19.584.769 hectáreas, con el 33\%; y por subutilización, 17.767.918 hectáreas, con el 30\%; y en uso adecuado, 22.585.466 hectáreas, es decir, el 38\%.

La tabla 7.2.3 muestra el aprovechamiento de la superficie de la tierra en Colombia desde 1996 hasta el 2009. Parte del conflicto de uso toca la topografia y aptitud de la tierra para actividades agrícolas o pecuarias, y no solo por sobreutilización. La superficie

350 Ministerio de Agricultura y Desarrollo Rural. No se incluyeron los programas regionales sobre La Mojana y la Altillanura colombiana.

351 DNP (2011): Prosperidad para Todos, Plan Nacional de Desarrollo 2010-2014 (tomo I). Bogotá, pág. 233. 
no agropecuaria incluye bosques no colonizados, colonizados, plantados, los eriales cuerpos de agua y zonas urbanas y semiurbanas. En términos globlales, esta superficie aumenta en el periodo: pasa de 56.724.132 a 63.232.815 hectáreas, aumentando 6,5 millones de hectáreas.

La superficie marginal cultivada en los parques naturales muestra una disminución en las tierras utilizadas para cultivos de uso ilícito: pasaron de 5.109.857 a 3.619.690 hectáreas. El área vinculada a actividades agropecuarias que producen agroalimentos disminuyó en 1.484.348 hectáreas durante el período: pasó del 46,8\% en 1996 al 44,6\% en el 2009. Su comportamiento interno afecta la producción agrícola de alimentos. Hay una relación inversa según los usos: decrecen las dedicadas a la agricultura y aumentan las del sector pecuario.

En las tierras agrícolas se afectan las dedicadas a cultivos transitorios y barbecho, que pasan de 4.060.686 a 1.283.121 hectáreas; pierden 2,8 millones de hectáreas dedicadas a producir bienes agrícolas, y similar comportamiento tienen las tierras en descanso. Los cultivos permanentes presentan un crecimiento lento, y las tierras para la producción pecuaria aumentan 2,3 millones de hectáreas en pastos, malezas y rastrojos. Estos dos últimos tienen más tierra que los cultivos transitorios.Y hay otro problema si gran parte de la producción agropecuaria se realiza en la zona Andina:

15\% del área del país, pero genera cerca de 75\% de la producción agrícola y reúne casi dos terceras partes de la población. Hemos descuidado el trópico, el otro 85\% del territorio nacional, donde se requieren grandes inversiones para incorporar las tierras útiles al aparato productivo. Estudios recientes del IGAC-ICA indican que Colombia posee unos 33.6 millones de hectáreas aptas para la producción agropecuaria, distribuidas entre 14.3 para agricultura y 19.3 para ganadería. Esto demuestra que hay así recursos suficientes para atender una mayor demanda alimentaria, [...] todavía un poco más de 50\% de los suelos con vocación agrícola están por utilizarse. Parte de ellos se usan en ganadería, en una mala utilización de los recursos, o simplemente son suelos ya degradados o en proceso de desertificación ${ }^{352}$.

352 MACHADO C., Absalón (1986): El problema alimentario en Colombia... Op. cit., pág. 73. 
Este inadecuado uso del suelo es un punto estructural que afecta la disponibilidad, la seguridad alimentaria nutricional, el medioambiente y la racionalidad económica.

\title{
7.2.3.2. Desplazamiento y despojo de tierras
}

Estos procesos ${ }^{353}$ han tenido dos momentos en la historia reciente del país, durante el siglo XX. El primero, en los años cincuenta, con la violencia liberal-conservadora. Sánchez dice al respecto:

\begin{abstract}
La politización partidista (liberal-conservadora) es una politización despolitizada. Pues bien, el terror de los años cincuenta no hace sino exacerbar ese sentido de la politización-despolitizada, que no crea actores sino adeptos ${ }^{354}$.
\end{abstract}

Este fenómeno generó reconcentración de la propiedad rural en algunas zonas del país. De los años ochenta hacia adelante se inicia otra etapa de violencia y desplazamiento, donde hay otros actores e intereses en las regiones colombianas:

353 Para la definición de la característica del despojo, se han presentado cuatro categorías explicativas por parte del Ministerio de Agricultura y Desarrollo Rural: una es la compra o ventas irregulares: por la fuerza, por dolor, por inducción de error, por fijar un precio que no corresponde con el valor comercial, por una les lesión enorme; dos, por la transferencia judicial: pertenencia; poseedores que se convierten ilegalmente en propietarios, procesos ejecutivos a partir de los cuales acreedores se quedan con las tierras, casos en los que los propietarios recuperan ilegalmente la propiedad definidos como procesos reivindicatorios y, finalmente, fraudes procesales definidos como conductas ilegales dentro de los procesos judiciales; tres, por la transferencia de derechos a través de instancias administrativas. En este aparte se categorizan prácticas de adjudicación de baldíos por autoridad competente, judicial o registral, incumplimiento de condiciones resolutorias como ventas inconsultas antes de los 12 años, acumulación de más de una UAF, revocatoria de la asignación y reasignación, aplicación de la caducidad administrativa y reasignación a 15 años, ventas sin consentimiento del INCODER, silencio administrativo positivo y posterior enajenación sin el cumplimiento de las formalidades, extinción de dominio y asignación a ocupantes, falsedad ideológica en documento público y el empleo de la figura de accesión para el cambio de propiedades colectivas a particulares; y cuatro, por desalojo forzado por la violencia: ocupación de hecho y abandono de baldíos.

354 SÁNCHEZ, Gonzalo (2008): Guerra y política en la sociedad colombiana., Editorial Nomos, Bogotá, pág. 31. Para este periodo se encuentra el texto informe más detallado sobre el fenómeno, el cual dice en su prólogo: "Este libro tormentoso y atormentado que llega a sus manos luego de cuarenta años de su primera aparición recoge la tragedia del pueblo colombiano desgarrado por una política nociva de carácter nacional y regional”. GUZMÁN C., Germán, FALS B., Orlando y UMAÑA L., Eduardo (2010): La violencia en Colombia. Editorial Nomos, Bogotá. 


\begin{tabular}{|c|c|c|c|c|c|c|c|c|c|c|}
\hline \multirow[b]{2}{*}{ SUPERFICIES } & \multicolumn{2}{|l|}{1996} & \multicolumn{2}{|l|}{2000} & \multicolumn{2}{|l|}{2002} & \multicolumn{2}{|l|}{2006} & \multicolumn{2}{|c|}{2009} \\
\hline & $\begin{array}{c}\text { Total } \\
\text { hectáreas }\end{array}$ & $\begin{array}{c}\% \\
\text { Total }\end{array}$ & $\begin{array}{c}\text { Total } \\
\text { hectáreas }\end{array}$ & $\begin{array}{c}\% \\
\text { Total }\end{array}$ & $\begin{array}{c}\text { Total } \\
\text { hectáreas }\end{array}$ & \begin{tabular}{|c|}
$\%$ \\
Total
\end{tabular} & $\begin{array}{c}\text { Total } \\
\text { hectáreas }\end{array}$ & $\%$ Total & $\begin{array}{c}\text { Total } \\
\text { hectáreas }\end{array}$ & $\%$ Total \\
\hline $\begin{array}{l}1 \text { SUPERFICIE PLANIMETRADA } \\
\text { DEL MARCO }\end{array}$ & 114.260 .322 & 100 & 114.174 .800 & 100 & 114.174 .800 & 100,00 & 114.174 .800 & 100,00 & 114.174 .800 & 100,00 \\
\hline $\begin{array}{l}1.1 \quad \text { No agropecuaria, excluida del } \\
\text { universo de estudio (Bosques, páramos } \\
\text { y sabanas) }\end{array}$ & 56.724 .132 & 49,64 & 59.167 .168 & 51,82 & 59.207 .239 & 51,86 & 69.308 .389 & 60,70 & 63.232 .815 & 55,38 \\
\hline Bosques no colonizados & 46.018 .763 & 40,28 & 44.713 .742 & 39,16 & 44.703 .112 & 39,15 & 44.866 .411 & 39,30 & 44.983 .216 & 39,40 \\
\hline Bosques colonizados & 7.313 .751 & 6,40 & 10.594 .892 & 9,28 & 10.599 .943 & 9,28 & 10.641 .246 & 9,32 & 10.701 .320 & 9,37 \\
\hline Bosques plantados & 19.577 & 0,02 & 19.531 & 0,02 & 19.524 & 0,02 & 19.595 & 0,02 & 19.631 & 0,02 \\
\hline Eriales y similares & 584.445 & 0,51 & 6.900 .565 & 6,04 & 690.851 & 0,61 & 701.475 & 0,61 & 674.434 & 0,59 \\
\hline Cuerpos de agua & 2.458 .286 & 2,15 & 2.819 .071 & 2,47 & 2.843 .402 & 2,49 & 2.845 .785 & 2,49 & 2.852 .681 & 2,50 \\
\hline Superficie urbana y semiurbana & 329.310 & 0,29 & 329.876 & 0,29 & 350.407 & 0,31 & 352.887 & 0,31 & 381.842 & 0,33 \\
\hline $\begin{array}{l}1.2 \text { Marginalmente cultivable en los } \\
\text { parques naturales }\end{array}$ & 5.109 .857 & 4,47 & 4.302 .178 & 3,77 & 4.304.407 & 3,77 & 3.577 .750 & 3,13 & 3.619 .690 & 3,17 \\
\hline $\begin{array}{l}1.3 \text { Superficie Agropecuaria } \\
\text { planimetrada, incluida en el universo de } \\
\text { estudio }\end{array}$ & 52.426 .333 & 45,88 & 50.705 .454 & 44,41 & 50.663 .154 & 44,37 & 51.169 .651 & 44,82 & 50.941 .985 & 44,62 \\
\hline 1.3.1 Agrícola & 8.121 .371 & 7,11 & 8.864 .498 & 7,76 & 7.321 .261 & 6,41 & 3.369 .311 & 2,95 & 3.353 .472 & 2,94 \\
\hline Cultivos transitorios y barbecho & 4.060 .686 & 3,55 & 4.432 .249 & 3,88 & 3.736 .388 & 3,27 & 1.324 .392 & 1,16 & 1.283 .121 & 1,12 \\
\hline Cultivos permanentes & 1.925 .742 & 1,69 & 2.301 .694 & 2,02 & 1.617 .455 & 1,42 & 1.936 .704 & 1,70 & 1.997 .652 & 1,75 \\
\hline Descanso & 2.134 .943 & 1,87 & 2.130 .555 & 1,87 & 1.967 .418 & 1,72 & 108.215 & 0,09 & 72.699 & 0,06 \\
\hline 1.3.2 Pecuaria & 36.810 .033 & 32,22 & 36.730 .385 & 32,17 & 151.511 & 0,13 & 38.804 .661 & 33,99 & 39.185.705 & 34,32 \\
\hline Pastos & 28.558 .607 & 24,99 & 28.982 .201 & 25,38 & 37.871 .188 & 33,17 & 31.016 .162 & 27,17 & 31.625 .117 & 27,70 \\
\hline Malezas y rastrojos ** & 8.251 .425 & 7,22 & 7.748 .183 & 6,79 & 28.763 .984 & 25,19 & 7.788 .499 & 6,82 & 7.560 .588 & 6,62 \\
\hline \begin{tabular}{|l|}
1.3 .3 Bosques \\
\end{tabular} & 9.826 .687 & 8,60 & 8.081 .363 & 7,08 & 9.107.199 & 7,98 & 7.726 .761 & 6,77 & 7.420 .425 & 6,50 \\
\hline Naturales & 9.483 .233 & 8,30 & 7.827 .886 & 6,86 & 7.740 .597 & 6,78 & 7.457 .475 & 6,53 & 7.036 .204 & 6,16 \\
\hline Plantados & 1.728 .926 & 1,51 & 253.477 & 0,22 & 7.508 .686 & 6,58 & 269.286 & 0,24 & 384.221 & 0,34 \\
\hline 1.3.4 Otros usos ${ }^{*}$ & & & 1.461 .458 & 1,28 & 231.912 & 0,20 & 1.268 .918 & 1,11 & 982.383 & 0,86 \\
\hline \multicolumn{11}{|c|}{${ }^{*}$ Incluye cuerpos de agua, eriales, superficie urbana - semiurbana y superficies marginalmente cultivables en parques naturales. } \\
\hline $\begin{array}{l}\text { ** Las fluctuaciones se deben fundamenta } \\
\text { por el encuestador. }\end{array}$ & 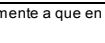 & & 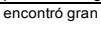 & & 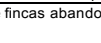 & & cual fuerc & (1) & 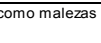 & strojos \\
\hline
\end{tabular}

A raíz de la violencia, tanto guerrillera como la de Mancuso,los dueños de esas tierras abandonaron eso y lo dejaron a la deriva, a expensas y al capricho de los ocupantes. Todos los dueños propietarios de esas tierras habían salido de ahí, ya había habido un despoblamiento de la zona.Y los que estaban ocupando tierras eran los lugartenientes de Mancuso y de todos esos tipos con sus respectivas mejoras ${ }^{355}$.

Este punto afecta la producción de agroalimentos por el desplazamiento y despojo. Reyes analiza los procesos de expulsión poblacional y reconfiguración de la acción política y militar de grupos armados paramilitares, y muestra los métodos empleados para propiciar el abandono y el despojo de tierras, que se diferencian a los identificados por el MADR. Esta acumulación por despojo se caracteriza, según Reyes ${ }^{356}$, por multiplicidad de acciones: la transferencia forzada de títulos bajo coacción a nombre del

355 Comisión Nacional de Reparación y Reconciliación (2010): La tierra en disputa. Memorias del despojo y resistencia campesina en la Costa Caribe (1960-2010). Taurus Pensamiento y Semana. 356 Comisión Nacional de Reparación y Reconciliación (2009): El despojo de tierras y territorios. Aproximación conceptual Área de Memoria Histórica, Línea de Investigación Tierra y Conflicto. Bogotá, pág. 20. 
comandante o mando medio del grupo paramilitar (a veces guerrillero); el corrimiento de cercas para englobar predios de desplazados; el uso de testaferros o familiares para ocultar la titularidad, hasta adjudicarla a combatientes campesinos o desplazados por las guerrillas; la venta generalmente forzada; la compra de deudas hipotecarias y crediticias a los bancos y propietarios endeudados, por parte de mandos paramilitares y otros particulares; y la expropiación violenta sin contraprestación económica.

Hay varias fuentes de información sobre el abandono de tierras en Colombia. Por un lado, la nota de los encuestadores del 2002, que clasifican como malezas y rastrojos las fincas abandonadas (ver tabla 7.2.3). Otra muestra las hectáreas estimadas y abandonadas por la población desplazada con diferentes cálculos: la Contraloría General de la República, 2,9 millones; el PMA, 4 millones; el sindicato de trabajadores del Incora, 4,4 millones; Codhes, 4,8 millones; el Gobierno nacional, 6,8 millones; las víctimas, 10 millones (tabla 7.2.4). Con diferentes fuentes, se reconoce la cantidad de tierras abandonadas por los desplazamientos.

En el proceso de reconstrucción de memoria, la Comisión Nacional de Reparación y Reconciliación muestra los autores intelectuales y materiales del despojo en la región Caribe, en tres departamentos, desde 1900 a 2010, como un problema estructural de

\begin{tabular}{|c|c|}
\hline \multicolumn{2}{|c|}{$\begin{array}{l}\text { Tabla 7.2.4. Colombia, estimativos de hectáreas abandonadas por la } \\
\text { población desplazada }\end{array}$} \\
\hline Fuente & $\begin{array}{c}\text { Millones de hectáreas } \\
\text { estimadas }\end{array}$ \\
\hline Ibáñez, Moya y Velásquez (1) & 1.2 \\
\hline Contraloría general de la República & 2.9 \\
\hline Programa Mundial de Alimentos (2) & 4 \\
\hline Sindicato de Trabajadores del INCORA & 4.4 \\
\hline CODHES & 4.8 \\
\hline $\begin{array}{c}\text { Acción Social - proyecto protección de tierrasy patrimonio de la } \\
\text { población desplazada (3) }\end{array}$ & 6.8 \\
\hline Movimiento Nacional de Víctimas de Estado (catastro alternativo) (4) & 10 \\
\hline \multicolumn{2}{|c|}{$\begin{array}{l}\text { (1) Ibáñez, A., Moya, A. y Velásquez, A. (2006) hacia una política para la población } \\
\text { desplazada, mimeo. (2) PMA (2001). Estudio de caso de las necesidades alimentarias de la } \\
\text { población desplazada en Colombia.(3) Acción Social - proyecto protección de tierras y } \\
\text { patrimonio de la población desplazada (2005). Dis eño de una metodología participativa para la } \\
\text { recolección de información y protección de bienes muebles. (4) Movimiento Nacional de } \\
\text { Crímenes de Estado (2007). Catastro alternativo, estrategia contra la impunidad y herramienta } \\
\text { para la reparación integral. }\end{array}$} \\
\hline $\begin{array}{l}\text { Fuente: Comisión Nacional de Reparación y Reconciliación (2009): El desp } \\
\text { Aproximación conceptual. Bogotá, pág } 26 .\end{array}$ & le tierras y territorios. \\
\hline
\end{tabular}




\begin{tabular}{|c|c|c|c|c|}
\hline \multirow{3}{*}{$\begin{array}{c}\text { Autores del despojo } \\
\text { (intelectuales/Materiales) }\end{array}$} & $\begin{array}{l}\text { ales y mat } \\
010 . \text { Córd }\end{array}$ & $\begin{array}{l}\text { teriales del } \\
\text { oba, Sucre }\end{array}$ & $\begin{array}{l}\text { spojo por p } \\
\text { Bolívar }\end{array}$ & íodos de \\
\hline & \multicolumn{4}{|c|}{ Períodos de Tiempo } \\
\hline & $1900-1960$ & $1960-1980$ & $1980-2000$ & $2000-2010$ \\
\hline $\begin{array}{l}\text { 1. Élites sociales y políticas regionales y } \\
\text { nacionales }\end{array}$ & $\mathbf{x X X}$ & $\mathbf{x X X}$ & $\mathbf{x X X}$ & $\mathbf{x X X}$ \\
\hline $\begin{array}{l}\text { 2. Hacendados ganaderos y terratenientes } \\
\text { tradicionales }\end{array}$ & $\mathbf{x X X}$ & $\mathbf{X X X}$ & $\mathbf{X X X}$ & $\mathbf{X X X}$ \\
\hline 3. Empresarios extranjeros & $\mathbf{X X X}$ & & & $\mathbf{X X X}$ \\
\hline 4. Empresarios ilegales & & & $\mathbf{X X X}$ & $\mathbf{X X X}$ \\
\hline 5. Narcotraficantes & & & $\mathbf{X X X}$ & $\mathbf{X X X}$ \\
\hline 6. Bandoleros - Pájaros & $\mathbf{X X X}$ & $\mathbf{X X X}$ & & \\
\hline 7. Grupos de Seguridad Privada & $\mathbf{X X X}$ & $\mathbf{X X X}$ & & \\
\hline 8. Paramilitares & & $x \times x$ & $x x x$ & $x x x$ \\
\hline 9. Guerrillas* & & $\mathbf{X X X}$ & $\mathbf{X X X}$ & $\mathbf{X X X}$ \\
\hline$x x x$ & \multicolumn{4}{|c|}{$\begin{array}{l}\begin{array}{l}\text { Momentos de permanencia y cambio de los agentes del } \\
\text { despojo }\end{array}\end{array}$} \\
\hline \multicolumn{5}{|c|}{ *Las guerrillas son señaladas como responsables del abandono más que del despojo de predios. } \\
\hline $\begin{array}{l}\text { Fuente: Comisión Nacional de Reparación y } \\
\text { Resistencia Campesina en la Costa Caribe } \\
\text { Nacional de Reparación y Reconciliación", Ta }\end{array}$ & $\begin{array}{l}\text { Reconciliación } \\
\text { 1960-2010) In } \\
\text { urus Pensam }\end{array}$ & $\begin{array}{l}\text { 2010. "La Tierr } \\
\text { forme del Grup } \\
\text { iento-Semana. }\end{array}$ & $\begin{array}{l}\text { Disputa Memc } \\
\text { e Memoria Histó } \\
\text { g. } 191\end{array}$ & $\begin{array}{l}\text { s del Despojo y } \\
\text { a de la Comisión }\end{array}$ \\
\hline
\end{tabular}

violencia en esta región (tabla 7.2.5). En forma continua, los autores intelectuales y materiales son las empresas extranjeras en el primero y último periodo; siempre han estado élites sociales y políticas, hacendados ganaderos y terratenientes, y en cada periodo van cambiando los autores.

En las encuestas del Gobierno nacional, Proyecto de Protección de Tierras y Patrimonio de la Población Desplazada, de Acción Social, se afirma:

Los registros oficiales muestran que de las 3.624 .426 personas expulsadas violentamente y forzadas a abandonar sus bienes entre 1995 y 2010, hay 256.480 jefes de hogar que afirman haber dejado abandonados 270.680 bienes inmuebles (predios) cuya área se calcula en 6.556.978 hectáreas ${ }^{357}$.

357 Agencia Presidencial para la Acción Social y la Cooperación Internacional (2010): Unidades agrícolas familiares. Tenencia y abandono forzado de tierras en Colombia. Proyecto Protección de Tierras y Patrimonio de la Población Desplazada, Bogotá, pág. 120. 
Tabla 7.2.6 Colombia 1995-2010, distribución de tierras abandonadas según rangos catastrales de tamaño de predios

\begin{tabular}{|l|r|r|r|r|}
\hline \multicolumn{1}{|c|}{ Rango de Área } & $\begin{array}{c}\text { No. De } \\
\text { Predios }\end{array}$ & $\begin{array}{c}\text { \% de } \\
\text { Predios }\end{array}$ & $\begin{array}{c}\text { Área } \\
\text { Abandonada } \\
\text { (has.) }\end{array}$ & $\begin{array}{c}\text { \% de área } \\
\text { abandonada } \\
\text { (has.) }\end{array}$ \\
\hline Menores de 10 has. & 167.467 & 60,98 & 689.442 & 10,51 \\
\hline De 10 menos de 50 has. & 72.771 & 26,50 & 1.634 .480 & 24,93 \\
\hline De 50 a menos de 200 has. & 28.546 & 10,39 & 2.348 .832 & 35,82 \\
\hline De 200 a 500 has. & 4.848 & 1,77 & 1.272 .411 & 19,41 \\
\hline De 500 a 1.000 has. & 1.008 & 0,37 & 611.812 & 9,33 \\
\hline Total & 274.640 & 100,00 & 6.556 .977 & 100,00 \\
\hline
\end{tabular}

Fuente: 2010. "Unidades Agrícolas Familiares, Tenencia y Abandono Forzado de Tierras en Colombia".

Publicado por la Agencia Presidencial para la Acción Social y la Cooperación Internacional - Acción Social.

Proyecto Protección de Tierras y patrimonio de la Población Desplazada. Tabla 7.2 Pág. 123 Cálculos del autor.

La tabla 7.2.6 tiene los rangos de áreas abandonadas por el despojo de tierras: los pequeños propietarios de menos de 10 hectáreas, con el 60,98\% de predios; y los de menos de 50, con el 26,5\%. El resto de rangos, de más de 50 a 1.000 hectáreas, tienen el 12,5\%. No sucede lo mismo con las áreas abandonadas: mientras los dos primeros rangos son predios que se tienen para la subsistencia y producción de alimentos, los otros son de ganadería y cultivos de agroindustria.

La anterior información de despojo de tierras y desplazamiento de población en las últimas décadas del siglo XX e inicios del XXI configura la dinámica calificada por la FAO como "proceso de relatifundización":

El acaparamiento de la propiedad rural no ha dejado de crecer, 3000 latifundistas con extensiones superiores a 2.000 hectáreas incrementaron sus propiedades con 31 millones de hectáreas adicionales entre 1984 y 1997, mientras que en este mismo período medio millón de campesinos solamente pudieron incrementar sus propiedades en 238.000 hectáreas, equivalentes a media hectárea promedio por familia ${ }^{358}$.

358 CARDOZA, Germán (2003): “Globalización, relatifundización y especulación”. Citado en FAO y Comunidad Andina (2004): Comunidad Andina: factores macroeconómicos, comerciales, sectoriales y la seguridad alimentaria. Pág. 118. 
La tendencia en las siguientes décadas es de procesos similares de concentración de la propiedad rural. La Presidencia muestra estas dinámicas de expulsión y desplazamiento forzado en el país:

Entre 1998 y 2002 la expulsión masiva de personas se concentró en los departamentos de Antioquia (98.212 personas), Chocó (41.577 personas), Magdalena (41.590 personas), Bolívar (35.542 personas) y Córdoba (17.852 personas), mientras que en el período 2003-2009 se concentró en los departamentos de Nariño (38.971), Antioquia (28.278), Chocó (24.824), Valle del Cauca (20.634) y Caldas $(13.648)^{359}$.

Machado relaciona esta acumulación por desposesión con problemas de disponibilidad de alimentos regionales y locales:

Los efectos que tiene el conflicto armado sobre la sociedad rural (desplazamiento forzado, abandono de la producción, gasto público militar creciente). La irrupción del narcotráfico y de los cultivos ilícitos tiene relación con la seguridad alimentaria. Este fenómeno induce al abandono de los cultivos de subsistencia alimentaria en zonas del interior para desplazar mano de obra hacia las áreas de colonización, lo cual disminuye la oferta de alimentos; las familias o cultivadores de coca abandonan también la producción familiar de alimentos y acuden a la compra de ellos a precios altos [...] afectando la oferta local y regional de alimentos ${ }^{360}$.

El conflicto vinculado con violencia política y narcotráfico en zonas rurales campesinas, el despojo y la creciente sustitución de alimentos por cultivos de uso ilícito y la demanda internacional de narcóticos han sido motivos para abandonar la producción

359 Agencia Presidencial para la Acción Social y la Cooperación Internacional: Desplazamiento forzado en Colombia. Pág. 4.

360 MACHADO, Absalón (2004): "Seguridad alimentaria y sistema agroalimentario". En Territorios y sistemas agroalimentarios locales. Varios Autores. Universidad Nacional de Colombia, Red de Desarrollo Rural y Seguridad Alimentaria, Bogotá, pág. 40. 
de agroalimentos. Este conflicto rural muestra el papel desempeñado por la agricultura en el nuevo modelo de acumulación por desposesión, donde los poderes regionales desarrollan múltiples acciones:

La expropiación violenta de tierras, del acceso a los dineros públicos, entre otros. El paraestado se ha mostrado igualmente como parte de una estrategia transnacional de resignificación de la tierra como fuente de valorización capitalista (biodiversidad, recursos hídricos, recursos minerales), de promoción de megaproyectos infraestructurales y energéticos; y de un nuevo tipo de agricultura de plantación, orientada principalmente a la producción de agrocombustibles ${ }^{361}$.

Combinando las dinámicas de despojo e integrándolas con la acumulación por desposesión, estas son prácticas que inciden sobre la disponibilidad nacional y regional de agroalimentos.

\subsubsection{La concentración de la tierra en Colombia 1996-2008 y la producción de alimentos}

Machado analiza el problema estructural de concentración de la tierra en Colombia desde 1960 y su tendencia hasta 1984. Las cifras de las siguientes décadas tienen una tendencia similar, agravada por otras dinámicas de despojo:

El índice de concentración de la propiedad (índice de Lorenz) paso de $85.19 \%$ en 1960 a $85.04 \%$ en 1970 y $83.9 \%$ en 1984 hubo una modificación muy leve e indicativa de la poca voluntad política del país para modificar y adecuar la estructura de la propiedad para un desarrollo más equilibrado y con menos tensiones sociales, [...] no se ha modificado en esencia la estructura de la propiedad ${ }^{362}$.

Según la información obtenida para esta investigación, puede afirmarse que la tendencia continúa: "La elevada concentración de la propiedad de la tierra, y adicionalmente, por cuenta de los fenómenos de desplazamiento forzado - 708.910 hogares entre 2007 y

361 ESTRADA A., Jairo (2010): Derechos del capital. Dispositivos de protección e incentivos a la acumulación en Colombia. Universidad Nacional de Colombia, Bogotá, pág. 35.

362 MACHADO C., Absalón (1986): El problema alimentario en Colombia... Op. cit., pág. 74. 
2010 - de despojo de tierras y de cultivos ilícitos, se ha agravado la situación social del campo" 363 . Este reconocimiento de la concentración de la propiedad y desplazamiento campesino afecta la disponibilidad.

Sobre la distribución de la tierra hay dos fuentes de información: una, la de los diseños muestrales del DANE-MADR, donde los PSM $^{364}$ son la unidad de medida de 1996 a 2004; y otra es la de unidades productivas de la Corporación Colombia Internacional (CCI) para el e 2008. Es necesaria esta aclaración, pues en términos metodológicos hay algunas diferencias en la forma de consecución; sin embargo, independientemente de la metodología desarrollada, las tendencias sobre la concentración de la propiedad se reafirman.

La siguiente tabla muestra la relación inversa entre número de predios de menos de 10 hectáreas y el total de área para estos: el 65\% de los predios tiene el 7,9\% del área, las mayores propiedades, con el 0,59\% de los predios, y tienen el 20,4\% del área. Esto relaciona los dos extremos de los usos.

\begin{tabular}{|c|c|c|c|c|c|c|c|c|c|c|c|c|c|}
\hline \multirow{2}{*}{ Tamaño (PSM) } & \multicolumn{2}{|c|}{ P S M } & \multicolumn{11}{|c|}{ Total y usos (hectáreas) } \\
\hline & Cantidad & $\%$ & Área & $\%$ & Área & * & ** & Área & * & ** & Área & * & ** \\
\hline \multicolumn{14}{|c|}{ Año 2004} \\
\hline TOTAL & 2.029 .742 & 100.0 & 51.138 .467 & 100,0 & 3.708 .455 & 7,3 & 100,0 & 38.682 .587 & 75,6 & 100,0 & 8.747 .425 & 17,1 & 100,0 \\
\hline 50 a menos de 200 & 149.958 & 7,4 & 14.238 .188 & 27,8 & 957.134 & 6,7 & 25,8 & 11.067 .041 & 77,7 & 28,6 & 2.214 .012 & 15,5 & 25,3 \\
\hline 200 a menos de 500 & 43.799 & 2,2 & 12.729 .304 & 24,9 & 576.365 & 4,5 & 15,5 & 10.429 .332 & 81,9 & 27,0 & 1.723 .606 & 13,5 & 19,7 \\
\hline 1000 a menos de 1200 & 12.022 & 0,6 & 10.462 .241 & 20,5 & 31.797 & 0,3 & 0,9 & 7.551 .511 & 72,2 & 19,5 & 2.878 .934 & 27,5 & 32,9 \\
\hline \multicolumn{14}{|c|}{ Año 1996} \\
\hline Total & 2.090 .386 & 100,0 & 52.426 .327 & 100,0 & 4.060 .681 & 7,7 & 100,0 & 36.810 .029 & 70,2 & 100,0 & 11.555 .613 & 22,0 & 100,0 \\
\hline 200 a menos de 500 & 30.609 & 1,5 & 8.626 .770 & 16,5 & 319.128 & 3,7 & 7,9 & 5.677 .107 & 65,8 & 15,4 & 2.630 .533 & 30,5 & 22,8 \\
\hline 500 a menos de 1200 & 16.112 & 0,8 & 13.969.304 & 26,6 & 57.503 & 0,4 & 1,4 & 10.254 .959 & 73,4 & 27,9 & 3.656 .840 & 26,2 & 31,6 \\
\hline Fuente : ENA, DANE- Proyect & Cy Ministeric & ulture & rrollo Rural & culbs & & & & centaje Horizor & ** & entaje V & & & \\
\hline
\end{tabular}

363 DNP (2011): Prosperidad para Todos, Plan Nacional de Desarrollo 2010-2014... Op. cit., pág. 232.

364 El PSM es la unidad de observación para las entrevistas, es decir, el elemento al que se dirige la encuesta y con cuya información se diligencian los formularios. En muchos casos coincide con el predio (concepto catastral) o con la finca. La dirección técnica, administrativa y económica de un PSM está a cargo de un productor, quien a veces la delega en un administrador, gerente o mayordomo. El PSM se concibe como un área continua; por tanto, si un productor explota varias fincas dentro de un PSM separadas por terrenos a cargo de otros productores, cada una de tales fincas constituye un PSM (MADR, Servicios de Información al Ciudadano). 


\begin{tabular}{|c|c|c|c|c|c|c|c|c|c|c|c|c|c|c|c|c|}
\hline \multirow{2}{*}{$\begin{array}{c}\text { Rango de tamaño } \\
\text { en hectáreas }\end{array}$} & \multicolumn{4}{|c|}{ Totales } & \multicolumn{4}{|c|}{ Agricolas./1 } & \multicolumn{4}{|c|}{ Pecuarias } & \multicolumn{4}{|c|}{ Forestales comerciales } \\
\hline & Área (ha) & $\%$ & $\begin{array}{l}\text { Unidades } \\
\text { Productivas }\end{array}$ & $\%$ & Área (ha) & $\%$ & \begin{tabular}{|c|} 
Unidades \\
Productivas
\end{tabular} & $\%$ & Área (ha) & $\%$ & $\begin{array}{c}\text { Unidades } \\
\text { Productivas }\end{array}$ & $\%$ & Area (ha) & $\%$ & $\begin{array}{c}\text { Unidades } \\
\text { Productivas }\end{array}$ & $\%$ \\
\hline Total Nacional & 42.963 .462 & 100 & 2.338 .553 & 100 & 3.467 .521 & 100 & 898.970 & 100 & 39.153.186 & 100 & 1.395 .411 & 100 & 342.755 & 100 & 44.172 & 100 \\
\hline $0 \mathrm{~A} 10$ & 2.864 .183 & 6,67 & 1.516 .491 & 64,8 & 781.721 & 23 & \begin{tabular}{ll|}
609.681 \\
\end{tabular} & 68 & 2.058 .800 & 5 & 880.379 & 63 & 23.662 & 7 & 26.431 & 60 \\
\hline 10 A 50 & 7.189 .148 & 16,7 & 583.579 & 25 & 1.078 .818 & 31 & 213.821 & 24 & 6.056 .637 & 15 & 358.320 & 26 & 53.693 & 16 & 11.437 & 26 \\
\hline 50 a 100 & 4.668 .715 & 10,9 & 115.812 & 4,95 & 467.312 & 13 & 38.669 & 4 & 4.152 .596 & 11 & 74.771 & 5 & 48.807 & 14 & 2.373 & 5 \\
\hline 100 a 500 & 12.162 .215 & 28,3 & 101.374 & 4,33 & 794.018 & 23 & 31.212 & 3 & \begin{tabular}{|l|l|}
11.175 .779 \\
\end{tabular} & 29 & 66.546 & 5 & \begin{tabular}{|l|l|}
192.419 \\
\end{tabular} & 56 & 3.615 & 8 \\
\hline Mayor de 500 & 16.079.201 & 37,4 & 21.297 & 0,91 & 345.653 & 10 & 5.587 & 1 & 15.709.375 & 40 & 15.395 & 1 & \begin{tabular}{l|l}
24.173 & \\
\end{tabular} & 7 & 315 & 1 \\
\hline \multicolumn{4}{|c|}{ Fuente: ENA, CCI-MADR-2008 Cálculos del autor. } & \multicolumn{13}{|c|}{$\begin{array}{l}\text { 1. Incluye cultivos transitorios ypermanentes; la suma de las unidades productivas no coincide con el total porque las UP } \\
\text { pueden tener los dos tipos de cultivo. }\end{array}$} \\
\hline
\end{tabular}

En las tierras dedicadas a usos agrícolas, pastos y bosques hay disminución del área: la de esta última pasa de 11.555.613 ha en 1996 a 8.747.425 ha en 2004, seguida de la agrícola, que perdió cerca de 300.000 ha; mientras tanto, los pastos y las malezas aumentan cerca de 2.000.000 ha. Para el 2008, la base de las unidades productivas tiene tendencias similares: mientras los pequeños y medianos tienen el $90 \%$ de las unidades, solo poseen el 22\% del área, y para los rangos de más 100 hectáreas tienen el 5\% de las unidades y el 66\% del área.

Al desagregar los usos agrícolas se encuentra: la dedicación es el 92\% de los pequeños y medianos productores, con el 51\% de área; los grandes solo tiene el 4\%, con el 33\% de área. En el sector pecuario hay $89 \%$ de las unidades productivas de pequeños y medianos, con un área del 20\%, organizados en 1.238.700 unidades con 8.115.436 ha; las grandes tienen el 6\% de unidades (81.941), un área del 69\%, con 26.885.153 ha. Una tendencia similar se encuentra cuando se ven los cultivos forestales comerciales.

\begin{tabular}{|c|c|c|c|c|c|c|c|c|}
\hline \multirow{2}{*}{$\begin{array}{c}\text { Rango de tamaño } \\
\text { en hectáreas }\end{array}$} & \multicolumn{4}{|c|}{ Transitorios/1 } & \multicolumn{4}{|c|}{ Permanentes $/ 1$} \\
\hline & Área (ha) & $\%$ & $\begin{array}{c}\text { Unidades } \\
\text { Productivas }\end{array}$ & $\%$ & Área (ha) & $\%$ & $\begin{array}{l}\text { Unidades } \\
\text { Productivas }\end{array}$ & $\%$ \\
\hline Total Nacional & 1.407 .437 & 100 & 613.065 & 100 & 2.060 .084 & 100 & 522.255 & 100 \\
\hline $\begin{array}{|lll|}0 & \text { A } & 10 \\
\end{array}$ & 287.521 & 20 & 412.716 & 67 & 494.200 & 24 & 327.368 & 63 \\
\hline 10 A 50 & 371.022 & 26 & 137.818 & 22 & 707.796 & 34 & 145.710 & 28 \\
\hline 50 a 100 & 177.732 & 13 & 30.191 & 5 & 289.579 & 14 & 25.796 & 5 \\
\hline 100 a 500 & 372.570 & 26 & 26.925 & 4 & 421.448 & 20 & 19.320 & 4 \\
\hline Mayor de 500 & 198.592 & 14 & 5.414 & 1 & 147.061 & 7 & 4.060 & 1 \\
\hline \multicolumn{9}{|c|}{$\begin{array}{l}\text { Fuente: ENA, CCI-MADR-2008 Cálculos del autor } 1 \text {. Incluye cultivos transitorios y permanentes; la } \\
\text { suma de las Unidades productivas no coincide con el total porque las UP pueden tener los dos tipos de } \\
\text { cultivo. }\end{array}$} \\
\hline
\end{tabular}


Respecto a los usos agrícolas transitorios y permanentes (tabla 7.2.9), se ve el área total y las unidades productivas. Los pequeños y medianos productores tienen más participación en usos permanentes que en transitorios, lo que muestra un fenómeno de sustitución hacia estos cultivos más rentables y con menos mano de obra.

\subsubsection{Disponibilidad y políticas}

La disponibilidad de alimentos en Colombia presenta desarticulación de políticas públicas, de acuerdo con los niveles de los gobiernos que las manejan, los intereses de las poblaciones en los territorios, las funciones que cada nivel de gobierno tiene, los vínculos entre instrumentos de política y centros de decisión para su aprobación, coordinación y ejecución. Esta desarticulación es analizada en el texto Conflictividad territorial en Colombia:

El desarrollo de la infraestructura económica básica depende todavía de las políticas nacionales y de la ejecución de los entes centrales, [...] las exenciones comerciales, fiscales y financieras dependen del Congreso y de la capacidad local y regional de promover estas iniciativas ante el Gobierno nacional, [...] los mecanismos de financiación para actividades productivas se encuentran en cabeza del Gobierno nacional, [...]-estos puntos- generan un conflicto entre el Gobierno nacional y los gobiernos territoriales en ocasiones las decisiones nacionales afectan las estrategias de desarrollo trazadas por las regiones ${ }^{365}$.

Así, la desarticulación de políticas afecta las dinámicas locales para producir agroalimentos, muestra la descoordinación intergubernamental e interinstitucional; por tanto, requiere mayor coordinación en función de las competencias institucionales y las acciones de la política pública. Por consiguiente, se reconoce que la política de seguridad alimentaria y nutricional debe ser construida sobre la participación y concertación de actores públicos y privados, y convertirse en una política de Estado $^{366}$. Este, si bien coordina sectores y regiones, respecto a su política debe señalarse: "Hay

365 ESAP y Fundación Buen Gobierno (2004): Conflictividad territorial en Colombia. Autores Varios. Bogotá, págs. 298 y ss.

366 Departamento Nacional de Planeación (2008): Conpes 113, Política Nacional de SAN. Bogotá. 
problemas de concertación con el sector agropecuario que tienen una visión corta con los programas de seguridad alimentaria y no hay integración de acciones en la política según el CONPES 113"367.

En la construcción del Conpes 113 participaron el MEN, el MPS, el MADR y el Incoder, los cuales ven la disponibilidad de alimentos vinculada con acciones directas por realizar en las zonas rurales. Sin embargo, no ven las acciones indirectas y generales de la política económica, como tampoco la apertura comercial que afecta la producción nacional de alimentos y va por otro ministerio. El documento analiza problemas de estabilidad y disponibilidad referidos a la "distribución interna de los alimentos relacionados con las dificultades en el acceso, especialmente en las regiones geográficas apartadas" ${ }^{368}$, y al comportamiento de su producción.

Por su parte, la FAO considera que en Colombia hay un "vacío institucional y conceptual, los programas enemigos de la seguridad alimentaria por el asistencialismo que mata la sostenibilidad, cuando se entregan semillas, herramientas baja la participación"369; por consiguiente, las acciones públicas no conllevan sostenibilidad de las políticas alimentarias, porque son orientadas con criterios asistenciales, y no de desarrollo. Esta tesis plantea un principio de desarrollo y autonomía sobre los mínimos de producción de agroalimentos regiolocales, a partir de las demandas de SAN en las ciudades ejes.

Otro punto que baja la disponibilidad es el limitado uso del recurso hídrico por la contaminación, la administración y la operación, a lo cual se agrega la falta de planeación territorial de mediano y largo plazo. Este es un problema de las políticas y las relaciones intergubernamentales, tanto por las competencias como por las capacidades institucionales y financieras para su desarrollo:

367 TRUjILlO, Claudia (2008): Entrevista. Funcionaria de la Secretaría de Salud del departamento del Huila. 6 de noviembre.

368 En la construcción de una política nacional se evidencia el problema de la distribución de las regiones apartadas, que sin desconocer su importancia, es hoy una situación menos problemática que la de los centros urbanos, que es donde se encuentra ubicada la mayoría de la población colombiana. Este es un problema de manejo de la disponibilidad para esas regiones, y no de los efectos que se tendrían por no poder sacar esos alimentos para el grueso de consumidores.

369 MORENO, Mario (2008): Entrevista. Director del "Proyecto apoyo a desplazados urbanos y comunidades vulnerables rurales en alto riesgo de desplazamiento Sucre-Bolívar-Choco". FAO, Cartagena, departamento de Bolívar, 24 de octubre. 
Se encuentran ineficiencias en la administración y operación de los distritos de riego. Estos dos aspectos afectan significativamente la capacidad de mejorar rendimientos e incrementar de manera sostenida la producción de alimentos ${ }^{370}$.

En relación con el agua y el suelo en las regiones, su contaminación afecta la disponibilidad, por el uso que se hace del suelo, que lleva a su agotamiento, al "acabose de suelo por mal manejo implicando que hay sectores donde ya no se puede producir por la contaminación hídrica por los químicos utilizados" ${ }^{371}$. Los controles sobre esta situación son mínimos, tanto en la fase de producción de insumos como en el uso de estos.

Por otro lado, la política de ordenamiento territorial y ambiental busca regular el uso de la oferta hídrica y que dueños de algunas áreas puedan "vender los predios en las montañas para la protección de las fuentes hídricas" 372 , las áreas estratégicas para las entidades territoriales y el planeamiento del manejo del agua en los municipios. Pero allí se presentan problemas administrativos y financieros en la coordinación para la ejecución de los recursos públicos para su adquisición. Sobre los recursos genéticos y la disponibilidad, el Conpes 113 señala:

El uso de semilla certificada ha disminuido dramáticamente en los últimos años. En el 2005, tan solo el 22\% del área sembrada correspondía a semilla certificada, mientras que en 1990 esta participación llegaba a 50\%. Esto ha afectado sustancialmente los rendimientos de las pequeñas unidades productivas ${ }^{373}$.

En las regiones, la concentración en la distribución de semillas afecta a los campesinos en su demanda; por ejemplo, para la producción de papa, pues "no hay semillas certificadas vendidas a pequeños productores" 374 de un producto base de la dieta alimentaria en Colombia.Yobre la financiación a los campesinos productores de alimentos puede indicarse:

370 DNP (2008): Conpes 113... Op. cit., pág. 12

371 BONILLA, Virginia (2008). Entrevista. Directora de la UMATA, municipio de Algeciras, departamento del Huila, 4 de noviembre.

372 MOSQUERA, Mauricio (2008): Entrevista. Director de la Unidad de Desarrollo Económico, municipio de Rivera, departamento del Huila, 6 de noviembre.

373 DNP (2008): Conpes 113... Op. cit., pág. 12.

374 CISNEROS, Mauricio (2008): Entrevista. Director de la UMATA, municipio de Ipiales, departamento de Nariño, 12 de noviembre. 
Sigue siendo bajo si se compara con el tamaño de la producción, a pesar de los esfuerzos del Gobierno para expandir la oferta de crédito agropecuario. A pesar de que en los últimos años el número de créditos otorgados a pequeños productores se ha incrementado un $506 \%{ }^{\prime 375}$.

El acceso al crédito para campesinos y aparceros para producir agroalimentos ha presentado dificultades: "Duré 7 meses tramitando 10 créditos para campesinos. No pude. Se requiere para seguridad alimentaria créditos para campesinos sin trabas con entidades al servicio del campesino" 376 . La financiación para los campesinos muestra otro problema histórico estructural de estas economías, que afecta directamente la producción de agroalimentos.

Sobre la innovación tecnológica, hay un rezago en los rendimientos de producción de alimentos de la canasta básica: el maíz, la leche, la papa ${ }^{377}$. Esto demanda del mercado un cambio en los conceptos: "Hace 12 años fomentar seguridad alimentaria era fomentar el atraso" ${ }^{378}$; los cambios tecnológicos requieren otra mirada local y regional frente a la disponibilidad en la SAN y su vínculo nacional. Los diferentes problemas en la estabilidad y la disponibilidad son del resorte de la acción pública estatal nacional; de manera directa e indirecta están las condiciones naturales. Las acciones para mitigar estos problemas, en conjunto con los gobiernos locales, son casi nulas; y solo se vuelven públicas en momentos de crisis por lluvia o sol.

\subsubsection{Las disponibilidades de alimentos}

\subsubsection{Nivel nacional}

La producción nacional de agroalimentos y materias primas agropecuarias se divide en productos transitorios y permanentes. La información de 1987 a 2009 se presenta en las tablas 1, 2, 3 y 4 del anexo C, en tanto la estructura de producción por tamaño

375 DNP (2008): Conpes 113... Op. cit., pág. 13

376 Entrevista en el municipio de Lebrija-Santander con el grupo de la UMATA (2008): PINZÓN, Hernando (Director), VILLAMIZAR, Judit y SOTO, Juan (técnicos). Entrevistados el 9 de diciembre.

377 FAOSTAT (2007).

378 Ibíd. 
de unidad productiva y proporción de hectáreas según cultivos, en las 7.2.10 y 7.2.11. En más de dos décadas analizadas, la superficie para producir agroalimentos y materias primas presenta disminución de estos productos, excepto el algodón (tabla 1, anexo C). Los agroalimentos y las materias primas se comportan diferente desde 1987 hasta 1990, último año en que cambia el modelo de desarrollo: los agroalimentos crecen en el periodo, a excepción del ajonjolí, el maní y el tabaco rubio. A partir de 1990, inicia el modelo de apertura y hay una caída de las hectáreas cosechadas.

Cultivos transitorios. En 1987, las hectáreas para cultivos semestrales tuvieron un crecimiento del $26,4 \%$, con 2.407.930 ha, y a partir de las políticas de apertura del modelo de desarrollo las hectáreas bajan 872.500 ha en 20 años. Los cultivos con mayor incidencia son ajonjolí, algodón, cebada, maní, sorgo y soya. A continuación se analiza la situación de unos agroalimentos de la dieta básica de la población colombiana.

Arroz. Crece el área de 384.500 ha en 1987 a 571.606 ha en 2009. Es el único producto que crece en el periodo, tanto en producción como en rendimientos. El crecimiento se sustenta en un mayor consumo y en la estructura del mercado arrocero, donde hay "28.128 productores de arroz paddy, alrededor de 10 empresas molineras, algunos empacadores sin molino, unos 10.000 comerciantes mayoristas y unos 400.000 puntos de venta al detal de todo tipo y tamaño" 379 . Este es un producto de la dieta básica, especialmente de los sectores de medios y bajos ingresos en todas las regiones, y es un también un producto en conflicto por la negociación del TLC con Estados Unidos, que posee excedentes de este.

Las cuatro regiones para producir arroz son: el centro, en los departamentos de Huila y Tolima, "donde se utiliza el sistema de riego y donde se encuentran localizados los distritos de riego mejor organizados de todo el país"380, Caquetá, Cundinamarca, Boyacá, Valle del Cauca y Cauca; otra es los Llanos Orientales, en los departamento de Meta, Casanare y Arauca, con arroz de riego mecanizado; la tercera es el Bajo Cauca, parte baja de la cuenca del río Cauca, Antioquía, Bolívar, Córdoba y Sucre, con secano mecanizado y manual; por último está la Costa Norte, con Cesar, La Guajira, Magdalena y los Santanderes.

379 MADR-IICA (2006): Observatorio Agrocadenas, Anuario 2005. Agroindustria y competitividad. Estructura y dinámica en Colombia 1992-2005. Bogotá, pág. 378.

380 Ibíd., pág. 378. 
Papa. Mantiene constantes las hectáreas de producción. El Observatorio de Agrocadenas indica:

La papa generó alrededor de 64.329 empleos en el año 2004 en cerca de 172.439 hectáreas distribuidas en 14 departamentos del país, [...] su consumo regularmente se hace en fresco, ya que su uso industrial [...] es mínimo (entre $8 \%$ y $4 \%$ de la producción anual), se utiliza principalmente en la fabricación de papas fritas, prefrita o precocida, congelada, papas deshidratadas y harinas o almidones de papa $^{381}$.

La tabla 1 del anexo C muestra que las hectáreas decaen de 157.250 en 1987 a 156.568 en 2009, en tanto la producción y los rendimientos aumentan de $2.242 .605 t$ en 1987 a 2.995.188 en el 2009. Esto implica cambios tecnológicos en sus procesos de producción.

Fríjol. Este producto que crece: pasa del 1,5\%, con 121.100 ha en 1987, a 122.963 ha en el 2009; la producción y el rendimiento crecen de 90.425 a 149.122.

Trigo. Este producto cae verticalmente en área, en un 71\%, entre 1987 a 2009: pasa de 40.800 ha a 11.837. Los departamentos donde todavía se produce algo son Nariño, con el 79\%, el cual se distribuye en los municipios de Ospina (26\%), Guaitarilla (24\%), Imués (21\%), Yacuanquer (10\%) e Iles 10\%. Boyacá produce el 18\% y Cundinamarca, el 2.6\%.

Otros cultivos transitorios que disminuyen en las hectáreas para producir son: ajonjolí, que pasa de 19.080 ha en 1987 a 2.926 ha en 2009; algodón, de 174.240 ha a 38.580 ha; sorgo, de 259.400 ha a 23.071 ha; soya, de 64.750 ha a 31.575 ha. En estos cultivos baja la producción y crecen los rendimientos. La cebada pasó de 46.900 ha a 3.107 ha en el mismo periodo; es la única que baja en producción y rendimientos.

Cultivos permanentes. Presentan la mayor dinámica de crecimiento, con diferencias en producción y rendimiento. Así, el área aumenta en todos los cultivos de 1.111.420 ha a 1.415.256 ha, es decir, crece el $27 \%$.

Arracacha. Cae en hectáreas sembradas de 5.500 a 5.018 entre 1987 y 2009; pero no así en la producción, que pasa de 46.200 toneladas a 49.567, con crecientes rendimientos por cambios tecnológicos. Es un producto importante en la dieta de la población de

381 Ibíd., pág. 258. 
la zona andina. El departamento con mayor producción es el Tolima, con el 70,5\% del total; seguido de Norte de Santander, con el 7.1\%; Huila, con el 4,9\%; Boyacá, con el 4,5\%; Valle del Cauca, con el 3,6\%. Otras áreas productoras en pequeña escala son Antioquia, Santander, La Guajira, Nariño y la zona cafetera.

Banano y el plátano de exportación. Presentan características similares: crece el área de producción y cae en rendimientos. El banano se produce en Antioquia, con el 72,8\%, y en Magdalena, con el 27,2\%. El plátano solo lo produce Antioquia.

Cacao. Crece en área y producción y cae en rendimientos. Se produce en Santander, con el 44,1\%; Arauca, con el 8,5\%; Huila, con el 8,3\%; Tolima, con el 8,3\%; Nariño, con el $5,6 \%$. Se expande al resto del país en pequeñas porciones de terreno. En la cadena se encuentran "cuatro tipos de agentes: agricultores (aproximadamente 25.000), acopiadores, exportadores e industria procesadora" 382 .

Caña de azúcar. Aumenta en área y producción, y cae en rendimientos: pasó de 108.000 ha en 1987 a 214.947 ha en el 2009. Sobre los vínculos y la forma como se hace la actividad en el territorio, puede decirse:

[Permite desarrollar] un conglomerado productivo o clúster compuesto por varias empresas dedicadas a una gran variedad de productos y servicios, [...] el azúcar como negocio central del conglomerado se ha desarrollado gradualmente mediante los proceso de expansión, diferenciación de producto, integración y diversificación ${ }^{383}$.

El mayor productor es Valle del Cauca, con el 83,8\%, seguido de Cauca, con el 13,1\%. Se ha expandido su producción a otros departamentos del eje cafetero, así como a Cesar y Norte de Santander.

Caña panelera. Disminuye el área de 232.000 ha a 194.221 ha, y aumenta la producción de 1.196.450 toneladas a 1.227.313. Los rendimientos pasan de 5.157 a 6.319. Su producción no está concentrad: se produce en Santander, con el 18,8\%; Boyacá, con el 14,8\%; Cundinamarca, con el 12,2\%; Antioquia, con el 11,1\%; Huila,

382 Ibíd., pág. 133.

383 Ibíd., pág. 96. 
con el 9,9\%. El 33\% restante se produce en otros departamentos. Se consume en todo el país, pues es parte de la dieta popular colombiana.

Caña para miel. Cae en área, rendimiento y producción, la cual está en tres departamentos: Boyacá, 79,2\%; Casanare, 15,8\%, y Guaviare, 5,0\%.

Cocotero. Cae en hectáreas, aumenta en producción y rendimientos. Se produce en Nariño, 38,5\%; Cauca, 31,4\%; Córdoba, 11,3\%; Chocó, 3,8\%; Bolívar, 3,8\%, y en otras partes del país.

Ñame. Es parte de la dieta básica regional de la Costa Atlántica colombiana; de hecho, solo allí se produce. El departamento de Bolívar produce el 43,6\%; Córdoba, el 34,3\%; Sucre, el 8,0\%; Antioquia en la parte Caribe, 7,8\%; Cesar, 3,8\%, y el resto se produce en otros departamentos de la Costa Atlántica y el Chocó.

Palma africana o de aceite. Es el cultivo de mayor crecimiento durante el periodo, con el 664,4\%: pasa de 51.500 ha en 1987 a 342.547 ha en el 2009. Los departamentos productores son: Meta, con el 30,9\%; Cesar, con el 16\%; Santander, con el 15,9\%; Magdalena, con el 12\%; Nariño, con el 7\%; Bolívar, con el 5,6\%; Casanare, con el 4,6\%, y Norte de Santander, con el 4,1\%. Es el cultivo de mayor expansión en Antioquia, Chocó, Caquetá, La Guajira y Cundinamarca, y está presente en las zonas de conflicto por la tierra y cambio de uso.

Yuca. Es un producto de consumo nacional con dinámicas de expansión en área, rendimientos y producción, la cual se da en todos los departamentos: Bolívar, con el 13\%; Córdoba, con el 12,8\%; Sucre, con el 9,4\%; Antioquia, con el 8,6\%, y Santander, con el 8,0\%. El 48,1\% restante se distribuye en los demás departamentos. Es un producto de la dieta básica del país.

\section{Disponibilidad de alimentos 2008 por área plantada, tamaño y número de explotaciones} de cultivos transitorios y permanentes. En este ítem se analiza la información del 2008, que no se diferencia significativamente de otros años y ayuda a entender quién tiene la responsabilidad en producir agroalimentos. La información para cultivos transitorios y permanentes es de proporción de área plantada, tamaño y número de explotaciones. Se tipifica que predios menores de 15 ha son pequeñas, entre 15 ha y 100 ha son medianas, y de más de 100 ha son grandes. 


\begin{tabular}{|c|c|c|c|c|c|c|}
\hline \multirow{3}{*}{ Cultivos } & \multicolumn{6}{|c|}{ Rango de tamaño de la explotación agropecuaria (ha) } \\
\hline & Menor a 15 & $\begin{array}{c}\text { Entre } 15 \mathrm{y} \\
100\end{array}$ & $\begin{array}{l}\text { Mayor a } \\
100\end{array}$ & Menor a 15 & $\begin{array}{l}\text { Entre } 15 \text { y } \\
100\end{array}$ & $\begin{array}{c}\text { Mayor a } \\
100\end{array}$ \\
\hline & \multicolumn{3}{|c|}{ Proporción del área plantada } & \multicolumn{3}{|c|}{$\begin{array}{c}\text { Proporción de las explotaciones } \\
\text { agropecuarias }\end{array}$} \\
\hline Algodón & $28,0 \%$ & $27,3 \%$ & $44,7 \%$ & $84,0 \%$ & $13,3 \%$ & $2,7 \%$ \\
\hline Cebada & $72,7 \%$ & $26,8 \%$ & $0,5 \%$ & $92,6 \%$ & $7,4 \%$ & $0,0 \%$ \\
\hline Soya & $8,2 \%$ & $28,9 \%$ & $62,9 \%$ & $51,6 \%$ & $30,7 \%$ & $17,7 \%$ \\
\hline Trigo & $88,3 \%$ & $11,1 \%$ & $0,6 \%$ & $96,4 \%$ & $3,6 \%$ & $0,0 \%$ \\
\hline Arroz mecanizado & $11,4 \%$ & $29,4 \%$ & $59,2 \%$ & $47,6 \%$ & $37,8 \%$ & $14,6 \%$ \\
\hline Arroz manual & $19,5 \%$ & $58,2 \%$ & $22,3 \%$ & $45,0 \%$ & $48,3 \%$ & $6,7 \%$ \\
\hline Arveja & $82,2 \%$ & $14,4 \%$ & $3,4 \%$ & $93,4 \%$ & $5,6 \%$ & $1,0 \%$ \\
\hline Cebolla cabezona & $69,8 \%$ & $24,5 \%$ & $5,8 \%$ & $83,3 \%$ & $14,1 \%$ & $2,6 \%$ \\
\hline Cebolla en rama & $88,5 \%$ & $10,4 \%$ & $1,1 \%$ & $96,2 \%$ & $3,4 \%$ & $0,4 \%$ \\
\hline Maíz & $31,4 \%$ & $35,3 \%$ & $33,2 \%$ & $76,3 \%$ & $19,2 \%$ & $4,5 \%$ \\
\hline Papa & $71,8 \%$ & $20,4 \%$ & $7,8 \%$ & $93,4 \%$ & $6,2 \%$ & $0,4 \%$ \\
\hline Sorgo & $13,4 \%$ & $40,7 \%$ & $45,8 \%$ & $46,8 \%$ & $40,8 \%$ & $12,4 \%$ \\
\hline Tabaco & $54,8 \%$ & $34,6 \%$ & $10,6 \%$ & $77,0 \%$ & $21,6 \%$ & $1,4 \%$ \\
\hline Frijol & $58,6 \%$ & $35,2 \%$ & $6,2 \%$ & $80,4 \%$ & $17,4 \%$ & $2,2 \%$ \\
\hline Hortalizas & $60,2 \%$ & $26,4 \%$ & $13,3 \%$ & $88,1 \%$ & $10,6 \%$ & $1,3 \%$ \\
\hline Otros transitorios & $63,7 \%$ & $27,9 \%$ & $8,3 \%$ & $84,0 \%$ & $13,9 \%$ & $2,0 \%$ \\
\hline Tomate & $64,9 \%$ & $29,0 \%$ & $6,1 \%$ & $81,6 \%$ & $16,8 \%$ & $1,6 \%$ \\
\hline \multicolumn{7}{|l|}{ Euente: ENA, MADR-CCI } \\
\hline
\end{tabular}

En términos metodológicos, los cultivos transitorios, caracterizados con los anteriores parámetros y que superan el 50\% de la producción de un agroalimento, serán responsables por su disponibilidad. En la tabla 7.2.10, los 11 agroalimentos producidos por economía campesina, en predios menores de 15 hectáreas, se caracterizan por:

Cebolla en rama. Es el cultivo con más producción: tiene el 88,5\% de área y el 96,2\% de los predios. Se produce en Boyacá, Nariño, Valle del Cauca, Antioquia, Risaralda y Santander.

Trigo. Tiene el 88,3\% de área. El 96.4\% de predios es producido en Nariño, Boyacá, Cundinamarca y Santander.

Arveja. Tiene el 82,2\% del área y el 93,4\% de las explotaciones. Es producida en Boyacá, Nariño, Cundinamarca, tres departamentos con más área sembrada.

Cebada. Tiene el 72,7\% del área y el 92,6\% de los predios. Es producida en Boyacá, Cundinamarca y Nariño.

Papa. Tiene el 71,8\% de área y el 93,4\% de los predios. Se produce en Cundinamarca, Boyacá, Nariño, Antioquia, Cauca y los Santanderes. 
Cebolla cabezona. Tiene el 69,8\% de área y el 83,3\% de los predios. Se produce en Boyacá, Cundinamarca y Santanderes.

Tomate.Tiene el 64,9\% de área y 81,6\% de los predios. Es producido en Boyacá, Norte de Santander, Valle del Cauca y Cundinamarca. Estos son los mayores productores, aunque se cultiva en todos los departamentos

Hortalizas. Tiene el $60,2 \%$ de área y el $88,1 \%$ de los predios. Se produce en Cundinamarca, Guajira, Córdoba, Santander, Boyacá,Tolima,Valle del Cauca,Antioquia, Nariño, Huila y Norte de Santander.

Fríjol. Tiene el 58,6\% del área y el 80,4\% de predios. Es producido en Antioquia, Huila, Tolima, Santander y Cundinamarca, los departamentos más productores, con el 67\%; el resto de departamentos producen el 33\%.

Los productos base de la agroindustria, que son comerciales, se producen en predios medianos entre 15 y 100 ha; solo el arroz manual tiene el 58,2\% de área y el 45\% de predios.

En los predios grandes (más de 100 ha) están la soya, con el 62,9\% de área y el 17,7\% de predios, y el arroz mecanizado, con 59,2\% del área y el 14,6\% de los predios. En los cultivos permanentes (tabla 7.2.11) se ven solo las plantaciones en edad productiva. Estos, por la estabilidad y la proyección de la inversión realizada, muestran expectativas de largo plazo de los productores.

\begin{tabular}{|c|c|c|c|c|c|c|}
\hline \multicolumn{7}{|c|}{\begin{tabular}{|c|} 
Tabla 7.2.11 Colombia, 2008: cultivos permanentes, proporción del área plantada y de las \\
explotaciones agropecuarias según tamaño de la explotación (total $n$ )acional.
\end{tabular}} \\
\hline \multirow{3}{*}{ Cultivos } & \multicolumn{6}{|c|}{ Rango de tamaño de la explotación agropecuaria (ha) } \\
\hline & Menor a 15 & $\begin{array}{c}\text { Entre } 15 \mathrm{y} \\
100\end{array}$ & $\begin{array}{c}\text { Mayor a } \\
100\end{array}$ & Menor a 15 & $\begin{array}{c}\text { Entre } 15 y \\
100\end{array}$ & $\begin{array}{c}\text { Mayor a } \\
100\end{array}$ \\
\hline & \multicolumn{3}{|c|}{ Proporción del área plantada } & \multicolumn{3}{|c|}{$\begin{array}{l}\text { Proporción de las explotaciones } \\
\text { agropecuarias }\end{array}$} \\
\hline Cacao & $31,3 \%$ & $51,2 \%$ & $17,5 \%$ & $53,3 \%$ & $41,3 \%$ & $5,4 \%$ \\
\hline Caña de azúcar & $4,0 \%$ & $42,3 \%$ & $53,7 \%$ & $34,5 \%$ & $51,9 \%$ & $13,6 \%$ \\
\hline Café & $56,5 \%$ & $37,2 \%$ & $6,4 \%$ & $80,8 \%$ & $18,1 \%$ & $1,0 \%$ \\
\hline Palma africana & $5,0 \%$ & $18,3 \%$ & $76,7 \%$ & $30,1 \%$ & $46,8 \%$ & $23,1 \%$ \\
\hline Plátano & $47,4 \%$ & $42,7 \%$ & $9,9 \%$ & $62,3 \%$ & $28,7 \%$ & $9,0 \%$ \\
\hline Banano consumo interno & $48,8 \%$ & $41,0 \%$ & $10,2 \%$ & $71,1 \%$ & $25,1 \%$ & $3,7 \%$ \\
\hline Mango & $39,4 \%$ & $39,5 \%$ & $21,0 \%$ & $70,5 \%$ & $21,5 \%$ & $8,0 \%$ \\
\hline Naranja & $23,7 \%$ & $52,9 \%$ & $23,4 \%$ & $54,2 \%$ & $35,3 \%$ & $10,5 \%$ \\
\hline Otros cítricos & $32,5 \%$ & $51,4 \%$ & $16,1 \%$ & $66,2 \%$ & $28,3 \%$ & $5,5 \%$ \\
\hline Otros frutales & $42,2 \%$ & $50,4 \%$ & $7,4 \%$ & $75,5 \%$ & $21,6 \%$ & $2,9 \%$ \\
\hline Otros permanentes & $32,6 \%$ & $45,1 \%$ & $22,3 \%$ & $72,8 \%$ & $24,9 \%$ & $2,2 \%$ \\
\hline Yuca & $27,3 \%$ & $40,9 \%$ & $31,8 \%$ & $49,4 \%$ & $37,5 \%$ & $13,1 \%$ \\
\hline Caña panelera & $41,3 \%$ & $51,2 \%$ & $7,5 \%$ & $73,9 \%$ & $23,8 \%$ & $2,3 \%$ \\
\hline
\end{tabular}


En los pequeños productores se encuentran el área de café, con el 56,5\% y el 80,8\% de predios, en Antioquia, Huila, Tolima, Caldas, Risaralda, Valle del Cauca, Cauca, Santander y otros departamentos. Los medianos productores tienen: naranja, con el 52,9\% del área y el 54,2\% en los predios. Se produce en Meta, Quindío,Valle del Cauca, Caldas, Santander, Magdalena y Antioquia. En algunos departamentos se encuentra asociado y cubre casi la totalidad de estos. Le siguen otros cítricos y frutales, y al final está la caña panelera, con el 51,2\%, y el cacao, con el 51,2\%.

Los mayores productores: la palma africana, con 76,7\%, y la caña de azúcar, con el 53,7\%. Se confirma, en este y otros trabajos y momentos, que la producción de alimentos en Colombia tiene el mayor sustento en área y número de predios, en las economías campesinas: le siguen las medianas fincas, en tanto las grandes producen unos pocos transitorios y de plantación.

\subsubsection{Lo regiolocal: la disponibilidad de los ejes dinamizadores}

Este apartado trabaja los elementos regionales y locales de la disponibilidad de agroalimentos, en los cuatro ejes dinamizadores, que son las ciudades capitales del departamento que dinamizan sus vínculos funcionales e influencias. La disponibilidad departamental del eje dinamizador presenta el contexto territorial de cada uno: Medellín, Cartagena, Neiva y Cúcuta, y cumple sus relaciones funcionales con la región inmediata. Se trabajan estos aspectos: uso de la tierra, desplazamiento y despojo, concentración de la tierra y producción de agroalimentos a nivel departamental, así como la comparación entre demandas ideales y disponibilidades de agroalimentos para cada eje, desde la oferta de cada departamento: Antioquia, Bolívar, Huila y Norte de Santander.

\subsection{La disponibilidad en el eje Medellín}

Su entorno inmediato es el departamento de Antioquia, con sus vínculos primarios y funcionales, y los agroalimentos que pasan por este entorno.

Uso de la tierra en Antioquia. En la tabla 7.2.12 (aprovechamiento de la tierra, periodo 1996-2008) se muestra que la superficie no agropecuaria crece del 36,2 \% al $37,0 \%$, aumentando $48.210 \mathrm{ha}$. La tierra dedicada al sector agropecuario disminuye en 22.712 ha: pasa del 63,8 \% al 63,3\% del total. 


\begin{tabular}{|c|c|c|c|c|c|c|c|c|c|c|c|c|c|c|c|}
\hline \multirow{3}{*}{ SUPERFICIES } & \multicolumn{3}{|c|}{1996} & \multicolumn{3}{|c|}{2000} & \multicolumn{3}{|c|}{2002} & \multicolumn{3}{|c|}{2004} & \multicolumn{3}{|c|}{2008} \\
\hline & \multirow{2}{*}{$\begin{array}{c}\text { Total } \\
\text { hectáreas }\end{array}$} & \multicolumn{2}{|c|}{$\%$} & \multirow{2}{*}{$\begin{array}{c}\begin{array}{c}\text { Total } \\
\text { hectáreas }\end{array} \\
\end{array}$} & \multicolumn{2}{|c|}{$\%$} & \multirow{2}{*}{$\begin{array}{c}\text { Total } \\
\text { hectáreas }\end{array}$} & \multicolumn{2}{|c|}{$\%$} & \multirow{2}{*}{$\begin{array}{c}\text { Total } \\
\text { hectáreas }\end{array}$} & \multicolumn{2}{|c|}{$\%$} & \multirow{2}{*}{$\begin{array}{c}\text { Total } \\
\text { hectáreas }\end{array}$} & \multicolumn{2}{|c|}{$\%$} \\
\hline & & 1 & 2 & & 1 & 2 & & 1 & 2 & & 1 & 2 & & 1 & 2 \\
\hline $\begin{array}{l}\text { SUPERFICIE PLANIMETRADA } \\
\text { DEL MARCO** }\end{array}$ & 6.335 .702 & 100 & & 6.361 .200 & 100 & & 6.361 .200 & 100 & & 6.361 .200 & 100 & & 6.361 .200 & 100 & \\
\hline $\begin{array}{l}\text { 1. Sector Agropecuario } \\
\text { planimetrado, incluido en el } \\
\text { universo de estudio }\end{array}$ & 4.040 .876 & 63,8 & $\mid 100,0$ & 4.049 .463 & 63,7 & 100,0 & 4.033 .109 & 63,4 & $\mid 100,0$ & 4.026 .153 & 63,3 & 100,0 & 4.018.164 & 63,2 & 100,0 \\
\hline 1.2 Agrícola & 401.970 & 6,3 & 9,9 & 415.211 & 13,1 & 20,5 & 317.650 & 9,9 & 15,7 & 328.347 & 5,2 & 8,2 & 294.105 & 4,6 & 7,3 \\
\hline \begin{tabular}{|l|}
$\begin{array}{l}\text { Cultivos transitorios y } \\
\text { barbecho }\end{array}$ \\
\end{tabular} & 136.820 & 2,2 & 3,4 & 113.326 & 6,5 & 10,3 & 85.594 & 5,0 & 7,9 & 116.272 & 1,8 & 2,9 & 37.528 & 0,6 & 0,9 \\
\hline Cultivos permanentes & 265.149 & 4,2 & 6,6 & 301.884 & 1,8 & 2,8 & 228.065 & 1,3 & 2,1 & 209.623 & 3,3 & 5,2 & 253.663 & 4,0 & 6,3 \\
\hline Descanso & & & & & & & 3.991 & 3,6 & 5,7 & 2.452 & 0,0 & 0,1 & 2.915 & 0,0 & 0,1 \\
\hline 1.3 Pecuaria & 2.856 .801 & 45,1 & 70,7 & 2.766 .822 & 43,5 & \begin{tabular}{|l|}
68,3 \\
\end{tabular} & 3.077 .587 & 0,1 & 0,1 & 3.208 .185 & 50,4 & \begin{tabular}{|l|}
79,7 \\
\end{tabular} & 3.039 .083 & 47,8 & 75,6 \\
\hline Pastos & 1.836 .968 & 29,0 & 45,5 & 1.960 .190 & 30,8 & \begin{tabular}{|l|l}
48,4 \\
\end{tabular} & 2.141 .200 & 48,4 & 76,3 & 2.239 .454 & 35,2 & \begin{tabular}{|l|l}
55,6 \\
\end{tabular} & 2.460 .303 & 38,7 & 61,2 \\
\hline Malezas y rastrojos & 1.019 .832 & 16,1 & 25,2 & 806.632 & 12,7 & 19,9 & 936.387 & 33,7 & 53,1 & 968.731 & 15,2 & \begin{tabular}{|l|l}
24,1 \\
\end{tabular} & 578.780 & 9,1 & 14,4 \\
\hline 1.4 Bosques & 697.963 & 11,0 & 17,3 & 774.889 & 12,2 & 19,1 & 575.886 & 14,7 & 23,2 & 436.732 & 6,9 & 10,8 & 619.225 & 9,7 & 15,4 \\
\hline Naturales & 662.410 & 10,5 & 16,4 & 705.745 & 11,1 & 17,4 & 535.246 & 9,1 & 14,3 & 394.532 & 6,2 & 9,8 & 548.740 & 8,6 & 13,7 \\
\hline Plantados & 84.141 & 1,3 & 2,1 & 69.144 & 1,1 & 1,7 & 40.639 & 8,4 & 13,3 & 42.200 & 0,7 & 1,0 & 70.485 & 1,1 & 1,8 \\
\hline 1.5 Otros usos & & & & 92.542 & 1,5 & 2,3 & 61.985 & 0,6 & 1,0 & 52.889 & 0,8 & 1,3 & 1.029 .273 & 16,2 & 25,6 \\
\hline 2. Sector no agropecuario & 2.294 .826 & 36,2 & & 2.311 .737 & 36,5 & & 2.328 .091 & 36,7 & & 2.335 .047 & 36,9 & & 2.343 .036 & 37,0 & \\
\hline
\end{tabular}

Al comparar en el interior del sector agropecuario las tierras dedicadas a la agricultura y a la ganadería, se evidencia que hay una dinámica distinta en términos del crecimiento: aumenta el uso de la tierra del sector pecuario del 70,7 \% al 75,6\% (columna 2 de la tabla 7.2.12), con 182.282 nuevas ha.

La tierra dedicada a la agricultura disminuye en los doce años de análisis: pasa del 9,9\% en 1986, con 401.970 ha, al 7,3\%, con 294.105 ha en el 2008 (segundo cambio). La tercera variación se presenta en los tipos de cultivos, donde los afectados son los de economía campesina que manejan los transitorios y barbecho: pasan del 3,4\% en 1986, con 136.820 ha, al 0,9\%, con 37.528 ha en el 2008.

Los cultivos permanentes pasan del 6,6\%, con 265.149 ha, al 6,3\%, con 253.663 ha. Este cultivo opera, en la mayoría de los casos, en grandes propiedades. Acá inciden las condiciones institucionales de la planeación pública del departamento, que en el periodo 2001-2003 “estableció como meta la siembra de 6.000 hectáreas en las subregiones de Magdalena Medio y Urabá en un plazo de 5 años"384. Por su parte, las tierras del sector pecuario pasan del 70,7\%, con 2.856.801 ha, al 75,6\%, con 3.039.083 ha, cambiando el uso de las tierras en el departamento con tierras para la ganadería. El departamento ha identificado en este sentido:

Las zonas de ladera, de población tradicionalmente campesina con sistemas mixtos de producción agropecuaria, vienen sufriendo un proceso de transformación hacia ganadería extensiva provocando grandes

384 ROMERO V., Mauricio (2011): La economía de los paramilitares. Redes de corrupción, negocios y política. Corporación Nuevo Arco Iris, Bogotá, pág. 292. 
procesos de degradación del suelo. [...] Las áreas con alto conflicto por el uso del suelo representan el $49 \%$ del área total del departamento; en conflicto medio el $23,67 \%$ y sin conflicto el $27,25 \%$ "385.

La dinámica sobre las tierras en el departamento muestra que se debilitan las estructuras campesinas y se fortalecen las grandes propiedades, a través de la ganadería y de los cultivos permanentes. Ello cambia en el mismo sentido los usos del suelo, especialmente hacia la ganadería.

Desplazamiento y despojo de tierras en Antioquia. La dinámica de desplazamiento y despojo en Antioquia está signada por diferentes masacres, que son la base para generar los procesos de desplazamiento de población y despojo de tierras: "Se presume que entre 1998 y el 2002 los paramilitares ejecutaron 101 masacres en Antioquia, con un promedio de 5.8 víctimas por masacre" ${ }^{386}$.

También se muestra el número de víctimas que hubo por masacre en algunos de los municipios de Antioquía: "Entre 1997 y 2001 el departamento pasó de tener 3.758 desplazados a 75.749. Ese número se redujo en el 2002 a 52.271, para un total de 226.646 en seis años" ${ }^{\prime 387}$. Estas masacres dejan las secuelas expresadas, entre otras, para el periodo 2004-2009 (tabla 7.2.13), en la cantidad de personas, predios, áreas y Unidades Agrícolas Familiares (UAF) abandonadas. Estas últimas representan un poco más de la quinta parte del país: $21,7 \%$, siendo este el departamento que muestra los más altos índices de despojo y abandono en Colombia.

\begin{tabular}{|c|c|c|c|c|c|c|c|c|c|c|}
\hline \multirow[t]{2}{*}{ Características } & \multicolumn{2}{|c|}{\begin{tabular}{|c|} 
Personas \\
relacionadas con \\
predios Abandonados
\end{tabular}} & \multicolumn{2}{|c|}{$\begin{array}{c}\text { Predios } \\
\text { Abandonados }\end{array}$} & \multicolumn{2}{|c|}{$\begin{array}{c}\text { Área (ha) } \\
\text { Registrada como } \\
\text { Abandonada }\end{array}$} & \multirow{2}{*}{\begin{tabular}{|c|}
$\%$ \\
participación \\
según área \\
abandonada \\
\end{tabular}} & \multirow{2}{*}{\begin{tabular}{|c|}
$\%$ \\
participación \\
según predios \\
abandonados \\
\end{tabular}} & \multicolumn{2}{|c|}{$\begin{array}{c}\text { No. UAF } \\
\text { abandonadas }\end{array}$} \\
\hline & Número & $\%$ & Número & $\%$ & Número & $\%$ & & & Número & $\%$ \\
\hline $\begin{array}{c}\text { Total } \\
\text { Departamento }\end{array}$ & 24.015 & 14,1 & 25.076 & 13,9 & 567.329 & 13,4 & 13.40 & 14.29 & 20.973 & 21,7 \\
\hline Total Colombia & 170.783 & 100 & 179.852 & 100 & 4.234.364 & 100 & 100 & 100 & 96.597 & 100 \\
\hline
\end{tabular}

385 DPN (2009): Plan de Desarrollo, Antioquia para Todos, Manos a la Obra, período 2008-2011. Medellín, pág. 170.

386 LOPEZ, Claudia (2007): "La ruta de la expansión paramilitar y la transformación política en Antioquia 1997-2007”. En Parapolítica: la ruta de la expansión paramilitar y los acuerdos políticos. Corporación Nuevo Arco Iris e Intermedio Editores, Bogotá, pág. 181.

387 Ibíd., pág. 183. 
La tabla 7.2.14 muestra que de las nueve regiones en que se divide Antioquia, siete son afectadas por abandono forzado de predios, sobre todo la región de oriente: 9 de los 23 municipios, relacionados con embalses, bosques, zona de páramo y zona andina; otras regiones el suroeste, occidente y norte, cada una con un municipio, que limita con la zona más conflictiva, Urabá, la cual afecta siete de los 11 municipios de la subregión y es la zona de mayor desarrollo ganadero y cultivos permanentes; y el Bajo Cauca, con tres de seis municipios de la subregión.

Tabla 7.2.14 Antioquia, municipios con mayor afectación por abandono forzado de predios hasta 2010

\begin{tabular}{|c|c|c|c|c|c|c|}
\hline Subregiones & $\begin{array}{l}\text { Municipio de } \\
\text { ubicación del } \\
\text { predio }\end{array}$ & $\begin{array}{c}\text { Área del } \\
\text { municipio }\end{array}$ & $\begin{array}{c}\text { Personas } \\
\text { relacionadas } \\
\text { con predios } \\
\text { abandonados }\end{array}$ & $\begin{array}{c}\text { Predios } \\
\text { abandonado } \\
\mathrm{s}\end{array}$ & $\begin{array}{c}\text { Área (ha) } \\
\text { registrada } \\
\text { como } \\
\text { abandonada }\end{array}$ & $\begin{array}{c}\text { \% Afectación } \\
\text { según área } \\
\text { del municipio }\end{array}$ \\
\hline \multirow{9}{*}{ Oriente } & Granada & 18.500 & 1.116 & 1.183 & 2.860 & 15.46 \\
\hline & Cocorná & 22.100 & 890 & 997 & 9.554 & 43.23 \\
\hline & Argelia & 25.700 & 768 & 824 & 8.045 & 31.30 \\
\hline & San Carlos & 71.000 & 771 & 813 & 12.559 & 17.79 \\
\hline & San Luis & 45.800 & 547 & 593 & 11.754 & 25.66 \\
\hline & Sonsón & 133.900 & 509 & 557 & 12.565 & 9.38 \\
\hline & Nariño & 31.700 & 404 & 450 & 5.270 & 16.62 \\
\hline & San Rafael & 36.600 & 362 & 399 & 4.784 & 13.07 \\
\hline & San Francisco & 36.800 & 356 & 390 & 9.037 & 26.56 \\
\hline Suroeste & Urrao & 258.500 & 789 & 861 & 16.776 & 6.49 \\
\hline \begin{tabular}{|l|} 
Occidente \\
\end{tabular} & Dabeiba & 190.500 & 860 & 934 & 24.647 & 12.94 \\
\hline Norte & Ituango & 237.500 & 651 & 714 & 21.499 & 9.05 \\
\hline \begin{tabular}{|c|}
$\begin{array}{c}\text { Magdalena } \\
\text { Medio }\end{array}$ \\
\end{tabular} & Yondó & 190.300 & 455 & 494 & 14.431 & 7.58 \\
\hline \multirow{7}{*}{ Urabá } & Turbo & 309.000 & 3.003 & 3.157 & 86.805 & 28.09 \\
\hline & Apartadó & 60.700 & 1.000 & 1.060 & 22.536 & 37.13 \\
\hline & Necocli & 137.700 & 988 & 1.049 & 26.695 & 19.39 \\
\hline & Mutatá & 111.900 & 904 & 972 & 33.048 & 29.53 \\
\hline & $\begin{array}{c}\text { San Pedro de } \\
\text { Uraba }\end{array}$ & 48.200 & 560 & 580 & 12.671 & 26.29 \\
\hline & Arboletes & 71.800 & 541 & 564 & 19.092 & 26.59 \\
\hline & Chigorodó & 61.500 & 430 & 457 & 10.206 & 16.59 \\
\hline \multirow{3}{*}{ Bajo Cauca } & El Bagre & 195.100 & 774 & 792 & 23.791 & 12.19 \\
\hline & Tarazá & 157.800 & 615 & 648 & 14.814 & 9.39 \\
\hline & Caucasia & 105.800 & 295 & 305 & 8.424 & 7.96 \\
\hline \multicolumn{2}{|c|}{ Total } & 2.758 .000 & 18.085 & 19.318 & 430.156 & \\
\hline
\end{tabular}

En estos municipios de las subregiones de Antioquia se dimensiona uno de los aspectos estructurales limitantes de la producción de agroalimentos en el departamento: el desplazamiento y el abandono de tierras. 
Concentración de la tierra 1996-2008. La identificación de las UAF por el Incora para Antioquia, y según las regiones relativamente homogéneas con sus municipios, son 9 , y en cada una se determinan los tamaños según el uso agricultura, ganadería o mixta (tabla 7.2.15).

Al comparar la información de las tablas 7.2.15 y el 7.2.16 (características de la dinámica de las UAF), se muestra que la categoría de microfundio, con tamaño promedio de 2 ha, no es compatible con la Resolución 41 de 1996, que identifica a la UAF más pequeña para producción agrícola entre 3 y 5 ha en la subregión 9:Valle de Aburrá y el Oriente Cercano. En las otras subregiones, las UAF son entre 5 y 20 ha.

Lo anterior revela que por un lado va la reglamentación y el diseño de política y por otro, la realidad agrícola del departamento. Además, las características de la pequeña propiedad, con promedio de 29 ha, no están para los desarrollos agrícolas con producción de agroalimentos. Esta pequeña área se utiliza para desarrollar actividades rurales solo si la producción es mixta o ganadera.

\begin{tabular}{|c|c|c|}
\hline \multicolumn{3}{|c|}{$\begin{array}{c}\text { Cuadro No. 7.2.15 Departamento de Antioquia Tamaño de las Unidades Agrícolas Familiares según región relativamente homogénea y } \\
\text { municipio }\end{array}$} \\
\hline $\begin{array}{l}\text { Regiones Relativamente } \\
\text { Homogéneas }\end{array}$ & Municipios & $\begin{array}{c}\text { Rangos de la Unidad } \\
\text { Agricola Familiar UAF Por } \\
\text { la pote ncialidad de } \\
\text { explotación }\end{array}$ \\
\hline I.URABA NORTE & Arboletes, Apartadó, Necocli, Turbo, San Pedro de Urabá, San Juan de Urabá y Carepa. & $\begin{array}{l}\text { agrícola, } 14-20 \text { ha; mixta: } 42-55 \text { ha } \\
\text { y ganadera } 55-68 \text { ha }\end{array}$ \\
\hline 2. URABA SUR & Chigorodó, Mutatá, Murindó y Vigía del Fuerte & $\begin{array}{c}\text { agricola: } 6-9 \text { ha; mixta: } 30-40 \text { ha } y \\
\text { ganadera: } 34-46 \text { ha }\end{array}$ \\
\hline 3. OCCIDENTE & $\begin{array}{l}\text { Frontino, Santa fe de Antioquia, Abriaqui, Buriticá, Cañas Gordas, Dabeiba, Giraldo, Peque, } \\
\text { Uramita, Anzá, Caicedo, Ebejico, Heliconia, Liborina, Olaya, Sabanalarga, San Jerónimo y } \\
\text { Sopetrán. }\end{array}$ & $\begin{array}{l}\text { agricola: } 6-8 \text { ha; mixta: } 24-32 \text { ha y } \\
\text { ganadera: } 57-77 \text { ha }\end{array}$ \\
\hline 4. SUROESTE & $\begin{array}{c}\text { Andes, Amagá, Angelópolis, Armenia, Caramanta, Fredonia, Montebello, Santa Bárbara, Titiribi, } \\
\text { Valparaiso, Venecia, Betania, Betulia, Bolivar, Concordia, Jericó, Pueblo Rico, Salgar, Támesis, } \\
\text { Tarso, Hispania, Jardin y Urrao. }\end{array}$ & $\begin{array}{l}\text { agricola: 5-7 ha; mixta: } 13-17 \text { ha y } \\
\text { ganadera: } 41-56 \text { ha }\end{array}$ \\
\hline 5. BAJOCAUCA & Caucasia, Cáceres, Tarazá, El Bagre, Zaragoza, Valdivia y Nechí & $\begin{array}{l}\text { agricola: 8-12 ha; mixta: } 48-65 \text { ha } \\
\text { y ganadera: } 50-67 \text { ha }\end{array}$ \\
\hline 6 ORIENTE LEJANO & Santuario, San Carlos, San Luis, San Francisco, San Rafel, Cocorná y Abejorral. & $\begin{array}{l}\text { 6-8 ha; mixta: } 15-20 \text { ha y } \\
\text { ganadera: } 52-71 \text { ha }\end{array}$ \\
\hline 7. NORDESTE & $\begin{array}{c}\text { Barbosa, Caracoli, Cisneros, Amalfi, Anorí, Remedios, San Roque, Segovia, Yolombó, Vegachí y } \\
\text { Yali. }\end{array}$ & 23-31 ha y ganadera: $39-53$ ha \\
\hline 8 NORTE & $\begin{array}{l}\text { Santa Rosa de Osos, Yarumal, Belmira, Carolina, Don Matías, Entreríos, Gómez Plata, Guadalupe, } \\
\text { San Pedro de Los Milagros, Angostura, Briceño, Campamento, Ituango, Toledo, San Juan de La } \\
\text { Montaña y San Andrés de Cuerquia. }\end{array}$ & $\begin{array}{l}\text { mixta: } 21-29 \text { has: } y \text { ganadera: } 30- \\
40 \text { ha }\end{array}$ \\
\hline $\begin{array}{l}9 \text { VALLE DEL ABURRA YEL ORIENTE } \\
\text { CERCANO }\end{array}$ & $\begin{array}{l}\text { Medellin, Bello, Concepción, Copacabana, Girardota, Envigado, Itaguí, Sabaneta, Caldas, La } \\
\text { Estrella, Ríonegro, Alejandría, Carmen de Viboral, Guarne, Marinilla, Guatapé, El Peñol, San } \\
\text { Vicente, Santo Domingo, Granada, El Retiro, La Ceja y La Unión. }\end{array}$ & $\begin{array}{c}\text { agricola: } 3-5 \text { ha; mixta: } 12-16 \text { ha } y \\
\text { ganadera: } 27-37 \text { ha }\end{array}$ \\
\hline
\end{tabular}

En la tabla 7.2.16, el tamaño promedio refleja la concentración de la gran propiedad; le siguen la mediana propiedad, la pequeña y el microfundio. Las situaciones extremas de gran propiedad y microfundio argumentan las relaciones de sobreutilización y subutilización del suelo en Antioquia. Lo único en que supera el microfundio a los demás predios es en los avalúos. 


\begin{tabular}{|c|c|c|c|c|c|}
\hline Características & Microfundio & $\begin{array}{l}\text { Pequeña } \\
\text { propiedad }\end{array}$ & $\begin{array}{c}\text { Mediana } \\
\text { propiedad }\end{array}$ & $\begin{array}{c}\text { Gran } \\
\text { propiedad }\end{array}$ & Promedio \\
\hline Distribución Porcentual & 12.0 & 24.5 & 32.9 & 30.5 & 100 \\
\hline Colombia & 12.4 & 18.3 & 25.2 & 44.1 & 100 \\
\hline $\begin{array}{l}\text { Tamaño Promedio de predios(ha) } \\
\text { escala de tenencia }\end{array}$ & 2 & 29 & 112 & 912 & 16 \\
\hline Promedio Colombia & 3 & 35 & 92 & 1474 & 25 \\
\hline $\begin{array}{c}\text { Avalúos por hectáreas }(\$ \\
\text { corrientes) }\end{array}$ & 3.328 .429 & 948.129 & 482.072 & 315.493 & 867.103 \\
\hline Promedio Colombia & 2.423.517 & 975.162 & 1.028 .447 & 338.649 & 804.335 \\
\hline \multicolumn{6}{|c|}{$\begin{array}{l}\text { Fuente: Presidencia de la República de Colombia y Acción Social (2010): Unidades Agrícolas Familiares, } \\
\text { tenencia y abandono forzado de tierras en Colombia. Proyecto Protección de Tierras y Patrimonio de la } \\
\text { Ppoblación Desplazada, Bogotá, págs. } 44 \text { yss. }\end{array}$} \\
\hline
\end{tabular}

La tabla 7.2.17, sobre los usos del suelo según tamaño, años 1996 y 2004, caracteriza la concentración, pues las fincas de tamaño de 0 a menos de 10 ha pasan de 436.253 ha, con $10,80 \%$, a 293.977 ha, con 7,10\%. Se evidencia una disminución en los predios de 10 a menos de 50 y de 50 a menos de 200 ha, mientras que en los predios de más de 200 se duplican sus hectáreas de 730.754 y 18,08\% en 1996 a 1462.766 y $36.30 \%$ en el 2004.

\begin{tabular}{|c|c|c|c|c|c|c|c|c|c|c|c|c|c|}
\hline \multicolumn{14}{|c|}{$\begin{array}{l}\text { Tabla 7.2.17 Departamento de Antioquia, distribución de los PSM, por usos del suelo, según tamaño, } \\
\text { años } 1996 \text { y } 2004\end{array}$} \\
\hline \multirow{3}{*}{ Tamaño (PSM) } & \multirow{2}{*}{\multicolumn{2}{|c|}{ P S M }} & \multicolumn{11}{|c|}{ U S O S (hectáreas) } \\
\hline & & & \multicolumn{2}{|c|}{ T otal } & \multicolumn{3}{|c|}{ Uso agrícola } & \multicolumn{3}{|c|}{ Pastos y malezas } & \multicolumn{3}{|c|}{ Bosques y otros usos } \\
\hline & Cantidad & $\%$ & Área & $\%$ & Área & * & ** & Área & * & ** & Área & * & ** \\
\hline \multicolumn{14}{|c|}{ Año 2004} \\
\hline TOTAL & 135.062 & 100,0 & 4.026 .153 & 100,0 & 328.347 & 8,2 & 100,0 & 3.208 .185 & 79,7 & 100,0 & 489.621 & 12,2 & 100,0 \\
\hline 0 a menos de 10 & 74.571 & 55,2 & 293.977 & 7,1 & 68.435 & 23,3 & 20,7 & 197.199 & 67,1 & 5,9 & 28.342 & 9,6 & 5,6 \\
\hline 10 a menos de 50 & 41.237 & 30,5 & 984.354 & 24,4 & 98.634 & 10,0 & 29,9 & 781.218 & 79,4 & 24,3 & 104.501 & 10,6 & 21,2 \\
\hline 50 a menos de 200 & 14.189 & 10,5 & 1.285 .057 & 31,9 & 59.523 & 4,6 & 18,0 & 1.043 .117 & 81,2 & 32,5 & 182.417 & 14,2 & 37,1 \\
\hline 200 a menos de 500 & 5.064 & 3,7 & 1.462 .766 & 36,3 & 101.755 & 7,0 & 30,9 & 1.186 .651 & 81,1 & 36,9 & 174.361 & 11,9 & 35,6 \\
\hline \multicolumn{14}{|c|}{ Año 1996} \\
\hline Total & 212.292 & 100,0 & 4.040 .871 & 100,0 & 401.966 & 9,9 & 100,0 & 2.856 .795 & 70,7 & 100,0 & 782.096 & 19,4 & 100,0 \\
\hline 0 a menos de 10 & 132.446 & 62,4 & 436.253 & 10,8 & 123.953 & 28,4 & 30,8 & 248.920 & \begin{tabular}{l|}
57,1 \\
\end{tabular} & 8,7 & 63.375 & 14,5 & $\overline{8,1}$ \\
\hline 10 a menos de 50 & 58.643 & 27,6 & 1.261 .743 & 31,2 & 164.616 & \begin{tabular}{l|l}
13,0 \\
\end{tabular} & 41,0 & 856.118 & 67,9 & 30,0 & 241.006 & 19,1 & 30,8 \\
\hline 50 a menos de 200 & 18.395 & 8,7 & 1.599 .780 & 39,6 & 94.092 & 5,9 & 23,4 & 1.148 .001 & 71,8 & 40,2 & 357.683 & 22,4 & 45,7 \\
\hline 200 a menos de 500 & 2.784 & 1,3 & 730.754 & 18,1 & 19.305 & 2,6 & 4,8 & 593.882 & 81,3 & 20,8 & 117.565 & 16,1 & 15,0 \\
\hline 500 a menos de 1000 & 24 & 0,01 & 12.341 & 0,3 & & - & & 9.874 & 80,0 & 0,3 & 2.467 & \begin{tabular}{|l|}
20,0 \\
\end{tabular} & 0,3 \\
\hline ente : ENA, DANE - Pro & -1 & & & & & & & * Porcenta & torizonta & & ${ }_{* * \text { Porc }}$ & e Ver & \\
\hline
\end{tabular}

En los cambios de uso del suelo rural, las dinámicas, según las estructuras y el tamaño de la propiedad, son: la disminución de las tierras de uso agrícola de las pequeñas y medianas propiedades, mientras crecen las grandes; se ve un traslado hacia la actividad pecuaria; se disminuyen las tierras de bosques y otros usos en todos los tamaños de la propiedad. 
Disponibilidad y política SAN en Antioquia. En la identificación de los problemas por resolver con la política SAN, el Plan de Desarrollo 2008-2011 ${ }^{388}$ considera mejorar la disponibilidad y responder a exigencias internacionales de orden legal, en sanidad e inocuidad agropecuaria. Propone, entonces, mejorar la disponibilidad para el mercado externo a partir de varias acciones:

Programa 9: Sanidad, inocuidad y gestión de riesgos agropecuarios; buscando la coordinación interinstitucional y la cooperación e integración de recursos públicos y privados para la realización de campañas y el desarrollo de las Medidas Sanitarias y Fitosanitarias (MSF) en especies estratégicas y de importancia económica agrícola y pecuaria, logrando estándares para el mercado internacional y la protección y sanidad agropecuaria en diagnóstico y control de plagas, enfermedades y otros riesgos ${ }^{389}$.

El gobierno departamental, en cumplimiento de requerimientos de la OMC sobre productos agropecuarios, crea y opera un fondo departamental para la sanidad y protección, con recursos institucionales para armonizar con las exigencias del comercio mundial en calidad e inocuidad. Esto lo realiza a través de un sistema de información y vigilancia epidemiológica departamental, instrumento que pondrá a competir al departamento en bienes agropecuarios, siendo el primer productor de banano de exportación.

Por otro lado, los municipios de la región inmediata del eje Medellín destinan su producción así: "El 60\% de los agroalimentos con destino a Medellín, 30\% para la costa y $10 \%$ para el resto del país" ${ }^{390}$. Sin embargo, hay problemas de disponibilidad en municipios cercanos, en la medida en que "la producción agropecuaria es nula en los minifundios" ${ }^{391}$, pero se ha impulsado "una granja demostrativa agroambiental para producir alimentos de pancoger y aromáticas" ${ }^{392}$. Con ello se busca producir

388 DPN (2009): Plan de Desarrollo: Antioquia para Todos... Op. cit., págs. 176 y ss.

389 Ibíd., pág. 182

390 RAMOS, Jorge (2008): Entrevista. Secretario de Desarrollo Agropecuario, municipio de Santuario, departamento de Antioquia, 4 de diciembre.

391 ESTRADA, Rafael (2008): Entrevista. Secretario de Medio Ambiente, municipio de Itagüí, área metropolitana del Valle de Aburrá, departamento de Antioquia, 4 de diciembre.

392 Ibíd. 
agroalimentos para el autoconsumo y para el mercado. Estos municipios inmediatos al eje son el primer anillo, y varios han sustituido el uso de la tierra de producción a una destinada a la recreación.

Otros elementos de la disponibilidad están referidos a dinámicas organizativas de los pequeños productores, como son "La Asociación de Productores de Mora de Envigado (ASPROMOEN), la Asociación de Productores de Leche de Envigado (ASPROLEN), la Asociación de Productores de la Vereda Perico de Envigado (ASPROPEN)" ${ }_{393}$. En estas organizaciones se realizan la producción individual, la asistencia técnica y el comercio de forma colectiva.

Disponibilidad de agroalimentos en Antioquia, 1987-2009. En el anexo C, las tablas 5 y 6 (sobre cultivos transitorios permanentes, periodo de 1987 a 2009) muestran los agroalimentos de la oferta inmediata para la ciudad eje Medellín. Relacionan variables de superficie, producción y rendimiento por cada agroalimento producido en Antioquia, parte de la canasta de la dieta básica de los pobladores.

Los cultivos transitorios (tabla 5, anexo C) refieren agroalimentos de la dieta del eje: fríjol, maíz, papa y arroz. El fríjol, en superficie cosechada, pasa de 38.300 ha en 1987 a 21.228 en el 2009; caída incrementada después de 1990. Parte de la superficie cultivada es reemplazada con crecimiento de los rendimientos, que pasan de 900 a 1.468 en el mismo periodo, lo cual hace que la producción no tenga una fuerte caída fuerte y disminuya en 3.297 t. Esta leguminosa seca es parte de la dieta antioqueña y, además, es su plato típico (la bandeja paisa).

El comportamiento del maíz es inverso entre el tecnificado y el tradicional: el primero crece en superficie, el segundo hace lo contrario. El crecimiento en rendimientos presenta el mismo sentido. Por su parte, la papa tiene un comportamiento más cíclico durante el periodo, resultado de la dinámica de precios y los reacomodos de pequeños y medianos productores orientados por los precios. La caída en superficie es 4.989 ha y en producción es de 68.259 t.Y el arroz, tanto el mecanizado como el manual, crece en superficie y producción, y cae en rendimientos. Globalmente, en este período pierde en total 73.112 ha y $86.362 t$ de producción.

393 SALAZAR, Camilo (2008): Entrevista. Secretario de Medio Ambiente y Desarrollo Rural, municipio de Envigado, área metropolitana del Valle de Aburrá, departamento de Antioquia, 3 de diciembre. 
Respecto al comportamiento de los cultivos permanentes (tabla 6, anexo C), la superficie cae en arracacha, cocotero, fique y plátano, productos de producción campesina. Por su parte, la palma africana, con información desde 2003 de manera continua, crece lento; si tomamos 1987 y 2009, hay una caída del 71\% en superficie, siendo un producto de medianas y grandes explotaciones.

Los seis productos que crecen en el periodo tienen características diferentes en las formas y estructuras de desarrollo de su producción; por una parte, están los de exportación: banano y plátano, producidos bajo condiciones especiales en grandes y medianas explotaciones, en la zona del Urabá antioqueño y entre relaciones laborales, tecnológicas y de mercadeo especializadas; los otros cuatro productos: cacao, caña panelera, ñame y yuca, se producen en pequeñas y medianas parcelas de economías campesinas, con otras circunstancias de producción y mercadeo.

Globalmente, los cultivos permanentes crecen en superficie 31.702: pasan de 115.843 ha a 147.545 ha, y en producción crecen $466.836 t$ : pasan de 1.531 .892 a 1.998.728, desde 1987 hasta el 2009.

\section{Comparación entre disponibilidad de agroalimentos en Antioquia y las demandas de agroalimentos del eje Medellín. Para realizar la comparación,} se calcularon las necesidades de alimentos y nutrición de la población de Medellín, convertidas en productos consumidos en la ciudad, y así se valora la disponibilidad que se requiere en el eje. Estos cálculos son explicados en el apartado de metodología (capítulo I) y resultan en demandas ideales de acuerdo con las necesidades nutricionales de la población. Lo que se hace en este punto es comparar esos requerimientos para la ciudad eje con la disponibilidad de agroalimentos en el entorno regional más inmediato: el departamento de Antioquia.

Este comparativo no considera autoconsumos realizados en las zonas productoras de agroalimentos ni pérdidas por manejo, empaque y transporte de cada producto; tampoco tiene en cuenta lo distribuido en el área metropolitana del Valle de Aburrá. Supone que la disponibilidad se dirige al mercado mayor de la región: la ciudad de Medellín. Los resultados de esta comparación concluyen que hay productos que son autosuficientes y se producen en el departamento y otros deficitarios que deben ser importados de otras zonas del país o del exterior. 
Los productos autosuficientes, de acuerdo con las demandas ideales de la ciudad eje, son productos de la dieta básica y se organizan en grupos de alimentos así: primer grupo, cereales, arroz y maíz; segundo grupo: raíces, tubérculos y plátanos (la papa, el plátano, la yuca y el ñame, para la comparación de ñame y arracacha, no se calculan en la demanda ideal); tercer grupo: hortalizas, verduras y leguminosas verdes (cebolla común, tomate y zanahoria); cuarto grupo: frutas (solo tenemos guayaba). En carnes, es el primer productor de carne de cerdo, así como en leguminosas secas, el frijol, los azúcares, la caña panelera y el café.

\begin{tabular}{|c|c|c|c|c|}
\hline \multicolumn{5}{|c|}{$\begin{array}{l}\text { Cuadro } 7.2 .18 \text { Comparativo de disponibilidad de la región inmediata por } \\
\text { grupos de agroalimentos y la demanda ideal del e je Medellín } 2006\end{array}$} \\
\hline Grupos de alimentos & Productos & $\begin{array}{l}\text { Demanda } \\
\text { ideal (ton) }\end{array}$ & $\begin{array}{l}\text { Producción } \\
2006\end{array}$ & $\begin{array}{c}\text { Déficit o } \\
\text { superávit }\end{array}$ \\
\hline \multirow{4}{*}{ 1. CEREALES } & Arroz & 49.152 & 57.121 & 7.969 \\
\hline & Avena & 17.632 & 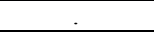 & 17.632 \\
\hline & Maíz & 13.363 & 85.711 & 72.348 \\
\hline & Trigo & - & . & \\
\hline \multirow{6}{*}{$\begin{array}{l}\text { 2. RAÍCES, } \\
\text { TUBÉRCULOS Y } \\
\text { PLÁTANOS }\end{array}$} & Ñame & - & 22.080 & 22.080 \\
\hline & Papa & 63.792 & 256.080 & 192.288 \\
\hline & Papa criolla & 16.086 & . & 16.086 \\
\hline & Plátano & & 3.450 & 3.450 \\
\hline & Yuca & 35.227 & 247.427 & 212.200 \\
\hline & Arveja & 30.882 & 163.411 & 132.529 \\
\hline \multirow{7}{*}{$\begin{array}{l}\text { 3. HORTALIZAS, } \\
\text { VERDURAS Y } \\
\text { LEGUMINOS AS } \\
\text { VERDES }\end{array}$} & Auyama & 10.620 & 3.826 & 6.794 \\
\hline & Cebolla Cabezona & 18.888 & 1.200 & $-\quad 17.688$ \\
\hline & Cebolla común & 4.857 & 340 & 4.517 \\
\hline & Habichuela & 3.028 & 16.327 & 13.299 \\
\hline & Tomate & 12.384 & 2.200 & $-\quad 10.184$ \\
\hline & Zanahoria & 19.153 & 23.692 & 4.539 \\
\hline & Banano & 32.686 & 35.483 & 2.797 \\
\hline \multirow{8}{*}{ 4. FRUTAS } & Guayaba & 21.697 & 17.826 & 3.871 \\
\hline & Limón & 50.170 & 67.477 & 17.307 \\
\hline & Mandarina & 35.955 & 7.072 & $-\quad 28.883$ \\
\hline & Mango & 47.416 & 2.750 & $-\quad 44.666$ \\
\hline & Mora & 31.175 & 3.533 & $-\quad 27.642$ \\
\hline & Naranja & 78.553 & 67.477 & $-\quad 11.076$ \\
\hline & Tomate de árbol & 51.428 & 30.190 & $-\quad 21.238$ \\
\hline & Carne de res & 30.112 & 70.500 & 40.388 \\
\hline \multirow{5}{*}{ 5. CARNES Y HUEVOS } & Carne de cerdo & 9.704 & 105.717 & 96.013 \\
\hline & Huevo de gallina & 7.852 & 57.981 & 50.129 \\
\hline & Pescado & 17.416 & 44.326 & 26.910 \\
\hline & Pollo & 14.320 & 2.007 & $-\quad 12.313$ \\
\hline & Fríjol & 9.192 & 67.956 & 58.764 \\
\hline \multirow{3}{*}{$\begin{array}{l}\text { 6. LEGUMINOSAS } \\
\text { SECAS Y MEZCLAS } \\
\text { VEGETALES } \\
\end{array}$} & Garbanzo & 5.805 & 30.045 & 24.240 \\
\hline & Lenteja & 5.128 & & 5.128 \\
\hline & Leche líquida & 5.515 & . & 5.515 \\
\hline 7. LÁCTEOS & Leche liquida & 148.591 & 235.062 & 86.471 \\
\hline \multirow{2}{*}{ 8. GRAS AS } & Aceite animal & - & & - \\
\hline & Aceite Vegetal & 13.439 & & $-\quad 13.439$ \\
\hline \multirow{2}{*}{ 9. AZÚCARES } & Café & - & & - \\
\hline & Caña Panelera & - & 160.358 & 160.358 \\
\hline
\end{tabular}


En los productos deficitarios se tiene, en el mismo orden de los grupos de alimentos: primero, la avena y trigo, producciones que son nulas en el departamento, aunque forman parte de la dieta. La papa criolla se ubica en el segundo lugar; en el tercero, cuarto y sexto, hay más déficit de productos regionales.

La conclusión central de este eje es que la producción del departamento, con 30 de los 38 productos de la demanda ideal y en su dinámica, tiene 19 productos que son autosuficientes para suplir la disponibilidad en el cumplimiento de la dieta básica de la población de Medellín. Aunque es deficitario en 16 de los productos requeridos, su distribución puede mirarse en función del desarrollo regiolocal, teniendo en cuenta que hay 5 productos que podrían ampliar su producción en el departamento con ciertos incentivos. Otros productos son del mercado nacional y cuatro del mercado internacional, que son esenciales en la dieta básica diaria de esta región y de las otras tres: avena, trigo, garbanzo y lenteja, los cuales se importan de Estados Unidos, Canadá, Chile, Argentina, México y Alemania.

\subsubsection{2.. La disponibilidad en el eje de Cartagena}

Uso de la tierra en Bolívar. La tabla 7.2.19, referida al aprovechamiento de la tierra en Bolívar en el periodo 1996 a 2008, muestra que la superficie no agropecuaria tiene un 43,5 \%, 1.147.343 ha, pero pasa al 42,6\%, con 1.105.771 ha (pierde 41.572 ha). La tierra dedicada al sector agropecuario permanece casi inalterable (gana $677 \mathrm{ha}$ ).

Al comparar en el interior del sector agropecuario las tierras dedicadas a la agricultura y a la ganadería, se encuentra una dinámica distinta en términos del crecimiento: aumenta el uso de la tierra del sector pecuario de 78,8 \% a 87,9\% (columna 2 de la tabla 7.2.19), con 136.388 nuevas hectáreas.

Por otra parte, la tierra para la agricultura disminuye: pasa del 4,5\% en 1986, con 117.307 ha, al 3,8 \%, con 98.496 ha en el 2008. Otro cambio se da en los cultivos con tenencia en la economía campesina: los transitorios y el barbecho pasan del $6,7 \%$ en 1986, con 99.525 ha, al 4,9\%, con 73.081 ha en el 2008. Los cultivos permanentes pasan del 1,2\% en 1986, con 17.782 ha, al 1,7\%, con 25.066 ha en el 2008. Esto hace que cambie el uso de las tierras en el departamento por el crecimiento de los cultivos permanentes y las tierras para ganadería, que son grandes y medianas propiedades. 
En el 2005, el Banco de la República confirmaba lo que en 1999 dijo la Secretaría de Agricultura y Desarrollo Rural de Bolívar sobre los usos inadecuados de la zona rural del departamento: la tierra dedicada a la agricultura era de 167.181 ha, cuando potencialmente se podían utilizar 350.000 ha; mientras que para la ganadería había 863.864 ha utilizadas y en potencia solo existen 700.000:

Las actividades en el uso de la tierra, las que deben tener una recomposición, de tal modo que se aproveche de la mejor forma su potencial, tales son:la agricultura, la ganadería, los bosques comerciales y los rastrojos. La agricultura y los bosques comerciales, por ejemplo, están siendo utilizados, el primero en un $50 \%$ y el segundo en tan solo un $5 \%$ de su potencial. Por otro lado, la utilización de los suelos para la ganadería y los rastrojos presentan una utilización que sobrepasa el potencial de uso de la tierra ${ }^{394}$.

\begin{tabular}{|c|c|c|c|c|c|c|c|c|c|c|c|c|c|c|c|}
\hline \multirow[t]{2}{*}{ SUPERFICIES } & \multirow{2}{*}{$\begin{array}{c}\text { Total } \\
\text { hectáreas }\end{array}$} & \multicolumn{2}{|c|}{$\%$} & \multirow{2}{*}{$\begin{array}{c}\text { Total } \\
\text { hectáreas }\end{array}$} & \multicolumn{2}{|c|}{$\%$} & \multirow{2}{*}{$\begin{array}{c}\text { Total } \\
\text { hectáreas }\end{array}$} & \multicolumn{2}{|c|}{$\%$} & \multirow{2}{*}{$\begin{array}{c}\text { Total } \\
\text { hectáreas }\end{array}$} & \multicolumn{2}{|c|}{$\%$} & \multirow{2}{*}{$\begin{array}{c}\text { Total } \\
\text { hectáreas }\end{array}$} & \multicolumn{2}{|r|}{$\%$} \\
\hline & & 1 & 2 & & 1 & 2 & & 1 & 2 & & 1 & 2 & & 1 & 2 \\
\hline $\begin{array}{l}\text { SUPERFICIE PLANIMETRADA } \\
\text { DEL MARCO* }\end{array}$ & 2.638 .695 & 100,0 & & 2.597 .800 & 100,0 & & 2.597 .800 & 100,0 & & 2.597 .800 & 100,0 & & 2.597 .800 & 100 & \\
\hline $\begin{array}{l}\text { 1. Sector Agropecuario } \\
\text { planimetrado, incluida en el } \\
\text { universo de estudio }\end{array}$ & 1.491 .352 & 56,5 & 100,0 & 1.492 .060 & 57,4 & 100,0 & 1.489 .807 & 57,3 & 100,0 & 1.488 .975 & 57,3 & 100,0 & 1.492 .029 & 57,4 & 100,0 \\
\hline 1.2 Agrícola & 117.307 & 4,4 & 7,9 & 179.803 & 13,8 & 12,1 & 126.912 & 4,9 & 8,5 & 75.742 & 2,9 & 5,1 & 98.496 & 3,8 & 6,6 \\
\hline $\begin{array}{l}\text { Cultivos transitorios y } \\
\text { barbecho }\end{array}$ & 99.525 & 3,8 & 6,7 & 156.642 & 6,9 & 10,5 & 82.237 & 3,2 & 5,5 & 60.633 & 2,3 & 4,1 & 73.081 & 2,8 & 4,9 \\
\hline Cultivos permanentes & 17.782 & 0,7 & 1,2 & 23.162 & 6,0 & 1,6 & 34.345 & 1,3 & 2,3 & 13.461 & 0,5 & 0,9 & 25.066 & 1,0 & 1,7 \\
\hline Descanso & & & & & 0,9 & 0,0 & 10.330 & 0,4 & 0,7 & 1.648 & 0,1 & 0,1 & 349 & 0,0 & 0,0 \\
\hline 1.3 Pecuaria & 1.174 .731 & 44,5 & 78,8 & 1.139 .990 & 43,9 & 76,4 & 1.218 .801 & 46,9 & 81,8 & 1.269 .606 & 48,9 & 85,3 & 1.311 .119 & 50,5 & 87,9 \\
\hline Pastos & 781.119 & 29,6 & 52,4 & 750.470 & \begin{tabular}{|l|}
28,9 \\
\end{tabular} & 50,3 & 818.163 & 31,5 & \begin{tabular}{|l|}
54,9 \\
\end{tabular} & 861.785 & 33,2 & 57,9 & 979.159 & 37,7 & 65,6 \\
\hline Malezas y rastrojos & 393.611 & 14,9 & 26,4 & 389.520 & 15,0 & 26,1 & 400.638 & 15,4 & 26,9 & 407.821 & 15,7 & 27,4 & 331.954 & 12,8 & 22,2 \\
\hline 1.4 Bosques & 181.532 & & & 129.038 & 5,0 & 8,6 & 85.906 & 3,3 & 5,8 & 72.497 & 2,8 & 4,9 & 36.318 & 1,4 & 2,4 \\
\hline \begin{tabular}{|l|} 
Naturales \\
\end{tabular} & & & & 125.143 & 4,8 & 8,4 & & & & 69.220 & 2,7 & 4,6 & 34.852 & 1,3 & 2,3 \\
\hline Plantados & & & & 3.895 & 0,1 & 0,3 & & & & 3.277 & 0,1 & 0,2 & 1.465 & 0,1 & 0,1 \\
\hline 1.5 Otros usos & & & & 43.229 & 1,7 & 2,9 & 58.187 & 2,2 & 3,9 & 71.130 & 2,7 & 4,8 & 46.097 & 1,8 & 3,1 \\
\hline 2. Sector no agropecuario & 1.147 .343 & 43,5 & & 1.105 .740 & 42,6 & & 1.107.993 & 42,7 & & 1.108 .825 & 42,68 & & 1.105 .771 & 42,6 & \\
\hline
\end{tabular}

Se confirma así la tendencia nacional de los conflictos de aptitudes y uso de las tierras: los usos agrícolas decrecen y la ganadería gana con tierras que deberían dedicarse a la agricultura.

Desplazamiento y despojo de tierras en Bolívar. En el 2009 se presentó un informe sobre la situación de los municipios del norte de Bolívar, incluida la ciudad eje de Cartagena respecto al desplazamiento y el despojo de tierras:

394 GERSON, Javier y PÉREZ,V. (2005): Bolivar: industrial, agropecuario y turístico. Documentos de Trabajo Sobre Economía Regional. Banco de la República-Sucursal Cartagena, n. ${ }^{\circ}$ 58, julio, pág. 19. 
Aproximadamente 28.100 personas de los municipios de Cartagena, Turbaco y Arjona se encuentran en riesgo, las cuales están discriminadas de la siguiente manera: Distrito de Cartagena: alrededor de 21.000. [...] En el Municipio de Turbaco, 1.800 personas residentes en la zona urbana y en los Corregimientos de San José del Chiquito, y en el Talón, Ciudad de las Mujeres. En el municipio de Arjona 800 personas habitantes de la zona urbana y en el área rural de la Vereda Rocha ${ }^{395}$.

Este departamento con alto desplazamiento y despojo tiene 14.903 predios abandonados y área de 343.882 ha, que son 5.952 UAF. Resalta en el proceso de despojo y abandono que la ciudad eje es la mayor receptora de esta población desplazada en la Costa Atlántica.

\begin{tabular}{|c|c|c|c|c|c|c|c|c|c|c|}
\hline \multicolumn{11}{|c|}{$\begin{array}{l}\text { Tabla 7.2.20 Bolívar, 2004-2009, predios y áreas abandonadas (ordenados según \% de } \\
\text { predios) }\end{array}$} \\
\hline \multirow[t]{2}{*}{ Características } & \multicolumn{2}{|c|}{$\begin{array}{c}\text { Personas } \\
\text { relacionadas con } \\
\text { predios Abandonados }\end{array}$} & \multicolumn{2}{|c|}{$\begin{array}{c}\text { Predios } \\
\text { Abandonados }\end{array}$} & \multicolumn{2}{|c|}{$\begin{array}{c}\text { Área (ha) } \\
\text { Registrada como } \\
\text { Abandonada }\end{array}$} & \multirow{2}{*}{\begin{tabular}{|c|}
$\%$ \\
participación \\
según área \\
abandonada
\end{tabular}} & \multirow{2}{*}{\begin{tabular}{|c|}
$\%$ \\
participación \\
según predios \\
abandonados
\end{tabular}} & \multicolumn{2}{|c|}{$\begin{array}{c}\text { No. UAF } \\
\text { abandonadas }\end{array}$} \\
\hline & $\mathrm{N}$ & $\%$ & Nún & $\%$ & Número & $\%$ & & & ro & $\%$ \\
\hline $\begin{array}{c}\text { Total } \\
\text { Departamento }\end{array}$ & 13.988 & 8,2 & 14.903 & 8,3 & 343.882 & 8,1 & 8.12 & 8.29 & 5.952 & 6,2 \\
\hline Total Colombia & 170.783 & 100 & 179.852 & 100 & 4.234 .364 & 100 & 100 & 100 & 96.597 & 100 \\
\hline \multicolumn{11}{|c|}{$\begin{array}{l}\text { Fuente: elaboración propia a partir de Presidencia de la República de Colombia y Acción Social (2010): Un } \\
\text { Familiares, tenencia, y abandono forzado de tierras en Colombia. Proyecto Protección de Tierras y Patrimo } \\
\text { Desplazada, Bogotá, págs. } 125 \text { y ss. }\end{array}$} \\
\hline
\end{tabular}

La Presidencia de la República muestra, en diferentes municipios del departamento, el abandono forzado de 12.117 predios hasta 2010. Los principales municipios donde la población ha sido despojada se ven en la tabla 7.2.21, con una clasificación subregional de la ZODES y municipal.

En el departamento, la zona con más problemas por abandono forzado de predios es la ZODES de Montes de María; y allí, el municipio El Carmen de Bolívar, con el 90,2\% del territorio afectado (4.032 predios abandonados y $81.184 \mathrm{ha}$ ), seguido del municipio de Zambrano, con 46,52 \% de territorio afectado y 13.350 ha. Los municipios de María la Baja y San Juan de Nepomuceno presentan, cada uno, el 26\% de territorio afectado.

La ZODES Dique tiene a Santa Rosa, un municipio dormitorio (a 30 minutos de Cartagena), con el 62,2\% del territorio, que registra 9.935 ha abandonadas y tiene el

395 CALERO CHACÓN, Jorge Enrique (2009): SAT. Informe de riesgo No 001-09 A.I. Defensoría Delegada para la Evaluación de Riesgos de la Población Civil como Consecuencia del Conflicto Armado, Sistema de Alertas Tempranas. pág. 5. 
segundo mayor índice de afectación del departamento. La ZODES Mojana muestra a San Jacinto, con el 53.28\% del territorio y 23.122 ha afectadas; seguido de Tiquicio, con 20,8\% y 15.764 ha, Achí con el 11,3\%, y Montecristo, con el 6,1\%.

En la ZODES Magdalena, el más afectado es San Pablo, con el 14,7\%, y 29.031 ha, seguido de Cantagallo, con el 12.5\%; Simití, con el 9,2\%, y Santa Rosa del Sur, con el 4,8\%. La diferencia en el total de hectáreas abandonadas de la tabla 7.2.20 (343.882) ante el registrado en la tabla 7.2.21 (255.479) se presenta porque el primer dato es el agregado del departamento y el segundo son los principales municipios afectados, explicación que también aplica para los predios abandonados.

\begin{tabular}{|c|c|c|c|c|c|c|}
\hline \multicolumn{7}{|c|}{$\begin{array}{c}\text { Tabla 7.2.21 Bolívar, municipios con mayor afectación por abandono forzado de } \\
\text { predios hasta } 2010\end{array}$} \\
\hline ZODES & $\begin{array}{l}\text { Municipio de } \\
\text { Ubicación del } \\
\text { predio }\end{array}$ & $\begin{array}{l}\text { Área del } \\
\text { Municipio }\end{array}$ & $\begin{array}{l}\text { Personas } \\
\text { relacionadas } \\
\text { con predios } \\
\text { abandonados }\end{array}$ & $\begin{array}{c}\text { Predios } \\
\text { Abandonado } \\
\mathrm{s}\end{array}$ & \begin{tabular}{|c|} 
Área (ha) \\
registrada \\
como \\
abandonada
\end{tabular} & $\begin{array}{l}\text { \% Afectación } \\
\text { según área } \\
\text { del municipio }\end{array}$ \\
\hline Dique & Santa Rosa & 15.100 & 449 & 468 & 9.395 & 62.22 \\
\hline \multirow{4}{*}{ Mojana } & San jacinto & 43.400 & 930 & 1.030 & 23.122 & 53.28 \\
\hline & Tiquicio & 75.800 & 430 & 450 & 15.764 & 20.80 \\
\hline & Montecristo & 208.900 & 412 & 435 & 12.806 & 6.13 \\
\hline & Achí & 102.500 & 404 & 427 & 11.608 & 11.32 \\
\hline \multirow{4}{*}{ Magdalena } & San Pablo & 197.700 & 1.325 & 1.392 & 29.031 & 14.68 \\
\hline & Simití & 134.500 & 535 & 566 & 12.392 & 9.21 \\
\hline & \begin{tabular}{|c|}
$\begin{array}{c}\text { Santa Rosa del } \\
\text { Sur }\end{array}$ \\
\end{tabular} & 236.000 & 434 & 449 & 11.308 & 4.79 \\
\hline & Cantagallo & 87.800 & 407 & 431 & 10.885 & 12.51 \\
\hline \multirow{5}{*}{$\begin{array}{l}\text { Montes de } \\
\text { María }\end{array}$} & $\begin{array}{c}\text { El Carmen de } \\
\text { Rolivar }\end{array}$ & 90.000 & 3.741 & 4.032 & 81.184 & 90,2 \\
\hline & Maria la Baja & 51.700 & 846 & 919 & 13.561 & 26.23 \\
\hline & $\begin{array}{c}\text { San Juan } \\
\text { Nepomuceno }\end{array}$ & 63.700 & 599 & 631 & 16.898 & 26.53 \\
\hline & Zambrano & 28.700 & 477 & 497 & $13-350$ & 46.52 \\
\hline & Córdoba & 57.300 & 378 & 390 & 7.525 & 13.13 \\
\hline \multicolumn{2}{|c|}{ Total } & 1.393 .100 & 11.367 & 12.117 & 255.479 & \\
\hline
\end{tabular}

Concentración de la tierra 1996-2008. Para analizar el proceso de concentración de la tierra en Bolívar se identifica la regionalización del Incora, según regiones relativamente homogéneas, que son cinco, según las tablas 7.2.22 y 7.2.23 (referidas a las características dinámicas de la UAF). Allí también se presenta conflicto entre lo formal y lo real.

El tamaño promedio del microfundio es de 8 hectáreas, pero la UAF más pequeña para producción agropecuaria está entre 26 ha a 36 ha en la subregión Canal del Dique, con municipios cerca de la ciudad eje y de Barranquilla. En las otras subregiones, la 
exigencia es mayor para cada UAF en hectáreas, lo cual muestra que por una parte va la reglamentación y el diseño de la política y por otra se encuentra la realidad agrícola. Se reconoce que las pequeñas propiedades son micropropiedades según la identificación del tamaño de lo que debe ser una UAF.

\begin{tabular}{|c|c|c|}
\hline $\begin{array}{l}\text { Regiones Relativamente } \\
\text { Homogéneas }\end{array}$ & Municipios & $\begin{array}{l}\text { Rangos de la Unidad } \\
\text { Agricola Familiar UAF. Por } \\
\text { la potencialidad de } \\
\text { explotación }\end{array}$ \\
\hline $\begin{array}{l}1 \text { Serranía de San Lucas áreas } \\
\text { geográicas caracterizadas asi: suelos } \\
\text { ondulados, fuertemente ondulados } \\
\text {,quebrados y escarpados, con altitud } \\
\text { superior a } 100 \text { m.s.n.m. }\end{array}$ & $\begin{array}{c}\text { Parcialmente áreas de los municipios de: Cantagallo, San Pablo, Simití, Santa Rosa del } \\
\text { Sur, Morales, Rio Viejo, Regidor, El Peñón, San Martín de Loba, Puerto Rico, } \\
\text { Montecristo, Barranco de Loba, Altos del Rosario y Pinillos }\end{array}$ & 85 a 115 hectáreas \\
\hline \multirow[t]{2}{*}{$\begin{array}{l}2 \text { Vega de los rios Cauca y } \\
\text { Magdalena y afluentes de estos: } \\
\text { suelos planos y ondulados, con altitud } \\
\text { de } 40 \text { a } 100 \text { m.s.n.m. }\end{array}$} & $\begin{array}{c}\text { Sur de Bolivar: parcialmente áreas de los municipios de: Cantagallo, San Pablo, Morales, } \\
\text { Rio Viejo, Regidor, El Peñón, San Martín de Loba, Achí, Montecristo, Tiquisio, Barranco } \\
\text { de Loba, Pinillos, Magangué, Altos del Rosario, Mompós, Cicuco, Talaigua Nuevo, San } \\
\text { Fernando, Hatillo de Loba y Margarita. }\end{array}$ & \multirow[t]{2}{*}{35 a 47 hectáreas } \\
\hline & Centro de Bolívar: Córdoba, Zambrano, Calamar, El Guamo y San Juan Nepomuceno. & \\
\hline $\begin{array}{l}\text { 3 Serranía Montes de Maria: } \\
\text { Comprende suelos ondulados a } \\
\text { fuertemente ondulados y quebrados, con } \\
\text { altitud entre } 100 \text { y } 300 \text { m.s.n.m. }\end{array}$ & $\begin{array}{c}\text { Guamo, Maria La Baja, Mahates, Zambrano y Córdoba, sobre la Serranía de Montes de } \\
\text { María }\end{array}$ & 35 a 48 hectáreas. \\
\hline $\begin{array}{l}4 \text { Canal del Dique: áreas planas, con } \\
\text { altitud entre } 10 \text { y } 20 \text { m.s.n.m. }\end{array}$ & Mahates, Arjona, San Estanislao, Turbana, Soplaviento y San Cristóbal. & 26 a 36 hectáreas. \\
\hline $\begin{array}{l}5 \text { Zona norte: comprende áreas } \\
\text { geográficas con suelos ondulados y } \\
\text { quebrados, con altitud de } 10 \text { a } 100 \\
\text { m.s.n.m. }\end{array}$ & $\begin{array}{l}\text { Cartagena, Santa Catalina, Clemencia, Santa Rosa, Villa Nueva, San Estanislao, Arjona, } \\
\text { Turbaco y Turbana, cercanos al Mar Caribe, pero no incluye las áreas de playas } \\
\text { colindantes con el Mar Caribe en los municipios de Cartagena y Santa Catalina. }\end{array}$ & 41 a 56 hectáreas. \\
\hline
\end{tabular}

La pequeña propiedad, con promedio de 52 hectáreas (tabla 7.2.23), se encuentra acorde con las siguientes subregiones:Vega, de los ríos Cauca y Magdalena y afluentes de estos, Serranía Montes de María, Canal del Dique y Zona Norte; para las cuales los rangos definidos se encuentran entre 26 a 56 hectáreas. En la subregión Serranía de San Lucas sobrepasa los mínimos, pues allí el rango es de 85 a 115 ha.

Tabla 7.2.23 Bolívar, 2009, características de la dinámica de las UAF

\begin{tabular}{|c|c|c|c|c|c|}
\hline Características & Microfundio & $\begin{array}{c}\text { Pequeña } \\
\text { propiedad }\end{array}$ & $\begin{array}{c}\text { Mediana } \\
\text { propiedad }\end{array}$ & $\begin{array}{c}\text { Gran } \\
\text { propiedad }\end{array}$ & $\begin{array}{c}\text { Promedio } \\
\text { departamento }\end{array}$ \\
\hline Distribución Porcentual & 14.2 & 29.9 & 21.9 & 34.0 & 100 \\
\hline Colombia & $\mathbf{1 2 . 4}$ & $\mathbf{1 8 . 3}$ & $\mathbf{2 5 . 2}$ & $\mathbf{4 4 . 1}$ & $\mathbf{1 0 0}$ \\
\hline $\begin{array}{c}\text { Tamaño Promedio de predios(ha) } \\
\text { escala de tenencia }\end{array}$ & 8 & 52 & 186 & 2.594 & 41 \\
\hline Promedio Colombia & $\mathbf{3}$ & $\mathbf{3 5}$ & $\mathbf{9 2}$ & $\mathbf{1 4 7 4}$ & $\mathbf{2 5}$ \\
\hline $\begin{array}{c}\text { Avalúos por hectáreas (\$ } \\
\text { corrientes) }\end{array}$ & 1.425 .794 & 787.803 & 1.007 .706 & 372.714 & 785.407 \\
\hline Promedio Colombia & $\mathbf{2 . 4 2 3 . 5 1 7}$ & $\mathbf{9 7 5 . 1 6 2}$ & $\mathbf{1 . 0 2 8 . 4 4 7}$ & $\mathbf{3 3 8 . 6 4 9}$ & $\mathbf{8 0 4 . 3 3 5}$ \\
\hline
\end{tabular}

Fuente: Presidencia de la República de Colombia y Acción Social (2010): Unidades Agrícolas Familiares, tenencia y abandono forzado de tierras en Colombia. Proyecto Protección de Tierras y Patrimonio de la Ppoblación Desplazada, Bogotá, págs. 44 yss. 
La tabla 7.2.23 refleja la tendencia de la concentración de la propiedad en Bolívar, a partir de la gran propiedad (el 34,0\% en UAF), seguida de la pequeña $(29,9 \%)$, la mediana $(21,9 \%)$ y el microfundio (14,2\%). Hay extremos de la gran propiedad y el microfundio: son los argumentos sobre el uso de tierras, con subutilización y sobreutilización del suelo; por otro lado, los promedios de hectáreas de la gran propiedad son de 2.594 ha: el microfundio, $8 \%$; la pequeña propiedad, 52\%, y la mediana, 186\%.Y la gran propiedad tiene los avalúos más bajos y el microfundio los más altos.

La tabla 7.2.24 (usos del suelo según tamaño, años 1996 y 2004) muestra dinámicas de concentración. Los predios de 0 a menos de 20 ha pasan de 206.078 ha, con el 12,14\%, a 125.540 ha, con el 8,4\%. También disminuyen los predios cuyo tamaño es de 20 a menos de 50. Mientras tanto, los predios de 50 a 100 aumentan sus hectáreas: pasan de 320.688 y $18.89 \%$ en 1996 a 336.384 y 22.59\% en el 2004; y los más dinámicos en crecer son los de más de 100 y menos de 500, que pasan de 279.214 ha, con $34,1 \%$, a 708.806 ha con $47,6 \%$.

Sobre los cambios de uso del suelo, bajan las tierras agrícolas de la pequeña, mediana y gran propiedad, y hay un traslado entre 1996 y 2004 de este de uso a la actividad pecuaria. Disminuye la gran propiedad y los microfundios en tierras de bosques y otros usos, mientras la pequeña propiedad presenta una relación inversa.

\begin{tabular}{|c|c|c|c|c|c|c|c|c|c|c|c|c|c|}
\hline Tabla 7.2.24 De & partamen & ito de & 3olívar, di & stribuci & ón de lo & PSI & M, por & usos del s & suelo, & , seg & tamaño, & 1996 & 004 \\
\hline \multirow{3}{*}{ Tamaño (PSM) } & \multirow{2}{*}{\multicolumn{2}{|c|}{ P S M }} & \multicolumn{11}{|c|}{ U S O S (he ctáreas) } \\
\hline & & & \multicolumn{2}{|c|}{ T otal } & \multicolumn{3}{|c|}{ Uso agrícola } & \multicolumn{3}{|c|}{ Pastos y malezas } & \multicolumn{3}{|c|}{ Bosques y otros usos } \\
\hline & Cantidad & $\%$ & Área & $\%$ & Área & * & ** & Área & * & ** & Área & * & ** \\
\hline \multicolumn{14}{|c|}{ Año 2004} \\
\hline TOTAL & 30.856 & 100,00 & 1.488 .975 & 100,00 & 75.742 & 5,09 & 100,00 & 1.269 .606 & 85,27 & 100 & 143.627 & 9,65 & 100,00 \\
\hline 0 a menos de 20 & 12.133 & 39,32 & 125.540 & 8,43 & 16.551 & 13,18 & 21,85 & 97.547 & 77,70 & 7,68 & 11.443 & 9,12 & 7,97 \\
\hline 20 a menos de 50 & 9.966 & 32,30 & 318.245 & 21,37 & 32.398 & 10,18 & 42,77 & 256.200 & 80,50 & 20,18 & 29.646 & 9,32 & 20,64 \\
\hline 50 a menos de 100 & 4.879 & 15,81 & 336.384 & 22,59 & 16.137 & 4,80 & 21,31 & 285.356 & 84,83 & 22,48 & 34.892 & 10,37 & 24,29 \\
\hline 100 a menos de 500 & 3.877 & 12,56 & 708.806 & 47,60 & 10.657 & 1,50 & 14,07 & 630.502 & 88,95 & 49,66 & 67.646 & 9,54 & 47,10 \\
\hline \multicolumn{14}{|c|}{ Año 1996} \\
\hline Total & 81.139 & 100 & 1.697 .427 & 100,00 & 158.288 & 9,33 & 100,00 & 1.326 .494 & 78,15 & 100 & 199.303 & 11,74 & 100,00 \\
\hline 0 a menos de & 29.989 & 36,96 & 206.078 & 12,14 & 40.984 & 19,89 & 25,89 & 151.767 & 73,65 & 11,44 & 13.318 & 6,46 & 6,68 \\
\hline 20 a menos de & 12.758 & 15,72 & 385.369 & 22,70 & 33.147 & 8,60 & 20,94 & 326.147 & 84,63 & 24,59 & 26.074 & 6,77 & 13,08 \\
\hline 50 a menos de 100 & 4.751 & 5,86 & 320.688 & 18,89 & 21.822 & 6,80 & 13,79 & 273.310 & 85,23 & 20,60 & 25.554 & 7,97 & 12,82 \\
\hline 100 a menos de 500 & 3.652 & 4,50 & 579.214 & 34,12 & 21.351 & 3,69 & 13,49 & 423.503 & 73,12 & 31,93 & 134.357 & 23,20 & 67,41 \\
\hline \multicolumn{8}{|c|}{ Fuente : ENA, DANE - Proyecto SISAC y Ministerio de Agricultura y Desarrollo Rural. Cálculo del Autor. } & \multicolumn{3}{|c|}{ * Porcentaje Horizontal } & \multicolumn{3}{|c|}{ ** Porcentaje Vertical } \\
\hline
\end{tabular}

Disponibilidad y política SAN en Bolívar. Las acciones para intervenir el sector agropecuario, como política del departamento de Bolívar, tienen varios puntos: el manejo de tierras y riego, de la Secretaria de Agricultura Departamental, y el reconocimiento de los Consejos Comunitarios de Comunidades Negras como entes que regulan las tierras tituladas colectivamente a estas. Esta Secretaría apoya los procesos respectivos. 
El Plan de Desarrollo Departamental considera un manejo agropecuario de manera integral, sustentable y competitivo para recuperar la dinámica económica agropecuaria, lo cual fortalece la capacidad institucional de la Secretaría de Agricultura y Desarrollo Rural, capacitación en los Centros de Desarrollo Tecnológico y Productivo (Cedetep), para apoyar la transferencia de tecnología y fortalecer la asistencia técnica rural directa, en articulación con los institutos técnicos agrícolas ${ }^{396}$.

En la disponibilidad regional de agroalimentos hay expectativas frente a la ciudad eje y el resto del país. Bustillo considera que "Bolívar es una despensa alimentaria del país"397. Además, plantea sobre los ZODES en Bolívar:

[Presentan un alto nivel de] especialización de suelos para cada uno de los centros zonales, lo cual ha permitido unas zonas y culturas especializadas vinculadas con la producción de alimentos hay problemas graves de conectividad y altos costos de transporte llevando a la pérdida de cosecha en diferentes municipios como Santa Rosa Sur y Malagana ${ }^{398}$.

Esto exige acciones gubernamentales en infraestructura vial y manejo de poscosecha. En otras zonas del departamento hay problemas latentes:

Cuellos de botella para los campesinos son: dificultad en el acceso al crédito. En el proceso de comercialización no hay un buen manejo de la poscosecha, baja de tecnificación, mal estado de las vías y tiempos adversos ${ }^{399}$.

Por otro lado, ante la situación social grave, se presentan acciones en pro de la seguridad alimentaria para las familias campesinas y pobres del casco urbano, de los municipios

396 Asamblea Departamental de Bolívar (2004): Ordenanza n. ${ }^{\circ} 11,11$ de mayo de 2004, que adopta el plan de desarrollo departamental 2004-2007: "Por el Bolívar que todos queremos", págs. 56 y ss.

397 BUSTILLO, Javier (2008): entrevista. Asesor del Gobernador del departamento de Bolívar, exalcalde de Magangué. 23 de octubre.

398 Ibíd.

399 FRIERI,Iván (2008): Entrevista.Funcionario de la Secretaría de Agricultura Departamental, departamento de Bolívar, 10 de octubre. 
cercanos a la ciudad eje. Allí Cardique promueve los patios productivos desde el 2005, considerados "una estrategia de educación ambiental para el fomento de la seguridad alimentaria en las cabeceras de los municipios de la jurisdicción de Cardique $^{400}$.

Esta política, desde la autoridad ambiental, busca mejorar las "condiciones de nutrición de la población al resolver a través de la experiencia de los patios productivos alimentos para la población de estos municipios del norte de Bolívar" ${ }^{401}$. En el municipio de Villanueva se informó que tenían "100 patios productivos para niños con bajo peso del Plan Atención Básica (PAB), para combatir la pobreza y la desnutrición" ${ }^{402}$, acción que se coordina con las instituciones en los otros niveles de gobierno.

Disponibilidad de agroalimentos en Bolívar 1987-2009. En el anexo C, las tablas 7 y 8 (cultivos transitorios y permanentes) muestran parte de la oferta disponible inmediata de la ciudad eje: Cartagena. Estas tablas relacionan superficie, producción y rendimiento por cada agroalimento producido en Bolívar. Los cultivos transitorios relacionan tres agroalimentos básicos en la dieta del eje: fríjol, maíz y arroz. El fríjol, desde 1987 a 2009, aumentó 9\% su área cosechada, y desde 1990 baja la superficie de 13.945 ha en 1990 a 3.269 en el 2009, posterior a la política de apertura comercial del Gobierno nacional. Esta caída se acompaña de baja en los rendimientos, que pasan de 868 a $662 t$.

Respecto al maíz, tanto el tecnificado como el tradicional se comportan diferente: el primero cae en superficie, que pasa de 4.700 ha en 1987 a 3.019 ha en el 2009; el tradicional es contrario: pasa de 43.200 a 63.576 ha en el periodo, y los rendimientos son diferentes (mayores en el tecnificado que en el tradicional). Este agroalimento es fundamental en la cultura de la Costa Atlántica colombiana y su consumo se hace con mucha formas de preparación. El arroz de riego, mecanizado y manual, crece en superficie: pasa de 13.800 ha en 1987 a 19.585 en 2009; la producción pasa de 41.400 $t$ a 66.361. En los rendimientos solo cae el arroz secano manual. En términos globales, en este periodo pierde 3.850 ha, pero aumentó la producción en $10.512 t$, lo que significa que crecieron los rendimientos en Bolívar.

\footnotetext{
400 FRANCO, Adolfo (2005): Contrato n. ${ }^{\circ}$ 111/04, Cartagena, 24 de abril.

401 BERRIO, Donaldo (2008): Entrevista. Coordinador de Educación Ambiental de Cardique, 23 de octubre. .

402 HERRERA, Rodolfo (2008): Entrevista. Director de la UMATA, municipio deVillanueva, departamento de Bolívar, 23 de octubre.
} 
Los cultivos permanentes en Bolívar se caracterizan por: la superficie cae en el cocotero, de 650 a 494 ha, y en el plátano, de 14.000 a 3.954 ha. Estos son de producción campesina y parte de la dieta regional.

Respecto a los otros agroalimentos, la caña panelera pasa de 200 a 743 ha y produce de 750 a $6.715 t$; el ñame pasa de 3.500 a 18.925 ha y produce de 33.300 a $208.005 t$; y la yuca, de 20.000 a 36.303 ha y produce de 140.000 a $339.766 t$. Estos agroalimentos aumentan área, producción y rendimientos y hacen parte de la dieta costeña, en especial el ñame, producto típico de esta región. La palma africana, con información continua a partir del 2002, crece en el último quinquenio. Es un producto de medianas y grandes explotaciones.

En general, los cultivos permanentes crecen en superficie de 42.217 a 63.675 ha, con el $51 \%$, y en producción de $281.010 t$ a $586.133 t$, con el $109 \%$ (implica crecer el doble en rendimientos).

\section{Comparación entre disponibilidad de agroalimentos en Bolívar y las demandas de agroalimentos del eje Cartagena. Para realizar la comparación, se calcularon} las necesidades de alimentos y nutrición de la población de Cartagena en términos de productos consumidos en la ciudad, y así se deduce la disponibilidad que se requiere en el eje. Estos cálculos son explicados en el capítulo 1 (ítem de metodología). Los productos resultan en demandas ideales de acuerdo con las necesidades nutricionales de la población; por ello, en este punto se comparar esas demandas para la ciudad eje con la disponibilidad de agroalimentos en el entorno regional inmediato: el departamento de Bolívar.

Este comparativo no considera autoconsumos realizados en las zonas productoras de agroalimentos, ni pérdidas por manejo, empaque y transporte de cada producto. Supone que la disponibilidad se dirige al mercado mayor de la región Cartagena. Los resultados de esta comparación permiten concluir que hay productos que son autosuficientes y se cultivan en el departamento, en tanto hay otros deficitarios que deben ser importados de otras zonas del país o del exterior.

Los productos autosuficientes, de acuerdo con las demandas ideales de la ciudad eje Cartagena, son los de la dieta básica. Pueden describirse por grupo de alimentos así: primero, los cereales: el arroz y el maíz; en el segundo grupo están las raíces, los tubérculos y los plátanos (encontramos el plátano y la yuca, porque para la comparación 
del ñame no se calculó la demanda ideal); en el tercer grupo, las hortalizas, las verduras y las leguminosas verdes (ahuyama, tomate); el cuarto grupo, frutas (guayaba, banano, cítricos, excepto naranja, y el mango); el quinto, leguminosas secas (el fríjol); en el sexto (lácteos) hay gran oferta conjuntamente con la producción del séptimo (carnes); y el último, de azúcares (la caña panelera).

Cuadro 7.2.25 Comparativo de disponibilidad de la región inmediata por grupos de agroalimentos y la demanda ideal del eje Cartagena

\begin{tabular}{|c|c|c|c|c|}
\hline Grupos de alimentos & Productos & $\begin{array}{c}\text { Demanda } \\
\text { ideal (ton) }\end{array}$ & $\begin{array}{c}\text { Producción } \\
2006 \\
\end{array}$ & $\begin{array}{c}\text { Déficit o } \\
\text { superávit }\end{array}$ \\
\hline \multirow{4}{*}{ 1. CEREALES } & Arroz & 19.493 & 79.517 & 60.024 \\
\hline & Avena & 6.980 & . & 6.980 \\
\hline & Maíz & 5.285 & 125.094 & 119.809 \\
\hline & Trigo & - & . & - \\
\hline \multirow{5}{*}{$\begin{array}{l}\text { 2. RAÍCES, } \\
\text { TUBÉRCULOS Y } \\
\text { PLÁTANOS }\end{array}$} & Name & - & 123.509 & 123.509 \\
\hline & Papa & 25.385 & . & 25.385 \\
\hline & Papa criolla & 6.411 & . & 6.411 \\
\hline & Plátano & 13.939 & 32.563 & 18.624 \\
\hline & Yuca & 12.189 & 236.394 & 224.205 \\
\hline \multirow{7}{*}{$\begin{array}{l}\text { 3. HORTALIZAS, } \\
\text { VERDURAS Y } \\
\text { LEGUMINOSAS } \\
\text { VERDES }\end{array}$} & Arveja & 4.217 & . & 4.217 \\
\hline & Auyama & 7.567 & 87 & 7.480 \\
\hline & Cebolla Cabezona & 1.934 & . & 1.934 \\
\hline & Cebolla común & 1.205 & . & 1.205 \\
\hline & Habichuela & 4.922 & . & 4.922 \\
\hline & Tomate & 7.593 & 96 & 7.497 \\
\hline & Zanahoria & 13.131 & . & 13.131 \\
\hline \multirow{8}{*}{ 4. FRUTAS } & Banano & 8.671 & 33.500 & 24.829 \\
\hline & Guayaba & 20.050 & 50.005 & 29.955 \\
\hline & Limón & 14.343 & 14.824 & 481 \\
\hline & Mandarina & 18.945 & 17.450 & 1.495 \\
\hline & Mango & 12.458 & 17.737 & 5.279 \\
\hline & Mora & 31.384 & . & 31.384 \\
\hline & Naranja & 20.543 & 13.122 & 7.421 \\
\hline & Tomate de árbol & 12.044 & & 12.044 \\
\hline \multirow{5}{*}{ 5. CARNES Y HUEVOS } & Carne de res & 3.868 & 30.621 & 26.753 \\
\hline & Carne de cerdo & 3.129 & 100 & 3.029 \\
\hline & Huevo de gallina & 6.937 & 1.931 & 5.006 \\
\hline & Pescado & 5.704 & . & 5.704 \\
\hline & Pollo & 3.661 & 2.348 & 1.313 \\
\hline \multirow{3}{*}{$\begin{array}{l}\text { 6. LEGUMINOSAS } \\
\text { SECAS Y MEZCLAS } \\
\text { VEGETALES }\end{array}$} & Fríjol & 2.312 & 2.818 & 506 \\
\hline & Garbanzo & 2.043 & . & 2.043 \\
\hline & Lenteja & 2.197 & . & 2.197 \\
\hline 7. LÁCTEOS & Leche líquida & 59.447 & 889.188 & 829.741 \\
\hline \multirow{2}{*}{ 8. GRASAS } & Aceite animal & - & . & \\
\hline & Aceite Vegetal & 5.346 & . & 5.346 \\
\hline \multirow{2}{*}{ 9. AZÚCARES } & Café & - & . & \\
\hline & Caña Panelera & - & 7.625 & 7.625 \\
\hline
\end{tabular}


En los productos deficitarios se tiene el mismo orden de los grupos de alimentos: avena y trigo no se cultivan en el departamento, aunque forman parte de la dieta; la papa y la papa criolla se ubican en el otro; en el tercer y quinto grupo se ubican todos; en el cuarto, la mora, la naranja y el tomate de árbol; y en el sexto es donde hay más déficit de productos de consumo general: lenteja y garbanzo.

La conclusión central de este eje es que la producción del departamento es mayoritariamente deficitaria: entre 38 agroalimentos, dispone de 13 que forman parte de la dieta básica de la población de Cartagena.

En el caso de la dinámica de esta ciudad eje, donde hay altos niveles de autosuficiencia alimentaria regional, la zona más inmediata es la ZODES Dique, que se caracteriza como una Zona de Desarrollo Económico con mayor potencialidad para el comercio nacional e internacional, por su localización cerca de los puertos y aeropuertos de Cartagena y Barranquilla, y por la posibilidad de transporte de mercancías desde y hacia el interior del país a través del Canal del Dique ${ }^{403}$. Una de sus características es esta:

Desarrollo agrícola, se basa en su gran mayoría en la economía del pequeño productor, cultivando con deficiencias tecnológicas y económicas, y con incidencia de factores climáticos adversos, y escasas o nulas infraestructuras de riegos ${ }^{404}$.

Esto afecta la disponibilidad del eje en su anillo inmediato. Por otro lado, en relación con la producción de carne, se encuentra en esta ZODES que el área de pastos y el número de cabezas de ganado representan el 29\% y el 23,8\% del total departamental, respectivamente. Existe facilidad y oportunidad de conseguir los insumos para el manejo del hato y se accede a la tecnología y al comercio mediante subastas y alianzas productivas.

En esta zona se ha intensificado la ganadería hasta el punto de que la mayor parte de las tierras está ocupada por pastos, mediante el sistema productivo de doble propósito (leche y carne). Se destacan las razas como cebú, criollo, pardo Holstein (que representa más del 90\%). La explotación ganadera tiene un privilegio porque se le facilita el acceso a los mercados de cadenas y abastos o plazas de mercados. Tiene también la

403 Gobernación de Bolívar, Op. cit., pág. 34.

404 Ibíd., pág. 35. 
oportunidad de contar con empresas procesadoras de lácteos en el mercado local y regional de la costa atlántica, así como comercializadoras de carne en pie mediante el sistema de subastas ${ }^{405}$.

\subsection{Disponibilidad en el eje de Neiva}

Uso de la tierra en Huila: se muestra en la tabla 7.2.26 (aprovechamiento de la tierra en Huila período 1996 a 2008). La superficie no agropecuaria aumenta el 1.6\% y pasa de 602.163 a 641.847 ha. La tierra del sector agropecuario cae en $1.6 \%$ pasa de 1.363.407 a 1.347.153 ha.

Al desagregar las cifras de la tierra para agricultura y ganadería, hay otros cambios (columna 2 de la tabla 7.2.26): la primera cae en los doce años de análisis, pasa del 14,7\% en 1986, con 200.349 ha, al 13,4\%, con 180.417 ha en el 2008. Por otro lado, se modifica el uso de la tierra para los cultivos, pues cambian en la economía campesina los transitorios y el barbecho, que pasan del 5,5\% en 1986, con 75.548 ha, al 2,5\% con 48.827 ha en el 2008, en tanto los cultivos permanentes crecen: pasan del 9,2\% en 1.986, con 124.801 ha, al 9,6\% con 129.457 ha en el 2008.

El otro cambio se da con las tierras del sector pecuario, que pasan de $76.1 \%$ en 1986 , con 1.037.113 ha, al 80,1\%, con 1.078.016 ha en el 2008. Los cambios de uso del suelo rural en el departamento aumentan la tierra para uso de cultivos permanentes y pastos para la ganadería.

Las dinámicas de usos del suelo conducen al departamento a identificar problemas de contaminación y regulación hídrica:

El 33.3\% de la extensión del territorio departamental, un alto conflicto de uso (la utilización del suelo en actividades económicas que no se corresponden con su potencial y con formas de producción adecuadas) y, por consiguiente, las actividades realizadas muestran baja productividad (40\% del suelo en ganadería extensiva que aporta solamente el 5.4\% al PIB Departamental). Los suelos están degradados

405 Ibíd., págs. 37 y ss. 
en diferentes niveles, [...] pérdida de capacidad de regulación de las cuencas abastecedoras de los acueductos municipales, disminución de la oferta hídrica superficial, deterioro de la calidad y uso ineficiente del recurso agua ${ }^{406}$.

Estos problemas develan prácticas nacionales, con mentalidades e intereses territoriales, similares en usos y manejo de suelos. Sobre las vocaciones del suelo por dedicación a la ganadería, se encuentra en el Plan de Desarrollo Territorial:

[Este] calcula en 2.043.000 hectáreas, de las cuales con vocación agrícola se ha estimado en 893.350 hectáreas (42.2\% del total); el área con vocación ganadera en 95.900 hectáreas (4.8\% del total); el área con vocación forestal en 1.053 .750 hectáreas (53\% del total), de la cual el 5.8\% tiene alguna posibilidad agropecuaria, el $22.9 \%$ son áreas de bosque protector y el $24.3 \%$ son áreas a proteger ${ }^{407}$.

\begin{tabular}{|c|c|c|c|c|c|c|c|c|c|c|c|c|c|c|c|}
\hline \multirow{3}{*}{ SUPERFICIES } & \multicolumn{3}{|c|}{1996} & \multicolumn{3}{|c|}{2000} & \multicolumn{3}{|c|}{2002} & \multicolumn{3}{|c|}{2004} & \multicolumn{3}{|c|}{2008} \\
\hline & \multirow{2}{*}{$\begin{array}{c}\text { Total } \\
\text { hectáreas }\end{array}$} & \multicolumn{2}{|c|}{$\%$} & \multirow{2}{*}{$\begin{array}{c}\text { Total } \\
\text { hectáreas }\end{array}$} & \multicolumn{2}{|c|}{$\%$} & \multirow{2}{*}{$\begin{array}{c}\text { Total } \\
\text { hectáreas }\end{array}$} & \multicolumn{2}{|c|}{$\%$} & \multirow{2}{*}{$\begin{array}{c}\text { Total } \\
\text { hectáreas }\end{array}$} & \multicolumn{2}{|c|}{$\%$} & \multirow{2}{*}{$\begin{array}{c}\text { Total } \\
\text { hectáreas }\end{array}$} & \multicolumn{2}{|c|}{$\%$} \\
\hline & & 1 & 2 & & 1 & 2 & & 1 & 2 & & 1 & 2 & & 1 & 2 \\
\hline $\begin{array}{l}\text { SUPERFICIE PLANIMETRADA } \\
\text { DEL MARCO** }\end{array}$ & 1.965 .570 & 100,0 & & 1.989 .000 & 100,0 & & 1.989 .000 & 100,0 & & 1.989 .000 & 100,0 & & 1.989 .000 & 100,0 & \\
\hline $\begin{array}{l}\text { 1. Sector Agropecuario } \\
\text { planimetrado, incluida en el } \\
\text { universo de estudio }\end{array}$ & 1.363 .407 & 69,4 & 100,0 & 1.357 .961 & 68,3 & 100 & 1.356 .280 & 68,2 & 100,0 & 1.352 .026 & 68,0 & 100 & 1.347 .153 & 67,7 & 100,0 \\
\hline 1.2 Agricola & 200.349 & 10,2 & 14,7 & 191.117 & 9,6 & 14,1 & 155.200 & 7,8 & 11,4 & 171.414 & 8,6 & 12,7 & 180.417 & 9,1 & 13,4 \\
\hline $\begin{array}{l}\text { Cultivos transitorios y } \\
\text { barbecho }\end{array}$ & 75.548 & 3,8 & 5,5 & 63.240 & 3,2 & 4,7 & 44.377 & 2,2 & 3,3 & 56.740 & 2,9 & 4,2 & 48.827 & 2,5 & 3,6 \\
\hline Cultivos permanentes & 124.801 & 6,3 & 9,2 & 127.878 & 6,4 & 9,4 & 108.024 & 5,4 & 8,0 & 112.257 & 5,6 & 8,3 & 129.457 & 6,5 & 9,6 \\
\hline Descanso & & - & & & & & 2.798 & 0,1 & 0,2 & 2.417 & 0,1 & 0,2 & 2.134 & 0,1 & 0,2 \\
\hline 1.3 Pecuaria & 1.037 .113 & 52,8 & 76,1 & 965.465 & 48,5 & 71,1 & 995.322 & 50,0 & 73,4 & 1.033 .831 & 52,0 & 76,5 & \begin{tabular}{|l|}
1.078 .016 \\
\end{tabular} & 54,2 & 80,0 \\
\hline Pastos & 604.575 & 30,8 & 44,3 & 566.530 & \begin{tabular}{|l|}
28,5 \\
\end{tabular} & 41,7 & 643.359 & 32,3 & 47,4 & 607.089 & 30,5 & 44,9 & 720.946 & 36,2 & 53,5 \\
\hline Malezas y rastrojos & 432.538 & 22,0 & 31,7 & 398.935 & \begin{tabular}{|l|}
20,1 \\
\end{tabular} & 29,4 & 351.963 & 17,7 & 26,0 & 426.742 & 21,5 & 31,6 & 357.069 & 18,0 & 26,5 \\
\hline 1.4 Bosques & 88.792 & 4,5 & 6,5 & 143.526 & 7,2 & 10,6 & 151.437 & 7,6 & 11,2 & 109.088 & 5,5 & 8,1 & 62.637 & 3,1 & 4,6 \\
\hline \begin{tabular}{|l|} 
Naturales \\
\end{tabular} & 87.904 & 4,5 & 6,4 & 141.493 & 7,1 & 10,4 & 149.643 & 7,5 & 11,0 & 107.953 & 5,4 & 8,0 & 60.094 & 3,0 & 4,5 \\
\hline Plantados & 888 & 0,0 & 0,1 & 2.033 & 0,1 & 0,1 & 1.794 & 0,1 & 0,1 & 1.135 & 0,1 & 0,1 & 2.543 & 0,1 & 0,2 \\
\hline 1.5 Otros usos & 37.151 & 1,9 & 2,7 & 57.853 & 2,9 & 4,3 & 54.321 & 2,7 & 4,0 & 37.693 & 1,9 & 2,8 & 26.083 & 1,3 & 1,9 \\
\hline 2. Sector no agropecuario & 602.163 & 30,6 & & 631.039 & \begin{tabular}{|l|}
31,7 \\
\end{tabular} & & 632.720 & 31,8 & & 636.974 & 32,0 & & 641.847 & 32,3 & \\
\hline
\end{tabular}

La información de la tabla 7.2.26 muestra un conflicto de uso racional del suelo rural, que se complementa con la estructura agraria propuesta por el Plan:

Muestra que el acceso a la tierra y los patrones de uso del suelo

406 Huila (2008). Diagnóstico Plan de Desarrollo Departamental., pág. 91.

407 Ibíd., pág. 104. 
están condicionados al antagonismo entre su vocación y uso, a la distribución de la tenencia y a la movilidad de la tierra como factor productivo. Por lo menos el $60 \%$ de la tierra con vocación agrícola es utilizada en ganadería extensiva, mientras una parte de la tierra destinada a cultivos está por fuera de su vocación agrícola 408 .

Se presentan conflictos de uso por aptitud, debido a la vocación del suelo, y de intensidad de uso, que conllevan una lenta degradación:

La eliminación de la vegetación natural, y la implantación de cultivos transitorios o semipermanentes, y la ganadería, a la par con otros procesos de degradación natural y antrópica, ha determinado un deterioro gradual y continuo de los suelos para cerca del $66 \%$ del total del área departamental $(1.249 .800 h a)^{409}$.

Desplazamiento y despojo de tierras en Huila. Se encuentran 4.472 personas con 4.702 predios abandonados y 47.081 ha en la misma condición, que son el $27.6 \%$ del departamento, representando 1.195 UAF.

\begin{tabular}{|c|c|c|c|c|c|c|c|c|c|c|}
\hline \multirow[t]{2}{*}{ Características } & \multicolumn{2}{|c|}{$\begin{array}{c}\text { Personas } \\
\text { relacionadas con } \\
\text { predios Abandonados }\end{array}$} & \multicolumn{2}{|c|}{$\begin{array}{c}\text { Predios } \\
\text { Abandonados }\end{array}$} & \multicolumn{2}{|c|}{$\begin{array}{c}\text { Área (ha) } \\
\text { Registrada como } \\
\text { Abandonada }\end{array}$} & \multirow{2}{*}{\begin{tabular}{|c|}
$\%$ \\
participación \\
según área \\
abandonada
\end{tabular}} & \multirow{2}{*}{$\begin{array}{c}\% \\
\text { participación } \\
\text { según predios } \\
\text { abandonados }\end{array}$} & \multicolumn{2}{|c|}{$\begin{array}{c}\text { No. UAF } \\
\text { abandonadas }\end{array}$} \\
\hline & Número & $\%$ & Número & $\%$ & Número & $\%$ & & & Número & $\%$ \\
\hline $\begin{array}{c}\text { Total } \\
\text { Departamento }\end{array}$ & 4.472 & 2,6 & 4.702 & 2,8 & 47.081 & 27,6 & 1.11 & 2.61 & 1.195 & 0,7 \\
\hline Total Colombia & 170.783 & 100 & 179.852 & 100 & 4.234 .364 & 100 & 100 & 100 & 96.597 & 100 \\
\hline
\end{tabular}

Las dinámicas de desplazamiento y abandono forzado de predios por municipios (tabla 7.2.28) muestran que la región subnorte es la más afectada por estos procesos:

Neiva se ubica en el segundo lugar de expulsión de personas 7.627 dentro del departamento del Huila ocupando el primer lugar el Municipio Algeciras, en tercer lugar se ubica el Municipio de

\footnotetext{
408 Ibíd. Pág 106

409 Ibíd., pág. 118.
} 
Colombia con 5.989, seguido de Pitalito en cuarto lugar con 4.466

y Garzón en el quinto con 3.590 ${ }^{410}$.

Los tres primeros municipios son reportados como graves por la Presidencia de la República hasta 2010; el cuarto y quinto municipio, reportados por el Plan Integral Único de Neiva, son por extensión, nivel de población y capacidad de producción los más importantes del departamento.

Los abandonos en Neiva, Pitalito y Garzón desarrollan dos caras: son centros expulsores y receptores de población desplazada, con la característica de que los tres reciben más población que la expulsada:

En recepción de Hogares y Personas a nivel Departamental Neiva se ubica en el primer lugar con 40.121 personas, en segundo lugar el Municipio de Pitalito con 13.428, en tercer lugar el Municipio de Garzón con 7.288, en cuarto lugar el Municipio de la Plata con 2.981 personas y en quinto lugar el Municipio de Campoalegre con 2.564 personas $^{411}$.

Esta información de la ciudad eje relaciona dinámicas regionales que indican cuáles territorios reciben población desplazada a lo largo del departamento.

\begin{tabular}{|c|c|c|c|c|c|c|}
\hline Subregión & $\begin{array}{c}\text { Municipio de } \\
\text { Ubicación del } \\
\text { predio }\end{array}$ & $\begin{array}{c}\text { Área del } \\
\text { Municipio }\end{array}$ & $\begin{array}{c}\text { Personas } \\
\text { relacionadas con } \\
\text { predios } \\
\text { abandonados }\end{array}$ & $\begin{array}{c}\text { Predios } \\
\text { Abandonados }\end{array}$ & \begin{tabular}{|c|} 
Área (ha) \\
registrada \\
como \\
abandonada
\end{tabular} & $\begin{array}{c}\text { \% Afectación } \\
\text { según área del } \\
\text { municipio }\end{array}$ \\
\hline \multirow{3}{*}{ Subnorte } & Algeciras & 67.200 & 487 & 513 & 4.574 & 6.81 \\
\hline & Colombia & 153.800 & 419 & 450 & 6.168 & 4.01 \\
\hline & Neiva & 146.800 & 418 & 438 & 4.861 & 3.31 \\
\hline \multicolumn{2}{|c|}{ Total } & 367.800 & 1.324 & 1.401 & 15.603 & \\
\hline
\end{tabular}

Concentración de la tierra 1996-2008. El diagnóstico del Plan de Desarrollo del Huila identificaba sobre la tenencia distribución de la tierra:

410 Alcaldía de Neiva (2011). Plan Integral Único de la Ciudad de Neiva, Secretaria de Gobierno y Convivencia Ciudadana Comité Territorial de Atención Integral a Población Desplazada., pág. 36. 411 Ibíd., pág. 37. 


\begin{tabular}{|c|c|c|}
\hline \multicolumn{3}{|c|}{$\begin{array}{l}\text { Tabla No.7.2.29 Departamento del Huila Tamaño de las Unidades Agrícolas familiares según región relativamente } \\
\text { homogénea y municipio }\end{array}$} \\
\hline $\begin{array}{l}\text { Regiones Relativamente } \\
\text { Homogéneas }\end{array}$ & Municipios & \begin{tabular}{|c|} 
Rangos de la Unidad \\
$\begin{array}{c}\text { Agricola Familiar UAF Por } \\
\text { la potencialidad de } \\
\text { explotación }\end{array}$ \\
\end{tabular} \\
\hline $\begin{array}{l}1 \text { Comprende los corregimientos e } \\
\text { inspecciones departamentales de }\end{array}$ & $\begin{array}{l}\text { Guadalupe: Resinas, Iquira: Rionegro, Isnos: Salto de Bordones y San } \\
\text { Vicente, La Argentina: todo el municipio, La Plata: Belén y Moscopán, } \\
\text { Oporapa: San Roque, Saladoblanco: Morelia, San Agustín: Alto Obispo, } \\
\text { Puerto Quinchana y Villa Fátima, Santa María: El Socorro y San Joaquin. }\end{array}$ & 18 a 30 hectáreas. \\
\hline $\begin{array}{l}2 \text { Comprende los corregimientos e } \\
\text { inspecciones departamentales de }\end{array}$ & \begin{tabular}{|c|} 
Neiva: Chapinero, El Colegio, Motilón, Órganos, Palacio, San Antonio, San \\
Bartolo, San Luis, Santa Helena, Vegalarga y Aipecito; Acevedo: San Adolfo \\
y San Marcos; Agrado ; A Aipe: Praga, Santa Rita y El Tesoro; Algeciras: El \\
Toro, La Arcadia y Paraíso; Altamira; Baraya: La Batalla, La Troja y Los \\
Laureles; Campoalegre: Otás y Piravante; Colombia: Las Lajas, Los Ríos, \\
Monguí, Potrero Grande, San Marcos, Santana, El Valll, Boquerón y San \\
Miguel; Elías: El Viso; Garzón: El Mesón, El Paráíso, El Recreo, Providencia, \\
San Antonio del Pescado y Zuluaga; Gigante: La Gran Via, Silvania y Vueltas \\
Arriba; Guadalupe: Miraflores; Iquira: Valencia de la Paz y San Luis; La \\
Plata: Gallego, San Andrés, San Vicente, Villa Losada, y Monserrate; \\
Nataga: todo el municipio; Oporapa: El Carmen; Paicol; Palermo: El \\
Caimán, Nilo, Ospina Pérez, Paraguay y San Juan; Palestina: todo el \\
municipio; Pital: Carmelo y El Socorro; Pitalito: Bruselas, Criollo, Chillurco, \\
Guacacallo y La Laguna; Saladoblanco: La Cabaña; San Agustín: El Palmar, \\
El Rosario, Los Chucos, Obando, y Praderas; Suaza: Gallardo y Guayabal; \\
Tarqui: El Vergel, La Esmeralda, Quituro y Ricabrisa; Tello: El Cedral, San \\
Andrés, Sierra de Gramal, Sierra de la Cañada y Anacleto García; Teruel: El \\
Almorzadero; Tesalia: Pacarní; Timaná, Cosanza, Naranjal y Santa Bárbara.
\end{tabular} & 30 a 50 hectáreas. \\
\hline $\begin{array}{c}3 \text { Comprende las inspecciones } \\
\text { departamentales y los } \\
\text { corregimientos de }\end{array}$ & \begin{tabular}{|} 
Altamira; Neiva: El Caguán, Fortalecillas, Guacirco, San Francisco y El \\
Triunfo; Aipé: La Ceja, El Patá y Potreritos; Baraya: Patía y Miramar; Elías: \\
Oritoguaz; Garzón: La Jagua; Gigante: Potrerillos y Rioloro; Hobo; \\
Palermo: Amborgo, Betania y El Juncal; Rivera: La Ulloa y Riverita; Tarqui: \\
Maito; Villavieja: Hato Nuevo, La Victoria, Potosí y San Alfonso; Yaguará.
\end{tabular} & 35 a 58 hectáreas. \\
\hline
\end{tabular}

\begin{tabular}{|c|c|c|c|c|c|}
\hline \multicolumn{6}{|c|}{ Tabla 7.2.30 Huila 2009 Características de la dinámica de las UAF } \\
\hline Características & Microfundio & $\begin{array}{l}\text { Pequeña } \\
\text { propiedad }\end{array}$ & $\begin{array}{c}\text { Mediana } \\
\text { propiedad }\end{array}$ & $\begin{array}{c}\text { Gran } \\
\text { propiedad }\end{array}$ & $\begin{array}{c}\text { Promedio } \\
\text { departamento }\end{array}$ \\
\hline Distribución Porcentual & 1.8 & 5.6 & 1.6 & 91 & 100 \\
\hline Colombia & 12.4 & 18.3 & 25.2 & 44.1 & 100 \\
\hline $\begin{array}{c}\text { Tamaño Promedio de predios(ha.) } \\
\text { escala de tenencia }\end{array}$ & 20 & 90 & 296 & 91.181 & 626 \\
\hline Promedio Colombia & 3 & 35 & 92 & 1474 & 25 \\
\hline $\begin{array}{l}\text { Avalúos por hectáreas (\$ } \\
\text { corrientes). }\end{array}$ & 74.079 & 46.445 & 39.983 & 23.492 & 25.963 \\
\hline Promedio Colombia & 2.423 .517 & 975.162 & 1.028 .447 & 338.649 & 804.335 \\
\hline \multicolumn{6}{|c|}{$\begin{array}{l}\text { Fuente: Presidencia de la República de Colombia y Acción Social (2010): Unidades Agrícolas Familiares, } \\
\text { tenencia y abandono forzado de tierras en Colombia. Proyecto Protección de Tierras y Patrimonio de la } \\
\text { Ppoblación Desplazada, Bogotá, págs. } 44 \text { yss. }\end{array}$} \\
\hline
\end{tabular}

\begin{tabular}{|c|c|c|c|c|c|c|c|c|c|c|c|c|c|}
\hline \multirow{3}{*}{ Tamaño (PSM) } & \multirow{2}{*}{\multicolumn{2}{|c|}{ P S M }} & \multicolumn{11}{|c|}{ U S O S (hectáreas) } \\
\hline & & & \multicolumn{2}{|c|}{ T otal } & \multicolumn{3}{|c|}{ Uso agrícola } & \multicolumn{3}{|c|}{ Pastos y malezas } & \multicolumn{3}{|c|}{ Bosques y otros usos } \\
\hline & Cantidad & $\%$ & Área & $\%$ & Área & * & ** & Área & * & ** & Área & * & ** \\
\hline \multicolumn{14}{|c|}{ Año 2004} \\
\hline TOTAL & 84.386 & 100 & \begin{tabular}{|l|}
1.352 .026 \\
\end{tabular} & 100 & 171.414 & 12,68 & 100,00 & \begin{tabular}{|l|}
1.033 .831 \\
\end{tabular} & 76,47 & 100,00 & 146.781 & 10,856 & 100,00 \\
\hline 0 a menos de 10 & 58.576 & 69 & 191.533 & 14,10 & 80.838 & $42,21$. & 47,10 & 92.915 & 48,51 & 8,80 & 17.778 & 9,282 & 12,00 \\
\hline 10 a menos de 50 & 20.258 & 24 & 428.402 & 31,60 & 65.881 & 15,38 & 38,30 & 307.713 & 71,83 & \begin{tabular}{|l|}
29,70 \\
\end{tabular} & 54.809 & 12,794 & 37,30 \\
\hline 50 a menos de 100 & 2.709 & 3,2 & 190.480 & \begin{tabular}{|l|}
14,00 \\
\end{tabular} & 17.141 & 9,00 & 10,00 & 157.283 & 82,57 & 15,20 & 16.056 & 8,429 & 10,90 \\
\hline 100 a menos de 500 & 2.842 & 3,3 & 541.611 & 40,00 & 7.554 & 1,39 & 4,40 & 475.920 & 87,87 & 46,00 & 58.137 & 10,734 & 39,60 \\
\hline \multicolumn{14}{|c|}{ Año 1996} \\
\hline Total & 149.568 & & \begin{tabular}{|l|}
2.046 .399 \\
\end{tabular} & & 361.707 & \begin{tabular}{|l|}
17,68 \\
\end{tabular} & & \begin{tabular}{|l|}
1.497 .648 \\
\end{tabular} & 73,18 & & 125.936 & 6,154 & \\
\hline 0 a menos de 10 & 47.416 & 61 & 177.041 & \begin{tabular}{|l|}
12,80 \\
\end{tabular} & 74.880 & 42,30 & 37,20 & 87.053 & 49,17 & 8,20 & 15.102 & 8,530 & 11,99 \\
\hline 10 a menos de 50 & 24.227 & 31 & 505.953 & \begin{tabular}{|l|l|}
37,00 \\
\end{tabular} & 86.481 & \begin{tabular}{|l|l|}
17,09 \\
\end{tabular} & 43,10 & 373.488 & 73,82 & 35,90 & 45.980 & 9,088 & 36,51 \\
\hline 50 a menos de 100 & 3.650 & 4,60 & 252.660 & \begin{tabular}{|l|}
18,50 \\
\end{tabular} & 22.133 & 8,76 & 11,00 & 202.931 & 80,32 & 19,50 & 27.594 & 10,921 & 21,91 \\
\hline 100 a menos de 500 & 2.632 & 3 & 427.751 & \begin{tabular}{|l|}
31,30 \\
\end{tabular} & 16.852 & 3,94 & 8,30 & 373.635 & 87,35 & 35,90 & 37.260 & 8,711 & 29,59 \\
\hline uente : ENA, DANE- Proyecto & AC y Ministe & terio de $t$ & Agricultura y $\mathrm{D}$ & sarroll & Rural. Cál & $\operatorname{del} \mathrm{Au}$ & & *Porcente & aje Horizor & & *Porc & entaje Ver & rtical \\
\hline
\end{tabular}


El número total de predios rurales registrados es de 85.809, con 1.680.096 hectáreas y 106.191 propietarios. De tales predios el $55.7 \%$ son mayores de 50 hectáreas, con el 57.3\% del área y el 9.9\% de los propietarios, y el $20.2 \%$ son menores de 10 hectáreas, con el $12.1 \%$ del área y el $26.1 \%$ de los propietarios $^{412}$.

Para analizar el proceso de concentración de la tierra en el Huila se tiene en cuenta la regionalización del Incora de las UAF, según regiones relativamente homogéneas, que son tres (tabla 7.2.29), así como desde las características dinámicas de las UAF (tabla 7.2.30). Así, se identifica la categoría de microfundio, tamaño promedio de 20 ha, pero la UAF más pequeña para producción agropecuaria debe tener de 18 a 30 ha en la subregión uno. En la dos, de 30 a 50 ha y en la tres, de 35 a 58 ha, hay una exigencia normativa mayor para cada UAF, sobre lo que sucede en la realidad. No alcanza al promedio de la pequeña propiedad 90 ha, lo cual muestra que por una parte va la reglamentación y el diseño de política y por otra la realidad agrícola del Huila.

La tabla 7.2.29 refleja la tendencia a la concentración de la propiedad: la gran propiedad, con el 91\% en UAF; seguida de la pequeña, con el 5.6\%; el microfundio, con el 1,8\%, y la mediana, con el 1,6\%. Hay una situación extrema de concentración de la primera. El microfundio en lo único que supera a las demás UAF es en los avalúos. El Plan Departamental considera: "Una gran proporción de los predios rurales son pequeños y, por lo general, inviables económicamente para el agronegocio de forma individual" ${ }^{413}$. Este es el departamento con más concentración de la propiedad rural.

La tabla 7.2.31 (usos del suelo según tamaño, años 1996 y 2004) caracteriza la concentración de los predios de 0 a menos de 10 ha, que pasan de 177.041 ha, con el $12,8 \%$, a 191.533 ha, con el $14.1 \%$. Los predios de 10 a menos de 50 y de 50 a 100 disminuyen sus ha: pasan de 505.953 y 37,0\% en 1996 a 428.402 y 31.6\% en el 2004. Los predios más dinámicos son los mayores de 100 y menos de 500, que pasan de 427.751 ha, con el 31,3\% a 541.611 ha, con el 40,0\%, en un claro proceso concentrador.

Disponibilidad y política SAN en Huila. Las acciones e intervención para la disponibilidad de agroalimentos parten del Plan Departamental, que considera objetivo

412 Huila (2008): Diagnóstico Plan... Op. cit., pág. 104.

413 Ibíd., pág. 106. 
estratégico elevar la productividad y competitividad del sector agropecuario, integrando actores, esfuerzos, recursos y confianza, en articulación con la agenda interna de productividad y competitividad con productores de materias primas básicas para aceites industriales o biocombustibles.

Por otro lado, este plan busca construir y fortalecer los encadenamientos productivos agroalimentarios, desde dos programas. Uno vincula la productividad y la competitividad: "Bien por el campo", estrategia que genera activos productivos con la economía campesina, en función de fortalecer los encadenamientos agroalimentarios con asociatividad y el desarrollo empresarial, así como calificar recursos humanos; consolidar la infraestructura física de café, secaderos y beneficiaderos ecológicos, frutales, cacao y tabaco; estimular estrategias en comercialización agropecuaria; ye implementar políticas de desarrollo rural integrado para la economía campesina, con los Centros Provinciales de Gestión Agroindustrial. El otro programa, "Agua para que la tierra produzca", provee infraestructura física para irrigar nuevas áreas factor de productividad y competitividad, así como adecuar suelos, modernizar la labranza y la reforma agraria ${ }^{414}$.

En algunos municipios del Huila se incentiva la disponibilidad de agroalimentos desde la escuela y la familia, como política de la entidad territorial, para "producir alimentos orgánicos a través de la huerta escolar o de café limpio y hortalizas en la huerta casera" ${ }^{415}$. Este programa significa una estrategia alimentaria para la población de la zona urbana y rural del municipio, que busca "autosuficiencia y autosostenibilidad a través de la huerta casera" ${ }^{416}$. Además, este propósito busca materializarse a través de la presentación de proyectos productivos promovidos directamente por los municipios: "Acá hay cinco grupos con treinta familias cada uno donde la administración municipal aporta $\$ 600.000$ pesos a cada grupo impulsando producción de alimentos con agricultura orgánica ${ }^{417}$.

414 Gobernación del Huila (2008): “Ordenanza n. ${ }^{\circ} 015$ de 2008, "por la cual se adopta el Plan de Desarrollo Departamental 2008-2011: Huila, Naturaleza Productiva. Págs. 175 y ss.

415 BONILLA, Virginia (2008). Entrevista. Directora de la UMATA, municipio de Algeciras, departamento del Huila, 5 de noviembre.

416 CORTES, Armando y CORTÉS, Yeris (2008): Entrevista. Director y técnico de la UMATA, municipio de Campoalegre, departamento del Huila, 6 de noviembre.

417 BONILLA, Virginia (2008): Entrevista. Directora de la UMATA, municipio de Algeciras, departamento del Huila, 5 de noviembre. . 
De acuerdo con las condiciones del territorio en el departamento, se promueven y se apoyan técnica, financiera y educativamente múltiples cadenas:

Cadenas de piscicultura (pescadores artesanales y piscícolas con estanques trucha, mojarra y cachama), producción de arroz, café especial, mantenimiento y establecimiento del cultivo de cacao, frutales y granja experimental con ganadería extensiva, además de una capacitación realizada en proyectos productivos y buenas prácticas agrícolas ${ }^{418}$.

Lo anterioro beneficia a la región inmediata, y a la ciudad eje Neiva, que también tiene dificultades para las economías campesinas, como las siguientes:

\begin{abstract}
Alza y altos costos en los insumos, y la sustitución de producción por los intereses de las pirámides para vivir, las condiciones nuevas del clima por sus variaciones, las dificultades de acceso al crédito para los campesinos y la falta de organización campesina ${ }^{419}$.
\end{abstract}

Disponibilidad de agroalimentos en Huila, 1987-2009. En el anexo C, las tablas 9 y 10 (cultivos transitorios y permanentes, periodo 1987-2009) muestran los agroalimentos en cuanto a la oferta disponible inmediata de la ciudad eje Neiva. Allí se relacionan superficie, producción y rendimiento.

Los cultivos transitorios crecen en ha y producción: pasan de 78.125 ha en 1987 a 90.973 en el 2009. Los tres agroalimentos básicos de dieta del eje (fríjol, maíz, y arroz) crecen en el periodo. Entre 1987 y 2009, el fríjol aumentó en 29\% su área cosechada, pero en 1990 cae en superficie: pasa de 21.282 ha en 1990 a 16.644 en el 2002, y desde este año se recupera y logra un crecimiento positivo de 5.083 ha en el periodo.

El comportamiento del maíz difiere entre tecnificado y tradicional: aunque ambos crecen, el primero pasa de 800 ha en 1987 a 14.860 en 2009, y un crecimiento de $1.758 \%$; el tradicional pasa de 5.900 a 16.452 ha (crece el 179\%); los rendimientos difieren y son

418 CORTES, Armando y CORTES, Yeris (2008). Entrevista... Op. cit.

419 BONILLA, Virginia, CORTÉS, Armando y CORTES, Yeris (2008): Entrevista... Op. cit. 
menores en el tecnificado que en el tradicional. Por su parte, el arroz de riego crece en superficie: pasa de 30.700 ha en 1987 a 34.046 en 2009, en tanto la producción pasa de $175.000 t$ a $255.291 t$. Los rendimientos también crecen en el periodo.

Entre 1987 y 2009, los cultivos permanentes son caracterizados porque la superficie cae en la arracacha, que pasa de 600 ha a 470 ha, y la caña panelera, que pasa de 10.500 a 5.233 ha y en la producción pasa de 48.700 a 42.308 t. Esto implica que los rendimientos crecieron. Por su parte, el plátano pasa de 13.200 ha a 25.581 ha (crece el 94\%) y cae en

\begin{tabular}{|c|c|c|c|c|}
\hline \multicolumn{5}{|c|}{$\begin{array}{l}\text { Cuadro 7.2.32 Comparativo de disponibilidad de la región inmediata por } \\
\text { grupos de agroalimentos y la demanda ideal del e je Neiva }\end{array}$} \\
\hline Grupos de alimentos & Productos & $\begin{array}{l}\text { Demanda } \\
\text { ideal (ton) }\end{array}$ & $\begin{array}{c}\text { Producción } \\
2006 \\
\end{array}$ & $\begin{array}{c}\text { Déficit o } \\
\text { superávit }\end{array}$ \\
\hline \multirow{4}{*}{ 1. CEREALES } & Arroz & 6.864 & 214.038 & 207.174 \\
\hline & Avena & 2.436 & . & $\underline{2.436}$ \\
\hline & Maíz & 1.844 & 73.300 & 71.456 \\
\hline & Trigo & 0 & . & - \\
\hline \multirow{6}{*}{$\begin{array}{l}\text { 2. RAÍCES, } \\
\text { TUBÉRCULOS Y } \\
\text { PLÁTANOS }\end{array}$} & Name & 0 & . & - \\
\hline & Papa & 8.892 & 702 & 8.190 \\
\hline & Papa criolla & & 4.776 & 4.776 \\
\hline & Plátano & 2.232 & . & 2.232 \\
\hline & Yuca & 4.880 & 116.586 & 111.706 \\
\hline & Arveja & 4.254 & 32.195 & 27.941 \\
\hline \multirow{7}{*}{$\begin{array}{l}\text { 3. HORTALIZAS, } \\
\text { VERDURAS Y } \\
\text { LEGUMINOS AS } \\
\text { VERDES }\end{array}$} & Auyama & 1.493 & 947 & 546 \\
\hline & Cebolla Cabezona & 2.670 & 678 & 1.992 \\
\hline & Cebolla común & 681 & 810 & 129 \\
\hline & Habichuela & 424 & 81 & 343 \\
\hline & Tomate & 1.741 & 6.500 & 4.759 \\
\hline & Zanahoria & 2.704 & 4.449 & 1.745 \\
\hline & Banano & 4.593 & . & $\underline{4.593}$ \\
\hline \multirow{8}{*}{ 4. FRUTAS } & Guayaba & 3.063 & 14.200 & 11.137 \\
\hline & Limón & 7.082 & 700 & 6.382 \\
\hline & Mandarina & 5.070 & 3801 & 1.269 \\
\hline & Mango & 6.692 & 1.200 & 5.492 \\
\hline & Mora & 4.401 & 3.169 & 1.232 \\
\hline & Naranja & 11.087 & 126 & 10.961 \\
\hline & Tomate de árbol & 7.258 & 920 & 6.338 \\
\hline & Carne de res & 4.253 & 207 & 4.046 \\
\hline \multirow{5}{*}{ 5. CARNES Y HUEVOS } & Carne de cerdo & 1.358 & 22.061 & 20.703 \\
\hline & Huevo de gallina & 1.099 & 17.981 & 16.882 \\
\hline & Pescado & 2.437 & 17.727 & 15.290 \\
\hline & Pollo & 2.004 & 15.385 & 13.381 \\
\hline & Fríjol & 1.286 & 4.077 & 2.791 \\
\hline \multirow{3}{*}{$\begin{array}{l}\text { 6. LEGUMINOS AS } \\
\text { SECAS Y MEZCLAS } \\
\text { VEGETALES }\end{array}$} & Garbanzo & 812 & 23.681 & 22.869 \\
\hline & Lenteja & 718 & & 718 \\
\hline & Leche líquida & 772 & & 772 \\
\hline 7. LÁCTEOS & Leche liquida & 20.940 & 549.419 & 528.479 \\
\hline \multirow{2}{*}{ 8. GRASAS } & Aceite animal & 0 & & - \\
\hline & Aceite Vegetal & 1.884 & & 1.884 \\
\hline \multirow{2}{*}{ 9. AZÚCARES } & Café & 0 & & - \\
\hline & Caña Panelera & 0 & 59.092 & 59.092 \\
\hline
\end{tabular}


producción y rendimientos. La yuca pasa de 3.700 a 3.721 ha, se mantiene durante el periodo y aumenta rendimientos y producción. Estos agroalimentos son de producción campesina y forman parte de la dieta regional.

\section{Comparación entre disponibilidad de agroalimentos en Huila y las demandas}

de agroalimentos del eje Neiva. Para realizar la comparación, se calcularon las necesidades de alimentos y nutrición de la población de Neiva en términos de productos consumidos en la ciudad. Así se deduce la disponibilidad que se requiere en el eje (estos cálculos son explicados en el capítulo I, ítem de metodología). Los productos resultan en demandas ideales de acuerdo con las necesidades nutricionales de la población de Neiva. Lo que se hace en este punto es comparar esas demandas para la ciudad eje con la disponibilidad de agroalimentos en el entorno regional inmediato: el departamento de Huila.

Este comparativo no considera autoconsumos realizados en las zonas productoras de agroalimentos ni pérdidas por manejo, empaque y transporte de cada producto. Supone que la disponibilidad se dirige al mercado mayor de la región: Neiva. Los resultados de esta comparación permiten concluir que hay productos que son autosuficientes y se cultivan en el departamento, en tanto hay otros deficitarios que deben ser importados de otras zonas del país o del exterior.

Los productos autosuficientes, de acuerdo con las demandas ideales de la ciudad eje Neiva, forman parte de la dieta básica.Así, se dividen por grupo de alimentos: el primero es el de los cereales: el arroz y el maíz; el segundo lo componen las raíces, los tubérculos

\begin{tabular}{|c|c|c|c|c|c|c|c|c|c|c|c|c|c|c|c|}
\hline \multirow{3}{*}{ SUPERFICIES } & \multicolumn{3}{|c|}{1996} & \multicolumn{3}{|c|}{2000} & \multicolumn{3}{|c|}{2002} & \multicolumn{3}{|c|}{2004} & \multicolumn{3}{|c|}{2008} \\
\hline & \multirow{2}{*}{$\begin{array}{c}\text { Total } \\
\text { hectáreas }\end{array}$} & \multicolumn{2}{|c|}{$\%$} & \multirow{2}{*}{$\begin{array}{c}\text { Total } \\
\text { hectáreas }\end{array}$} & \multicolumn{2}{|c|}{$\%$} & \multirow{2}{*}{$\begin{array}{c}\text { Total } \\
\text { hectáreas }\end{array}$} & \multicolumn{2}{|c|}{$\%$} & \multirow{2}{*}{$\begin{array}{c}\text { Total } \\
\text { hectáreas }\end{array}$} & \multicolumn{2}{|c|}{$\%$} & \multirow{2}{*}{\begin{tabular}{|c|} 
Total \\
hectáreas
\end{tabular}} & \multicolumn{2}{|c|}{$\%$} \\
\hline & & 1 & 2 & & 1 & 2 & & 1 & 2 & & 1 & 2 & & 1 & 2 \\
\hline $\begin{array}{l}\text { SUPERFICIE PLANIMETRADA } \\
\text { DEL MARCO** }\end{array}$ & 2.230 .955 & 100,0 & & 2.165 .800 & 100,0 & & 2.165 .800 & 100,0 & & 2.165 .800 & 100,0 & & 2.165 .800 & 100,0 & \\
\hline $\begin{array}{l}\text { 1. Sector Agropecuario } \\
\text { planimetrado, incluida en el } \\
\text { universo de estudio }\end{array}$ & 1.279 .045 & 57,3 & 100 & 1.277 .189 & 59,0 & 100 & 1.277 .807 & 59,0 & 100 & 1.321 .574 & 61,0 & 100 & 1.319 .285 & 60,9 & 100 \\
\hline 1.2 Agrícola & 131.679 & 5,9 & 10,3 & 116.899 & 5,4 & 9,2 & 123.825 & 5,7 & 9,7 & 167.213 & 7,7 & 12,7 & 128.210 & 5,9 & 9,7 \\
\hline $\begin{array}{l}\text { Cultivos transitorios y } \\
\text { barbecho }\end{array}$ & 58.933 & 2,6 & 4,6 & 51.227 & 2,4 & 4,0 & 47.959 & 2,2 & 3,8 & 55.652 & 2,6 & 4,2 & 38.118 & 1,8 & 2,9 \\
\hline Cultivos permanentes & 72.745 & 3,3 & 5,7 & 65.673 & 3,0 & 5,1 & 69.230 & 3,2 & 5,4 & 107.347 & 5,0 & 8,1 & 88.099 & 4,1 & 6,7 \\
\hline Descanso & & & 0,0 & & & 0,0 & 6.637 & 0,3 & 0,5 & 4.214 & 0,2 & 0,3 & 1.993 & 0,1 & 0,2 \\
\hline 1.3 Pecuaria & 843.501 & 37,8 & 65,9 & 937.422 & 43,3 & 73,4 & 977.293 & 45,1 & 76,5 & 964.355 & 44,5 & 73,0 & 928.824 & \begin{tabular}{|l|}
42,9 \\
\end{tabular} & 70,4 \\
\hline Pastos & 444.390 & 19,9 & 34,7 & 507.261 & 23,4 & 39,7 & 447.242 & 20,7 & 35,0 & 466.833 & 21,6 & 35,3 & 448.925 & 20,7 & 34,0 \\
\hline Malezas y rastrojos & 399.110 & 17,9 & 31,2 & 430.162 & 19,9 & 33,7 & 530.049 & 24,5 & 41,5 & 497.522 & 23,0 & 37,6 & 479.899 & 22,2 & 36,4 \\
\hline 1.4 Bosques & 280.345 & 12,6 & 21,9 & 200.403 & 9,3 & 15,7 & 159.875 & 7,4 & 12,5 & 167.900 & 7,8 & 12,7 & 212.258 & 9,8 & 16,1 \\
\hline Naturales & 276.277 & 12,4 & 21,6 & 199.798 & 9,2 & 15,6 & 158.186 & 7,3 & 12,4 & 167.196 & 7,7 & 12,7 & 266.516 & 12,3 & 20,2 \\
\hline Plantados & & & & 606 & 0,0 & 0,0 & 1.689 & 0,1 & 0,1 & 704 & 0,0 & 0,1 & 5.743 & 0,3 & 0,4 \\
\hline 1.5 Otros usos & & & & 22.465 & 1,0 & 1,8 & 16.812 & 0,8 & 1,3 & 22.106 & 1,0 & 1,7 & 49.993 & 2,3 & 3,8 \\
\hline 2. Sector no agropecuario & 951.910 & 42,7 & & 888.611 & 41,0 & & 887.993 & 41,0 & & 844.226 & 39,0 & & 846.515 & 39,1 & \\
\hline
\end{tabular}


y los plátanos (arracacha, plátano y yuca); el tercer grupo es de las hortalizas, las verduras y las leguminosas verdes (tomate); en el cuarto se encuentran las leguminosas secas (el fríjol); en el quinto están los lácteos, del que hay gran oferta, conjuntamente con el sexto, que es la producción de carnes; y por último, el séptimo, está conformado por los azúcares (la caña panelera).

En los productos deficitarios se tiene un orden similar por grupos: en el primer grupo están la avena y el trigo, ambos de producción nula en el departamento, aunque formen parte de la dieta; la papa y las papa criolla se ubican en el segundo; en el tercero, cuarto y quinto están todos los alimentos; y el sexto es el que tiene más déficit: son los productos de consumo general, como la lenteja y el garbanzo. La conclusión central de este eje es que la producción no es autosuficiente en el departamento. En términos disponibilidad, entre 38 agroalimentos dispone tan solo de 17, que son de alguna manera sustanciales para el cumplimiento de la dieta básica de la población.

\subsection{Disponibilidad eje de Cúcuta}

Uso de la tierra en Norte de Santander. Este aspecto se muestra en la tabla 7.2.33 (aprovechamiento de tierra en el departamento, periodo 1996 a 2008). El sector no agropecuario pasa del 42,7\% al 39.1\%, de 951.910 ha a 846.515 ha. La tierra del sector agropecuario crece de $57,3 \%$ al $60.9 \%$, y en superficie, del 1.279.045 a 1.319.285 ha.

Al desagregar las cifras de agricultura y ganadería (columna 2 de la tabla 7.2.33), se ve que la tierra dedicada a la primera tiene varios cambios: uno, disminuye en los doce años, pues pasa del 10,3\% en 1986, con 131.679 ha, al 9,7\%, con 128.210 ha en el 2008 . También disminuyen los cultivos de economía campesina, transitorios y barbecho, que pasan del 4,6\% en 1986, con 72.745 ha, al 2.9\%, con 38.118 ha en el 2008; en el tercero, los cultivos permanentes aumentan: pasan del $5,7 \%$ en 1.986 , con 72.745 ha, al $6,7 \%$, con 88.099 ha en el 2008.

Otro cambio es el aumento de las tierras dedicadas al sector pecuario, que pasan del $66,0 \%$ en 1986, con 843.501 ha al 70,4\%, con 928.824 ha en el 2008. Por último, el área de bosques, con 21,6\% en 1996 y 280.345 ha, pasan en 2008 al 16,1\% y 212.258 ha. Esta disminución se debe a procesos acelerados de deforestación, para usos dirigidos hacia la actividad pecuaria y los cultivos permanentes. Estos diferentes cambios del uso del suelo de las tierras en el departamento, cambian las relaciones y las estructuras de propiedad de la tierra. 
Desplazamiento y despojo de tierras en Norte de Santander. Se maneja una cifra de 4.521 personas (4.806 predios, 118.989 ha). Estos abandonos representan 5.021 UAF (tabla 7.2.34).

\begin{tabular}{|c|c|c|c|c|c|c|c|c|}
\hline \multicolumn{2}{|c|}{ Tabla 7.2.34 Norte de Santander, 2004-2009, predios y áreas abandonadas (ordenados según \% de } \\
predios)
\end{tabular}

En la anterior dirección, el Plan de Desarrollo Departamental consideraba:

[En] diciembre de 2007 el total de personas desplazadas fue de 73.445 representados en 9.933 hogares. El departamento tiene el $4.04 \%$ de la Población Desplazada, con respecto a esta los 100 municipios más afectados en el país, por la doble condición de expulsor y receptor en el departamento hay dos. En la subregión Norte (Tibú, Sardinata, El Tarra) suman 23.881, ocupando el 47\% del total de las personas expulsadas, Cúcuta es el tercer municipio expulsor con 3.956 personas. Los municipios receptores, Cúcuta recibe el 69 \% y 36.612 personas de un total de 53.329; Ocaña ocupa el segundo lugar con el $8 \%$ y 4.160 personas $^{420}$.

\begin{tabular}{|c|c|c|c|c|c|c|}
\hline \multicolumn{7}{|c|}{$\begin{array}{c}\text { Tabla 7.2.35 Norte de Santander Municipios con mayor afectación por abandono forzado de } \\
\text { predios hasta } 2010\end{array}$} \\
\hline Subregión & $\begin{array}{l}\text { Municipio de } \\
\text { Ubicación del } \\
\text { predio }\end{array}$ & $\begin{array}{l}\text { Área del } \\
\text { Municipio }\end{array}$ & $\begin{array}{l}\text { Personas } \\
\text { relacionadas } \\
\text { con predios } \\
\text { abandonados }\end{array}$ & $\begin{array}{c}\text { Predios } \\
\text { Abandonado } \\
\mathrm{s}\end{array}$ & $\begin{array}{c}\text { Área (ha) } \\
\text { registrada } \\
\text { como } \\
\text { abandonada }\end{array}$ & $\begin{array}{l}\text { \% Afectación } \\
\text { según área } \\
\text { del municipio }\end{array}$ \\
\hline \multirow{2}{*}{ Norte } & Tibú & 237.700 & 1.819 & 1924 & 53.259 & 19.46 \\
\hline & El Tarra & 68.700 & 369 & 379 & 8.548 & 12.44 \\
\hline \multirow{2}{*}{ Occidental } & Convención & 90.700 & 327 & 343 & 6.465 & 7.13 \\
\hline & San Calixto & 38.700 & 283 & 326 & 3.725 & 9.62 \\
\hline \multicolumn{2}{|c|}{ Total } & 435.800 & 2.798 & 2.972 & 71.997 & \\
\hline \multicolumn{7}{|c|}{$\begin{array}{l}\text { Fuente: Presidencia de la República de Colombia y Acción Social (2010): Unidades Agrícolas Familiares, tenencia y } \\
\text { abandono forzado de tierras en Colombia. Proyecto Protección de Tierras y Patrimonio de la Población Desplazada, } \\
\text { Bogotá, págs. } 149 \text { y ss.9 yss. }\end{array}$} \\
\hline
\end{tabular}

La ciudad eje de Cúcuta tiene la connotación de ser receptora y expulsora de población desplazada por la violencia.

420 DNP (2008): Un Norte para Todos, Plan de Desarrollo para Norte de Santander 20082011. Cúcuta, pág. 7. 


\begin{tabular}{|c|c|c|}
\hline \multicolumn{3}{|c|}{$\begin{array}{c}\text { Cuadro No. 7.2.36 Departamento de Norte de Santander Tamaño de las Unidades Agrícolas Familiares según región relativamente homogénea y } \\
\text { municipio }\end{array}$} \\
\hline Regiones Relativamente Homogéneas & Municipios & $\begin{array}{c}\text { Rangos de la Unidad Agricola } \\
\text { Familiar UAF Por la } \\
\text { potencialidad de explotación }\end{array}$ \\
\hline $\begin{array}{c}1 \text { PROVINCIA SEMIARIDA Y } \\
\text { SUBHÚMEDA-CLIMA CALIDO, } \\
\text { corregimientos y veredas de: }\end{array}$ & 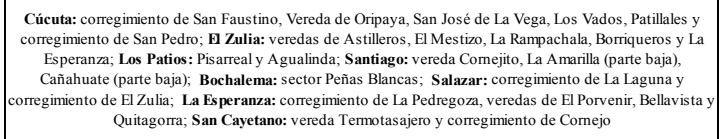 & 37 a 50 hectáreas \\
\hline $\begin{array}{c}2 \text { PROVINCIA HÚMEDA Y } \\
\text { PERHÚMEDA CLIMA CALIDO }\end{array}$ & 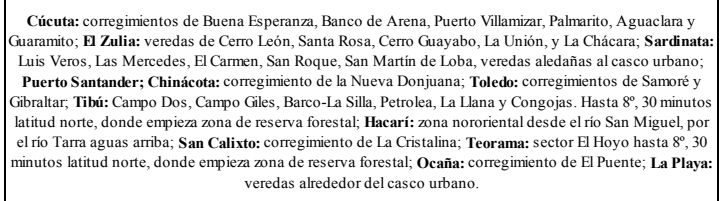 & $\begin{array}{l}\text { de } 6 \text { a } 10 \text { hectáreas. Mixta o } \\
\text { ganadera: de } 26 \text { a } 36 \text { ha }\end{array}$ \\
\hline $\begin{array}{l}\text { 3 PROVINCIA SUBHÚMEDA CLIMA } \\
\text { MEDIO }\end{array}$ & Ábrego: distrito de riego y área de influencia; corregimientos de Soltadero, El Chorro y El Tabaco; El Tarra. & \\
\hline $\begin{array}{l}\text { 4 PROVINCIA HÚMEDA Y } \\
\text { PERHÚMEDA CLIMA MEDIO } \\
\text { corregimientos y veredas de: }\end{array}$ & 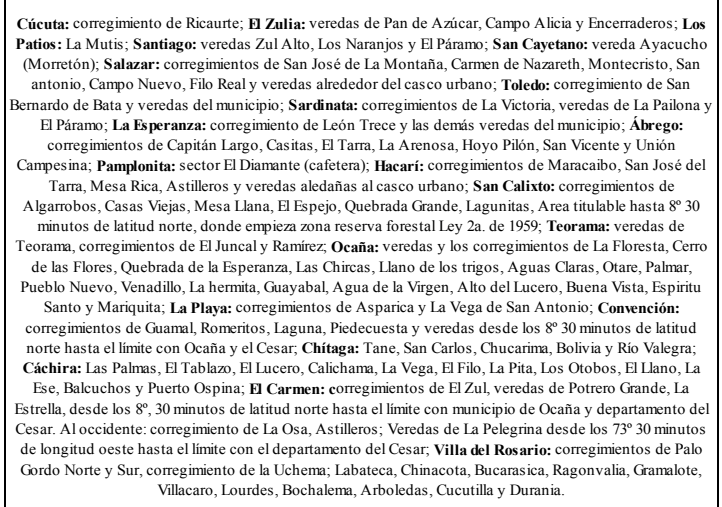 & 14 a 19 hectáreas \\
\hline $\begin{array}{l}\text { 5 PROVINCIA SUBHÚMEDA CLIMA } \\
\text { FRÍO }\end{array}$ & Chinácota: veredas de Iscalá, sur, centro y norte; Herrán, Pamplona y Pamplonita & $17 \mathrm{a} 23$ hectáreas. \\
\hline $\begin{array}{c}6 \text { PROVINCIA HÚMEDA Y } \\
\text { PERHÚMEDA CLIMA FRIOO }\end{array}$ & \begin{tabular}{|} 
Cáchira: las quebradas Las Piñas, Veguitas, Ahumada, Explayadas, La Caramba, Rausa, Galvanes, Siete, \\
Lagunas, El Fique, Ramirez, Guamito; Ábrego: veredas Paramito, Alto de Las Cruces en el corregimiento de \\
Casitas y Tres Morros; E Zulia: Campo Alicia y El Espartillo; Sardinata: cerro El Espartillo y Espardillo; \\
Salazar: Sabanitas o Sabanillas; Bochalema: veredas de Nebraska y Espejuelo; Mutiscua; Silos; Chitagá: El \\
Alizal, El Hatico, Aguasucia, Burgúa, El Cacao, Samaria y Casa Vieja.
\end{tabular} & 10 a 13 hectáreas. \\
\hline
\end{tabular}

Concentración de la tierra 1996-2008. La concentración de la tierra requiere identificar la regionalización del Incora en UAF, según las regiones relativamente homogéneas, que son seis (tabla 7.2.36). En la concentración de la propiedad, el DANE y el IGAC identifican esta situación:

Existen 92.384 propietarios rurales de los cuales 5.310 poseen propiedades mayores de 100 hectáreas; un área de 1.191.574 hectáreas, es decir el $43 \%$ de la superficie del departamento está en poder del $5.7 \%$ de los propietarios. Los dueños minifundistas son 
24.861, ocupando un área total de 20.488 hectáreas, para un total de 19.145 predios menores de 3 hectáreas ${ }^{421}$.

Esto significa que no alcanza la tierra de cada predio de pequeños propietarios para constituir una UAF ni un microfundio (tabla 7.2.37).

Las tablas 7.2.36 y 7.2.37 (características de las dinámicas de las UAF) muestra que en la categoría de microfundio, su tamaño promedio es de cuatro hectáreas, pero la UAF más pequeña para producción agropecuaria debe tener entre 6 y 10 ha. En la provincia 2 y 3 , esta reglamentación, en unos casos, alcanza para la pequeña propiedad (21 ha), especialmente para la provincia 5, en tanto para la 6 estaría por encima. Para las provincias 1,2 y 3 , en explotación mixta y ganadera, está por debajo de la UAF.

En términos de concentración de la propiedad y la dinámica de las UAF, la mediana y gran propiedad suman el $77,9 \%$, en tanto la pequeña y el microfundio suman el $22,1 \%$. Aquí los avalúos por hectárea son las cifras altas en el microfundio, y les siguen la pequeña propiedad, la mediana y la grande.

\section{Tabla 7.2.37 Norte de Santander 2009 Características de la dinámica de las UAF}

\begin{tabular}{|c|c|c|c|c|c|}
\hline Características & Microfundio & $\begin{array}{l}\text { Pequeña } \\
\text { propiedad }\end{array}$ & $\begin{array}{c}\text { Mediana } \\
\text { propiedad }\end{array}$ & $\begin{array}{c}\text { Gran } \\
\text { propiedad }\end{array}$ & $\begin{array}{c}\text { Promedio } \\
\text { departamento }\end{array}$ \\
\hline Distribución Porcentual & 9.3 & 12.8 & 42.4 & 35.5 & 100 \\
\hline Colombia & 12.4 & 18.3 & 25.2 & 44.1 & 100 \\
\hline $\begin{array}{c}\text { Tamaño Promedio de predios(ha.) } \\
\text { escala de tenencia }\end{array}$ & 4 & 21 & 59 & 871 & 28 \\
\hline Promedio Colombia & 3 & 35 & 92 & 1474 & 25 \\
\hline $\begin{array}{l}\text { Avalúos por hectáreas ( } \$ \\
\text { corrientes). }\end{array}$ & 830.321 & 466.313 & 251.731 & 106.211 & 281.221 \\
\hline Promedio Colombia & 2.423.517 & 975.162 & 1.028 .447 & 338.649 & 804.335 \\
\hline \multicolumn{6}{|c|}{$\begin{array}{l}\text { Fuente: Presidencia de la República de Colombia y Acción Social (2010): Unidades Agrícolas Familiares, } \\
\text { tenencia y abandono forzado de tierras en Colombia. Proyecto Protección de Tierras y Patrimonio de la } \\
\text { Ppoblación Desplazada, Bogotá, págs. } 44 \text { yss. }\end{array}$} \\
\hline
\end{tabular}

La tendencia hacia la concentración es lenta y cae por la división predial, caracterizada por aumento en los predios con tamaño entre 10 a menos de 50 y de 0 a 10 (tabla 7.2.38).

Los predios de más de 50 ha tienen una dinámica inversa: caen en número de predios de 6.845 a 6.314, y en área caen de 587.285 a 579.480 ha.

421 Departamento Administrativo Nacional de Estadística -Instituto Geográfico Agustín Codazzi (2004). Estudio General de Suelos y Zonificación de Tierras Departamento de Norte de Santander. Tomo I Capítulo VI Pág. 293. 
En el uso de los predios, el mayor porcentaje lo tienen los agrícolas de 0 a menos de 50 ha, con un $84,3 \%$, en tanto los mayores usos están en predios de 10 a 50 ha, que crecen en el periodo. Los predios más grandes dedican menos suelo a usos agrícolas y caen del 23,8\% en 1996 al 15,7\% en el 2004. El área dedicada a pastos aumenta en los predios de más de 10 hectáreas, y cae en los de menos de 10 ha. Independientemente del tipo de predio, los encontrados por encima del promedio departamental dedicado a ganadería (73,0\%) son de 10 a menos de 500 ha, con 75,0\% y 74,7\%. Los pequeños y microfundios tienen el $55.7 \%$.

\begin{tabular}{|c|c|c|c|c|c|c|c|c|c|c|c|c|c|}
\hline \multirow{3}{*}{ Tamaño (PSM) } & \multirow{2}{*}{\multicolumn{2}{|c|}{ P S M }} & \multicolumn{11}{|c|}{ U S O S (hectáreas) } \\
\hline & & & \multicolumn{2}{|l|}{ T otal } & \multicolumn{3}{|c|}{ Uso agrícola } & \multicolumn{3}{|c|}{ Pastos y malezas } & \multicolumn{3}{|c|}{ Bosques y otros usos } \\
\hline & Cantidad & $\%$ & Área & $\%$ & Área & * & ** & Área & * & ** & Área & * & ** \\
\hline \multicolumn{14}{|c|}{ Año 2004} \\
\hline TOTAL & 63.096 & 100 & 1.321.574 & 100 & 167.214 & 12,7 & 100,0 & 964.355 & 72,97 & 100,00 & 190.006 & 14,38 & 100,00 \\
\hline 0 a menos de 10 & 29.657 & 47 & 128.177 & 10 & 47.117 & 36,8 & 28,2 & 71.440 & 55,74 & 7,41 & 9.623 & 7,51 & 5,06 \\
\hline 10 a menos de 50 & 27.124 & 43 & 613.918 & 46 & 93.857 & 15,3 & 56,1 & 458.260 & 74,65 & 47,52 & 61.799 & 10,07 & 32,52 \\
\hline 50 a menos de 500 & 6.314 & 10,0 & \begin{tabular}{l|l}
579.480 \\
\end{tabular} & 44 & 26.240 & 4,5 & 15,7 & 434.656 & 75,01 & 45,07 & 118.585 & 20,46 & 62,41 \\
\hline \multicolumn{14}{|c|}{ Año 1996} \\
\hline Total & 53.987 & & 691.755 & & 131.674 & 19,03 & 100,0 & 843.496 & 121,94 & 100,00 & 303.857 & 43,93 & 100,00 \\
\hline 0 a menos de 10 & 27.895 & 46 & 117.194 & 9 & 31.918 & 27,24 & 24,2 & 71.659 & 61,15 & 8,50 & 13.611 & 11,61 & 4,48 \\
\hline 10 a menos de 50 & 26.092 & 43 & 574.561 & 45 & 68.483 & 11,92 & 52,0 & 382.861 & 66,64 & 45,39 & 123.215 & 21,45 & 40,55 \\
\hline 50 a menos de 500 & 6.846 & 11 & 587.285 & 46 & 31.273 & 5,33 & 23,8 & 388.976 & 66,23 & 46,11 & 167.031 & 28,44 & 54,97 \\
\hline \multicolumn{8}{|c|}{ Fuente : ENA, DANE- Proyecto SISAC y Ministerio de Agricultura y Desarrollo Rural. Cálculo del autor. } & \multicolumn{3}{|c|}{ *Porcentaje Horizontal } & \multicolumn{3}{|c|}{ ** Porcentaje Vertical } \\
\hline
\end{tabular}

Disponibilidad y política SAN en Norte de Santander. Las acciones y la intervención para la disponibilidad de agroalimentos son consideradas en el objetivo del Plan de Desarrollo Departamental:

Contribuir a mejorar las condiciones de vida de la población del Departamento, a través del desarrollo de procesos articulados de producción y transformación agropecuaria y forestal con buenas prácticas agrícolas ${ }^{422}$.

Además, este plan propone impulsar y fortalecer cuatro cadenas productivas. Una es la las cadenas agrícolas: hortofrutícola, palma-aceite, biodiesel, cacao-chocolate y caña de azúcar, a partir de diagnosticar el sector cacaotero, impulsar la producción de biocombustibles y adquirir tierra para pequeños productores.

Por otro lado, los cultivos de arroz, café, maíz, papa, trigo, yuca, caña panelera, tabaco y flores se desarrollan para contribuir a sostener la seguridad alimentaria, especialmente campesina. Con ello se busca fortalecer el sector cafetero y sostener la productividad de

422 DNP (2008): Un Norte para Todos... Op. cit., pág. 22. 
actividades no incluidas en las cadenas. De hecho, esta es la política para estas economías. Por su parte, La cadena de ganado, carne, leche y subproductos lácteos busca mejorar praderas, impulsar repoblamiento y apoyar la sanidad ganadera. La disponibilidad de la región inmediata a Cúcuta tiene otros mercados por fuera de esta:

La producción del municipio tiene como destinos Cúcuta, Bucaramanga y Venezuela, con diferentes productos: trucha, papa amarilla, cilantro, remolacha, zanahoria, repollo, apio España, arracacha, habichuela, plátano y yuca y se han desarrollado e impulsado formas de organización de agricultores municipales, mujeres emprendedoras y la asociación de productores de leche de Mutiscua ${ }^{423}$.

También otras zonas de la región inmediata tienen dificultades como esta: "El gobierno no apoya por los precios altos de los insumos, el manejo de la asignación de crédito, [...] falta de voluntad política de los diferentes niveles de gobierno para impulso a la seguridad alimentaria" ${ }^{424}$.

Entre tanto, otras acciones se orientan a mejorar ingresos y complementar la dieta a partir de la integración de acciones de disponibilidad y acceso para la población:

Inversión en semillas con la asociación de mujeres campesinas, desarrollar huertas integrales agrosostenibles, desarrollo de la piscicultura como auxilio al campesino fomentando estanques para el complemento de la dieta alimenticia ${ }^{425}$.

Disponibilidad de alimentos en Norte de Santander. En el anexo C, las tablas 11 y el 12 (cultivos transitorios y permanentes, periodo 1987-2009) muestran los agroalimentos en cuanto a la oferta disponible más inmediata de la ciudad eje: Cúcuta. Allí se relacionan superficie, producción y rendimiento por agroalimento producido.

423 GAMBOA, Miguel (2008): Entrevista. Alcalde de Mutiscua, departamento de Norte de Santander, 27 de noviembre.

424 VILLAMIZAR, Judith, SOTO, Juan Vicente y PINZÓN, Hernando (2008): Entrevistas. Técnicos y director de la UMATA, municipio de Lebrija, departamento de Santander, 9 de diciembre. 425 RINCÓN, Felipe (2008): Entrevista. Técnico de la UMATA, municipio de Lebrija, departamento de Santander, 9 de diciembre. 
Los cultivos transitorios crecen: las hectáreas pasan de 38.905 en 1987 a 48.533 en el 2009, es decir, se amplían en 9.628 ha y 106.059 t en producción. Los tres agroalimentos básicos de la dieta del eje: fríjol, maíz y arroz, se comportan diferente. El fríjol, entre 1987 y 2009, aumentó 53\% su área cosechada; pasó de 4.300 ha a 6.566 ha en el 2009. Sucedió también así con la producción, que aumentó 189\%, de 3.540 t a 10.222 t, y en rendimientos pasó de $823 t$ a $1.557 t$.

Entre 1987 y el 2009, la superficie destinada al maíz cae en las variedades de tecnificado y tradicional: pasó de 11.800 ha a 9.686 ha, y en producción pasó de 15.300 t a 12.274 $t$. Los rendimientos permanecen constantes. Por su parte, en el mismo periodo, el arroz de riego aumentó de 16.100 ha a 28.973 ha, y la producción pasó de 86.700 t a 180.099 t. También sucedió así con los rendimientos. Si la comparación es desde 1990, la cifra cambia con caída en superficie y producción.

Respecto a los otros agroalimentos de la canasta básica, en periodo 1987-2009, debe indicarse: la papa cae en superficie, pues pasa de 4.200 ha a 2.814 ha, y la producción crece: pasa de $61.560 t$ a $74.170 t$. Los rendimientos crecen al pasar de 14.657 a 26.357 . El trigo presenta lo mismo en el resto del país: cae en superficie y producción, pero crece en rendimientos.

Los cultivos permanentes, entre 1987 y 2009, se caracterizan por presentar crecimiento continuo en casi todos los productos y en superficie: pasan de 33.400 ha a 55.856 ha, y en producción pasan de $211.880 t$ a $329.115 t$, con un crecimiento constante en las dos décadas. Los únicos agroalimentos que en el periodo decrecen en superficie son: la yuca, que pasa de 11.500 a 10.334 ha, en tanto su producción aumentó de 115.000 $t$ a 145.072, lo que implicó que los rendimientos aumentaron; y la caña de azúcar, que presenta información solo de 1990 a 2009: pasa de 913 ha a 899 ha, aumentando la producción y los rendimientos.

El producto que más creció fue la palma africana, que en la superficie pasó de 200 ha a 8.093 ha y en la producción pasó de $360 t$ a 28.153 t. Ello muestra un cambio de producción a mediano y largo plazo en el departamento. El cacao crece en área y producción, pero baja en rendimientos.

\section{Comparación entre disponibilidad de agroalimentos en Norte de Santander} y las demandas de agroalimentos del eje Cúcuta. Para realizar la comparación, se calcularon las necesidades de alimentos y nutrición de la población de Cúcuta, 


\begin{tabular}{|c|c|c|c|c|}
\hline \multicolumn{5}{|c|}{$\begin{array}{r}\text { Cuadro } 7.2 .39 \text { Comparativo de dis ponibilidad de la región inmediata por } \\
\text { grupos de agroalime ntos y la demanda ide al del e je Cúcuta }\end{array}$} \\
\hline Grupos de alimentos & Productos & $\begin{array}{l}\text { Demanda } \\
\text { ideal (ton) }\end{array}$ & $\begin{array}{c}\text { Producción } \\
2006 \\
\end{array}$ & $\begin{array}{c}\text { Déficit o } \\
\text { superávit }\end{array}$ \\
\hline \multirow{4}{*}{ 1. CEREALES } & Arroz & $12.734,2$ & 5.820 & 6.914 \\
\hline & Avena & $4.539,7$ & & 4.540 \\
\hline & Maíz & $3.432,6$ & 12.748 & 9.315 \\
\hline & Trigo & 0,0 & 36 & 36 \\
\hline \multirow{6}{*}{$\begin{array}{l}\text { 2. RAÍCES, } \\
\text { TUBÉRCULOS Y } \\
\text { PLÁTANOS }\end{array}$} & Ñame & 0,0 & 100 & 100 \\
\hline & Papa & $16.547,4$ & 90.740 & 74.193 \\
\hline & Papa criolla & & 7.749 & 7.749 \\
\hline & Plátano & $4.166,3$ & . & $4.166,3$ \\
\hline & Yuca & $9.083,6$ & 79.322 & 70.238 \\
\hline & Arveja & $7.926,3$ & 147.702 & 139.776 \\
\hline \multirow{7}{*}{$\begin{array}{l}\text { 3. HORTALIZAS, } \\
\text { VERDURAS Y } \\
\text { LEGUMINOSAS } \\
\text { VERDES }\end{array}$} & Auyama & $2.762,5$ & 1.192 & 1.571 \\
\hline & Cebolla Cabezona & $4.952,3$ & 2.608 & 2.344 \\
\hline & Cebolla común & $1.263,9$ & 50.608 & 49.344 \\
\hline & Habichuela & 787,5 & 606 & 182 \\
\hline & Tomate & $3.224,7$ & 1.300 & 1.925 \\
\hline & Zanahoria & $4.994,3$ & 20.890 & 15.896 \\
\hline & Banano & $8.545,5$ & 4.000 & 4.545 \\
\hline \multirow{8}{*}{ 4. FRUTAS } & Guayaba & $5.677,1$ & 8.050 & 2.373 \\
\hline & Limón & $13.127,0$ & 19.251 & 6.124 \\
\hline & Mandarina & $9.392,3$ & 9.520 & 128 \\
\hline & Mango & $12.404,0$ & 6.107 & 6.297 \\
\hline & Mora & $8.156,4$ & 90 & 8.066 \\
\hline & Naranja & $20.548,2$ & 4.100 & 16.448 \\
\hline & Tomate de árbol & $13.450,8$ & 634 & 12.817 \\
\hline & Carne de res & $7.885,2$ & 2.000 & 5.885 \\
\hline \multirow{5}{*}{ 5. CARNES Y HUEVOS } & Carne de cerdo & $2.520,9$ & 22.061 & 19.540 \\
\hline & Huevo de gallina & $2.039,1$ & 57.981 & 55.942 \\
\hline & Pescado & $4.521,2$ & 17.727 & 13.206 \\
\hline & Pollo & $3.717,5$ & . & $3.717,5$ \\
\hline & Fríjol & $2.386,2$ & 4.077 & 1.691 \\
\hline \multirow{3}{*}{$\begin{array}{l}\text { 6. LEGUMINOSAS } \\
\text { SECAS Y MEZCLAS } \\
\text { VEGETALES }\end{array}$} & Garbanzo & $1.507,1$ & 8.675 & 7.168 \\
\hline & Lenteja & $1.331,3$ & . & $1.331,3$ \\
\hline & Leche líquida & $1.431,7$ & . & $1.431,7$ \\
\hline 7. LÁCTEOS & Leche liquida & $38.883,6$ & 454.618 & 415.734 \\
\hline \multirow{2}{*}{ 8. GRASAS } & Aceite animal & 0,0 & & - \\
\hline & Aceite Vegetal & $3.497,8$ & & 3.498 \\
\hline \multirow{2}{*}{ 9. AZÚCARES } & Café & 0,0 & & - \\
\hline & Caña Panelera & 0,0 & 45.679 & 45.679 \\
\hline
\end{tabular}

en términos de productos consumidos en la ciudad. Así se calcula la disponibilidad que se requiere en el eje, lo que es explicado en el capítulo I (ítem de metodología). Estos agroalimentos resultan en demandas ideales de acuerdo con las necesidades nutricionales de la población de Cúcuta. Lo que se hace en este punto es comparar esas demandas para la ciudad eje con la disponibilidad de agroalimentos en el entorno regional inmediato: el departamento de Norte de Santander.

Este comparativo no considera autoconsumos realizados en las zonas productoras de agroalimentos ni pérdidas por manejo, empaque y transporte de cada producto. Supone 
que la disponibilidad se dirige al mercado mayor de la región Cúcuta. Los resultados de esta comparación permiten concluir que hay productos que son autosuficientes y se cultivan en el departamento, en tanto otros son agroalimentos deficitarios que deben ser importados de otras zonas del país o del exterior.

Los productos autosuficientes, de acuerdo con las demandas ideales de la ciudad eje Cúcuta, son los de la dieta básica por grupos de alimentos. El primero es el de cereales, con el maíz; en el segundo grupo están raíces, tubérculos y plátanos (arracacha, papa, plátano y yuca); para el tercero son hortalizas, verduras y leguminosas verdes (tomate y cebolla cabezona); el cuarto son frutas (guayaba y limón); el siguiente es el de leguminosas secas (fríjol); y en el de lácteos hay gran oferta conjuntamente con los grupos referidos a la producción de carnes y los azúcares (la caña panelera).

En los productos deficitarios se tiene, en el mismo orden anterior: un primer grupo de arroz, avena y trigo (los dos últimos son de producción casi nula en el departamento, aunque forman parte de la dieta); la papa criolla se ubica en el segundo; en el tercero, la arveja, la ahuyama, la cebolla común, la habichuela y la zanahoria; en el cuarto solo ubican dos productos: guayaba y limón; y el último, el de mayor déficit, tiene productos de consumo general: lenteja y garbanzo.

La conclusión central es que la producción del departamento en este eje no es autosuficiente: en disponibilidad, entre 33 agroalimentos, tiene 18, que de algún modo son productos importantes para el cumplimiento de la dieta básica de la población de Cúcuta.

\subsection{DISTRIBUCIÓN DE ALIMENTOS}

\subsubsection{Elementos generales de la distribución de alimentos}

Por distribución se entienden las condiciones de acopio, transporte, almacenamiento y comercialización de agroalimentos, para que una población los adquiera (figura 7.3.1). Estas condiciones se abordan a partir de las siguientes preguntas. La primera es: ¿quién distribuye los alimentos?, que está referida a las formas organizativas, administrativas y de control de estas diversas técnicas, así como los sectores sociales vinculados con cada proceso de acopio, selección, almacenamiento y comercialización. 
Figura No. 7.3.1 Sistema alimentario. La distribución en la cadena alimentaria.

Sistema alimentario, condiciones para la distribución de alimentos regionales y locales.

\begin{tabular}{|c|c|c|}
\hline \multicolumn{3}{|c|}{$\begin{array}{c}\text { Infraestructura de acopio, transporte, almacenamiento y comercialización de } \\
\text { agroalimentos, en los territorios urbano-rurales y sus condiciones económicas, } \\
\text { políticas, técnicas e higienico sanitarias. }\end{array}$} \\
\hline & & \\
\hline $\begin{array}{c}\text { 1. Formas organizativas } \\
\text { de los sectores sociales } \\
\text { vinculados con acopio, } \\
\text { transporte y } \\
\text { comercialización urbano } \\
\text { rural. }\end{array}$ & $\begin{array}{c}\text { 2. Normas urbanísticas y } \\
\text { de salud pública sobre } \\
\text { infraestructura para } \\
\text { distribución de alimentos y } \\
\text { equipamientos urbanos } \\
\text { rurales. }\end{array}$ & $\begin{array}{l}\text { 3. Controles y } \\
\text { regulaciones de calidad e } \\
\text { inocuidad: ambiental y } \\
\text { humana, públicos, } \\
\text { comunitarios y privados. }\end{array}$ \\
\hline & & \\
\hline \multicolumn{3}{|c|}{$\begin{array}{l}\text { Los espacios de acopio, almacenamiento y comercialización, ubanos y rurales: } \\
\text { 1. Las ciudades ejes, políticas públicas, controles urbanos, de salud pública y } \\
\text { medio ambiente. } 2 \text {. Los sitios de distribución de los centros regionales } \\
\text { dinamizadores, cercanos a los municipios y zonas productoras de alimentos. }\end{array}$} \\
\hline \multicolumn{3}{|c|}{$\begin{array}{l}\text { Las relaciones de poder e intergubernamentales, interlocales e interinstitucionales } \\
\text { al interior de las ciudades eje y su entorno regio-local. }\end{array}$} \\
\hline
\end{tabular}

¿En qué condiciones los distribuye? Esta pregunta relaciona la infraestructura urbana y rural, el transporte de agroalimentos, la organización física relacionada con el tamaño y la estructura de distribución, así como las condiciones internas de las infraestructuras para distribuir técnicamente de acuerdo con los bienes alimenticios para transportar, almacenar, y el requisito de higiene y sanidad necesario en cada caso.

¿Cómo se almacenan agroalimentos en las zonas urbanas y rurales? Esta pregunta está relacionada con los productores, los acopios en las parcelas y los compradores finales en grandes centros de abastecimiento, en tiendas de barrio, mercados de cadena y plazas de mercado. Hay diversos canales para almacenar agroalimentos en los territorios, en el sitio de producción y en los abastecimientos urbanos.

Finalmente, ¿cómo, dónde y quién controla los procesos de distribución?, pregunta que relaciona los procesos regulatorios por niveles de Estado y Gobiernos nacional y subnacionales, que van de controles vía salud pública para licencias de distribución de agroalimentos, hasta licencias urbanísticas para utilizar espacios con equipamientos, según tipos de distribución (otorgados por regulación de los planes de ordenamiento territorial).

\subsubsection{Evolución de la distribución}

La comercialización de agroalimentos que independiza al productor del consumidor se presenta cuando estos actores de la cadena alimentaria no pueden realizarlo 
directamente. Allí aparece el comerciante ${ }^{426}$ y se rompe la relación entre el productor directo y el consumidor. Además, el capital agrario se diferencia del capital comercial, que crece a costas del trabajo campesino y de los consumidores urbanos.

Con el tiempo, cuando el capital comercial se vincula al financiero, se combinan e integran las formas organizativas y administrativas del proceso comercial. Esta es una tendencia cuya expresión se centraliza en las grandes superficies de las ciudades, lo cual genera nuevas relaciones en los centros urbanos y con la zona rural. Los cambios en la distribución de alimentos se dan desde el siglo XIX, cuando los productos se diferenciaban por el alimento por consumir según la clase social ${ }^{427}$. Hoy se clasifican por la zona urbana donde esté la gran superficie.

Hoy, la distribución de alimentos enfoca distintas características de estos: su capacidad nutricional, su inocuidad y su producción por organismos genéticamente modificados (OGM).Estas situaciones llevan a la segregación en la distribución por tipo de alimentos, así como sus contenidos; por ejemplo, "muchos agricultores de EE.UU. tienen su parcela dividida en dos partes: la plantación biológica para el consumo personal y la plantación con plaguicidas para la venta al mercado" ${ }^{2} 28$.

Otro aspecto por analizar en la distribución de agroalimentos es su relación con sus precios finales, que afectan tanto productor campesino como al consumidor urbano:

426 "El mercader apareció como intermediario entre consumidores y productores; el comerciante conoce el mercado mejor que estos últimos, lo domina en cierta manera y utiliza esto para explotar al campesino. Al comerciante en cereales y en ganado asociose pronto el usurero, cuando no era una misma persona”. KAUTSKY, Karl (1975): La cuestión agraria. Estudio de las tendencias de la agricultura moderna y de la política agraria de la socialdemocracia. Editorial Latina, Medellín, pág. 17.

427 "La revolución que se produce en la venta al por menor, con la aparición de los grandes almacenes, y el cambio de las relaciones de poder entre comerciantes y productores fue en parte resultado de las nuevas relaciones espaciales. El mercado de los productos alimenticios de la ciudad se vio liberado de una estrecha y azarosa dependencia de proveedores locales, y recurría cada vez más a proveedores de provincias y del extranjero, provocando una auténtica revolución del consumo. En 1870, la gran mayoría de las huertas y corrales que una vez habían florecido en la ciudad habían desaparecido. La burguesía podía buscar las verduras frescas de Argelia y de las provincias, y los pobres podían suplementar su dieta con patatas del oeste y nabos del este". HARVEY, David (2006): París, capital de la modernidad. Ediciones Akal, Madrid, pág. 142.

428 PÉREZ, María Isabel (2006): La manzana de Blancanieves. Salud, industria y alimentación. Icaria, Barcelona., pág. 19. 
La remuneración del proveedor y la del distribuidor, que se concede la parte más importante, [...] los jefes de la distribución moderna llevan al ciudadano-consumidor-contribuyente a pagar tres veces lo que los grandes distribuidores se niegan a pagar a sus proveedores ${ }^{429}$.

Esta dinámica comercial presente en Colombia, en las regiones de las ciudades eje, muestra las transferencias económicas de productores y consumidores a distribuidores, práctica continua desde su nacimiento. En la distribución de agroalimentos, los productores y consumidores se ven afectados por el manejo de los precios de los distribuidores, que expresan una "intermediación innecesaria que deriva en la especulación" ${ }^{430}$, reconocida en los escenarios de encuentro entre los tres actores.

La FAO anota que antes de que los consumidores urbanos tengan sus alimentos, estos pasan por costos adicionales, que son diferentes por diferentes razones:

La ineficacia del mercado; el escaso desarrollo de los sistemas de abastecimiento alimentario urbanos; la ausencia de transparencia del mercado; la falta de economías de escala a lo largo del sistema de distribución; los altos costos de transporte y las elevadas pérdidas materiales en todas las etapas de la distribución. La urbanización carece en gran medida de planificación y las autoridades locales a menudo no tienen políticas claras sobre el desarrollo de infraestructuras y servicios que permitan satisfacer las necesidades futuras ${ }^{431}$.

En Colombia, los planes de ordenamiento territorial son el instrumento de planificación urbana para orientar la espacialización de estos equipamientos urbanos y rurales, que son permitidos con las licencias urbanísticas para usos del suelo según regulación de la ciudad. Respecto a la distribución de alimentos en centros urbanos, la FAO planteó que durante el siglo XXI —el "siglo de las ciudades" — se presenta el reto de poder:

429 MONTAGUT, Xavier y VIVAS, Esther (2007): Supermercados, no gracias. Grandes cadenas de distribución impactos y alternativas (2. ${ }^{a}$ ed.). Icaria, Barcelona, pág. 53.

430 SOLÓRZANO FRAGA, Alfonso (1996): "Por una política social del abasto". En Transporte y abasto alimentario en las ciudades latinoamericanas. Universidad Nacional Autónoma de México, México, pág. 91.

431 FAO (s. f.): Alimentos para las ciudades, Esfera multidisciplinaria. Mercadeo urbano de alimentos. Recuperado de www.fao.org/fcit/index.asp. 
Proporcionar cantidades adecuadas de alimentos nutritivos y al alcance de la población urbana, en especial para los pobres. Haciendo más eficientes todas las actividades de suministro y distribución de alimentos en las ciudades: acopio, embalaje, almacenamiento, transporte, procesamiento, ventas al por mayor y al por menor y ventas ambulantes ${ }^{432}$.

La identificación de diferentes formas, estructuras y tamaños para distribuir agroalimentos requiere tener en cuenta, en cada caso, la inocuidad:

El predominio de los canales informales, la preferencia por productos en estado fresco y la deficiente infraestructura de comercialización perjudica el logro de otro de los objetivos de la seguridad alimentaria: garantizar la inocuidad de los alimentos ${ }^{433}$.

En este sentido, se requieren los controles públicos de parte del Estado, los Gobiernos nacional subnacionales y la ciudadanía, en articulación con los comités de consumidores. La FAO considera que las ventas minoristas informales realizadas en vías públicas suministran alimentos baratos a los consumidores urbanos de bajos ingresos ${ }^{434}$, lo cual afecta la salud; sin embargo, en términos culturales, económicos y sociales forman parte de las formas de distribución de alimentos en todas las ciudades ejes analizadas en esta investigación. Otro punto es la dinámica de concentración de la distribución. Francia muestra la tendencia general en muchos países:

Las relaciones entre los productores de bienes de consumo (70.000 empresas, 300.000 agricultores) y los sesenta millones de consumidores son similares al paso en el estrangulamiento de un reloj de arena. En el punto en que se estrecha, seis agrupaciones de distribuidores controlan la venta de más del 90\% de los productos de gran consumo ${ }^{435}$.

432 FAO (s. f.): Alimentos para las ciudades... Op. cit., pág. 20.

433 FAO y Comunidad Andina (2004): Comunidad Andina: factores macroeconómicos, comerciales, sectoriales y la seguridad alimentaria. Pág. 98.

434 FAO (1999): Enfoques. La comercialización de alimentos en las ciudades. Departamento de Agricultura y Protección al Consumidor.

435 MONTAGUT, Xavier y VIVAS, Esther (2007): Supermercados, no gracias... Op. cit., pág. 51. 
Estas dinámicas concentradoras de distribución de agroalimentos dejan en manos del mercado este proceso, por lo cual se pierde la capacidad de distribución y de regulación real por parte del Estado:

El retiro de la participación estatal en el abasto de alimentos, las empresas privadas han aumentado sensiblemente su participación en el sistema de distribución de productos de consumo generalizado, registrando en los últimos años, un explosivo crecimiento de las tiendas de autoservicio y supermercados, y ahora no solo de firmas nacionales sino, de manera más sostenida, de empresas transnacionales ${ }^{436}$.

Las tendencias y los hábitos de consumo hacen variar las condiciones de infraestructura para la oferta de los alimentos de los centros urbanos: "En los últimos 20 años, el consumo de alimentos entre los colombianos ha tenido drásticas variaciones que reflejan los avances en la estructura de comercialización y distribución de alimentos vía supermercados, hipermercados, centrales de abastos" 437.

\subsubsection{Relación de origen y destino de los agroalimentos}

El origen de los agroalimentos determina incidencias locales y regionales en la parte del consumo y la disponibilidad regional o nacional, como muestra el caso de México:

La producción agrícola nacional se ha reducido en un $60 \%$, y en algunas Centrales de Abasto, la mayoría de los productos que se comercian son del exterior, como es el caso de Baja California. Esto implica una doble problemática: por un lado el sistema de abasto que se impone en la economía urbana afecta el acceso a los alimentos de sectores de la población de escasos recursos, y por otro, está impactando negativamente en la producción de alimentos del país ${ }^{438}$.

436 SOlÓRZANO FRAGA, Alfonso (1996): Por una política social... Op. cit., pág. 94.

437 URIBE CALA, Álvaro Francisco (1998): Grandes transformaciones del sector agropecuario colombiano en la última década: Una visión regional. Elementos para la focalización regional y la priorización temática en agendas de investigación y desarrollo tecnológico agroalimentario. Editorial Produmedios Corpoica, Tibaitatá, pág. 47.

438 SOLÓRZANO FRAGA, Alfonso (1996): Por una política social... Op. cit., pág. 93. 
Por lo tanto, es importante acercar los espacios regiolocales entre la disponibilidad, la distribución y el acceso, con un vínculo más directo del origen y destino de los agroalimentos de los centros urbanos y las ciudades ejes. Este acercamiento al origen de los agroalimentos para diferentes áreas urbanas encuentra otras formas de comercio directo y más justas entre el campo, la ciudad, el productor y el consumidor:

Cuando los pobres de América Latina han perdido toda soberanía alimentaria, solo la alianza de larga duración entre los pobres de la ciudad y el campo puede darle salida. [...] En algunas periferias, como en barrios de Ciudad Bolívar (Bogotá) y sobre todo en El Alto, se han creado mercados donde los campesinos venden directamente sus productos a los pobres de la ciudad ${ }^{439}$.

Estas relaciones combinan solidaridad y subsistencia por las necesidades que tienen sectores pobres de la ciudad y el campo.

\subsubsection{Colombia: características en la distribución de alimentos}

En la década del treinta del siglo XX hubo un proceso de intervención del Estado que creó organizaciones públicas, como el Instituto Nacional de Abastecimiento (INA), cuyo objetivo era este:

Facilitar la producción, distribución, importación y exportación de productos alimenticios de origen agrícola de primera necesidad, con el fin de procurar la regulación de los precios de los mismos, apoyar la agricultura y aumentar la producción nacional evitando la especulación ${ }^{440}$.

En 1968, el INA se constituye en el Instituto de Mercadeo Agropecuario (Idema), que define para los productos agropecuarios las funciones de comprar, vender y distribuir; mantener existencias reguladoras; importar productos alimenticios; exportar excedentes; asumir el mercado exterior; y promover el procesamiento, el almacenamiento y la

439 ZIBECHI, Raúl (2009): Los territorios como sustento... Op. cit., pág. 328.

440 SOJO, José R. (1970): El comercio en la historia de Colombia. Cámara de Comercio de Bogotá, pág. 28. 
distribución ${ }^{441}$. En este contexto, se promovieron más valores agregados a los productos agropecuarios con las organizaciones sociales. Esta intervención y regulación del Idema amplió la infraestructura para la comercialización mayorista de agroalimentos, en diferentes centro urbanos de Colombia ${ }^{442}$.

En Colombia, hoy las orientaciones las da el mercado, y la distribución de agroalimentos está cruzada por procesos de compra en sitios de producción, acopio, transporte y distribución de agroalimentos en los centros de consumo, con intermediarios rurales y urbanos que dependen, en su comportamiento económico, del tipo de productor en el momento de la compra. Forero y Rudas señalan respecto a los intermediarios vinculados al comercio de productos con alta perecebilidad de la economía campesina:

[Existía] una compleja red de intermediarios rural-urbanos, que desarrollaban su actividad dentro de lo que la literatura económica ha llamado la informalidad, [...] la predominancia de la informalidad económica en los sistemas de acopio y distribución rural-urbana de la producción campesina, la podemos extender sin lugar a dudas a todas las zonas del país en que predomina la producción agrícola parcelaria $^{443}$.

Esta red de intermediarios recorre los mercados de distintos municipios rurales, y tiene capacidad de acopio, transporte y dinero para la compra directa en la plaza de mercado o en la parcela, así como para llevar los agroalimentos a los centros urbanos. Por otro lado, los problemas en la comercialización de agroalimentos en los centros urbanos, vinculados al poder comercial, son consecuencia de la centralización del acopio de estos:

Hay mucha fallas y desequilibrios, empezando por los problemas de acopio en las zonas rurales y las peripecias de los campesinos y muchos productores para vender sus productos. [...] Las inversiones del Estado en comercialización han privilegiado las zonas urbanas apoyando

441 Ibíd., pág. 35.

442 BALLESTEROS SANTAFÉ, Óscar Javier (1998): “La nueva política de comercialización agropecuaria y la liquidación del Idema”. Revista Planeación y Desarrollo, Departamento Nacional de Planeación, vol. XXIX, No 2, abril -junio, Bogotá, pág. 15,

443 FORERO, A. Jaime y RUDAS, Guillermo (1991): "Los acopiadores rurales de la producción campesina". En Tres estudios sobre la comercialización de alimentos en Colombia. Pontificia Universidad Javeriana y ECOE Ediciones, Bogotá, págs. 133 y ss. 
grandes centrales mayoristas. Aunque nadie duda de la necesidad de apoyarlas, allí se han fortalecido los poderes del control del mercado y los precios con perjuicio para agricultores y consumidores ${ }^{444}$.

No se trata solo de un problema de infraestructura de comercialización, sino de ver las condiciones y tendencias de concentración y su implicación en los productores y consumidores de alimentos, pues por vía de los precios, en muchos casos, en las centrales de abastos de las ciudades "los productores tienen que regalar lo que producen porque les pagan muy barato. Falta una política de precios sustentados" ${ }^{445}$. La solución depende de acciones del Gobierno nacional, pues los gobiernos subnacionales no intervienen en esta dinámica.

El Ministerio de Agricultura y la Corporación Colombia Internacional (CCI) consideran que en Colombia la comercialización de agroalimentos tiene un proceso de modernización que supera el modelo tradicional, tipo "reloj de arena":

Numerosos agricultores venden sus productos a acopiadores veredales o regionales que, a su vez, los venden a los mayoristas en los principales centros de consumo; ellos por su parte abastecen a minoristas de plazas de mercado y tiendas de barrio, a donde llegan los consumidores domésticos (último eslabón de la cadena) ${ }^{446}$.

La anterior situación de comercialización de agroalimentos conllevó desarrollar dos modelos: uno, el descentralizado, en el que mayoristas, las grandes cadenas y los industriales tienen intervenciones concretas:

Comprando de manera directa al productor o a intermediarios que tienen sus propios sistemas de acopio, orientando a los productores sobre las características de la demanda en términos de variedades, calidades, volúmenes y tiempos en que son requeridos por los consumidores ${ }^{447}$.

444 MACHADO C., Absalón (1986): El problema alimentario en Colombia... Op. cit., pág. 78.

445 MOSQUERA, Mauricio (2008). Entrevista. Director de la Unidad de Desarrollo Económico, municipio de Rivera, departamento del Huila, 6 de noviembre.

446 Corporación Colombia Internacional y Ministerio de Agricultura y Desarrollo Rural (2003): Comercialización y encadenamientos productivos en el sector agroalimentario. Bogotá, pág. 9.

447 Ibíd., pág. 9. 
Esto reduce los intermediarios en la cadena de agroalimentos. El otro modelo, de comercialización centralizada con estrategia, se enfoca en al análisis del arroz como producto cuya industria “cumple la misión que desempeñan los comerciantes mayoristas en otros casos: concentra el flujo de información y la distribuye hacia los extremos de la cadena" ${ }^{448}$. Este alimento de la dieta global, nacional, regional y local se incluye como bien transable en la Bolsa Nacional Agropecuaria.

La organización de canales de comercialización de alimentos en Colombia (tabla 7.3.1) muestra, al final del siglo XX, la tendencia de organización de estos en tradicionales y supermercados. Los tradicionales tienen más del 99\% de los establecimientos: 146.597 para el 2000, y no supera el 47\% de las ventas. Por su parte, los supermercados tienden a la concentración, expansión y disminución de establecimientos: 1.101 con mayor participación en el mercado, 54,2\%.

\begin{tabular}{|c|c|c|c|c|c|c|c|c|c|}
\hline \multirow[b]{2}{*}{ Año } & \multicolumn{3}{|c|}{ Total } & \multicolumn{3}{|c|}{ Tradicionales* } & \multicolumn{3}{|c|}{ Supermercados } \\
\hline & $\begin{array}{c}\text { No. } \\
\text { Establec. }\end{array}$ & $\begin{array}{c}\% \\
\text { Establec. }\end{array}$ & $\begin{array}{c}\% \\
\text { Ventas }\end{array}$ & $\begin{array}{c}\text { No. } \\
\text { Establec. }\end{array}$ & $\begin{array}{c}\% \\
\text { Establec. }\end{array}$ & $\begin{array}{c}\% \\
\text { Ventas }\end{array}$ & $\begin{array}{c}\text { No. } \\
\text { Establec. }\end{array}$ & $\begin{array}{c}\% \\
\text { Establec. }\end{array}$ & $\begin{array}{c}\% \\
\text { Ventas }\end{array}$ \\
\hline 1998 & 141.791 & 100 & 100 & 140.657 & 99.2 & 45.9 & 1.134 & 0.8 & 54.1 \\
\hline 1999 & 143.620 & 100 & 100 & 142.615 & 99.3 & 46.4 & 1.005 & 0.7 & 53.6 \\
\hline 2000 & 147.698 & 100 & 100 & 146.597 & 99.3 & 45.8 & 1.101 & 0.7 & 54.2 \\
\hline \multicolumn{2}{|c|}{ * No incluye Licorerias } & \multicolumn{8}{|c|}{ Elaboro: AC Nielsen -2001 Universo de establecimientos detallistas. } \\
\hline
\end{tabular}

La Oficina Comercial de la Embajada de España en Colombia realizó un análisis sobre la situación del comercio y su proceso de concentración y globalización:

El negocio de los supermercados se ha fragmentado en los últimos años en Colombia, resultando de ello cuatro grupos claramente diferenciados: Los grandes jugadores: Éxito-Cadenalco, Olímpica y Carulla-Vivero, los cuales tienen cerca del 60\% del mercado y están en constante expansión, ya sea por medio de la absorción de las cadenas más pequeñas en ciudades donde no tienen presencia fuerte o de la construcción de nuevos almacenes ${ }^{449}$.

448 Ibíd., pág. 10.

449 Oficina Comercial de la Embajada de España en Colombia (s. f.): Comercio y distribución en Colombia. Pág. 8 
También se tienen en cuenta cadenas como Makro y Carrefour, en proceso de crecimiento, y se espera la entrada de nuevos grupos internacionales, como Ahold y WalMart. Sobre las cajas de compensación Cafam y Colsubsidio, se mantienen en el mercado por mejores y más servicios. Sin embargo, la compra de Comfama por Carulla Vivero abrió el debate acerca de si los recursos de estas deben enfocarse a supermercados o bien, destinarse a frentes como salud, educación y recreación. En esta discusión, Éxito adquiere Cafam. Hay supermercados medianos como La 14 y Surtimax, caracterizados por sus posiciones regionales pero débiles nacionalmente. Este tipo de cadenas resultan atractivas para los grandes jugadores ${ }^{450}$.

En el Huila se da un proceso de concentración en la comercialización regional de frutas. En Surabastos hay varias empresas comercializadoras para el mercado internacional. Marketing On Line exporta a España maracuyá, lulo y tomate de árbol. Así, esta empresa "compra directamente a los productores en la finca, certificados por el ICA, acompañan a los campesinos con asistencia técnica en producción, selección y empaque a Bogotá, España y el resto a SURABASTOS por los estándares ICA" ${ }^{451}$. Desde esta lógica de comercialización, lo que no compra el mercado internacional queda para la región o para el resto del país.

Otro punto de las dinámicas de distribución de alimentos en Colombia se refiere a las tiendas de barrio, con gran arraigo en todos los centros urbanos del país y en especial los sectores populares:

[Estos] controlan una fracción mayoritaria del mercado de alimentos en Colombia, aún a pesar del gran crecimiento de los supermercados en los últimos años. Las tiendas de barrio manejan aproximadamente el 51 por ciento del mercado de alimentos en el país, [...] en las zonas de bajos recursos de las grandes ciudades es particularmente importante porque, además de su cercanía a los clientes, son una fuente importante de ingresos para miles de hogares ${ }^{452}$.

450 Ibíd., pág. 10.

451 JORDÁN,Viviana A. (2008). Entrevista. Gerente de Marketing On line, con puesto en la plaza de Surabastos del municipio de Neiva, departamento del Huila, 7 de noviembre.

452 FAO (2010): Análisis socioeconómico de tiendas de alimentos en áreas urbanas de bajos recursos en Latinoamérica Informe de caso: Colombia. Informe elaborado por Alejandro Guarín, con estudios de caso presentados por Carlos Barbosa (Soacha), Carlos Gallo (Manizales), John Jairo Lara (Medellín). Bogotá, pág. 1. 
Por tanto, es un sector clave para la seguridad alimentaria, donde pueden desarrollarse diferentes acciones para mejorar sus condiciones y las del entorno.

\subsubsection{Distribución en los ejes dinamizadores}

Este punto presenta los esquemas de distribución de algunos agroalimentos en los ejes dinamizadores, con la información y sistematización de las visitas realizadas a los mayores centros de acopio de cada eje y de otras ciudades. Este análisis se realiza teniendo en cuenta el carácter regional del mercado, pero también se presentan los gastos de las familias según canales de distribución de seis productos de la dieta alimentaria básica; por último, e en este apartado se abordan algunas reglas urbanas sobre usos del suelo y comercio de agroalimentos.

La Encuesta Nacional de Hogares del DANE informa gastos por canal de distribución de las familias, organizado con seis grupos de alimentos: pan y cereales: carnes; pescado; leche, queso y huevos; aceites y grasas, y frutas, con información para las cuatro ciudades eje. Además, tiene en cuenta ocho formas de comercialización de alimentos: una, las grandes superficies; dos, la central mayorista de abastecimiento; tres, los graneros; cuatro, las plazas de mercado y galerías; cinco, los supermercados de barrio; seis, las tiendas de barrio; siete, los vendedores ambulantes o ventas callejeras; y ocho, espacios varios.

\subsubsection{Distribución en el eje Medellín}

La distribución de agroalimentos se analiza con información de las entrevistas realizadas en la Central Mayorista de Antioquia, espacio que atiende productores y consumidores en el municipio de Itagüí, a 10 minutos de Medellín, en el Área Metropolitana delValle de Aburrá. En esta central se comercializa el mayor porcentaje de agroalimentos para la ciudad eje y el área metropolitana.

Un punto crítico en la comercialización de La Mayorista se refiere a la logística para distribuir directamente a los pequeños y medianos tenderos. El objetivo futuro es "distribuir directamente desde La Mayorista a las pequeñas y medianas tiendas" ${ }^{453}$, en los barrios de la ciudad eje.

453 QUINTERO, Marta (2009). Entrevista. Coordinadora de mercadeo de la central mayorista de Antioquia. 
Condiciones de la distribución de algunos productos de la canasta familiar en el eje Medellín. La sistematización de la información se expresa en la construcción de los esquemas de distribución de algunos agroalimentos básicos, resultado de las visitas realizadas a comerciantes de La Mayorista.

En la distribución de panela, el productor la negocia con el intermediario local, y este la distribuye en el mercado al mayorista, quien tiene tres demandantes (figura 7.3.2): las familias; los mercados satélites de La Mayorista, que son supermercados y plazas de mercado de barrios y comunas; y, por último, otros municipios que la comercializan para el consumo de las familias. Para su distribución, hay entre dos y tres intermediarios entre el productor de panela y el consumidor, lo cual incrementa precios a las familias.

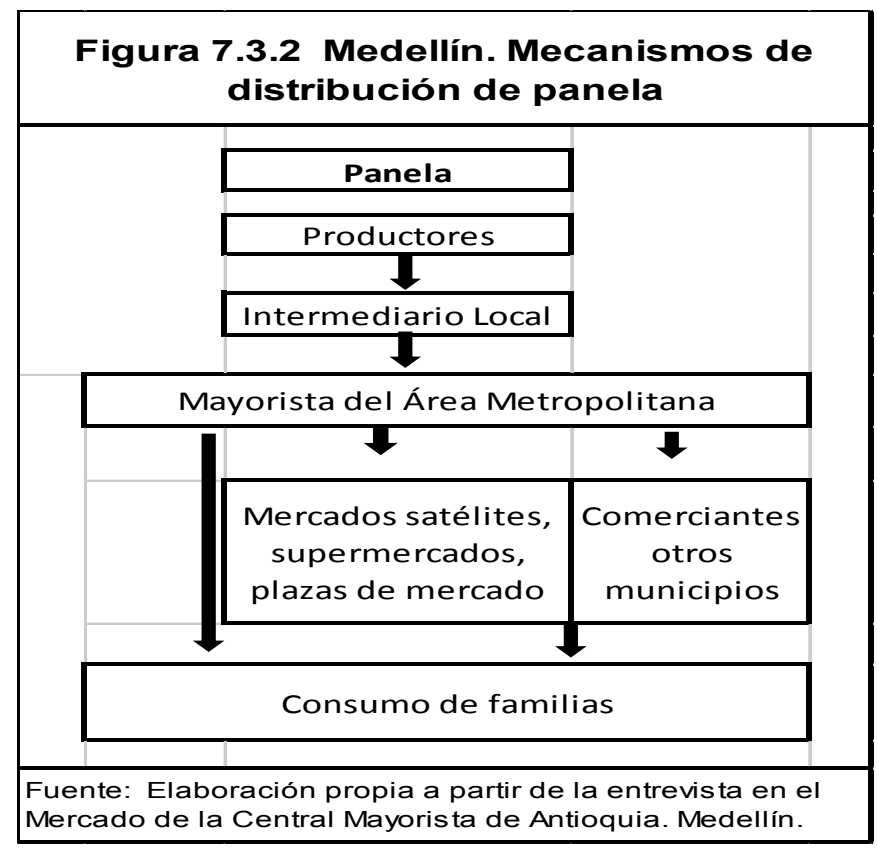

Otros agroalimentos que integra la dieta de esta ciudad eje son el maíz y el fríjol, con mínimo tres o cuatro intermediarios antes de llegar a las familias. Estas producciones son realizadas en estructuras de economía campesina. La primera intermediación de estos agroalimentos es local: quien acopia en el municipio productor y el que distribuye al comerciante regional que lleva a la ciudad eje.Y allí hay dos compradores: el comerciante de la ciudad especializado en productos para Medellín y el mayorista del área metropolitana, quien tiene información y manejo de precios y mercados metropolitanos delValle de Aburrá. Continuar esta distribución toma otros caminos. 


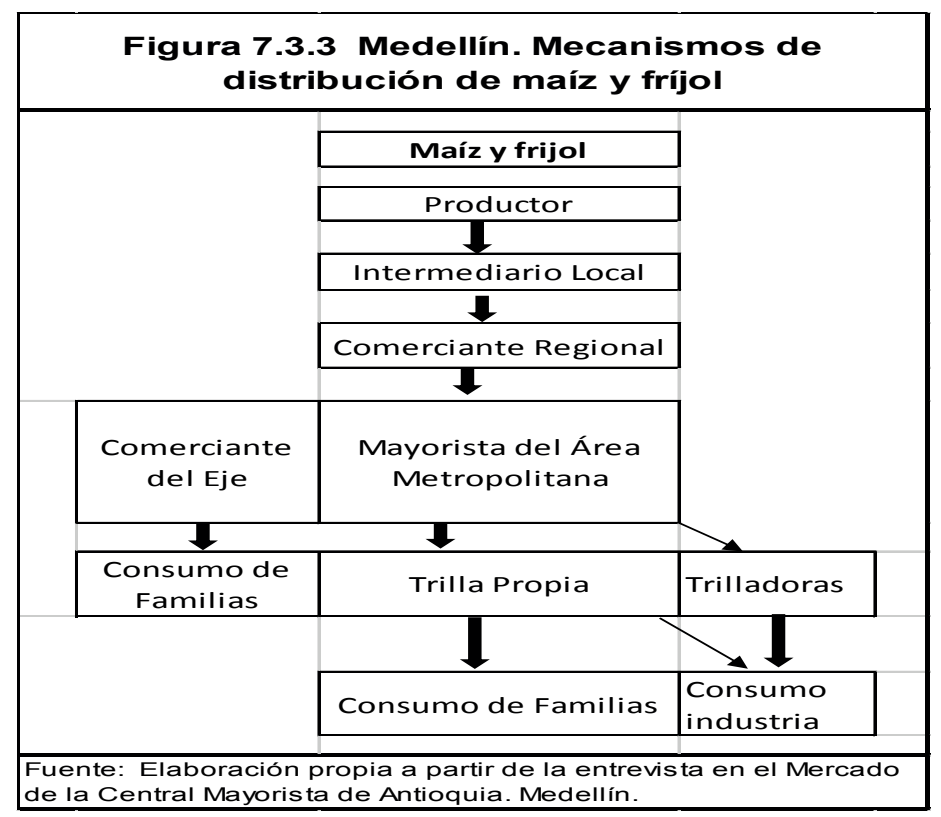

Por la vía del comerciante del eje, se distribuye a las familias, y en este caso solo hay tres intermediaciones. Por el otro lado, el mayorista metropolitano lo redistribuye en esta área, lo trilla directamente o lo vende a otras trilladoras, quienes lo llevan al consumo familiar o industrial, donde hay cuatro intermediaciones.

Respecto al plátano, con formas de distribución local y regional, directamente se vende la cosecha completa a algunos intermediarios; los comerciantes tienen vínculos directos con productores. La intermediación entre productores y consumidores puede ser de uno, dos o tres niveles, según como accedan las familias (figura 7.3.4). Hay una sola intermediación entre el productor directo y consumidor vía un comerciante mayorista, quien compra directo al productor de plátano y luego vende a las familias; otros tienen dos intermediaciones: productor, intermediario local, mayorista y familias.

Hay tres intermediaciones, por la vía del intermediario local: mayorista del área metropolitana, mercados satélites, supermercados, plazas de mercado y tiendas de barrio para la ciudad eje y el consumidor final. En elValle de Aburrá intervienen otros comerciantes del área metropolitana. El origen del plátano que llega a la ciudad eje está en el Choco, Urabá y la Costa Atlántica, y es parte de la dieta y cultura de esta región y de Medellín. 


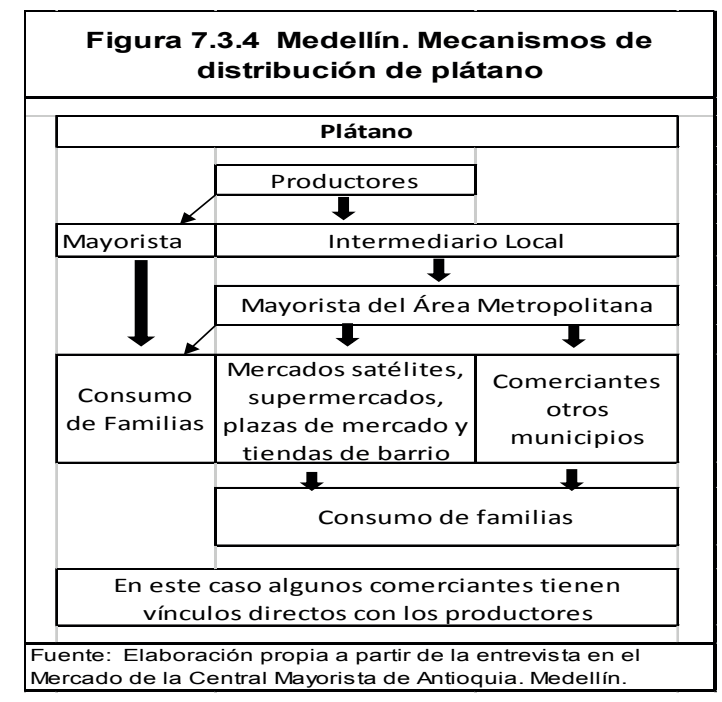

Las frutas y verduras presentan el mismo mecanismo que la panela, pero se diferencia en que la compra en la parcela es excepcional: generalmente es de los productores directos hacia el mercado local (figura 7.3.5).

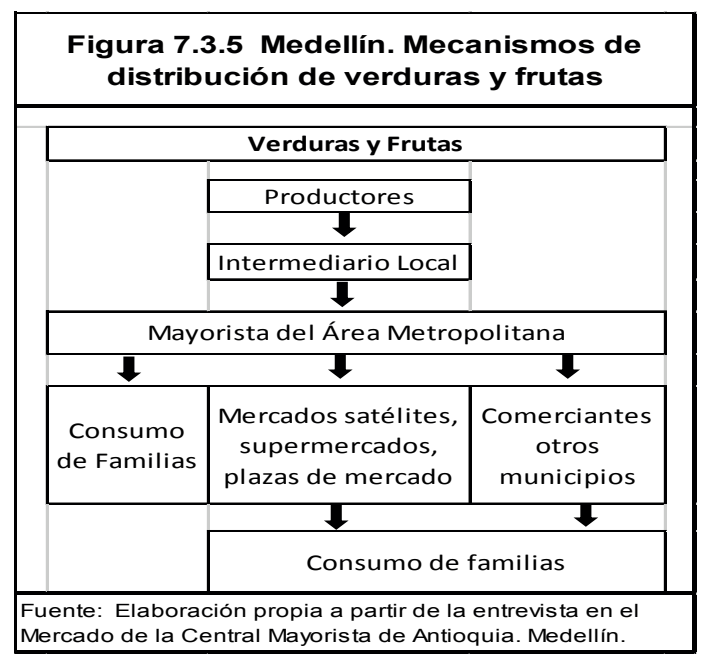

Por otra parte, la distribución de abarrotes va del productor hacia el mayorista, quien distribuye tanto a tiendas y supermercados como a reempacadores y para el consumo familiar.

Estos distintos caminos entre productor y consumidor final de agroalimentos aumentan con cada intermediación el precio para las familias, lo cual afecta su capacidad de compra y seguridad alimentaria personal, familiar o comunitaria. Esta dinámica se 


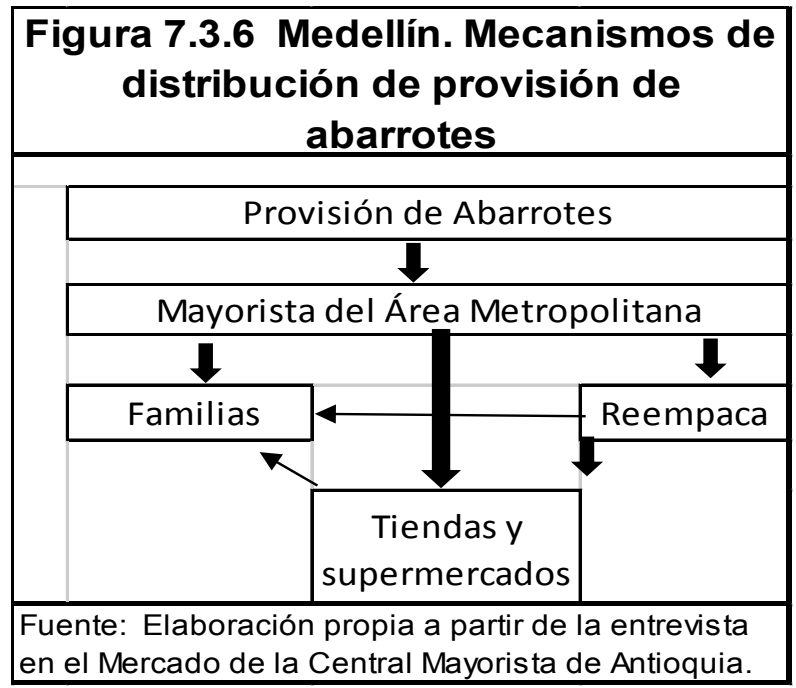

origina independientemente de la fluctuación de precios, las situaciones naturales y los periodos de cosecha o escasez.

Gasto de las familias según canal de distribución. En el primer grupo de alimentos, las tiendas de barrio ocupan el primer lugar en gastos y en hogares atendidos en este canal; luego están los grandes supermercados y, por último, los supermercados de barrio. Los totales de gastos mensuales son $\$ 22.784 .407 .993$, con una cobertura del $94 \%$, donde las tiendas tienen el 62,9\% del gasto y atienden al 79,3\% de las familias.

Para el segundo y tercer grupos de alimentos (carnes y pescados), la población usa los mismos canales que el primero, con un total de $94 \%$ y $91 \%$ del gasto, y el $93 \%$ y $92 \%$ de los hogares. La relación de cambio tiene a los grandes supermercados en el primer lugar y las tiendas de barrio en el segundo. Los supermercados de barrio ocupan el tercer lugar. En el caso del pescado, las tiendas son la primera fuente de adquisición para las familias.

El cuarto grupo (leche, queso y huevos), con los tres canales anteriores: hay un tal de $94 \%$ en gasto y $93 \%$ en hogares. Al desagregar las tiendas, estas tienen el 71,4\% del gasto y el 80,7\% de los hogares; les siguen los supermercados de barrio y los grandes supermercados. Respecto al quinto grupo (grasas y aceites), este sigue la misma dinámica: el 93\% en gasto y el 93\% de hogares. Las tiendas reciben el 50.3\% del gasto y el $62.8 \%$ de los hogares; luego están los supermercados de barrio y, finalmente, los grandes supermercados. 


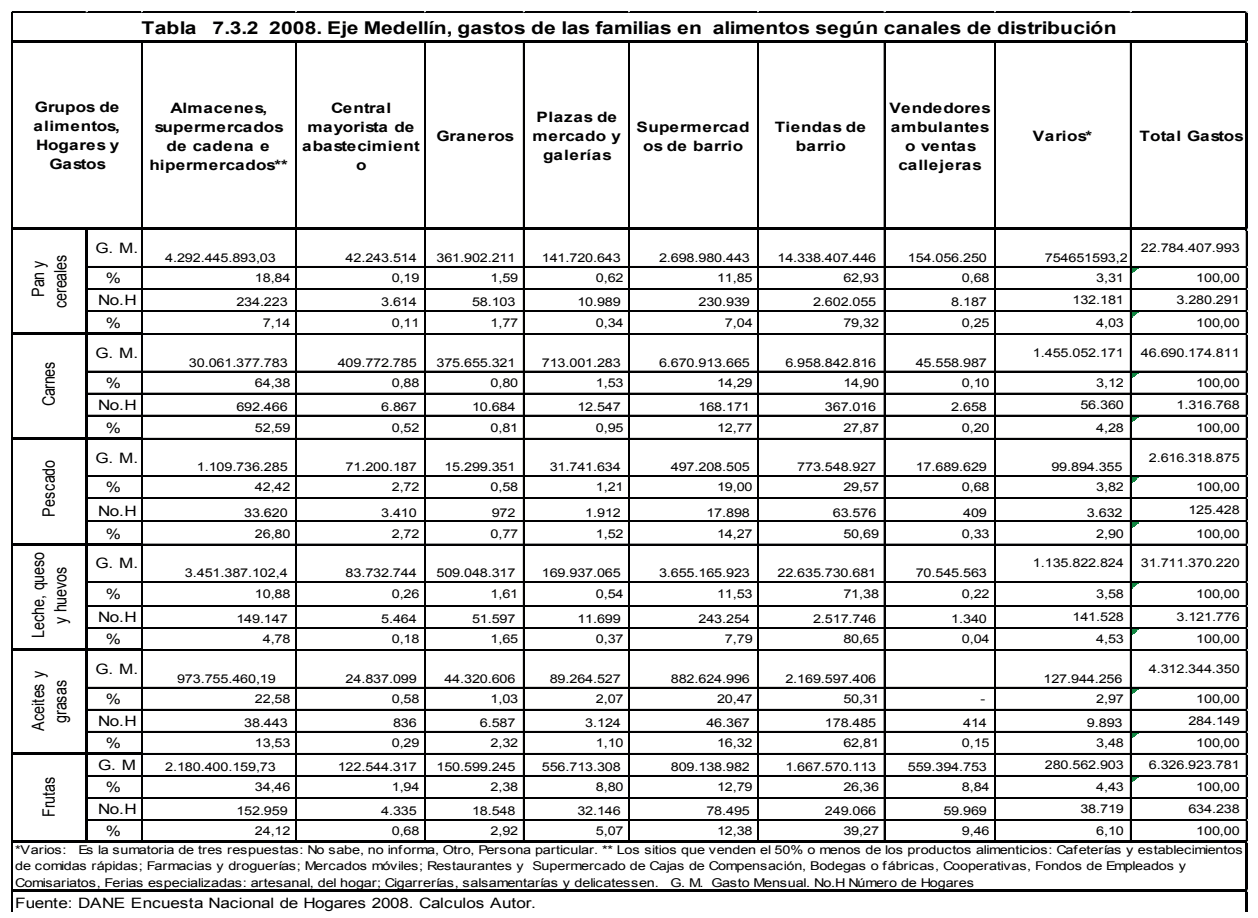

El sexto grupo (frutas), con similar dinámica a la anterior, tiene $74 \%$ en gasto y $76 \%$ de hogares. Los grandes supermercados son los primeros en gastos, con 34,5\%, y el 24,1\% de los hogares. Las tiendas tienen el 26,4\% del gasto y 39,3\% de hogares. Por último, los supermercados de barrio tienen el 12,8\% de gastos y el 12,4\% de hogares.

Reglamentaciones. Estas se refieren a la ubicación espacial urbana de infraestructuras que permiten el abastecimiento de alimentos a los pobladores de la ciudad eje Medellín. Su POT, en el contexto del área metropolitana delValle de Aburrá, explica:

Los procesos de planificación conjunta de Región Metropolitana, como objetivo construir una Región con equilibrio territorial y ambiental. No sólo entendido como el equilibrio que reconoce la protección de la base natural y de los recursos disponibles en el territorio como elementales para la sostenibilidad urbana (agua, alimentos, materias primas, insumos industriales, energía). Sino además como una relación simbiótica e innegable entre lo urbano y lo rural ${ }^{454}$.

454 Municipio de Medellín (2006): Plan de Ordenamiento Territorial. Documento técnico de soporte, primera parte: “Generalidades la región y la metrópoli. Medellín, pág. 51. 
Se integran allí diferentes espacios que no pueden verse aislados de la ciudad eje y de su área metropolitana (el Valle de Aburrá). Además, el reglamento del Acuerdo Plan de Ordenamiento Territorial considera:

Los Equipamientos de Infraestructuras Comerciales corresponden a los Centros Comerciales, Malls, Hipermercados, grandes superficies y similares, los cuales se regirán por las normas específicas y su ubicación será la estipulada en el Plano de Usos Generales del Suelo ${ }^{455}$.

Por tanto, en relación con equipamientos e infraestructuras necesarias para abastecer de agroalimentos a la ciudad, se tienen en cuenta las de almacenamiento y distribución de producción primaria, con las plazas o galerías de mercado y tiendas. ${ }^{456}$

\subsubsection{Distribución en el eje Cartagena}

La distribución de agroalimentos es analizada con la información de las entrevistas realizadas en el Mercado de Bazurto de Cartagena, espacio que atiende productores, consumidores y distribuidores de agroalimentos en los barrios de la ciudad, como también en municipios cercanos a productores y funcionarios.

\section{Condiciones de la distribución de algunos productos de la canasta familiar en el eje Cartagena. La distribución de agroalimentos se caracteriza por la identidad alimentaria de la Costa Caribe, con tres de sus productos de mayor consumo: yuca, maíz y ñame (este último es exclusivo de esta dieta). Estos son seguidos del plátano, el fríjol y la zaragoza.}

La distribución de estos productos tiene dos rutas desde el campesino productor al consumidor, y dada la cercanía de la ciudad eje a los municipios abastecedores del norte de Bolívar: un primer camino va directo desde el campesino hasta el comerciante mayorista de Bazurto, mercado urbano de mayor acopio de agroalimentos de la ciudad eje, con altos índices de insalubridad, el cual vende directo a las familias, los hoteles y los restaurantes. En este caso, hay solo una intermediación.

455 Alcaldía de Medellín (2006): Acuerdo POT n. 46 de 2006 (parágrafo del artículo 54). Medellín.

456 Ibíd., pág. 165. "El sistema estructurante, equipamientos". En Documento técnico de soporte, pág. 165. 
El otro camino es el comercio local, que compra, acopia y redistribuye a los mayoristas de Bazurto, quienes tienen dos canales: directo a las familias, hoteles y restaurantes; o con los carretilleros ${ }^{457}$, que distribuyen al detal por barrios y calles en carretillas con gran surtido de agroalimentos. Estos vendedores informales dependen del crédito en especie del mayorista, que debe ser cubierto en la tarde del mismo día, mecanismo que se denomina "gota a gota" y tiene altas tasas de interés.

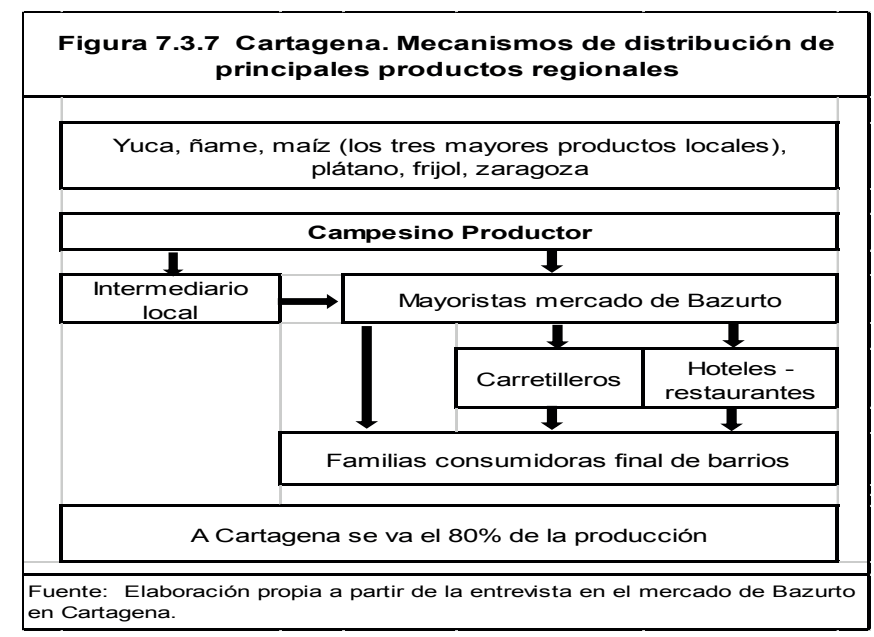

En la ciudad eje Cartagena, parte del comercio de agroalimentos se hace por medio de "los carretilleros los que surten los barrios populares con una financiación del 10\% diario de parte de los mayoristas de Bazurto y en algunos casos deben pagar el alquiler de $\$ 2.000$ por carretilla" ${ }^{458}$. Estos mecanismos de financiación se presentan en municipios de la región inmediata; así, en Villanueva (Bolívar), el control del microcrédito es manejado por "cachacos, paisas, los cuales llevan la contabilidad en cartulinas y vienen todos los días, prestan y no viven acá [con un mecanismo de cobro a partir del miedo]: cuidado me queda mal, llega el de la moto y los deudores salen corriendo en busca de la plata que deben pagar" ${ }^{459}$. Este mecanismo se utiliza en el mercado de Bazurto de

457 Los carretilleros son personas que redistribuyen agroalimentos a las familias, por la ciudad, halando un carro de dos ruedas. Presentan altos índices de informalidad; sin embargo, es un mecanismo de distribución importante en la ciudad y especialmente en los barrios populares de Cartagena y en varias zonas urbanas del país. En algunos casos, las carretillas son propias, en tanto en otros son alquiladas a los carretilleros.

458 MENDOZA, Marcos (2008): Entrevista. Exalcalde del municipio de Villanueva, Bolívar, 22 de octubre.

459 MENDOZA, Arleth (2008): Entrevista. Trabajadora social del municipio de Villanueva, Bolívar, 23 de octubre. 
Cartagena. Esta vía tiene tres intermediaciones (más la adición de los intereses que paga el carretillero a su prestamista mayorista de Bazurto). Es un mecanismo ágil y accesible en los barrios populares por el tipo de "menudeo" ofrecido, aunque los precios afecten el acceso de estas familias. A la ciudad eje llega el 80\% de la producción agroalimentaria regional del norte, el centro de Bolívar y parte del sur del departamento del Atlántico. Uno de los productos típicos para la alimentación de los cartageneros es el bollo de maíz, el cual se distribuye por diferentes canales de comercialización, que van desde la tienda, el supermercado y directo por productores de bollo, quienes lo venden en las calles y los barrios de la ciudad (figura 7.3.8).

Este producto elaborado por mujeres de los municipios productores de maíz, con la siguiente división de trabajo familiar: la mujer los elabora, procesa, empaca y cocina, y el hombre sale a venderlos fuera del municipio productor (en ocasiones, se ven mujeres en esta etapa).

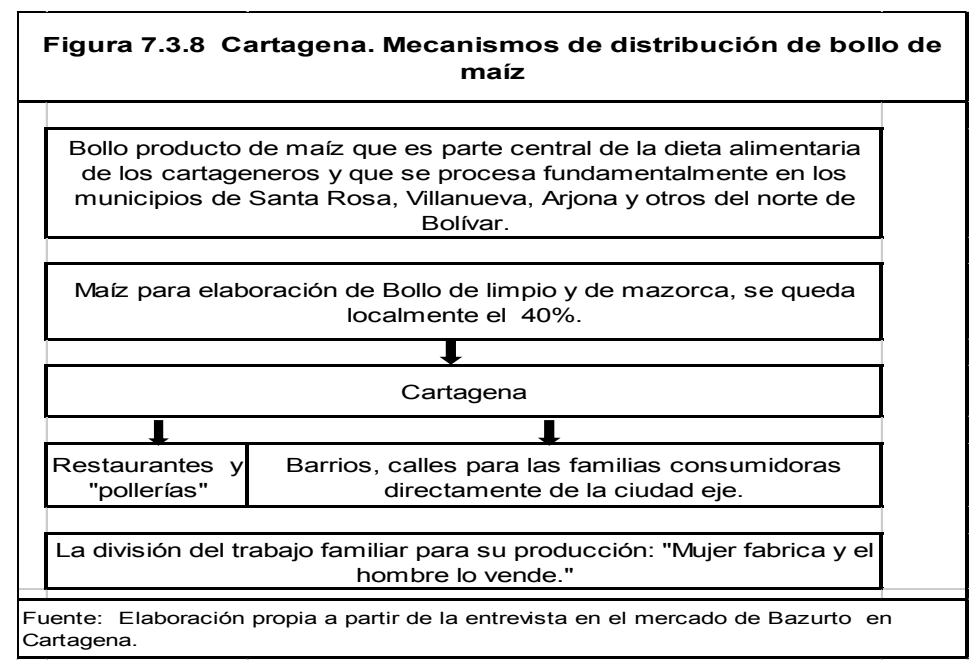

Respecto a la distribución de verduras y frutas (figura 7.3.9), este presenta dos o tres niveles de intermediaciones que dependen del camino tomado para acceder a su compra. El productor campesino tiene vínculos con el intermediario local, que lleva los agroalimentos a los mayoristas de Bazurto. Allí, los agroalimentos toman dos vías para llegar al consumidor final: una directo a las familias, y otro a través de los supermercados, las tiendas y los carretilleros. Con estas dos últimas formas, las familias van a la tienda, o el carretillero le lleva a la puerta de la casa, en cuyo precio se asume el costo del crédito del carretillero. 


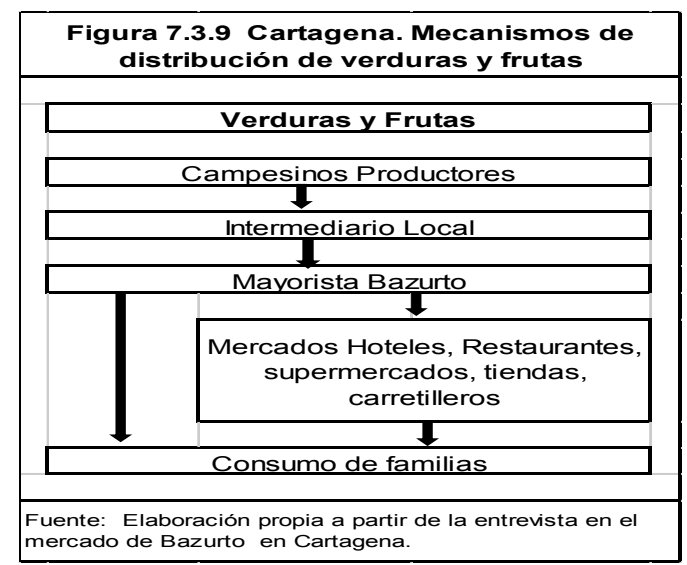

Gasto de las familias según canal de distribución de alimentos. Respecto al pan y los cereales, las tiendas de barrio ocupan el primer lugar en gastos, con el 71,7\%, y el $86,6 \%$ de hogares. Luego están los grandes supermercados y, por último, varios. Los totales de gastos mensuales son: \$7.133.971.968, con una participación del 91\% del gasto del eje, y 1.108.924 hogares atendidos, con una cobertura del 96\%.

En el grupo carnes, los tres primeros canales de comercialización tienen un 90\% del gasto y $93 \%$ de los hogares; las tiendas de barrio tienen $66,6 \%$ del gasto y el $82,9 \%$ de hogares, que es el mayor componente atendido por este canal. Luego están los grandes supermercados, con el $18,5 \%$ y el $7,9 \%$ respectivamente; tercero, los supermercados de barrio, con el $5,29 \%$ y el 2,36\%.

Por su parte, en el grupo pescados, la particularidad de la ciudad eje, se maneja por cuatro sectores, con $85 \%$ del gasto y el $90 \%$ de los hogares: primero están las tiendas de barrio, con el 37,5\% de gastos y el 50,6\% de hogares; luego están los vendedores ambulantes o las ventas callejeras, carretilleros o carros, con el 29,5\% del gasto y el 24,7\% de hogares; tercero, los grandes supermercados, con el 11,4\% y el 7,0\%, respectivamente; por último, varios, con el 7,0\% en gastos y el 8,0\% en hogares. Es el segundo producto con más vendedores en las ciudades eje.

El grupo de leche, queso y huevos tiene la misma dinámica del primer grupo, con el 94\% en gasto y el $97 \%$ en hogares, en este, las tiendas reciben el 80,2\% del gasto y el 91,2\% de los hogares; luego están los grandes supermercados, con el 10,7\% y el 3,7\%, respectivamente; por último, están varios. 


\begin{tabular}{|c|c|c|c|c|c|c|c|c|c|c|}
\hline \multicolumn{2}{|c|}{$\begin{array}{l}\text { Grupos de } \\
\text { alimentos, } \\
\text { Hogares y } \\
\text { Gastos }\end{array}$} & \multirow{2}{*}{\begin{tabular}{|c|}
$\begin{array}{c}\text { Almacenes, } \\
\text { supermercados } \\
\text { de cadena e } \\
\text { hipermercados }\end{array}$ \\
926.595 .838 \\
\end{tabular}} & \multirow{2}{*}{\begin{tabular}{|r|}
$\begin{array}{c}\text { Central } \\
\text { mayorista de } \\
\text { abastecimiento }\end{array}$ \\
111.251 .472 \\
\end{tabular}} & \multirow{2}{*}{$\begin{array}{l}\text { Graneros } \\
124.459 .912 \\
\end{array}$} & \multirow{2}{*}{$\begin{array}{c}\begin{array}{c}\text { Plazas de } \\
\text { mercado y } \\
\text { galerias }\end{array} \\
42.602 .918 \\
\end{array}$} & \multirow{2}{*}{\begin{tabular}{|c}
$\begin{array}{c}\text { Supermercados } \\
\text { de barrio }\end{array}$ \\
216.474 .432 \\
\end{tabular}} & \multirow{2}{*}{$\begin{array}{c}\begin{array}{c}\text { Tiendas de } \\
\text { barrio }\end{array} \\
5.116 .829 .307\end{array}$} & \multirow{2}{*}{\begin{tabular}{|c|}
$\begin{array}{c}\text { Vendedores } \\
\text { ambulantes o } \\
\text { ventas } \\
\text { callejeras }\end{array}$ \\
115.628 .471
\end{tabular}} & \multirow{2}{*}{$\begin{array}{l}\text { Varios }^{*} \\
480.129 .618 \\
\end{array}$} & \multirow{2}{*}{\begin{tabular}{|l} 
Total Gastos \\
7.133 .971 .968 \\
\end{tabular}} \\
\hline \multirow{4}{*}{ 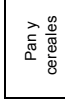 } & G.M. & & & & & & & & & \\
\hline & $\%$ & 13 & 2 & 2 & 1 & 3 & 72 & 2 & 7 & 100 \\
\hline & No.H & 58.050 & 3.021 & 9.534 & 5.880 & 11.474 & \begin{tabular}{l|l|}
959.957 \\
\end{tabular} & 15.487 & 45.520 & 1.108 .924 \\
\hline & $\%$ & 5 & 0 & 1 & 1 & 1 & 87 & 1 & 4 & 100 \\
\hline \multirow{4}{*}{ 怘 } & G.M. & 2.234 .147 .068 & 186.090.908 & 348.394.399 & 138.435 .999 & 627.702 .943 & 8.048 .143 .379 & 165.123.676 & 339.381 .048 & 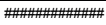 \\
\hline & $\%$ & 18 & 2 & 3 & 1 & 5 & 67 & 1 & 3 & 100 \\
\hline & No.H & 50.814 & 4.486 & 9.105 & 5.732 & 15.140 & 530.738 & 5.222 & \begin{tabular}{|l|l|}
19.083 \\
\end{tabular} & 640.320 \\
\hline & $\%$ & 8 & 1 & 1 & 1 & 2 & 83 & 1 & 3 & 100 \\
\hline \multirow{4}{*}{ ర্] } & G.M. & 217.200 .224 & 38.526 .976 & 52.193 .991 & \begin{tabular}{|l|}
112.732 .791 \\
\end{tabular} & 74.266 .920 & $\begin{array}{l}712.869 .329 \\
\end{array}$ & 561.039 .911 & \begin{tabular}{|l|}
132.851 .911 \\
\end{tabular} & 1.901.682.052 \\
\hline & $\%$ & 11 & 2 & 3 & 6 & 4 & 37 & 30 & 7 & 100 \\
\hline & No.H & 6.519 & 1.756 & 1.991 & 3.775 & 1.632 & 47.258 & 23.089 & 7.427 & 93.447 \\
\hline & $\%$ & 7 & 2 & 2 & 4 & 2 & 51 & 25 & 8 & 100 \\
\hline \multirow{4}{*}{ 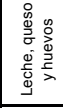 } & G.M. & 687.679 .796 & 12.158.283 & \begin{tabular}{|l|}
82.584 .261 \\
\end{tabular} & 30.472 .662 & 192.157.634 & 5.149 .326 .070 & 55.896.283 & 207.379 .616 & 6.417.654.607 \\
\hline & $\%$ & 11 & 0 & 1 & 0 & 3 & 80 & 1 & 3 & 100 \\
\hline & No.H & 34.542 & 610 & 7.848 & 1.635 & 10.691 & 863.919 & 5.010 & 23.017 & 947.272 \\
\hline & $\%$ & 4 & 0 & 1 & 0 & 1 & 91 & 1 & 2 & 100 \\
\hline \multirow{4}{*}{ 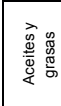 } & G.M. & 288.472 .879 & 40.460 .917 & 51.629 .998 & \begin{tabular}{|l|l|}
19.241 .057 \\
\end{tabular} & \begin{tabular}{|l|l|}
95.056 .139 \\
\end{tabular} & 1.141 .383 .722 & & \begin{tabular}{|l|}
37.627 .872 \\
\end{tabular} & 1.673 .872 .585 \\
\hline & $\%$ & 17 & 2 & 3 & 1 & 6 & 68 & & 2 & 100 \\
\hline & No.H & 10.722 & 1.663 & 3.264 & 2.381 & 4.236 & 252.568 & & 4.492 & 279.326 \\
\hline & $\%$ & 4 & 1 & 1 & 1 & 2 & 90 & & 2 & 100 \\
\hline \multirow{4}{*}{ 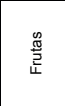 } & G.M & 300.608 .171 & 9.507 .796 & 41.031 .214 & 36.186 .577 & \begin{tabular}{|l|l|}
64.386 .118 \\
\end{tabular} & 924.298 .431 & 236.618 .470 & \begin{tabular}{|l|l|}
66.611 .943 \\
\end{tabular} & 1.649.248.721 \\
\hline & $\%$ & 18 & 1 & 2 & 2 & 4 & 56 & 14 & 2 & 100 \\
\hline & No.H & 25.139 & 1.250 & 6.257 & 6.272 & 6.929 & 281.488 & 36.742 & 9.536 & 373.613 \\
\hline & $\%$ & 7 & 0 & 2 & 2 & 2 & 75 & 10 & 3 & 100 \\
\hline
\end{tabular}

Por otro lado, el grupo de grasas y aceites está en la misma dinámica del segundo, con tres canales que cubren el $91 \%$ en gasto y el $96 \%$ de hogares; las tiendas cubren el $68,2 \%$ del gasto y el 90,4\% de hogares; los grandes supermercados tiene el 17,2\% y el 3,8\%, respectivamente; y finalmente, los supermercados de barrio, con el 5,7\% de gastos y el $1,5 \%$ de hogares.

En el grupo de frutas está la misma dinámica que la del pescado, con el $76 \%$ en gasto y el $85 \%$ de hogares; las tiendas de barrio son primero en gastos, con $56,0 \%$, y con el $75.3 \%$ en hogares; los grandes supermercados tienen el 18,2\% del gasto y el 6,7\% de cobertura de hogares; finalmente, los vendedores ambulantes tienen el 14,4\% y el $9,8 \%$, respectivamente.

Reglamentaciones. El principal sitio de distribución de agroalimentos en Cartagena es el Mercado de Bazurto, ubicado en el mismo lugar desde mediados de la década del sesenta del siglo XX:

Después de la lamentable y trágica explosión en el año 1965 del antiguo Mercado Municipal de Cartagena, para entonces ubicado 
entre el Arsenal y el perímetro donde hoy se encuentra el Centro de Convenciones de Cartagena de Indias: Julio César Turbay Ayala, las autoridades municipales del momento optaron por su reubicación en el sector de 'Las Quintas', lugar este, donde actualmente se encuentra operando el envejecido, destartalado e insalubre dispensario de alimentos y servicios comerciales, Mercado de Bazurto ${ }^{460}$.

Esta expresión refleja las condiciones de la comercialización de alimentos en Cartagena, en este sitio. El POT del 2001 consideró su reubicación, dado que la zona en que está es un "cuello de botella", y por cuanto el Plan de 1948 consideró al respecto:

Debía mantenerse libre para facilitar el transporte en la ciudad de Cartagena. El mercado fue finalmente trasladado generando, tal como había sido previsto, graves problemas de congestión urbana pues ha seguido cumpliendo las funciones de mercado central para el área que concentra la mayor población urbana y del centro de abastecimiento mayorista, que aún la ciudad espera ver construido ${ }^{461}$.

Por esto, hay conflictos urbanísticos, higiénicos, sanitarios, congestión de transporte urbano y problemas de inocuidad en la distribución de los alimentos de la ciudad eje. Desde hace varios años se han identificado los principales problemas por la ubicación y administración de este mercado:

Hace aproximadamente veinte años, la ciudad de Cartagena de Indias perdió el control de su mercado más grande de alimentos: El Mercado de Bazurto durante el proceso de privatización de la empresa de energía eléctrica de la ciudad, identificando algunos problemas:

$\mathbf{1}^{\text {o }}$. Vendedores Informales y Espacio Público: Los vendedores formales del interior del casco del edificio de Bazurto al no disponer de servicios de agua y recolección de basuras, encontraron que sus clientes evitaban entrar a comprarles. Fue así como estos empezaron

460 El Universal (2012): "Mercado de Bazurto, un container de problemas en la gestión distrital".

461 Secretaría de Planeación Distrital de Cartagena (2009): Revisado y aprobado Arq. Antonio Nieves González Director Administrativo de Control Urbano, pág. 3. 
a salir en su búsqueda y montaron sus puestos de venta en los espacios públicos de los alrededores del mercado. Esta práctica atrajo nuevos compradores y estos a su vez indujeron la aparición de cada vez más vendedores informales.

2o. Tráfico: El mayor número de vendedores informales minoristas ubicados en las calles ha atraído más compradores que se aglomeran en las calles alrededor del Mercado.

$3^{\circ}$. Gobernabilidad y Capacidad Institucional: El mercado y su comunidad padecen de una gran desconfianza entre los actores mismos - vendedores detallistas y mayoristas, clientes (tenderos y jefes de hogar) y funcionarios del gobierno. Por otro lado las asociaciones de vendedores existentes no han logrado asociar a todos los comerciantes de la zona generándose una gran atomización ${ }^{462}$.

Estos problemas de manejo del mayor mercado de alimentos de la ciudad llevan a una convivencia de condiciones no aptas para comercializar en medio de una población con altos índices de pobreza. Desde el 2001, la propuesta del POT consideró en su artículo 17, punto 4: "El Sistema de Mercados. Con el fin de descentralizar la actividad de abastecimiento de alimentos de la población urbana, se definirán mercados para cada una de las 4 zonas, complementadas con mercados móviles" ${ }^{463}$. Las reglamentaciones sobre este problema urbano de distribución de alimentos en la ciudad se consideran prioritarias y de urgente solución.

\subsubsection{Distribución en el eje Neiva}

La distribución de agroalimentos se analiza con información de entrevistas en el mercado de Surabastos de Neiva y en municipios cercanos con productores y funcionarios.

462 Massachusetts Institute of Technology, Department of Urban Studies and Planning y Universidad Tecnológica de Bolívar (2010): "Retos y oportunidades para la acción en Bazurto: análisis de cuatro cadenas de abastecimiento e implicaciones para la ciudad de Cartagena (resumen ejecutivo). Cartagena, págs. 5 y ss. De este documento solo se enumeran 3 de los 5 problemas identificados por estas universidades.

463 Alcaldía de Cartagena (2001): Decreto No 0977 de 2001, por medio del cual se adopta el Plan de Ordenamiento Territorial del Distrito Turístico y Cultural de Cartagena de Indias. 


\section{Condiciones de la distribución de algunos productos de la canasta familiar}

en el eje Neiva. Las dinámicas de comercialización de esta ciudad eje encuentran en su contexto regiolocal las mismas condiciones de concentración del comercio de alimentos y frutas. En el caso del fríjol en el Huila se encuentra:

La estructura de mercadeo se caracteriza por la concentración en el manejo de la producción por parte de los mayoristas regionales, quienes manejan a los intermediarios transportadores regionales; estos a su vez, a los comisionistas y estos a los productores ${ }^{464}$.

El departamento del Huila es productor de diversos agroalimentos, y para su comercialización tiene distintos espacios de acopio en los mercados locales y en el regional Surabastos de la ciudad eje. Allí, el productor campesino va excepcionalmente. Esta comercialización tiene poca intermediación para las familias, lo que disminuye los costos (figura 7.3.10).

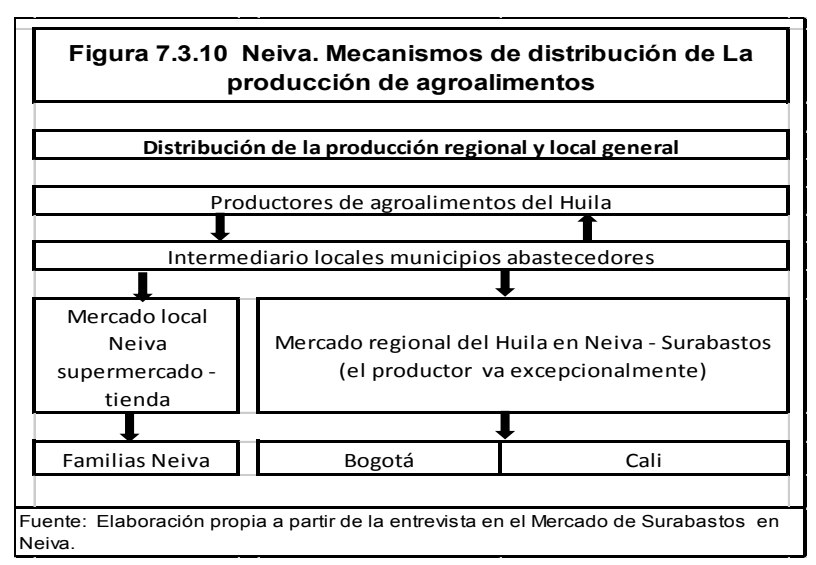

Por la importancia del Huila, contexto regiolocal de la ciudad eje de Neiva, y dada su producción frutícola, es un gran centro de acopio de frutas a través de Surabastos. La figura 7.3.11 muestra la concentración en el comercio de frutas; entre el 80 y 85\% del mercado se controla por 6 comerciantes, el 10\% está entre 10 y 15 comerciantes y el $5 \%$ entre 20 y 25 pequeños comerciantes.

464 FORERO A., Jaime y RUDAS, Guillermo (1991): Los acopiadores rurales de la producción... Op. cit., pág. 144. 


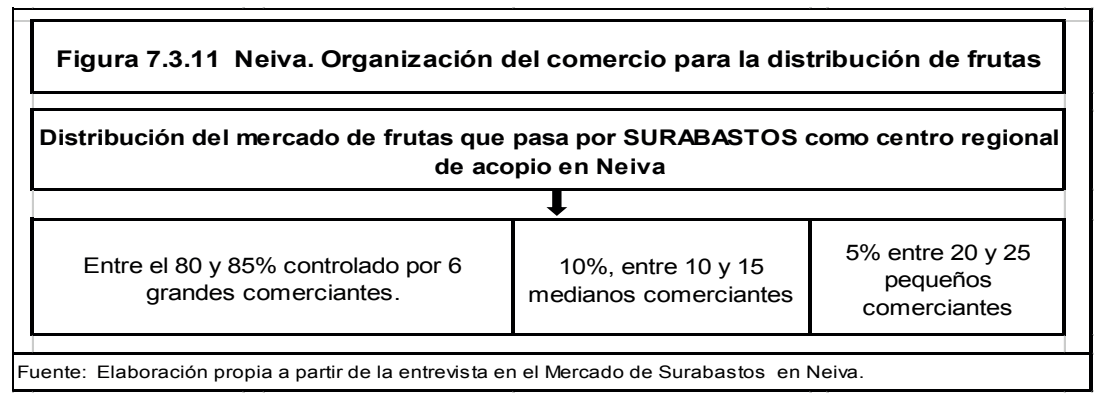

La cadena de frutas para el mercado regional se complementa con la entrada a Surabastos de los campesinos, espacio que tienen en época de cosecha para vender sus productos, igual que los comerciantes de otros municipios. Surabastos es utilizado por las familias directamente, sin intermediación entre productor y consumidor (figura 7.3.12).

\begin{tabular}{|c|c|c|c|}
\hline \multicolumn{4}{|c|}{ Figura 7.3.12 Neiva. Mecanismos de distribución de frutas } \\
\hline \multicolumn{4}{|c|}{ CADENA DE FRUTALES SURABASTOS MERCADO REGIONAL } \\
\hline \multicolumn{4}{|c|}{ 10. Entrada para la distribución } \\
\hline Campesinos & \multicolumn{2}{|c|}{$\begin{array}{l}\text { Espacio para campesino de productos de } \\
\text { cosecha }\end{array}$} & $\begin{array}{c}\text { Comerciantes locales } \\
\text { de otros municipios }\end{array}$ \\
\hline \multicolumn{4}{|c|}{ 2o. Comercio de mayoristas } \\
\hline \multicolumn{2}{|c|}{$\begin{array}{c}\text { Fruta fina; productos americanos } \\
\text { importados, La Camponesa, Javier Cleves }\end{array}$} & $\begin{array}{c}\text { Cholupa y maracuyá: } \\
\text { frutas Neiva y bodega } 111\end{array}$ & $\begin{array}{l}\text { Papaya, sandía y } \\
\text { melón: 1a. Bodega }\end{array}$ \\
\hline \multicolumn{2}{|c|}{$\begin{array}{l}\text { 3o. A. Otros mercados: nacionales y } \\
\text { regionales }\end{array}$} & \multicolumn{2}{|c|}{ 3o. B. Mercado local Neiva } \\
\hline \multicolumn{2}{|c|}{$\begin{array}{l}\text { Bogotá Corabastos, Carrefour, YEP, } \\
\text { Carulla, Pitalito - Florencia, Ibagué }\end{array}$} & \multicolumn{2}{|c|}{$\begin{array}{l}\text { Supermercados - tiendas - fruvers - carretilleros } \\
\text { informales del centro y de los barrios- familias }\end{array}$} \\
\hline \multicolumn{4}{|c|}{ Familias } \\
\hline
\end{tabular}

Los mayoristas dependen de la calidad de la fruta, por las exigencias del mercado internacional luego de estar seleccionada; el resto se ofrece al comercio local con espacio para el acceso de familias, y luego a otros destinos, locales y regionales. Dada la cercanía a zonas productoras de granos y cereales, esta provisión pasa del mayorista a las familias, las tiendas y los reempacadores (figura 7.3.13). 


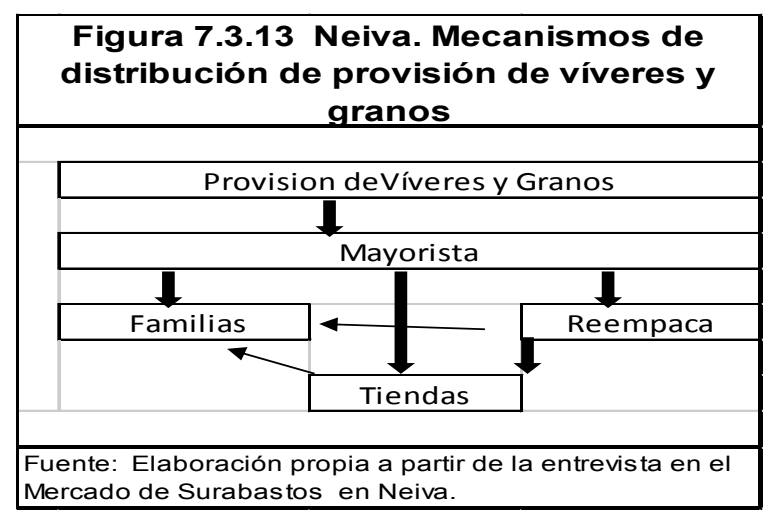

Las acciones públicas nacionales, en articulación con el programa Red de Seguridad Alimentaria (RESA), otorgan un incentivo que promueve procesos organizativos a campesinos que participan en el comercio de agroalimentos y en nuevos productos que mejoren sus ingresos: "[Hay] grupos asociativos para participar en las ferias agropecuarias, ruedas de negocios para la comercialización para construir nuevos mercados con comercio para Neiva con 4 grupos organizados" ${ }^{465}$. Con ello busca mejorarse las condiciones de seguridad alimentaria en el campo y en la ciudad eje.

No obstante, hay problemas de manejo de la información de destino de los agroalimentos en municipios de la región del eje: "No hay información del consumo local y por ejemplo, la cebolla se vende en el mercado local, va a Neiva y vuelve" ${ }^{466}$. Esta movilidad de agroalimentos implica altos costos económicos, ambientales, sociales y de acceso.

Por otro lado, el intercambio y la comercialización de agroalimentos en varias zonas del Huila están vinculados a la "estrategia de seguridad alimentaria de RESA a través del trueque" ${ }^{467}$, y se evidencia en municipios de la región inmediata, como también en la principal distribuidora de agroalimentos del eje Neiva, Surabastos: "Se presentan espacios los días martes, jueves, viernes, sábado y domingo para los mercados campesinos del departamento del Huila, y así puedan comercializar sus productos de cosecha" ${ }^{468}$.

465 BONILLA, Virginia (2008): Entrevista. Directora de la UMATA, municipio de Algeciras, departamento del Huila, 5 de noviembre.

466 Ibíd.

467 CORTÉS, Armando y CORTÉS, Yeris (2008): Entrevista. Director y técnico de la UMATA, municipio de Campoalegre, departamento del Huila, 6 de noviembre.

468 MOLANO, Danleyner (2008): Entrevista. Coordinador de la plaza de Surabastos, municipio de Neiva, departamento del Huila, 6 de noviembre. 


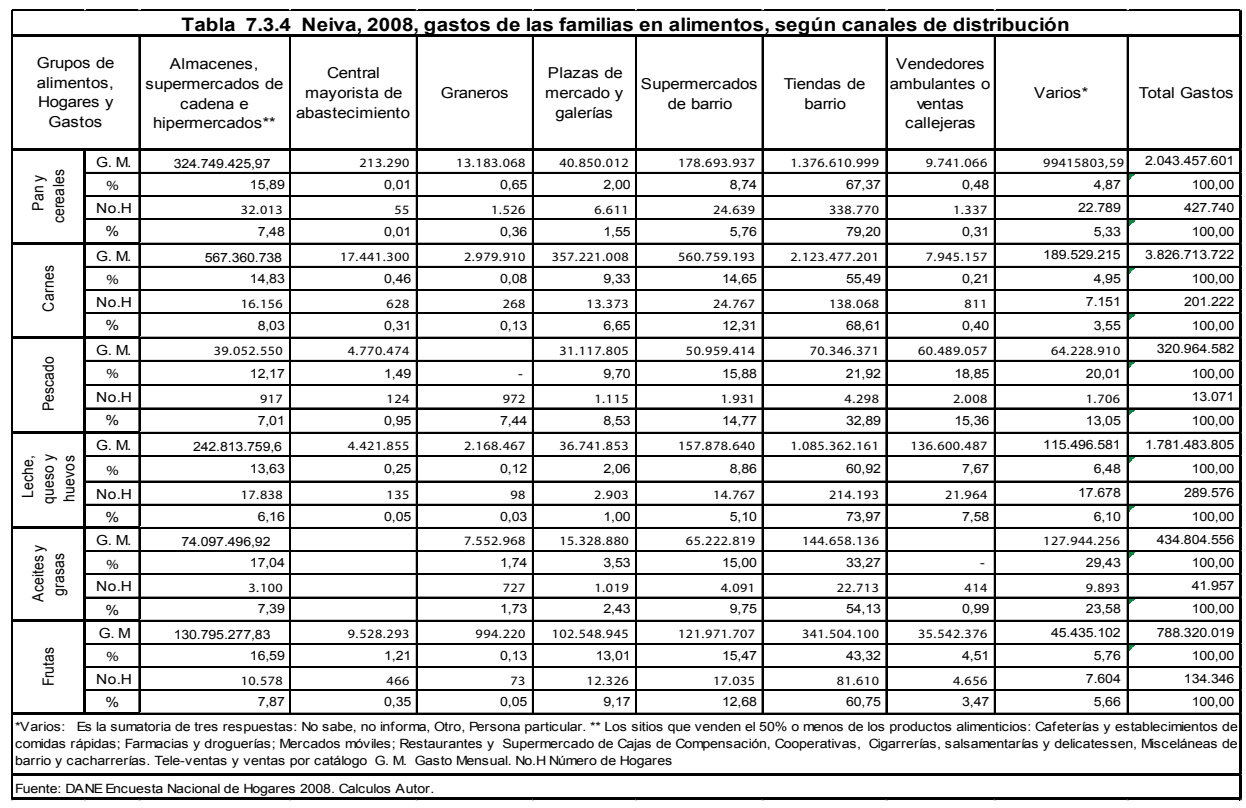

Esto beneficia a los pobladores de la ciudad, pues mejora el acceso por la vía de comercio directo entre productor y consumidor, por cuanto hay precios más bajos. Esta es una práctica en varias ciudades a través de los llamados mercados campesinos.

Gasto de las familias según canal de distribución. Respecto al primer grupo, pan y cereales, las tiendas de barrio son primeras en gastos, con el 67,4\%, y en hogares, con el 79,2\%. Les siguien los grandes supermercados, con el 15,9\% en gastos y el 7,5\% en hogares; y los supermercados de barrio, con el 8,74\% en gastos y el 5,76\% de hogares. La cobertura de estos tres canales es $92 \%$ en ambos ítems.

En el grupo de carnes, los tres primeros canales, con un total de $85 \%$ del gasto y el $89 \%$ de los hogares, son: las tiendas de barrio, que tiene un primer lugar en gastos, con el $55,5 \%$, y cubre el 68,6\% de hogares, lo cual representa la mayor atención dada por este canal de comercio; a su vez, los grandes supermercados tienen el 14,8\% del gasto y el $8,03 \%$ de cobertura de hogares, mientras los supermercados de barrio tienen el 14,7\% y el $12.31 \%$, respectivamente.

En el grupo de pescados de esta ciudad eje se manejan cuatro canales, con un total de 77\% del gasto y el 76\% de hogares: primero, las tiendas de barrio, que representan en gastos el 21,9\% y en hogares el 32,9\%; el segundo grupo en gastos lo ocupa la columna de "varios", con el 20,0\%, y le siguen los vendedores ambulantes o las ventas callejeras, 
con el 18.9\%, y los supermercados de barrio, con el 15,9\%. En cobertura de hogares, están los vendedores ambulantes o las ventas callejeras, con el 15,4\%, los supermercados de barrio, con el 14,8\%, y varios, con el 13,1\%.

El grupo leche, queso y huevos tiene cuatro canales, con el $83 \%$ en gasto y el $88 \%$ en hogares: las tiendas de barrio cubren el 60,9\% y el 74,0\%, respectivamente; en los gastos siguen los grandes supermercados, con el 13,6\%, y los supermercados de barrio, con el $8,9 \%$; en cuanto a hogares, están los vendedores ambulantes o las ventas callejeras, con el 7,6\%, y los grandes supermercados, con el 6,2\%.

En el grupo de grasas y aceites hay cuatro canales, con el 95\% en gasto y en hogares: las tiendas tiene el 33,3\% y el 54,1\%, respectivamente; luego, sobre los gastos, se ubica la columna "varios", con el 29,4\%, los grandes supermercados, con el 17,0\%, y los supermercados de barrio, con el 15,0\%. En cobertura de hogares, varios tienen el $23,6 \%$, en tanto los supermercados de barrio cubre el $9,75 \%$ y los grandes supermercados, el 7,4\%.

En el grupo de frutas hay cuatro canales, con el $88 \%$ en gasto y el $90 \%$ de hogares: las tiendas de barrio cubre el 43,3\% y el 60,8\%, respectivamente. Son ellas el primer canal de comercio de frutas del eje. En relación con los gastos, los grandes supermercados cubre el 16,6\%; los supermercados de barrio, el 15,5\%; las plazas de mercado y galerías, el $13,0 \%$. Respecto a la cobertura de hogares, los supermercados de barrio tienen el 12,7\%; las plazas de mercado y galerías, el 9,2\%; y los grandes supermercados, el 7,9\%. Las tiendas de barrio son el principal centro de distribución de alimentos y ocupan el mayor porcentaje de uso por los pobladores.

Reglamentaciones. En el Plan de Ordenamiento Territorial de Neiva se prevé sobre los abastos y el comercio: "Comprende las instalaciones destinadas al proceso de recepción, embalaje, almacenaje de productos no procesados y a su distribución en el Municipio, tales como plazas de mercado, mataderos, frigoríficos y centrales de abastos entre otros" ${ }^{469}$. Los permisos que han sido otorgados en Neiva para grandes superficies se adjudicaron para los supermercados Éxito, Olímpica, Carulla, Comfamiliar Huila, Yep, Ley, Supermercado Superior y Supermercado Centro Sur ${ }^{470}$.

469 Plan de ordenamiento territorial del municipio de Neiva. P.O.T. Artículo 20 http://cdim. esap.edu.co/

470 Ibíd., pág. 25. 


\subsubsection{Distribución en el eje Cúcuta}

La distribución de agroalimentos se analiza con información de entrevistas en el mercado de Cenabastos de San José de Cúcuta, y en municipios cercanos como centros de relevo de almacenamiento y del área inmediata con productores y funcionarios.

\section{Condiciones de la distribución de algunos productos de la canasta familiar} en el eje Cúcuta. La comercialización de agroalimentos para el consumo en Cúcuta se vincula con el área metropolitana de seis municipios: Puerto Santander, Los Patios, Villa del Rosario, El Zulia, San Cayetano y San José de Cúcuta. Además, está en la frontera con Venezuela, y allí el mercado se ve afectado por la tasa de cambio del Bolívar y los precios de lado y lado de la frontera, así como por las políticas de los Gobiernos nacionales y del orden departamental, metropolitano y local.

Respecto a los mecanismos de comercio de fríjol fresco (figura 7.3.14), el productor campesino lo vende al intermediario local, y el producto toma dos vías: la directa a las familias o la del mayorista de Cenabastos, que lo distribuye por las estructuras de comercio de la ciudad y el área metropolitana, para llegar al consumo. Parte de este agroalimento va al mercado venezolano con el mecanismo normal de comercio.

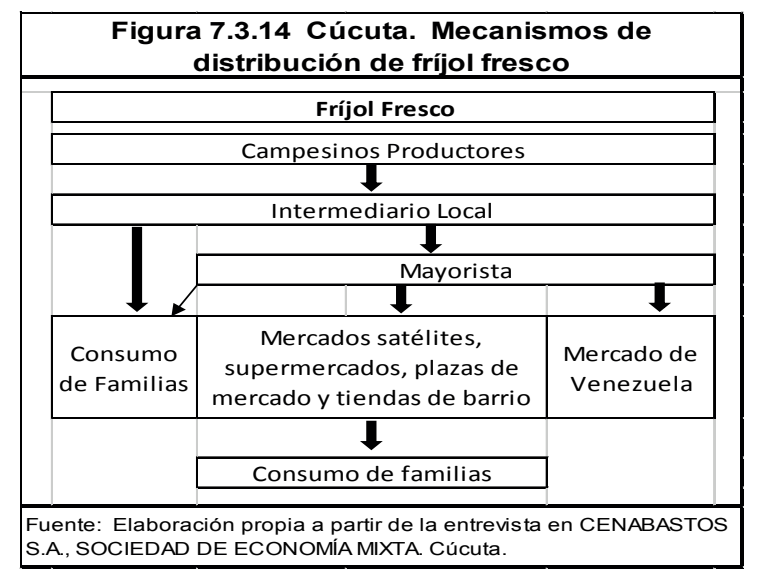

La distribución de arroz en la central de Cenabastos (figura 7.3.15) vincula las relaciones comerciales con Venezuela, porque este llega por diferentes medios y se procesa en los molinos de la región. Este comercio exterior en la frontera es independiente de las relaciones entre Bogotá y Caracas, ya que la vida en la frontera y el día a día permiten la importación legal o clandestina, y los excedentes se llevan al interior del país. 
El arroz, base de la dieta alimentaria de colombianos y venezolanos en la zona de frontera, tiene origen en el interior de Colombia. Su dinámica comercial está en función de las condiciones de importaciones de Venezuela y la tasa de cambio del Bolívar.

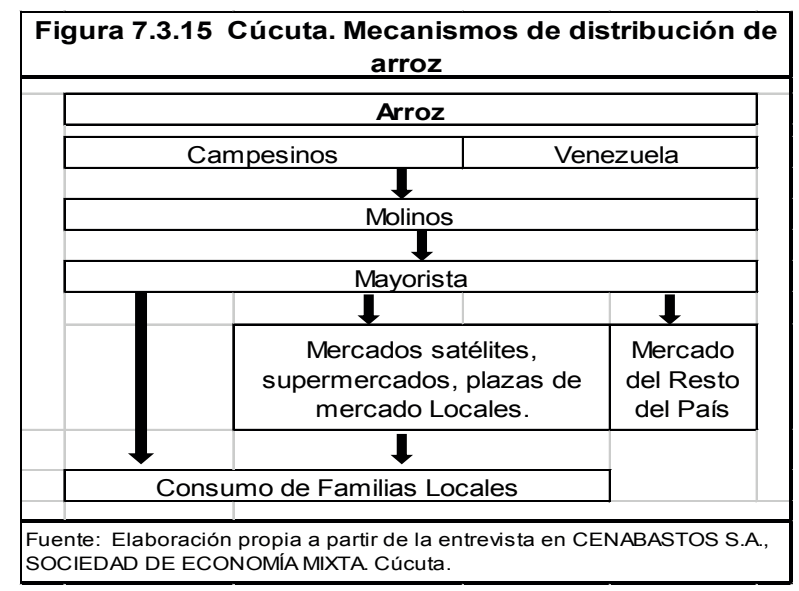

La papa, con origen en el Norte de Santander, tiene tres vías para llegar a las familias (figura 7.3.16): los productores campesinos lo venden al intermediario local, y este lo divide: una parte va directamente a las familias y otra, al mayorista de Cenabastos. Este último es quien la distribuye a las familias, o bien, por los comercios de la ciudad y el área metropolitana, para llegar al consumo. Otra parte va al mercado de Venezuela.

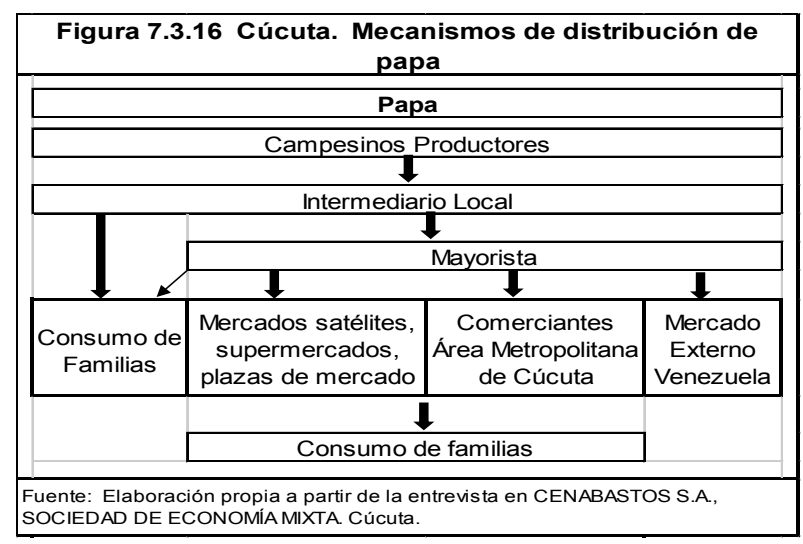

Respecto al comercio de plátano (figura 7.3.17), los campesinos lo venden al intermediario local, y este lo divide: una parte va directamente a las familias y otra, al mayorista de Cenabastos. Este último es quien lo distribuye en el comercio de la ciudad y el área metropolitana, para llegar al consumidor. Este agroalimento no ingresa al mercado venezolano y es parte de la dieta regional del oriente colombiano. 
En la región inmediata de la ciudad eje, Norte de Santander, hay centros regionales de distribución de alimentos que funcionan como espacios de relevo de acopio de alimentos, lo dinámica que afecta los precios a causa de la intermediación comercial. En Pamplona hay diferentes comerciantes: "Los que llevan a Cúcuta y/o Bucaramanga entregándolo a otro comerciante antes del tendero o consumidor final con procesos de reempaque" ${ }^{471}$. Esto afecta el acceso vía precios para las familias.

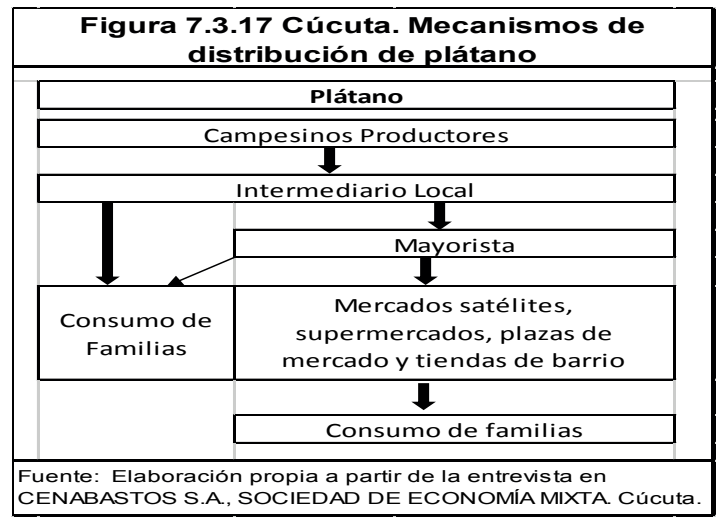

Gasto de las familias según canal de distribución. El grupo de pan y cereales se distribuye por varios canales: las tiendas de barrio, que en gastos cubre el 32,8\% y en hogares, el 55,2\%. En relación con los gastos, siguen los supermercados de barrio, con el 32,8\%; los grandes supermercados, con el 17,6\%; y varios, con el 10,3\%. En relación con los hogares, siguen los supermercados de barrio, con el 27,8\%; varios, con el 11,7\%; y las plazas de mercado y galerías, con el 2,3\%.

El grupo de carnes tiene cuatro canales de comercio, con el 89\% del gasto y el 91\% de los hogares. En relación con lo primero gastos, los supermercados de barrio tienen el 42,4\%, las tiendas de barrio cubre el 28\%, las plazas de mercado y galerías, el 11,0\% y varios tienen el $8,1 \%$. En relación con los hogares, las tiendas de barrio tienen el $39,0 \%$, los supermercados de barrio, el 36,9\%; varios, el 7,9\%; y las plazas de mercado y galerías, el 7,6\%.

El grupo de pescados tiene cuatro canales que manejan el mercado, con el $74 \%$ del gasto y el 84\% de hogares. Primero están los supermercados de barrio, con el 32,0\% y el 32,4\%, respectivamente En relación con los gastos, varios cubre el 14,5\%, en tanto

471 BUSTOS C., José J. (2008): Entrevista. Profesor Instituto Superior de Educación Rural ISER, municipio de Pamplona, Norte de Santander, 27 de noviembre. 
las tiendas de barrio tienen el 13,9\% y los vendedores ambulantes o las ventas callejeras, el 13,2\%. En relación con los hogares, las tiendas de barrio cubre el 28,1\%; varios, el 12,1\%; y los vendedores ambulantes o las ventas callejeras, el 11,7\%.

\begin{tabular}{|c|c|c|c|c|c|c|c|c|c|c|}
\hline \multicolumn{2}{|c|}{$\begin{array}{c}\text { Grupos de } \\
\text { alimentos, } \\
\text { Hogares y } \\
\text { Gastos }\end{array}$} & \multirow{2}{*}{\begin{tabular}{|c} 
Almacenes, \\
$\begin{array}{c}\text { supermercados de } \\
\text { cadena e } \\
\text { hipermercados }\end{array}$ \\
$811.756 .260,15$
\end{tabular}} & \multirow{2}{*}{\begin{tabular}{|r|}
$\begin{array}{c}\text { Central } \\
\text { mayorista de } \\
\text { abastecimiento }\end{array}$ \\
14.300 .796 \\
\end{tabular}} & \multirow{2}{*}{$\begin{array}{l}\text { Graneros } \\
31.935 .340\end{array}$} & \multirow{2}{*}{\begin{tabular}{|c|}
$\begin{array}{c}\text { Plazas de } \\
\text { mercado y } \\
\text { galerias }\end{array}$ \\
121.219 .297 \\
\end{tabular}} & \multirow{2}{*}{\begin{tabular}{|c|}
$\begin{array}{c}\text { Supermercados } \\
\text { de barrio }\end{array}$ \\
1.513 .278 .097 \\
\end{tabular}} & \multirow{2}{*}{$\begin{array}{c}\begin{array}{c}\text { Tiendas de } \\
\text { barrio }\end{array} \\
1.606 .464 .236\end{array}$} & \multirow{2}{*}{\begin{tabular}{|c|}
$\begin{array}{c}\text { Vendedores } \\
\text { ambulantes o } \\
\text { ventas } \\
\text { callejeras }\end{array}$ \\
33.791 .726 \\
\end{tabular}} & \multirow{2}{*}{\begin{tabular}{|l|} 
Varios* $^{*}$ \\
476821779
\end{tabular}} & \multirow{2}{*}{$\begin{array}{c}\text { Total Gastos } \\
4.609 .567 .530\end{array}$} \\
\hline \multirow{4}{*}{ 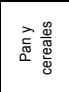 } & G. M. & & & & & & & & & \\
\hline & $\%$ & 17,61 & 0,31 & 0,69 & 2,63 & 32,83 & 34,85 & $\begin{array}{ll}0,73 \\
\end{array}$ & 10,34 & 100,00 \\
\hline & No.H & $13.129,43$ & 1.632 & 2.542 & 15.764 & 189.433 & 375.899 & 3.535 & 79.489 & 681.423 \\
\hline & $\%$ & 1,93 & 0,24 & 0,37 & 2,31 & 27,80 & 55,16 & 0,52 & \begin{tabular}{ll|}
11,67 \\
\end{tabular} & 100,00 \\
\hline \multirow{4}{*}{ 岕 } & G. M. & 778.762 .362 & 199.995 .776 & & \begin{tabular}{|l}
1.092 .424 .685 \\
\end{tabular} & 4.213 .080 .731 & 2.785 .400 .966 & 73.588 .872 & 805.562 .734 & 9.948 .816 .127 \\
\hline & $\%$ & 7,83 & 2,01 & -1 & 10,98 & 42,35 & 28,00 & 0,74 & 8,10 & 100,00 \\
\hline & No.H & 21.553 & 6.365 & 9.105 & 35.471 & 171.451 & 181.299 & 3.508 & 36.499 & 465.251 \\
\hline & $\%$ & 4,63 & 1,37 & 1,96 & 7,62 & 36,85 & 38,97 & 0,75 & 7,85 & 100,00 \\
\hline \multirow{4}{*}{ 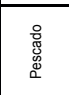 } & G. M. & 109.968 .436 & 55.584 .626 & 1.750 .384 & 102.904 .804 & 327.071 .093 & 142.469 .134 & 135.166 .140 & 148.724 .095 & 1.023 .638 .713 \\
\hline & $\%$ & 10,74 & 5,43 & 0,17 & 10,05 & 31,95 & 13,92 & 13,20 & 14,53 & 100,00 \\
\hline & No.H & 2.594 & \begin{tabular}{|l|}
1.387 \\
\end{tabular} & 202 & 3.459 & 15.701 & 13.652 & \begin{tabular}{ll|}
5.678 \\
\end{tabular} & 5.849 & 48.522 \\
\hline & $\%$ & 5,35 & 2,86 & 0,42 & 7,13 & 32,36 & 28,14 & 11,70 & 12,06 & 100,00 \\
\hline \multirow{4}{*}{ 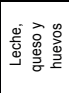 } & G. M. & $258.765 .385,8$ & 38.963 .244 & 7.841 .301 & 106.026 .922 & 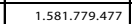 & 1.944 .616 .312 & 68.511 .483 & 378.573 .809 & 4.385 .077 .935 \\
\hline & $\%$ & 5,90 & 0,89 & \begin{tabular}{l|l|}
0,18 \\
\end{tabular} & 2,42 & \begin{tabular}{|l|}
36,07 \\
\end{tabular} & 44,35 & 1,56 & 8,63 & 100,00 \\
\hline & No.H & 16.308 & \begin{tabular}{ll|}
1.977 \\
\end{tabular} & 221 & 7.722 & 132.006 & 345.866 & 6.715 & 51.718 & 562.533 \\
\hline & $\%$ & 2,90 & 0,35 & 0,04 & 1,37 & 23,47 & 61,48 & 1,19 & 9,19 & 100,00 \\
\hline \multirow{4}{*}{ 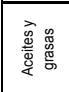 } & G. M. & $70.368 .044,22$ & 5.872 .327 & 12.771 .122 & 35.004 .726 & 553.611 .396 & 356.739 .298 & $\begin{array}{l}4.418 .028 \\
\end{array}$ & 50.560 .444 & 1.089 .345 .385 \\
\hline & $\%$ & 6,46 & 0,54 & 1,17 & 3,21 & 50,82 & 32,75 & 0,41 & 4,64 & 100,00 \\
\hline & No.H & 3.896 & 492 & 829 & 3.121 & 40.929 & 41.355 & 414 & 5.297 & 96.333 \\
\hline & $\%$ & 4,04 & 0,51 & 0,86 & 3,24 & 42,49 & 42,93 & 0,43 & 5,50 & 100,00 \\
\hline \multirow{4}{*}{ 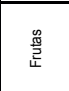 } & G.M & $125.968 .211,45$ & 175.759 .560 & & 246.732 .479 & 574.773 .246 & 363.336 .869 & 193.011 .380 & 126.833 .157 & 1.806 .414 .902 \\
\hline & $\%$ & 6,97 & 9,73 & - & 13,66 & 31,82 & 20,11 & 10,68 & 7,02 & 100,00 \\
\hline & No.H & 14.039 & 10.115 & 6.257 & 35.219 & 91.086 & 93.525 & 31.194 & 21.440 & 302.874 \\
\hline & $\%$ & 4,64 & 3,34 & 2,07 & 11,63 & 30,07 & 30,88 & 10,30 & 7,08 & 100,00 \\
\hline
\end{tabular}

En el grupo leche, queso y huevos hay tres canales, que cubren el $90 \%$ en gasto y el $89 \%$ en hogares. Las tiendas tienen el 44,4\% del gasto y el 61,48\% de los hogares; les siguen los supermercados de barrio, con el 36,1\% del gasto y el 23,5\% de los hogares; y varios, con $8,6 \%$ y $9,2 \%$, respectivamente.

El grupo grasas y aceites tiene tres canales, con el 90\% en gasto y el $89 \%$ de hogares. En relación con lo primero, los supermercados de barrio cubre el 50,8\%, las tiendas de barrio tienen el 32,8\% y los grandes supermercados, el 6.5\%. En relación con la cobertura de hogares, las tiendas de barrio cubre el 42,9\%, los supermercados de barrio, el 42,5\%, y los grandes supermercados, el 4,0\%.

El grupo frutas tiene cuatro canales, con el 76\% en gasto y el $83 \%$ de hogares. En relación con los gastos de las familias, los supermercados de barrio cuentan con el $31,8 \%$, en tanto las tiendas de barrio cubren el 20,1\%; las plazas de mercado y galerías, el 13,7\%, y los vendedores ambulantes o las ventas callejeras, el 10,7\%. En relación con la cobertura de los hogares, las tiendas de barrio tienen el 30,9\%; los supermercados de 
barrio, el 30,1\%; las plazas de mercado y galerías, el 11,6\%; y los vendedores ambulantes o las ventas callejeras, el 10.3\%.

Reglamentaciones. En las diferentes reglamentaciones que se tienen sobre los usos del suelo en Cúcuta, tanto los planes de desarrollo municipal (Ley 152 de 1994) como los planes de ordenamiento territorial (Ley 388 de 1997) consideran como objetivo mejorar las diversas condiciones sobre las infraestructuras de comercialización de agroalimentos de la ciudad y del área metropolitana.

El Plan de Desarrollo 2008-2011 consideró potenciar y "fomentar la industria agroalimentaria que transforme y comercialice productos de gran producción provincial: lácteos, cárnicos, hortofrutícola, acuícola" ${ }^{472}$, además de promover los procesos de asociación para la comercialización, los mercados campesinos y las condiciones generales de mercadeo de agroalimentos en la ciudad. Por su parte, el POT, con el programa de Desarrollo Agroindustrial y de Comercialización Agropecuaria, planteó acciones con el fin de mejorar la producción de agroalimentos y sus relaciones entre lo urbano y lo rural:

Fortalecer y capacitar a los pequeños productores en el mercado, manejo de post-cosecha y comercialización del producto. Crear un centro de comercialización en la central de abastos. Impulsar el mercadeo agropecuario. Proyectar la construcción de centros de acopio, localizados estratégicamente ${ }^{473}$.

\subsection{ACCESO A LOS ALIMENTOS}

\subsubsection{Elementos generales del acceso}

Por acceso se entiende la capacidad que tiene una persona, una familia, una comunidad o una población de adquirir los alimentos necesarios para su vida. Conviene preguntarse: ¿quiénes consumen alimentos?, ¿cómo acceden a ellos? Las situaciones del acceso se refieren a la capacidad de la población de generar, individual o familiarmente, ingresos vía salarios o rentas, la vinculación individual familiar o colectiva a programas sociales

472 Plan de Desarrollo Municipal 2008-2011. Cúcuta., pág. 163 y ss.

473 Plan de Ordenamiento Territorial Cúcuta., pág. 12. 
públicos o privados y la capacidad de generar bienes y servicios para "truequear" (figura 7.4.1). Estas condiciones relacionan la distribución del ingreso, los niveles de empleo y pobreza en una región, una ciudad, un barrio, una familia o algunos individuos, y las inversiones locales públicas sociales de un Estado.

Cuando el acceso a los alimentos se da vía ingreso salarial o rentas, se analizan sus condiciones, el nivel de empleo, los salarios y los precios de los alimentos en cada ciudad eje. Machado anota sobre esto:

La caída en la inflación es un indicador positivo para la seguridad alimentaria en cuanto permite un mayor acceso a los alimentos; sin embargo, está contrarrestado con el elevado índice de desempleo y de pobreza tanto urbana como rural. [...] Los diseñadores de la política macroeconómica cantan victoria con las bajas en las tasas de inflación, pero no la relacionan con la distribución del ingreso, el aumento de la pobreza y del desempleo, donde los éxitos de la política no aparecen ${ }^{474}$.

Se requiere, por tanto, un diseño macro que relacione otros aspectos de las políticas nacionales que afectan el acceso de las poblaciones a los alimentos. Es importante incluso considerar la declaración de la FAO:

Nosotros, declaramos nuestro firme empeño en eliminar el hambre y reducir todas las formas de malnutrición. El hambre y la malnutrición son inaceptables en un mundo que posee a la vez los conocimientos y los recursos necesarios para acabar con esta catástrofe humana. Reconocemos que el acceso a una alimentación nutricionalmente adecuada y sana es un derecho de cada persona. Reconocemos que mundialmente hay alimentos suficientes para todos y que el problema principal es el de un acceso desigual a esos alimentos ${ }^{475}$.

474 MACHADO C., Absalón (2004): "Seguridad alimentaria y sistema agroalimentario". En Territorios y sistemas agroalimentarios locales. Universidad Nacional de Colombia, Red de Desarrollo Rural y Seguridad Alimentaria, Bogotá, pág. 39.

475 FAO (1992): Declaración mundial sobre la nutrición. Primer punto de la declaración realizada por los Ministros y Plenipotenciarios, representantes de 159 Estados y de la Comunidad Económica Europea en la Conferencia Internacional sobre Nutrición. Roma, diciembre de 1992. 
Si el acceso se hace vía programas sociales y subsidios, o vía trueque, se requieren principios de solidaridad, caridad, autonomía y responsabilidad social, así como el impulso a la organización social, económica y cultural de la población al hablar de programas públicos, comunitarios y privados de ayuda. Entonces aparecen las siguientes preguntas: ¿quiénes son los pobladores que no pueden acceder, vía ingreso, a los alimentos necesarios?, ¿dónde se encuentran ubicados espacialmente?, ¿qué tipo de ingesta requieren?, ¿qué consecuencias ha tenido la falta de alimentos sobre la salud de esta población?, ¿qué tipo de cultura poseen sobre los hábitos de alimentación? Otros cuestionamientos para orientar las acciones públicas sobre el acceso son:

¿Cómo interviene un programa gubernamental en las decisiones de consumo de alimentos para cambiar los resultados nutricionales? ¿Cómo están vinculados los diversos programas de consumo y las políticas gubernamentales? ¿Cómo están vinculados los programas de consumo al resto del sector alimentario? ${ }^{476}$

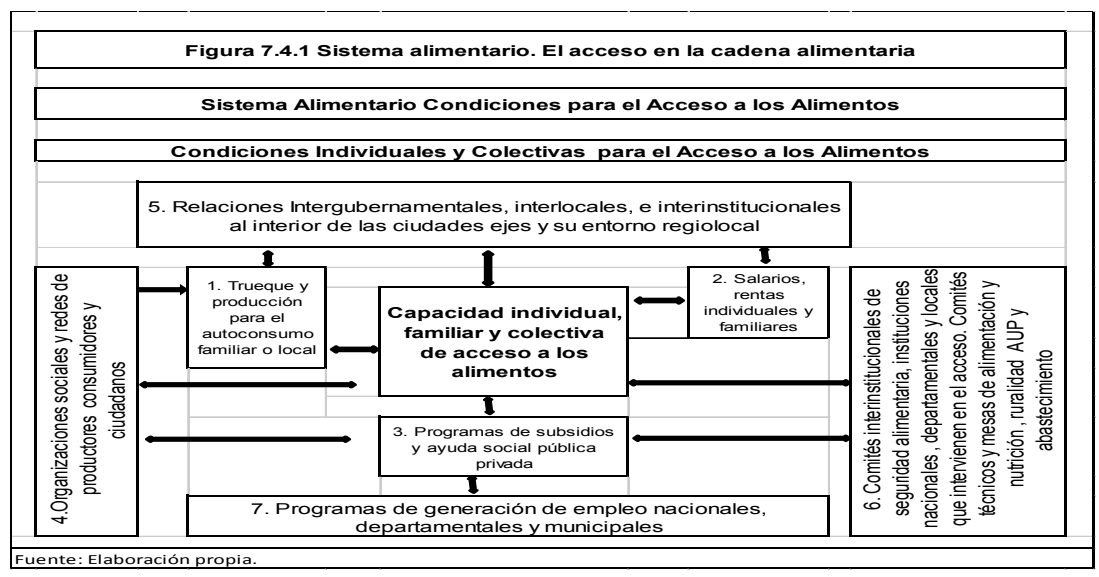

Los diversos programas focalizan las acciones de asistencia o de caridad, privilegiando indicadores de cobertura, y no de desarrollo. Estas iniciativas requieren una visión integradora de políticas en los Gobiernos nacional y subnacionales, al igual que acciones de los organismos internacionales, las ONG, las organizaciones comunitarias y el sector privado. Por otro lado, el acceso requiere diferenciar entre demanda y necesidad alimentaria, para diseñar las políticas públicas. En cada caso, las acciones variarán, como lo advierten Toro y Gagliardini:

476 TIMMER C., Peter, FALCÓN, Walter P. y PEARSON, Scott R. (1985): Análisis de políticas alimentarias. Banco Mundial, Tecnos, Madrid, pág. 34. 
Si tratamos el problema del hambre en términos de mercado es más evidente que cuanto más pobre se es (en términos de ingresos), más dificultad existe para nutrirse diariamente, y más dependiente se estará de las fluctuaciones de los precios de los alimentos en el mercado. Ya no estaremos hablando de necesidades alimentarias sino de demandas alimentarias ${ }^{477}$.

Las necesidades alimentarias permiten estudiar el acceso, y pensar acciones de desarrollo regiolocal a partir de las brecha consideradas en la tabla 1.8 del anexo $\mathrm{B}$, que relaciona evidencias entre necesidades potenciales y soluciones reales.

\subsubsection{Acceso, cultura y SAN}

El acceso en Colombia se vincula a la cultura, los regionalismos y su alimentación, y está identificada así: el ajiaco para un bogotano, el bollo y suero para un costeño de la costa atlántica, una bandeja paisa para un antioqueño y cafetero, una carne para un llanero, un caldo de papas para un boyacense, un cuy para los nariñenses de la cordillera. Hay en cada región una cultura alimentaria, así que "la alimentación queda ubicada, fuera de toda duda, dentro del marco cultural de las relaciones sociales y culturales de los individuos" ${ }^{478}$.

Al analizar la cultura y los hábitos de consumo de los alimentos, se evidencian cambios generados por la modernización, la globalización y la urbanización; estos, al modificar los patrones de consumo y los hábitos nutricionales, inciden en la morbimortalidad, pues cambian los hábitos de vida, por sedentarismo y consumo de alimentos con dietas y comidas rápidas como parte de la cultura urbana. La homogenización de la dieta es una tendencia en la urbanización y la alimentación en la globalización, que está referida a lo siguiente:

A la creciente similitud de las dietas de todo el mundo; y se caracteriza por una mayor dependencia con respecto a un menor número de

477 TORO S., Francisco J. y GAGLIARDINI, Giuliaserena (2006): “La seguridad alimentaria y la FAO: una revisión crítica de los informes sobre el estado mundial de la agricultura y la alimentación". Revista Bibliográfica de Geografía y Ciencias Sociales, Universidad de Barcelona.Vvol. XI, n. ${ }^{\circ}$ 637, 5 de marzo, pág. 15.

478 MEDINA, E., Xavier (2011): Prólogo. En Sabores culturales. Ensayos sobre alimentación y cultura. Unión Europea, pág. 11. 
cereales básicos (el trigo y el arroz), así como por un mayor consumo de carne, productos lácteos, aceites comestibles, sal y azúcar, y un menor aporte de fibras dietéticas ${ }^{479}$.

La otra tendencia es la adaptación dietética por el ritmo que la vida urbana impone:

En los hogares en los que ambos progenitores suelen recorrer grandes distancias para ir a trabajar y tienen horarios de trabajo muy largos, se consumen más comidas fuera de casa y se adquiere un mayor número de alimentos elaborados de marca ${ }^{480}$.

Por tanto, las condiciones espaciales del trabajo urbano lejos de la vivienda y los nuevos alimentos cambian el patrón de consumo, que es orientado por la publicidad. Ciertamente, estos cambios de alimentación implican problemas de salud:

La gente consume una mayor cantidad de aceites, carne y productos lácteos y menos fibras dietéticas, así como más comidas rápidas y menos platos caseros, actualmente hay un doble reto: el hambre y el aumento de la diabetes, de las enfermedades cardiovasculares ${ }^{481}$.

Los cambios culturales en los hábitos alimenticios tienen dos consecuencias: para los que acceden sin restricciones, hay problemas de salud por obesidad; y para los que no acceden, hay desnutrición con consecuencias a lo largo de su vida. De este modo, las relaciones entre cultura, salud y nutrición deben ser base de la seguridad alimentaria nutricional y de las políticas públicas, pues de esto depende la aceptación de la población al acceso.

Esto es así porque hay "una serie de factores (que) intervienen en la existencia y supervivencia de los hábitos y prácticas alimentarías" ${ }^{482}$. Estos factores pueden ser los productos disponibles, los territorios que determinan hábitos culturales alimenticios

479 FAO (2004): El estado de la inseguridad alimentaria en el mundo... Op. cit., pág. 19.

480 TORO S., Francisco J.Y GAGLIARDINI, Giuliaserena (2006): La seguridad alimentaria y la FAO... Op. cit., pág. 10.

481 FAO (2004). El estado de la inseguridad alimentaria en el mundo... Op. cit., pág. 23.

482 Ministerio de Salud e Instituto Colombiano de Bienestar Familiar (2000): Guías alimentarias para la población colombiana mayor de dos años. Bogotá, pág. 42. 
y las acciones que deben desarrollarse para implementar políticas diferenciadas en la cadena alimentaria de cada región.

\subsubsection{Características e intervenciones en el acceso a los alimentos}

En este apartado se caracterizan las condiciones socioeconómicas de las poblaciones vulnerables en sus territorios y el contexto regional. Se analiza también el IPC de los alimentos, el empleo y los programas y proyectos públicos para el desarrollo de políticas de SAN del orden nacional, departamental y municipal.

En el acceso hay descoordinación de las acciones de las políticas de SAN entre los niveles del Gobierno nacional, departamental y municipal, lo cual se expresa así: "Hay un conflicto por distribución con el ICBF por sobreoferta y sin coordinación con el departamento" 483 . Ello por un manejo clientelar de funcionarios que desconocen los procesos por desarrollar, lo cual deriva en desajustes administrativos: "Ponen personas que no sabemos, cómo le exijo a una persona cuando yo no sé del tema" ${ }^{484}$. La descoordinación institucional pública y privada lleva, en diversos casos, a encontrar diferentes bolsas y acciones:

Bolsa común local donde están ICBF, departamento y municipio que operaban con la parroquia; bolsa común departamental entre departamento y comité de cafeteros opera en lo municipal a través de una ONG con 1000 cupos cuando no se necesitan; bolsa común ICBF municipio operada por la parroquia donde se presenta duplicidad de repartos ${ }^{485}$.

Por tanto, estas acciones demandan mayor coordinación en tiempos, recursos financieros públicos, personal y políticas. Por tanto, es necesaria la aplicación de acciones públicas locales con políticas descentralizadoras nacionales, integradas a la seguridad alimentaria a través de las transferencias automáticas:"El gobierno le pegó con seguridad alimentaria

483 PERDOMO, Liliana y CABRERA, Rocío (2008): Entrevista. Grupo de la Secretaria de Educación Departamental, municipio de Neiva, departamento de Huila, 3 de noviembre.

484 Ibíd.

485 MORALES, María Edid (2008): Entrevista. Oficina de Asuntos Sociales de la Secretaria de Planeación Municipal, municipio de Campoalegre, departamento del Huila, 5 de noviembre. 
en el sistema general de participación" ${ }^{486}$, en la medida en que obligó a todos los municipios a dedicar parte de las transferencias para seguridad alimentaria. Cuando las acciones son responsabilidad del gobierno local, funcionan con menos traumatismos; y cuando integran diferentes niveles de Gobierno (nacional y subnacionales) en un mismo territorio, las situación se vuelve compleja.

\subsubsection{Acceso a nivel nacional}

Este punto trabaja los elementos que permiten a los individuos y a las familias tener acceso a los alimentos por empleo, salarios y política pública gubernamental.

El comportamiento del índice de precios al consumidor de los alimentos a nivel nacional ${ }^{487}$ está vinculado a la capacidad de acceso de los individuos y los hogares. En el periodo 1990-2008 hubo un crecimiento anual de precios de alimentos de entre el 3\% y el 5\%. Este comportamiento incide en la capacidad de compra por parte de individuos y hogares con ingresos fijos en salarios y rentas.

Otro aspecto es el comportamiento del empleo nacional, condición que más afecta el acceso a los alimentos por la vía de los salarios; por tanto, el índice de desempleo y el número de personas desocupadas configuran un componente estructural para acceder a los alimentos. Las personas con esta dificultad, en el periodo 2001-2009, eran 2.504.100.

Un punto adicional por tener presente es la informalidad488 y su magnitud: "La ocupación urbana en Colombia, se puede decir, sin lugar a dudas, que el carácter del

486 TOVAR, Jorge (2008): Entrevista. Exalcalde del municipio de Santa Rosa de Lima, departamento de Bolívar, 22 de octubre.

487 Información tomada del DANE (periodo 1990-2008).

488 La informalidad y su rápida expansión es un fenómeno que hace años se convirtió en una característica estructural de la ocupación laboral colombiana, y como es sabido, se trata de una modalidad de empleo donde, la mayoría de las veces, las garantías básicas para el bienestar del trabajador como la protección social, el ingreso adecuado y la estabilidad son muy precarias, o en el peor de los casos, no existen. Desde esta perspectiva, el predominio del empleo de baja productividad es uno de los factores relevantes de la desigualdad social; tanto así que la CEPAL considera la generación de empleo productivo como una meta y una condición necesaria para crecer con equidad (DANE, 2004). 
empleo es fundamentalmente de tipo informal" ${ }^{489}$. Esto significa diferenciar el análisis de acceso a los alimentos por la vía del ingreso individual, en la medida en que la informalidad soporta altos índices de trabajo e ingreso en todas las ciudades; en los ejes dinamizadores, se expresa en carretilleros, pimpineros y el comercio informal de todas las ciudades, con las acciones tipificadas como "rebusque".

\section{Programas nacionales de SAN en lo rural-urbano, según información}

del Sisbén. Los programas nacionales del gobierno para mejorar la nutrición de la población vulnerable se hacen con intervenciones públicas institucionales. El ICBF es la principal institución nacional para el acceso a la población, especialmente la infantil. El ICBF490, a través del Programa "Desayunos Infantiles con Amor" (periodo juliodiciembre del 2008), entregó complemento alimentario a 1.156 .640 niños y niñas entre 6 meses y 5 años de edad, pertenecientes a familias de los niveles 1 y 2 del Sisbén, en 1.101 municipios. Se logró así el 100\% de la meta del Sistema de Seguimiento a las Metas del Gobierno (SIGOB) del 2008.

Para el 2009, la meta era de 1.300.000 desayunos infantiles, y a junio 30 de 2009 se había entregado 1.170.502 desayunos con una inversión de \$144.000 millones. Con el Programa de Alimentación Escolar, el ICBF, en el periodo julio-diciembre del 2008, atendió un total de 3.893.056 escolares durante 157 días.

El Programa Hogares del ICBF, dirigido a atender la primera infancia, y el Programa Nacional de Alimentación para el Adulto Mayor "Juan Luis Londoño de la Cuesta" entregan un complemento alimentario, que puede ser ración preparada o ración para preparar. Para garantizar la vinculación y permanencia de los niños, las niñas y los adolescentes, así como a los hijos de personas desplazadas, se implementan los Hogares Comunitarios de Bienestar y Alimentación Escolar.

Por otro lado, mediante el Conpes 102 de 2006, y a través de convenios con Acción Social, desde el 2007 el ICBF cofinancia el Programa Familias en Acción, para beneficiar a familias vulnerables con niños y niñas menores de 7 años (Sisbén nivel 1 y desplazados), en el componente de nutrición infantil. En el programa de ingreso social de Familias en Acción, se entregan subsidios de nutrición o educación a los niños y

489 DANE (2003): Documentos técnicos sobre mercado laboral (2004). Informalidad laboral en las trece principales áreas y ciudades colombianas 2001-2003 (abril-junio). Bogotá.

490 ICBF (2009): Informe al Congreso de la República de Colombia. Bogotá. 
las niñas menores de 7 años de las familias en situación de pobreza, focalizadas a través del Sisbén (metodología III) y la Red Unidos. También se hacen entregas a familias desplazadas o indígenas.

El programa Familias en Acción otorga apoyo monetario directo a la madre beneficiaria, condicionado a cumplir compromisos de la familia en: educación, garantizar la asistencia escolar de los menores; y salud, asistencia de los niños y niñas menores a las citas de control de crecimiento y desarrollo programadas, y cumplir el esquema completo de vacunación.

Las intervenciones públicas de acceso requieren información de población focalizada con el Sisbén ${ }^{491}$, que describe ${ }^{492}$ los territorios según la población ubicada en centros urbanos, centros poblados ${ }^{493}$ y territorios rurales dispersos. La información de la población colombiana es consolidada en marzo del 2009 (tabla 7.4.1) y es descrita de acuerdo con territorios. Así, se muestra que a nivel nacional la composición por estratos socioeconómicos en Colombia es: en el 1, con 18.987 .739 y el 54,4\%; en el 2, con 11.412.366 y el 32,7\%; en el 3, con 4.358 .924 y el $12.5 \%$; y en el 4 y siguientes, con 162.777 y el $0,5 \%$. La concentración de población en estratos 1 y $2(87,1 \%)$ revela las condiciones de desigualdad en el país.

La distribución espacial de las personas y los estratos en el país se organiza en: urbanas en estrato 1, donde hay 11.613.206 personas y el 46.9\%; en el estrato 2 hay 9.022 .286 y el $36.4 \%$; en el 3 hay 4.042 .834 y el 16\%; y para el 4 y siguientes hay 109.617 y el $0.4 \%$. En Colombia, la mayoría de la población está ubicada en las zonas urbanas, donde los estratos 1 y 2 representan 30.400.105 personas, con el 83,3\% vulnerable en términos sociales, económicos y culturales.

491 El Sisbén es el Sistema de Identificación de Potenciales Beneficiarios de Programas Sociales. Es un sistema de información con instrumentos de focalización que identifica los hogares y las personas más pobres y vulnerables en todo el país y en cada municipio.

492 Esta descripción de personas y hogares es similar a la información de los municipios eje.

493 Centro poblado: concepto creado por el DANE para fines estadísticos, útil para la identificación de núcleos de población. Se define como una concentración de mínimo veinte viviendas contiguas, vecinas o adosadas entre sí, ubicadas en el área rural de un municipio o de un corregimiento departamental. Dicha concentración presenta características urbanas tales como la delimitación de vías vehiculares y peatonales. 


\begin{tabular}{|c|c|c|c|c|c|c|c|c|c|c|}
\hline \multicolumn{1}{|c|}{ Tabla 7.4.1 Sisbén Colombia, total de personas en corte 3 de marzo de 2009} \\
\hline \multirow{2}{*}{$\begin{array}{c}\text { Tipo de } \\
\text { Territorio }\end{array}$} & $\mathbf{1}$ & $\mathbf{1 0}$ & $\mathbf{2}$ & $\mathbf{3}$ & $\mathbf{3}$ & $\mathbf{4}$ y mas & \multicolumn{3}{c|}{ Total } \\
\cline { 2 - 12 } & No. & $\%$ & No. & $\%$ & No. & $\%$ & No. & $\%$ & No. & $\%$ \\
\hline Urbano & 11.613 .206 & 46,9 & 9.022 .286 & 36,4 & 4.042 .834 & 16,3 & 109.617 & 0,4 & 24.787 .943 & 100 \\
\hline Centro Poblado & 2.980 .709 & 80,8 & 645.005 & 17,5 & 63.458 & 1,7 & 2.056 & 0,1 & 3.691 .228 & 100 \\
\hline Rural Disperso & 4.393 .824 & 68,2 & 1.745 .075 & 27,1 & 252.632 & 3,9 & 51.104 & 0,8 & 6.442 .635 & 100 \\
\hline Total & 18.987 .739 & 54,4 & 11.412 .366 & 32,7 & 4.358 .924 & 12,5 & 162.777 & 0,5 & 34.921 .806 & 100 \\
\hline Fuente: Sistema de Identificación de Potenciales Beneficiarios de Programas Sociales - Sisbén DNP. Cálculos del autor. \\
\hline
\end{tabular}

Para los centros poblados del país, la población por estratos es: en el 1 hay 2.980.709 (80,8\%); el 2 hay con 645.005 (17,5\%); el tres tiene 63.458 (1,7\%); y el 4 y siguientes tienen $2.056(0.1 \%)$. La población en las zonas rurales dispersas del país tiene una distribución por estratos así: en el 1, 4.393 .824 (68,2\%); en el dos, 1.745 .075 (27,1\%); en el 3, 252.632 (3,9\%); y en el 4 y siguientes, $51.104(0,8 \%)$.

La información de los hogares colombianos consolidados a marzo del 2009 (tabla 7.4.2) muestra el total nacional $(9.172 .436)$ y su distribución por estratos socioeconómicos: el 1 tiene 4.580.254 (49,9\%); el 2, 3.218 .306 (35,1\%); el 3, 1.321.439 (14.4\%); y el 4 y más, 52.437 (0,6\%). Hay altos índices de hogares vulnerables en Colombia de acuerdo con el Sisbén, ya que el 85\% están en estratos 1 y 2, los más vulnerables en lo social, lo económico y lo cultural.

Los hogares en los estratos 1 y 2 son 7.798.560, concentrados en las zonas urbanas (81\%), en centros poblados $(97,9 \%)$ y en zonas rurales dispersas (94,2\%). En los dos últimos territorios está la mayor inequidad socioeconómica del país. La muestra nacional indica que en estos estratos están las poblaciones vulnerables objeto de acciones en SAN.

\begin{tabular}{|c|c|c|c|c|c|c|c|c|c|c|}
\hline \multicolumn{11}{|c|}{ Tabla 7.4.2 Sisbén Colombia, total de hogares, corte 3 de marzo de 2009} \\
\hline \multirow{3}{*}{$\begin{array}{l}\text { Tipo de } \\
\text { Territorio }\end{array}$} & \multicolumn{10}{|c|}{ Estratos } \\
\hline & \multicolumn{2}{|l|}{1} & \multicolumn{2}{|l|}{2} & \multicolumn{2}{|l|}{3} & \multicolumn{2}{|c|}{4 y mas } & \multicolumn{2}{|c|}{ Total } \\
\hline & No. & $\%$ & No. & $\%$ & No. & $\%$ & No. & $\%$ & No. & $\%$ \\
\hline Urbano & 2.836 .565 & 42,8 & 2.531 .224 & 38,2 & 1.222.832 & 18,5 & 35.627 & 0,5 & 6.626 .248 & 100 \\
\hline Centro Poblado & 689.919 & 76,7 & 190.355 & 21,2 & 19.042 & 2,1 & 641 & 0,1 & 899.957 & 100 \\
\hline Rural Disperso & 1.053 .770 & 64,0 & 496.727 & 30,2 & 79.565 & 4,8 & 16.169 & 1,0 & 1.646.231 & 100 \\
\hline Total & 4.580 .254 & 49,9 & 3.218 .306 & 35,1 & 1.321 .439 & 14,4 & 52.437 & 0,6 & 9.172 .436 & 100 \\
\hline
\end{tabular}

Por consiguiente, como consecuencia de la inflación baja, los medios niveles de desempleo con alta informalidad y las inequidades socioeconómicas, debe trabajarse en lo siguiente: dados los ingresos salariales, individuales y familiares y las condiciones de 
vulnerabilidad social de la mayoría de población, son urgentes acciones desde la renta básica para cumplir los ODM, diferenciando en zonas rurales y urbanas por regiones.

\subsubsection{Acceso en los ejes dinamizadores}

\subsection{Acceso en el eje dinamizador Medellín}

Características sociodemográficas del eje dinamizador. La ciudad tiene la distribución por estratos (tabla 7.4.3) así: estrato 1, 396.804 personas (25,7\%); estrato 2, 716.961 (46,4\%); estrato 3, 428.237 (27,7\%); y estratos cuatro y siguientes, 4.719 $(0,3 \%)$. La concentración poblacional en los estratos 1 y 2 es del 72,1\%, con una media por debajo de la nacional (15\%).

Respecto a la distribución espacial de la población, en la zona urbana los estratos son: en el 1, 387.688 (25,9\%); en el 2, 684.644 (45,7\%); en el 3, $422.806(28,2 \%)$; y en el 4 y siguientes, $4.414(0,3 \%)$. En los estratos 1 y 2 está el 71,6\% de pobladores, por debajo del promedio nacional $(83,3 \%)$. En los centros poblados, la población por estratos es: en el 1, 8.644 (19,9\%); en el 2, 30.350 (69,9\%); en el 3, 4.326 (10\%); y en 4 y siguientes, $77(0.2 \%)$. Estos porcentajes también están por debajo del promedio nacional.

Por su parte, en las zonas rurales dispersas, la población por estratos es: en el 1, 492 (13\%); en el 2, 1.957 (51,7\%); en el 3, 1.105 (29.2\%); y en el 4 y siguientes, 228 (6,0\%). Esto muestra una dinámica similar en los estratos 1 y 2, en tanto en el 4 se observa una dinámica mayor con indicadores por debajo del nivel nacional.

\begin{tabular}{|c|c|c|c|c|c|c|c|c|c|c|}
\hline \multirow{3}{*}{$\begin{array}{l}\text { Tipo de } \\
\text { Territorio }\end{array}$} & \multicolumn{10}{|c|}{ Estratos } \\
\hline & \multicolumn{2}{|l|}{1} & \multicolumn{2}{|l|}{2} & \multicolumn{2}{|l|}{3} & \multicolumn{2}{|c|}{4 y mas } & \multicolumn{2}{|c|}{ Total } \\
\hline & No. & $\%$ & No. & $\%$ & No. & $\%$ & No. & $\%$ & No. & $\%$ \\
\hline Urbano & 387.668 & 25,9 & 684.644 & 45,7 & 422.806 & 28,2 & 4.414 & 0,3 & 1.499 .532 & 100 \\
\hline Centro Poblado & 8.644 & 19,9 & 30.350 & 69,9 & 4.326 & 10,0 & 77 & 0,2 & 43.397 & 100 \\
\hline Rural Disperso & 492 & 13,0 & 1.957 & 51,7 & 1.105 & 29,2 & 228 & 6,0 & 3.782 & 100 \\
\hline Total & 396.804 & 25,7 & 716.951 & 46,4 & 428.237 & 27,7 & 4.719 & 0,3 & 1.546 .711 & 100 \\
\hline
\end{tabular}

La característica de este eje es que los estratos predominantes son el 2 y el 3, con el 74,1\% de las personas de Medellín; el 1 es la cuarta parte y está debajo de los otros. Además, hay mejoras en las condiciones socioeconómicas de sus pobladores, con indicadores por debajo de la tendencia nacional y de los otros ejes dinamizadores. 
El total de hogares (tabla 7.4.4) es 396.015, y su distribución por estratos es: en el 1, 396.804 (25,7\%); en el 2, 716.951 (46,4\%); en el 3, 428.237 (27,7\%); y en el 4 y siguientes, 4.719 (0,3\%). Esto muestra medianos indicadores de hogares vulnerables en Medellín. De acuerdo con la identificación del Sisbén, 74,1\% de los hogares están en estratos 2 y 3 , que son de mediana vulnerabilidad social, económica y cultural. La mayor concentración de hogares en los estratos 2 y 3 está en la zona urbana de Medellín.

\begin{tabular}{|c|c|c|c|c|c|c|c|c|c|c|}
\hline \multirow{3}{*}{$\begin{array}{l}\text { Tipo de } \\
\text { Territorio }\end{array}$} & \multicolumn{10}{|c|}{ Estratos } \\
\hline & \multicolumn{2}{|c|}{1} & \multicolumn{2}{|l|}{2} & \multicolumn{2}{|l|}{3} & \multicolumn{2}{|c|}{4 y mas } & \multicolumn{2}{|c|}{ Total } \\
\hline & No. & $\%$ & No. & $\%$ & No. & $\%$ & No. & $\%$ & No. & $\%$ \\
\hline Urbano & 84.968 & 22,1 & 174.895 & 45,5 & 122.971 & 32,0 & 1.374 & 0,4 & 384.208 & 100 \\
\hline Centro Poblado & 1.865 & 17,3 & 7.706 & 71,5 & 1.193 & 11,1 & 19 & 0,2 & 10.783 & 100 \\
\hline Rural Disperso & 115 & 11,2 & 504 & 49,2 & 326 & 31,8 & 79 & 7,7 & 1.024 & 100 \\
\hline Total & 86.948 & 22,0 & 183.105 & 46,2 & 124.490 & 31,4 & 1.472 & 0,4 & 396.015 & 100 \\
\hline
\end{tabular}

Comportamiento del índice de precios al consumidor de alimentos en el eje dinamizador. En Medellín, la evolución de este índice muestra la incidencia en la capacidad de acceso a los alimentos de individuos y hogares en el eje, para el periodo $1990-2008^{494}$, y un crecimiento de precios de alimentos que al año promedian entre el 3\% y el 6\% en 18 años. Ello afecta a todos los ciudadanos, pero en especial a los que dependen de ingresos fijos, salarios y rentas para comprar alimentos. Hay menor vulnerabilidad por las relaciones familiares y su carácter social y cultural.

Comportamiento del empleo en el eje dinamizador. El empleo en Medellín (tabla 7.4.5) refleja una de las condiciones que afectan el acceso a los alimentos por la vía de salarios: la tasa de desempleo y el número de personas desocupadas, que en el 2009 fue de 273.900. Esto baja la capacidad de demanda individual y familiar de alimentos de los sectores asalariados; por tanto, la solidaridad a partir de los ingresos familiares y las redes sociales en el territorio alivia la vulnerabilidad de los afectados por esta situación.

\begin{tabular}{|c|c|c|c|c|c|c|c|c|c|}
\hline \multicolumn{10}{|c|}{ Tabla 7.4.5 Medellín, tasa de Desempleo: desocupados/PEA, 2001 - 2009} \\
\hline Año & $\begin{array}{c}\% \text { Población } \\
\text { en edad de } \\
\text { trabajar }\end{array}$ & $\begin{array}{c}\text { Tasa Global } \\
\text { de } \\
\text { Participación }\end{array}$ & $\begin{array}{l}\text { Tasa de } \\
\text { Ocupación }\end{array}$ & $\begin{array}{c}\text { Tasa de } \\
\text { Desempleo }\end{array}$ & $\begin{array}{c}\text { Población } \\
\text { total }\end{array}$ & $\begin{array}{c}\text { Población en } \\
\text { edad de } \\
\text { trabajar }\end{array}$ & $\begin{array}{c}\text { Población } \\
\text { económicam } \\
\text { ente activa }\end{array}$ & Ocupados & $\begin{array}{c}\text { Desocupado } \\
\text { s }\end{array}$ \\
\hline 2001 & 80,1 & 60,8 & 49,8 & 18,1 & $2.915,4$ & $2.335,8$ & $1.420,4$ & $1.163,2$ & 257,2 \\
\hline 2002 & 80,4 & 61,9 & 51,4 & 17,0 & $2.970,3$ & $2.389,2$ & $1.479,3$ & $1.227,6$ & 251,7 \\
\hline 2003 & 80,7 & 62,6 & 52,7 & 15,7 & $3.023,7$ & $2.441,4$ & $1.527,6$ & $1.287,9$ & 239,8 \\
\hline 2004 & 81,0 & 61,8 & 52,4 & 15,1 & $3.075,6$ & $2.492,4$ & $1.540,1$ & $1.307,0$ & 233,1 \\
\hline 2005 & 81,4 & 59,6 & 51,4 & 13,8 & $3.125,5$ & $2.543,4$ & $1.517,0$ & $1.308,1$ & 208,9 \\
\hline 2006 & 81,8 & 57,8 & 50,0 & 13,4 & $3.173,0$ & $2.594,8$ & $1.499,5$ & $1.297,9$ & 201,7 \\
\hline 2007 & 82,2 & 59,4 & 52,2 & 12,1 & $3.220,7$ & $2.647,0$ & $1.572,8$ & $1.383,3$ & 189,5 \\
\hline 2008 & 82,6 & 60,8 & 52,5 & 13,6 & $3.268,5$ & $2.698,8$ & $1.641,1$ & $1.418,2$ & 222,9 \\
\hline 2009 & 82,9 & 63,6 & 53,7 & 15,7 & $3.316,2$ & $2.749,6$ & $1.749,5$ & $1.475,5$ & 273,9 \\
\hline
\end{tabular}

494 Información tomada del DANE (periodo 1990-2008) para todas las ciudades ejes. 
Políticas y programas del eje dinamizador de SAN. Lo planteado en la mesa de seguridad alimentaria presenta cambios conceptuales para las acciones SAN en el eje dinamizador:

[En los] programas de asistencia alimentaria desde hace más de 70 años (...) sólo recientemente se ha empezado a trascender ese enfoque asistencial para pensar en soluciones más estructurales que den salida al círculo generacional de la pobreza y el hambre, se considera parte de los avances presentados con la complementación o los subsidios, lo que nos señala un largo camino por recorrer para llegar a posicionar el derecho a la alimentación como una cuestión mucho más fundamental e integral ${ }^{495}$.

Según el Perfil alimentario de los hogares urbanos de Medellín, en el 31,3\% de hogares de estratos 2 y 3 por lo menos un integrante recibía algún tipo de asistencia social alimentaria $^{496}$. El Acuerdo 038 de 2005 establece e institucionaliza en Medellín la Política Pública de Soberanía y Seguridad Alimentaria y Nutricional, con un enfoque y algunos principios y estrategias que garantizan el acceso de la población a una alimentación suficiente, equilibrada y sana.

Se crea también el Sistema Municipal de Seguridad y Soberanía Alimentaria y Nutricional con tres instrumentos centrales: el Plan Municipal (definido por la Administración Municipal), el Comité Municipal y la Gerencia del Plan Municipal.Este sistema tiene siete estrategias: complementación alimentaria, desarrollo rural sostenible, agricultura urbana, comercialización y transformación de alimentos, mejoramiento de ingresos para las familias, educación, e investigación y salud.

En el contexto inmediato, la Gobernación de Antioquia describe la precariedad creciente en el departamento. En el 2000, el 64,1\% de la población era del Sisbén, estratos 1 y 2497; en el 2002 había las siguientes tasas de mortalidad: materna de 69,9 por 100.000 nacidos

495 Documento elaborado por la Mesa de Seguridad Alimentaria, Cuarto Congreso de Ciudad, Medellín, octubre 1 y 2 de 2007. La redacción estuvo a cargo de Carolina Maldonado Lizarazo, antropóloga e investigadora del Grupo Medio Ambiente y Sociedad, de la Universidad de Antioquia, págs. 10 y ss.

496 Documento elaborado por la mesa de Seguridad Alimentaria... Op. cit., pág. 14.

497 Gobernación de Antioquia y otros (2004); Perfil alimentario y nutricional de los hogares del departamento de Antioquia. Medellín, pág. 20. 
vivos; infantil de 14,8 por 1.000 nacidos vivos; por desnutrición en menores de cinco años de 16,3 por 100.000; por enfermedad diarreica aguda en menores de cinco años de 11,2 por 100.000; y por infección respiratoria aguda de 17,2 por 100.000 .

El programa de SAN "Mejoramiento Alimentario y Nutricional de Antioquia" (MANA) se ha desarrollado así:

Con un principio general de corresponsabilidad familia,sociedad y Estado, y transversal a todas las secretarias del departamento con autonomía administrativa con programas de complementación alimentaria para todos los municipios receptores, para las personas con Sisbén uno y dos, se entrega como mínimo una ración diaria de complementación ${ }^{498}$.

Las dificultades presentadas se relacionan con las necesidades de coordinación interinstitucional que apunten a una solución integral:

No tener el total del presupuesto al inicio de la vigencia que garantice nuestros programas, se requieren más esfuerzos de integración de los responsables de seguridad alimentaria (agua acueducto, hospitales y centros de recuperación) y mayor autonomía administrativa ${ }^{499}$.

Sin embargo, para los iniciadores de este programa, otros factores han dificultado su buen desarrollo: "El hambre no es un problema de comida sino de la multicausalidad de comida; hay manejo de paternalismo y machismo; y el manejo con la naturaleza que en cada inundación trae su menaje anual, también hay problemas de contratación que afectan el proceso" $" 500$. Estas dificultades con la SAN en el departamento plantean la necesidad de "construir una visión integral de cada problema vinculado a la seguridad alimentaria a partir de estrategias sectoriales" ${ }^{501}$. Lo anterior se argumenta desde la experiencia en un programa catalogado con éxito a nivel internacional, que propone la salida por la integralidad, pero con las estrategias sectoriales.

498 DUQUE, Magnolia (2008): Entrevista. Gerente del MANA, municipio de Medellín, departamento de Antioquia, 1 de diciembre.

499 Ibíd.

500 MONSALVE, Patricia (2008): Entrevista. Funcionaria del MANA, Medellín, departamento de Antioquia, 1 de diciembre.

501 Ibíd. 
Los funcionarios en algunos municipios del Área Metropolitana del Valle de Aburrá señalan dificultades en la aplicación del programa, por la "desarticulación del MANA por miopía y visión"502; y en Medellín se considera que "la complementación alimentaria está embolatada con la contratación pública" ${ }^{503}$, lo cual forma hace parte de la descoordinación organizacional entre niveles de gobiernos subnacionales.

\subsection{Acceso en el eje dinamizador Cartagena}

Características sociodemográficas del eje dinamizador. En Cartagena, las personas por estratos socioeconómicos son: en el 1, 518.328 (67,3\%); en el 2, 223.973 (29,1\%); el 3, 27.273 (3,5\%); y en el 4 y siguientes, 145 (0,0\%). Los estratos 1 y 2, con el 96,4\% del total de la población, presentan las mayores desigualdades en las ciudades ejes.

\begin{tabular}{|c|c|c|c|c|c|c|c|c|c|c|}
\hline \multirow{3}{*}{$\begin{array}{l}\text { Tipo de } \\
\text { Territorio }\end{array}$} & \multicolumn{10}{|c|}{ Estratos } \\
\hline & \multicolumn{2}{|l|}{1} & \multicolumn{2}{|l|}{2} & \multicolumn{2}{|l|}{3} & \multicolumn{2}{|c|}{$4 y$ mas } & \multicolumn{2}{|c|}{ Total } \\
\hline & No. & $\%$ & No. & $\%$ & No. & $\%$ & No. & $\%$ & No. & $\%$ \\
\hline Urbano & 455.276 & 64,7 & 220.645 & 31,4 & 27.134 & 3,9 & 142 & 0,0 & 703.197 & 100 \\
\hline Centro Poblado & 58.257 & 95,7 & 2.541 & 4,2 & 98 & 0,2 & 3 & 0,0 & 60.899 & 100 \\
\hline Rural Disperso & 4.795 & 85,3 & 787 & 14,0 & 41 & 0,7 & 0 & 0,0 & 5.623 & 100 \\
\hline Total & 518.328 & 67,3 & 223.973 & 29,1 & 27.273 & 3,5 & 145 & 0,0 & 769.719 & 100 \\
\hline
\end{tabular}

En las zonas urbanas, los estratos son: en el 1, 455.276 personas (64.7\%); en el 2, 220.645 (31,4\%); en el 3, 27.134 (3,9\%); y en el 4 y siguientes, 142 (0,0\%). Los estratos 1 y 2 tienen el 96,1\%, el más alto del país. En los centros poblados, los estratos son: en el 1, 58.257 (95,7\%); en el 2, 2.541 (4,2\%); en el 3, 98 (0,2\%); y en el 4 y siguientes, 3 $(0,0 \%)$. Los estratos 1 y 2 tienen el 99.9\%, el más alto del país.

Por su parte, en las zonas rurales dispersas, los estratos son: en el 1, 4.795 (85;3\%); en el estrato 2, 787 (14\%); en el 3, 41 (0,7\%). En los siguientes estratos no hay personas.

Esta ciudad eje tiene los más altos índices de desigualdad social, reflejados en la distribución poblacional por estratos. Los más vulnerables (los estratos 1 y 2) conforman el 96,4\% de la población de Cartagena, por encima del promedio nacional.

502 SALAZAR, Camilo (2008): Entrevista. Secretario de Medio Ambiente y Desarrollo Rural, municipio de Envigado, Área Metropolitana delValle de Aburrá, 3 de diciembre.

503 BLANDON, Ángelo (2008): Entrevista. Funcionario de Medellín Solidaria, departamento de Antioquia, 3 de diciembre. 
El total de hogares en Cartagena (tabla 7.4.7) es 152.974; y su distribución por estratos socioeconómicos es este: el estrato 1, 97.458 (63,7\%); el 2, 48.360 (31,6\%); el 3, 7.117 (4,7\%); y el 4 y siguientes, 39 (0,0\%). Hay altos indicadores de hogares vulnerables: el 95.3\% de estos están en los estratos 1 y 2, de mayor vulnerabilidad social, económica y cultural.

La mayor concentración de hogares en estrato 1 está en las zonas urbanas de Cartagena (63,7\%), y sumando el estrato 2 tienen el 95,3\% del total. Está por encima de los indicadores nacionales y es uno de los más graves de los cuatro ejes dinamizadores.

\begin{tabular}{|c|c|c|c|c|c|c|c|c|c|c|}
\hline \multirow{3}{*}{$\begin{array}{l}\text { Tipo de } \\
\text { Territorio }\end{array}$} & \multicolumn{10}{|c|}{ Estratos } \\
\hline & \multicolumn{2}{|c|}{1} & \multicolumn{2}{|c|}{2} & \multicolumn{2}{|c|}{3} & \multicolumn{2}{|c|}{4 y mas } & \multicolumn{2}{|c|}{ Total } \\
\hline & No. & $\%$ & No. & $\%$ & No. & $\%$ & No. & $\%$ & No. & $\%$ \\
\hline Urbano & 85.331 & 60,9 & 47.577 & 34,0 & 7.088 & 5,1 & 38 & 0,0 & 140.034 & 100 \\
\hline Centro Poblado & 11.180 & 95,0 & 568 & 4,8 & 19 & 0,2 & 1 & 0,0 & 11.768 & 100 \\
\hline Rural Disperso & 947 & 80,8 & 215 & 18,3 & 10 & 0,9 & 0 & 0,0 & 1.172 & 100 \\
\hline Total & 97.458 & 63,7 & 48.360 & 31,6 & 7.117 & 4,7 & 39 & 0,0 & 152.974 & 100 \\
\hline
\end{tabular}

\section{Comportamiento del índice de precios al consumidor y de alimentos en el} eje dinamizador. En Cartagena, la evolución de este índice muestra la incidencia en la capacidad de acceso a los alimentos de individuos y hogares en el eje para el periodo 1990-2008, además de un crecimiento de precios de alimentos que al año promedian entre el 3\% y el 5\% en 18 años. Ello afecta a todos los ciudadanos, en especial a los que dependen de ingresos fijos, los salarios y las rentas para comprar alimentos (tendencia similar a la nacional). En las condiciones de desigualdad de la ciudad eje, esto se convierte en una situación crítica, agravada por las condiciones sociales, culturales y económicas, además de los altos índices de segregación y concentración del ingreso.

\begin{tabular}{|r|r|r|r|r|r|r|r|r|r|}
\hline \multicolumn{8}{|c|}{ Tabla 7.4.8 Cartagena, tasa de desempleo: desocupados/PEA, 2001-2009 } \\
\hline Año & $\begin{array}{c}\text { \%Población } \\
\text { en edad de } \\
\text { trabajar }\end{array}$ & $\begin{array}{c}\text { Tasa Global } \\
\text { de } \\
\text { Participación }\end{array}$ & $\begin{array}{c}\text { Tasa de } \\
\text { Ocupación }\end{array}$ & $\begin{array}{c}\text { Tasa de } \\
\text { Desempleo }\end{array}$ & $\begin{array}{c}\text { Población } \\
\text { total }\end{array}$ & $\begin{array}{c}\text { Población en } \\
\text { edad de } \\
\text { trabajar }\end{array}$ & $\begin{array}{c}\text { Población } \\
\text { económicam } \\
\text { ente activa }\end{array}$ & Ocupados & Desocupados \\
\hline 2001 & 75,4 & 55,1 & 45,6 & 17,3 & 800,1 & 603,6 & 332,8 & 275,1 & 57,7 \\
\hline 2002 & 75,6 & 53,1 & 45,2 & 15,0 & 810,8 & 613,4 & 325,8 & 277,1 & 48,7 \\
\hline 2003 & 75,8 & 53,9 & 45,9 & 15,0 & 821,3 & 622,9 & 335,9 & 285,6 & 50,3 \\
\hline 2004 & 76,0 & 52,5 & 44,7 & 14,7 & 831,7 & 632,5 & 331,8 & 282,9 & 48,9 \\
\hline 2005 & 76,3 & 55,6 & 47,0 & 15,5 & 842,3 & 642,3 & 357,5 & 302,0 & 55,5 \\
\hline 2006 & 76,5 & 55,9 & 47,5 & 15,0 & 853,3 & 653,0 & 365,0 & 310,1 & 54,9 \\
\hline 2007 & 76,8 & 57,7 & 49,8 & 13,7 & 864,7 & 664,4 & 383,5 & 331,1 & 52,4 \\
\hline 2008 & 77,2 & 53,0 & 46,6 & 12,0 & 876,3 & 676,3 & 358,2 & 315,1 & 43,1 \\
\hline 2009 & 77,5 & 56,2 & 48,8 & 13,1 & 888,0 & 688,6 & 387,2 & 336,3 & 50,9 \\
\hline Fuente: Dane. & \multicolumn{70}{|c|}{} \\
\hline
\end{tabular}

Comportamiento en el empleo del eje dinamizador. El empleo en Cartagena (tabla 7.4.8) refleja una de las condiciones que afectan el acceso a los alimentos por la 
vía de salarios: la tasa de desempleo y el número de personas desocupadas, que en el 2009 fue de 50.900 personas. Esto baja la capacidad de demanda individual y familiar de alimentos de los sectores asalariados; por tanto, la solidaridad a partir de los ingresos familiares y las redes sociales en el territorio alivia la vulnerabilidad de los afectados por esta situación. También se resaltan los grandes contrastes entre opulencia y pobreza.

Políticas y programas del eje dinamizador de SAN. Esta ciudad eje presenta los mayores niveles de pobreza y desnutrición. Se han impulsado diferentes programas de lucha contra el hambre, que enfrentan problemas, porque "o hay continuación de programas, comedores comunitarios dotados sin continuidad por gobiernos, falta de continuidad en los recursos humanos, capacitación sin continuidad, escasos recursos financieros $" 504$. Estos son puntos críticos de las acciones en una ciudad con altos niveles de desigualdad.

Adicionalmente, se presenta descoordinación de acciones públicas entre mínimo dos niveles de gobierno, bien sea los subnacionales; o entre uno subnacional y el nacional; o, más complejo, entre los tres niveles. Esto puede puede derivar en "islas sin consensos institucionales. En la alimentación escolar los contratos con las asociaciones de padres este año no tienen interventoría, y el ICBF constituye asociaciones y contrata sin injerencia del Distrito aunque este ponga plata" ${ }^{505}$.

Hay clara disparidad de intervenciones públicas, sin coordinación por los niveles de gobierno que las aplican. Entre los niveles subnacionales se resentan traslados de programas de nutrición del gobierno departamental de Bolívar al distrital de Cartagena: "Solamente ahora se va a implementar por parte de la alcaldía, actualmente hay un convenio ICBF y alcaldía" ${ }^{506}$.

En los programas de acceso de municipios cercanos a la ciudad eje se requiere una evaluación clara y una interventoría sobre los operadores de los alimentos y la planeación de las instituciones educativas, si se tiene en cuenta la siguiente coyuntura:

504 MENDIVIL, Josefina (2008): Entrevista. Coordinadora del Plan de Emergencia Social Pedro Romero (PES), Alcaldía Mayor del Distrito de Cartagena, departamento de Bolívar, 24 de octubre.

505 Ibíd.

506 VILlALBA B., María (2008): Entrevista. Funcionaria líder del Programa de Nutrición, Alcaldía Mayor del Distrito de Cartagena, departamento de Bolívar, 21 de octubre. 
[Hay] deserción por almuerzo de los operadores ICBF-departamento para todos los municipios de Bolívar, mientras que la gente de la calle busca comprar almuerzo en la escuela, por ejemplo, mi hijo no vino a clase y sí llevó el almuerzo a casa por directores permisivos ${ }^{507}$.

Por otra parte, hay ciertos manejos de programas por parte de los beneficiarios en la ciudad eje: "Los subsidios han generado conflictos familiares entre hermanos al usar la plata para beber, y en la zona suroriental de Cartagena esperan la mensualidad en el barrio Candelaria para bailar con el 'rey' de Rocha" ${ }^{508}$. Sucede en la ciudad, donde los problemas de pobreza y desnutrición son más graves.

\subsection{Acceso en el eje dinamizador Neiva}

Características sociodemográficas del eje dinamizador. En Neiva,la distribución de la población por estratos (tabla 7.4.9) es esta: el estrato 1, 125.248 personas $(46,9 \%)$; el 2, 99.475 (37,3\%); el 3, 33.315 (14,4\%); y el 4 y siguientes, 3.925 (1,5\%). Los estratos 1 y 2 tienen el 84,2\% de las personas del eje. En la zona urbana, los estratos son: en el 1, 105.636 (43,6\%); en el 2, 94.539 (39,0\%); en el 3, 38.062 (15,7\%); y en el 4 y siguientes, 3.896 (1,6\%). Para los centros poblados, los estratos son: el 1, 10.918 (81,9\%); el 2, 2.375 (17,8\%); el 3, 30 (0,2\%); y en el 4 y siguientes no hay cifras. Por su parte, en las zonas rurales dispersas, los estratos son: en el 1, 8.694 (75,6\%); en el 2, 2.561 (22,3\%); en el 3, 223 (1,9\%); y en el cuatro y más $29(0,3 \%)$

\begin{tabular}{|c|c|c|c|c|c|c|c|c|c|c|}
\hline \multirow{4}{*}{$\begin{array}{l}\text { Tipo de } \\
\text { Territorio }\end{array}$} & \multicolumn{10}{|c|}{ Sisbén Neiva, total de personas, corte 3 de marzo de 2009} \\
\hline & \multicolumn{10}{|c|}{ Estratos } \\
\hline & \multicolumn{2}{|l|}{1} & \multicolumn{2}{|c|}{2} & \multicolumn{2}{|l|}{3} & \multicolumn{2}{|c|}{4 y mas } & \multicolumn{2}{|c|}{ Total } \\
\hline & No. & $\%$ & No. & $\%$ & No. & $\%$ & No. & $\%$ & No. & $\%$ \\
\hline Urbano & 105.636 & 43,6 & 94.539 & 39,0 & 38.062 & 15,7 & 3.896 & 1,6 & 242.133 & 100 \\
\hline Centro Poblado & 10.918 & 81,9 & 2.375 & 17,8 & 30 & 0,2 & 0 & 0,0 & 13.323 & 100 \\
\hline Rural Disperso & 8.694 & 75,6 & 2.561 & 22,3 & 223 & 1,9 & 29 & 0,3 & 11.507 & 100 \\
\hline Total & 125.248 & 46,9 & 99.475 & 37,3 & 38.315 & 14,4 & 3.925 & 1,5 & 266.963 & 100 \\
\hline
\end{tabular}

Los hogares de Neiva son 77.038 y su distribución por estratos socioeconómicos es esta: el estrato 1, 33.273 hogares (43,2\%); en el 2, 31.159 hogares (40,4\%); en el 3,

507 TOVAR, Jorge (2008): Entrevista. Exalcalde del municipio de Santa Rosa de Lima, Bolívar, 22 de octubre.

508 TOVAR, Jorge y MENDOZA, Marcos (2008): Entrevistas. Exalcaldes de los municipios de Santa Rosa de Lima y Villanueva, respectivamente, en el departamento de Bolívar, 22 de octubre. 
11.423 hogares $(14,8 \%)$; y en el cuatro y siguientes, 1.183 hogares (1,5\%). Hay altos indicadores de hogares vulnerables en Neiva: el 83,6\% de estos se encuentran en estratos 1 y 2, los de mayor vulnerabilidad (tabla 7.4.10).

La concentración de hogares en estratos 1 y 2 está en la zona urbana de Neiva, con $82.3 \%$, mientras en la rural hay una mínima parte. Además, hay una mínima proporción de la población que está vinculada con la producción local de alimentos, mientras que la demanda en la ciudad va en ascenso. Esta situación es normal por las áreas municipales, pero se requiere que la región SAN inmediata, el departamento del Huila, soporte los mínimos alimentarios.

\begin{tabular}{|c|c|c|c|c|c|c|c|c|c|c|}
\hline \multirow{4}{*}{$\begin{array}{c}\text { Tipo de } \\
\text { Territorio }\end{array}$} & \multicolumn{10}{|c|}{ Sisbén Neiva, total de hogares, corte 3 de marzo de 2009} \\
\hline & \multicolumn{10}{|c|}{ Estratos } \\
\hline & \multicolumn{2}{|c|}{1} & \multicolumn{2}{|c|}{2} & \multicolumn{2}{|c|}{3} & \multicolumn{2}{|c|}{4 y más } & \multicolumn{2}{|c|}{ Total } \\
\hline & No. & $\%$ & No. & $\%$ & No. & $\%$ & No. & $\%$ & No. & $\%$ \\
\hline Urbano & 28.377 & 40,3 & 29.594 & 42,0 & 11.336 & 16,1 & 1.171 & 1,7 & 70.478 & 100 \\
\hline Centro Poblado & 2.828 & 77,4 & 817 & 22,3 & 11 & 0,3 & 0 & 0,0 & 3.656 & 100 \\
\hline Rural Disperso & 2.068 & 71,2 & 748 & 25,8 & 76 & 2,6 & 12 & 0,4 & 2.904 & 100 \\
\hline Total & 33.273 & 43,2 & 31.159 & 40,4 & 11.423 & 14,8 & 1.183 & 1,5 & 77.038 & 100 \\
\hline
\end{tabular}

Los indicadores socioeconómicos de la ciudad eje muestran respecto a una gran porcentaje de la población:

[Esta] vive con un alto índice de Necesidades Básicas Insatisfecha (NBI) 32\%; comparables a las cifras más altas de pobreza en el mundo, el 52,6\% de la población vive bajo la línea de pobreza, de los cuales el $26,6 \%$ vive en condiciones de miseria y $15,68 \%$ no alcanza a cubrir las necesidades de calorías y nutrientes ${ }^{509}$.

Frente a la herramienta de estratificación socioeconómica, el 90,8\% de la población está en los niveles 1,2 y 3 , habitando en viviendas subsidiables en servicios públicos; el $1,2 \%$ de la población contribuye con estos aportes, estratos 5 y 6 ; y el $8 \%$ de los habitantes paga el costo real del servicio (estrato 4).

La población desplazada a Neiva es de 10.610 familias; los mayores expulsores están en los departamentos de Caquetá, con el 42,6\%; otros municipios del Huila, con el 27,6\%, y Putumayo, con el 9.5\%. El desplazamiento forzado hacia Neiva desde la

509 Alcaldía municipal de Neiva (2009): Plan de Desarrollo Municipal 2008-2011. Diagnóstico, pág.3. 
región inmediata: Huila, y los departamentos vecinos por la confrontación armada incide en el hecho de que el Huila sea más receptor que expulsor de población. Según las cifras de Acción Social, a diciembre de 2007, en el Huila 54.683 personas fueron recibidas en Neiva y Pitalito, frente a 37.210 expulsadas de los municipios de Algeciras, Neiva, Colombia y Acevedo.

\section{Comportamiento del índice de precios al consumidor de alimentos en el} eje dinamizador. En Neiva, la evolución de este índice muestra la incidencia en la capacidad de acceso a los alimentos de individuos y hogares en el eje, para el periodo 1990-2008, y un crecimiento de precios de alimentos que al año promedian entre el $3 \%$ y el 7\% en 18 años. A pesar de encontrarse en una región productora de alimentos y frutas para los mercados nacional e internacional, esta situación afecta a todos, en especial a los que dependen de ingresos fijos, los salarios y las rentas para comprar alimentos (tendencia superior a la nacional). Esto, en las condiciones de desigualdad de la ciudad eje, se convierte en una situación crítica.

Comportamiento del empleo en el eje dinamizador. El empleo en Neiva (tabla 7.4.11) refleja una de las condiciones que afectan el acceso a los alimentos por la vía de salarios: la tasa de desempleo y el número de personas desocupadas (en el 2009 la cifra fue de 22.100). Esto baja la capacidad de demanda individual y familiar de alimentos de los asalariados; por tanto, la solidaridad a partir de los ingresos familiares y las redes sociales en el territorio alivia la vulnerabilidad de los afectados por esta situación.

La información oficial del DANE solo reporta una cifra de desempleo desde 2006 para la ciudad de Neiva, pues el estudio se aplicó en 13 grandes centros urbanos del país, dentro de los cuales no fue considerada sino desde este año. Según cálculos estimados de Planeación Municipal, el desempleo en la ciudad de Neiva asciende al 24\%, en tanto la tasa de subempleo es del 34\%, datos que contradicen la información del DANE para el $2008(13,9 \%)$.

\begin{tabular}{|c|c|c|c|c|c|c|c|c|c|}
\hline Año & $\begin{array}{c}\text { \% Población } \\
\text { en edad de } \\
\text { trabajar }\end{array}$ & $\begin{array}{c}\text { Tasa Global } \\
\text { de } \\
\text { Participación }\end{array}$ & $\begin{array}{c}\text { Tasa de } \\
\text { Ocupación }\end{array}$ & $\begin{array}{c}\text { Tasa de } \\
\text { Desempleo }\end{array}$ & $\begin{array}{c}\text { Población } \\
\text { total }\end{array}$ & $\begin{array}{c}\text { Población en } \\
\text { edad de } \\
\text { trabajar }\end{array}$ & $\begin{array}{c}\text { Población } \\
\text { económicam } \\
\text { ente activa }\end{array}$ & Ocupados & Desocupados \\
\hline 2006 & 38,7 & 28,3 & 24,0 & 7,6 & 149,9 & 116,0 & 65,7 & 55,7 & 10,0 \\
\hline 2007 & 77,8 & 60,2 & 51,7 & 14,1 & 302,0 & 234,8 & 141,3 & 121,5 & 19,9 \\
\hline 2008 & 78,3 & 64,0 & 55,1 & 13,9 & 304,8 & 238,7 & 152,8 & 131,5 & 21,3 \\
\hline 2009 & 78,9 & 63,3 & 54,2 & 14,4 & 307,5 & 242,7 & 153,7 & 131,5 & 22,1 \\
\hline
\end{tabular}


Políticas y programas del eje dinamizador de SAN. En la evaluación realizada por funcionarios de la ciudad eje y del departamento del Huila respecto a los programas para que las poblaciones vulnerables tengan acceso a los alimentos, se evidencia dificultades vinculadas a la dieta, la inocuidad y los procesos administrativos de contratación pública: "El ICBF son [sic] estrictos en lineamientos pero en supervisión a restaurantes débiles, informando que hay riesgo y fin" ${ }^{510}$. Esta situación de falta de veeduría sobre los operadores por parte de una entidad con incidencia nacional es una queja generalizada en varios municipios del país.

Se evidencia que, por la forma de contratación pública, los que ganan los concursos no pertenecen a la región o al municipio donde deben operar, lo cual genera quejas de este tipo: "Contratan ONG de Neiva o nacionales que desconocen las realidades locales sobre alimentación" 511 . Este desconocimiento afecta la dieta local o regional y muestra la tendencia homogenizadora de la alimentación, que en mucha ocasiones desconoce las prácticas culturales de alimentación regional o local.

En las zonas rurales de los municipios abastecedores de la ciudad eje de Neiva sucede que "las acciones del ICBF en la zona rural dispersa con 150 familias donde los giros llegan retardados" 512 . Por ello, se hace un llamado a su cumplimiento y aumento, pues "se debe mejorar la financiación para aumentar la ración y mejorarla" "513; además, "la gobernación es demorada para transferir recursos al ancianato, hogares de paso" Estas descoordinaciones sobre la ejecución de las políticas son señaladas en varias de las entrevistas, con los conflictos generados en algunas zonas en relación con el destino del subsidio monetario dado a los beneficiarios.

Entre los procesos administrativos existentes que generan conflictos en los municipios y comunidades donde se ejecutan y que inciden en las dinámicas de acceso está el

510 MORAlES, María Edid (2008). Oficina de Asuntos Sociales de la Secretaria de Planeación Municipal, municipio de Campoalegre, departamento del Huila. Entrevistada en noviembre 5 de 2008 .

511 Ibíd.

512 BONILLA, Virginia (2008): Entrevista. Directora de la UMATA, municipio de Algeciras, departamento del Huila, 5 de noviembre.

513 MORALES, María Edid (2008): Entrevista. Oficina de Asuntos Sociales de la Secretaria de Planeación Municipal, municipio de Campoalegre, departamento del Huila, 5 de noviembre. 514 BARRERA, Néstor (2008): Entrevista. Secretario de Gobierno Municipal, municipio de Rivera, departamento del Huila noviembre 5 de 2008. 
relacionado con los restaurantes escolares, que son acciones para acceder a los alimentos por estudiantes en condición de vulnerabilidad:

[Hay] dificultades administrativas, por el manejo de los docentes, por manipulación y conflicto con los contratistas y por otro lado no hay coordinación en la asignación de casas por las condiciones locativas, los costos y el acceso, generando conflictos con las comunidades ${ }^{515}$.

Por tanto, no es solo descoordinación entre instituciones, sino generación de conflictos por la asignación a una $\mathrm{u}$ otra comunidad y por las condiciones locativas para ofrecer la alimentación. Esto se genera en la misma dirección con los colegios: "Las quejas de las instituciones educativas por demora en los comités de restaurante, ya que las instituciones educativas no estaban adecuadas para dar comida" ${ }^{16}$.

Por otro lado, se presenta la falta de control en los colegios por parte de los padres de familia, que no tienen "vínculos con asociaciones de padres para procesos de veedurías locales o con los profesores, aunque con la Federación de Cafeteros hay seguimiento" 517. Esto identifica una salida en los casos vinculados con las estructuras educativas públicas: las veedurías allí pueden construir acciones de control ciudadano sobre los programas alimentarios públicos y privados.

\subsection{Acceso en el eje dinamizador Cúcuta}

Características sociodemográficas del eje dinamizador. La distribución de personas por estratos socioeconómicos (tabla 7.4.12) es esta: para el estrato 1,262.240 persona (46\%); en el 2, 253.863 (44,5\%); en el 3, 53.304 (9,3\%); y el 4 y siguientes, $1.101(0,2 \%)$. Los estratos 1 y 2 suman 90,5\% de la población, siendo la segunda ciudad eje con más desigualdad.

En la zona urbana, la población por estratos es: para el 1, 243.313 personas (44,4\%); en el 2, 250.930 (45,8\%); en el 3, 53.208 (9,3\%); y el 4 y siguientes, 1.001 (0,2\%). En

515 PERDOMO Liliana, CABRERA Rocío (2008): Entrevistas. Grupo de la Secretaría de Educación Departamental, municipio de Neiva, departamento del Huila, 3 de noviembre.

516 ROSAS, Patricia (2008): Entrevista. Funcionaria de la Secretaría de Educación, municipal de Pasto, departamento de Nariño, 10 de noviembre.

517 Ibíd. 
los centros poblados, la población por estratos es: para el 1, 7.939 (93,7\%); en el 2, 525 $(6,2 \%)$; en el tres, $10(0,1 \%)$; y el 4 y siguientes no hay cifras. Por su parte, en las zonas rurales dispersas, la población por estratos es: para el 1, 10.988 (81,5\%); en el 2, 2.408 $(17,9 \%)$; en el 3, 86 (0,6\%); y el 4 y siguientes no hay cifras significativas.

\begin{tabular}{|c|c|c|c|c|c|c|c|c|c|c|}
\hline \multirow{3}{*}{$\begin{array}{c}\text { Tipo de } \\
\text { Territorio }\end{array}$} & \multicolumn{10}{|c|}{ Estratos } \\
\hline & \multicolumn{2}{|l|}{1} & \multicolumn{2}{|c|}{2} & \multicolumn{2}{|c|}{3} & \multicolumn{2}{|c|}{4 y más } & \multicolumn{2}{|c|}{ Total } \\
\hline & No. & $\%$ & No. & $\%$ & No. & $\%$ & No. & $\%$ & No. & $\%$ \\
\hline Urbano & 243.313 & 44,4 & 250.930 & 45,8 & 53.208 & 9,7 & 996 & 0,2 & 548.447 & 100 \\
\hline Centro Poblado & 7.939 & 93,7 & 525 & 6,2 & 10 & 0,1 & 0 & 0,0 & 8.474 & 100 \\
\hline Rural Disperso & 10.988 & 81,5 & 2.408 & 17,9 & 86 & 0,6 & 5 & 0,0 & 13.487 & 100 \\
\hline Total & 262.240 & 46,0 & 253.863 & 44,5 & 53.304 & 9,3 & 1.001 & 0,2 & 570.408 & 100 \\
\hline
\end{tabular}

En Cúcuta hay 150.048 hogares (tabla 7.4.13) y su distribución por estratos socioeconómicos es: para el 1, 64.527 (43\%); en el 2, 69.373 (46\%); en el 3, 15.844 (11\%); y en 4 y siguientes, 304 (0,2\%). Esto evidencia altos indicadores de hogares vulnerables, ya que el $89,2 \%$ se encuentran en los estratos 1 y 2 , los cuales son los de mayor vulnerabilidad social y económica y segregación cultural. Cúcuta es la segunda ciudad con más desigualdad al respecto.

\begin{tabular}{|c|c|c|c|c|c|c|c|c|c|c|}
\hline \multirow{3}{*}{$\begin{array}{l}\text { Tipo de } \\
\text { Territorio }\end{array}$} & & & & & Estrato & & & & & \\
\hline & \multicolumn{2}{|c|}{1} & \multicolumn{2}{|c|}{2} & \multicolumn{2}{|c|}{3} & \multicolumn{2}{|c|}{4 y mas } & \multicolumn{2}{|c|}{ Total } \\
\hline & No. & $\%$ & No. & $\%$ & No. & $\%$ & No. & $\%$ & No. & $\%$ \\
\hline Urbano & 57.522 & 40,5 & 68.285 & 48,1 & 15.810 & 11,1 & 303 & 0,2 & 141.920 & 100 \\
\hline Centro Poblado & 2.904 & 93,0 & 214 & 6,9 & 4 & 0,1 & 0 & 0,0 & 3.122 & 100 \\
\hline Rural Disperso & 4.101 & 81,9 & 874 & 17,5 & 30 & 0,6 & 1 & 0,0 & 5.006 & 100 \\
\hline Total & 64.527 & 43,0 & 69.373 & 46,2 & 15.844 & 10,6 & 304 & 0,2 & 150.048 & 100 \\
\hline
\end{tabular}

El desplazamiento forzado ha hecho que en Cúcuta, al 31 de diciembre de 2007, se encuentren 36.612 (7.322 familias) que provienen de otros municipios y departamentos, y son registradas como desplazadas en la oficina de Acción Social. La ciudad es receptora de desplazamiento forzado por violencia, sin tener los equipamientos urbanos y los servicios básicos necesarios para recibir nuevos asentamientos. La ubicación de estas familias se hace especialmente en barrios ilegales y periféricos de la ciudad, pertenecientes a las comunas 6, 7, 8 y 9. Con la política nacional en el Norte de Santander se desarrolla un proyecto a través del Centro de Servicios de la Alta Consejería para la Reintegración (ACR), que atiende 40 municipios y cuya sede es Cúcuta.

Comportamiento del índice de precios al consumidor de alimentos del eje dinamizador. En Cúcuta, la evolución de este índice muestra la incidencia en la 


\begin{tabular}{|c|c|c|c|c|c|c|c|c|c|}
\hline Año & $\begin{array}{c}\text { \% Población } \\
\text { en edad de } \\
\text { trabajar }\end{array}$ & $\begin{array}{c}\text { Tasa Global } \\
\text { de } \\
\text { Participación }\end{array}$ & $\begin{array}{l}\text { Tasa de } \\
\text { Ocupación }\end{array}$ & \begin{tabular}{|c|} 
Tasa de \\
Desempleo
\end{tabular} & $\begin{array}{c}\text { Población } \\
\text { total }\end{array}$ & $\begin{array}{c}\text { Población en } \\
\text { edad de } \\
\text { trabajar }\end{array}$ & $\begin{array}{c}\text { Población } \\
\text { económicam } \\
\text { ente activa }\end{array}$ & Ocupados & Desocupados \\
\hline 2001 & 73,9 & 65,8 & 55,7 & 15,4 & 682,0 & 503,7 & 331,5 & 280,4 & 51,0 \\
\hline 2002 & 74,1 & \begin{tabular}{l|l}
66,6 \\
\end{tabular} & 55,5 & 16,6 & 691,1 & 512,0 & 341,0 & 284,5 & 56,6 \\
\hline 2003 & 74,3 & 65,0 & 53,4 & 17,8 & 700,3 & 520,3 & 338,2 & 278,1 & 60,1 \\
\hline 2004 & 74,5 & \begin{tabular}{|l|}
61,9 \\
\end{tabular} & 52,3 & 15,5 & 709,6 & 528,6 & 327,4 & 276,6 & 50,8 \\
\hline 2005 & 74,7 & 60,2 & 51,4 & 14,6 & 718,9 & 537,0 & 323,1 & 276,0 & 47,1 \\
\hline 2006 & 75,1 & 59,7 & 52,1 & 12,7 & 727,8 & 546,7 & 326,2 & 284,7 & 41,5 \\
\hline 2007 & 75,6 & 61,1 & 54,4 & 11,0 & 736,6 & 556,8 & 340,1 & 302,9 & 37,2 \\
\hline 2008 & 76,1 & 61,3 & 55,6 & 9,3 & 745,6 & 567,2 & 347,8 & 315,6 & 32,3 \\
\hline 2009 & 76,6 & 62,5 & 55,0 & 11,9 & 754,5 & 577,9 & 361,2 & 318,1 & 43,1 \\
\hline
\end{tabular}

capacidad de acceso a los alimentos de individuos y hogares en el eje, para el periodo de 1990 a 2008, y un crecimiento de precios de alimentos que al año promedian entre el 3\% y el 6\% en 18 años. Ello afecta a todos los ciudadanos, en especial a los que dependen de ingresos fijos, salarios y rentas para comprar alimentos (tendencia superior a la nacional). Esto, en las condiciones de la ciudad eje como segunda en desigualdad, se vuelve una situación crítica, a pesar de que es una zona de frontera y centro principal del área metropolitana, donde los perfiles comerciales son los mayores generadores de empleo y presentan altos niveles de informalidad.

El bajo crecimiento económico y la limitada capacidad de generar empleo de buena calidad estimulan la economía informal como una forma alternativa de subsistencia o de reducción de costos. Desde los años ochenta, el trabajo informal y el subempleo vienen ganando en participación dentro de la población, que se considera ocupada, en un eje tipificado por el comercio.

\begin{tabular}{|c|c|c|c|}
\hline \multicolumn{4}{|c|}{$\begin{array}{c}\text { Tabla 7.4.15 Plan de Desarrollo de Cúcuta, componente: Pobreza y Población } \\
\text { Vulnerable }\end{array}$} \\
\hline PROGRAMAS & PROYECTOS & METAS DEL PROGRAMA & ENTIDADES \\
\hline $\begin{array}{l}\text { ATENCIÓN A } \\
\text { POBLACIONES } \\
\text { VULNERABLES. }\end{array}$ & $\begin{array}{l}\text { पComplemento } \\
\text { nutricional para grupos } \\
\text { vulnerables. }\end{array}$ & $\begin{array}{c}\text { Suministro de refrigerios, mercados y } \\
\text { atención integral al } 70 \% \text { de las } \\
\text { asociaciones que se encuentren } \\
\text { inscritas en Bienestar Social y cumplan } \\
\text { procesos legales de conformación y } \\
\text { operatividad, con incrementos del 10\% } \\
\text { anual. }\end{array}$ & \multirow{5}{*}{$\begin{array}{l}\text { Departamento } \\
\text { administrativo de } \\
\text { Bienestar Social y } \\
\text { Programas Especiales }\end{array}$} \\
\hline \multirow{6}{*}{\begin{tabular}{|c|} 
Brindar atención \\
institucionalizada, \\
protección yasistencia a \\
los grupos \\
poblacionales que por \\
sus condiciones de \\
marginalidad o \\
exclusión no tiene \\
capacidad para generar \\
o acceder a los \\
mecanismos formales \\
para la satis facción de \\
sus necesidades \\
básicas. Busca la \\
seguridad alimentaria \\
de preescolar y \\
escolares focalizados, \\
la educación yatención \\
alimentaría familiar y el \\
establecimiento de un \\
sistema de vigilancia \\
nutricional y de \\
\end{tabular}} & $\begin{array}{c}\text { Atención y } \\
\text { fortalecimiento nutricional } \\
\text { a los grupos asociados } \\
\text { de tercera edad. }\end{array}$ & $\begin{array}{l}\text { Cobertura de subsidios para el } 80 \% \\
\text { de los adultos mayores e implementar } \\
\text { estrategias que permitan ampliar la } \\
\text { cobertura del programa dirigido a } \\
\text { mejorar los estilos de vida saludables }\end{array}$ & \\
\hline & $\begin{array}{c}\text { Atención Integral básica } \\
\text { para la población adulta } \\
\text { mayor a través de los } \\
\text { hogares vida. }\end{array}$ & $\begin{array}{l}\text { Adecuación de un espacio para brindar } \\
\text { atención integral a } 150 \text { adultos mayores } \\
\text { en estado de abandono en el cuatrienio }\end{array}$ & \\
\hline & \begin{tabular}{|c|} 
Fortalecer convenios \\
para mejorar atención a \\
niños.
\end{tabular} & $\begin{array}{l}\text { DApoyar convenios de cooperación que } \\
\text { avalen procesos de atención a } \\
\text { población infantil vulnerable. }\end{array}$ & \\
\hline & $\begin{array}{l}\text { DFortalecer convenios de } \\
\text { alimentación infantil. }\end{array}$ & $\begin{array}{l}\square \text { Atender el } 50 \% \text { de la población escolar } \\
\text { con edades de } 6 \text { a } 12 \text {, con Sisben } 1 \text { y } 2 \text {. }\end{array}$ & \\
\hline & \begin{tabular}{|l} 
Apoyo a la reintegración \\
social y económica de la \\
población des movilizada
\end{tabular} & \begin{tabular}{|c|}
$\begin{array}{c}\text { Orientar y promover la participación de } \\
\text { la población desmovilizada en los } \\
\text { diferentes proyectos para población } \\
\text { vulnerable. }\end{array}$ \\
\end{tabular} & $\begin{array}{c}\text { S.Gobierno y Alta } \\
\text { consejería de la } \\
\text { Presidencia de la } \\
\text { República } \\
\end{array}$ \\
\hline & $\begin{array}{l}\text { Implementación de } \\
\text { Política Pública de } \\
\text { Seguridad Alimentaria. }\end{array}$ & $\square$ Crear el banco de alimentos & $\begin{array}{l}\text { Responsable: Bienestar } \\
\text { Social, Educación, } \\
\text { Planeación, ICBF }\end{array}$ \\
\hline FAMILIAS EN ACCIÓN & $\begin{array}{l}\text { DFortalecimiento del } \\
\text { programa Presidencial. }\end{array}$ & $\begin{array}{c}\text { Impulsar familias en acción en las } \\
\text { comunas } 1,3,4,5,6,7,8,9,10 \text { y en el } \\
\text { sector rural }\end{array}$ & $\begin{array}{c}\text { Responsable:Secretaria } \\
\text { Equidad de Género y } \\
\text { Presidencia }\end{array}$ \\
\hline
\end{tabular}


Políticas de acceso y programas del eje dinamizador de SAN. El plan de desarrollo municipal para la vigencia 2008-2011 define diversas intervenciones de política en torno a la generación de ingresos y la asistencia alimentaria directa. Estas acciones afectan la seguridad alimentaria de la población y la posibilidad de materializar su derecho a una alimentación adecuada en términos nutricionales y culturales (tabla 7.4.15), a partir de programas locales y nacionales.

Por otro lado, se ha venido desarrollado un banco de alimentos desde la iglesia, a través de la diócesis de Cúcuta.

\subsection{USO BIOLÓGICO Y UTILIDAD DE LOS ALIMENTOS}

Para desbravar a la niña y darle lustre había que empezar por sacarle
de adentro el hambre, poco a poco en un plan ascendente y calculado
de nutrición que tomaría meses, empezando por el caldo de papa
con perejil, siguiendo con el potaje de avena o cebada perlada y
evolucionando sin apremio hacia las habichuelas, las lentejas y las
habas, porque a una criatura que ha aprendido a alimentarse de
aire, como la mata de sábila, no puede aterrizarla sin solución de
continuidad en el chorizo y en el mondongo porque la revientas ${ }^{518}$.

El uso biológico y la utilidad de los alimentos hacen referencia a la capacidad de los individuos para asimilar la ingesta nutricional. La argumentación de los elementos generales se da por las condiciones nutricionales de la población, la vulnerabilidad biológica o la insuficiencia calórico-proteica, que son derivados de la falta de derechos de acceso alimentario ${ }^{519}$.

Por otro lado, se relacionan las particularidades del uso biológico y utilidad, lo cual muestra las condiciones y los niveles de desnutrición presentados en las regiones en función de la información de la ENSIN ${ }^{520}$, que ha realizado dos encuestas (en el 2005 y

518 RESTREPO, Laura (2005): La novia oscura. Alfaguara, Bogotá, pág. 28.

519 SCHEJTMAN, Alexander (1994): Economía política de los sistemas alimentarios en América Latina. Oficina Regional de la FAO para América Latina y el Caribe, División Agrícola Conjunta FAO/Cepal, Santiago de Chile, págs. 193 y ss.

520 Encuesta Nacional de la Situación Nutricional en Colombia 2005 y 2010. 
en el 2010), las cuales permiten comparar informaciones sobre niveles de desnutrición y sobrepeso u obesidad, mostrando dos caras de una sola necesidad: nutrición adecuada, sana y continua para los diferentes individuos.

En este punto, por los niveles de agregación de la información en relación con los ejes dinamizadores, no hay información comparable y homogénea; su desarrollo es diferente al resto del capítulo.

\subsubsection{Elementos generales de uso biológico y utilidad de los alimentos}

Para conocer las condiciones de uso y utilidad de los alimentos relacionados con las situaciones fisicas, biológicas, culturales e individuales para asimilar el consumo de alimentos, se necesita saber el estado de nutrición o desnutrición ${ }^{521}$ de los individuos, por tres razones: la individual, que relaciona las condiciones de asimilación físicobiológica de los alimentos; la de responsabilidad de la sociedad, en relación con la situación de desnutrición de los individuos; y la institucional, que relaciona la forma en que el Estado interviene en las políticas públicas de SAN. Estas tres razones (individual, social e institucional) muestran que la desnutrición vincula varios aspectos:

Incapacidad del sistema para garantizar a toda la comunidad una seguridad nutricional, [...] para dar pleno desarrollo a las potencialidades biológicas de todos los individuos de la sociedad cualquiera sea su estatus socioeconómico y cualquiera su localización geográfica ${ }^{522}$.

Por tanto, hay responsabilidades integradas de dos cuerpos (sociedad y Estado), para que esta tarea se cumpla con la orientación e inversión de las políticas públicas en SAN, en función de que enfrenten la desnutrición de la población. La evolución de desnutrición

521 "La desnutrición puede deberse a una inadecuada utilización biológica de los alimentos o a una cantidad y calidad en la ingesta alimentaria insuficiente para los requerimientos de un individuo, que pueden explicarse por cuatro tipos de factores: medioambientales, socioculturales, económicos y político-institucionales. La prevalencia de desnutrición no es un mero accidente en la región sino un reflejo de existencia de grandes inequidades en el ingreso y del bajo nivel de importancia que los temas de la alimentación y nutrición han tenido en la agenda política de los países”. MARTÍNEZ, Rodrigo y FERNÁNDEZ, Andrés (2006): Modelo de análisis del impacto social y económico de la desnutrición infantil en América Latina. Santiago de Chile, pág. 7

522 MACHADO C., Absalón (2003): “El problema alimentario en Colombia”. En Ensayos sobre seguridad alimentaria. Universidad Nacional de Colombia, Red de Desarrollo Rural y Seguridad Alimentaria, Bogotá, pág. 69. 
de la población colombiana refleja las condiciones individuales para realizar acciones según tipo de desnutrición. Hay dos situaciones sobre las condiciones de este problema: una, a fines de los años 70, se refiere a la desnutrición infantil:

El estudio Nacional de Salud (1977-1978) encontró que 611.596 niños menores de 5 años estaban desnutridos (peso para la edad desnutrición global), o sea $19.4 \%$ de la población infantil, y otros 622.309 niños (19.7\%), se encontraban en riesgo de desnutrición ${ }^{523}$.

La segunda situación, a partir de los resultados de la encuesta sobre alimentación realizada por el DANE, el DRI y el PAN en 1981, donde se identifica:

60\% de la población no alcanzaba el mínimo consumo de calorías, mientras el de proteínas era excesivamente inadecuado para $20 \%$ más pobre e inadecuado para el siguiente $20 \%$; es decir $40 \%$ no alcanzaba la recomendación mínima (70 gramos/día $)^{524}$.

Esta encuesta muestra, según las características nutricionales de las poblaciones, la demanda de los requerimientos mínimos que han de ser intervenidos con la política pública de SAN. Por tanto, exige identificar los grupos de alimentos, su capacidad nutritiva y físico-biológica individual, los hábitos alimenticios, la cultura regional, local y familiar, y el vínculo con la globalización, la educación del núcleo familiar o de quienes organizan la dieta en sitios de acceso público.

Conocer las condiciones anteriores permite determinar el objetivo de la política pública, al combinar acciones de acceso con las de uso y utilidad, porque "las necesidades nutricionales difieren en cierta medida durante los diversos períodos de la vida" Esto implica orientaciones para la familia, la comunidad, la escuela y el Estado, con el fin de sugerir a los individuos y las familias unas prácticas adecuadas de consumo de alimentos. Así, en el diseño de política pública, y en función de la población en riesgo, se identifican dos problemas relacionados con el uso biológico de los alimentos:

523 Ibíd., pág. 71 y ss.

524 Ibíd., pág. 74.

525 LATHAM, Michael C. (2002): Nutrición humana en el mundo en desarrollo. FAO, Roma, pág. 51. En el capítulo I sobre los elementos metodológicos (punto 1.1.8.3) se muestran las formas de cálculo de estas demandas nutricionales. 
La vulnerabilidad biológica de grupos específicos (mujeres embarazadas, nodrizas, niños en edad preescolar) o la falta de micronutrientes en regiones o grupos sociales determinados (yodo, vitamina A); la insuficiencia calórico-proteica derivados de la falta de derechos de acceso alimentario ${ }^{526}$.

Por tanto, la vulnerabilidad biológica y la insuficiencia calórica forman parte del diagnóstico para el diseño de la política pública vinculada con el uso y la utilidad. Martínez y Fernández ${ }^{527}$ consideran la desnutrición como una circunstancia vinculada a la salud pública, por varios factores: la inadecuada utilización biológica de los alimentos y la ingesta alimentaria insuficiente para los requerimientos individuales, aspectos explicados por factores medioambientales, socioculturales, económicos, políticoinstitucionales y biomédicos (figura 7.5.1).

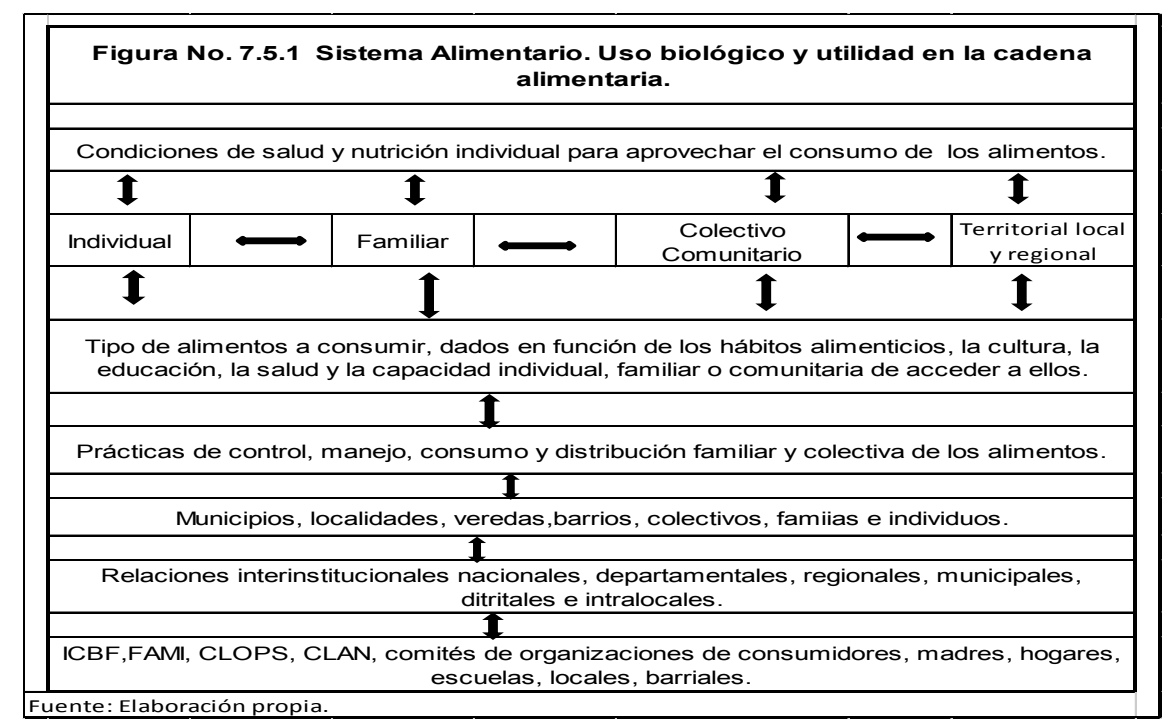

526 SCHEJTMAN, Alexander (1994): Economía política de los sistemas alimentarios en América Latina... Op. cit., pág. 194.

527 MARTÍNEZ, Rodrigo y FERNÁNDEZ, Andrés (2006): Modelo de análisis del impacto social y económico de la desnutrición infantil en América Latina. Cepal, ONU y PMA, Serie Manuales n. ${ }^{\circ}$ 52, Santiago de Chile, pág. 9. 


\subsubsection{Cadena alimentaria, inocuidad, nutrición y gobiernos}

La cadena vincula los agroalimentos a condiciones de inocuidad y capacidad proteica en cada parte:

La posibilidad de incorporar aspectos nutricionales en el origen de los alimentos puede plantear problemas a los sistemas de producción. Tal vez los agricultores necesitan también adoptar nuevas decisiones en los planos tecnológico y agrícola para satisfacer las demandas de un régimen saludable e inocuo como consecuencia de los nuevos reglamentos y normas, los cambios de los hábitos mundiales de consumo ${ }^{528}$.

Esto exige orientación de políticas de inocuidad y nutrición en el interior de los procesos de la cadena alimentaria; en cada uno puede existir la ausencia de uno $\mathrm{u}$ otro aspecto, lo que afecta el consumo final de los agroalimentos. La figura 7.5.2 relaciona los vínculos entre condiciones generales que afectan al individuo y llevan a la desnutrición. Estos se muestran a partir de las condiciones medioambientales, sociales, culturales, económicas, político-institucionales, así como desde el análisis biomédico y los servicios públicos domiciliarios. El combinar estas condiciones de afectación conduce a dos deficiencias: una deficiente utilización biológica de los alimentos y la cantidad y calidad de la ingesta para los individuos, llevando a la desnutrición.

Figura No. 7.5.2 Elementos asociados al desarrollo de la desnutrición

\begin{tabular}{|c|c|c|}
\hline \multicolumn{3}{|c|}{ DESNUTRICIÓN } \\
\hline $\begin{array}{c}\text { Deficiente utilización } \\
\text { biológica de los alimentos }\end{array}$ & & $\begin{array}{c}\text { Deficiente cantidad y calidad } \\
\text { de íngesta alimentaria }\end{array}$ \\
\hline & & \\
\hline BIOMÉDICOS & $\begin{array}{c}\text { Servicios Públicos } \\
\text { Domiciliarios }\end{array}$ & PRODUCTIVOS \\
\hline Medioambientales & $\begin{array}{l}\text { Socio - culturales - } \\
\text { económicos }\end{array}$ & Político-institucionales \\
\hline $\begin{array}{l}\text { on y Ajuste Tesis } \\
\text { y económico de }\end{array}$ & $\begin{array}{l}\text { nento: Rodr } \\
\text { ción infantil }\end{array}$ & $\begin{array}{l}\text { ernández 2006. "Modelo de análisis } \\
\text { isión de desarrollo social Santiago }\end{array}$ \\
\hline
\end{tabular}

528 FAO (2003): Estrategia de la FAO relativa al enfoque de calidad e inocuidad de los alimentos basados en la cadena alimentaria... Op. cit., pág. 68. 
La desnutrición tiene consecuencias en la vida del individuo y las familias. El Banco Mundial y la FAO plantean los efectos sobre la economía y la pobreza ${ }^{529}$, destacando tres aspectos: baja productividad, deficiente educación y mayores costos en salud: por tanto, la SAN encadena las estructuras sociales, educativas y administrativas del sector público.

La relación entre desnutrición e inequidad social está "reflejando una fuerte inequidad en contra de los grupos de personas más vulnerables" ${ }^{530}$; por tanto, las condiciones que generan desnutrición deben analizarse a partir del uso biológico, así como desde el tipo de desnutrición que relaciona calidad e inocuidad de los alimentos. Allí "no hay mediciones de procesos y no hay medidas de la desnutrición" ${ }^{531}$, detalladas para el caso de los ejes dinamizadores.

\subsubsection{Salud, alimentación y nutrición}

Los vínculos entre uso biológico, salud, alimentos, nutrición ${ }^{532}$ y desarrollo humano son reconocidos por diferentes disciplinas y ciencias que los relacionan en el marco de la SAN. La relación salud y alimentación, en la política pública, implica analizar el desarrollo de las personas a lo largo de la vida, que incluye costos para estas y la sociedad. En este sentido, debe considerarse este vínculo para la SAN e implementar acciones con una relación sistémica que explique e integre actividades preventivas más que curativas. De hecho, diferentes estudios muestran que "cada niño que sufre un retraso en su desarrollo físico o cognitivo debido al hambre y la malnutrición

529 "Pérdidas directas en productividad debidas al mal estado fisico, pérdidas indirectas ocasionadas por un mal funcionamiento cognoscitivo y deficientes niveles de escolaridad, y pérdidas debidas a mayores costos en la atención de salud". Banco Mundial (2006): Reposicionando la nutrición como prioridad para el desarrollo. Una estrategia para intervenciones de gran escala. Washington, pág. 8. Por su parte, la FAO establece: "La desnutrición redunda en pérdidas de productividad importantes, por ejemplo a causa de la tasa elevada de morbilidad y trastornos del desarrollo cognoscitivo". FAO (1996): “Cumbre Mundial sobre la Alimentación”. Documento técnico $\mathrm{n}^{\circ} 5$, op. cit., pág. 22.

530 ICBF (2010): Mapas de la situación nutricional en los municipios de Colombia. Bogotá, pág. 13. 531 MENDIVIL, Josefina (2008): Entrevista. Coordinadora del Plan de Emergencia Social Pedro Romero (PES), Alcaldía Mayor del Distrito de Cartagena, departamento de Bolívar, 24 de octubre.

532 FAO (1992): Declaración Mundial sobre la Nutrición. Primer punto de la declaración realizada por los ministros y plenipotenciarios, representantes de 159 Estados y de la Comunidad Económica Europea en la Conferencia Internacional sobre Nutrición. Roma, diciembre. "Declaramos asimismo nuestro firme compromiso de actuar juntos para asegurar un bienestar nutricional duradero a todos en un mundo pacífico, justo y con un medio ambiente sano". 
corre el riesgo de perder entre el 5 y el 10 por ciento de sus ingresos a lo largo de toda su vida" ${ }^{533}$.

Los efectos que una persona padece sobre el conjunto de la sociedad, la economía, la familia y el individuo por causa de la desnutrición, en los diferentes momentos de su vida, exige identificar la población por intervenir. Por ello, es necesario prever estas situaciones, mitigarlas a corto plazo y luego, en el mediano, eliminarlas. Una política pública en SAN determina a quiénes afecta el hambre, incluyendo población infantil, adolescentes, mujeres gestantes y adultos mayores, donde tiene mayor impacto el déficit nutricional y alimentario, con efectos irreversibles en los recién nacidos: "Desde el momento de su nacimiento la balanza se inclina en su contra" 534 . El hambre relacionada con malnutrición y desnutrición identifica problemas generacionales. Por tanto, debe garantizarse el acceso y las acciones diferenciadas para los grupos vulnerables de la población.

Las capacidades nutricionales de los alimentos que deben tenerse en cuenta en la política pública en SAN han de considerar la ciencia: "La alimentación debe cubrir con plena eficiencia el conjunto de necesidades nutricionales impuestas por el flujo permanente del organismo humano" 535 , como también la cantidad suficiente, la calidad en la composición del alimento, la proporción adecuada y la disponibilidad biológica, la cultura de la comunidad, la familia y el individuo. Otra acción para lograr una nutrición adecuada en condiciones de dificil acceso es la capacitación y educación mínima en nutrición, para mejorar los niveles de vida de la población:

Todas las personas requieren los mismos nutrientes a lo largo de la vida, pero en cantidades que para cada individuo varían de acuerdo con la edad, el ritmo de crecimiento, el sexo, tamaño corporal, peso, actividad, estado de salud y condiciones climáticas en que él habita ${ }^{536}$.

533 FAO (2004): El estado de la inseguridad alimentaria en el mundo 2004. Seguimiento de los avances en la consecución de los objetivos de la Cumbre Mundial sobre Alimentación y de los Objetivos de Desarrollo del Milenio. FAO, Roma, pág. 5.

534 Ibíd., pág. 8.

535 VARGAS OVIEDO, Wenceslao (1991): Fundamentos de ciencia alimentaria. Fundación para la Investigación Interdisciplinaria y la Docencia y Universidad Nacional de Colombia, Bogotá, págs. 46 y ss.

536 LOWENBERG, Miriam E. (1968): "Food and man”. J. Wiley and Sons, Nueva York. Citado en VAR GAS OVIEDO, Wenceslao (1991): Fundamentos de ciencia... Op. cit., pág. 34. 
Por consiguiente, capacitar en nutrición debe orientarse por este criterio, que determina necesidades de alimentos en función de poblaciones específicas. Implica también combinar políticas generales con particulares, nacionales, regionales y locales, cuyo trabajo está en función de diferentes procesos continuos de capacitación e investigación sobre las poblaciones por intervenir.

La $\mathrm{FAO}^{537}$ considera cuatro ejes para el diseño de una política pública: a) reconocer las ventajas de una dieta variada; b) determinar el cubrimiento de las necesidades nutricionales según el ciclo vital, con prioridad en los periodos de mayor riesgo: el embarazo, la lactancia, la infancia y la edad avanzada; c) vigilar la calidad e inocuidad de los alimentos a través de la cadena alimentaria; y d) promover el mantenimiento activo de las personas. En Colombia, a partir del Conpes 113 se identifican los efectos negativos de la desnutrición:

La desnutrición es una condición patológica inespecífica que puede ser reversible o no, ocasionada por la carencia de múltiples nutrientes, derivada de un desequilibrio provocado por un insuficiente aporte de energía, un gasto excesivo, o la combinación de ambos, que afecta en cualquier etapa del ciclo vital, en especial a lactantes y niños ${ }^{538}$.

Así, es necesario el uso biológico de los alimentos para considerar el estado nutricional de las personas y orientar la canasta en cuestión ${ }^{539}$. Se requiere, entonces, construir dietas acordes con las necesidades alimentarias de la población y la disponibilidad de alimentos regionales. Para ello, han de desarrollarse acciones con miras a “organizar los balances nutricionales a partir de productos con capacidad nutricional y producciones en pequeñas escalas de la región"

Por otro lado, se hace un llamado desde los territorios para demandar programas de alimentación y nutrición, a pesar de paradojas como esta: “Necesitamos más cobertura

537 FAO (s. f.): Nutrition education for the public. Food, Nutrition and Agriculture n. ${ }^{\circ} 16$.

538 DNP (2008): Conpes 113, Política Nacional de Seguridad Alimentaria y Nutricional (PSAN). Bogotá, marzo, Bogotá, pág. 22.

539 Dado que para las ciudades ejes no se presentan informaciones específicas sobre desnutrición, en esta parte se hacen observaciones sobre el uso biológico de los alimentos.

540 CORTÉS, Armando y CORTÉS, Yeris (2008): Entrevista. Director y técnico de la UMATA, municipio de Campoalegre, departamento del Huila, 6 de noviembre. 
porque hay mucha pobreza [...] Campoalegre es la capital arrocera del departamento del Huila y hay mucha gente aguantando hambre" ${ }^{541}$. Por los procesos de contratación pública, su asignación cambia los operadores, lo cual deriva en diferentes problemas, como "restaurantes con mala alimentación, con otros directivos de la misma asociación. Nosotros ampliamos cobertura y calidad" ${ }^{542}$; hasta la mala calidad de los alimentos: "Sobraba comida, se desperdiciaba porque los niños no la comían, y se organizaba como lavaza para los cerdos" ${ }^{443}$, por la presentación, el agrado y la cultura. Si se adecua solo a lo que tiene cada municipio, hay problemas de balances nutricionales:

La gente tiene la costumbre de comer yuca, maíz y ñame. Hay un desbalance nutricional por consumir los tres alimentos básicos del municipio, la pobreza que existe crea los desbalances generando un problema de seguridad alimentaria, además que el $80 \%$ de la producción se va para Cartagena ${ }^{544}$.

Por tanto, lo regiolocal como medida territorial va más allá de los límites políticoadministrativos, y así la región SAN debe ir hasta el territorio que cubra sus necesidades y requerimientos nutricionales.

\subsubsection{Particularidades del uso biológico y la utilidad de los alimentos, niveles nacionales y regionales}

El uso biológico y la utilidad de los alimentos remiten a las condiciones particulares nutricionales de las poblaciones. Allí han de tenerse en cuenta el tipo de desnutrición de cada una en los territorios y las situaciones culturales, individuales y familiares de las personas sobre las que se busca intervenir desde acciones de SAN.

541 MORALES, María Edid (2008): Entrevista. Oficina de Asuntos Sociales de la Secretaría de Planeación Municipal, municipio de Campoalegre, departamento del Huila, 5 de noviembre. 542 LLANOS SALINA, Oliver (2008): Entrevista. Presidente de la Asociación de Padres de Familia del Colegio Misael Pastrana, municipio de Rivera, departamento del Huila, 5 de noviembre.

543 Ibíd.

544 HERRERA, Rodolfo (2008): Entrevista. Director de la UMATA, municipio deVillanueva, departamento de Bolívar, 23 de octubre. 


\subsubsection{Condiciones nacionales de uso y utilidad}

Las particularidades sobre desnutrición en Colombia se ven en diferentes periodos, desde la década del cincuenta del siglo XX. La Misión Currie planteó sobre la desnutrición:

Es característica de una gran proporción del pueblo colombiano. Se manifiesta en formas diferentes como peso, estatura y otras medidas anormales; reducida capacidad de trabajo y presencia de determinados síntomas clínicos. La causa inmediata de las deficiencias nutritivas es una dieta proporcionalmente baja en proteínas, grasas, vitaminas y minerales esenciales ${ }^{545}$.

Desde esa década, la situación se agrava en diferentes casos. Hoy se tiene la información agregada sobre este comportamiento a nivel nacional y departamental, sin llegar al municipal. En el 2005 se realizó la primera Encuesta Nacional de la Situación Nutricional (ENSIN) en Colombia ${ }^{546}$, y en el 2010, la segunda, aplicada por el Instituto Colombiano de Bienestar Familiar ICBF. Allí se identifica la prevalencia de problemas nutricionales, con lo cual se busca orientar las decisiones de política pública nutricional y facilita evaluar el impacto en los diferentes grupos poblacionales presentes en todo el territorio nacional.

Desnutrición en menores de 0 a 4 años. La desnutrición en todas sus formas y edades, al igual que la malnutrición, es grave en cualquier momento de la vida; pero la peor se expresa en estas edades, por la irreversibilidad de sus consecuencias para la vida. La encuesta ENSIN del 2010 dice:

La desnutrición se asocia con el aumento de la mortalidad infantil, debido a las alteraciones que se presentan en el sistema inmune y al incremento de las enfermedades infecciosas, [...] al igual que el

\footnotetext{
545 BIRF y Gobierno de Colombia (1951): Bases de un Programa de Fomento para Colombia. Informe de una Misión dirigida por CURRIE, Lauchlin (2.a ed.). Banco de la República, Bogotá, pág. 209.

546 La información de esta parte es una síntesis tomada de las dos encuestas en mención: Encuesta Nacional de la Situación Nutricional en Colombia 2005, aplicada por el Instituto Colombiano de Bienestar Familiar, Dirección de Evaluación; y la realizada en el 2010, publicada en agosto de 2011.
} 
sobrepeso o la obesidad, se puede presentar conjuntamente con deficiencias de algunos micronutrientes, aumentando el riesgo de restricción del crecimiento intrauterino, morbimortalidad materna e infantil $1^{547}$.

\begin{tabular}{|c|c|c|c|c|c|c|c|c|c|c|c|c|c|c|c|c|c|c|}
\hline \multirow{3}{*}{ Características } & \multicolumn{6}{|c|}{$\begin{array}{l}\text { Retraso en la talla }(<-2 \text { de }) \\
\text { desnutrición crónica }\end{array}$} & \multicolumn{6}{|c|}{ Desnutrición global (<-2 de) } & \multicolumn{6}{|c|}{$\begin{array}{l}\text { Sobrepeso u obesidad IMC } \\
\qquad(>2 \text { de)b }\end{array}$} \\
\hline & \multicolumn{3}{|c|}{2005} & \multicolumn{3}{|c|}{2010} & \multicolumn{3}{|c|}{2005} & \multicolumn{3}{|c|}{2010} & \multicolumn{3}{|c|}{2005} & \multicolumn{3}{|c|}{2010} \\
\hline & \multicolumn{3}{|c|}{$\frac{2005}{\mathrm{IC}}$} & \multirow{2}{*}{\begin{tabular}{l|l|l}
$\%$ \\
13
\end{tabular}} & \multicolumn{2}{|c|}{ IC } & $\%$ & \multicolumn{2}{|c|}{ IC } & $\%$ & \multicolumn{2}{|c|}{ IC } & \multicolumn{3}{|c|}{\begin{tabular}{l|l} 
& 2005 \\
$\%$ & $1 C$
\end{tabular}} & \multirow{2}{*}{\begin{tabular}{|l|}
$\%$ \\
5
\end{tabular}} & \multicolumn{2}{|c|}{ IC } \\
\hline Total & 16 & 15 & 17 & & 13 & 14 & 4,9 & 4 & 5 & 3,4 & 3 & 4 & 5 & 4 & 5 & & 5 & 6 \\
\hline \multicolumn{19}{|l|}{ Edad (años) } \\
\hline$<1$ & 9 & 7,5 & 11 & 10 & 8,8 & 12 & 5,5 & 4 & 7 & 4,3 & 4 & 5 & 6 & 5 & 7 & 5 & 4 & 6 \\
\hline 1 & 19 & 17 & 21 & 16 & 14 & 18 & 4,2 & 3 & 5 & 3,3 & 3 & 4 & 7 & 6 & 8 & 7 & 6 & 8 \\
\hline 2 & 17 & 15 & 19 & 16 & 14 & 17 & 4,6 & 4 & 6 & 3,5 & 3 & 4 & 6 & 4 & 7 & 5 & 4 & 6 \\
\hline 3 & 18 & 16 & 20 & 13 & 11 & 14 & 5,2 & 4 & 6 & 3,1 & 3 & 4 & 4 & 3 & 5 & 6 & 5 & 7 \\
\hline 4 & 16 & 14 & 18 & 11 & 10 & 13 & 5 & 4 & 6 & 3 & 2 & 4 & 3 & 2 & 3 & 4 & 3 & 5 \\
\hline \multicolumn{19}{|l|}{ SEXO } \\
\hline Femenino & 15 & 13 & 16 & 12 & 11 & 13 & 4,6 & 4 & 5 & 3,3 & 3 & 4 & 5 & 4 & 5 & 5 & 4 & 5 \\
\hline Masculino & 17 & 16 & 19 & 14 & 13 & 15 & 5,2 & 5 & 6 & 3,5 & 3 & 4 & 5 & 5 & 6 & 6 & 5 & 6 \\
\hline \multicolumn{19}{|l|}{$\begin{array}{l}\text { Nivel del } \\
\text { SISBEN }\end{array}$} \\
\hline 1 & 19 & 18 & 20 & 17 & 16 & 18 & 6,1 & 5 & 7 & 4,7 & 4 & 5 & 4 & 4 & 5 & 4 & 4 & 5 \\
\hline 2 & 12 & 10 & 14 & 11 & 8,8 & 13 & 2,7 & 2 & 4 & $* 2,2$ & 1 & 3 & 6 & 4 & 7 & 5 & 4 & 7 \\
\hline 3 & 9,9 & 7,5 & 12 & 8,3 & 6,7 & 10 & $\star 2,7$ & 1 & 4 & $* 1,6$ & 1 & 3 & 5 & 3 & 7 & 7 & 6 & 9 \\
\hline 4 o más & 9 & 7,3 & 11 & 9,1 & 8 & 10 & 3,1 & 2 & 4 & 2,2 & 2 & 3 & 6 & 5 & 8 & 6 & 5 & 7 \\
\hline \multicolumn{19}{|c|}{ 1. Se incluyeron sólo niños y niñas que durmieron en la casa la noche anterior } \\
\hline \multirow{2}{*}{\multicolumn{19}{|c|}{ 2. Se incluyeron sólo niños y niñas que tuvieran los tres indicadores $W h z$, Waz y Whz dentro de los rangos permitidos }} \\
\hline \multirow{2}{*}{\multicolumn{19}{|c|}{$\begin{array}{l}\text { 3. Se incluyeron sólo niños y niñas que tuvieran menos de } 60 \text { meses de edad o (O-59 meses). } \\
\text { 4.En la desagregación de peso y talla al nacer, se hizo solo si la madre del niño o la niña hubiese sido encuestada. }\end{array}$}} \\
\hline & & & & & & & & & & & & & & & & & & \\
\hline \multicolumn{19}{|c|}{ a. Intervalo de confianza del $95 \%$. } \\
\hline \multicolumn{19}{|c|}{ b. Denominado como obesidad por la Resolución 2121 del 9 de junio de 2010.} \\
\hline ente: " & & & & 1 & te & & Cla & vis & & 1. & & ILI & $-\mathbb{I N}$ & & & ${ }_{C}$ & & \\
\hline
\end{tabular}

Por estas circunstancias, en la comparación de las dos encuestas (2005 y 2010) hay una disminución relativa para algunas edades en desnutrición; no sucede lo mismo con el sobrepeso, cuya dinámica se encuentra en aumento, en especial en el sexo masculino. La información del tabla 7.5.1 caracteriza la desnutrición presente en los estratos más pobres de la sociedad (el 1 y el 2); en el 3 es menor; y en el cuatro y siguientes aumenta la desnutrición crónica. La desnutrición crónica entre el 2005 y el 2010 aumenta en los menores de un año, y en los demás rangos disminuye; por otro lado, la tendencia a la obesidad se ve en todas las edades, en ambos sexos y con un crecimiento alto en el estrato tres.

Para este mismo rango de edad, la información por regiones (tabla 7.5.2) muestra una distribución desigual: en la mayoría hay una baja de la desnutrición; sin embargo, en unas tienen mayor incidencia que en otras. Hay disminución en la zona urbana, no igual en la rural. No se encuentra información detallada de las ciudades eje, pero los

547 Encuesta Nacional de la Situación Nutricional en Colombia 2010. Profamilia -Instituto Nacional de Salud- Bienestar familiar- Ministerio de Protección Social. 1a. Edición Agosto 2011., pág. 76. 
agregados regionales de sus entornos inmediatos: los departamentos, muestran menores índices de desnutrición en el periodo 2005-2010 para la desnutrición crónica.

Desnutrición crónica en baja estatura para la edad, niños de 0 a 4 años. En este rango, el $12 \%$ de los niños presentan baja estatura para la edad y $2,1 \%$ desnutrición crónica severa. Los porcentajes de desnutrición son mayores en niños entre uno y dos años de edad, en aquellos cuyo orden de nacimiento es de 6 o más meses y en menores, cuyo intervalo entre nacimientos es menor a 24 meses. Las diferencias en la prevalencia de desnutrición crónica, según educación formal de la madre y nivel del Sisbén, son marcadas: $17,2 \%$ de los niños con Sisbén 1 tienen retraso en el crecimiento, porcentaje mayor que el de $5,7 \%$ presente en los niveles 3 a 6 .

El retraso en crecimiento de este rango infantil es alto en todas las regiones del país, mayor en las regiones Atlántica, Bogotá, en la subregión de Cauca y Nariño sin litorales, en La Guajira, Cesar y Magdalena. Los departamentos con mayores prevalencias de desnutrición crónica son: La Guajira, Boyacá, Nariño, Magdalena, Córdoba y Cauca. En el área rural, la desnutrición es el doble con respecto a la zona urbana: 17,1\% frente a 9,5\%; y cerca de 3 veces el porcentaje de niños con desnutrición crónica severa: 3,7\% frente al $1,4 \%$.

\begin{tabular}{|c|c|c|c|c|c|c|}
\hline \multirow{3}{*}{ Características } & \multicolumn{6}{|c|}{ Retraso en talla o desnutrición crónica } \\
\hline & \multicolumn{3}{|c|}{2005} & \multicolumn{3}{|c|}{2010} \\
\hline & $\%$ & \multicolumn{2}{|c|}{ IC } & $\%$ & \multicolumn{2}{|c|}{ IC } \\
\hline Total & 15,9 & 15 & 16,8 & 13,2 & 12,5 & 13,9 \\
\hline \multicolumn{7}{|c|}{ Área } \\
\hline Urbana & 12,8 & 11,8 & 13,8 & 11,6 & 10,8 & 12,5 \\
\hline Rural & 22,3 & 20,5 & 24 & 17 & 15,5 & 18,5 \\
\hline \multicolumn{7}{|c|}{ Regiones/Subregiones/Departamentos } \\
\hline $\begin{array}{c}\text { Región } \\
\text { Amazonía y Orinoquía }\end{array}$ & 11,2 & 8,7 & 13,6 & 13,8 & 12,2 & 15,6 \\
\hline Región Atlántica & 18 & 16,4 & 19,6 & 15,4 & 14 & 17 \\
\hline $\begin{array}{l}\text { Bolivar, Norte, San } \\
\text { Andrés y Providencia }\end{array}$ & 13,8 & 10,7 & 16,9 & 10,5 & 7,9 & 13,7 \\
\hline Bolívar & 17,5 & 13,9 & 21,1 & 10,8 & 8,1 & 14,3 \\
\hline Región Central & 14,4 & 12,6 & 16,2 & 10,7 & 9,3 & 12,2 \\
\hline Antioquia sin Medellín & 17,2 & 13,2 & 21,2 & 11,8 & 8,7 & 15,9 \\
\hline Medellín A. M. & 13,2 & 9,4 & 17 & 8,5 & 5,9 & 12,1 \\
\hline \begin{tabular}{|l|} 
Antioquia \\
\end{tabular} & 15,7 & 12,8 & 18,6 & 10,2 & 8 & 12,8 \\
\hline Huila & 15,9 & 11,5 & 20,2 & 11,7 & 8,6 & 15,9 \\
\hline Región Oriental & 14,5 & 12,2 & 16,8 & 11,3 & 9,9 & 12,9 \\
\hline $\begin{array}{c}\text { Norte de Santander, } \\
\text { Santander }\end{array}$ & 11,5 & 7,9 & 15 & 9,1 & 7,4 & 11,2 \\
\hline Norte de Santantder & $* 12,3$ & 7,4 & 17,2 & 9,8 & 7,6 & 12,5 \\
\hline Región Pacífica & 15,8 & 13,9 & 17,8 & 12,3 & 10,7 & 14,2 \\
\hline Regíon Bogotá D C & 16,9 & 13,7 & 20,1 & 16,4 & 14,1 & 18,9 \\
\hline \multicolumn{7}{|c|}{ 1. Se incluyeron sólo niños y niñas que durmieron en la casa la noche anterior } \\
\hline \multicolumn{7}{|c|}{ 2. Se incluyeron sólo niños y niñas que tuvieran los tres indicadores Whz, Waz y Whz dentro de los rangos permitidos. } \\
\hline \multicolumn{7}{|c|}{ 3. Se incluyeron sólo niños y niñas que tuvieran menos de 60 meses de edad o (0-59 meses). } \\
\hline \multicolumn{7}{|l|}{ a. Intervalo de confianza del $95 \%$} \\
\hline
\end{tabular}


Estado nutricional en niños de 5 a 9 años. Por primera vez en Colombia se cuenta con información sobre el estado nutricional de los niños en edad escolar.

Retraso en crecimiento. El 12,6\% de los niños entre 5 y 9 años tiene retraso en crecimiento (estatura baja para su edad), y es mayor en los hombres (14,5\%) que en la mujeres $(10,6 \%)$. Se presentan diferencias significativas entre niveles del Sisbén: 19\% en el nivel 1 frente a 5,8\% en el nivel 3-6, por lo que es preocupante el predominio numérico de los niños en pobreza. En el área rural, el porcentaje es alto (18,5\%) y en la urbana es de 9,7\%; la población rural dispersa muestra alta prevalencia de retraso en crecimiento (20,6\%). Las regiones que más sufren el fenómeno son: la Atlántica, con el 15,2\% (La Guajira, Cesar y Magdalena 19,5\%), y el Cauca y Nariño sin litorales, con el 19,5\%. Los departamentos con más prevalencias de retraso en crecimiento en niños de 5 a 9 años son La Guajira, Boyacá, Nariño, Magdalena, Amazonas, Córdoba, Cesar, Caquetá y Sucre.

Desnutrición global. El 5,4\% presenta desnutrición global (bajo peso para su edad) y la prevalencia es mayor en los hombres $(6,8 \%)$ que en las mujeres (4\%). La prevalencia es mayor entre los niños de 5 años (7\%), en tanto para los de 9 años es de 4,6\%. El nivel 1 del Sisbén muestra una prevalencia de 8,8\%, y el nivel 3-6 tiene el 2.7\%. Es evidente que la desnutrición está estrechamente ligada a la pobreza, pues en todos los indicadores el porcentaje de déficit en los niños pertenecientes al nivel 1 de Sisbén es mucho mayor.

En la zona rural, la prevalencia de desnutrición global es mayor que en el área urbana (7,5\% frente a 4,4\%). En la región Atlántica, la subregión de La Guajira, Cesar y Magdalena tiene alta desnutrición global, 8,9\% y 10,1\%, respectivamente. Al respecto, no hay datos por departamentos, debido a que la muestra no es suficiente para estimar prevalencias bajas con aceptable nivel de precisión.

Desnutrición aguda. En los niños entre 5 y 9 años, el 1,1\% muestra desnutrición aguda (bajo peso para la estatura). Para este indicador no es posible obtener datos desagregados por características demográficas, socioeconómicas ni geográficas, por cuanto la muestra es insuficiente.

Estado nutricional en niños de 5 a 17 años. La situación de desnutrición y exceso de peso de los niños y jóvenes de 5 a 17 años (tabla 7.5.3) tiene dinámicas diferentes, reflejadas en una tendencia a disminuir los indicadores de desnutrición en el total urbano y rural. Lo mismo sucede en las regiones, incluidas las ciudades ejes, que tienden a disminuir la desnutrición en este rango. 
Además, hay un incremento por exceso de peso en todo el país: en todas las regiones se presenta un aumento del índice, desde lo rural y urbano hasta cada región identificada en los estudios de la ENSIN, con las ciudades ejes y sus contextos. Las excepciones son las regiones de la Amazonía y la Orinoquía, pues allí los índices de desnutrición aumentan en el periodo de 2005 a 2010; pero también son la excepción en la medida en que en estas disminuyen los índices de exceso de peso, mostrando un comportamiento diferente al resto del país.

En los niños de 5 a 9 años, el porcentaje de déficit en estatura para la edad es similar al de 0 a 4 años. Las deficiencias en peso y de estatura son mayores en niños que en niñas. Los departamentos con mayores prevalencias de retraso en crecimiento en niños de 5 a 9 años son, en orden, La Guajira, Boyacá, Nariño, Magdalena, Amazonas, Córdoba, Cesar, Caquetá y Sucre. Por otra parte, los departamentos con prevalencias altas en retraso en crecimiento en niños y jóvenes de 10 a 17 años son: Nariño, La Guajira,

\begin{tabular}{|c|c|c|c|c|c|c|c|c|c|c|c|c|c|c|c|c|c|c|}
\hline \multirow{3}{*}{ Características } & \multicolumn{6}{|c|}{$\begin{array}{l}\text { Retraso en la talla }(<-2 \text { de) } \\
\text { desnutrición crónica }\end{array}$} & \multicolumn{6}{|c|}{ Delgadez $(<-2$ de $)$} & \multicolumn{6}{|c|}{ Exceso de peso IMC (>1 de) } \\
\hline & \multicolumn{3}{|c|}{2005} & \multicolumn{3}{|c|}{2010} & \multicolumn{3}{|c|}{2005} & \multicolumn{3}{|c|}{2010} & \multicolumn{3}{|c|}{2005} & \multicolumn{3}{|c|}{2010} \\
\hline & $\%$ & \multicolumn{2}{|c|}{ IC } & $\%$ & \multicolumn{2}{|c|}{ IC } & $\%$ & \multicolumn{2}{|c|}{ IC } & $\%$ & \multicolumn{2}{|c|}{ IC } & $\%$ & \multicolumn{2}{|c|}{ IC } & $\%$ & \multicolumn{2}{|c|}{ IC } \\
\hline Total & 13,9 & 13,3 & 14,5 & 10,0 & 9,6 & 10,5 & 3,0 & 2,8 & \begin{tabular}{|l|l|}
3,3 \\
\end{tabular} & 2,1 & 2,0 & 2,3 & 13,9 & 13,4 & \begin{tabular}{|l|l|}
4 & 14,5 \\
\end{tabular} & 17,5 & 17,0 & 18,0 \\
\hline \multicolumn{19}{|c|}{ Área } \\
\hline Urbana & 11,0 & 10,4 & 11,6 & 7,9 & 7,4 & 8,4 & 3,0 & 2,8 & 3,3 & 2,2 & 2,0 & 2,4 & 15,9 & 15,2 & \begin{tabular}{|l|l|}
2 & 16,6 \\
\end{tabular} & 19,2 & 18,6 & 19,8 \\
\hline Rural & 20,4 & 19,2 & 21,6 & 15,2 & 14,2 & 16,3 & 3,0 & 2,5 & 3,5 & 1,9 & 1,6 & 2,2 & 9,4 & 8,7 & 10,7 & 13,4 & 12,4 & 14,3 \\
\hline \multicolumn{19}{|c|}{ Regiones/Subregiones/Departamento } \\
\hline $\begin{array}{c}\text { Región Amazonía y } \\
\text { Orinoquía }\end{array}$ & 12,0 & 10,1 & 13,8 & 14,3 & 13,0 & 15,6 & *2,0 & 1,2 & 2,9 & 1,8 & 1,4 & 2,2 & 18,1 & 16,4 & 419,8 & 15,9 & 14,7 & 17,1 \\
\hline Región Atlántica & 15,2 & 14,2 & 16,3 & 11,4 & 10,5 & 12,3 & 5,0 & $4,4,5$ & 5,6 & 3,3 & 3,0 & 3,8 & 10,6 & 9,8 & 11,5 & 13,0 & 12,2 & 13,8 \\
\hline $\begin{array}{c}\text { Bolívar Norte, San } \\
\text { Andrés }\end{array}$ & 11,6 & 9,0 & 14,3 & 8,0 & 6,5 & 9,9 & 6,7 & 4,7 & 8,7 & 3,9 & 2,9 & 5,2 & 10,7 & 8,7 & 12,7 & 15,5 & 13,5 & 17,4 \\
\hline $\begin{array}{c}\text { Bolívar Sur, Córdoba, } \\
\text { Sucre }\end{array}$ & 16,1 & 14,3 & 17,9 & 12,3 & 10,8 & 13,9 & 4,9 & 4,0 & 5,7 & 2,7 & 2,2 & 3,4 & 8,9 & 7,6 & 10,1 & 10,1 & 9,0 & 11,2 \\
\hline Bolívar & 12,9 & 10,4 & 15,4 & 9,4 & 7,6 & 11,5 & 5,8 & 4,17 & 7,5 & 3,2 & 2,3 & 4,4 & 9,0 & 7,2 & 10,8 & 13,2 & 11,3 & 15,1 \\
\hline Region Central & 13,1 & 12,0 & 14,2 & 9,1 & 8,3 & 10,0 & 2,7 & 2,2 & 3,2 & 1,9 & 1,6 & 2,3 & 14,3 & 13,1 & 15,6 & 18,3 & 17,2 & 19,4 \\
\hline Antioquia sin Medellín & 14,4 & 11,8 & 17,0 & 11,1 & 9,0 & 13,7 & 3,2 & 2,1 & 4,3 & $\star 2,0$ & 1,3 & 3,1 & 14,1 & 10,7 & 17,4 & 16,1 & 13,1 & 19,0 \\
\hline Medellín A.M & 9,3 & 7,3 & 11,3 & 5,8 & 4,5 & 7,4 & $* 3,0$ & 1,8 & 4,2 & 2,0 & 1,4 & 2,8 & 14,4 & 11,6 & 17,3 & 20,3 & 18,1 & 22,5 \\
\hline Antioquia & 12,2 & 10,4 & 14,0 & 8,3 & 7,0 & 9,8 & 3,1 & 2,3 & 3,9 & 2,0 & 1,5 & 2,6 & 14,2 & 12,0 & 16,5 & 18,3 & 16,5 & 20,1 \\
\hline Huila & 13,8 & 10,8 & 16,7 & 11,6 & 9,7 & 14,0 & 2,6 & 1,7 & 3,5 & $* 1,9$ & 1,3 & 1,9 & 13,2 & 11,1 & 15,2 & 18,6 & 15,7 & 21,5 \\
\hline Region Oriental & 14,2 & 12,6 & 15,7 & 10,5 & 9,6 & 11,6 & 2,7 & 2,13 & 3,2 & 1,9 & 1,6 & 2,4 & 14,0 & 12,7 & 15,2 & 17,1 & 15,9 & 18,2 \\
\hline Norte de Santander, & 13,0 & 10,5 & 15,4 & 9,3 & 8,0 & 10,8 & 3,3 & 2,4 & 4,1 & 2,4 & 1,9 & 3,1 & 13,3 & 11,4 & 15,1 & 17,4 & 15,7 & 19,1 \\
\hline Norte de Santander & 14,8 & 10,4 & 19,1 & 10,1 & 8,1 & 12,4 & 3,8 & 2,4 & 5,2 & 3,3 & 2,4 & 4,4 & 11,8 & 9,3 & 14,4 & 15,1 & 13,1 & 17,0 \\
\hline Region Pacífica & 13,6 & 12,2 & 15,0 & 10,8 & 9,5 & 12,3 & 2,5 & 2,0 & 3,0 & 1,8 & 1,5 & 2,2 & 15,1 & 13,7 & 16,5 & 20,1 & 18,9 & 21,3 \\
\hline Region Bogotá & 12,9 & 10,9 & 14,8 & 7,2 & 6,0 & 8,7 & $* 1,1$ & 0,6 & 1,6 & 1,2 & 0,8 & 1,7 & 17,4 & 15,4 & 19,3 & 21,0 & 19,3 & 22,7 \\
\hline \multicolumn{19}{|c|}{ 1. Se incluyeron solo niños y niñas que durmieron en la casa la noche anterior. } \\
\hline \multirow{2}{*}{\multicolumn{19}{|c|}{ 2. Se incluyeron sólo niños y niñas que tuvieran los tres indicadores Whz, Waz y Whz dentro de los rangos permitidos. }} \\
\hline & & & & & & & & & & & & & & & & & & \\
\hline \multicolumn{19}{|l|}{ 4. No incluye gestantes. } \\
\hline \multicolumn{19}{|c|}{ Intervalo de confianza de $95 \%$. } \\
\hline
\end{tabular}


Boyacá, Cauca, Vaupés, Amazonas, Sucre, Magdalena, Tolima, Caquetá, Putumayo, Norte de Santander y Cesar. En los niños y jóvenes de 10 a 17 años, la delgadez es un problema porque indica un consumo insuficiente de calorías; en Córdoba y Atlántico tienen prevalencias altas: $15,1 \%$ y $12,4 \%$, respectivamente.

Estado nutricional en las gestantes. Se requiere identificar en forma oportuna el bajo peso materno, por ser uno de los factores que afectan el peso al nacer. La encuesta incluyó la toma de medidas antropométricas a las embarazadas entre 13 y 49 años de edad, presentes en los hogares (1.621 mujeres).

Según el índice de masa corporal (IMC) gestacional, el bajo peso se encuentra en una quinta parte de las mujeres en embarazo (20,7\%). En las gestantes de 13 a 18 años, el bajo peso se halló en 33,2\%. El exceso de peso (sobrepeso y obesidad) se presenta en $30 \%$ de las embarazadas: $23 \%$ corresponde a sobrepeso y $7 \%$ a obesidad. Estas condiciones son mayores a medida que aumenta la edad de la mujer: 18,6\% en las de 13 a 18 años frente a 53,5\% en las de 37 a 49 años, y a medida que aumenta el trimestre de embarazo: $25 \%$ en el primero y $39,1 \%$ en el tercero.

Situación de la población adulta. El promedio de peso aumenta con la edad, sobre todo en las mujeres. Todos los indicadores de deficiencia nutricional muestran prevalencias mayores en los niveles 1 y 2 del Sisbén, lo que ratifica que la situación nutricional de la población se determina por la pobreza e inequidad social. En la zona rural, son mayores las prevalencias que en la urbana, lo que implica condiciones de exclusión del campesinado. En la población adulta, la delgadez prevalece más en personas de 18 a 22 años y en población con menor nivel del Sisbén. La región Atlántica tiene mayores prevalencias de delgadez en adultos, especialmente en Bolívar, Atlántico y Córdoba. El sobrepeso y la obesidad son un problema de salud pública en Colombia que afecta en especial a la población adulta. La prevalencia de obesidad es mayor en las mujeres; el problema se incrementa con la edad y se encuentra en todos los estratos socioeconómicos, siendo mayor en el área urbana.

La prevalencia de exceso de peso empieza a ser importante desde los 10 años, y los departamentos con índices más altos en el grupo de 10 a 17 años corresponden a los que tienen mayor sobrepeso y obesidad en adultos: San Andrés, Amazonas, Vichada, Putumayo, Guaviare, Tolima, Arauca, Guainía y Cundinamarca. 



\section{CONCLUSIONES}

T a presentación de conclusiones se estructura relacionando los objetivos con la hipótesis planteada. Se presentan así: las generales, referidas a los niveles de gobierno y a las políticas públicas; las relacionadas con el enfoque sectorial de la política pública de seguridad alimentaria nutricional en el periodo de análisis; las vinculadas a las dinámicas territoriales en los componentes de la cadena alimentaria; y, por último, las descriptoras de los elementos relacionados con los desarreglos institucionales y las regiones de seguridad alimentaria nutricional.

\section{Generales}

La orientación de las políticas públicas en la cadena agroalimentaria la hacen instituciones globales, en tanto la formulación se realiza a través del Gobierno nacional en función de cada componente de la cadena alimentaria. La dirección de estas políticas y la forma como inciden en los territorios reflejan desajustes intergubernamentales entre la decisión nacional y las dinámicas subnacionales en los territorios; por ejemplo, los efectos sobre la disponibilidad de agroalimentos, la cual disminuye o aumenta en los territorios como consecuencia de las políticas nacionales.

Otro aspecto se relaciona con las decisiones públicas nacionales aprobadas en cumbres internacionales. En este escenario, el Estado colombiano es garante de los compromisos allí adquiridos, los cuales se expresan en los diseños de política pública y en los programas a través de los cuales buscan cumplir estos compromisos; por ejemplo, los objetivos del milenio y el derecho a la alimentación adecuada. Estas acciones son obligaciones vinculantes para el Estado colombiano.

Las reformas descentralizadoras del Estado en Colombia durante las dos últimas décadas cambiaron las dinámicas de las relaciones entre los diferentes niveles de gobierno, al determinar para cada uno competencias sobre seguridad alimentaria nutricional. Estas competencias llevan al Gobierno nacional al manejo de las políticas macroeconómicas y sectoriales para actividades productivas, es decir, la disponibilidad y las sociales; mientras tanto, los gobiernos subnacionales deben responder, a través de los componentes de acceso y uso biológico, por las condiciones de reproducción social en el territorio, implementando en este las políticas SAN. 
Se observó que en la inocuidad, punto transversal de la cadena alimentaria, las acciones de política pública, las responsabilidades y las competencias gubernamentales e institucionales exigen alta coordinación entre ellas, por su carácter interdisciplinario y sistémico. Esta exigencia se efectúa a través de tres componentes de la cadena alimentaria: disponibilidad, distribución y acceso.

\section{Relacionadas con el enfoque sectorial de la política de SAN}

En Colombia, la política de seguridad alimentaria nutricional tiene un enfoque sectorial, lo que implica que se realiza para todos los componentes de la cadena desde cada política. Entre tanto, para los territorios, estas políticas se aplican de manera general, según las decisiones tomadas por el Gobierno nacional, y son ejecutadas además por los gobiernos subnacionales.

Lo anterior se presenta porque las competencias de cada nivel de gobierno tienen intervenciones distintas frente a la misma decisión. Por ejemplo, en el caso de la política sectorial para la disponibilidad, su competencia sobre el tipo de producción agroalimentaria la tiene el Gobierno nacional, y la opera a través de las políticas públicas agraria, de comercio exterior y económica, las cuales inciden en las condiciones para la producción de agroalimentos en los territorios; por ello, los gobiernos subnacionales dependen de los agroalimentos determinados por las políticas del nivel central. En este sentido, las desarticulaciones intergubernamentales relacionadas con las políticas que atañen a la disponibilidad se muestran así: mientras el Gobierno nacional dispone de sus políticas con diferentes instrumentos o acuerdos tipo TLC, que afectan los procesos productivos de agroalimentos en los territorios, las competencias subnacionales, aunque quieran determinar acciones productivas agroalimentarias locales, deben acogerse a las nacionales.

Las competencias para los gobiernos subnacionales frente a la disponibilidad de agroalimentos son de dos tipos para los territorios: por un lado, de acuerdo con los planes de ordenamiento territorial, determinar los usos del suelo rural, a través de las funciones otorgadas por la constitución política de 1991 y la ley 388 de 1997; por otro lado, los planes de desarrollo municipal y distrital, ley 152 de 1994, pueden incentivar producción de agroalimentos para mejorar los ingresos de los campesinos y otros productores rurales.

La desarticulación entre el nivel nacional y el subnacional se evidencia en que el primero diseña políticas macro y de comercio exterior sobre los agroalimentos 
que se producen en los territorios; en este sentido, busca que el mercado externo resuelva la disponibilidad y abra al comercio internacional de agroalimentos el mercado colombiano, respecto a los mismos productos que en el nivel subnacional se están incentivando. Se mencionan solo los casos del trigo, el arroz y la cebada, que, de ser autosuficientes, pasaron a depender hoy del mercado externo para su disponibilidad.

El enfoque sectorial para los componentes de acceso y uso biológico expresa identidad institucional para acciones públicas, orientado por los principios de poblaciones vulnerables, riesgo nutricional y ciclo vital. Estos se aplican a través de la política social, con diversos programas que buscan mejorar las condiciones de nutrición de la población en los territorios. En este punto se encuentra unanimidad institucional e intergubernamental en la aplicación de los principios para las acciones públicas alimentarias; no obstante, la dinámica de intervención se desarrolla de manera institucional y no interinstitucional. Esta última funciona solo para distribuirse el territorio según las intervenciones de los Gobiernos nacional, departamental, municipal y distrital.

Otra forma de ver la sectorialidad de la política de SAN es a través del análisis de la inocuidad de los agroalimentos, elemento transversal a la cadena alimentaria que presenta desarticulaciones en el nivel institucional; por ejemplo, en la disponibilidad hay competencias subnacionales sobre qué tipo de uso darle a los suelos, pero no se ejerce control sobre el desarrollo y manejo del proceso productivo de agroalimentos; tampoco sobre los niveles de calidad de los agroalimentos producidos en las regiones inmediatas a los ejes; o respecto al nivel de contaminación del suelo y del agua utilizados para su producción. Otro aspecto es el relacionado con los agroalimentos importados, en la medida en que las instituciones nacionales son responsables sobre su manejo desde la llegada al puerto, así como sobre su seguimiento desde los tiempos de duración del producto y su fecha de vencimiento.

\section{Vinculadas a las dinámicas territoriales}

En Colombia y en las regiones inmediatas a los ejes dinamizadores estudiados, la disponibilidad de agroalimentos se vio afectada en el periodo analizado por distintos motivos: por la violencia económica, política y de los grupos armados ilegales; por los cambios en la política nacional de comercio exterior; por el despojo de tierras y el desplazamiento de población (en su gran mayoría, pequeños productores campesinos). 
El proceso de despojo de tierras y el desplazamiento de población generaron una dinámica de relatinfundización de varias zonas rurales. Dado que los propietarios desplazados y desposeídos eran dueños de pequeños predios, menores de 10 ha (que suman el 60,98\%) o de menos de 50 ha (que suponen el 26,50\%), el 87,48\% de predios abandonados han sido abandonados como consecuencia de desplazamientos forzosos de la población. Una característica histórica de la producción de agroalimentos en Colombia, es que su mayor área y número de predios son manejados sobre la estructura de la economía campesina; por tanto, esta relatinfundización combina despojo con desposesión en las regiones inmediatas a los ejes dinamizadores, lo que afecta la disponibilidad y el desarrollo territorial.

Simultáneamente, hay un proceso de concentración de la propiedad, el cual, para el periodo de análisis, muestra que los predios de más de 200 ha aumentaron en número y cantidad de tierras; y en este tamaño de propiedad no se producen agroalimentos, lo cual cambia la orientación de su producción hacia materias primas y prolonga los conflictos entre los usos y las aptitudes de los suelos rurales.

Por otra parte, la violencia en cada territorio, que lleva implícitos desplazamientos poblacionales que dejan predios abandonados, tuvo dos efectos sobre la cadena alimentaria: la baja disponibilidad de agroalimentos para los ejes dinamizadores y las condiciones precarias de los desplazados, que deben acudir a las instituciones nacionales, departamentales, municipales o distritales para tener acceso a los alimentos gracias a políticas sociales. Otra forma de expulsar campesinos productores de agroalimentos es el cambio del uso y la tenencia de la tierra. Esta forma se presenta en regiones inmediatas a los ejes dinamizadores, en especial Neiva y otros territorios del país como Cauca y Nariño, donde la ilusión del rentismo acabó con la producción.

En las cuatro regiones estudiadas se produjeron cambios básicos, resultado de las políticas de diferentes Gobiernos nacionales y que afectan la disponibilidad de agroalimentos: por un lado, cambios en los usos del suelo rural, al sustituir cultivos semestrales por permanentes, en la mayoría de casos, materias primas; por otro lado, la sustitución de tierras al servicio de la agricultura por la ganadería.

Otro aspecto encontrado en la investigación, y que repercute negativamente sobre la disponibilidad de agroalimentos en las regiones inmediatas, es la sustitución de cultivos en los territorios por cuenta de la acción de las políticas nacionales, que cambian a su vez por razones y presiones externas e internas: por el diseño de seguridad nacional y la 
política de protección a la agricultura norteamericana y europea; por los compromisos en el manejo y la represión a la producción de cultivos de uso ilícito en varios territorios; y por la sustitución de agroalimentos por materias primas, en especial aceite de palma.

Los efectos de las políticas nacionales sectoriales económica, agraria y de comercio exterior durante el periodo contemplado en la investigación afectaron los diferentes territorios productores de agroalimentos, materias primas y productos destinados a la exportación: entre 1996 y 2009, los cultivos semestrales disminuyeron a 1.484.348 ha, en tanto en 1987 tenían 2.407.930 ha en producción. Con estas políticas y el modelo de apertura comercial, se perdieron 872.500 ha en veinte años, lo que afectó la disponibilidad nacional y regional de agroalimentos destinados a la dieta básica de la población.

Debido a estas políticas, el conflicto entre usos y aptitudes de los suelos, el uso inapropiado de la tierra y su mal aprovechamiento son frecuentes en las regiones inmediatas a los ejes dinamizadores. En Colombia, las cifras son: sobreutilización de la tierra, 19.584.769 ha (el 33\%); subutilización de la tierra, 17.767.918 ha (el 30\%); uso adecuado de la tierra, 22.585.466 ha (el 38\%). Por tanto, el 63\% del suelo aprovechable está mal utilizado, lo cual expresa una falta de coordinación y exigencia interinstitucional e intergubernamental sobre el control de las dinámicas territoriales para producir agroalimentos.

A partir de la comparación de las brechas de demanda y oferta de agroalimentos, se identificó en cada territorio un manejo de los espacios vacíos o mal utilizados para el desarrollo territorial. La desintegración de políticas públicas de desarrollo nacional y subnacional no complementan las acciones a partir de los mínimos requerimientos de agroalimentos para la SAN, en cada región inmediata y eje dinamizador.

Por otro lado, hay desconocimiento entre la institucionalidad nacional y la identificación de la estructura de la propiedad territorial: la primera desarrolla las políticas sobre regulación del tamaño de la propiedad rural con las unidades agrícolas familiares, las cuales determinan rangos de tamaño según regiones relativamente homogéneas, con sus potencialidades de explotación agropecuaria; pero en las estructuras de propiedad territoriales, estas regulaciones no vinculan los tamaños reales existentes en las regiones inmediatas, puesto que en la mayoría de casos los rangos del tamaño de la propiedad que hay son menores a los que ha sido reglamentados. Todo ello evidencia un desconocimiento del Gobierno nacional de las estructuras reales de la propiedad en los territorios subnacionales. 
En los casos estudiados, la distribución de los agroalimentos se regula por el mercado, desde el encuentro entre el productor y el comerciante en los municipios. De acuerdo con el agroalimento, hay unas u otras condiciones de manejo de los intermediarios o los compradores directos, dependiendo del productor y el tipo de producto al momento de la compra, tanto en los municipios productores como en los centros de abastecimiento de los ejes dinamizadores. Cuanto mayor sea el número de intermediarios, mayor será el precio de los agroalimentos, lo cual dificulta su acceso a los pobladores urbanos por su baja capacidad adquisitiva.

En la comercialización de agroalimentos en los ejes dinamizadores crecen las grandes superficies; sin embargo, las tiendas de barrio desempeñan un papel importante para su distribución, por varias razones: por su cercanía y el conocimiento directo de las familias; por cubrir áreas próximas en los barrios; por la forma y el tamaño del empaque que se usa en la distribución; por el diseño de unidades de medida acordes con los niveles de pago inmediato de los pobladores; por el conocimiento y la confianza entre tenderos y consumidores; y por la mayor facilidad de crédito a las familias vecinas, que se ajusta a los periodos de ingreso de los pobladores.

En la distribución, la inocuidad ha de tener en cuenta el manejo de los agroalimentos desde el sitio de compra al productor hasta el almacenamiento para el comercio. En los ejes dinamizadores se identificó que, acorde con las normas, se exige cumplir ciertos controles organizativos y sanitarios para el manejo de los establecimientos, según las regulaciones urbanas de los planes de ordenamiento municipales o distritales, además de las normas sanitarias establecidas por las instituciones de salud locales.

En relación con las políticas de acceso, hay desajustes intergubernamentales e interinstitucionales causados por la intervención del Gobierno nacional sobre los territorios subnacionales. Estos desajustes son de distinto tipo: los que se relacionan con la continuidad de algunos programas nacionales, y los que se deben a la intervención en las regiones sin tener en cuenta su cultura y las lógicas de desarrollo territorial.

Por estratos socioeconómicos, la población de los ejes dinamizadores muestra características de vulnerabilidad social y económica, por la alta concentración de personas con altos niveles de pobreza, expresada en los estratos sociales vulnerables. Así, los estratos uno y dos suponen el 96,4\% de la población en Cartagena; en Cúcuta, el 90,5\%; en Neiva, el 84,2\%; y en Medellín, el 72,1\%. Estas desigualdades en las ciudades 
eje exigen una mayor coordinación interinstitucional e intergubernamental en las acciones públicas vinculadas a la cadena alimentaria, así como en los componentes de acceso y uso biológico.

En relación con el acceso, hay varios puntos que la investigación identificó en las condiciones de inocuidad. Uno fundamental es el atinente al acceso en sitios públicos, como restaurantes y comedores comunitarios. En estos establecimientos hay ciertos controles por parte de las secretarías de salud pública, tanto municipales como distritales, que tienen que ver con el control de permisos sanitarios de tratamiento y el manejo para la preparación de comidas; mientras que en los hogares depende de las dinámicas de cada familia, lo que requiere educación a las cabezas de hogar para su preparación, consumo y almacenamiento domésticos.

\section{Relacionadas con las regiones inmediatas, los ejes dinamizadores y la SAN}

El manejo político-administrativo de las regiones inmediatas a los ejes dinamizadores: los departamentos, se caracteriza porque cada uno organiza y administra su territorio con figuras diferentes (zonas de desarrollo económico [Zodes], regiones, provincias), según las condiciones de disponibilidad para las poblaciones de los ejes dinamizadores. Allí, la relación intergubernamental se da a través de acciones interinstitucionales entre gobiernos subnacionales. En específicos, el departamento incide en dos direcciones sobre los municipios de su jurisdicción: por un lado, en las condiciones de disponibilidad de agroalimentos de la región inmediata, apoyándolos; por otro, integrando las acciones públicas relacionadas con el acceso.

Las regiones inmediatas son identificadas como aquellos territorios que, por los vínculos de origen y destino de los agroalimentos con los ejes dinamizadores, suplen un alto porcentaje de dicha demanda; mientras que la región SAN incluye la parte de los agroalimentos que, para su dieta, fueron importados. En este sentido, la región SAN actual incorpora las regiones inmediatas y las zonas de producción de agroalimentos en el exterior; esta última, para el caso de las leguminosas secas y cereales, que antes se producían en el país. La dinámica de origen y destino de estos productos importados rompe el principio de "la comida cerca de la mesa".

En este sentido, no hay un proceso de priorización de la disponibilidad identificada y organizada para cada uno de los ejes dinamizadores de las regiones inmediatas, partiendo de la cercanía a la mesa, como tampoco sobre las regularidades del ciclo productivo de 
cada agroalimento. En esta dirección hay acciones para la disponibilidad en los planes de desarrollo nacional, al igual que en los niveles subnacionales.

Las regiones SAN, identificadas como aquellas partes del territorio nacional que tienen la capacidad de suplir la oferta de agroalimentos necesarios para una población o una región, y que son estratégicas para la autonomía agroalimentaria, presentan desarreglos institucionales y gubernamentales. Según esta investigación, tales desarreglos se relaciona con la cultura alimentaria, dadas las características regionales existentes; y con el criterio de cercanía: la comida debe estar cerca a la mesa. Estos desarreglos no reconocen las particularidades regionales, los menores costos ambientales por transporte, la utilización de los espacios territoriales para acciones de desarrollo rural, y tampoco identifican las demandas y ofertas de agroalimentos que suple una región SAN.

El Gobierno nacional estructura la Política de Seguridad Alimentaria Nutricional desconociendo los procesos que identifican los mínimos de seguridad alimentaria nutricional, de acuerdo con los requerimientos kilo calóricos de la población de cada eje dinamizador y región inmediata. Estos mínimos se traducen en agroalimentos para estructurar la base de las acciones de la política pública SAN regional.

No hay una combinación simultánea e integral en la aplicación de la política nacional y las acciones en los niveles subnacionales, que estén en función de las condiciones de cada territorio, con la identificación de los mínimos requerimientos para las regiones SAN. Por tanto, el diseño de la política de seguridad alimentaria nutricional realizado en el gobierno central no discute su aplicación con los gobiernos subnacionales, y en este sentido no hay concertación intergubernamental en la política SAN; solo hay o dirección o ejecución.

Por los desarreglos interinstitucionales e intergubernamentales, se desconocen las necesidades y los requerimientos mínimos de SAN en cada territorio, que son la base de la coordinación de políticas de SAN en términos de comercio internacional, precios, exigencias y controles sobre la inocuidad; también, con relación al ordenamiento territorial, que determina usos del suelo rural, de acuerdo con las competencias de los gobiernos municipales y distritales, o de la región inmediata productora de agroalimentos.

Lo que se produce en las regiones inmediatas a los ejes dinamizadores, al desconocer las condiciones de nutrición y los requerimientos kilocalóricos de la pirámide poblacional 
en cada eje, lleva a que los vínculos de origen y destino, entre producción y consumo de agroalimentos, estén desarticulados en relación con las demandas de la población desde sus necesidades de nutrición.

Por lo tanto, finalmente puede indicarse que no se identifican las condiciones de vida y los estados de nutrición de los diferentes grupos etáreos que determinan el uso y la utilidad biológica de los agroalimentos en cada uno de los ejes dinamizadores y las regiones inmediatas. Al no existir información disponible o al estar dispersa sobre los mínimos requerimientos kilocalóricos, y dadas las diferentes condiciones de vulnerabilidad de las poblaciones, se deriva que las acciones desarrolladas sean desarticuladas y solo operen como acciones de "de buena voluntad". 



\section{ANEXO A \\ METODOLÓGICO SOBRE EL TRABAJO EN LOS TERRITORIOS SAN ENTREVISTAS SEMIESTRUCTURADAS}

\section{Información de fuente primaria (entrevistas)}

Objetivos:

- Caracterizar las dinámicas territoriales que inciden sobre la SAN, a través de la cadena alimentaria, a partir de la identificación de los programas institucionales.

- Identificar las relaciones interinstitucionales entre niveles de gobierno en relación con la SAN.

- Identificar las condiciones en que opera la cadena alimentaria en cada territorio.

\section{Personas entrevistadas y preguntas realizadas}

Se realizaron preguntas abiertas que permitían contrapreguntar y ampliar la información sobre la base del desarrollo de las entrevistas, que fueron realizadas de manera grupal e individual, según la disponibilidad de los participantes.

\subsection{De las regiones inmediatas a las ciudades ejes y de otros territorios}

- Funcionarios de organizaciones públicas de los diferentes niveles de gobierno (municipal, distrital, departamental, nacional, de los sectores: desarrollo social, agropecuario, económico, medio ambiente, educación y salud).

\section{Esquema de entrevista}

- ¿Cuáles son los programas que tiene el municipio en seguridad alimentaria?

- ¿Cuáles son los programas que tiene el departamento en seguridad alimentaria?

- ¿Cuáles han sido las dificultades presentadas en la ejecución de los programas de seguridad alimentaria en el municipio y en el departamento?

- ¿Cómo se han presentado las relaciones intergubernamentales para ejecutar los programas de seguridad alimentaria? 
- Organizaciones y asociaciones (asociaciones de padres de familia, productores campesinos)

\section{Esquema de entrevista}

- ¿Qué beneficios han traído los programas de seguridad alimentaria del gobierno?

- ¿Qué dificultades han tenido en la aplicación de las acciones de seguridad alimentaria en el municipio?

- Plazas de mercado (comerciantes, mayoristas, minoristas, administradores)

\section{Esquema de entrevista}

- ¿Qué productos se comercializan en esta plaza de mercado?

- ¿Cuál es el origen de los productos que llegan a esta plaza de mercado?

- ¿Cuál es el destino de los productos que comercializan en esta plaza de mercado?

- ¿Por cuántos comerciantes pasan los productos desde el campesino hasta el consumidor final?

\section{Relación de personas entrevistadas}

En las siguientes tablas anexos se relacionan las personas entrevistadas durante la investigación; se presentan los nombres y apellidos, el cargo, la entidad u organización donde labora, los teléfonos, el correo electrónico y el municipio donde se realizó la entrevista y la fecha de esta. Esta información se ha ordenado en función de los ejes dinamizadores y los otros territorios que fueron visitados. 


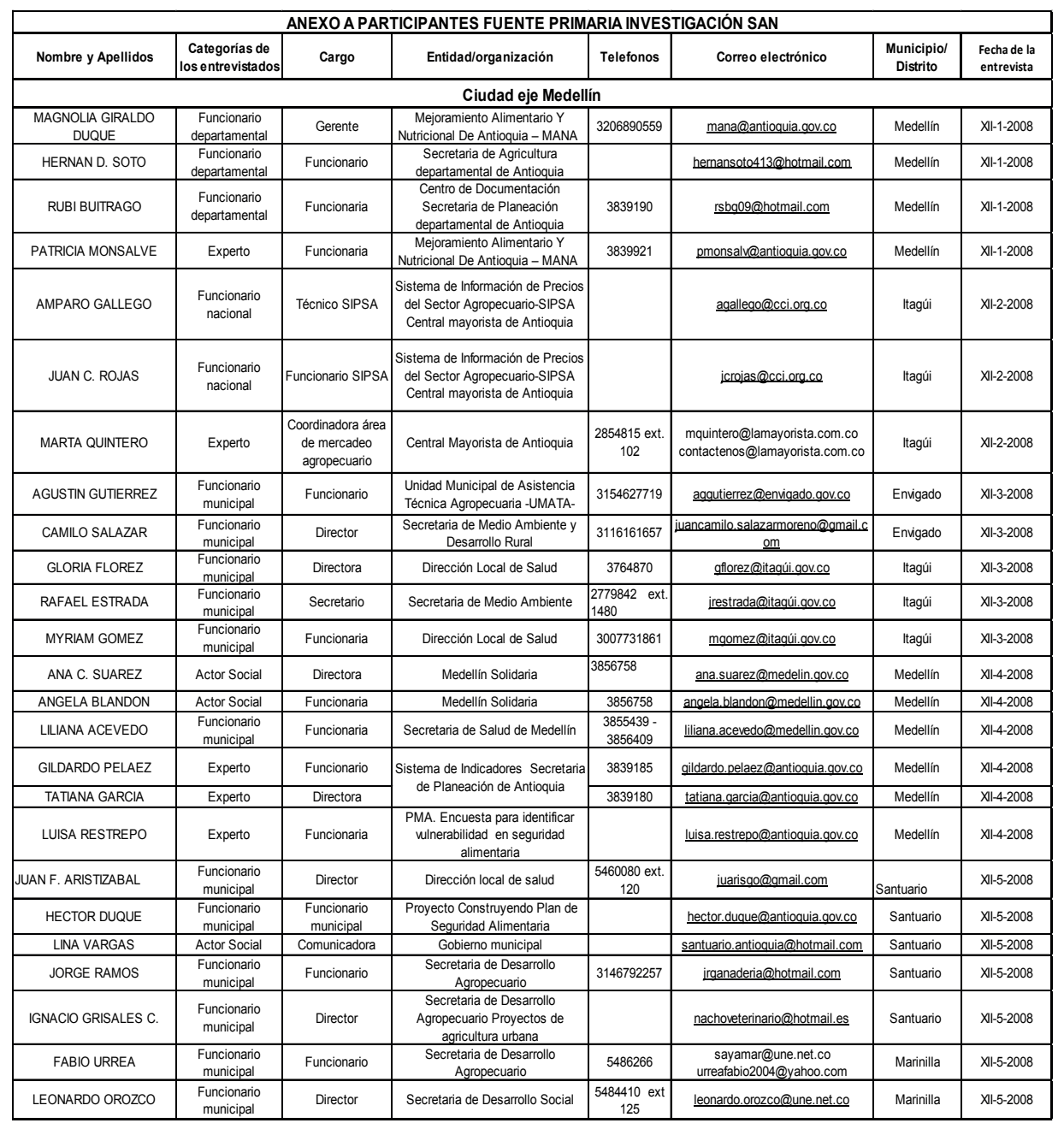




\begin{tabular}{|c|c|c|c|c|c|c|c|}
\hline \multicolumn{8}{|c|}{ ANEXO A PARTICIPANTES FUENTE PRIMARIA INVESTIGACIÓN SAN } \\
\hline Nombre y Apellidos & \begin{tabular}{|c|} 
Categorias de \\
los entrevistados
\end{tabular} & Cargo & Entidad/organización & Telefonos & Correo electrónico & $\begin{array}{c}\text { Municipio/ } \\
\text { Distrito }\end{array}$ & $\begin{array}{c}\text { Fecha de la } \\
\text { entrevista }\end{array}$ \\
\hline \multicolumn{8}{|c|}{ Ciudad eje Cartagena } \\
\hline LUIS MAGIL GUALDERA & $\begin{array}{c}\text { Funcionario } \\
\text { distrital }\end{array}$ & Funcionario & $\begin{array}{l}\text { Unidad Municipal de Asistencia } \\
\text { Técnica Agropecuaria -UMATA- }\end{array}$ & \begin{tabular}{|l|}
$3175004164 /$ \\
3126877731
\end{tabular} & & Cartagena & IX-20-2008 \\
\hline OSCAR BRIEVA & $\begin{array}{c}\text { Funcionario } \\
\text { distrital }\end{array}$ & Funcionario & $\begin{array}{c}\text { Plan de Emergencia Social Pedro } \\
\text { Romero }\end{array}$ & 3164543803 & & Cartagena & $1 X-20-2008$ \\
\hline JORGE NUÑEZ & $\begin{array}{c}\text { Funcionario } \\
\text { distrital }\end{array}$ & Funcionario & $\begin{array}{l}\text { Unidad Municipal de Asistencia } \\
\text { Técnica Agropecuaria -UMATA- }\end{array}$ & 3135012735 & jomanu55@hotmail.com & Cartagena & IX-20-2008 \\
\hline DELIA BOSSA & Experto & $\begin{array}{l}\text { Profesional } \\
\text { universitaria }\end{array}$ & $\begin{array}{c}\text { Secretaria de Educación Distrital } \\
\text { Proyectos Permanetes Distrito de } \\
\text { Cartagena }\end{array}$ & 3006157639 & & Cartagena & $\mid X-20-2008$ \\
\hline CARMENCITA JULIAO & Experto & $\begin{array}{c}\text { Funcionaria } \\
\text { encargada de } \\
\text { nutrición }\end{array}$ & $\begin{array}{c}\text { Secretaria de Salud departamental } \\
\text { departamento de Bolivar }\end{array}$ & 3008146151 & addaherher@hotmail.com & Cartagena & $1 X-20-2008$ \\
\hline ADDA HERRERA & $\begin{array}{l}\text { Funcionario } \\
\text { departamental }\end{array}$ & $\begin{array}{l}\text { Funcionaria } \\
\text { encargada de } \\
\text { nutrición }\end{array}$ & $\begin{array}{c}\text { Secretaria de Salud departamental } \\
\text { departamento de Bolivar }\end{array}$ & 3008146151 & addaherher@hotmail.com & Cartagena & $1 X-20-2008$ \\
\hline DELSY HERNANDEZ & $\begin{array}{l}\text { Funcionario } \\
\text { departamental }\end{array}$ & Funcionaria & $\begin{array}{c}\begin{array}{c}\text { Secretaria de Planeación } \\
\text { departamental. Unidad de } \\
\text { desarrollo social/ Departamento de } \\
\text { Bolivar }\end{array} \\
\end{array}$ & & planeacionbolivar@gmail.com & Cartagena & $1 X-20-2008$ \\
\hline LUDY PAYARES & $\begin{array}{l}\text { Funcionario } \\
\text { departamental }\end{array}$ & Funcionaria & $\begin{array}{c}\text { Secretaria de Planeación } \\
\text { departamental. Unidad de } \\
\text { desarrollo social/ Departamento de } \\
\text { Bolivar }\end{array}$ & & planeacionbolivar@gmail.com & Cartagena & $1 X-20-2008$ \\
\hline DAVID ACUÑA & $\begin{array}{c}\text { Funcionario } \\
\text { departamental }\end{array}$ & Funcionario & $\begin{array}{c}\text { Secretaria de Agricultura } \\
\text { departamental departamento de } \\
\text { Bolivar } \\
\end{array}$ & $\begin{array}{c}6601182 y \\
6649862\end{array}$ & & Cartagena & IX- $20-2008$ \\
\hline CARLOS BARRAZA & $\begin{array}{l}\text { Funcionario } \\
\text { departamental }\end{array}$ & Funcionario & $\begin{array}{c}\text { Secretaria de Agricultura } \\
\text { departamental departamento de } \\
\text { Bolivar }\end{array}$ & $\begin{array}{c}6601182 y \\
6649862\end{array}$ & & Cartagena & $1 X-20-2008$ \\
\hline IVÁN FRIERI & $\begin{array}{l}\text { Funcionario } \\
\text { departamental }\end{array}$ & Funcionario & $\begin{array}{c}\text { Secretaria de Agricultura } \\
\text { departamental departamento de } \\
\text { Bolivar }\end{array}$ & & ifrile@hotmail.com & Cartagena & IX-21-2008 \\
\hline MARIA LUISA VILLALBA & Experto & $\begin{array}{c}\text { Lider porgrama de } \\
\text { nutrición }\end{array}$ & $\begin{array}{l}\text { Secretaria de Salud Distrital } \\
\text { Distrito de Cartagena }\end{array}$ & \begin{tabular}{|c|}
6640037 Ext. \\
105
\end{tabular} & mvillalba28@hotmail.com & Cartagena & $1 X-21-2008$ \\
\hline IVET MOGOLLON & Experto & Asesora & \begin{tabular}{|c|} 
Secretaria de Educación Distrital \\
Distrito de Cartagena
\end{tabular} & 3126913483 & $\begin{array}{l}\text { imogollon@sercartagena.gov.co ; } \\
\text { ivettemogollon@gmail.com }\end{array}$ & Cartagena & $\mid X-21-2008$ \\
\hline VICTOR CASTRO & $\begin{array}{c}\text { Funcionario } \\
\text { distrital }\end{array}$ & Funcionario & $\begin{array}{l}\text { Unidad Municipal de Asistencia } \\
\text { Técnica Agropecuaria -UMATA- }\end{array}$ & 3116555671 & & \begin{tabular}{|c|}
$\begin{array}{c}\text { María la Baja- } \\
\text { Bolivar }\end{array}$ \\
\end{tabular} & IX-22-2008 \\
\hline RUBEN AGUIRRE & $\begin{array}{c}\text { Funcionario } \\
\text { distrital }\end{array}$ & Alcalde & Municipio María La Baja & $310-6565285$ & & \begin{tabular}{|c|}
$\begin{array}{c}\text { Maria la Baja- } \\
\text { Bolivar }\end{array}$ \\
\end{tabular} & IX-22-2008 \\
\hline JORGE LUIS TOVAR & Actor social & Ex-alcalde & $\begin{array}{l}\text { Gobiemo del Municipio Santa Rosa } \\
\text { de Lima }\end{array}$ & & jorgeluistovar@hotmail.com & $\begin{array}{c}\text { Santa Rosa de } \\
\text { Lima }\end{array}$ & IX-22-2008 \\
\hline MARCOS MENDOZA & Actor social & Ex-alcalde & $\begin{array}{l}\text { Gobierno del Municipio de } \\
\text { Villanueva }\end{array}$ & 3145078428 & & Villanueva & IX-22-2008 \\
\hline FRANKLIN CABARCAS & $\begin{array}{l}\text { Funcionario } \\
\text { distrital }\end{array}$ & Alcalde & $\begin{array}{c}\text { Gobiemo del Municipio Santa Rosa } \\
\text { de Lima }\end{array}$ & \begin{tabular}{|l|}
$3017486276 /$ \\
$3145106257 /$ \\
3145941258
\end{tabular} & & $\begin{array}{c}\text { Santa Rosa de } \\
\text { Lima }\end{array}$ & IX-22-2008 \\
\hline JORGE MENDOZA ARIZA & $\begin{array}{c}\text { Funcionario } \\
\text { distrital }\end{array}$ & Alcalde & $\begin{array}{l}\text { Gobierno del Municipio de } \\
\text { Villanueva }\end{array}$ & 3017124255 & jorgeluis291170@yahoo.es & Villanueva & IX-22-2008 \\
\hline JAVIER BUSTILLO & Actor social & $\begin{array}{c}\text { Asesor - Exalcalde } \\
\text { Magangue }\end{array}$ & Gobernación de Bolivar & & javierbustillop@gmail.com & Cartagena & $1 X-23-2008$ \\
\hline DONALDO BERRIO & $\begin{array}{l}\text { Funcionario } \\
\text { departamental }\end{array}$ & $\begin{array}{l}\text { Coordinador } \\
\text { Educación }\end{array}$ & $\begin{array}{c}\text { Corporación Autónoma del Canal } \\
\text { del Dique CARDIQUE }\end{array}$ & 3008368823 & & Cartagena & IX-23-2008 \\
\hline APOLINAR REDONDO & Experto & Ing. Forestal & $\begin{array}{c}\begin{array}{c}\text { Corporación Autónoma del Canal } \\
\text { del Dique CARDIQUE }\end{array} \\
\end{array}$ & & & Cartagena & IX-23-2008 \\
\hline SADY BETTY HOYOS & $\begin{array}{l}\text { Funcionario } \\
\text { departamental }\end{array}$ & $\begin{array}{l}\text { DIRECTORA } \\
\text { Centro de }\end{array}$ & $\begin{array}{c}\text { Corporación Autónoma del Canal } \\
\text { del Dique CARDIQUE }\end{array}$ & 3157331687 & sbettina36@hotmail.com & Cartagena & IX-23-2008 \\
\hline RODOLFO HERRERA & $\begin{array}{l}\text { Funcionario } \\
\text { distrital }\end{array}$ & Director & $\begin{array}{l}\text { Unidad Municipal de Asistencia } \\
\text { Técnica Agropecuaria -UMATA- }\end{array}$ & 3156991688 & rodolfoherrera51@gmail.com & $\begin{array}{l}\text { Villanueva- } \\
\text { Bolivar }\end{array}$ & IX-24-2008 \\
\hline ARLETH MENDOZA T. & $\begin{array}{c}\text { Funcionario } \\
\text { distrital }\end{array}$ & Trabajadora Social & $\begin{array}{l}\text { Gobierno del Municipio de } \\
\text { Villanueva }\end{array}$ & 3135025328 & arlethmendoza@hotmail.com & $\begin{array}{l}\text { Villanueva- } \\
\text { Bolivar }\end{array}$ & IX-24-2008 \\
\hline JOSE MARIA RUIZ & Actor social & $\begin{array}{l}\text { Productor } \\
\text { campesino }\end{array}$ & $\begin{array}{c}\text { Asociación municipal de ususarios } \\
\text { campesinos }\end{array}$ & 3135678370 & & $\begin{array}{l}\text { Villanueva- } \\
\text { Bolivar }\end{array}$ & IX-24-2008 \\
\hline JERONIMO MENDOZA & $\begin{array}{c}\text { Funcionario } \\
\text { distrital }\end{array}$ & $\begin{array}{l}\text { Jefe rentas } \\
\text { municipales }\end{array}$ & $\begin{array}{c}\text { Gobierno del Municipio de } \\
\text { Villanueva }\end{array}$ & 3106449533 & jermeuis.67@hotmail.com & $\begin{array}{c}\text { Villanueva- } \\
\text { Bolivar }\end{array}$ & $1 X-24-2008$ \\
\hline MARIO MORENO & $\begin{array}{l}\text { Funcionario } \\
\text { nacional }\end{array}$ & \begin{tabular}{|c|} 
Director “Proyecto \\
apoyo a \\
desplazados \\
urbanos y \\
comunidades \\
wulnerables rurales \\
en alto riesgo de \\
desplazamiento \\
\end{tabular} & FAO - Colombia & 3134880528 & marioalexandermoreno@fao.org.co & Cartagena & $\mid X-25-2008$ \\
\hline JOSEFINA MENDIVIL & $\begin{array}{l}\text { Funcionario } \\
\text { distrital }\end{array}$ & Coordinadora & $\begin{array}{c}\text { Plan de Emergencia Social Pedro } \\
\text { Romero - Cartagena }\end{array}$ & 3175004164 & & Cartagena & IX-25-2008 \\
\hline LUIS A. MENDOZA & Actor social & Lider de seguridad & alimentaria para afrodescendientes & 3145891719 & danimendoza_10@hotmail.com & Cartagena & $1 X-25-2008$ \\
\hline
\end{tabular}




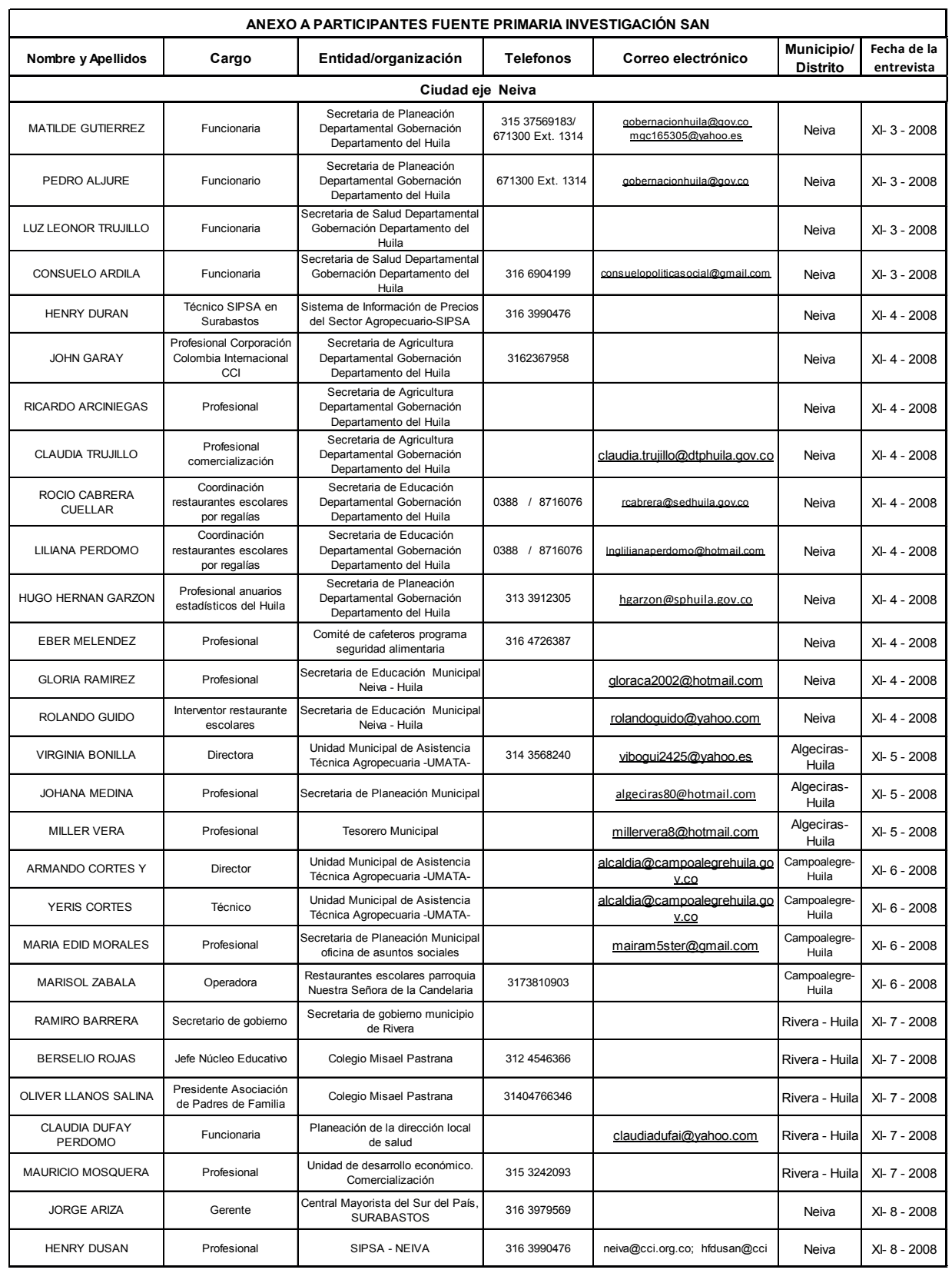




\begin{tabular}{|c|c|c|c|c|c|c|}
\hline \multicolumn{7}{|c|}{ ANEXO A PARTICIPANTES FUENTE PRIMARIA INVESTIGACIÓN SAN } \\
\hline Nombre y Apellidos & Cargo & Entidad/organización & Telefonos & Correo electrónico & $\begin{array}{c}\text { Municipio/ } \\
\text { Distrito }\end{array}$ & $\begin{array}{r}\text { Fecha de la } \\
\text { entrevista }\end{array}$ \\
\hline \multicolumn{7}{|c|}{ Ciudad eje Cúcuta } \\
\hline FERNANDO GONZALEZ & Director & $\begin{array}{l}\text { Unidad Municipal de Asistencia } \\
\text { Técnica Agropecuaria -UMATA- }\end{array}$ & 312525602 & & Mutiscua & IX-25-2008 \\
\hline MISAEL GAMBOA & Alcalde & Gobierno municipal & 3112560261 & mutiscuacompartel@yahoo.com & Mutiscua & $\mid X-25-2008$ \\
\hline $\begin{array}{l}\text { DEIMAR LEONARDO } \\
\text { CONTRERAS }\end{array}$ & Secretario General & Gobierno municipal & 3132619598 & & Mutiscua & IX-25-2008 \\
\hline LUIS DAVID CAÑAS & Campesino & $\begin{array}{c}\text { Asociación de agricultores } \\
\text { municipales }\end{array}$ & 3133837766 & & Mutiscua & |X-25-2008 \\
\hline JESUS A CASTELLANOS & Campesino & $\begin{array}{c}\text { Asociación de agricultores } \\
\text { municipales }\end{array}$ & 3132490420 & & Mutiscua & IX-25-2008 \\
\hline OSWALDO HURTADO & Rector & $\begin{array}{l}\text { Instituto Superior de Educación } \\
\text { Rural ISER. }\end{array}$ & $\begin{array}{c}\text { Cll } 8 \text { \# 8-155 } \\
\text { Teléfono 568-2597| }\end{array}$ & & Pamplona & IX-24-2008 \\
\hline $\begin{array}{l}\text { JOSE JAVIER BUSTOS } \\
\text { CORTES }\end{array}$ & Docente & $\begin{array}{l}\text { Instituto Superior de Educación } \\
\text { Rural ISER. }\end{array}$ & 3124746253 & jojabuco12@gamil.com & Pamplona & IX-24-2008 \\
\hline EFRAIN CUY & Docente & Universidad de Pamplona. & 3172791785 & & Pamplona & IX-27-2008 \\
\hline LUIS ARAQUE & Control Interno & Hospital de Pamplona & 3158310391 & & Pamplona & IX-27-2008 \\
\hline BEATRIZ PEÑA & $\begin{array}{l}\text { Estudiante Gestión } \\
\text { Agropecuaria }\end{array}$ & $\begin{array}{l}\text { Instituto Superior de Educación } \\
\text { Rural ISER. }\end{array}$ & & bepeca 1906@hotmail.com & Pamplona & IX-27-2008 \\
\hline ORLANDO LIZARAZO & $\begin{array}{c}\text { Técnico Información } \\
\text { cosechas } \\
\end{array}$ & \begin{tabular}{|c|}
$\begin{array}{c}\text { Sistema de Información de Precios } \\
\text { del Sector Agropecuario-SIPSA }\end{array}$ \\
\end{tabular} & & & Pamplona & IX-27-2008 \\
\hline NORA RODRIGUEZ & Administradora & Centro Acopio Pamplona & 3177730466 & capanzoo5@hotmail.com & Pamplona & IX-27-2008 \\
\hline $\begin{array}{c}\text { GLADYS ESPERANZA } \\
\text { BUITRAGO } \\
\end{array}$ & \begin{tabular}{|l|}
$\begin{array}{l}\text { Profesional manejo de la } \\
\text { información agropecuaria }\end{array}$ \\
\end{tabular} & \begin{tabular}{|c|}
$\begin{array}{c}\text { Sistema de Información de Precios } \\
\text { del Sector Agropecuario-SIPSA }\end{array}$ \\
\end{tabular} & & $\begin{array}{c}\text { gbuitrago@ccc.org.co; } \\
\text { gladysbuitio556@hotmail.com }\end{array}$ & Pamplona & IX-27-2008 \\
\hline TATIANA GELLAL & Funcionaria & $\begin{array}{c}\text { Secretaria de Salud Departamental } \\
\text { gobemación Norte de Santander }\end{array}$ & & anati17@hotmail.com & Cúcuta & IX-28-2008 \\
\hline CARMEN QUINTANA & Funcionaria & \begin{tabular}{|c|} 
Secretaria de Salud Departamental \\
gobernación Norte de Santander
\end{tabular} & & carela21@hotmail.com & Cúcuta & IX-28-2008 \\
\hline JAIRO E. WALDO & Funcionario & $\begin{array}{l}\text { Instituto Geográfico Agustin } \\
\text { Codazzi IGAC- } \\
\end{array}$ & 3124157075 & & Cúcuta & IX-28-2008 \\
\hline ALVARO BARBOSA REYES & Ingeniero distrito de riego & \begin{tabular}{|c|} 
Secretaria de Agricultura \\
Departamental gobernación \\
Departamento Norte de Santander
\end{tabular} & & inalbar@hotmail.com & Cúcuta & IX-28-2008 \\
\hline ABIMAEL VACCA & Parroco & Diócesis & & $\frac{\text { caritadiocesanacucuta@yahoo. }}{\text { com }}$ & Cúcuta & IX-28-2008 \\
\hline
\end{tabular}




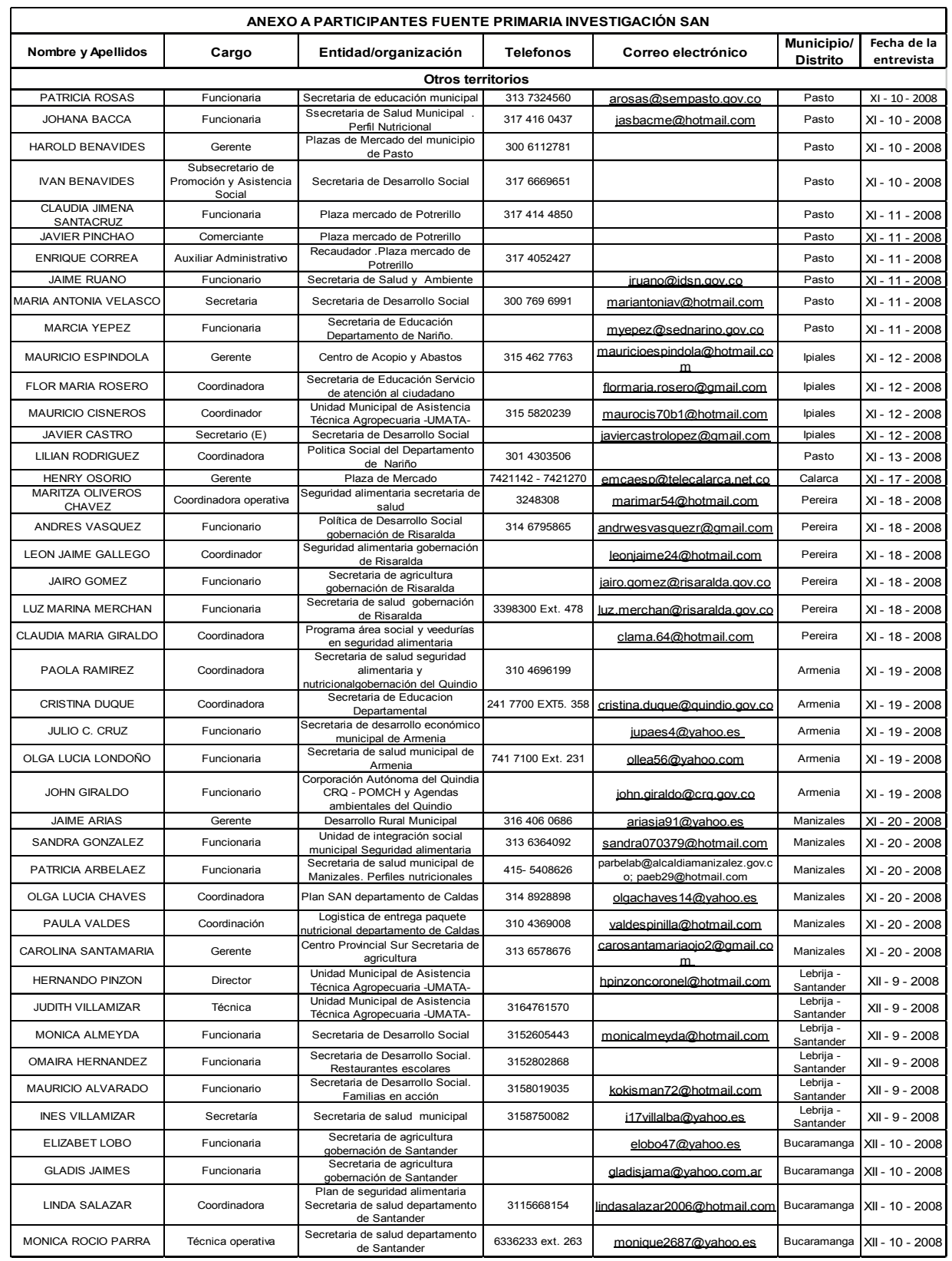





\section{ANEXO B}

\section{METODOLOGÍA PARA DETERMINAR LA DEMANDA IDEAL Y REAL DE LOS MUNICIPIOS EJES DINAMIZADORES}

Este anexo permite dar cuenta de los criterios para determinar los ejes dinamizadores y el departamento como la unidad político-administrativa denominada región $S A N$, con incidencia en las políticas y orientaciones que permiten abastecer los productos que se consumen en los ejes dinamizadores objeto de estudio (Medellín, Cartagena, Cúcuta y Neiva); además, se establece que tanto estos como el departamento, forman parte integral de la denominada región $S A N$.

\section{Canasta de alimentos}

Para el desarrollo de la investigación en SAN, la canasta de alimentos se convierte en el punto de partida para el análisis de la cadena alimentaria en la fase de disponibilidad, producida en los departamentos de Antioquia, Bolívar, Norte de Santander y Huila. ¿Por qué y cómo determinar la canasta de alimentos? La canasta de alimentos ha sido identificada por las guías alimentarias del ICBF, lo que permite estimar la demanda de la población en los centros urbanos de los casos de estudio: los municipios ejes dinamizadores. Se siguieron dos pasos: primero, la cuantificación de las recomendaciones nutricionales de cada grupo poblacional; y segundo, la traducción de dicha recomendaciones en alimentos y cantidades. Para tal tarea, el documento base utilizado fue Las guías alimentarias para la población colombiana mayor de dos años, del ICBF.

Los productos seleccionados que constituyen la canasta de alimentos se definen por los siguientes criterios:

a. Que formen parte de la lista de los 50 alimentos prioritarios que definió el ICBF como resultado de la Encuesta Nacional de Nutrición del 2005.

b. Que estén en los grupos de alimentos consumidos por más del 60\% de los colombianos, según la Guía alimentaria para la población colombiana mayor de 2 años.

c. Que estén en los alimentos que selecciona el IPC para el análisis de precios en las principales 13 ciudades del país, de las cuales 4 son los ejes dinamizadores.

d. Para definir la región, se seleccionaron únicamente los productos agropecuarios, 
pues los agroindustriales demandan otro manejo, por cuanto no determinan la región, aunque son necesarios para la seguridad alimentaria.

De acuerdo con los criterios anteriormente mencionados, se seleccionaron 37 agroalimentos (tabla 1.1). Se listan según tipo de producto y el grupo al que pertenecen. Además de esta canasta nacional, se identifican, con alguna variación, las regionales, atendiendo la oferta, la costumbre, la cultura local y la importancia del consumo. Los siguientes criterios se tienen en cuenta para su construcción: importancia del consumo en la región del producto; porcentaje de consumo (puede ser del 40\%); importancia del consumo por micronutrientes y macronutrientes de cada uno de los productos, y el nivel de producción respectivo.

\begin{tabular}{|c|c|c|c|c|c|}
\hline \multicolumn{6}{|c|}{ Tabla No. 1.1 ALIMENTOS DE LA CANASTA AGROPECUARIA } \\
\hline $\begin{array}{c}\text { Grupo de } \\
\text { Alimentos }\end{array}$ & Productos & \begin{tabular}{|c|} 
Total \\
Productos por \\
Grupo \\
\end{tabular} & $\begin{array}{c}\text { Grupo de } \\
\text { Alimentos }\end{array}$ & Productos & $\begin{array}{c}\text { Total Productos } \\
\text { por Grupo } \\
\end{array}$ \\
\hline \multirow{4}{*}{ 1. CEREALES } & Arroz & \multirow[t]{4}{*}{ 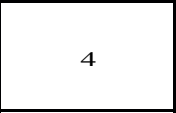 } & \multirow{8}{*}{ 4. FRUTAS } & Banano & \multirow{8}{*}{8} \\
\hline & Avena & & & Guay aba & \\
\hline & Maíz & & & Limón & \\
\hline & Trigo & & & Mandarina & \\
\hline \multirow{5}{*}{$\begin{array}{l}\text { 2. RAICES, } \\
\text { TUBERCULOS } \\
\text { Y PLATANOS }\end{array}$} & Name & \multirow{5}{*}{5} & & $M$ ango & \\
\hline & Papa & & & Mora & \\
\hline & Papa criolla & & & Naranja & \\
\hline & Plátano & & & Tomate de árbol & \\
\hline & Yuca & & \multirow{5}{*}{$\begin{array}{l}\text { 5. CARNES Y } \\
\text { HUEVOS }\end{array}$} & Carne de res & \multirow{5}{*}{5} \\
\hline \multirow{7}{*}{$\begin{array}{c}3 . \\
\text { HORTALIZAS, } \\
\text { VERDURAS Y } \\
\text { LEGUIMINOS } \\
\text { AS VERDES }\end{array}$} & Arveja & \multirow{7}{*}{7} & & Carne de cerdo & \\
\hline & Ahuy ama & & & $\begin{array}{c}\text { Huevo de } \\
\text { gallina }\end{array}$ & \\
\hline & Cebolla Cabezona & & & Pescado & \\
\hline & Cebolla común & & & Pollo & \\
\hline & Habichuela & & \multirow{3}{*}{$\begin{array}{c}6 . \\
\text { LEGUMINOS AS } \\
\text { SECAS Y } \\
\text { MEZCLAS } \\
\end{array}$} & Fríjol & \multirow{3}{*}{3} \\
\hline & Tomate & & & Garbanzo & \\
\hline & Zanahoria & & & Lenteja & \\
\hline 7. LACTEOS & Leche liquida & 1 & \multirow{3}{*}{ 9. AZUCARES } & Café & \multirow{3}{*}{2} \\
\hline \multirow{2}{*}{ 8. GRAS AS } & Aceite animal & \multirow{2}{*}{2} & & Cã̃a Panelera & \\
\hline & Aceite Vegetal & & & Cana Panelera & \\
\hline & Total Pro & ctos de la & anasta agroalim & entaria : 37 & \\
\hline
\end{tabular}

Definida la canasta de agroalimentos nacional, se establecen las cantidades de producto que suplen los requerimientos nutricionales de la población según el nivel etario, con el fin de limitar geográficamente la oferta alimentaria (ubicación geoespacial de la región como unidad política administrativa en el departamento). Se definen dos tipos de demanda: la demanda real y la demanda ideal de alimentos, las cuales son comparadas con la producción departamental y las demandas del eje dinamizador.

\section{Relaciones entre la canasta de alimentos y los requerimientos nutricionales de la población}

Los vínculos entre la canasta de alimentos y los requerimientos nutricionales de la población en las ciudades ejes dinamizadores y la población colombiana se definen a 
partir del consumo actual real e ideal de alimentos, por rangos de edad, de acuerdo con la información suministrada por la Encuesta Nacional de Nutrición (ENSIN) del 2005. Además, se tienen en cuenta los parámetros definidos en las Guías alimentarias para la población colombiana respecto a los intercambios de alimentos, que se definen así:

Agrupaciones en las cuales los alimentos incluidos en cada una de las listas, poseen aproximadamente el mismo valor de energía, carbohidratos, proteínas y grasas, por lo tanto, un alimento se puede reemplazar por otro dentro de la misma lista ${ }^{548}$.

Estos parámetros se ordenan de acuerdo con los grupos de alimentos establecidos: cereales, raíces y tubérculos, hortalizas, verduras y leguminosas verdes, frutas, carnes, huevos, leguminosas secas y mezclas vegetales, lácteos, grasas, azúcares y dulces (tabla 1.2.).Esto permite hacer comparaciones entre productos de diversos grupos alimentarios y requerimientos nutricionales, por rango de población, en los ejes dinamizadores.

Tabla No. 1.2 Valor Calórico y Nutricional de un Intercambio de Alimentos según Agrupaciones de Alimentos

\begin{tabular}{|l|c|c|c|c|c|}
\hline \multicolumn{1}{|c|}{ Grupos de Alimentos } & Intercambios & K/cal & Carbohidratos & Gras as & Proteínas \\
\hline $\begin{array}{l}\text { 2. Hortalizas, Verduras y leguminosas } \\
\text { Verdes }\end{array}$ & 1 & 35 & 7 & 0 & 2 \\
\hline 3. Frutas & 1 & 40 & 10 & 0 & 0 \\
\hline 4. Carnes, Huevos, Leguminosas Secas & 1 & 165 & 16 & 5 & 13 \\
\hline 5. Lácteos & 1 & 135 & 10 & 7 & 8 \\
\hline 6. Grasas & 1 & 45 & 0 & 5 & 0 \\
\hline 7. Azúcares y Dulces & 1 & 60 & 15 & 0 & 0 \\
\hline Fuente: Sistema de Lista de Intercambio de alimentos, Pontificia Universidad Javeriana, Carrera de Nutrición, 1996 \\
\hline
\end{tabular}

Una vez son determinadas las kilocalorías de los grupos de alimentos, se construyen los números de intercambios por grupos de alimentos y sus vínculos con las kilocalorías estandarizadas. Esta información se desagrega en rangos de kilocalorías, para ajustar las recomendaciones nutricionales a los requerimientos calóricos, como se muestra en la tabla 1.3.

548 ICBF (2000): Guías alimentarias para la población colombiana mayor de dos años. Bases técnicas. Bogotá, pág. 38. 


\begin{tabular}{|c|c|c|c|c|c|c|c|c|c|c|c|}
\hline Grupos de Alimentos & $\begin{array}{l}1000 \\
\text { Kcal }\end{array}$ & $\begin{array}{l}1200 \\
\text { Kcal }\end{array}$ & $\begin{array}{l}1400 \\
\text { Kcal }\end{array}$ & $\begin{array}{l}1600 \\
\text { Keal }\end{array}$ & $\begin{array}{l}1800 \\
\text { Keal }\end{array}$ & $\begin{array}{l}2000 \\
\text { Kcal }\end{array}$ & $\begin{array}{l}2200 \\
\text { Kcal }\end{array}$ & $\begin{array}{l}2400 \\
\text { Kcal }\end{array}$ & $\begin{array}{l}2600 \\
\text { Kcal }\end{array}$ & $\begin{array}{l}2800 \\
\text { Kcal }\end{array}$ & $\begin{array}{l}3000 \\
\text { Keal }\end{array}$ \\
\hline $\begin{array}{l}\text { 1. Cereales, Raíces, } \\
\text { Tubérculos y Plátanos }\end{array}$ & 2 & $2 \frac{1}{2}$ & 3 & 4 & $41 / 2$ & $51 / 2$ & 6 & 7 & 7 & 9 & 10 \\
\hline \begin{tabular}{|c|} 
2. Hortalizas, Verduras y \\
leguminosas Verdes
\end{tabular} & 1 & 1 & 2 & 2 & 2 & 2 & 2 & 2 & 2 & 2 & 2 \\
\hline 3. Frutas & 2 & 3 & 4 & 4 & 4 & 4 & 4 & 4 & 4 & 4 & 4 \\
\hline $\begin{array}{l}\text { 4. Carnes, Huevos, } \\
\text { Leguminosas Secas }\end{array}$ & $01-\mathrm{feb}$ & $01-\mathrm{feb}$ & 1 & 1 & 1 & 1 & 2 & 2 & 2 & 2 & 2 \\
\hline 5. Lácteos & $11 / 2$ & 2 & 2 & 2 & 2 & 2 & 2 & 2 & $21 / 2$ & $21 / 2$ & $21 / 2$ \\
\hline 6. Grasas & 3 & 4 & 5 & 5 & 6 & 6 & 6 & 8 & 8 & 8 & $81 / 2$ \\
\hline 7. Azúcares y Dulces & $21 / 2$ & $21 / 2$ & $31 / 2$ & 4 & 4 & 5 & 5 & 5 & 5 & 5 & 5 \\
\hline
\end{tabular}

Lo anterior se cruza con las recomendaciones de consumo nutricional diario en kilocalorías, lo cual permite ajustar los rangos de edad y compatibilizarlos con la lista de intercambios. Se tiene en cuenta que el consumo de la población en condiciones nutricionales debe estar entre el 90\% y el 100\% de los requerimientos o estándares establecidos, en función de no tener problemas de malnutrición.

La política alimentaria vinculada con acceso y uso y utilidad, expresada en el Plan Decenal para la promoción y apoyo a la lactancia materna 1998-2000, recomienda que se consuma la leche materna como único alimento en los primeros seis meses de $v^{2} a^{549}$, por las condiciones nutricionales y los requerimientos durante este periodo. Por otra parte, la ENSIN ${ }^{550}$ sugiere para otro rango de población, los niños de 6-23 meses, los siguientes alimentos: leches (líquida y en polvo); otros lácteos (queso, kumis y yogur); frutas fuente de vitamina A (mango, papaya, zapote, durazno, chontaduro); otras frutas (guayaba, naranja, banano y granadilla); verduras fuente de vitamina A (ahuyama, acelga, espinaca, zanahoria); otras verduras (lechuga, arveja verde, habichuela, brócoli); cereales (arroz, maíz, trigo, cebada, avena y sus productos derivados, tales como pan, pastas, arepa y galletas); tubérculos y plátanos (papa, yuca, ñame, arracacha, plátano); carnes y huevo (carnes rojas, blancas, productos derivados, vísceras, atún, sardinas y huevo); leguminosas (fríjol, lenteja, garbanzo, soya, maní, habas, arveja seca); grasas (alimentos fritos en aceite o cualquier grasa) y dulces (no incluye chocolate [bebida] y agua de panela). El anterior listado permite establecer una dieta que provee la cantidad de kilocalorías establecidas para el rango en mención.

549 ICBF (2006): Encuesta Nacional de la Situación nutricional en Colombia, 2005. Bogotá, pág. 185.

550 Ibíd., pág. 187. 
Ahora bien, una vez fueron establecidos los rangos calóricos y la población por edad y sexo (tabla 1.4), se calculó la demanda real en cada uno de los cuatro ejes dinamizadores (Medellín, Cartagena, Cúcuta y Neiva), con base en la información de la población.

\begin{tabular}{|c|c|c|}
\hline \multicolumn{3}{|c|}{$\begin{array}{l}\text { Tabla No. } 1.4 \text { Reque rimientos De Consumo Diario De } \\
\text { Kilocalorías Según Rangos de Edad y Sexo }\end{array}$} \\
\hline \multirow[t]{2}{*}{ Calorías } & Rango & Edad y Sexo \\
\hline & $0^{*}$ & $0-5$ meses \\
\hline 800 Kcal. & $1 *$ & 6 meses- 11 meses (ambos sexos) \\
\hline $1000 \mathrm{Kcal}$ & 2 & 1 año (ambos sexos) \\
\hline $1200 \mathrm{Kcal}$ & 3 & 2 años (ambos sexos) \\
\hline $1400 \mathrm{Kcal}$ & 4 & 3 años (ambos sexos) \\
\hline $1600 \mathrm{Kcal}$ & 5 & 4-6 años (ambos sexos) \\
\hline \multirow{2}{*}{$1800 \mathrm{Kcal}$} & \multirow{2}{*}{6} & 7-8 años (ambos sexos) \\
\hline & & Mujeres $75+$ \\
\hline \multirow{3}{*}{$2000 \mathrm{Kcal}$} & \multirow{3}{*}{7} & 9 años (ambos sexos) \\
\hline & & Mujeres entre 10-12 años \\
\hline & & Mujeres entre 50-74 años \\
\hline \multirow{2}{*}{$2200 \mathrm{Kcal}$} & \multirow{2}{*}{8} & Hombres entre $10-12$ años \\
\hline & & Mujeres entre 13-49 años \\
\hline $2400 \mathrm{Kcal}$ & 9 & Hombres $75+$ \\
\hline $2600 \mathrm{Kcal}$ & 10 & Hombres 13-15 años \\
\hline $2800 \mathrm{Kcal}$ & 11 & Hombres entre 50-74 años \\
\hline $3000 \mathrm{Kcal}$ & 12 & Hombres entre $16-49$ años \\
\hline \multicolumn{3}{|c|}{$\begin{array}{l}\text { * El tratamiento del rango } 0 \text { y } 1 \text { merece especial atención por dos razones: i) } \\
\text { Organizaciones internacionales, el Plan Nacional de alimentación de alimentación y } \\
\text { nutricion en Colombia y el Plan Decenal para la promoción y apoyo a la lactancia } \\
\text { materna } 1998-2000 \text {, recomiendan la leche materna como unico alimento durante los } \\
\text { primeros seis meses de vida y, ii) la información poblacional suministrada por el DANE } \\
\text { no desagrega el numero de habitantes de este rango por meses. }\end{array}$} \\
\hline
\end{tabular}

Otro aspecto requerido para identificar la demanda real de la población colombiana fue el consumo de los productos alimenticios seleccionados. La fuente principal de esta información fue la ENSIN 2005 (tabla 1.5). Dado que esta encuesta maneja información para la población de 1 a 64 años, para la población mayor se manejó el supuesto según el cual el consumo es similar al del rango 50-64 años.

A su vez, para los productos a lo que no se les relaciona porcentaje de consumidores, se supuso y manejó la frecuencia de consumo de alimentos, el cual es producto de un estudio entre el ICBF y Nutrir ${ }^{551}$. En el manejo de la información. se hicieron los siguientes supuestos:

- El porcentaje de consumo de alimentos para el rango 2 (población de 1 año de ambos sexos) se supone igual al rango 3 (población de 2 años de ambos sexos).

551 ICBF y Nutrir (1998): "Frecuencia de consumo de alimentos. Consolidado nacional 1998”. En Guías alimentarias para la población colombiana mayor de dos años. Bogotá, pág. 51. 
- Para el rango 6, que está constituido por niños y niñas de 7-8 años y mujeres mayores de 75 años, se promedian los porcentajes consumidos en los dos rangos del estudio precitado.

- Para el rango 7 (población de ambos sexos de 9 años, mujeres entre 50-64 años, mujeres entre 10 y 12 años y mujeres entre 65 y 74 años) se supuso el consumo promedio del rango 6.

- Para el rango 9 se utilizan los porcentajes de consumo de la población mayor de 60 años.

- Para el rango 12 se promedia el porcentaje de población entre 18 y 59 años y 60 y más años.

Este consumo se establece por micronutrientes y macronutrientes aportados por cada alimento. La tabla contiene los aportes por cada 100 gramos consumidos de los productos seleccionados, en energía (gr), proteínas (gr), grasa (gr), carbohidratos totales, sodio $(\mathrm{mg})$, calcio $(\mathrm{mg})$, fósforo $(\mathrm{mg})$, hierro $(\mathrm{mg})$, vitamina A (ug), tiamina $(\mathrm{mg})$, riboflavina $(\mathrm{mg})$, niacina $(\mathrm{mg})$ y vitamina $\mathrm{C}(\mathrm{mg})$. La fuente es la información nutricional de la FAO, consolidada en la tabla de alimentos del ICBF, que permite determinar el déficit o superávit por micro- y macronutrientes. De esta forma, pueden hacerse recomendaciones en el consumo y la producción de alimentos, para que la población garantice su seguridad alimentaria y nutricional.

La canasta de alimentos se define como la demanda ideal a que cualquier persona debe acceder para estar en condiciones de nutrición óptimas. Parte de considerar las recomendaciones nutricionales en cuanto al consumo adecuado de cada producto, según la lista de intercambios, desagregada por alimento y cantidades equivalentes. Para esto, se proponen dietas diarias por rango calórico. Para definir la demanda ideal de cada uno de los productos que poseen estos requerimientos nutricionales, debe tener en cuenta la tabla 1.4.

Por su parte, para realizar el cálculo que permite relacionar los requerimientos nutricionales con los productos que los contienen, y las cantidades de producto, se tuvo en cuenta que el ICBF establece una cantidad de alimento en gramos o centímetro cúbico por intercambio (según información de la tabla 1.6); con cierta cantidad de caloría debe consumirse una cantidad determinada de intercambios, como muestra la tabla 1.2 de este anexo. 


\begin{tabular}{|c|c|c|c|}
\hline \multicolumn{4}{|c|}{$\begin{array}{l}\text { Tabla No. 1.5 CONSUMO NACIONAL DE LOS PRINCIPALES } \\
\text { ALIMENTOS }\end{array}$} \\
\hline $\begin{array}{l}\text { GRUPOS DE } \\
\text { ALIMENTOS } \\
\end{array}$ & Productos & $\%$ Cons umo $*$ & $\begin{array}{c}\text { Cantidad cons umida } \\
\text { promedio/día }\end{array}$ \\
\hline \multirow{5}{*}{ 1. Cereales } & Arroz & & \\
\hline & Harina de maíz & 6,2 & 49.7 \\
\hline & trigo & & \\
\hline & Avena (preparada) & $6,60 \%$ & 29.3 \\
\hline & Maíz & $6.20 \%$ & 87.6 \\
\hline \multirow{5}{*}{$\begin{array}{l}\text { 2. Raíces, Tubérculos y } \\
\text { Plátanos }\end{array}$} & Papa & $54.50 \%$ & 230.8 \\
\hline & Papa criolla & & \\
\hline & Plátano (maduro) & $43.40 \%$ & 202.7 \\
\hline & Yuca & $19.30 \%$ & 83.2 \\
\hline & Name & $53.78 \%$ & \\
\hline \multirow{6}{*}{ 3. Hortalizas y verduras } & Tomate & 38.7 & 45.8 \\
\hline & Cebolla Cabezona & $30.10 \%$ & 31.8 \\
\hline & Cebolla común & $21.70 \%$ & 6.7 \\
\hline & $\begin{array}{c}\text { Arveja verde (semilla } \\
\text { entera) }\end{array}$ & $16.90 \%$ & 48.9 \\
\hline & Zanahoria & $28.70 \%$ & 30.4 \\
\hline & Habichuela & & 36.8 \\
\hline \multirow{7}{*}{ 4. Frutas } & Limón & $11.70 \%$ & 45.6 \\
\hline & Mango & $8.70 \%$ & 174.7 \\
\hline & Banano & $7.80 \%$ & 113.1 \\
\hline & Guayaba & $7.70 \%$ & 102.2 \\
\hline & Tomate de árbol & $7.00 \%$ & 66.6 \\
\hline & Naranja & $6.90 \%$ & 308.3 \\
\hline & Moras & $6.00 \%$ & 61.6 \\
\hline \multirow{5}{*}{$\begin{array}{l}\text { 5. Carnes, huevos y } \\
\text { Pescado }\end{array}$} & Carne de res & $42 \%$ & 58 \\
\hline & Carne de cerdo & & \\
\hline & Huevo de Gallina & $36.50 \%$ & 64.8 \\
\hline & Pollo & 23,3 & 68 \\
\hline & Pescado & $10 \%$ & 95.1 \\
\hline \multirow{3}{*}{$\begin{array}{l}\text { 6. leguminos as secas y } \\
\text { mezclas vegetales }\end{array}$} & Fríjol rojo & $15.00 \%$ & 149.3 \\
\hline & Garbanzo & & \\
\hline & Lenteja & $7.80 \%$ & 181.1 \\
\hline 7. Lácteos & Leche Líquida & $47.20 \%$ & 235.2 \\
\hline \multirow{2}{*}{ 8. Grasas } & Aceite vegetal & $18.70 \%$ & 12.3 \\
\hline & Aceite animal & $15.50 \%$ & 3.8 \\
\hline \multirow{2}{*}{ 9. Azúcares y dulces } & Café & $47.60 \%$ & 180.6 \\
\hline & Panela & $41.50 \%$ & 55.4 \\
\hline
\end{tabular}

En este sentido, se estableció una relación que combina los alimentos seleccionados, de tal manera que la suma en gramos fuera equivalente a la cantidad de producto recomendado en cada intercambio. Este ejercicio se hizo para cada rango de calorías de la tabla 1.3, cuyo resultado es el consumo que las personas deberían realizar por producto (en gramos o centímetros cúbicos) para satisfacer las kilocalorías recomendadas.

Con las relaciones entre las demandas reales de la población y los requerimientos nutricionales, se realizó un cálculo de las demandas ideal y real en cada uno de los municipios ejes dinamizadores, incluyendo el producto, los rangos de edad y el sexo. Se calculan estas en toneladas anuales de producto consumido y qué se debería comer. La finalidad del ejercicio era establecer el déficit o superávit de abastecimiento de cada 
alimento en el eje dinamizador, relacionado con su entorno más inmediato, que es el departamento. De esta manera, era posible hacer recomendaciones en términos de producción para dinamizar el desarrollo regiolocal, a partir de los mínimos de SAN de la población del eje.

La ENSIN, para aproximarse al tamaño de cada alimento consumido ${ }^{552}$ por el encuestado, utilizó un juego de sesenta modelos de alimentos y figuras geométricas, elaboradas en porcelanicrón, que reproducían diferentes porciones y tamaños ${ }^{553}$. A cada modelo se le asignó un código y se elaboró un libro en el que se listaron todos los alimentos para el registro respectivo. En el caso de los líquidos, se usaron fotografias en tamaño real y a todo color de tazas, vasos y cucharas de diferentes tamaños, y cucharones de servir, a los cuales también se les asignó un código.

\begin{tabular}{|c|c|c|}
\hline \multicolumn{3}{|c|}{$\begin{array}{c}\text { Tabla No. 1.6 Cantidad de alime nto que compone un } \\
\text { intercambio }\end{array}$} \\
\hline GRUPOS DE & PRODUCTOS & Gramos \\
\hline \multirow{5}{*}{ 1. Cereales } & Arroz & 40 \\
\hline & Harina de Maíz & 42 \\
\hline & Harina de Trigo & 40 \\
\hline & \begin{tabular}{|l|} 
Avena \\
\end{tabular} & 40 \\
\hline & Arepa de Maíz & 100 \\
\hline \multirow{5}{*}{$\begin{array}{l}\text { 2. Raíces, Tubérculos y } \\
\text { Plátanos }\end{array}$} & Ñame & 134 \\
\hline & Papa & 154 \\
\hline & Papa Criolla & 168 \\
\hline & Plátano & 100 \\
\hline & Yuca & 96 \\
\hline \multirow{7}{*}{$\begin{array}{l}\text { 3. Hortalizas, Verduras y } \\
\text { Leguminos as Verdes }\end{array}$} & Arveja Verde & 30 \\
\hline & \begin{tabular}{|l|} 
Auyama \\
\end{tabular} & 90 \\
\hline & Zanahoria & 97 \\
\hline & Tomate & 47 \\
\hline & Habichuela & Libre Consumo \\
\hline & Cebolla Común & \\
\hline & Cebolla Cabezona & \\
\hline \multirow{8}{*}{ 4. Frutas } & Banano & 48 \\
\hline & Guayaba & 111 \\
\hline & Mandarina & 105 \\
\hline & Mango & 69 \\
\hline & Mora & 174 \\
\hline & Naranja & 114 \\
\hline & Limón & 160 \\
\hline & Tomate de árbol & 133 \\
\hline \multirow{5}{*}{ 5. Carnes, Huevos } & Carne de Cerdo & 81 \\
\hline & Carne de Res & 100 \\
\hline & Huevo & $90 \mathrm{~g} \mathrm{o} 2 \mathrm{unid}$ \\
\hline & Pollo & 84 \\
\hline & Pescado & 148 \\
\hline \multirow{3}{*}{ 6. Leguminos as Secas } & Fríjol Rojo & 60 \\
\hline & Garbanzo & 53 \\
\hline & Lenteja & 57 \\
\hline 7. Lácteos y De rivados & Leche entera & $240 \mathrm{cc}$ \\
\hline \multirow{2}{*}{ 8. Gras as } & Aceite Vegetal & $5 \mathrm{cc}$ \\
\hline & Aceite Animal & $6 \mathrm{~g}$ \\
\hline \multirow{2}{*}{ 9. Azúcares y Dulces } & Café & \\
\hline & Panela & \\
\hline
\end{tabular}

552 Se acudió a Catalina Borda, directora técnica de la ENSIN, quien aclaro que esta encuesta nacional trabajaba el peso de los alimentos cocinados.

553 ENSIN (2005), pág. 234. Estos modelos fueron estandarizados en la Universidad Antioquia, al pesa las porciones, medidas con alimentos reales. 
Esta metodología difiere de los cálculos realizados, porque se suponía que el consumo de la ENSIN estaba en peso bruto de cada alimento. Sin embargo, con la aclaración de la directora técnica de la encuesta, quien afirmó que para convertir los alimentos cocidos en peso bruto era necesario aplicar un factor de ajuste, el cual sumaba o dividía (tabla 1.7), se hacen los cálculos más reales.

En la tabla 1.7 se presenta el factor de ajuste de algunos de los alimentos enviados por Catalina Borda; para los demás, se supuso que el peso de los alimentos cocidos era igual al peso bruto. De esta manera, se ajusta la demanda calculada inicialmente y se establece si existe déficit o superávit de cada alimento en cuanto a lo consumido realmente y a lo que se debería consumir en cada uno de los ejes dinamizadores. Calculadas las demandas de los cuatro ejes, se procedió a determinar la oferta de agroalimentos en los departamentos respectivos.

\begin{tabular}{|c|c|}
\hline \multicolumn{2}{|c|}{$\begin{array}{l}\text { Tabla No. } 1.7 \text { Factor de ajuste para peso } \\
\text { neto de los alimentos }\end{array}$} \\
\hline PRODUCTOS & $\begin{array}{l}\text { FACTOR DE AJUS TE } \\
\text { DEMANDA REAL }\end{array}$ \\
\hline Cebolla común & Sumar $5 \%$ del peso \\
\hline Habichuela & Sumar $10 \%$ del peso \\
\hline Tomate & Sumar $20 \%$ del peso \\
\hline Zanahoria & Sumar $15 \%$ del peso \\
\hline Banano & Sumar $30 \%$ del peso \\
\hline Guayaba & Sumar $25 \%$ del peso \\
\hline Limon & Sumar $50 \%$ del peso \\
\hline Mango & Sumar $40 \%$ del peso \\
\hline Mora & Sumar $10 \%$ del peso \\
\hline Naranja & Sumar $40 \%$ del peso \\
\hline Tomate de arbol & Sumar $40 \%$ del peso \\
\hline Pollo & Sumar $40 \%$ del peso \\
\hline Frijol & Dividir por 2 \\
\hline Lenteja & Dividir por 2 \\
\hline Pastas & Dividir por 4 \\
\hline \multicolumn{2}{|c|}{$\begin{array}{l}\text { Fuente: ENSIN } 2005 \text { Pág. Y charla con Catalina Borda } \\
\text { funcionaria de la ENSIN. }\end{array}$} \\
\hline
\end{tabular}

\section{Caracterización general del municipio eje dinamizador y determinación de la región SAN inmediata: el departamento}

Para determinar las regiones SAN, se tienen en cuenta áreas urbanas y rurales con sus características diferenciadoras, cuyos procesos de determinación y construcción empiezan a identificarse para efectos de ubicación geográfica. Una vez son definidas las canastas regionales de alimentos, pueden delimitarse las regiones en general, lo que representa un primer paso para iniciar la caracterización desde el punto de vista agrario. 
En términos territoriales, las regiones SAN tienen de base inicial la población total de eje dinamizador, cuyo análisis ubica los límites a partir de las demandas ideal y real de cada agroalimento, desde la construcción de las canastas regionales y a partir de criterios de oferta de alimentos en un rango entre el 60\% y 70\% del total de la demanda de cada eje. Por tanto, para definir una región SAN, el componente central está relacionado con las cantidades demandadas y ofrecidas de alimentos.

Una vez identificada la región SAN, que es el departamento donde está el municipio eje, se busca caracterizarlo en lo político, lo administrativo, lo regional, lo social, lo económico, lo cultural y lo ambiental. Ello permite identificar formas y relaciones sociales que se presentan en cada uno, al igual que sus vínculos con los ejes dinamizadores.

Con los ejes dinamizadores se analiza la información pertinente a la capacidad de demanda alimentaria de cada uno, con su caracterización social, económica, política y administrativa, especialmente los diferentes programas vinculados y por considerar en el tema de la SAN. Adicionalmente, se tienen en cuenta los vínculos con programas y proyectos de orden departamental, nacional o internacional que se ejecutan en cada eje dinamizador. El trabajo se argumenta desde dos grandes direcciones para la SAN: una, en total para cada eje; y otra, en particular para los estratos de ingresos bajos o sin ingresos.

El análisis de las relaciones sociales, económicas y políticas son particulares en cada uno de los ejes: por ejemplo, el caso de Cúcuta, limítrofe con Venezuela, presenta condiciones especiales en cuanto a su abastecimiento alimentario. Igualmente, las condiciones viales geográficas para este municipio son particulares y deben incluirse en la definición de la región SAN.

En la tabla 1.8 se caracteriza la propuesta de construcción de las regiones SAN, a partir de diferenciar la demanda ideal y real de alimentos requeridos y los consumidos; también se presentan la región ideal y la real, que vinculan la producción de alimentos requeridos y consumidos. Esto permite identificar una serie de brecha de demanda y oferta de agroalimentos, los cuales se relacionan con la dinámica del contexto regional que tiene cada eje dinamizador.

\section{Caracterización particular de los municipios ejes dinamizadores}

Para caracterizar los ejes dinamizadores, se trabajó la información de cada uno por requerimientos nutricionales de la población y la canasta de alimentos. Por una parte, 
se determinaron 12 rangos (tabla 1.4), sobre los requerimientos de consumo diario de kilocalorías, según rangos de edad y sexo; posteriormente, la información de estos rangos se comparó con la que presenta la tabla 1.5 (consumo nacional de los principales agroalimentos). Esta integración con la información de población por estructura de edades ayuda a determinar, en cada uno de los ejes dinamizadores, cómo deben ser los requerimientos calóricos traducidos en productos, cuyo resultado final puede observarse en las tablas 1.9 hasta 1.12. Estas presentan las relaciones entre los productos por grupos de alimentos y las relaciones entre las demandas reales e ideales; en este sentido, muestran los niveles de déficit o superávit en cada eje dinamizador.

Tabla No. 18 Caracterización y Construcción General de las regiones SAN

\section{DEMANDAS}

(1). Demanda Ideal (DI). Cantidad de alimentos que suplen los requerimientos nutricionales de la población del municipio eje dinamizador.

(2) Demanda Real (DR). Cantidad de alimentos consumido por la población del municipio eje dinamizador.

Relaciones entre: uno, las caracterís ticas de las brechas de demanda y oferta de productos agroalimentarios; dos, los territorios, la region y el eje dinamizador

\section{REGIÓN}

(3) Región SAN ideal (RSI).Territorio productor de alimentos que satisfacen la demanda con los requerimientos nutricionales necesarios para la población del eje dinamizador; departamento del municipio eje dinamizador

(4) Región SAN Real (RSR). Donde se producen los alimentos consumidos por la población del eje dinamizador, cuya base es el departamento del municipio eje dinamizador.

\section{Brechas de Demanda (BD):}

1. Si (DI) igual a (RSI) = Buena Alimentación de la población del eje dinamizador.

2. Si (DI) menor a (DR) $=$ Mala Alimentación de la población del eje

$$
\text { dinamizador. }
$$

\section{Brechas de la oferta (BO):}

3. Si (RSI) Mayor o igual a (DI) $=$ Región SAN ideal para el eje dinamizador.

4. Si (RSI) menor a (DI) = Región SAN ideal de ficitaria para el eje dinamizador..

5. Si (RSR) mayor o igual a (DR) $=$ Región SAN Real para el eje dinamizador.

6. Si (RSR) menor a (DR) = Región SAN Real de ficitaria para el eje dinamizador.

Resultados de las relaciones entre brechas y te rritorios

Si tenemos las siguientes relaciones de resultados entre las brechas de demanda y de oferta, se permiten espacios para el des arrollo territorial a partir del cubrimiento de alguna de las brechas:

7. Si se integran las brechas 1 y 3 Tenemos una Región SAN Ideal Continua Constante.

8. Si se integran las brechas 1 y 4 Tenemos que la Región SAN Ideal deficitaria, pos ee es pacios regiolocales de crecimiento y des arrollo agroalimentario.

9. Si se integran las brechas 1 y 5 se deben realizar ajustes en la producción de agroalimentos reales a ideales, con cambios en las prácticas de consumo del eje dinamizador.

10. Si se integran las brechas 1 y 6 se deben realizar ajustes mayores en la producción de agroalimentos reales a ideales, con cambios en las prácticas de consumo del eje dinamizador.

11. Si se integran las brechas 2 y 3 Brechas de ajuste menor territorialmente para producción agroalimentaria y dinámicas educativas y culturas les para integrar un cons umo nutritivo en los ejes dinamizadores.

12. Si se integran las brechas 2 y 4 Brechas de ajus te mayor territorialmente para producción agroalimentaria, y dinámicas educativas y culturas les para integrar un cons umo nutritivo en los ejes dinamizadores.

13. Si se integran las brechas 2 con 5 y 6 Brechas que requieren de ajustes integrales entre producción agroalimentaria regional y dinámicas educativas y culturas les para integrar un cons umo nutritivo en los ejes dinamizadores. 


\subsection{Características del eje Medellín}

Se encuentra un gran déficit en las comparaciones entre demanda ideal y real, lo cual conlleva que los productos en los que recae el déficit sean aquellos que no representan altos índices de proteínas; mientras en los que hay superávit, se vinculan relaciones entre proteína y carbohidratos, en una cultura regional típica en consumo de carne de cerdo, maíz y grasas. Que se tenga un déficit en 25 productos agroalimentarios (de 37) permite concluir que parte de la población del eje esté comiendo y quedando satisfecha; sin embargo, se muestran bajos niveles de nutrición, subalimentada o sobrealimentada en algunos casos.

\begin{tabular}{|c|c|c|c|c|}
\hline GRUPOS DE ALIMENTOS & PRODUCTOS & $\begin{array}{c}\text { DEMANDA } \\
\text { IDEAL }\end{array}$ & $\begin{array}{c}\text { DEMANDA } \\
\text { REAL }\end{array}$ & \begin{tabular}{|c|} 
DÉFICIT O \\
SUPERÁVIT
\end{tabular} \\
\hline \multirow{4}{*}{ 1. CEREALES } & Arroz & 49.152 & 53.609 & 4.456 \\
\hline & Avena & 17.632 & - & $(17.632$ \\
\hline & Maiz & 13.363 & - & $(13.363$ \\
\hline & Trigo & - & - & - \\
\hline \multirow{5}{*}{$\begin{array}{l}\text { 2. RAICES, TUBERCULOS } \\
\text { Y PLATANOS }\end{array}$} & Ñame & - & - & - \\
\hline & Papa & 63.792 & 98.146 & 34.354 \\
\hline & Papa criolla & 16.086 & - & $(16.086$ \\
\hline & Platano & 35.227 & 69.443 & 34.216 \\
\hline & Yuca & 30.882 & 13.115 & $(17.767)$ \\
\hline \multirow{7}{*}{$\begin{array}{c}\text { 3. HORTALIZAS, } \\
\text { VERDURAS Y } \\
\text { LEGUIMINOSAS VERDES }\end{array}$} & Arveja & 10.620 & 6.634 & $(3.986$ \\
\hline & Auyama & 18.888 & - & $(18.888$ \\
\hline & Cebolla Cabezona & 4.857 & 8.386 & 3.529 \\
\hline & Cebolla comun & 3.028 & 1.232 & $(1.796$ \\
\hline & Habichuela & 12.384 & 3.099 & $(9.285)$ \\
\hline & Tomate & 19.153 & 17.177 & $(1.976$ \\
\hline & Zanahoria & 32.686 & 8.190 & $(24.496$ \\
\hline \multirow{8}{*}{ 4. FRUTAS } & Banano & 21.697 & 1.611 & $(20.085$ \\
\hline & Guayaba & 50.170 & 4.930 & $(45.240)$ \\
\hline & Limon & 35.955 & 5.360 & $(30.595)$ \\
\hline & Mandarina & 47.416 & - & $(47.416$ \\
\hline & Mango & 31.175 & 11.815 & $(19.360)$ \\
\hline & Mora & 78.553 & - & $(78.553$ \\
\hline & Naranja & 51.428 & - & $(51.428)$ \\
\hline & Tomate de arbol & 30.112 & 3.394 & $(26.718$ \\
\hline \multirow{5}{*}{ 5. CARNES Y HUEVOS } & Carne de res & 9.704 & 19.648 & 9.944 \\
\hline & Carne de cerdo & 7.852 & - & $(7.852$ \\
\hline & Huevo de gallina & 17.416 & 18.137 & 721 \\
\hline & Pescado & 14.320 & 5.875 & $(8.445)$ \\
\hline & Pollo & 9.192 & 17.593 & 8.401 \\
\hline \multirow{3}{*}{$\begin{array}{l}\text { 6. LEGUMINOS AS SECAS } \\
\text { Y MEZCLAS VEGETALES }\end{array}$} & Frijol & 5.805 & 7.167 & 1.361 \\
\hline & Garbanzo & 5.128 & - & $(5.128$ \\
\hline & Lenteja & 5.515 & 4.127 & $(1.388$ \\
\hline 7. LACTEOS & Leche liquida & 148.591 & 69.282 & $(79.309$ \\
\hline \multirow{2}{*}{ 8. GRASAS } & Aceite animal & - & 1.520 & 1.520 \\
\hline & Aceite Vegetal & 13.439 & 22.551 & 9.111 \\
\hline \multirow{2}{*}{ 9. AZUCARES } & Café & - & 77.060 & 77.060 \\
\hline & Caña Panelera & - & - & - \\
\hline
\end{tabular}




\subsection{Características del eje Cartagena}

Se encuentra también un gran déficit entre demanda ideal y real. Los productos sobre los que recae el déficit son aquellos que no representan altos índices de proteínas. Llama especial atención el bajo consumo real de pescado y el mayor consumo de carne y pollo. Respecto a los consumos regionales, se presenta ausencia de información sobre la producción regional de ñame, que se consume en esta parte del país. El déficit en 23 productos agroalimentarios conlleva que la población del eje tenga bajos niveles de nutrición, subalimentada o sobrealimentada en algunos casos.

\begin{tabular}{|c|c|c|c|c|}
\hline GRUPOS DE ALIMENTOS & PRODUCTOS & $\begin{array}{l}\text { DEMANDA } \\
\text { IDEAL }\end{array}$ & $\begin{array}{l}\text { DEMANDA } \\
\text { REAL } \\
\end{array}$ & \begin{tabular}{|c|} 
DÉFICIT O \\
SUPERÁVIT \\
\end{tabular} \\
\hline \multirow{4}{*}{ 1. CEREALES } & Arroz & 19.493 & 21.387 & 1.895 \\
\hline & Avena & 6.980 & - & $(6.980)$ \\
\hline & Maiz & 5.285 & - & $(5.285)$ \\
\hline & Trigo & - & - & - \\
\hline \multirow{5}{*}{$\begin{array}{c}\text { 2. RAICES, TUBERCULOS Y } \\
\text { PLATANOS }\end{array}$} & Name & - & - & - \\
\hline & Papa & 25.385 & 39.209 & 13.823 \\
\hline & Papa criolla & 6.411 & - & $(6.411)$ \\
\hline & Platano & 13.939 & 27.546 & 13.607 \\
\hline & Yuca & 12.189 & 5.139 & $(7.050)$ \\
\hline \multirow{7}{*}{$\begin{array}{l}\text { 3. HORTALIZAS, VERDURAS } \\
\text { Y LEGUIMINOSAS VERDES }\end{array}$} & Arveja & 4.217 & 2.640 & $(1.577)$ \\
\hline & Auyama & 7.567 & - & $(7.567)$ \\
\hline & Cebolla Cabezona & 1.934 & 3.306 & 1.372 \\
\hline & Cebolla comun & 1.205 & 487 & $(719)$ \\
\hline & Habichuela & 4.922 & 1.300 & $(3.622)$ \\
\hline & Tomate & 7.593 & 6.798 & $(796)$ \\
\hline & Zanahoria & 13.131 & 3.234 & $(9.897)$ \\
\hline \multirow{8}{*}{ 4. FRUTAS } & Banano & 8.671 & 750 & $(7.922)$ \\
\hline & Guayaba & 20.050 & 2.057 & $(17.993)$ \\
\hline & Limon & 14.343 & 2.213 & $(12.131)$ \\
\hline & Mandarina & 18.945 & - & $(18.945)$ \\
\hline & Mango & 12.458 & 5.004 & $(7.454)$ \\
\hline & Mora & 31.384 & - & $(31.384)$ \\
\hline & Naranja & 20.543 & - & $(20.543)$ \\
\hline & Tomate de arbol & 12.044 & 1.374 & $(10.671)$ \\
\hline \multirow{5}{*}{ 5. CARNES Y HUEVOS } & Carne de res & 3.868 & 7.790 & 3.922 \\
\hline & Carne de cerdo & 3.129 & - & $(3.129)$ \\
\hline & Huevo de gallina & 6.937 & 7.337 & 399 \\
\hline & Pescado & 5.704 & 2.435 & $(3.270)$ \\
\hline & Pollo & 3.661 & 7.031 & 3.369 \\
\hline \multirow{3}{*}{$\begin{array}{l}\text { 6. LEGUMINOS AS SECAS Y } \\
\text { MEZCLAS VEGETALES }\end{array}$} & Frijol & 2.312 & 2.998 & 685 \\
\hline & Garbanzo & 2.043 & - & $(2.043)$ \\
\hline & Lenteja & 2.197 & 1.723 & $(474)$ \\
\hline 7. LACTEOS & Leche liquida & 59.447 & 29.544 & $(29.903)$ \\
\hline \multirow{2}{*}{ 8. GRASAS } & Aceite animal & - & 511 & 511 \\
\hline & Aceite Vegetal & 5.346 & 7.674 & 2.328 \\
\hline \multirow{2}{*}{ 9. AZUCARES } & Café & - & 29.491 & 29.491 \\
\hline & Caña Panelera & - & - & - \\
\hline
\end{tabular}




\subsection{Características del eje Cúcuta}

Se encuentra un déficit entre la demanda ideal y la real, porque los productos sobre los que recae el déficit son aquellos que no representan altos índices de proteínas; mientras que los que tienen superávit están vinculados con proteínas y carbohidratos. Con un déficit en 22 productos agroalimentarios, la población del eje está comiendo con bajos niveles de nutrición y está subalimentada o sobrealimentada en algunos casos. Adicionalmente, la dieta basada en enlatados es mayor, por el comercio con el vecino país, que permite que ingresen a precios bajos y sean consumidos por los pobladores de Cúcuta y su área metropolitana.

\begin{tabular}{|c|c|c|c|c|}
\hline \multicolumn{5}{|c|}{ Tabla No. 1.11 Demanadas e je dinamizador Cúcuta } \\
\hline $\begin{array}{c}\text { GRUPOS DE } \\
\text { ALIMENTOS } \\
\end{array}$ & PRODUCTOS & $\begin{array}{c}\text { DEMANDA } \\
\text { IDEAL } \\
\end{array}$ & $\begin{array}{c}\text { DEMANDA } \\
\text { REAL } \\
\end{array}$ & \begin{tabular}{|c|} 
DÉFICIT O \\
SUPERÁVIT
\end{tabular} \\
\hline \multirow{4}{*}{ 1. CEREALES } & Arroz & 12.734 & 13.994 & 1.259 \\
\hline & Avena & 4.540 & - & $(4.540)$ \\
\hline & Maiz & 3.433 & - & $(3.433)$ \\
\hline & Trigo & - & - & - \\
\hline \multirow{5}{*}{$\begin{array}{l}\text { 2. RAICES, } \\
\text { TUBERCULOS Y } \\
\text { PLATANOS }\end{array}$} & Name & - & - & - \\
\hline & Papa & 16.547 & 25.595 & 9.048 \\
\hline & Papa criolla & 4.166 & - & $(4.166)$ \\
\hline & Platano & 9.084 & 18.035 & 8.952 \\
\hline & Yuca & 7.926 & 3.360 & $(4.567)$ \\
\hline \multirow{7}{*}{$\begin{array}{l}\text { 3. HORTALIZAS, } \\
\text { VERDURAS Y } \\
\text { LEGUIMINOS AS } \\
\text { VERDES }\end{array}$} & Arveja & 2.763 & 1.722 & $(1.040)$ \\
\hline & Auyama & 4.952 & - & $(4.952)$ \\
\hline & Cebolla Cabezona & 1.264 & 2.150 & 886 \\
\hline & Cebolla comun & 788 & 319 & $(469)$ \\
\hline & Habichuela & 3.225 & 841 & $(2.384)$ \\
\hline & Tomate & 4.994 & 4.437 & $(558)$ \\
\hline & Zanahoria & 8.545 & 2.112 & $(6.434)$ \\
\hline \multirow{8}{*}{ 4. FRUTAS } & Banano & 5.677 & 517 & $(5.160)$ \\
\hline & Guayaba & 13.127 & 1.314 & $(11.813)$ \\
\hline & Limon & 9.392 & 1.426 & $(7.966)$ \\
\hline & Mandarina & 12.404 & - & $(12.404)$ \\
\hline & Mango & 8.156 & 3.284 & $(4.872)$ \\
\hline & Mora & 20.548 & - & $(20.548)$ \\
\hline & Naranja & 13.451 & - & $(13.451)$ \\
\hline & Tomate de arbol & 7.885 & 870 & $(7.015)$ \\
\hline \multirow{5}{*}{ 5. CARNES Y HUEVOS } & Carne de res & 2.521 & 5.078 & 2.557 \\
\hline & Carne de cerdo & 2.039 & - & $(2.039)$ \\
\hline & Huevo de gallina & 4.521 & 4.796 & 275 \\
\hline & Pescado & 3.717 & 1.574 & $(2.144)$ \\
\hline & Pollo & 2.386 & 4.580 & 2.194 \\
\hline \multirow{3}{*}{$\begin{array}{l}\text { 6. LEGUMINOSAS } \\
\text { SECAS Y MEZCLAS } \\
\text { VEGETALES }\end{array}$} & Frijol & 1.507 & 1.942 & 435 \\
\hline & Garbanzo & 1.331 & - & $(1.331)$ \\
\hline & Lenteja & 1.432 & 1.118 & (314) \\
\hline 7. LACTEOS & Leche liquida & 38.884 & 19.203 & $(19.680)$ \\
\hline \multirow{2}{*}{ 8. GRASAS } & Aceite animal & - & 344 & 344 \\
\hline & Aceite Vegetal & 3.498 & 5.160 & 1.662 \\
\hline \multirow{2}{*}{ 9. AZUCARES } & Café & - & 19.247 & 19.247 \\
\hline & Caña Panelera & - & - & - \\
\hline
\end{tabular}




\subsection{Características del eje Neiva}

Hay un gran déficit en las comparaciones entre demanda ideal y real; los productos sobre los cuales recae el déficit son aquellos que no representan altos índices de proteínas; mientras que los que tienen superávit están relacionados con proteínas y carbohidratos. El déficit en 23 productos agroalimentarios conlleva que parte de la población del eje esté comiendo con bajos niveles de nutrición, esté subalimentada o sobrealimentada en algunos casos, lo cual se da especialmente por ser una zona productora de frutas.

\begin{tabular}{|c|c|c|c|c|}
\hline GRUPOS DE ALIMENTOS & PRODUCTOS & $\begin{array}{l}\text { DEMANDA } \\
\text { IDEAL }\end{array}$ & $\begin{array}{l}\text { DEMANDA } \\
\text { REAL }\end{array}$ & \begin{tabular}{|l} 
DÉFICIT O \\
SUPERÁVIT
\end{tabular} \\
\hline \multirow{4}{*}{ 1. CEREALes } & Arroz & 6.864 & 7.552 & 688 \\
\hline & Avena & 2.436 & - & $(2.436)$ \\
\hline & Maiz & 1.844 & - & $(1.844)$ \\
\hline & Trigo & - & - & - \\
\hline \multirow{5}{*}{$\begin{array}{l}\text { 2. RAICES, TUBERCULOS } \\
\text { Y PLATANOS }\end{array}$} & Name & - & - & - \\
\hline & Papa & 8.892 & 13.807 & 4.915 \\
\hline & Papa criolla & 2.232 & - & $(2.232)$ \\
\hline & Platano & 4.880 & 9.739 & 4.859 \\
\hline & Yuca & 4.254 & 1.815 & $(2.439)$ \\
\hline \multirow{7}{*}{$\begin{array}{c}\text { 3. HORTALIZAS, } \\
\text { VERDURAS Y } \\
\text { LEGUIMINOSAS VERDES }\end{array}$} & Arveja & 1.493 & 929 & $(564)$ \\
\hline & Auyama & 2.670 & - & $(2.670)$ \\
\hline & Cebolla Cabezona & 681 & 1.161 & 480 \\
\hline & Cebolla comun & 424 & 172 & $(252)$ \\
\hline & Habichuela & 1.741 & 452 & $(1.289)$ \\
\hline & Tomate & 2.704 & 2.395 & (309) \\
\hline & Zanahoria & 4.593 & 1.140 & $(3.453)$ \\
\hline \multirow{8}{*}{ 4. FRUTAS } & Banano & 3.063 & 282 & $(2.781)$ \\
\hline & Guayaba & 7.082 & 708 & $(6.374)$ \\
\hline & Limon & 5.070 & 768 & $(4.302)$ \\
\hline & Mandarina & 6.692 & - & $(6.692)$ \\
\hline & Mango & 4.401 & 1.771 & $(2.630)$ \\
\hline & Mora & 11.087 & - & (11.087) \\
\hline & Naranja & 7.258 & - & $(7.258)$ \\
\hline & Tomate de arbol & 4.253 & 468 & $(3.785)$ \\
\hline \multirow{5}{*}{ 5. CARNES Y HUEVOS } & Carne de res & 1.358 & 2.740 & 1.382 \\
\hline & Carne de cerdo & 1.099 & - & $(1.099)$ \\
\hline & Huevo de gallina & 2.437 & 2.586 & 149 \\
\hline & Pescado & 2.004 & 848 & $(1.156)$ \\
\hline & Pollo & 1.286 & 2.471 & 1.185 \\
\hline \multirow{3}{*}{$\begin{array}{l}\text { 6. LEGUMINOS AS S ECAS } \\
\text { Y MEZCLAS VEGETALES }\end{array}$} & Frijol & 812 & 1.044 & 232 \\
\hline & Garbanzo & 718 & - & $(718)$ \\
\hline & Lenteja & 772 & 603 & $(168)$ \\
\hline 7. LACTEOS & Leche liquida & 20.940 & 10.310 & $(10.630)$ \\
\hline \multirow{2}{*}{ 8. GRASAS } & Aceite animal & - & 188 & 188 \\
\hline & Aceite Vegetal & 1.884 & 2.820 & 936 \\
\hline \multirow{2}{*}{ 9. AZUCARES } & Café & - & 10.413 & 10.413 \\
\hline & Caña Panelera & - & - & - \\
\hline & & - & - & - \\
\hline \multirow{5}{*}{ 1. CEREALES } & Galleta & 1.579 & 349 & $(1.230)$ \\
\hline & Harina de Maiz & 3.016 & - & $(3.016)$ \\
\hline & Harina de trigo & 2.104 & - & $(2.104)$ \\
\hline & Pastas & 2.432 & 398 & $(2.034)$ \\
\hline & Pan & 3.412 & 3.224 & $(188)$ \\
\hline \multirow{3}{*}{ 5. CARNES Y HUEVOS } & Atun & 758 & - & $(758)$ \\
\hline & Salchicha & 785 & 450 & (335) \\
\hline & Salchichon & 447 & - & $(447)$ \\
\hline \multirow{3}{*}{ 7. LACTEOS } & Leche en Polvo & 1.205 & 94 & $(1.111)$ \\
\hline & Queso & 2.010 & 909 & $(1.101)$ \\
\hline & Yogurt & 6.381 & - & (6.381) \\
\hline 8. GRASAS & Mantequilla & 2.254 & - & $(2.254)$ \\
\hline \multirow{3}{*}{ 9. AZUCARES } & Azucar & 3.970 & 1.548 & $(2.422)$ \\
\hline & Chocolate & 1.657 & 357 & $(1.300)$ \\
\hline & Panela & 2.668 & 2.583 & (85) \\
\hline
\end{tabular}




\subsection{Características generales de los ejes}

En los cuatro ejes, los productos agroalimentarios sobre los cuales recae un superávit entre demanda ideal y real, donde esta última es mayor, son: el arroz, la papa, el plátano, la cebolla cabezona, la carne de res, los huevos, el pollo, el fríjol, los aceites y el café. Todos ellos son componentes sustanciales en la alimentación en las ciudades ejes dinamizadores, lo cual indica una dieta fundamentalmente determinada por carbohidratos y proteínas. 
ANEXO C

TABLAS ESTADÍSTICAS DE AGROALIMENTOS EN COLOMBIA, PERIODO 1987-2009

\begin{tabular}{|c|c|c|c|c|c|c|c|c|c|c|c|c|c|c|c|}
\hline \multirow{2}{*}{ Cultivo } & \multirow{2}{*}{\begin{tabular}{|c|}
1987 \\
1 \\
\end{tabular}} & \multicolumn{2}{|l|}{1990} & \multicolumn{2}{|c|}{1994} & \multicolumn{2}{|l|}{1998} & \multicolumn{2}{|c|}{2002} & \multicolumn{2}{|l|}{2006} & \multicolumn{2}{|l|}{2008} & \multicolumn{2}{|l|}{2009} \\
\hline & & 1 & 2 & 1 & 2 & 1 & 2 & 1 & 2 & 1 & 2 & 1 & 2 & 1 & 2 \\
\hline Ajonjolí & 19.080 & 12.450 & \begin{tabular}{|l|}
$-34,7$ \\
\end{tabular} & 14.099 & $-26,1$ & 6.163 & $|-67,7|$ & 4.724 & $-75,2$ & 4.315 & $\mid-77,4$ & 3.658 & $-80,8$ & 2.926 & $|-84,7|$ \\
\hline Algodón & 174.240 & 200.540 & 15,1 & 71.782 & $-58,8$ & 47.510 & \begin{tabular}{|l|}
$-72,7$ \\
\end{tabular} & 43.866 & $-74,8$ & 56.333 & \begin{tabular}{|l|}
$-67,7$ \\
\end{tabular} & 39.303 & \begin{tabular}{|l|}
$-77,4$ \\
\end{tabular} & 38.580 & \begin{tabular}{|l|}
$-77,9$ \\
\end{tabular} \\
\hline Cebada & 46.900 & 54.300 & \begin{tabular}{|l|l}
15,8 \\
\end{tabular} & 29.009 & $-38,1$ & 6.132 & \begin{tabular}{|l|}
$-86,9$ \\
\end{tabular} & 3.779 & \begin{tabular}{|l|}
$-91,9$ \\
\end{tabular} & 1.810 & \begin{tabular}{|l|}
$-96,1$ \\
\end{tabular} & 2.474 & \begin{tabular}{|l|}
$-94,7$ \\
\end{tabular} & 3.107 & -93,4 \\
\hline Frijol & 121.100 & 164.600 & \begin{tabular}{|l|l|}
35,9 \\
\end{tabular} & 144.823 & 19,6 & 121.118 & \begin{tabular}{|l|}
0,0 \\
\end{tabular} & 108.072 & $-10,8$ & 116.670 & \begin{tabular}{|l|}
$-3,7$ \\
\end{tabular} & 122.687 & 1,3 & 122.963 & 1,5 \\
\hline Maiz Total $* *$ & 622.800 & 836.900 & \begin{tabular}{|l|l}
34,4 \\
\end{tabular} & 762.456 & 22,4 . & 461.491 & \begin{tabular}{|l|}
$-25,9$ \\
\end{tabular} & 554.692 & $-10,9$ & 608.136 & \begin{tabular}{|l|}
$-2,4$ \\
\end{tabular} & 586.193 & \begin{tabular}{|l|l|}
$-5,9$ \\
\end{tabular} & 565.749 & \begin{tabular}{|l|l|}
$-9,2$ \\
\end{tabular} \\
\hline Maní & 4.020 & 3.350 & \begin{tabular}{|l|}
$-16,7$ \\
\end{tabular} & 6.994 & 74,0 & 1.789 & \begin{tabular}{|l|}
$-55,5$ \\
\end{tabular} & 1.314 & $-67,3$ & 2.462 & $-38,8$ & 2.435 & $\mid-39,4$ & 2.849 & -29,1 \\
\hline Papa & 157.250 & 161.350 & 2,6 & $\begin{array}{ll}184.397 \\
\end{array}$ & 17,3 & 164.759 & 4,8 & 163.841 & 4,2 & 162.144 & 3,1 & 157.105 & \begin{tabular}{|l|}
$-0,1$ \\
\end{tabular} & 156.568 & \begin{tabular}{|l|}
$-0,4$ \\
\end{tabular} \\
\hline Arroz Total ${ }^{*}$ & 384.500 & 521.100 & \begin{tabular}{|l|l}
35,5 \\
\end{tabular} & 408.284 & \begin{tabular}{|l|l}
6,2 \\
\end{tabular} & 402.850 & 4,8 & 468.906 & 22,0 & 434.073 & \begin{tabular}{|l|l|}
12,9 \\
\end{tabular} & 488.297 & 27,0 & 571.606 & 48,7 \\
\hline Sorgo & 259.400 & 273.000 & 5,2 & 219.285 & $-15,5$ & 62.627 & \begin{tabular}{|l|l|}
$-75,9$ \\
\end{tabular} & 69.509 & $-73,2$ & 52.539 & \begin{tabular}{|l|}
$-79,7$ \\
\end{tabular} & 21.886 & \begin{tabular}{|l|}
$-91,6$ \\
\end{tabular} & 23.071 & \begin{tabular}{|l|}
$-91,1$ \\
\end{tabular} \\
\hline Soya & 64.750 & $\begin{array}{l}116.150 \\
\end{array}$ & \begin{tabular}{|l|l|}
79,4 \\
\end{tabular} & 56.610 & $-12,6$ & 33.952 & \begin{tabular}{|l|}
$-47,6$ \\
\end{tabular} & 26.907 & $-58,4$ & 28.897 & $-55,4$ & 26.359 & $-59,3$ & 31.575 & $-51,2$ \\
\hline Tabaco Rubio & 10.350 & 7.490 & \begin{tabular}{|l|}
$-27,6$ \\
\end{tabular} & 3.315 & \begin{tabular}{|l|}
$-68,0$ \\
\end{tabular} & 4.969 & \begin{tabular}{|l|l|}
$-52,0$ \\
\end{tabular} & 6.478 & $-37,4$ & 9.131 & \begin{tabular}{|l|}
$-11,8$ \\
\end{tabular} & 7.935 & $-23,3$ & 4.599 & $-55,6$ \\
\hline Trigo & 40.800 & 56.700 & \begin{tabular}{|l|l|}
39,0 \\
\end{tabular} & 51.191 & 25,5 & 19.058 & \begin{tabular}{|l|l|}
$-53,3$ \\
\end{tabular} & 17.853 & $-56,2$ & 17.534 & $-57,0$ & 14.142 & \begin{tabular}{|l|}
$-65,3$ \\
\end{tabular} & 11.837 & $-71,0$ \\
\hline Total Has. & 1.905 .190 & 2.407 .930 & \begin{tabular}{|l|l}
26,4 \\
\end{tabular} & 1.952 .244 & \begin{tabular}{|l|}
2,5 \\
\end{tabular} & 1.332 .419 & \begin{tabular}{|l|}
$-30,1$ \\
\end{tabular} & 1.469 .941 & \begin{tabular}{|l|}
$-22,8$ \\
\end{tabular} & 1.494 .043 & \begin{tabular}{|l|}
$-21,6$ \\
\end{tabular} & 1.472 .474 & \begin{tabular}{|l|}
$-22,7$ \\
\end{tabular} & 1.535 .429 & \begin{tabular}{|l|} 
\\
\end{tabular} \\
\hline \multicolumn{3}{|c|}{$\begin{array}{l}\text { * Incluye arroz riego, secano mecanizado } \\
\text { y manual. }\end{array}$} & \multicolumn{6}{|c|}{ *** Incluye maíz tecnificado y tradicional } & & : Has. & & \multicolumn{4}{|c|}{ 2. Variación con base 1987} \\
\hline
\end{tabular}

\begin{tabular}{|c|c|c|c|c|c|c|c|c|c|c|c|c|}
\hline abla No. 2 & & & & & $\begin{array}{l}\text { endim } \\
1987 \text { - }\end{array}$ & to9 & e & & & & & \\
\hline te & $D_{N}$ & 1987 & 1990 & & 1994 & & 2002 & & 2006 & & 2009 & \\
\hline Cultivo & Var. & 1 & 1 & 2 & 1 & 2 & 1 & 2 & 1 & 2 & 1 & 2 \\
\hline in & $\bar{P}$ & 10.890 & 8.230 & (24) & 8.768 & (19) & 3.096 & (72) & 3.580 & (67) & 2.180 & $(80)$ \\
\hline A jonjoli & $\mathrm{R}$ & 571 & 661 & 16 & 622 & \begin{tabular}{l|l}
9 \\
\end{tabular} & 655 & 15 & 830 & 45 & 745 & 31 \\
\hline A & $P$ & 320.530 & \begin{tabular}{|l|}
314.170 \\
\end{tabular} & (2) & 145.558 & (55) & 92.211 & (71) & 114.882 & (64) & 78.434 & (76) \\
\hline Algodón & $\mathrm{R}$ & 1.840 & 1.567 & (15) & 2.028 & 10 & 2.102 & 14 & 2.039 & 11 & 2.033 & 11 \\
\hline $\mathrm{Cal}$ & $P$ & 91.600 & 100.400 & 10 & 57.702 & (37) & 7.180 & (92) & 3.121 & (97) & 5.085 & (94) \\
\hline Cebada & $\mathrm{R}$ & 1.953 & 1.849 & (5) & 1.989 & 2 & 1.900 & (3) & 1.724 & (12) & 1.637 & (16) \\
\hline Fín & $P$ & 90.425 & 132.150 & 46 & 134.956 & 49 & 119.870 & 33 & 135.130 & 49 & 149.122 & 65 \\
\hline Frijol & $\mathrm{R}$ & 747 & 803 & 8 & 932 & 25 & 1.109 & 49 & 1.158 & 55 & 1.213 & 62 \\
\hline (1) & $P$ & 198.600 & 265.600 & 34 & 298.786 & 50 & 518.983 & 161 & 635.796 & 220 & 617.282 & 211 \\
\hline Tecnificado & $\mathrm{R}$ & 2.549 & 2.705 & 6 & 2.740 & 7 & 3.677 & 44 & 3.988 & 56 & 4.017 & 58 \\
\hline Maíz & $P$ & 661.000 & 947.700 & 43 & 886.578 & 34 & 654.862 & (1) & 710.536 & 7 & 639.024 & (3) \\
\hline Tradicional & $\mathrm{R}$ & 1.213 & 1.283 & 6 & 1.357 & 12 & 1.583 & 31 & 1.583 & 31 & 1.551 & 28 \\
\hline & $P$ & 5.950 & 4.760 & (20) & 9.176 & 54 & 1.994 & (66) & 3.414 & (43) & 3.147 & (47) \\
\hline Maní & $\mathrm{R}$ & 1.480 & 1.421 & (4) & 1.312 & (11) & 1.517 & 2 & 1.387 & (6) & 1.105 & (25) \\
\hline D & $P$ & 2.242 .605 & 2.464 .400 & 10 & 2.938 .631 & 31 & \begin{tabular}{|l|}
2.834 .820 \\
\end{tabular} & 26 & \begin{tabular}{|l|}
2.885 .482 \\
\end{tabular} & 29 & 2.995 .188 & 34 \\
\hline Papa & $\mathrm{R}$ & 14.261 & 15.274 & 7 & 15.936 & 12 & 17.302 & 21 & 17.796 & 25 & 19.130 & 34 \\
\hline & $P$ & 1.377 .000 & 1.520 .900 & 10 & 1.158 .724 & (16) & 1.553 .357 & 13 & \begin{tabular}{|l}
1.638 .997 \\
\end{tabular} & 19 & 1.922 .443 & 40 \\
\hline Arroz Riego & $\mathrm{R}$ & 5.430 & \begin{tabular}{l|l}
4.598 \\
\end{tabular} & (15) & 4.726 & (13) & 5.970 & 10 & 6.652 & 23 & 6.456 & 19 \\
\hline Arroz Sec. & $P$ & 424.300 & 538.700 & 27 & 413.153 & (3) & 685.647 & 62 & 691.677 & 63 & 1.008 .412 & 138 \\
\hline Mec. & $R$ & 4.269 & 3.489 & (18) & 3.876 & (9) & 4.437 & 4 & 4.992 & 17 & 4.692 & 10 \\
\hline Arroz Sec. & $P$ & 63.300 & \begin{tabular}{|l|l|}
57.000 \\
\end{tabular} & (10) & 85.336 & 35 & 108.913 & 72 & 80.152 & 27 & 96.794 & 53 \\
\hline Manu & $\mathrm{R}$ & 2.010 & 1.588 & (21) & 1.510 & (25) & 2.010 & 0 & 1.632 & (19) & 1.643 & (18) \\
\hline $\mathrm{S}$ & $P$ & 703.800 & $\begin{array}{l}777.400 \\
\end{array}$ & 10 & 649.319 & (8) & 222.601 & (68) & 168.425 & (76) & 61.888 & (91) \\
\hline Sorgo & $\mathrm{R}$ & 2.713 & 2.848 & 5 & 2.961 & \begin{tabular}{l|l}
9 \\
\end{tabular} & 3.202 & 18 & 3.206 & 18 & 2.683 & (1) \\
\hline Sor & $P$ & 128.210 & 232.140 & 81 & 109.391 & (15) & 61.660 & (52) & 48.000 & (63) & 63.795 & (50) \\
\hline Soya & $\mathrm{R}$ & 1.980 & 1.999 & 1 & 1.932 & (2) & 2.292 & 16 & 1.661 & (16) & 2.020 & 2 \\
\hline The P Ph & $P$ & 15.610 & 11.645 & (25) & 5.698 & (64) & 13.490 & (14) & 17.773 & 14 & 8.844 & (43) \\
\hline $\mathrm{R}$ & $\mathrm{R}$ & 1.508 & 1.555 & 3 & 1.719 & 14 & 2.082 & 38 & 1.946 & 29 & 1.923 & 28 \\
\hline$T-i$ & $P$ & 74.200 & 104.800 & 41 & 105.183 & 42 & 38.409 & (48) & 39.590 & (47) & 19.888 & (73) \\
\hline Trigo & $\mathrm{R}$ & 1.819 & 1.848 & 2 & 2.055 & 13 & 2.151 & 18 & 2.258 & 24 & 1.680 & (8) \\
\hline $\begin{array}{r}\begin{array}{c}\text { Total Produc } \\
\text { Toneladas }\end{array} \\
\end{array}$ & & 6.408 .020 & 7.479 .995 & 117 & 7.006 .957 & 109 & 6.917 .093 & 108 & 7.176 .555 & 112 & 71.526 & 120 \\
\hline 1ente: $\mathrm{E}$ & IA & C1. & & & 1: Produ & ión & Rendim & & 2. $Y$ & ción & on base 1 & \\
\hline
\end{tabular}




\begin{tabular}{|c|c|c|c|c|c|c|c|c|c|c|c|c|c|c|c|}
\hline \multirow{3}{*}{ Cultivo } & \multirow{2}{*}{\multicolumn{3}{|c|}{\begin{tabular}{|c|r}
\multicolumn{2}{c}{ Tabla No. 3 COI } \\
1987 & 1990 \\
\end{tabular}}} & \multirow{2}{*}{\multicolumn{2}{|c|}{1994}} & \multirow{2}{*}{\multicolumn{2}{|c|}{1998}} & \multirow{2}{*}{\multicolumn{2}{|c|}{2002}} & \multirow{2}{*}{\multicolumn{2}{|c|}{2006}} & \multirow{2}{*}{\multicolumn{2}{|c|}{2008}} & \multirow{2}{*}{\multicolumn{2}{|c|}{2009}} \\
\hline & & & & & & & & & & & & & & & \\
\hline & & & 2 & 1 & 2 & 1 & 2 & 1 & 2 & 1 & 2 & 1 & 2 & 1 & 2 \\
\hline Arracacha & 5.500 & 7.876 & 43,2 & 7.066 & 28,5 & 6.540 & 18,9 & 8.087 & 47,0 & 7.659 & 39,3 & 6.487 & 17,9 & 5.018 & 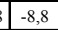 \\
\hline \begin{tabular}{|l|} 
Banano \\
Exportación*
\end{tabular} & 24.900 & 32.400 & 30,1 & 44.475 & 78,6 & 40.500 & 62,7 & 42.300 & 69,9 & 43.791 & 75,9 & 44.224 & 77,6 & 42.655 & 5171,3 \\
\hline Cacao & 104.790 & 120.712 & 15,2 & 108.551 & 3,6 & 95.413 & $-8,9$ & 99.002 & $-5,5$ & 109.843 & 4,8 & 108.109 & 3,2 & 109.528 & \begin{tabular}{|l|l|} 
& 4,5 \\
\end{tabular} \\
\hline Caña Azúcar & 108.000 & 112.640 & \begin{tabular}{|l|}
4,3 \\
\end{tabular} & 154.461 & 43,0 & 174.445 & \begin{tabular}{|l|}
61,5 \\
\end{tabular} & 218.706 & 102,5 & 182.861 & 69,3 & 158.749 & 47,0 & 214.947 & \begin{tabular}{|l|l|}
199,0 \\
\end{tabular} \\
\hline Caña Panela** & 232.000 & 199.634 & $-14,0$ & 210.858 & $-9,1$ & 210.473 & $-9,3$ & 243.118 & 4,8 & 202.008 & \begin{tabular}{|l|}
$-12,9$ \\
\end{tabular} & 197.464 & $-14,9$ & 203.919 & \begin{tabular}{|l|l|}
87,9 \\
\end{tabular} \\
\hline Caña Miel*** & & & & 7.959 & 100,0 & 8.211 & 3,2 & 5.673 & $-28,7$ & 6.752 & $-15,2$ & 5.482 & $-31,1$ & 5.588 & \begin{tabular}{|l|l|}
8 & $-29,8$ \\
\end{tabular} \\
\hline \begin{tabular}{|l|} 
Cocotero \\
\end{tabular} & 14.800 & 15.860 & 7,2 & 11.043 & $-25,4$ & 10.916 & $-26,2$ & 12.041 & $-18,6$ & 13.980 & $-5,5$ & 15.077 & 1,9 & 13.674 & \begin{tabular}{|l|l|}
4 & $-7,6$ \\
\end{tabular} \\
\hline Fique & 19.300 & 15.756 & \begin{tabular}{|l|}
$-18,4$ \\
\end{tabular} & 15.388 & $-20,3$ & 18.311 & $-5,1$ & 17.391 & $-9,9$ & 18.124 & $-6,1$ & 18.480 & $-4,2$ & 19.813 & \begin{tabular}{|l|l|}
3 & 2,7 \\
\end{tabular} \\
\hline \begin{tabular}{|l|} 
Ñame \\
\end{tabular} & 15.700 & 4.547 & $-71,0$ & 11.709 & $-25,4$ & 15.294 & $-2,6$ & 21.678 & 38,1 & 25.595 & 63,0 & 28.729 & 83,0 & 35.850 & \begin{tabular}{|l|l|}
128,3 \\
\end{tabular} \\
\hline \begin{tabular}{|l|} 
Palma \\
Africana****
\end{tabular} & 51.560 & 89.671 & 73,9 & 125.321 & 143,1 & 7.493 & 186,1 & 173.964 & 237,4 & 208.875 & 305,1 & 45.532 & 376,2 & 342.547 & $\begin{array}{l}7 \\
7\end{array} 664,4$ \\
\hline \begin{tabular}{|l|l} 
Plátano \\
Exp.***** \\
\end{tabular} & 6.080 & 7.000 & 15,1 & 12.783 & 110,2 & 14.038 & 130,9 & 13.899 & 128,6 & 16.612 & 173,2 & 15.598 & 156,5 & 15.156 & \begin{tabular}{|l|l} 
& 149,3
\end{tabular} \\
\hline Plátano & 358.900 & 344.803 & \begin{tabular}{|l|}
$-3,9$ \\
\end{tabular} & 375.370 & 4,6 & 366.035 & 2,0 & 379.091 & 5,6 & 362655 & 1,0 & 343635 & $-4,3$ & 335226 & $-6,6$ \\
\hline \begin{tabular}{|l|} 
Tabaco Negro \\
C.I.
\end{tabular} & 4.590 & 3.542 & $-22,8$ & 3.613 & $-21,3$ & 2.760 & $-39,9$ & 3.165 & $-31,0$ & 6126 & 33,5 & 2749 & $-40,1$ & 2591 & $-43,6$ \\
\hline $\begin{array}{l}\text { Tabaco Negro } \\
\text { Exp. }\end{array}$ & 6.200 & 8.874 & 43,1 & 7.635 & 23,1 & 9.551 & 54,0 & 3.868 & $-37,6$ & 2020 & $-67,4$ & 919 & $-85,2$ & 891 & $-85,6$ \\
\hline Yuca & 159.100 & 207.310 & 30,3 & 189.603 & 19,2 & 177.029 & 11,3 & 172.124 & 8,2 & 189612 & 19,2 & 183215 & 15,2 & 182313 & 14,6 \\
\hline Total has. & 1.111 .420 & 1.170 .625 & 105 & 1.285 .833 & 116 & \begin{tabular}{|l|l|} 
& \\
\end{tabular} & 117 & \begin{tabular}{|l|l|} 
& \\
\end{tabular} & 127 & \begin{tabular}{|l|l|}
1.396 .512 \\
\end{tabular} & 126 & \begin{tabular}{|l|}
1.374 .449 \\
\end{tabular} & 124 & 1.529 .716 & 127,3 \\
\hline \multicolumn{15}{|c|}{\begin{tabular}{|l|l|} 
Fuente: *Para Antioquia AUGURA y para M agdalena Evaluaciones Agropecuarias, $* * * * *$ AUGURA & $* * * * *$ Producción y rendimiento en términos de Aceite crudo.
\end{tabular}} & \\
\hline $\begin{array}{l}* \text { Producción } \\
\text { Panela } \\
\end{array}$ & endimiento & en términ & & $* * *$ & érminos & de miel. & & & & 0007 & & lesde & & & \\
\hline
\end{tabular}

\begin{tabular}{|c|c|c|c|c|c|c|c|c|c|c|c|c|c|c|}
\hline \multicolumn{3}{|c|}{ Tabla No. 4 COLOMBIA } & \multicolumn{12}{|c|}{$\begin{array}{r}\text { Producción y Rendimientos } \\
1987-2009\end{array}$} \\
\hline \multirow{2}{*}{ Cultivos } & \multirow[t]{2}{*}{ Var. } & \multirow[t]{2}{*}{1987} & \multicolumn{2}{|l|}{1990} & \multicolumn{2}{|l|}{1994} & \multicolumn{2}{|l|}{1998} & \multicolumn{2}{|l|}{2002} & \multicolumn{2}{|l|}{2006} & \multicolumn{2}{|l|}{2009} \\
\hline & & & 1 & 2 & 1 & 2 & 1 & 2 & 1 & 2 & 1 & 2 & 1 & 2 \\
\hline \multirow{2}{*}{ Arracacha } & $\mathbf{P}$ & 46.200 & 80.391 & 74 & 77.362 & 67 & 69.622 & 51 & 95.012 & 106 & 86.575 & 87 & 49.567 & 7 \\
\hline & $\mathbf{R}$ & 8.400 & 10.207 & 22 & 10.949 & 30 & 10.646 & 27 & 11.748 & 40 & 11.304 & 35 & 9.878 & 18 \\
\hline \multirow{2}{*}{$\begin{array}{c}\text { Banano } \\
\text { Exportación* }\end{array}$} & $\mathbf{P}$ & \begin{tabular}{|l|}
1.090 .950 \\
\end{tabular} & 1.243 .614 & 14 & \begin{tabular}{|l|}
1.845 .012 \\
\end{tabular} & \begin{tabular}{|l|}
69 \\
\end{tabular} & 1.435 .753 & 32 & \begin{tabular}{|l|}
1.424 .314 \\
\end{tabular} & 31 & 1.519 .386 & 39 & 1.741 .106 & 60 \\
\hline & $\mathbf{R}$ & 43.813 & 38.383 & -12 & 41.484 & \begin{tabular}{|l|}
-5 \\
\end{tabular} & 35.451 & -19 & 33.672 & -23 & 34.696 & -21 & 39.720 & -9 \\
\hline \multirow{2}{*}{ Cacao } & $\mathbf{P}$ & 53.680 & 56.153 & \begin{tabular}{l|l|}
5 \\
\end{tabular} & 50.624 & -6 & 50.685 & -6 & 48.187 & -10 & 53.667 & 0 & 60.320 & 12 \\
\hline & $\mathbf{R}$ & 512 & 465 & -9 & 466 & \begin{tabular}{|l|}
-9 \\
\end{tabular} & 531 & 4 & 487 & -5 & 489 & -5 & 551 & 8 \\
\hline \multirow{2}{*}{ Caña Azúcar } & $\mathbf{P}$ & \begin{tabular}{|l|}
1.477 .982 \\
\end{tabular} & 1.521 .366 & 3 & \begin{tabular}{|l|}
2.045 .874 \\
\end{tabular} & 38 & \begin{tabular}{|l|l}
2.102 .809 \\
\end{tabular} & 42 & \begin{tabular}{|l|}
2.881 .661 \\
\end{tabular} & 95 & 2.163 .543 & 46 & 2.303 .680 & 56 \\
\hline & $\mathbf{R}$ & 13.685 & 13.506 & -1 & 13.245 & -3 & 12.054 & -12 & 13.176 & -4 & 11.832 & -14 & 11.910 & -13 \\
\hline \multirow{2}{*}{ Caña Panela** } & $\mathbf{P}$ & \begin{tabular}{|l|}
1.196 .450 \\
\end{tabular} & 1.092 .629 & -9 & 1.239 .403 & 4 & 1.309 .679 & 9 & 1.587 .893 & 33 & 1.241 .904 & 4 & 1.227 .313 & 3 \\
\hline & $\mathbf{R}$ & 5.157 & 5.473 & 6 & 5.878 & 14 & 6.223 & 21 & 6.531 & 27 & 6.148 & 19 & 6.319 & 23 \\
\hline \multirow{2}{*}{ Caña Miel ${ }^{* \star *}$} & $\mathbf{P}$ & & & & 66.675 & & 61.199 & & 24.391 & & 27.439 & & 22.955 & \\
\hline & $\mathbf{R}$ & & & & 8.377 & & 7.453 & & 4.300 & & 4.064 & & 4.108 & \\
\hline \multirow{2}{*}{ Cocotero } & $\mathbf{P}$ & 88.200 & 119.308 & 35 & 87.212 & -1 & 71.299 & -19 & 95.854 & 9 & 113.412 & 29 & 102.921 & 17 \\
\hline & $\mathbf{R}$ & 5.959 & 7.523 & 26 & 7.898 & 33 & 6.532 & 10 & 7.961 & 34 & 8.112 & 36 & 7.527 & 26 \\
\hline \multirow{2}{*}{ Fique } & $\mathbf{P}$ & 23.520 & 21.607 & -8 & 21.353 & -9 & 23.125 & -2 & 19.884 & -15 & 21.193 & -10 & 23.101 & -2 \\
\hline & $\mathbf{R}$ & 1.219 & 1.371 & 13 & 1.388 & 14 & 1.263 & 4 & 1.143 & -6 & 1.169 & -4 & 1.166 & -4 \\
\hline \multirow{2}{*}{ Name } & $\mathbf{P}$ & 139.100 & 28.322 & -80 & 123.952 & -11 & 164.918 & 19 & 236.584 & 70 & 268.787 & 93 & 379.927 & 173 \\
\hline & $\mathbf{R}$ & 8.860 & 6.229 & -30 & 10.586 & 19 & 10.783 & 22 & 10.914 & 23 & 10.502 & 19 & 10.598 & 20 \\
\hline \multirow{2}{*}{$\begin{array}{c}\text { Palma } \\
\text { Africana }^{* * * *}\end{array}$} & $\mathbf{P}$ & 147.000 & 251.961 & 71 & 376.860 & 156 & 491.198 & 234 & 623.790 & 324 & 717.806 & 388 & 863.509 & 487 \\
\hline & $\mathbf{R}$ & 2.851 & 2.810 & $\mid-1$ & 3.007 & 5 & 3.330 & 17 & 3.586 & 26 & 3.437 & 21 & 3.345 & 17 \\
\hline \multirow{2}{*}{ Plátano Exp. } & $\mathbf{P}$ & 74.900 & 90.900 & 21 & 119.375 & 59 & 134.414 & 79 & 113.528 & 52 & 126.089 & 68 & 114.820 & 53 \\
\hline & $\mathbf{R}$ & 12.319 & 12.986 & 5 & 9.339 & -24 & 9.575 & -22 & 8.168 & -34 & 7.590 & -38 & 7.576 & -39 \\
\hline \multirow{2}{*}{ Plátano } & $\mathrm{P}$ & \begin{tabular}{|l|}
2.374 .260 \\
\end{tabular} & 2.425 .043 & 2 & 2.395 .615 & 1 & 2.425 .831 & 2 & 2.994 .022 & 26 & 2915171 & 23 & 2616717 & 10 \\
\hline & $R$ & 6.615 & 7.033 & 6 & 6.382 & -4 & 6.627 & 0 & 7.898 & 19 & 8038,41392 & 22 & 7805,8295 & 18 \\
\hline Tabaco Negro & $\mathrm{P}$ & 6.910 & 6.244 & \begin{tabular}{|l|}
-10 \\
\end{tabular} & 5.980 & \begin{tabular}{|l|}
-13 \\
\end{tabular} & 4.986 & -28 & 5.917 & -14 & 9858 & 43 & 4658 & -33 \\
\hline C.I. & $R$ & 1.505 & 1.763 & 17 & 1.655 & 10 & 1.807 & 20 & 1.870 & 24 & 1609,20666 & \begin{tabular}{|lll}
7 \\
\end{tabular} & 1797,761482 & 19 \\
\hline Tabaco Negro & $\mathrm{P}$ & 12.350 & 15.100 & 22 & 15.227 & 23 & 16.938 & 37 & 7.068 & -43 & 3665 & -70 & 1713 & -86 \\
\hline Exp & $R$ & 1.992 & 1.702 & \begin{tabular}{|l|}
-15 \\
\end{tabular} & 1.994 & 0 & 1.773 & -11 & 1.827 & \begin{tabular}{l|l|}
-8 \\
\end{tabular} & \begin{tabular}{|l|}
1814,356436 \\
\end{tabular} & -9 & 1922,558923 & -3 \\
\hline & $\mathrm{P}$ & \begin{tabular}{|l|}
1.260 .390 \\
\end{tabular} & \begin{tabular}{|l|}
1.939 .019 \\
\end{tabular} & \begin{tabular}{|l|l}
54 \\
\end{tabular} & \begin{tabular}{|l|}
1.794 .611 \\
\end{tabular} & 42 & \begin{tabular}{|l|}
1.598 .166 \\
\end{tabular} & 27 & \begin{tabular}{|l|l|}
1.779 .250 \\
\end{tabular} & 41 & 1977314 & 57 & 1984427 & 57 \\
\hline Yuca & $R$ & 7.922 & 9.353 & \begin{tabular}{|l|}
18 \\
\end{tabular} & 9.465 & \begin{tabular}{|l|}
19 \\
\end{tabular} & 9.028 & 14 & 10.337 & 30 & \begin{tabular}{|l|}
10428,21129 \\
\end{tabular} & 32 & \begin{tabular}{|l}
10884,72572 \\
\end{tabular} & 37 \\
\hline nte: & & 年 & 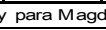 & 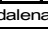 & 5 & & & & & & & & & \\
\hline & & & & & & & & & & & & & & \\
\hline roducciór & & té & s de $\mathrm{F}$ & & & & & & & & & & & \\
\hline & & & & & & & & & & & & & & \\
\hline & & & & & & & & & & & & & & \\
\hline
\end{tabular}




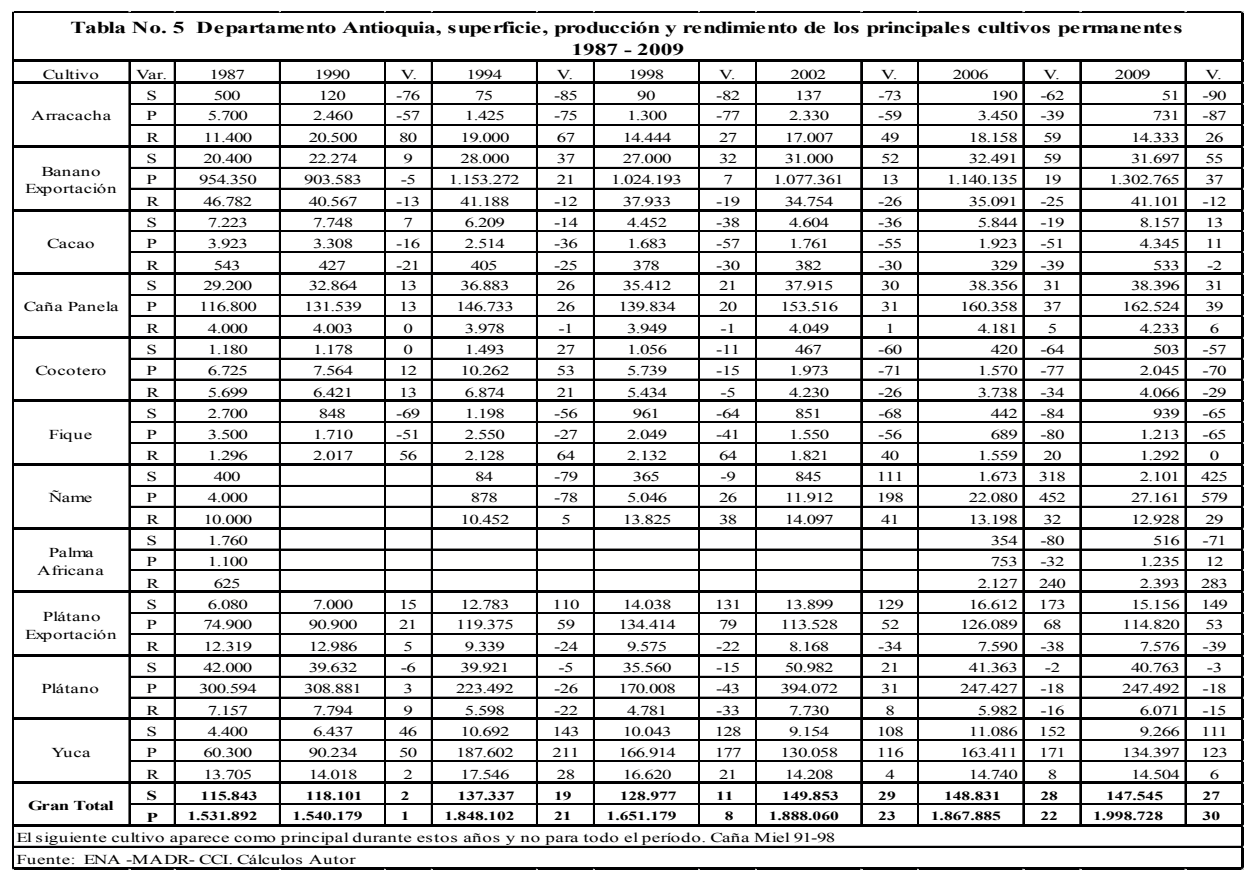

\begin{tabular}{|c|c|c|c|c|c|c|c|c|c|c|c|c|c|c|}
\hline \multicolumn{15}{|c|}{$\begin{array}{l}\text { Tabla No. } 6 \text { Departamento Antioquia, Superficie, Producción y Rendimiento de los Principales Cultivos Transitorios } \\
\qquad 1987-2009\end{array}$} \\
\hline Cultivo & Var. & 1987 & 1990 & $\%$ & 1994 & $\%$ & 1998 & $\%$ & 2002 & $\%$ & 2006 & $\%$ & 2009 & $\%$ \\
\hline \multirow{3}{*}{ Frijol } & $\mathrm{S}$ & 38.300 & 37.834 & -1 & 28.259 & -26 & 23.526 & -39 & 22.536 & -41 & 22.773 & -41 & 21.228 & -45 \\
\hline & $P$ & 34.470 & 35.045 & 2 & 30.342 & -12 & 23.817 & -31 & 27.519 & -20 & 30.045 & -13 & 31.173 & -10 \\
\hline & $R$ & 900 & 926 & 3 & 1.074 & 19 & 1.012 & 12 & 1.221 & 36 & 1.319 & 47 & 1.468 & 63 \\
\hline \multirow{3}{*}{$\begin{array}{c}\text { Maíz } \\
\text { Tecnificado }\end{array}$} & $\mathrm{S}$ & 800 & 400 & -50 & 11.550 & 1.344 & 6.762 & 745 & 7.536 & 842 & 4.675 & 484 & 5.161 & 545 \\
\hline & $P$ & 1.600 & 800 & -50 & 24.274 & 1.417 & 12.337 & 671 & 17.758 & 1.010 & 11.522 & 620 & 12.921 & 708 \\
\hline & $\mathrm{R}$ & 2.000 & 2.000 & 0 & 2.102 & 5 & 1.824 & -9 & 2.357 & 18 & 2.465 & 23 & 2.504 & 25 \\
\hline \multirow{3}{*}{$\begin{array}{c}\text { Maíz } \\
\text { Tradicional }\end{array}$} & $\mathrm{S}$ & 107.500 & 126.700 & 18 & 80.212 & -25 & 46.839 & -56 & 52.196 & -51 & 43.349 & -60 & 40.866 & -62 \\
\hline & $P$ & 109.200 & 145.400 & 33 & 115.041 & 5 & 58.361 & $\begin{array}{r}-47 \\
\end{array}$ & 84.015 & -23 & 74.189 & -32 & 66.153 & -39 \\
\hline & $\mathrm{R}$ & 1.016 & 1.148 & 13 & 1.434 & 41 & 1.246 & 23 & 1.610 & 58 & 1.711 & 68 & 1.619 & 59 \\
\hline \multirow{3}{*}{ Papa } & $\mathrm{S}$ & 16.400 & 18.600 & 13 & 20.440 & 25 & 15.940 & -3 & 14.592 & -11 & 15.444 & -6 & 11.502 & -30 \\
\hline & $\mathrm{P}$ & 264.120 & 310.100 & 17 & 341.211 & 29 & 256.293 & -3 & 228.826 & -13 & 256.080 & -3 & 195.461 & -26 \\
\hline & $\mathrm{R}$ & 16.105 & 16.672 & 4 & 16.694 & 4 & 16.079 & 0 & 15.682 & -3 & 16.581 & 3 & 16.994 & 6 \\
\hline \multirow{3}{*}{$\begin{array}{l}\text { ArrozSec. } \\
\text { Mec. }\end{array}$} & $\mathrm{S}$ & 4.300 & 6.700 & 56 & 3.949 & -8 & 5.251 & 22 & 8.532 & 98 & 8.192 & 91 & 5.678 & 32 \\
\hline & $\mathrm{P}$ & 18.500 & 18.500 & 0 & 14.110 & -24 & 18.304 & -1 & 40.470 & 119 & \begin{tabular}{ll|}
36.847 \\
\end{tabular} & 99 & 24.946 & 35 \\
\hline & $\mathrm{R}$ & 4.302 & 2.761 & -36 & 3.573 & -17 & 3.486 & -19 & 4.743 & 10 & 4.498 & 5 & 4.393 & 2 \\
\hline \multirow{3}{*}{$\begin{array}{c}\text { ArrozSec. } \\
\text { Manual }\end{array}$} & $\mathrm{S}$ & 4.600 & & & 16.474 & 258 & 6.849 & 49 & 7.767 & 69 & 13.316 & 189 & 14.363 & 212 \\
\hline & $\mathrm{P}$ & 10.100 & & & 20.312 & 101 & 7.449 & -26 & 12.471 & 23 & 20.274 & 101 & 20.974 & 108 \\
\hline & $\mathrm{R}$ & 2.196 & & & 1.233 & -44 & 1.088 & -50 & 1.606 & -27 & 1.523 & -31 & 1.460 & -33 \\
\hline \multirow{2}{*}{ Gran Total } & $\mathrm{s}$ & 171.900 & 190.234 & 11 & 160.884 & -6 & 105.166 & -39 & 113.158 & -34 & 107.749 & -37 & 98.798 & -43 \\
\hline & $P$ & 437.990 & 509.845 & 16 & 545.290 & 24 & 376.560 & -14 & 411.059 & -6 & 428.957 & -2 & 351.628 & -20 \\
\hline \multicolumn{15}{|c|}{ Los siguientes cultivos aparecen como principales durante estos años y no para todo el período. Ajonjoli 1987-1998; Arroz Riego 1987-94; Sorgo 87-94; Tabaco Rubio 87-94 } \\
\hline & & & & & & & & & & & & & & \\
\hline
\end{tabular}




\begin{tabular}{|c|c|c|c|c|c|c|c|c|c|c|c|c|c|c|}
\hline Cultivo & Var. & 1987 & 1990 & V. & 1994 & V. & 1998 & V. & 2002 & V. & 2006 & V. & 2009 & V. \\
\hline \multirow{3}{*}{ Ajonjolí } & $\mathrm{S}$ & 370 & 1.136 & 207 & 3.105 & 739 & 1.093 & 195 & 1.216 & 229 & 1.481 & 300 & 1.167 & 215 \\
\hline & $\mathrm{P}$ & 274 & 1.065 & 289 & 2.104 & 668 & 706 & 158 & 984 & 259 & 1.333 & 386 & 942 & 244 \\
\hline & $\mathrm{R}$ & 741 & 938 & 27 & 678 & -8 & 646 & -13 & 809 & 9 & 900 & 22 & 807 & 9 \\
\hline \multirow{3}{*}{ Algodón } & $\mathrm{s}$ & 14.600 & 10.200 & -30 & 1.689 & -88 & 170 & -99 & 1.940 & -87 & & & & \\
\hline & $\mathrm{P}$ & 20.440 & 15.300 & -25 & 3.244 & -84 & 191 & -99 & 3.208 & -84 & & & & \\
\hline & $\mathrm{R}$ & 1.400 & 1.500 & 7 & 1.921 & 37 & 1.124 & -20 & 1.654 & 18 & & & & \\
\hline \multirow{3}{*}{ Fríjol } & $\mathrm{s}$ & 3.000 & 13.945 & 365 & 12.813 & 327 & 8.827 & 194 & 5.593 & 86 & 3.324 & 11 & 3.269 & 9 \\
\hline & $P$ & 2.100 & 12.110 & 477 & 11.254 & 436 & 7.773 & 270 & 4.855 & 131 & 2.818 & 34 & 2.132 & 2 \\
\hline & $\mathrm{R}$ & 700 & 868 & 24 & 878 & 25 & 881 & 26 & 868 & 24 & 848 & 21 & 652 & -7 \\
\hline \multirow{3}{*}{$\begin{array}{c}\text { Maíz } \\
\text { Tecnificado }\end{array}$} & $\mathrm{S}$ & 4.700 & 4.700 & 0 & 3.350 & -29 & 771 & -84 & 7.370 & 57 & 6.962 & 48 & 3.019 & -36 \\
\hline & $\mathrm{P}$ & 10.700 & 9.400 & -12 & 7.541 & -30 & 2.393 & -78 & 22.732 & 112 & 22.617 & 111 & 8.248 & -23 \\
\hline & $\mathrm{R}$ & 2.277 & 2.000 & -12 & 2.251 & -1 & 3.104 & 36 & 3.084 & 35 & 3.249 & 43 & 2.732 & 20 \\
\hline \multirow{3}{*}{$\begin{array}{c}\text { Maíz } \\
\text { Tradicional }\end{array}$} & $\mathrm{S}$ & 43.200 & 56.200 & 30 & 68.250 & 58 & 37.603 & -13 & 49.952 & 16 & 64.131 & 48 & 63.576 & 47 \\
\hline & $P$ & 58.900 & 89.300 & 52 & 111.863 & 90 & 59.530 & 1 & 81.926 & 39 & 102.477 & 74 & 96.525 & 64 \\
\hline & $\mathrm{R}$ & 1.363 & 1.589 & 17 & 1.639 & 20 & 1.583 & 16 & 1.640 & 20 & 1.598 & 17 & 1.518 & 11 \\
\hline \multirow{3}{*}{ Arroz Riego } & $\mathrm{S}$ & 2.200 & 5.200 & 136 & 1.745 & -21 & 2.824 & 28 & 4.450 & 102 & 5.162 & 135 & 3.550 & 61 \\
\hline & $\mathrm{P}$ & 8.700 & 15.900 & 83 & 6.675 & -23 & 15.381 & 77 & 21.861 & 151 & 28.286 & 225 & 19.697 & 126 \\
\hline & $\mathrm{R}$ & 3.955 & 3.058 & -23 & 3.825 & -3 & 5.447 & 38 & 4.913 & 24 & 5.480 & 39 & 5.548 & 40 \\
\hline \multirow{3}{*}{$\begin{array}{l}\text { Arroz Sec. } \\
\text { Mecanizado }\end{array}$} & $\mathrm{S}$ & 6.900 & 11.500 & 67 & 9.020 & 31 & 16.363 & 137 & 15.946 & 131 & 12.972 & 88 & 8.762 & 27 \\
\hline & $P$ & 20.700 & 43.400 & 110 & 30.847 & 49 & 66.571 & 222 & 57.615 & 178 & 50.190 & 142 & 35.049 & 69 \\
\hline & $\mathrm{R}$ & 3.000 & 3.774 & 26 & 3.420 & 14 & 4.068 & 36 & 3.613 & 20 & 3.869 & 29 & 4.000 & 33 \\
\hline \multirow{3}{*}{$\begin{array}{c}\text { Arroz Sec. } \\
\text { Manual }\end{array}$} & $\mathrm{s}$ & 4.700 & 3.100 & -34 & 1.928 & -59 & 6.160 & 31 & 6.975 & 48 & 5.740 & 22 & 7.274 & 55 \\
\hline & $\mathrm{P}$ & 12.000 & 5.600 & -53 & 3.291 & -73 & 11.595 & -3 & 19.074 & 59 & 10.414 & -13 & 11.615 & -3 \\
\hline & $\mathrm{R}$ & 2.553 & 1.806 & -29 & 1.707 & -33 & 1.882 & -26 & 2.735 & 7 & 1.814 & -29 & 1.597 & -37 \\
\hline \multirow{3}{*}{ Sorgo } & $\mathrm{S}$ & 16.700 & 13.500 & -19 & 16.668 & 0 & 7.563 & -55 & 6.618 & -60 & 5.165 & -69 & 2.700 & -84 \\
\hline & $\mathrm{P}$ & 35.000 & 26.600 & -24 & 37.107 & 6 & 23.233 & -34 & 21.539 & -38 & 13.218 & -62 & 5.118 & -85 \\
\hline & $\mathrm{R}$ & 2.096 & 1.970 & -6 & 2.226 & 6 & 3.072 & 47 & 3.255 & 55 & 2.559 & 22 & 1.896 & -10 \\
\hline \multirow{2}{*}{ Gran Total } & $\mathbf{S}$ & 96.000 & 118.345 & & 115.463 & & 80.281 & & 98.844 & & 103.456 & & 92.150 & \\
\hline & $\mathbf{P}$ & 168.814 & 218.675 & & 213.926 & & 187.373 & & 233.794 & & 231.353 & & 179.326 & \\
\hline
\end{tabular}

\begin{tabular}{|c|c|c|c|c|c|c|c|c|c|c|c|c|c|c|}
\hline \multicolumn{2}{|c|}{ Tabla No. 8} & \multicolumn{13}{|c|}{$\begin{array}{l}\text { Departamento Bolívar, Superficie, Producción y Rendimiento de los Principales Cultivos } \\
\text { Permanentes } 1987-2009\end{array}$} \\
\hline Cultivo & Var. & 1987 & 1990 & v. & 1994 & v. & 1998 & V. & 2002 & V. & 2006 & V. & 2009 & V. \\
\hline \multirow{3}{*}{ Cacao } & $\mathrm{S}$ & 667 & 845 & 27 & 1.026 & 54 & 663 & -1 & 686 & 3 & 1.948 & 192 & 2.888 & 333 \\
\hline & $\mathrm{P}$ & 280 & 398 & 42 & 525 & 88 & 415 & 48 & 486 & 74 & 995 & 255 & 839 & 200 \\
\hline & $\mathrm{R}$ & 420 & 471 & 12 & 512 & 22 & 626 & 49 & 708 & 69 & 511 & 22 & 291 & -31 \\
\hline \multirow{3}{*}{$\begin{array}{c}\text { Caña } \\
\text { Panela }\end{array}$} & $\mathrm{S}$ & 200 & 380 & 90 & 688 & 244 & 1.058 & 429 & 1.303 & 552 & 1.150 & 475 & 743 & 272 \\
\hline & $\mathrm{P}$ & 750 & 2.935 & 291 & 4.872 & 550 & 6.510 & 768 & 13.379 & 1.684 & 7.625 & 917 & 6.715 & 795 \\
\hline & $\mathrm{R}$ & 3.750 & 7.724 & 106 & 7.081 & 89 & 6.153 & 64 & 10.268 & 174 & 6.630 & 77 & 9.038 & 141 \\
\hline \multirow{3}{*}{ Cocotero } & $\mathrm{S}$ & 650 & 793 & 22 & 783 & 20 & 768 & 18 & 1.060 & 63 & 853 & 31 & 494 & -24 \\
\hline & $\mathrm{P}$ & 3.180 & 3.542 & 11 & 3.530 & 11 & 4.370 & 37 & 3.955 & 24 & 4.288 & 35 & 2.781 & -13 \\
\hline & $\mathrm{R}$ & 4.892 & 4.467 & -9 & 4.508 & -8 & 5.690 & 16 & 3.731 & -24 & 5.027 & 3 & 5.630 & 15 \\
\hline \multirow{3}{*}{ Ñame } & $\mathrm{S}$ & 3.500 & 3.190 & -9 & 6.020 & 72 & 5.559 & 59 & 7.985 & 128 & 11.262 & 222 & 18.925 & 441 \\
\hline & $\mathrm{P}$ & \begin{tabular}{|l|}
33.300 \\
\end{tabular} & 20.900 & -37 & 61.875 & 86 & \begin{tabular}{|l|}
60.343 \\
\end{tabular} & 81 & 113.620 & 241 & 123.509 & 271 & 208.005 & 525 \\
\hline & $\mathrm{R}$ & 9.514 & 6.552 & -31 & 10.278 & 8 & 10.855 & 14 & 14.229 & 50 & 10.967 & 15 & 10.991 & 16 \\
\hline \multirow{3}{*}{$\begin{array}{c}\text { Palma } \\
\text { Africana }\end{array}$} & $\mathrm{S}$ & & & & & & & & 740 & & 6.760 & 814 & 12.555 & 1.597 \\
\hline & $\mathrm{P}$ & & & & & & & & 1.336 & & 15.952 & 1.094 & 46.488 & 3.380 \\
\hline & $\mathrm{R}$ & & & & & & & & 1.805 & & 2.360 & \begin{tabular}{|l|}
31 \\
\end{tabular} & 3.703 & 105 \\
\hline \multirow{3}{*}{ Plátano } & $\mathrm{S}$ & 14.000 & 6.841 & \begin{tabular}{|l|}
-51 \\
\end{tabular} & 9.731 & -30 & 8.362 & -40 & 6.032 & -57 & 5.457 & -61 & 3.954 & -72 \\
\hline & $\mathrm{P}$ & 98.000 & 45.250 & -54 & 79.266 & -19 & \begin{tabular}{|l|}
66.937 \\
\end{tabular} & -32 & 46.560 & -52 & 32.563 & -67 & 27.355 & -72 \\
\hline & $\mathrm{R}$ & 7.000 & 6.615 & -6 & 8.146 & 16 & 8.005 & 14 & 7.719 & 10 & 5.967 & -15 & 6.918 & -1 \\
\hline \multirow{3}{*}{$\begin{array}{l}\text { Tabaco } \\
\text { Negro Exp. }\end{array}$} & $\mathrm{S}$ & 3.200 & 2.274 & -29 & 2.782 & -13 & 3.153 & -1 & 741 & -77 & 710 & -78 & 368 & -89 \\
\hline & $\mathrm{P}$ & 5.500 & 3.425 & -38 & 4.679 & -15 & 8.408 & 53 & 1.579 & -71 & 1.480 & -73 & 672 & -88 \\
\hline & $\mathrm{R}$ & 1.719 & 1.506 & -12 & 1.682 & -2 & 2.667 & 55 & 2.131 & 24 & 2.085 & 21 & 1.826 & 6 \\
\hline \multirow{3}{*}{ Yuca } & $\mathrm{S}$ & 20.000 & 28.365 & 42 & 17.152 & -14 & \begin{tabular}{|l|}
22.654 \\
\end{tabular} & 13 & 25.072 & 25 & 25.272 & 26 & 36.303 & 82 \\
\hline & $\mathrm{P}$ & 140.000 & 261.730 & 87 & 174.183 & 24 & \begin{tabular}{|l|}
211.299 \\
\end{tabular} & 51 & 264.135 & 89 & 236.394 & 69 & 339.766 & 143 \\
\hline & $\mathrm{R}$ & 7.000 & 9.227 & 32 & 10.155 & 45 & 9.327 & 33 & 10.535 & 51 & 9.354 & 34 & 9.359 & 34 \\
\hline
\end{tabular}




\begin{tabular}{|c|c|c|c|c|c|c|c|c|c|c|c|c|c|c|}
\hline \multicolumn{2}{|c|}{ Tabla No. 11} & \multicolumn{13}{|c|}{$\begin{array}{l}\text { Departamento Norte de Santander, Superficie, Producción y Rendimiento de los Principales } \\
\text { Cultivos Transitorios } 1987-2009\end{array}$} \\
\hline Cultivo & Var. & 1987 & 1990 & V. & 1994 & V. & 1998 & V. & 2002 & v. & 2006 & V. & 2009 & v. \\
\hline \multirow{3}{*}{ Fríjol } & $\mathrm{S}$ & 4.300 & 5.050 & 17 & 7.646 & 78 & 4.863 & 13 & 4.215 & -2 & 5.858 & 36 & 6.566 & 53 \\
\hline & $\mathrm{P}$ & 3.540 & 8.587 & 143 & 9.435 & 167 & 5.539 & 56 & 6.055 & 71 & 8.675 & 145 & 10.222 & 189 \\
\hline & $\mathrm{R}$ & 823 & 1.700 & 107 & 1.234 & 50 & 1.139 & 38 & 1.437 & 74 & 1.481 & 80 & 1.557 & 89 \\
\hline \multirow{3}{*}{$\begin{array}{c}\text { Maiz } \\
\text { Tecnificado }\end{array}$} & $\mathrm{S}$ & 900 & 400 & -56 & & & & & 50 & -94 & 80 & -91 & 500 & -44 \\
\hline & $\mathrm{P}$ & 2.300 & 800 & -65 & & & & & 300 & -87 & 480 & -79 & 2.310 & 0 \\
\hline & $\mathrm{R}$ & 2.556 & 2.000 & -22 & & & & & 6.000 & 135 & 6.000 & 135 & 4.620 & 81 \\
\hline \multirow{3}{*}{$\begin{array}{c}\text { Maíz } \\
\text { Tradicional }\end{array}$} & $\mathrm{S}$ & 10.900 & 20.600 & 89 & 16.717 & 53 & 8.678 & -20 & 8.654 & -21 & 8.990 & -18 & 9.186 & -16 \\
\hline & $\mathrm{P}$ & 13.100 & 28.800 & 120 & 20.172 & 54 & 10.830 & -17 & 13.015 & -1 & 12.268 & -6 & 11.774 & -10 \\
\hline & $\mathrm{R}$ & 1.202 & 1.398 & 16 & 1.207 & 0 & 1.248 & 4 & 1.504 & 25 & 1.365 & 14 & 1.282 & 7 \\
\hline \multirow{3}{*}{ Papa } & $\mathrm{s}$ & 4.200 & 4.400 & 5 & 2.948 & -30 & 3.297 & -22 & 2.641 & -37 & 3.203 & -24 & 2.814 & -33 \\
\hline & $\mathrm{P}$ & 61.560 & 76.500 & 24 & 47.992 & -22 & 44.574 & -28 & 76.173 & 24 & 90.740 & 47 & 74.170 & 20 \\
\hline & $\mathrm{R}$ & 14.657 & 17.386 & 19 & 16.280 & 11 & 13.520 & -8 & 28.848 & 97 & 28.330 & 93 & 26.357 & 80 \\
\hline \multirow{3}{*}{ Arroz Riego } & $\mathrm{S}$ & 16.100 & 34.500 & 114 & 18.030 & 12 & 24.059 & 49 & 29.654 & 84 & 20.642 & 28 & 28.973 & 80 \\
\hline & $\mathrm{P}$ & 86.700 & 167.000 & 93 & 83.585 & -4 & 121.330 & 40 & 168.879 & 95 & 120.134 & 39 & 180.099 & 108 \\
\hline & $\mathrm{R}$ & 5.385 & 4.841 & -10 & 4.636 & -14 & 5.043 & -6 & 5.695 & 6 & 5.820 & 8 & 6.216 & 15 \\
\hline \multirow{3}{*}{ Sorgo } & $\mathrm{s}$ & 1.400 & 1.700 & 21 & 1.080 & -23 & 156 & -89 & & & & & & \\
\hline & $\mathrm{P}$ & 4.400 & 5.700 & 30 & 3.164 & -28 & 588 & -87 & & & & & & \\
\hline & $\mathrm{R}$ & 3.143 & 3.353 & 7 & 2.930 & -7 & 3.769 & 20 & & & & & & \\
\hline \multirow{3}{*}{ Tabaco Rubio } & $\mathrm{S}$ & 505 & 196 & -61 & 249 & -51 & & & 910 & 80 & 1.458 & 189 & 415 & -18 \\
\hline & $\mathrm{P}$ & 805 & 499 & -38 & 465 & -42 & & & 2.454 & 205 & 2.638 & 228 & 740 & -8 \\
\hline & $\mathrm{R}$ & 1.594 & 2.546 & 60 & 1.867 & 17 & & & 2.697 & 69 & 1.809 & 14 & 1.783 & 12 \\
\hline \multirow{3}{*}{ Trigo } & $\mathrm{s}$ & 600 & 900 & 50 & 727 & 21 & 51 & -92 & 87 & -86 & 19 & -97 & 79 & -87 \\
\hline & $\mathrm{P}$ & 1.000 & 1.300 & 30 & 1.291 & 29 & 146 & -85 & 150 & -85 & 36 & -96 & 149 & -85 \\
\hline & $\mathrm{R}$ & 1.667 & 1.444 & -13 & 1.776 & 7 & 2.863 & 72 & 1.733 & 4 & 1.957 & 17 & 1.886 & 13 \\
\hline \multirow{2}{*}{ Gran Total } & $\mathbf{S}$ & 38.905 & 67.746 & 74 & 47.397 & 22 & 41.104 & 6 & 46.210 & 19 & 40.250 & 3 & 48.533 & 25 \\
\hline & $\mathbf{P}$ & 173.405 & 289.186 & 67 & 166.105 & -4 & 183.007 & 6 & 267.025 & 54 & 234.971 & 36 & 279.464 & 61 \\
\hline \multicolumn{15}{|c|}{$\begin{array}{l}\text { Los siguientes cultivos ap arecen como principales durante estos años y no para todo el períodoArroz Sec. Mec. 1987-90-94, Arroz Sec. Manual 1987, } \\
\text { Soy a } 1987 .\end{array}$} \\
\hline
\end{tabular}

\begin{tabular}{|c|c|c|c|c|c|c|c|c|c|c|c|c|c|c|}
\hline \multicolumn{2}{|c|}{ Tabla No. 12} & \multicolumn{13}{|c|}{$\begin{array}{c}\text { Departamento Norte de Santander, Superficie, Producción y Rendimiento de los Principales } \\
\text { Cultivos Permanentes } 1987-2009\end{array}$} \\
\hline Cultivo & \begin{tabular}{|l|} 
Var. \\
\end{tabular} & 1987 & 1990 & v. & 1994 & v. & 1998 & v. & 2002 & v. & 2006 & v. & 2009 & v. \\
\hline \multirow{3}{*}{ Arracacha } & $\mathrm{S}$ & 100 & 385 & 285 & 199 & 99 & 464 & 364 & 423 & 323 & 490 & 390 & 594 & 494 \\
\hline & $\mathrm{P}$ & 700 & 5.775 & 725 & 1.602 & 129 & 3.798 & 443 & 7.176 & 925 & 7.749 & 1.007 & 8.760 & 1.151 \\
\hline & $R$ & 7.000 & 15.000 & 114 & 8.050 & 15 & 8.185 & 17 & 16.963 & 142 & 15.814 & 126 & 14.747 & 111 \\
\hline \multirow{3}{*}{ Cacao } & $\mathrm{s}$ & 5.700 & 7.000 & 23 & 13.000 & 128 & 12.883 & 126 & 9.959 & 75 & 9.968 & 75 & 12.860 & 126 \\
\hline & $\mathrm{P}$ & 3.220 & 2.886 & -10 & 5.500 & 71 & 6.081 & 89 & 4.271 & 33 & 4.301 & 34 & 6.277 & 95 \\
\hline & $\mathrm{R}$ & 565 & 412 & -27 & 423 & -25 & 472 & -16 & 429 & -24 & 431 & -24 & 488 & -14 \\
\hline \multirow{3}{*}{ Caña Azúcar } & $\mathrm{S}$ & & 913 & & 200 & -78 & 180 & -80 & 272 & -70 & 969 & 6 & 899 & -2 \\
\hline & $\mathrm{P}$ & & 9.093 & & 1.320 & -85 & 2.124 & -77 & 3.092 & -66 & 10.420 & 15 & 9.803 & 8 \\
\hline & $\mathrm{R}$ & & 9,959 & & 6,600 & -34 & 11,797 & 18 & 11,366 & 14 & 10,753 & 8 & 10,903 & 9 \\
\hline \multirow{3}{*}{ Caña Panela } & $\mathrm{S}$ & 8.900 & 8.058 & -9 & 10.363 & 16 & 13.622 & 53 & 10.311 & 16 & 10.479 & 18 & 9.598 & 8 \\
\hline & $\mathrm{P}$ & 32.600 & 30.620 & -6 & 37.752 & 16 & 52.262 & 60 & 44.203 & 36 & 45.679 & 40 & 45.632 & 40 \\
\hline & $\mathrm{R}$ & 3.663 & 3.800 & 4 & 3.643 & -1 & 3.837 & 5 & 4.287 & 17 & 4.359 & 19 & 4.754 & 30 \\
\hline \multirow{3}{*}{$\begin{array}{l}\text { Palma } \\
\text { Africana }\end{array}$} & $\mathrm{S}$ & 200 & 2.045 & 923 & 2.130 & 965 & 1.385 & 593 & 2.016 & 908 & 5.123 & \begin{tabular}{|l|}
2.462 \\
\end{tabular} & 8.093 & 3.947 \\
\hline & $\mathrm{P}$ & 360 & 4.499 & 1.150 & 6.708 & 1.763 & 6.156 & 1.610 & 8.365 & 2.224 & 12.819 & \begin{tabular}{|l|l|}
3.461 \\
\end{tabular} & 28.153 & 7.720 \\
\hline & $\mathrm{R}$ & 1.800 & 2.200 & 22 & 3.149 & 75 & 4.445 & 147 & 4.149 & 131 & 2.502 & 39 & 3.479 & 93 \\
\hline \multirow{3}{*}{ Plátano } & $\mathrm{S}$ & 10.000 & 12.500 & 25 & 13.611 & 36 & 12.324 & 23 & 11.857 & 19 & 12.540 & 25 & 13.478 & 35 \\
\hline & $\mathrm{P}$ & 60.000 & 75.000 & 25 & 84.098 & 40 & 75.957 & 27 & 81.350 & 36 & 79.322 & 32 & 85.419 & 42 \\
\hline & $\mathrm{R}$ & 6.000 & 6.000 & 0 & 6.179 & 3 & 6.163 & 3 & 6.861 & 14 & 6.326 & 5 & 6.338 & 6 \\
\hline \multirow{3}{*}{ Yuca } & $\mathrm{S}$ & 11.500 & 8.986 & -22 & 9.667 & -16 & 8.253 & -28 & 7.793 & -32 & 10.446 & -9 & 10.334 & -10 \\
\hline & $\mathrm{P}$ & 115.000 & 89.860 & -22 & 73.370 & -36 & 55.120 & -52 & 113.038 & -2 & 147.702 & 28 & 145.072 & 26 \\
\hline & $\mathrm{R}$ & 10.000 & 10.000 & 0 & 7.590 & -24 & 6.679 & -33 & 14.506 & 45 & 14.140 & 41 & 14.038 & 40 \\
\hline \multirow{2}{*}{ Gran Total } & $\mathbf{s}$ & 36.400 & 39.887 & 10 & 49.170 & 35 & \begin{tabular}{|l|}
49.111 \\
\end{tabular} & 35 & 42.631 & 17 & 50.015 & 37 & 55.856 & 53 \\
\hline & $\mathbf{P}$ & 211.880 & 217.733 & 3 & 210.350 & -1 & 201.498 & -5 & 261.495 & 23 & 307.992 & 45 & 329.116 & 55 \\
\hline
\end{tabular}




\section{BIBLIOGRAFÍA}

\section{Académica}

ABOITES, M. Gilberto (1992): "Problemas que plantea la biotecnología en el marco legislativo de la propiedad intelectual: el caso de México”. En La biotecnología y sus repercusiones socioeconómicas $y$ políticas. Instituto de Investigaciones Sociales, UNAM, Departamento de Sociología, UAMAZC e Instituto de Investigaciones Económicas, México.

AGUDELO, Luis Carlos (2005): “La articulación urbano-regional. Indicadores de sostenibilidad y ordenación del territorio. Huella ecológica y ecosistemas estratégicos en Medellín”. En Región, ciudad y áreas protegidas. Manejo ambiental participativo. FESCOL, ECOFONDO, ACCION AMBIENTAL y CEREC, Bogotá.

AGUILAR,V. Luis F. (1992): El estudio de las políticas públicas. Colección Antologías de Política Pública (1. antología). Grupo Editorial Miguel Ángel Porrúa, México.

- (1992): La hechura de las políticas. Colección. Antologías de Política Pública (2. antología). Grupo Editorial Miguel Ángel Porrúa, México.

- (1993): Problemas públicos y agenda de gobierno. Colección Antologías de Política Pública (3. ${ }^{2}$ antología) Grupo Editorial Miguel Ángel Porrúa, México.

- (1993): La implementación de las políticas. Colección Antologías de Política Pública (4. ${ }^{2}$ antología). Grupo Editorial Miguel Ángel Porrúa, México.

ALTIERI, Miguel A. (2010): “¿Por qué la agricultura campesina? Agroecología, movimientos sociales y políticas a favor de la soberanía alimentaria”. En ¿Cambio de rumbo en las políticas agrarias latinoamericanas? Estado, movimientos sociales campesinos y soberanía alimentaria. Icaria Antrazyt Soberanía Alimentaria, Barcelona.

ÁLVAREZ, Marcelo y MEDINA, Xavier (2008): Identidades en el plato. El patrimonio cultural alimentario entre Europa y América. Icaria Observatorio de la Alimentación, Barcelona.

ALZATE, Óscar y LÓPEZ, Juan Diego (2003): Una estrategia de seguridad alimentaria para el Pacífico colombiano desde la perspectiva de las comunidades. Red de Desarrollo Tecnológico y Fortalecimiento Institucional para la Pequeña Producción Agropecuaria del Pacífico Colombiano (Red de Seguridad Alimentaria), PRONATTA, Proyecto DFID, Colombia (mimeo).

AMÍN, Samir (1999): Los desafíos de la mundialización. Siglo XXI Editores y UNAM, México.

ARANGO, R. Mariano (1990): “Tendencias productivas y recientes en la economía campesina (1975-1987)". En El campesino contemporáneo, cambios recientes en los países andinos. Cerec, Fescol y Tercer Mundo Editores, Varios Autores, Bogotá.

ARANGO, Rodolfo y LEMAITRE, Julieta (2002): Jurisprudencia constitucional sobre el derecho al mínimo vital. Universidad de los Andes, Facultad de Derecho, Centro de Investigaciones Sociojurídicas (CIJUS), Estudios Ocasionales, Bogotá. 
ARANGO, Rodolfo (2005): El concepto de los derechos sociales fundamentales. Universidad Nacional de Colombia y LEGIS, Bogotá.

ARANGUREN, Felipe L. (2012): El negocio del hambre. La especulación con alimentos. Icaria Más Madera, Barcelona.

ARNOLD, Thurman (1962): The symbols of government.Yale University Press. United States of America.

BALLESTEROS S., Óscar Javier (1998): “La nueva política de comercialización agropecuaria y la liquidación del Idema”. Revista Planeación y Desarrollo, Departamento Nacional de Planeación, volumen XXIX, número 2, abril-junio de 1998, Bogotá, Colombia

BARKIN, David y SUÁREZ, Blanca (1986): El fin de la autosuficiencia alimentaria. Centro de Ecodesarrollo Océano, México.

BENKO, Georges y LIPIETZ, Alain (1994). "Las regiones que ganan distritos y redes. Los nuevos paradigmas de la geografía económica" En El nuevo debate regional. Edicions Alfons El Magnánim, Generalitat Valenciana, Diputació Provincial de Valéncia.

BERTALANFFY, Ludwig Von (1989): Teoría general de los sistemas (7. eimpresión). Fondo de Cultura Económica, México.

BETANCOURT G. Mauricio (2006): "Historia y sociedad en Cundinamarca.Aporte histórico, figuras y documentales de la vida política y de lo público" (ponencia presentada en el Seminario de Historia de Cundinamarca: Perspectivas para el Siglo XXI). Fusagasugá, septiembre 22 y 23 de 2004, ESAP.

- (2006): “La Seguridad Alimentaria Nutricional (San). Un acercamiento a la política pública" (ponencia presentada en la Universidad del Valle, Foro Internacional Sobre Globalidad, Gobernabilidad y Territorio: Procesos Locales y Regionales; Panel: Gobernabilidad Política de los Territorios). En Cuadernos de Administración, Universidad del Valle, número doble, agostodiciembre de 2006 y enero-junio de 2007.

- (2008): Modulo: Política pública local. ESAP, APT.

- (2005): "La seguridad alimentaria y nutricional. Elementos para la construcción de una política pública para Bogotá“. Universidad Externado de Colombia, Bogotá.

- (2011): Planeación pública, participación y medio ambiente: construyendo la democracia local ¿... imprevisión...? Volúmenes I-II, segunda edición revisada y ampliada.

CAMACHO R., Salvador (1858): Camino carretero al Magdalena. Bogotá.

CARDOZA, Germán (2003): "Globalización, relatifundización y especulación”. Citado en FAO y COMUNIDAD ANDINA (2004): Comunidad Andina:factores macroeconómicos, comerciales, sectoriales y la seguridad alimentaria.

CASTELLS, Manuel y HALL, Peter (1994): Las tecnópolis del mundo: la formación de los complejos industriales del siglo XXI. Alianza Editorial, Madrid.

CASTELLS, Manuel (1989): The informational city. Information technology, cconomic reestructuring, and the urban-regional process. Cambridge, Massachusetts. 
- (1996): The information age: economy society and culture. Volume I: the rise of the network society. Cambridge, Massachusetts.

- (1997): The information age: economy society and culture. Volume II: the power of identity. Cambridge, Massachusetts.

— (1998): The information age: economy society and culture. Volume III: end of millenium. Cambridge, Massachusetts.

- (2001): La galaxia internet, reflexiones sobre internet, empresa y sociedad. Plaza y Janés Editores, Barcelona.

- (2010): Comunicación y poder. Alianza Editorial, Madrid.

CHOSSUDOVSKY, Michel (2003): Globalización de la pobreza y el nuevo orden mundial. Siglo XXI Editores, Argentina.

CIRAD y SAR (1996): Systémes agroalimentaires localisés: organisations, innovation dans le développement Local. Rapport Cirad. Citado en MUCHNIK, José:"Identidad territorial de los alimentos: alimentar el cuerpo humano y el cuerpo social". En Territorios y sistemas agroalimentarios locales. Universidad Nacional de Colombia, Red de Desarrollo Rural y Seguridad Alimentaria, Bogotá.

CORAGGIO, José L. (1989): "Sobre la espacialidad social y el concepto de región”. En La cuestión regional en América Latina.Varios Autores. Quito Ediciones, Quito.

- (2004): La gente o el capital. Desarrollo local y economía del trabajo. Editorial Espacio, Buenos Aires. CORIAT, Benjamín (1982): El taller y el cronometro. Ensayo sobre el taylorismo, el fordismo y la producción en masa. Siglo XXI Editores, México.

CUERVO, Luis M.y GONZÁLEZ, Josefina (1997): Industria y ciudades en la era de la mundialización (1980-1991). Un enfoque socioespacial. Colciencias, CIDER y Tercer Mundo Editores, Bogotá.

CUERVO, Luis M. (1999): "El rompecabezas de la intervención económica territorial”. En Territorios. Revista de Estudios Regionales y Urbanos, CIDER, Universidad de los Andes, Bogotá.

- (1999): “¿Existe una cultura económica territorial?” En Menorías del Primer Seminario Internacional sobre Territorio y Cultura. Universidad de Caldas, Manizales.

— (2003): "Ciudad y globalización en América Latina: estado del arte”. ILPES-Cepal, Serie Gestión Pública n. ${ }^{\circ}$ 37, Santiago de Chile.

- (2006): “Globalización y territorio”. ILPES-Cepal, Serie Gestión Pública n. ${ }^{\circ}$ 56, Santiago de Chile.

DE CASTRO, Josué (1975): Geopolítica del hambre. Ensayo sobre los problemas alimentarios y demográficos del mundo (5. ${ }^{a}$ ed.). Solar/Hachette, Buenos Aires.

DE SOUSA S., Boaventura (1998): La globalización del derecho. Los nuevos caminos de la regulación y la emancipación. Universidad Nacional de Colombia, Facultad de Derecho, Ciencias Políticas y Sociales e Instituto Latinoamericano de Servicios legales Alternativos (ILSA), Bogotá.

DESMARAIS, Anette A. (2007): La Vía Campesina: la globalización y el poder del campesinado. 
Editorial Popular, Madrid.

DOGLIOTTI, Fabrizio y MONTAGUT, Xavier (2006): Alimentos globalizados, soberanía alimentaria y comercio justo. Icaria Antrazyt Soberanía Alimentaria, Barcelona.

DUCH, Gustavo (2011): Alimentos bajo sospecha. Recetas para una alimentación inteligente. Los libros del Lince, Barcelona.

ELIZALDE H., Antonio (2003): Planificación estratégica territorial y políticas públicas para el desarrollo local. Cepal e Instituto Latinoamericano y del Caribe de Planificación Económica y Social (ILPES), Serie Gestión Pública n. ${ }^{\circ}$ 29, Santiago de Chile.

ESCOBAR, Iván (2007): “Subregiones”. En Antioquia ralidad territorial, dinámicas y transformaciones recientes (tomo I: Conocimiento, regionalización y organización del territorio). Gobernación de Antioquia y Universidad Nacional de Colombia, Medellín.

ESTRADA A, Jairo (2010): Derechos del capital, dispositivos de protección e incentivos a la acumulación en Colombia. Universidad Nacional de Colombia, Facultad de Derecho, Ciencias Políticas y Sociales e Instituto Unidad de Investigaciones Jurídico-Sociales Gerardo Molina, Bogotá.

EVANS, Peter (2007): Instituciones y desarrollo en la era de la globalización neoliberal. Editorial Gente Nueva, Bogotá.

FEBRER, María Teresa de (2004): Agencia de Información Solidaria. 17 de noviembre de 2004

FERRAJOLI, Luigi (2007): “Los derechos fundamentales”. En Teoría del neoconstitucionalismo. Ensayos escogidos. Instituto de Investigaciones Jurídicas (UNAM) y Editorial Trotta, Madrid.

FORERO A. Jaime y RUDAS, Guillermo (1991): "Los acopiadores rurales de la producción campesina". En Tres estudios sobre la comercialización de alimentos en Colombia. Serie Investigación y Desarrollo n. ${ }^{\circ}$ 2, Pontificia Universidad Javeriana, Facultad de Ciencias Económicas y Administrativas y ECOE Ediciones, Bogotá.

FRANCO, L.Vilma y RESTREPO, J. Diego (2011): “Empresarios palmeros, poderes de facto y despojo de tierras en el Bajo Atrato". En La economía de los paramilitares. Redes de corrupción negocios y política. Corporación Nuevo Arco Iris, Bogotá.

FRANCO S., Francisco J. (2008): Construcción cultural del territorio desde lo popular: cotidianidad y proyectos de futuro en Bogotá y Soacha. Escuela Superior de Administración Pública, Bogotá.

FURIÓ, Elies (1996): Evolución y cambio en la economía regional. Editorial Ariel, Barcelona.

GALINDO, Alberto (1961-1966): "Exponiendo en la discusión sobre la Reforma Agraria. Historia de las leyes, legislatura de 1961" (segunda etapa: reforma agraria, tomo II. Imprenta Nacional, Bogotá.

GARAY, Luis Jorge y RODRÍGUEZ, Adriana (2005): Colombia: diálogo pendiente. Documentos de Política Pública para la Paz, Planeta Paz y Ediciones Anthropos, Bogotá.

GARCÍA, Antonio (1981): "Naturaleza y límites de la modernización capitalista de la agricultura”. Citado en MACHADO, C. Absalón (2003): Ensayos sobre seguridad alimentaria. Universidad Nacional de Colombia, Red de Desarrollo Rural y Seguridad Alimentaria, Bogotá. 
GARCÍA G, Jorge (1982). “¿Se ha protegido la producción de alimentos en Colombia?”. En Minagricultura 80 años. La agricultura y las políticas sectoriales.TM, Banco Ganadero, Caja Agraria y VECOL, Bogotá.

GARCÍA, José L. (1999): En Memorias del Primer Seminario Internacional sobre Territorio y Cultura. Universidad de Caldas, Manizales, Colombia.

GARCÍA O., Francisco (2009): El ingenio y el hambre de la revolución agrícola a la transgénica. Crítica, Barcelona.

GARCÍA, Rolando (2008): Sistemas complejos: conceptos, métodos y fundamentación epistemológica de la investigación interdisciplinaria (1. ${ }^{a}$ reimpresión). Gedisa, Serie Filosofia de la Ciencia, Barcelona.

GERSON, Javier y PÉREZ V. (2005): Bolivar: industrial, agropecuario y turístico. Documentos de Trabajo Sobre Economía Regional, Publicación del Banco de la República n. 58, julio, Cartagena, Colombia.

GIMÉNEZ, Gilberto (2000): “Territorio, cultura e identidades. La región sociocultural” En MARTÍN-BARBERO, Jesús y otros (Eds.): Cultura y región. CES, Universidad Nacional de Colombia y Ministerio de Cultura, Bogotá.

GÓMEZ M., María Paula (2006): El derecho a la alimentación en la Constitución, la jurisprudencia y los instrumentos internacionales. Defensoría del Pueblo y Prosedher, Serie DESC, Bogotá.

GÓMEZ G., Luis Jaír (2001): El sistema agroalimentario y la sostenibilidad ecológica: los efectos de una diacronía. Universidad Nacional de Colombia, y Editorial Lealon, Medellín.

GRACIA A., Mabel (1996): Paradojas de la alimentación contemporánea. Icaria e Institut Catalá d'Antropología, Barcelona.

GUZMÁN C., Germán, FALS B., Orlando y UMAÑA L., Eduardo (2010): La violencia en Colombia.Editorial Nomos, Colección Punto de Lectura, Bogotá.

HABERMAS, Jürgen (1998): Facticidad y validez sobre el derecho y el Estado democrático de derecho en términos de teoría del discurso. Editorial Trotta, Madrid.

GHANEM, Hafez (2008): “El estado de la inseguridad alimentaria en el mundo" (presentación edición del informe de la FAO sobre el hambre).

HARVEY, David (2008): París, capital de la modernidad. Ediciones Akal, Madrid.

HAUENSTEIN SWAN, Samuel y VAITLA, Bapu (2007): The justice eating. The struggle for food and dignity in recent humanitarian crisis. Hunger Watch Report, 2007-2008. Action Against Hunger.

HELLER, Herman (1987): Teoría del Estado. Fondo de Cultura Económica, México.

HELMSING, A.H.J. (2000): "Hacia una reapreciación de la territorialidad del desarrollo económico". En Territorios, Revista de Estudios Regionales y Urbanos. CIDER, Universidad de los Andes, Bogotá.

HERNÁNDEZ, Julio y HERRERA, Danilo (2003): “Cadenas alimentarias, políticas para la competitividad. En COMUNIICA, edición número 3, etapa II, julio-septiembre de 2003. 
HERNÁNDEZ R., Felipe (2010): Que tus alimentos sean tu medicina (7.. ed.). RBA Libros, Barcelona.

HERREÑO H.,Ángel L. (2004): “Evolución política y legal del concepto de territorio ancestral indígena en Colombia”. En El otro derecho 31-32: derecho a la tierra, conceptos, experiencias y desafíos. ILSA y Ediciones Anthropos, Bogotá.

HERZ S., Carlos (2008): “Descentralización: ¿Desafio pendiente en la región andina? En Procesos de descentralización en la región andina: Bolivia, Perú, Ecuador y Colombia. Ministerio Federal de Cooperación Económica y Desarrollo e Inwent Capacity Building International Germany, Perú.

JACOBS, Jane (1986): Las ciudades y la riqueza de las naciones, principios de la vida económica. Editorial Ariel, Barcelona.

JESSOP, Robert (1999): Crisis del estado de bienestar. Hacia una nueva teoría del Estado y sus consecuencias sociales. Facultad de Derecho y Ciencias Políticas y Facultad de Ciencias Económicas, Universidad Nacional de Colombia y Siglo del Hombre Editores, Bogotá.

- (2008): El futuro del Estado capitalista. Los Libros de la Catarata, Serie Reversos del Leviatán, Madrid.

KAUTSKY, Karl (1975): La cuestión agraria. Estudio de las tendencias de la agricultura moderna y de la política agraria de la socialdemocracia. Editorial Latina, Medellín.

KEET, Dot. Activista e investigadora del Alternative Information and Development Center (AIDC) en Sudáfrica (entrevista). En VIVAS, Esther y MONTAGUT, Xavier (2009): Del campo al plato. Los circuitos de producción y distribución de alimentos. Icaria Antrazyt Soberanía Alimentaria, Barcelona.

LATHAM, Michael C. (2002): Nutrición humana en el mundo en desarrollo. FAO, Roma.

LAWRENCE, Felicity (2008): Eat your heart out. Penguin Books Ltd.

LE CORBUSIER (1971): Principios de urbanismo (La Carta de Atenas). Discurso preliminar de Jean Giraudoux. Editorial Ariel, Barcelona.

LIRA C., Luis (2003): a cuestión regional y local en América Latina. ILPES-Cepal, Serie Gestión Pública n. ${ }^{\circ} 44$, Santiago de Chile.

LÓPEZ, Claudia (2007): "La ruta de la expansión paramilitar y la transformación política en Antioquia 1997-2007”. En Parapolítica: la ruta de la expansión paramilitar y los acuerdos políticos. Corporación Nuevo Arco Iris e Intermedio Editores, Bogotá.

LOWENBER G, Miriam E. y otros (1968). Food and man. J. Wiley and Sons, Nueva York, 1991

LUHMANN, Niklas (1998): Sistemas sociales: lineamientos para una teoría general. Anthropos, Universidad Iberoamericana México y Pontificia Universidad Javeriana, Bogotá.

MACHADO C., Absalón (1986): "El papel de la agricultura y los sistemas alimentarios". En Ensayos sobre seguridad alimentaria. Universidad Nacional de Colombia, Red de Desarrollo Rural y Seguridad Alimentaria, Bogotá, 2003.

- (1986b): "El problema alimentario en Colombia". En Ensayos sobre seguridad alimentaria. Universidad Nacional de Colombia, Red de Desarrollo Rural y Seguridad Alimentaria, Bogotá. 
- (2004): "Seguridad alimentaria y sistema agroalimentario". En Territorios y sistemas agroalimentarios locales. Varios Autores. Universidad Nacional de Colombia, Red de Desarrollo Rural y Seguridad Alimentaria, Bogotá.

MACHADO C., Absalón y TORRES O., Jorge (1987): El sistema agroalimentario, una visión integral de la cuestión agraria en América latina. CEGA y Siglo XXI Editores, Bogotá.

MADELEY, John (2003): El comercio del hambre: el precio que pagan los pobres por el comercio libre. Intermón Oxfam, Barcelona.

MADR-IICA (2006): Observatorio Agrocadenas. Anuario 2005. Agroindustria y competitividad. Estructura y dinámica en Colombia 1992-2005. Bogotá.

MANCANO F., Bernardo (2009): “Territorio, teoría y política". En Las configuraciones de los territorios rurales en el siglo XXI. Pontificia Universidad Javeriana, Departamento de Desarrollo Rural y Regional, Maestría en Desarrollo Rural, Facultad de Estudios Ambientales y Rurales, Bogotá.

MÁRQUEZ, Germán (2005): “Ecosistemas estratégicos para la sociedad: bases conceptuales y metodológicas". En Región, ciudad y áreas protegidas, manejo ambiental participativo. Fescol, Ecofondo-Accion Ambiental y Cerec, Bogotá.

MARTÍNEZ, Rodrigo y FERNÁNDEZ, Andrés (2006): Modelo de análisis del impacto social y económico de la desnutrición infantil en América Latina. CEPAL, ONU y PMA, Serie Manuales 52, Santiago de Chile.

MAX-NEEF, Manfred A. (2004): “América Latina en el sistema mundial”. En Cuadernos de Discusión n. ${ }^{\circ}$ 4: Fundamentos de la transdisciplinariedad. Universidad Austral de Chile, Universidad de Alicante, Universidad de Cuenca y FES.

MEDELLÍN T., Pedro (1989): “La reforma del Estado en América Latina: desnacionalización del Estado y transnacionalización del capital. En La reforma del Estado en América Latina. FESCOL, Bogotá.

- (1998): El retorno a la política: La gubernamentalización del gobierno. Tercer Mundo Editores, PNUD, Alcaldía de Bogotá y CIDER, Bogotá.

MEDINA R., José M. (2006): "La lucha contra el hambre desde el enfoque de los DESC". En Seminario Seguridad Alimentaria y Lucha contra el Hambre. CEHAP, Universidad de Córdoba, Argentina.

MEDINA, E. Xavier (2011). "Prólogo". En Sabores culturales. Ensayos sobre alimentación y cultura. Universitat Oberta de Catalunya, España.

MÉNY, Ives y THOENIG, Jean-Claude (1992): Las políticas públicas. Editorial Ariel, Barcelona.

MEYERS, Diana T. (1988): Los derechos inalienables. Editorial Alianza y Universidad de Madrid.

WINDFUHR, Michael y JONSÉN, Jennie (2005): Soberanía alimentaria: hacia la democracia en sistemas alimentarios locales. FIAN-Internacional.

MONCAYO J., Édgard (2004): Nuevos enfoques del desarrollo territorial: Colombia en una perspectiva latinoamericana. Universidad Nacional de Colombia, Red de Estudios de Espacio y Territorio, UNDP y Cepal, Bogotá. 
MONGRAGÓN, Héctor (2002): Colombia: o mercado de tierras o reforma agraria. ANUCURFensuagro, Bogotá.

MONSALVE S., Sofia (2004): "Derecho a la tierra y derechos humanos". En Derecho a la tierra. Conceptos, experiencias y desafíos. El Otro Derecho 31-32. Instituto Latinoamericano de Servicios Sociales Alternativos (ILSA) y Ediciones Anthropos. Bogotá.

MONTAGUT, Xavier (2010): "Introducción”. En ¿Cambio de rumbo en las políticas agrarias latinoamericanas? Estado, movimientos sociales campesinos y soberanía alimentaria. Icaria Antrazyt Soberanía Alimentaria, Barcelona.

MONTAGUT, Xavier y VIVAS, Esther (2007): Supermercados, no gracias. Grandes cadenas de distribución, impactos y alternativas (2.a ed.). Icaria Antrazyt Soberanía Alimentaria, Barcelona.

MONTAGUT, Xavier y DOGLIOTTI, Fabricio (2006): Alimentos globalizados, soberanía alimentaria y comercio justo. Icaria Antrazyt, Consum Arxa Solidari, Agéncia Catalana de Cooperació al Desenbvolupament y Generalitat de Catalunya, Barcelona.

MONTAÑEZ G., Gustavo (2001): "Introducción. Razón y pasión del espacio y el territorio". En Espacio y territorios. Razón, pasión e imaginarios. Universidad Nacional de Colombia, Red de Estudios Espacio y Territorio, Bogotá.

MOORE L., Francés y COLLINS, Joseph (1982): Comer es primero. Más allá del mito de la escasez. Siglo XXI Editores, México.

MORALES G., Juan Carlos (2006): El hambre al servicio del neoliberalismo. Ediciones Desde Abajo, Bogotá.

MORÓN, Cecilio y SCHEJTMAN, Alejandro (1997): "Situación de la seguridad alimentaria en América Latina”. En Universidad de Chile y FAO (1997): Producción y manejo de datos de composición química de alimentos en nutrición. Santiago de Chile.

MUCHNIK, José (2004): "Identidad territorial de los alimentos: alimentar el cuerpo humano y el cuerpo social". En Territorios y sistemas agroalimentarios locales. Varios Autores. Universidad Nacional de Colombia, Red de Desarrollo Rural y Seguridad Alimentaria, Bogotá.

MULLER, Pierre (1998): “Génesis y fundamentos del análisis de políticas públicas”. En Innovar, Revista de Ciencias Administrativas y Sociales, n. ${ }^{\circ}$ 11, enero-junio.

MUÑOZ DE BUSTILLO, Rafael (2000): "Retos y restricciones del Estado de bienestar en el cambio de siglo". En El Estado de bienestar en el cambio de siglo. Una perspectiva comparada. Alianza Editorial. Madrid.

NANSEN, Karin (2002): "Nuestro mundo no está en venta". En Con la comida no se juega. Transgénico vs. soberanía alimentaria. FICA, Bogotá.

NEGRI, Toni y HARDT, Michael (2001): Imperio. Ediciones Desde Abajo, Bogotá.

NEIRA G., María (2003): "En qué dirección va la seguridad alimentaria”. En Revista de Salud Pública, n. ${ }^{\circ} 3$, mayo-junio.

NOGUEIRA D., Ángel (1997): "Niklas Luhmann: la sociedad como teoría de sistemas 
autorreferenciales y autopoiéticos de comunicación. Nuevos presupuestos críticos, nuevos conceptos e hipótesis en la investigación sociológica de la sociedad contemporánea”. En Revista Anthropos, Huellas del Conocimiento, N. ${ }^{\text {os }} 173-174$, julio-octubre, Barcelona.

OSZLAK, Óscar (1994): “Estado y sociedad: las nuevas fronteras”. En El rediseño del Estado. Una perspectiva internacional de Bernardo Kliksberg. Instituto Nacional de Administración Pública de México y Fondo de Cultura Económica, México.

PALMER, Ingrid (1972): “Science and agricultural production". Ginebra, UNRISD. Citado en MOORE LAPPE, Francés y COLLINS, Joseph (1982): Comer es primero. Más allá del mito de la escasez. Siglo XXI Editores, México.

PATEL, Raj (2007). Stuffed \& starved. From farm to fork, the hidden battle for the world food system. Portobello Books.

PAUTASSI, Laura C. (2009): "Los difusos vínculos de articulación entre las políticas públicas y los derechos humanos". En Derecho a la alimentación. Políticas públicas e instituciones contra el hambre. LOM Ediciones y Fundación Henry Dunant América Latina, Iniciativa América Latina y Caribe sin Hambre, Santiago de Chile.

PÉREZ, María Isabel (2006): La manzana de Blancanieves. Salud, industria y alimentación. Icaria Editorial, Barcelona.

— (2011): Caos en la alimentación. Ediciones ElViejo Topo, Málaga, España.

PÉREZ S., Bernardo (2007): "El paramilitarismo en Cundinamarca y Bogotá, 1997-2006”. En Parapolítica: la ruta de la expansión paramilitar y los acuerdos políticos. Corporación Arco Iris e Intermedio, Bogotá.

PIPITONE, Ugo (2003). Ciudades, naciones, regiones: los espacios institucionales de la modernidad. Fondo de Cultura Económica, Serie Economía, México.

PODGGE, Thomas (2005): La pobreza en el mundo y los derechos humanos. Paidós Estado y Sociedad, n. ${ }^{\circ}$ 134, Barcelona.

POLÉSE, Mario (1998): Economía urbana y regional. Introducción a la relación entre territorio y desarrollo. Libro Universitario Regional, Costa Rica.

POULANTZAS, Nicos (1977): Poder político y clases sociales en el estado capitalista (15. ${ }^{a}$ ed.). Siglo XXI Editores, México.

RESTREPO, Darío (2006): "Las fracturas del Estado en América Latina”. En Historias de descentralización, transformación del régimen político y cambio en el modelo de desarrollo América Latina, Europa y EUA. UN, GTZ, USAID y Agencia Colombiana de Cooperación, Bogotá.

RESTREPO, Laura (2005): La novia oscura. Editorial Alfaguara, Bogotá.

REYES P., Alejandro (2009): Guerreros y campesinos. El despojo de la tierra en Colombia. Fescol y Norma, Bogotá.

RIECHMANN, Jorge (2004): Cultivos y alimentos transgénicos: una guía crítica. Ediciones Pensamiento Crítico, Bogotá. 
ROBERTS, Paul (2009): El hambre que viene, la crisis alimentaria y sus consecuencias. Ediciones Bailén, Barcelona.

ROBIN, Marie-Monique (2008): El mundo según Monsanto: de la dioxina a los OGM. Una multinacional que les desea lo mejor. Ediciones Península, Barcelona.

ROBLEDO, Jorge E. (2009): La verdadera hecatombe. El debate del TLC permanece. Ediciones Aurora, Bogotá.

RODRÍGUEZ, Bladimir (2005): "Nuestro pan de cada día. La huella ecológica alimentaria de Bogotá". En Región, ciudad y áreas protegidas. Manejo ambiental participativo. Fescol, Ecofondo, Accion Ambiental y Cerec, Bogotá.

ROMERO V., Mauricio (2011): La economía de los paramilitares. Redes de corrupción, negocios y política. Corporación Nuevo Arco Iris, Colección Debate, Bogotá.

ROTH D.,André-Noel (2002): Políticas públicas, formulación, implementación y evaluación. Ediciones Aurora, Bogotá.

SABATIER, Paul A. (2010): Teorías del proceso de las políticas públicas. Proyecto Modernización del Estado, Jefatura de Gabinete de Ministros, Presidencia de la Nación-República Argentina, Buenos Aires.

SAGAWE, Thorsten (2006): "Niveles supramunicipales y niveles intermedios en la construcción de los Estados modernos (Baviera- Miami, Dade Country)". En Historias de descentralización, transformación del régimen político y cambio en el modelo de desarrollo América Latina, Europa y EUA. UN, GTZ, USAID y Agencia Colombiana de Cooperación, Bogotá.

SÁNCHEZ, Gonzalo (2008): Guerra y política en la sociedad colombiana. Editorial Nomos, Colección Punto de Lectura, Bogotá.

SANTOS, Milton (2000): La naturaleza del espacio. Técnica y tiempo. Razón y emoción. Ariel Geografía, Barcelona.

SCHEJTMAN, Alexander (1994): Economía política de los sistemas alimentarios en América Latina. FAO/Cepal, Santiago de Chile.

SEN, Amartya (2000): Desarrollo y libertad. Editorial Planeta, Bogotá.

- (2002): El derecho a no tener hambre. Universidad Externado de Colombia, Centro de investigación en Filosofia y Derecho, Bogotá.

SILVA RAMOS, Rodrigo (1969): "Viejo Tolima” (canción colombiana regional).

SMITH, Adam (1958): Investigación sobre la naturaleza y causas de la riqueza de las naciones (2. ${ }^{a}$ ed.). Fondo de Cultura Económica, Serie Economía, México.

SOJO, José R. (1970): El comercio en la historia de Colombia. Cámara de Comercio de Bogotá, Bogotá.

SOLÓRZANO FRAGA, Alfonso (1996): "Por una política social del abasto". En Transporte y abasto alimentario en las ciudades latinoamericanas. Universidad Nacional Autónoma de México, México. 
STIGLITZ, Joseph E. (2002). El malestar en la globalización. Santillana Ediciones Generales y Taurus Pensamiento, Madrid.

- (2003): Los felices 90, la semilla de la destrucción. Santillana Ediciones Generales y Taurus Pensamiento, Madrid.

SUÁREZ M., Aurelio (2007): El modelo agrícola colombiano y los alimentos en la globalización. Ediciones Aurora, Bogotá.

SUBIRATS, Joan, KNOEPFEL, Peter, LARRUE, Corrine y VARONE, Frédéric (2012): Análisis y gestión de políticas públicas. Ariel Ciencias Sociales, Barcelona.

TIMMER C., Peter, FALCON, Walter P. y PEARSON, Scott R. (1985): Análisis de políticas alimentarias. Banco Mundial y Editorial Tecnos, Madrid.

TORO S., Francisco J. y GAGLIARDINI, Giuliaserena (2006): "La seguridad alimentaria y la FAO: una revisión crítica de los informes sobre el estado mundial de la agricultura y la alimentación”. Revista Bibliográfica de Geografía y Ciencias Sociales, Serie Documental de Geocrítica, Universidad de Barcelona, vol. XI, n. ${ }^{\circ}$ 637, marzo.

VARGAS, Mónica (coord.) (2008): Agrocombustibles, ¿otro negocio es posible? Icaria Antrazyt Ecología, Barcelona.

VARGAS OVIEDO, Wenceslao (1991): Fundamentos de ciencia alimentaria. Fundación para la Investigación Interdisciplinaria y la Docencia y Universidad Nacional de Colombia, Bogotá.

VARGASV., Alejo (1999): Notas sobre el estado y las políticas públicas. Almudena Editores, Bogotá.

Varios Autores (2004): Conflictividad territorial en Colombia. ESAP y Fundación Buen Gobierno, Bogotá.

VARÓN, Orminso, DÍAZ, Ricardo y DONADO, José (2008): Crisis alimentaria en Colombia. Universidad La Gran Colombia, Bogotá.

VIVAS, Esther y MONTAGUT, Xavier (2009): Del campo al plato. Los circuitos de producción y distribución de alimentos. Icaria Antrazyt Soberanía Alimentaria, Barcelona.

VIVERO, José L. y RAMÍREZ, Pablo (2009): “Leyes, políticas e instituciones contra el hambre en el contexto latinoamericano". En Derecho a la alimentación, políticas públicas e instituciones contra el hambre. LOM Ediciones, Fundación Henry Dunant América Latina, Iniciativa América Latina y Caribe sin Hambre, Santiago de Chile.

- (2009): "Hambre, derechos humanos y la consolidación del Estado en América Latina". En Derecho a la alimentación, políticas públicas e instituciones contra el hambre. LOM Ediciones, Fundación Henry Dunant América Latina DESC y Políticas Públicas, Iniciativa América Latina Sin Hambre. Santiago de Chile.

VERNON, James (2007): Hunger: a modern history. The President and Fellow of Harvard College.

WALLERSTEIN, Immanuel (1979): El moderno sistema mundial. La agricultura capitalista $y$ los orígenes de la economía-mundo europea en el siglo XVI. Siglo XXI de España Editores, Madrid.

WINDSCHEID B., Lehrbuch des Pandektenrechts (1906). citado en HABERMAS, Jürgen 
(1998): Facticidad y validez sobre el derecho y el Estado democrático de derecho en términos de teoría del discurso. Editorial Trotta, España.

ZIBECHI, Raúl (2009): “Los territorios como sustento del conflicto social”. En Las configuraciones de los territorios rurales en el siglo XXI. Pontificia Universidad Javeriana, Facultad de Estudios Ambientales y Rurales y Colciencias, Bogotá.

ZULUAGA N., Jaime (2009): “Orígenes, naturaleza y dinámica del conflicto armado". En Las otras caras del poder. Territorio, conflicto y gestión pública en municipios colombianos. GTZ y Foro Nacional por Colombia, Bogotá.

\section{Informes Institucionales y gubernamentales}

Agencia Presidencial para la Acción Social y la Cooperación Internacional (2010): Unidades agrícolas familiares, tenencia y abandono forzado de tierras en Colombia. Proyecto Protección de Tierras y Patrimonio de la Población Desplazada, Bogotá.

Alcaldía de Cúcuta (2009): Plan de Desarrollo Municipal 2008-2011. Cúcuta.

Alcaldía de Medellín (2006). Plan de Ordenamiento Territorial: "El Sistema Estructurante, Equipamientos” (documento técnico de soporte, primera parte). Medellín.

Alcaldía de Neiva (2011): Plan Integral Único de la Ciudad de Neiva. Secretaria de Gobierno y Convivencia Ciudadana, Comité Territorial de Atención Integral a Población Desplazada.

Alcaldía de Neiva (2009): Plan de Desarrollo Municipal 2008-2011. Diagnóstico.

Alcaldía Mayor de Bogotá (2000): Plan de Alimentación y Nutrición del Distrito Capital (19992003). Un Plan con Viabilidad Local. Bogotá.

Asamblea Departamental de Bolívar (2004): Ordenanza n. 11 , del 11 de mayo de 2004, adopta el plan de desarrollo departamental 2004-2007: "Por el Bolívar que todos queremos".

Asociación Europea de Comercio Justo (EFTA) (1998): Anuario de Comercio Justo 1998-2000. Citado En FERNÁNDEZ,YON y MAETZ, Materne (2003): Tendencias del comercio mundial y de productos agrícolas. FAO, Dirección de Asistencia para las Políticas.

Banco Mundial (2008): Informe sobre el Desarrollo Mundial 2008. Agricultura para el desarrollo. Banco Mundial, Mundi-Prensa y Mayo Ediciones, Bogotá.

- (2006): Reposicionando la nutrición como prioridad para el desarrollo. Una estrategia para intervenciones de gran escala. Washington

BARCO,Virgilio (1987): Así estamos cumpliendo. Plan de Desarrollo de Economía social.Departamento Nacional de Planeación, Bogotá.

- (1987). Plan de economía Social. Departamento Nacional de Planeación, Bogotá.

BIRF y Gobierno de Colombia (1951): Bases de un programa de fomento para Colombia. Banco de la República, Bogotá. 
CALERO CH., Jorge Enrique (2009): Sat, Informe de riesgo n. ${ }^{\circ}$ 001-09 A.I. Defensoría delegada para la evaluación de riesgos de la población civil como consecuencia del conflicto armado. Sistema de Alertas Tempranas.

Cédula Real del 14 de febrero de 1503, la Reina Católica expedida en Alcalá de Henares. Citado en SOJO, José R. (1970): El comercio en la historia de Colombia. Cámara de Comercio de Bogotá, Bogotá.

Cepal (2002): “Globalización y desarrollo” (vigesimonoveno periodo de sesiones). Brasilia, 6-10 de mayo. - (2006): "La protección social de cara al futuro: acceso, financiamiento y solidaridad" (trigésimo primer periodo de sesiones). Montevideo, Uruguay, 20-24 de marzo.

- (2009): Economía y territorio en América Latina y el Caribe. Desigualdades y politicas. Santiago de Chile.

CLICHEVSKY, Nora (2006): Regularizando la informalidad del suelo en América Latina y el Caribe. Una evaluación sobre la base de 13 países y 71 programas. Cepal, Serie Manuales n. ${ }^{\circ}$ 50, División de Desarrollo Sostenible y Asentamientos Humanos, Santiago de Chile.

Comisión Nacional de Reparación y Reconciliación (2009): El despojo de tierras y territorios. Aproximación conceptual. Área de Memoria Histórica, Bogotá.

- (2010): La Tierra en Disputa. Memorias del despojo y resistencia campesina en la costa Caribe (19602010). Ministerio de Agricultura y Desarrollo Rural, Taurus Pensamiento y Semana, Bogotá.

Conferencia Internacional de la Vía Campesina (1996), Tlaxcala, México.

CURRIE, Lauchlin (1951): Bases de un programa de fomento para Colombia (2. ${ }^{a}$ ed.). Banco de la República, Bogotá.

Departamento Nacional de Estadística (2004): Informalidad laboral en las trece principales áreas y ciudades colombianas, 2001-2003. DANE, Documentos Técnicos sobre Mercado Laboral, abriljunio, Bogotá.

Departamento Nacional de Estadística y Departamento Administrativo de la Presidencia de la República (1986): El Plan Social por la Paz, una estrategia de participación comunitaria. Bogotá.

Departamento Nacional de Estadística e Instituto Geográfico Agustín Codazzi (2004): Estudio general de suelos y zonificación de tierras, departamento de Norte de Santander (tomo I, capítulo VI).

Departamento Nacional de Planeación, Programa de Naciones Unidas para el Desarrollo, Programa Nacional de Desarrollo Humano y Agencia de Cooperación Técnica Alemana al Desarrollo (2006): Los municipios colombianos hacia los Objetivos de Desarrollo del Milenio. Salud, educación y reducción de la pobreza. Bogotá.

— (1972): Las cuatro estrategias. Bogotá.

- (1976): Para Cerrar la Brecha: Plan de Desarrollo Social, Económico y Regional 1975-1978. Bogotá.

- (1980): Plan de Integración Nacional 1979-1982 (tomo II). Bogotá.

- (1998): Políticas para el cambio económico y social. Selección de documentos aprobados por el Conpes (tomo III). Bogotá. 
- (1999): Plan Nacional de Desarrollo 1998-2002: Cambio para Construir la Paz (tomos 1- 2). Bogotá.

- (2003): Plan Nacional de Desarrollo 2002-2006: Hacia un Estado Comunitario. Bogotá.

- (2005): Conpes 91, las metas y estrategias de Colombia para el logro de los Objetivos de Desarrollo del Milenio 2015 (ODM). Bogotá.

- (2005): Conpes 3375, Política Nacional de Sanidad Agropecuaria e Inocuidad de Alimentos para el Sistema de Medidas Sanitarias y Fitosanitarias. Bogotá.

- (2006): Conpes 102, sobre la Red de Protección para la Reducción de la Extrema Pobreza. Bogotá. - (2007): Plan Nacional de Desarrollo 2006-2010: Estado Comunitario, Desarrollo para Todos (tomo I- II). Bogotá.

- (2008): Conpes 113, Política Nacional de SAN. Bogotá.

- (2011): Prosperidad para Todos. Plan Nacional de Desarrollo 2010-2014 (tomo I). Bogotá.

Encuesta Nacional de la Situación Nutricional en Colombia 2005 y 2010 (ENSIN) (2005). Bogotá.

FAO (2007): Estado mundial de la alimentación 2004-2005. Bogotá.

- (1992): La alimentación y la agricultura en el mundo: enseñanzas de los cincuenta últimos años. Roma

- (1992): Declaración Mundial sobre la Nutrición. Roma.

- (1996): La alimentación y el comercio internacional (vol. 3). Documentos Técnicos de Referencia, Cumbre Mundial Sobre la Alimentación, documento n. ${ }^{\circ} 12$.

— (1995): "Nutrition education for the public". Food, Nutrition and Agriculture, n. 16.

- (1996): Cumbre Mundial sobre la Alimentación. Documento técnico n. ${ }^{\circ} 5$.

- (1999): Enfoques. La comercialización de alimentos en las ciudades. Departamento de Agricultura y Protección al Consumidor.

— (2002): "Nutrición internacional y problemas alimentarios mundiales en perspectiva". Roma.

- (2003): Estrategia de la FAO relativa al enfoque de calidad e inocuidad de los alimentos basado en la cadena alimentaria: documento marco para la formulación de la futura orientación estratégica. Comité de Agricultura, $17^{\circ}$ período de sesiones, 31 de marzo-4 de abril, Roma.

- (2004): El estado de la inseguridad alimentaria en el mundo 2004. Seguimiento de los avances en la consecución de los objetivos de la Cumbre Mundial sobre Alimentación y de los Objetivos de Desarrollo del Milenio. FAO, Roma.

- (2005): Examen de las políticas sobre productos alimenticios básicos 2003-2004. Roma

- (2010): Análisis socioeconómico de tiendas de alimentos en áreas urbanas de bajos recursos en Latinoamérica Informe de caso: Colombia. Bogotá.

- (2011): “El estado de la inseguridad alimentaria en el mundo, ¿cómo afecta la volatilidad de los precios internacionales a las economías nacionales y la seguridad alimentaria?”. Roma. 
FAO y Comunidad Andina (2004): Comunidad Andina: factores macroeconómicos, comerciales, sectoriales y la seguridad alimentaria. Bogotá.

Foro Mundial de La Habana (2002): "Declaración final sobre soberanía alimentaria”. En Con la comida no se juega. Transgénico vs. soberanía alimentaria. FICA, Bogotá.

GRAIN (s. f.): "Soberanía alimentaria y sistema alimentario mundial. Respuesta a viaje de Chirac por África francófona".

ICBF (2000): Guías alimentarias para la población colombiana mayor de dos años. Bases técnicas. Bogotá.

- (2006): Encuesta Nacional de la Situación Nutricional en Colombia 2005 (1. a ed.). Dirección de Evaluación, Bogotá.

- (2009): Informe al Congreso de la República de Colombia. Bogotá.

- (2010): Mapas de la situación nutricional en los municipios de Colombia. Bogotá.

ICBF y Nutrir (1998): "Frecuencia de consumo de alimentos. Consolidado nacional 1998" En Guías alimentarias para la población colombiana mayor de dos años. Bogotá.

Instituto Colombiano de Reforma Agraria (1988): 25 años de reforma agraria en Colombia. Ministerio de Agricultura e Instituto Colombiano de la Reforma Agraria, Bogotá.

Massachusetts Institute of Technology Department of Urban Studies and Planning y Universidad Tecnológica de Bolívar (2010): Retos y oportunidades para la acción en Bazurto. Análisis de cuatro cadenas de abastecimiento e implicaciones para la ciudad de Cartagena (resumen ejecutivo). Cartagena

Ministerio de Agricultura y Departamento Nacional de Planeación (s.f.): "Estrategias y políticas para el desarrollo agropecuario en Colombia", "El desarrollo agropecuario en colombia". En Informe final de la Misión de Estudios del Sector Agropecuario (tomo 1). Bogotá.

Ministerio de Agricultura y Desarrollo Rural, IICA y Observatorio de Agrocadenas (2006): Agroindustria y competitividad. Estructura y dinámica en Colombia 1992-2005. Bogotá.

Ministerio de Agricultura y Desarrollo Rural y Observatorio de Agrocadenas (2001): La cadena de oleaginosas, aceites y grasas. Bogotá.

Ministerio de Salud e Instituto Colombiano de Bienestar Familiar (2000): Guías alimentarias para la población colombiana mayor de dos años. Bogotá.

Oficina Comercial de la Embajada de España en Colombia (s. f.): Comercio y distribución en Colombia. Bogotá.

ONU (2005): "El derecho a la alimentación". Nota del Secretario General. Documento A/60/30, septiembre.

Plan Nacional de Rehabilitación (PNR) y Programa Presidencial para la Convivencia (1994): Memorias del PNR 1982-1994. Bogotá.

Presidencia de la República, Acción Social (2010): Unidades agrícolas familiares, tenencia y abandono forzado de tierras en Colombia. Proyecto de Protección de Tierras y Patrimonio de la Población Desplazada, Bogotá. 
Presidencia de la República, Consejería para la Reconciliación, Normalización y Rehabilitación y Secretaría de Integración Popular (1988): Plan Nacional de Rehabilitación: una estrategia de desarrollo social y regional para la reconciliación 1986-1990. Bogotá.

Presidencia de la República y Departamento Nacional de Planeación (1991): La Revolución Pacífica: Plan de Desarrollo Económico y Social 1990-1994. Bogotá.

Profamilia, Instituto Nacional de Salud, Instituto Nacional de Bienestar Familiar y Ministerio de Protección Social (2010). Encuesta Nacional de la Situación Nutricional en Colombia 2010 (1. ${ }^{\text {a }}$ ed.). Bogotá.

Programa Nacional de Desarrollo Humano, Departamento Nacional de Planeación y otros (2004): Las regiones colombianas frente a los objetivos del milenio. Bogotá.

Real Cédula del 3 de octubre de 1614. En SOJO, José R. (1970): El comercio en la historia de Colombia. Bogotá.

Secretaría de Planeación Distrital de Cartagena (2009). Revisado y aprobado Arq. Antonio Nieves González Director Administrativo de Control Urbano. Colombia.

\section{Legislación y jurisprudencia}

Alcaldía de Cartagena (2001): Decreto 0977 de 2001, por medio del cual se adopta el Plan de Ordenamiento Territorial del Distrito Turístico y Cultural de Cartagena de Indias.

Congreso de la República (1991): Constitución Política de Colombia. Bogotá.

Congreso de la República de Colombia (1995): Ley 160 de 1995, normas que reglamentan y desarrollan. Bogotá.

Congreso de la República de Colombia (1998): Ley 489 de 1998, por la cual se dictan normas sobre la organización y funcionamiento de las entidades del orden nacional. Diario Oficial 43.464, Bogotá.

Congreso de la República de Colombia (2001): Ley 715 de 2001, por la cual se dictan normas orgánicas en materia de recursos y competencias y organiza la prestación de los servicios de educación y salud. Diario Oficial 44.654, Bogotá.

Congreso de la República de Colombia (2009): Ley 1355 de 2009, de salud pública y adopta medidas para control, atención y prevención. Bogotá.

Corte Constitucional de Colombia (1990): Sentencia T-1006/99. Bogotá.

Corte Constitucional de Colombia (1992): Sentencia T-426/92.

Gobernación del Huila (2002): Ordenanza n." 015 de 2008, "Por la cual se adopta el Plan de Desarrollo Departamental 2008-2011: "Huila Naturaleza Productiva".

Ley 388 DE 1997, julio 18. Reglamentada por los Decretos Nacionales 150 y 507 de 1999; 932 y 1337 de 2002; 975 y 1788 de 2004; 973 de 2005; 3600 de 2007; 4065 de 2008; 2190 de 2009; Reglamentada parcialmente por el Decreto Nacional 1160 de 2010; modifica la Ley 9 de 1989, y la Ley 2 de 1991. 
Ministerio de Educación Nacional e Instituto Colombiano de Bienestar Familiar (2002): Directiva del ministro de educación nacional y del director del instituto colombiano de bienestar familiar, 2002, para: alcaldes distritales y municipales, secretarios de educación, rectores y directores de establecimientos educativos, directores regionales y seccionales de agencias ICBF; con orientaciones sobre el uso de los recursos de alimentación escolar del sistema general de participaciones de la Ley 715. Bogotá

Presidencia de la República de Colombia (2002): Decreto 159 de 2002, Modificado parcialmente por los Decretos Nacionales 072 de 2005 y 852 de 2009 distribución de los recursos de la participación de propósito general y de la asignación para los programas de alimentación escolar. Bogotá.

Presidencia de la República de Colombia (2007): Decreto 3039 de 2007, Plan Nacional de Salud Pública (PNSP) 2007-2010. Bogotá.

Presidencia de la República de Colombia (2009): Decreto 2055 de 2009, por el cual se crea la Comisión Intersectorial de Seguridad

Procuraduría General de la Nación Circular 023 de 2010, sobre planes de ordenamiento territorial.

\section{Hemerografía}

El Tiempo (2011, 6 de octubre): “El País tiene cada vez más terratenientes”.

El Universal (2011): "Mercado de Bazurto, un container de problemas en la gestión Distrital”.

Le Monde Diplomatique (2008, mayo), edición número 67, dedicada al tema alimentario mundial.

\section{Cibergrafía}

FAO (2003): Agua para la producción sostenible de alimentos. Recuperado de www.fao.org/ docrep/006/y4525s/y4525s05.htm

FAO (s. f.): Alimentos para las ciudades, esfera multidisciplinaria. Mercadeo urbano de alimentos. Recuperado de www.fao.org/fcit/index.asp.

GUTIÉRREZ, Laura (s. f.): "La OMC: significado, funciones y objetivos. Política y sociedad". Recuperado de http://suite101.net/article/la-omc-significado-funciones-y-objetivos-a70547

SÁNCHEZ ROMERO, Gerardo D. (2011): Revista Mad, Universidad de Chile, n. ${ }^{\circ}$ 24, mayo, págs. 30-60. Recuperado de www.revistamad.uchile.cl

ZIEGLER, Jean (2001): "La esquizofrenia de Naciones Unidas: una lucha sin medios contra el hambre". Recuperado de http://www.aithne.net/index.php?e=news\&id=201\&lang=6 







Este trabajo de investigación sobre la Política de Seguridad Alimentaria Nutricional (SAN) y Desarrollo Territorial en Colombia se desarrolla en el marco del doctorado en Gobierno y Administración Pública de la Universidad Complutense de Madrid y el Instituto Ortega y Gasset. El objeto de esta investigación es la evolución y el cambio de la Política de Seguridad Alimentaria Nutricional en el periodo 1987-2008 en Colombia, en el contexto de la globalización. Esta investigación se desarrolla por las implicaciones del tema para la población colombiana, dado que es un problema social, ambiental y económico que afecta a comunidades, familias e individuos de diferentes edades, sectores sociales y territorios. 